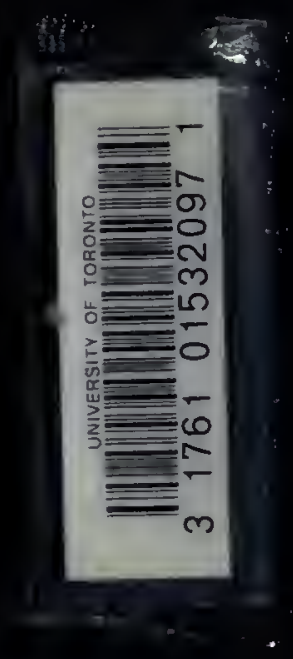

INMOF GRPNTE Jitror 




\section{Digitized by the Internet Archive in 2007 with funding from Microsoft Corporation}




THE WATERLILIES 

..

3 


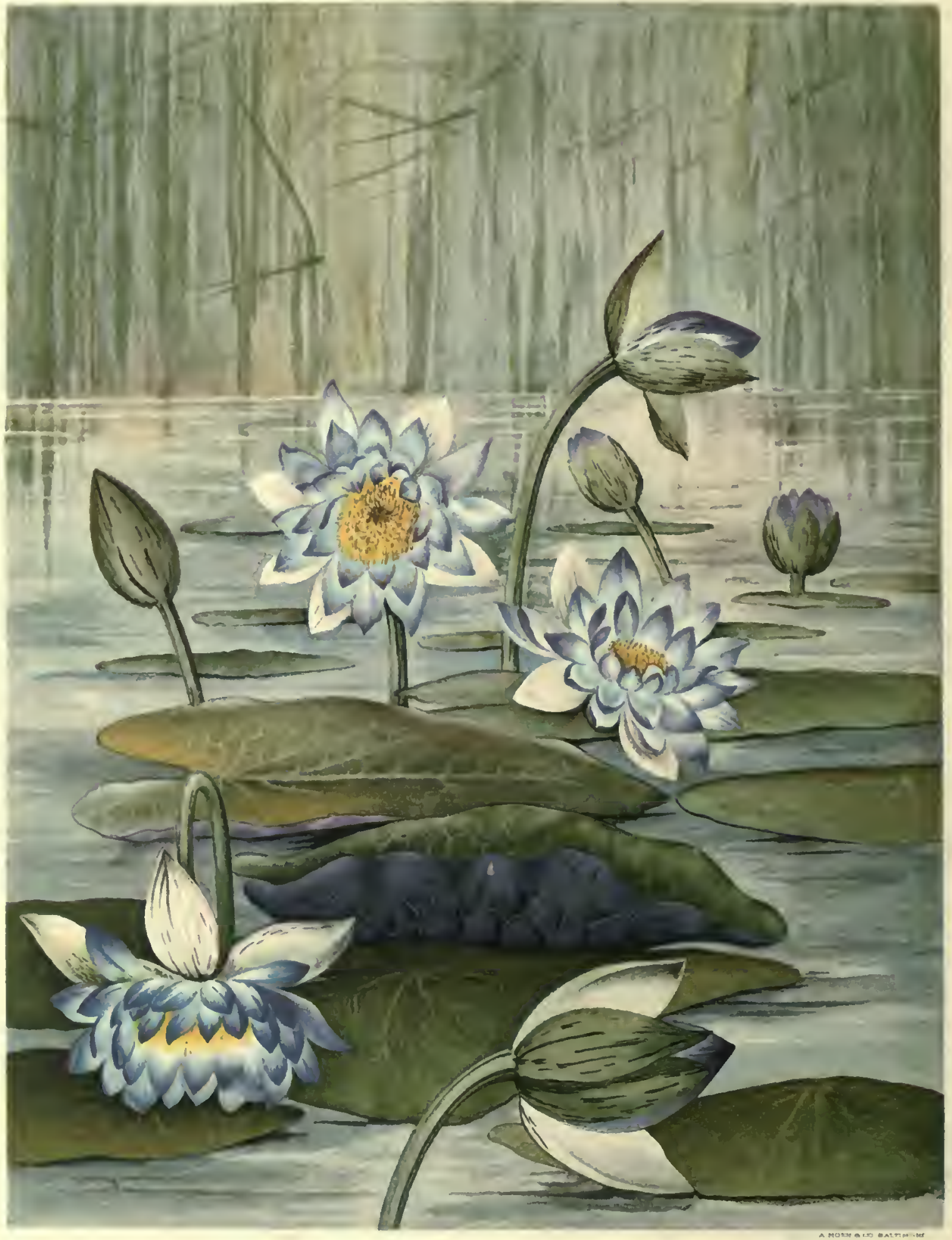

NYMPHAEA GIGANTEA VIOLACEA. 


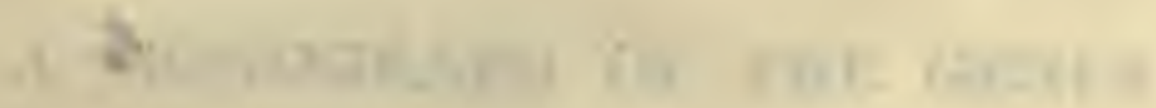

$$
\text { smomisas }
$$

$$
\begin{aligned}
& \text { |16) }
\end{aligned}
$$

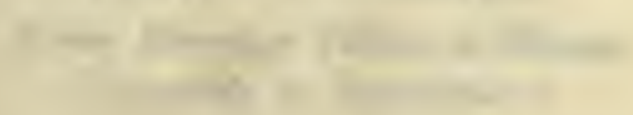

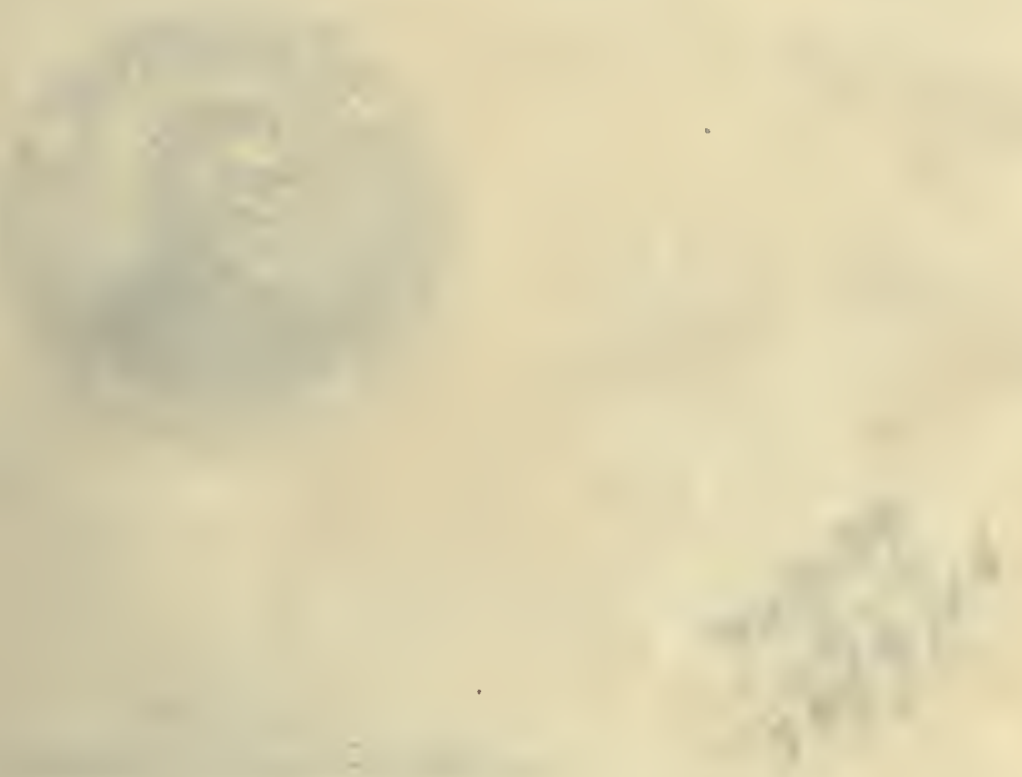





\title{
THE WATERLILIES
}

\section{A MONOGRAPH OF THE GENUS \\ NYMPHAEA}

\author{
$B Y$ \\ HENRY S. CONARD \\ Senior Harrison Fellow in Botany \\ University of Pennsy/vania
}

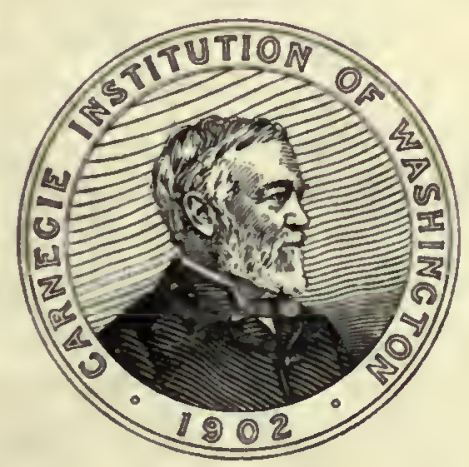

Published by

'The Carnegie Institution of Washington

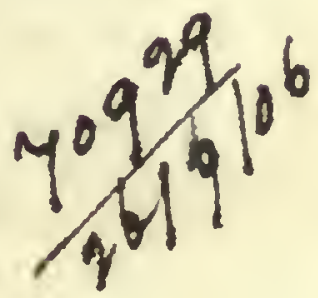
1905 


\section{QK 495 N97C 7}

Cop. 2

CARNEGIE INSTITUTION OF WASHINGTON

Publication No. 4

MAI TIMORE, MD., U. S. A. 


\section{PREFACE.}

This work is the outcome of four years' study on the Harrison Foundation in the University of Pennsylvania. It would have been difficult or impossible without the generous support given by the Provost and the Board of Trustees. In the University Botanic Garden over thirty species and varieties of waterlily were cultivated, and several hybrids originated. These and other collections of living plants furnished excellent material for the present review of the group.

Nothing like a complete synopsis of the Waterlilies has hitherto been put before the English-speaking world. DeCandolle made a special study of the genus Nymphaea for his Prodromus, and both Lehmann and Planchon gave much attention to the genus from 1850 to 1853 . Beginning in 1855 and continuing until 1888 , a number of exhaustive treatises by Robert Caspary went far toward perfecting our knowledge of these plants. Indeed, had the learned doctor of Königsberg assembled his vast knowledge into one connected whole, the present work would be needed chiefly as a translation. Since his day, however, great strides have been made in the culture and hybridization of waterlilies, with the result that they now appear in almost every collection of plants. Already by crossing and recrossing and the use of horticultural names, serious confusion exists concerning the identities of the parent species. It has therefore seemed important to bring together the knowledge of the genus in all of its botanical relations and in its bearings on human life and history. In the present attempt there may be many omissions, in spite of the utmost efforts in collating the material, but the paper may serve to show how incomplete is our knowledge of any one group of plants, and it is hoped that it may make the way of the future investigator easier.

In the adoption of the generic name Nymphaea, the writer regrets that he is at variance with a number of American botanists for whom he has the utmost respect; but a glance at the synonymy of Nymphaea, 
page 125 , shows the leading facts. It seemed patent to the writer that all of the general, and several special, arguments against a change of name are particularly cogent in the present example. The new code, however, proposed by a committee of the Botanical Club of the American Association for the Advancement of Science, seems to sanction the nomenclature here chosen.' In the use of specific names, authorities have been omitted wherever possible, since the names adopted in Chapter $\mathrm{V}$ are followed. Citations of literature are based on the bibliography on pages 243 to 263 .

Throughout the time occupied by the preparation of this work, I have been deeply indebted to Professor John M. Macfarlane, to whom I desire to express my gratitude.

To Mr. William Tricker, formerly of Riverton, N. J., and through him to the Henry A. Dreer Co., of Philadelphia, I am under obligation for the privilege of studying their magnificent collection of waterlilies. Acknowledgment is also due to Dr. J. W. Harshberger, of the University of Pennsylvania, and Dr. J. N. Rose, of the National Herbarium, for suggestions and herbarium material ; to Mr. A. J. Mela, of Helsingfors, Finland; J. J. Soar, of Little River, Fla.; Wm. Gollan, Saharanpur, India ; Wm. Fawcett, of Kingston, Jamaica ; R. M. Gray, gardener to O. Ames, North Easton, Mass.; Gopal Chandradatta, Calcutta, India ; Sr. Alberto Löfgren, director of the Botanical Garden of Sao Paulo, Brazil ; the director of the Royal Botanic Garden of Tokyo, Japan; to the Gray Herbarium, Boston Natural History Society, Massachusetts Horticultural Society, Columbia University; to the Academy of Natural Sciences of Philadelphia for library facilities; and to John B. Lieberg, Joseph H. Painter, Chas. C. Abbott, Prof. Conway MacMillan, Albert J. Edmunds, E. D. Sturtevant, and C. G. Pringle for various courtesies. Mr. Frederick V. Coville and Mr. J. C. Bay, of Washington, D. C., have also given helpful aid and criticism while the matter was going through the press.

In order to give the greatest possible accuracy to the taxonomic portion of the monograph, I was enabled by the trustees of the Carnegie Institution of Washington to examine important type material in several European herbaria, viz, in Kew, British Museum, Linnaean Society, Muséum d' Histoire Naturelle, the herbaria of De Candolle, Delessert, and Barbey-Boissier, and the herbaria of Munich, Berlin, and Copenhagen. The results of this trip were very valuable, thanks to the courteous assistance 
of those in charge of the various collections. The principal changes resulting in the manuscript were in the addition of a few species.

That the book appears in its present form is also due to the Carnegie Institution, on account of their acceptance of the manuscript for publication. Were it not for this privilege, much of the illustrative material must have been omitted. These many obligations I have felt keenly, and have tried in a measure to meet by conscientious care in the execution of every detail.

University of Pennsyluania, Phiradelphia, December I, Ig04.
Henry S. Conard, Senior Harrison Fellow. 



\section{CONTENTS}

Preface $\ldots \ldots \ldots \ldots \ldots \ldots \ldots \ldots \ldots \ldots \ldots \ldots$ iii-
Description of Plates $\ldots \ldots \ldots \ldots \ldots$ ix-
List of Text Figures $\ldots \ldots \ldots \ldots \ldots \ldots$ xii-xi

I. History

Pre-Linnaean Literature .......... I0

II. Structure $\ldots \ldots \ldots \ldots \ldots \ldots \ldots \ldots . .27$

The Root................... 28

The Stem................. 37

The Leaf................... 54

The Flower, Fruit, and Seed..... 77

III. Development ................. 95

Organogeny and Embryology...... 95

Germination and Early Growth.... 106

IV. Physiology $\ldots \ldots \ldots \ldots \ldots \ldots \ldots \ldots$ I13

V. TAXoNomy ................... 125

Nymphaeae Apocarpiae......... I27

Anecphya ................ 127

N. gigantea.............. 128

Brachyceras ............. I3 I

N. elegans ............... I3I

N. ampla ............... I 34

N. flavo-virens ........... I37

N. stellata ............... I40

N. caerulea ............... I4I

N. micrantha ............. 146

N. heudelotii ............. I47

N. ovalifolia .............. I50

N. calliantha .............. I5I

N. capensis ............. I53

N. sulfurea $\ldots \ldots \ldots \ldots \ldots \ldots$ I6 I

N. stuhlmanni ........... I6I
PAOE Nymphaeae Syncarpiae ............ $16_{3}$

Castalia .................. I6

Xanthantha ............... 163

N. mexicana ............ 163

Chamaenymphaca........... 167

N. tetragona $\ldots \ldots \ldots \ldots \ldots$ I67

N. fennica ............. I 70

Eucastalia .............. I 7 I

N. candida $\ldots \ldots \ldots \ldots \ldots$ I 72

N. alba ............... I75

N. odorata ............ I79

N. tuberosa $\ldots \ldots \ldots \ldots \ldots$. I 89

Lotos .................. 192

N. lotus ............... 194

N. zenkeri ............... I97

N. pubescens ............. 198

N. rubra ................ 199

Hydrocallis ............... 200

N. a mazonum ............200

N. rudgeana $\ldots \ldots \ldots \ldots \ldots \ldots .204$

N. blanda ...............206 206

N. lasiophylla ............207 207

N. gardneriana ............ 208

N. jamesoniana ............ 209

N. stenaspidota ........... 209

N. tenerinervia .............210

N. oxypetala .............. 210

N. gibertii ............... 210

VI. Distribution .................. $2 \mathbf{1 3}$

Geographical ...............213

Geological ..................215

VII. Hybrids AND Garden VARieties..... 219

General .................... 219

Taxonomic .................... 225

VIII. Culture and Uses.............. 235

Bimliograpti y .................... 243

INDEX $\ldots \ldots \ldots \ldots \ldots \ldots \ldots \ldots \ldots \ldots, 265$ 



\section{DESCRIPTION OF PLATES.}

Prate I. Frontispiece. Nymphaea gigantea violacea. From a painting made by Mrs. E. Rowan, in the Cape York Peninsula, Australia.

Plate 2. Nymphaea odorata. I-7, development of leaf and stipules; 1,2 , front and back views of the same rudiment; 3 , older; 4,5 , front and side views of one rudiment; 6 , 7 , frcnt and back views; 8 , rhizome with roots and leaves trimmed off, natural size; 9 , transverse section of rhizome, natural size. A. Koronski del.

Plate 3. Nymphaea gigantea. Under side of leaf and details of flower. 1 , anterior sepal; 2 , outermost stamen; 3 , inner stamens; 4 , median petal; 5 , vertical section of ovary; 6 , outermost petal. Photograph from plant grown at University of Pennsylvania.

Platx 4. Nymphaea elegans. Flower and under side of leaf. From plant grown at University of Pennsylvania; stock of the Dreer Co. A. Koronski del.

Plate 5. Nymphaea ampla, from Caspary, 1878, pl. 28. I, flower from hb. St. Petersburg, coll. B. Jaeger, No. 233, Hayti, with 149 stamens, 24 carpels; 2, leaf from hb. Geo. Engelmann, coll. Wright, No. 1857 , Cuba; 3 , flower, seen from the side; 4 , rays of stigma and carpellary styles; 5 , stamens (2-5 from the same specimen); 6, two carpels of a flower in hb. St. Petersburg, coll. Karwinski, I84I, in Colipa River, Mexico.

Plate 6. Nymphaea flavo-virens ( $N$. gracilis Hort, not Zucc., I832). Flower and under side of leaf, Photo. from plant grown at University of Pennsylvania, from stock obtained from the Dreer Co.

Plate 7. Nymphaea stellata versicolor. Under surface of leaf and details of flower. a, sepal; b-e, petals of successive whorls; f, stamens; g, closed flower. From plant grown by the Dreer Co. (Mr. W. Tricker), from seed sent by W. Gollan, Saharanpur, India.

Plate 8. Nymphaea caerulea. Flower and under side of leaf. From plant grown at University of Pennsylvania.

Plıte 9. Nymphaea micrantha. I, under side of leaf; 2, upper side with young plant developing; 3 caudex, with a branch; 4 , scars of leaves and of a flower, from surface of a caudex, enlarged; 5 , cross section of caudex; 6 , longitudinal section of a caudex; 7 , superficial tangential section through leaf cushions of Fig. $4 ; l$, base of a petiole; $f$, base of a peduncle; 8 , section a little deeper than $7 ; 9$, same as 8 , a little deeper. From a drawing in color by $\mathrm{R}$. Caspary, now in hb. Berlin, by kind permission of the Directors.

Plate 10. Nymphaea capensis. Under side of leaf. From plant grown at University of Pennsylvania; stock from Dreer Co.

Plate Ir. Nymphaea capensis zanzibariensis. Flower and leaf. Plant grown at University of Pennsylvania; stock of Dreer Co. A. Koronski del. 
Prate 12. Nymphaea sulfurea. I, 5, leaves viewed from the upper surface; 2, under side of leaf; 3, a closed flower; 4, fully open flower; 6, rhizome. From a co-typc in hb. British Museum, by courtesy of the Curators. P. Highly del.

Plate 13. Nymphaea mexicana. Flower and leaf, natural size. From plants grown at University of Pennsylvania, from roots collected in Little Rivcr, Fla., by Prof. J. M. Macfarlane. A. Koronski del.

Plate 14. Nymphaea tetragona. Flower and under side of leaf, natural size. From plants grown by the Dreer Co.

Plate 15. Nymphaea alba rubra, I-2I; N. candida, 22. Nymphaca alba rubra. I, partly opcned flower; 2, fully open flower on its last day; 3-8, petals; 9-12, stamens of successive whorls from outside inward, viewed from front, sidc and back; 13 , ovary stripped of sepals, petals and stamcns, from the side; 14 stigma and styles from above; 15, section of ovary; 16, pollen, from pole and from side; 17-19, fruits; 20, petal; 21, stigmatic lobes. Nymphaea candida. 22, flower cut in half. From drawings in color by R. Caspary, now in hb. Berlin, by kind permission of the Directors.

Plate 16. Nymphaea lotus. Leaf, flower, transverse and vertical section of fruit. Photographed by P. Highley from a spccimen coll. Schwcinfurth, Nov., 1887, at Damietta, Egypt, in lib. British Museum, by courtesy of the Curators.

PLATE 17. Nymphaea pubescens. Flower and under side of leaf. From a plant grown by the Dreer Co. (Mr. Wm. Tricker), from seed sent by Mr. W. Gollan, Saharanpur, India.

PLAte 18. Nymphaea rubra. I, flower of second day, between 9 and 9.30 a. m.; 2 , flower at same time of third day; 3 , flower at same time of first day; 4 , flower of fourth day, between 8.45 and 9 a.m.; 5 , sepal from outer and inner sides; 6 , petals of first (at left) and second whorls; 7 , petal of innermost whorl; 8-Io, stamens from outer and inner sides; II, 12, dry pollen; 13-15, pollen germinating in sugar solution; 16, 17, pollen, examined in citron-oil, 18, 19, in water, 20, in dilute sulphuric acid; 21, germinating pollen; 22 , section of carpellary style; $23-26$, hairs of ovary, 24 treated with potash ; 27, pistil seen from above; 28, ovary of Fig. 3, with stamens; 29, ovary un second day. From color drawings by R. Caspary, in hb. Berlin, by kind permission of the Directors.

Plate 19. Nymphaea amazonum. I, closed flower after its first night; 2, fully open flower, second night between 4.30 and $4.45 \mathrm{a}$. m.; 3 , the samc flower on the first night between 4.30 and 5 a.m.; 4 , sepal, inner side; 5 , petal of outermost whorl, from without; $6,7,8,9$ petals of the next four whorls; 10-13, stamens of successive whorls; 14, I5, side and section views of ovary after the second night; 16, ovary after the first uight; 17, transverse section of ovary; 18, 19, pollen, dry and in water; 20 , epidermis of ovary. From color drawings by R. Caspary, in hb. Berlin, by kind permission of the Directors.

Plate 20. Nymphaca rudgeana. I, flower on its first night, I0.15 p. m.; 2, the same between 9.20 and 9.40 p. m.; 3, 4, ripc fruits; 5, closed fower after first night; 6, flower with 3 outer whorls of floral lcaves removed; 7 , sepal froin within; 8 , petal of outermost whorl; 9, petal of second whorl; 10, pctal of fourth whorl; Ir, stamen of outermost whorl of four; 12, stamen of second whorl of four; 13, stamen of third whorl of seven or eight; I4, 15, inner and innermost stamens; 16-19, views of ovary; 20, 21, 22, pollen in dilute sulphuric acid, dry, and in water; 23, ripe fruit with floral leaves removed; 24, transverse scction of ovary; 25-27, sections of carpellary style at apex, just below the club-shaped apex, and at base; 28 , papilla of stigina. From eolor drawings by $\mathrm{R}$. Caspary, in hb. Berlin, by kind permission of the Directors. 
Plate 21. Nymphaea blanda, N. blanda fenzliana, N. tenerinervia, N. stenaspidota. From Caspary, I878, pl. 36. I-7, N. tenerinervia, from a spccimen coll. Martius at Joazeiro, Province of Bahia, Brazil. I, flower; 2, lower surface of leaf; 3, apex of outer stamen; 4, of innermost stamen; 5 , carpellary style; 6 , upper surface of leaf, near the point of insertion of the petiole, showing series of raised dots and short raised lines; the arrow points to the inscrtion of the petiolc; 7 , outer surface of scpal showing short crowded raised lines; 8 , outer surface of sepal of $N$. stcnaspidota with raised dots between the rather long raised lines; 9-12, $N$. blanda fenzliana, specimen from San Juan de NicaPagua, in hb. Vienna. 9, young fruit; IO, II, outer and median stamens, from hb. Bentham; 12, leaf; 13-16, N. blanda. 13, flower viewed from side, coll. Parker in British Guiana; 14 , leaf of the same; 15 , part of upper surface of same leaf, showing raphid-like lines and raised dots; 16 , leaf of Mcyer's type, coll. Dr. Rodscheid in the Essequibo River (from hb. Griscbach).

Plate 22. Nymphaea lasiophylla and N. rudgcana, from Caspary, 1878, pl. 34. I-7, N. lasiophylla. I, 2, flower from face and back; 3, lcaf, showing lower side, with distant lobes; 4 , part of a larger leaf seen from above, lobes touching; 5,6 , outermost and innermost stamens; 7 , part of lower surface of leaf marked with raised dots and branching lines; 8-r9, N. rudgeana. 8, leaf of a plant from Jamaica, cult. in Berlin Botanical Garden; 9, Io, II, stipules of three leaves of a Jamaica plant, cult. in Königsberg Botanical Garden; 12, fruit, raised at Königsberg; I3, another fruit, raised at Königsberg, with persistent sepals and petals; I4, Königsberg fruit in median section; I5, small flower, coll. Poeppig, No. 3033, 1832, in the Island of Colares of the Amazon, in hb. Bcrlin; 16, sepal of a flower, coll. Sello at Victoria, Brazil; I7, I8, stamens of this flower; 19, apices of median and innermost stamens showing a narrow rim of the connective, but no appendage.

Plate 23. Nymphaea jamesoniana, from Caspary, 1878, pl. 32. 1, 2, flower from front and back, in hb. Boissier; s, sepal; 3, 4, 5, innermost, outer and outermost stamens; 6, 7, leaves, from hb. St. Petersburg and hb. Lehm; 8, part of Icaf from beneath, showing forkcd branching lines and raphid-like idioblasts.

Plate 24. Nymphaea stenaspidota and $N$. gardncriana, from Caspary, I878, pl. 33. I-3, N. stenaspidota. I, whole plant from type of hb. Lehm; s, sepal; 2, flower; 3, part of leaf, upper surface, showing raised dots, the arrow points toward point of insertion of petiole; 4-II, N. gardneriana. 4, flower, from hb. Vienna; s, sepal; 5, 6, 7, upper part of outermost, mcdian and innermost stamens; 8,9 , Io, leaves; II, upper surface of lcaf showing scries of raised dots, with raphid-like lines interspersed, the arrow as in Fig. 3.

Plate 25. Nymphaea oxypetala, from Caspary, 1878, pl. 31. I, 2, flower, from hb. Boissier, from face and back; 3,4 , outermost and innermost stanens; 5 , three carpellary styles, with surface of stigma and axile proccss; 6,7 , leaves from hb. Lehm. and St. Petersburg; 8 , globose idioblasts of inner facc of anther at the point of Fig. 3 .

Plate 26. Nymphaea pennsylvania $=N$. caerulea $\times$ zanzibariensis. From the original plant grown at University of Pennsylvania. A. Koronski dcl.

Plate 27. Nymphaea capensis $\times$ zanzibariensis. Flower and under side of leaf. From plants raised at Univcrsity of Pennsylvania.

Plate 28. Nymphaca elegans $X$ zanzibariensis. Flower and under side of leaf. From plants raised at University of Pennsylvania.

Plate 29. Nymphaca favo-virens $\times$ zanzibariensis. Flower and under side of leaf. From plants raised and bred at University of Pennsylvania.

Plate 30. Nymphaea omarana, hybrid. Stock from Drcer Co. A. Koronski del. 


\section{LIST OF TEXT FIGURES.}

Tail-piece.-Guest at a fcast, with lotus (aftcr Wilkinson)

PAGE

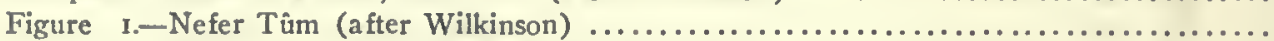

2.-Egyptian lotus (designs after Wilkinson)

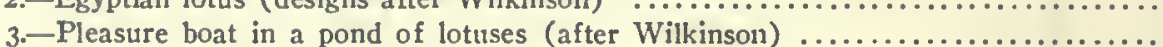

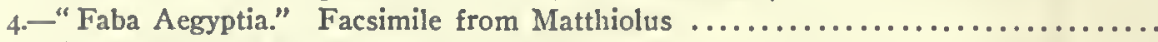

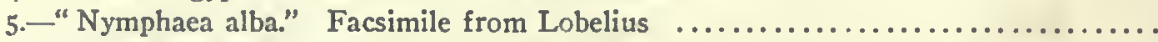

6.-Longitudinal section of root tip of $N$. caerulea $\ldots \ldots \ldots \ldots \ldots \ldots \ldots \ldots \ldots \ldots . . . \ldots \ldots$

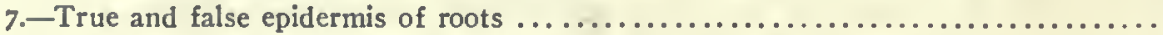

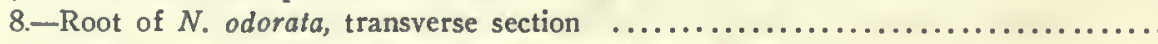

9.-Contractile root of $N$. flavo-virens, transverse section $\ldots \ldots \ldots \ldots \ldots \ldots \ldots \ldots \ldots$

10.-Vascular bundles of the roots of $N$. odorata $\ldots \ldots \ldots \ldots \ldots \ldots \ldots \ldots \ldots . . . \ldots \ldots$

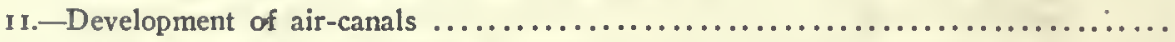

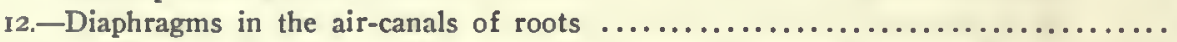

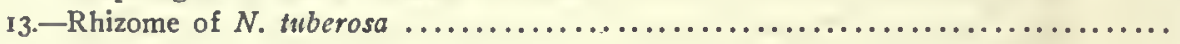

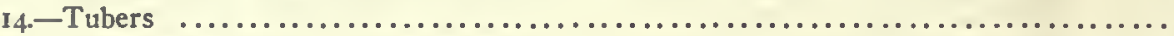

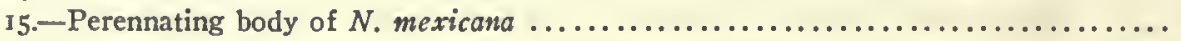

$16-$ Rhizome of $N$. odorata; transverse section of internode $\ldots \ldots \ldots \ldots \ldots \ldots \ldots \ldots . .$.

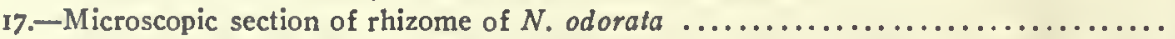

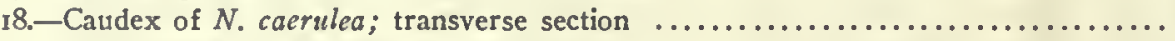

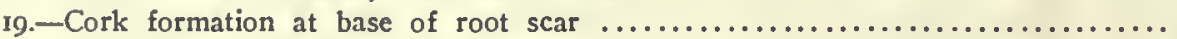

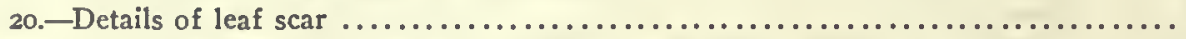

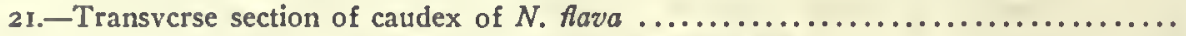

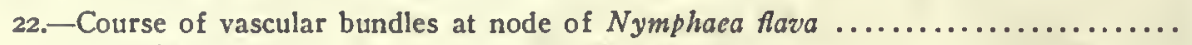

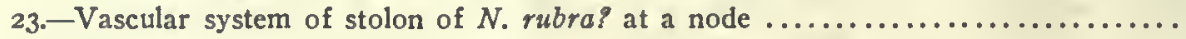

24.- - Stipules

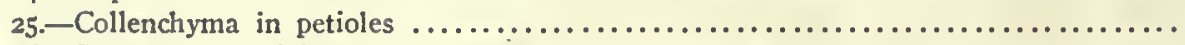

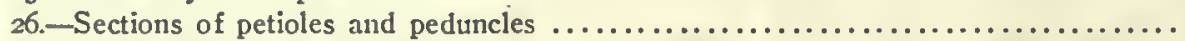

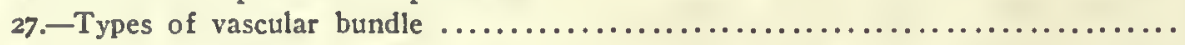

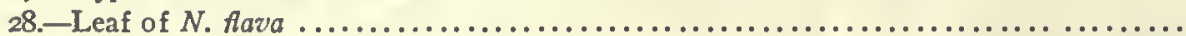

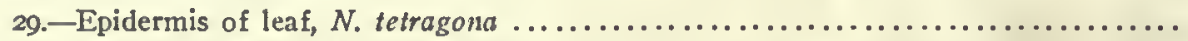

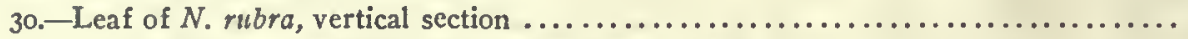

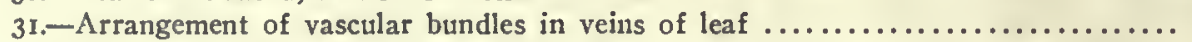

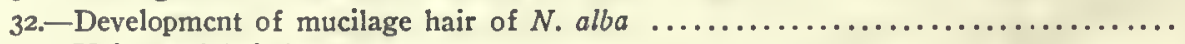

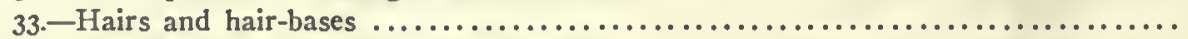

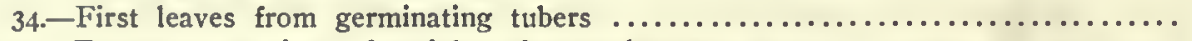

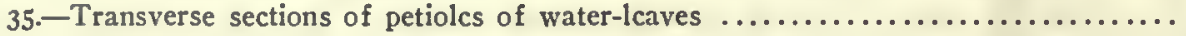

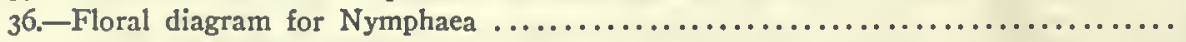

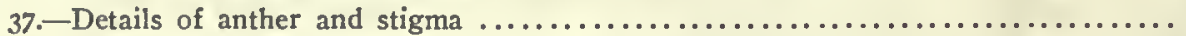

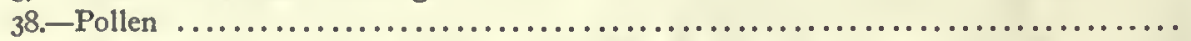

39.-Diagram of ovary (Brachyceras) in longitudinal section $\ldots \ldots \ldots \ldots \ldots \ldots \ldots . .$.

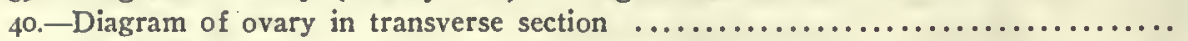

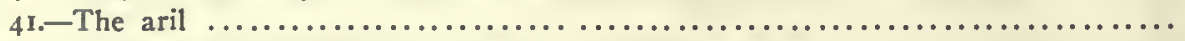

42.-Sections of outer ccll-layer of testa (after Weberbauer) $\ldots \ldots \ldots \ldots \ldots \ldots \ldots \ldots$

43.-Distribution of vascular bundles from the chalaza (after Clifflot).$\ldots \ldots \ldots \ldots$.

I 
FAGR

45.-Development of flower ........................................ 99

46.-Ovule of $N$. odorata from a half-grown bud $\ldots \ldots \ldots \ldots \ldots \ldots \ldots \ldots \ldots \ldots \ldots$. 102

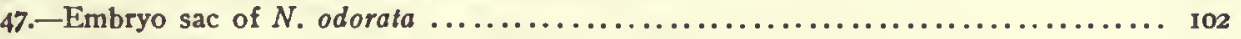

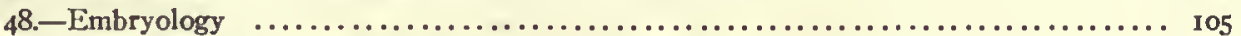

49.-Seedlings of a hybrid Nymphaea of the Lotos group $\ldots \ldots \ldots \ldots \ldots \ldots \ldots \ldots \ldots . \ldots \ldots$

50.-Seedling leaves .................................................. 110

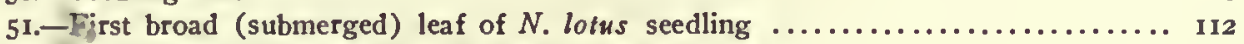

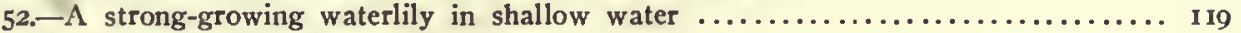

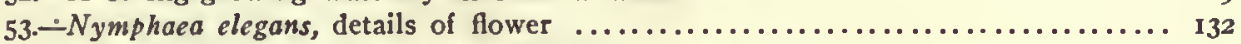

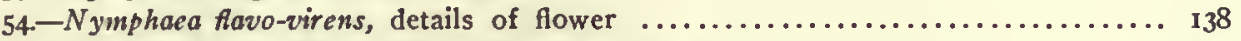

55.- Nymphaea caerulea, details of flower and fruit ........................ 142

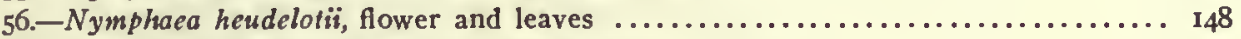

57.-Nymphaea heudelotii nana, leaf and flowers.......................... 149

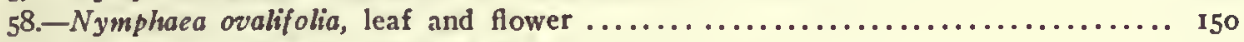

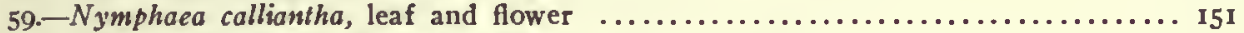

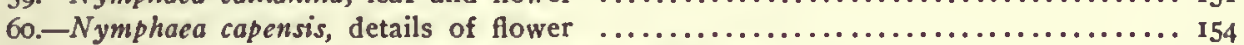

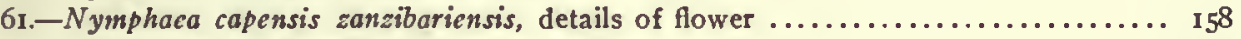

62.-Nymphaea stuhlmannii, leaf and flower .............................. 162

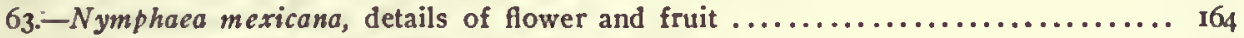

64. -Nymphaea mexicana, seedling leaves ................................. 165

$65 .-N y m p h a c a$ tetragona, details of flower $\ldots \ldots \ldots \ldots \ldots \ldots \ldots \ldots \ldots \ldots \ldots \ldots \ldots \ldots . \ldots \ldots$

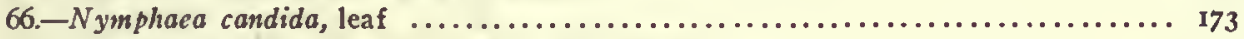

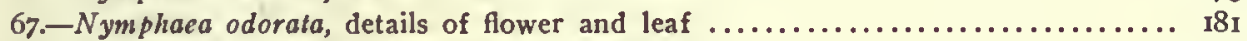

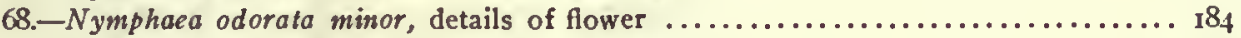

69. - Nymphaca odorata gigantea, details of flower......................... I 87

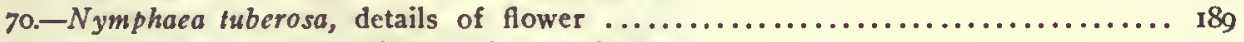

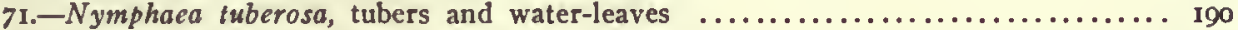

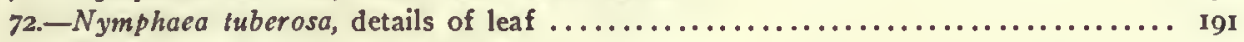

73. -Floral organs of the Lotos group ................................... I93

74.-Early leaves of the Lotos group, from germinating tuber ................ 195

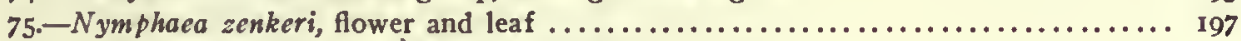

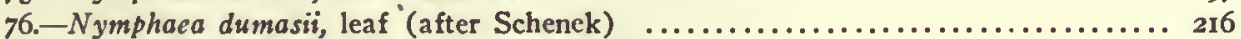

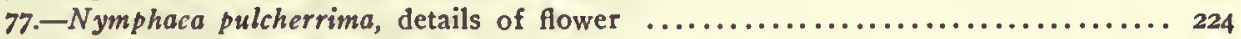

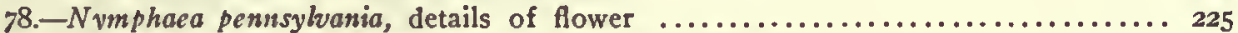

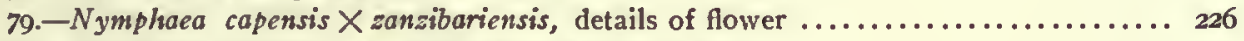

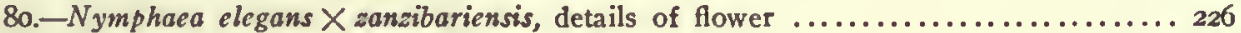

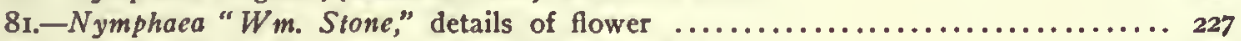

82.-Nymphaca "Mrs. C. W. Ward," details of flower ...................... 228 



\section{THE WATERLILIES}

HENRY S. CONARD

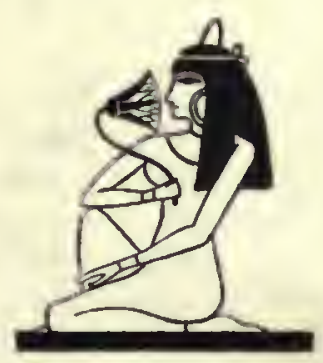





\section{CHAP'TER I.}

\section{HISTORICAL.}

\section{ORIENTAL LITERATURE.}

Man was probably impressed from the first with the grace and beauty of the waterlilies; for their distribution is worldwide. There is evidence enough that the seeds and roots (tubers) of various species have been used for food by many savage races, as in Australia, Madagascar, West Africa and Central America; but naturally it remained for more civilized peoples to rise to anything like an æsthetic interest. A Chinese writer of the eleventh century A. D., Chou Tun-I, is thus quoted in Giles's "Gems of Chinese Literature,"-

Since the opening days of the T'ang dynasty [600 A. D.], it has been fashionable to admire the paeony; but my favorite is the waterlily. How stainless it rises from its slimy bed! How modestly it reposes on the clear pool-an emblem of purity and truth! Symmetrically perfect, its subtle perfume is wafted far and wide; while there it rests in spotless state, something to be regarded reverently from a distance, and not to be profaned by familiar approach.

In my opinion, the chrysanthemum is the flower of retirement and culture; the paeony, the flower of rank and wealth; the waterlily, the Lady Virtue sans pareille.

Alas! few have loved the chrysanthemum since T'ao Yüan-ming; and none now love the waterlily like myself; whereas the paeony is a general favorite with all mankind.

The waterlily of China is the little Nymphaea tetragona, which, though pure white and of pleasant scent, never attains to much more than a pigmy size; and its odor is not nearly so rich as that of our own $N$. odorata. It is interesting also to note that our author is expressing only a personal opinion, one which is not at all general, and which indeed may be regarded as heretical.

India is much richer in gorgeous varieties of waterlily than any other portion of the globe. By day the blue $N$. stellata exhibits several shades of color, even running off by degrees into pink in parts of Bengal. At night and early in the morning the great white $N$. lotus and the deep crimson $N$. rubra expand their flowers 6 to io inches in 
diameter, and the display is enriched by every shade of color connecting the one form with the other. That these have found place in the rich literature of the Hindus is quite certain. But some confusion has arisen on account of the presence and importance of Nelumbo nucifera, the pink-tipped sacred lotus of India. Nelumbo is unquestionably the sacred plant of the Buddhists, the flower upon which Buddha sits, the padma of the Hindu prayer. The only question is whether the few statements assigning a religious value to Nymphaea are to be entirely disregarded, or whether plants of this genus did really receive a minor degree of worship. "Lotus-eyed," "lotus-hearted" and the figure of water on the lotus leaf, all so frequent in Sanskrit literature, certainly refer to Nelumbo. ${ }^{1}$ But when we read in the Mahabharata (Vana Parva, ch. $307,19)$ of a hero "possessed of a complexion bright as the coppercolored lotus leaves," we think at once of $N$. rubra or its varieties. An examination of the Sanskrit, however, ${ }^{2}$ reveals that the root padma occurs here (padmatâmradalojjualain), showing that the plant in the poet's mind was Nelumbo, and we may translate "lotus-petals" in place of "lotusleaves," improving the simile. Again in Adi Parva (ch. I, 86) we read "As the Full-Moon with its mild light opens the buds of the waterlily, so does this Purana with the light of Sruti expand the human intellect." This waterlily is probably $N$. lotus or $N$. rubra, as they are night bloomers. Kâlidâsa makes a similar reference in Sakoontala,

\footnotetext{
"And now

While the round Moon withdraws his looming disc Beneath the western sky, the full-blown flower Of the night-loving lotus sheds her leaves In sorrow for his loss, bequeathing naught But the sweet memory of her loveliness To my bereavëd sight:" (Williams, I856, p. 92.)
}

There is some poetic license here; for Nelumbo does not open at night, but does shed its petals when full-blown, while Nymphaea lotus opens at night, but retreats under water after three nights, taking its petals with it! It seems, however, that $N$. lotus is the plant referred to; for Williams adds in a note (p. I4) that "the moon is often called the 'lover or lord of the lotuses'."

${ }^{1}$ Cf. Dhammapada, ch. IV, 58, 9; ch. xxvi, 40I; Müller I88I. Mahabharata, Adi Parva, ch. 122, 29; ch. 199, 11; Vana parva, ch. 5, 16; ch. 231, 13; ch. 307, 23; Dutt 1895 .

Kindly made for me by my learned friend Albert J. Edmunds of Philadelphia. 
Nymphaea stellata is alluded to in the same poem (p. 15) thus-

"—_ thoughtlessly attempts

To cleave in twain the hard acacia's stem

With the soft edge of a blue lotus leaf."

Graceful and appreciative as are these literary references, and many such might be added, they cannot be regarded as having any religious significance. The Sanskrit words utpala and kamala for the blue lotus $(N$. stellata), kumuda the white night lotus $(N$. lotus) and pundarika white lotus flower, so far as we know, have no religious associations (Macdowell, Elwell, Lanman). Williams (p. 5, notes) states very pertinently that the lotus "is as favorite a subject of allusion and comparison with Hindu poets as the rose is with Persian."

On the other hand, it is stated in an early number of the "Botanical Magazine" (1805) that when a Hindu once entered the study of Sir William Jones where a flower of Nymphaea lotus chanced to lie for examination, he "made prostrations before it" as though this were an act of piety. This reverence is further said to "pervade Hindostan, Tibet and Nepal." Tratinnick (1822) considers the same species to be the sacred lotus of India, without giving evidence. Pickering ( 1879 ) records that $N$. stellata is said to be "distinctly figured in the cave-temples of Adjunta," and that he himself saw it figured in Braminical cave-temples elsewhere in India. Nymphaea rubra appears as the "autumn lotus" in Dhammapada, 285, according to Pickering, and he thinks that this species may be the padma of the Hitopadesa and Vetala panchavinsati I; Graham is quoted as having observed it around Bombay, "in tanks, particularly in the neighborhood of caves or temples." But to the writer, none of these records present any certain evidence of the religious importance of Nymphaeas in India. The account in the "Botanical Magazine" is the most suggestive, but is by no means conclusive, and the use of the flowers as decorative designs for temples indicates no more than an appreciation of their beauty. The presence of the plants themselves "especially near temples," if the observation is trustworthy, may be explained both by the beauty of the flowers and the food-value of seeds and tubers. In the absence, therefore, of any direct evidence that waterlilies are regarded as sacred in India, I believe we have no sufficient reason for attributing this regard to them. 


\section{EGYPTIAN ARCHAOLOGY.}

In Egypt the relations of the waterlilies to the social and religious life were more extended. But after an impartial examination of the facts available, I am strongly of opinion that they received no worship or even reverence here. The teachings of archæological research were brought together long ago by Duppa (1813-1816), and to some extent by Tratinnick (1822), and more recently by Dr. Pleyte (1875), whereas the critical observations of Schweinfurth from I 882 to 1886 have added many interesting facts, and placed many points beyond the reach of doubt. In spite of a complete unanimity among scholars, considerable confusion exists in the popular mind as to the identity of the so-called Sacred Lotus of Egypt. In America, at least, Nelumbo nucifera is commonly styled

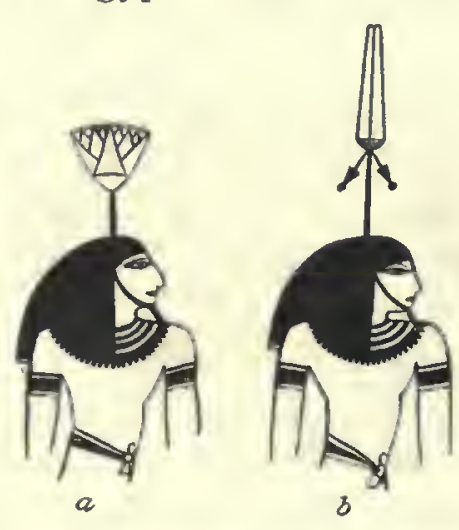

Fra. 1.-Nefer 'Tûm (after Wilkinson).

Sacred or Egyptian Lotus. But Pickering, Pleyte, Joret and Schweinfurth from the botanical side, and Wilkinson, at least, among archæologists, unite in the opinion that $\mathrm{Ne}$ lumbo is never found on the ancient monuments, and that it was not known in Egypt before the advent of the Persians. Not until the Roman period did it find a place in Egyptian art; it does become more or less prominent at this time. But this comes within the limit of recorded history and is discussed in another place.

We must understand, therefore, that the "lotus" of the palmy days when Egypt was truly Egyptian was a waterlily native to the Nile Valley and Delta. Two species are figured on the monuments and tombs, $N$. lotus, the white night-lotus, and $N$. caerulea, the blue diurnal one; of these the latter occurs very much more frequently. Pleyte found the white lotus only on a single tomb, belonging to the XII dynasty, about 2500 в. с. $;^{1}$ this example, however, was plainly distinguishable from the allied species. Schweinfurth $(1884 c)$ found petals of the white lotus along with those of the blue in the funeral wreaths of Ramses II and Amenhotep I, but he never observed any carvings or pictures of this plant, though he says Unger found such at Beni-Hassan. The lotus borne on the head of Nefer Tum in one of his manifestations (Wilkinson, I883, 2:180; Wiedemann, 1897, p. 138) is long and obtuse and suggests

\footnotetext{
'Petrie's dates are followed throughout.
} 
$N$. lotus rather than $N$. caerulea, but it is too much conventionalized to offer any conclusive argument (Fig. $\mathrm{I}, b$ ).

Since the leaves of the blue species are entire and its petals acute, whereas the white one has sharply dentate leaves and broad petals rounded at the apex, the difference is usually evident even in very crude representations (Fig. 2). We recognize the blue one easily in manifold applications. It occurs, according to Schweinfurth (I883 b), on all the ancient monuments of Egypt. The use of its tuberous rhizome for food, is said to have been given to the people by Menes, or perhaps even by Isis (Pickering; Diodorus). At convivial meetings a flower of the blue lotus was presented to each of the guests, and in feasts for the dead, the feasters delighted themselves with the color and odor of this lotus (Buckley). In a carving figured by Wilkinson, the guests are distin-

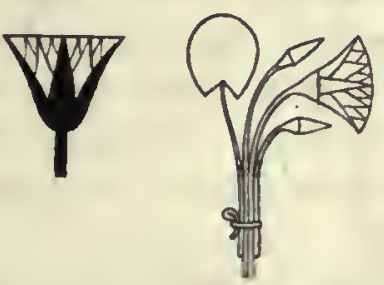

Fra. 2.-Egyptian lotus (designs after Wilkinson)

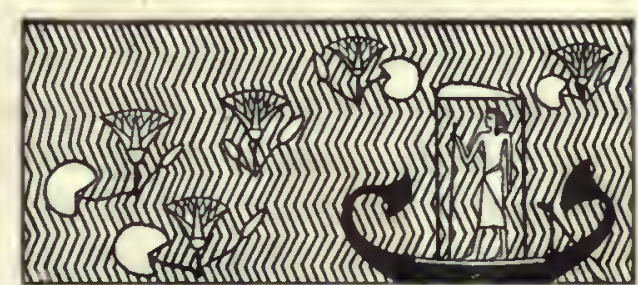

Fig. 3.-Pleasure boat in a pond of lotuses (after Wilkinson).

guished from the hosts and servants partly by their lotuses (see page I, underneath title). In most of these picturings the flowers are considerably conventionalized, but Schweinfurth saw them in the temple of Ramses II at Abydos, and on coffins of the Ptolemaic period, distinctly painted blue. One of Champollion's figures shows a lotus with green sepals, blue outer petals and red inner petals, all of the parts being tipped with black; the red and black must have been inserted for love of variety! An interesting Theban picture shows a pleasure boat, being towed round a pond by three slaves; the water is represented by the characteristic wavy lines, and is made more vivid by a liberal sprinkling of lotuses, both leaf and flower, over the water-surface ${ }^{1}$ (Fig. 3 ).

Just as the blue lotus appears in figures of social life and in recreation, it occurs as a favorite flower in religious observances. It is figured among offerings to the gods in the IV dynasty (Pickering;

I This lotus has also been found depicted on the pavement of the palace of Sardanapalus, but has evidently been copied by the Assyrian artists from Egyptian sources (Bonavia, 1894). 
Pleyte), and stands in front of Osiris at the judgment of the dead (Buckley). "When the Egyptians approached the place of divine worship," Diodorus tells us, "they held the flower of the "agrostis' in their hand, indicating that man had proceeded from a well-watered or marshy land, and that he required a moist rather than a dry aliment" (Wilkinson, $r: 428$ ). This "agrostis" Wilkinson considers to be another name for the lotus (1. c. $3: 350)$. The god Nefer Tûm "was figured as a man crowned with an upspringing lotus flower (Fig. I), a symbol of the resurrection, and of his power to grant continuous life in the world to come" (Wiedemann, p. ${ }^{1} 3^{8}$ ). In one manifestation this is distinctly the blue lotus (Fig. I, a). Ahi, an infant deity is "sometimes represented as sitting on the lotus flower," the vase from which the plant grows representing a lake of water (Wilkinson $3: 132-3$ ). "Osiris, too, swam on a lotus leaf, and Harpocrates was cradled in one" (Whewell). Hâpi, or the Nile, a god widely known and honored, "was sometimes resolved into the Nile of Upper and the Nile of Lower Egypt, the lotus being considered emblematic of the former, and the papyrus of the latter; a design consisting of both plants tied together formed a favorite subject for the decoration of the royal throne, as typifying the king's rule over Upper and Lower Egypt" (Wiedemann, p. I45-6).

The use of flowers in funeral decorations seems to have been very prominent in the XIX to XXI dynasties. The custom was to lay wreaths and semicircles of flowers on the breast of the enwrapped corpse until the sarcophagus was quite packed with these floral tributes. Flowers of Nymphaea caerulea on petioles 18 to 20 inches long were fastened between the bands encircling the mummies of Ramses II and the priest Nisboni, scattered singly all over them (Schweinfurth $188_{3} b$ ). Breastwreaths consisting mostly of petals and sepals of the same plant, sometimes also with petals of $N$. lotus, were found in the coffins of Ramses II, Amenhotep I, Ahmes I (1580 в. с.), the priest Nisboni, the princess Nzi-Khonsu, and the mummy of the case marked KENT, from the XX and XXI dynasties, found at Deir-el-Bahari (Thebes) in July $188 \mathrm{I}$. These are probably the "Egyptian wreaths" of Pliny and Plutarch, the "lotus garlands" of Athenæus. Most of these plant-remains date from nearly 2000 B. C., but those of Ramses II were renewed about I IOO B. c. ; for in moving these sarcophagi at that time into their secret resting-place in the Valley of the Tombs of the Kings, to avoid the marauding hordes from the desert, that of Ramses was accidentally broken; a new coffin and new floral decorations were therefore supplied. The wreaths of 
Amenhotep are perhaps older than the Trojan war! (Schweinfurth, I 883 b). In every case the preservation of the vegetable relics was as perfect as in newly-dried herbarium specimens; they were easily soaked out in water, and Schweinfurth was able not only to identify them beyond doubt and to find out the manner in which the wreaths were fastened together, but also to prepare and mount examples for the Boolak Museum, where his success is attested by eleven cases of plants. Specimens were also sent to the British and several continental museums. A wreath of lotus petals from the coffin of Ramses II was figured in Nature, in I 883 (Schweinfurth, 18836 b). Such a wreath consists of foliage leaves of Mimusops schimperi folded in two or in four and stitched together with fibers from the date-palm in such a manner as to clamp and hold the lotus petals without piercing them; the whole was then strung on strips of leaves of the date-palm. The mummy marked keNT had small whole flowers of $N$. caerulea woven in the wreaths by means of papyrus threads. Sometimes, as in the case of the princess Nzi-Khonsu, the whole body of the mummy was covered several layers deep with these garlands laid in concentric semicircles from the chin downward. It is interesting to note in passing, that Schweinfurth was not able to detect the slightest difference between these ancient plant remains and the species now growing in Egypt. Either these species are not suffering transmutations, or the changes are infinitely slow. Of real importance, however, is the conclusion that since the species are unchanged, the climate also of Egypt must be very nearly the same as it was four thousand years ago. If this be true, the absence of Nelumbo and Papyrus from modern Egypt cannot be attributed to meteorological changes, but we are strengthened in the conclusion that these plants only existed there in ancient times through artificial, i. e. human, agencies, namely by cultivation.

Several additional references to the Egyptian lotus are unquestionably meant for a species of Nymphaea, but whether the blue or the white, the writer cannot now say. Bes, probably a god adopted from the negro tribes, was, at the end of the New Kingdom (500 B. C. ?) "fused with . . . and endowed with all the attributes of the young sun-god, and represented like him as sitting upon a lotus flower" (Wiedemann, p. I67). Plutarch says the Egyptians "characterize the sun as though it sprang every day fresh out of the lotus plant" (Wilkinson, 3: I $32-3$ ), and Proclus pretends that the lotus was particularly typical of the sun, which it appeared to honor by the expansion and contraction of its petals (l. c., p. 350). Wilkinson indicates that this lotus is always $N$. lotus L. (p. I $32-3)$, but 
in this he is certainly mistaken; for the one referred to by Proclus is evidently diurnal, and therefore must be $N$. caerulea. The reader may also be warned against the statement of Prichard that "Nymphaea lotus and $N$. Nelumbo [ = Nelumbo nucifera] appear plentifully on the sculptures of Thebes." The unanimous voice of later observers sufficiently negatives this.

So it appears that the lotus was enjoyed in many ways, but especially as an ornament, a thing of beauty. It was the emblem of the Nile God, for it was the evident product of the river. It was offered to Osiris as any treasured object is consigned to the gods. It was laid upon the bodies of the dead, but other plants could take its place at seasons of the year when the lotus was out of bloom. Thus we see no decided evidence that it was a sacred flower, or an object of worship. It was the "favorite flower in the hands of the Egyptians" (Wilkinson, 3: 1 32-3) as the rose or others might be in the hands of any modern people. It was the symbol of Nefer Tûm and the resurrection just as Lilium longiflorum has a similar significance with us and is used for decoration at Easter.

\section{PRE-LINN EAN LITERATURE.}

The facts of the foregoing account are drawn from the researches of scholars during the past hundred years, and have had no influence upon the growth of botanical science. The beginnings of our present knowledge of the waterlilies are to be found in early Greek and Roman literature, from which a growth can be continuously traced. It is true, however, that classic writers became acquainted with one or two African species of Nymphaea by traveling in Egypt and noting the customs of the people and the plants which surrounded them. For example, Herodotus (Bk. 2, §92) tells us that when the Nile "is full and has made the plains like a sea, great numbers of lilies (xpivov), which the Egyptians call lotus ( $\left.\lambda \omega^{\prime} 0_{5}\right)$, spring up in the water: these they gather and dry in the sun, then having pounded the middle of the lotus, which resembles a poppy, they make bread of it and bake it. The root also of this lotus is fit for food, and is tolerably sweet, and is round, and of the size of an apple." This evidently refers to a Nymphaea, probably to $N$.lotus L.; for the white-flowered form would be more likely to appeal to the writer as a "lily" than the blue $N$. caerulea. The description applies equally well to either species; perhaps, like most other early writers, Herodotus did not distinguish between the two, or did not notice 
that there were two varieties. He goes on to mention other "lilies, like roses," with fruit "like a wasp's nest," and edible seeds "of the size of an olive stone"; this is evidently Nelumbo nucifera. He also uses the word "lotus" in book IV, par. I77, to designate a tree whose fruit is the food of the Lotophagi (Lotus-eaters) and their neighbors the Machyles, tribes of Northern Africa. This, the Forgetful Lotus, is a species of Zizyphus.

Theophrastus ( $\mathrm{Bk} .9$, ch. I 3 ), in a chapter dealing with various plants and roots, speaks of some which are "sour, others bitter, others sweet."

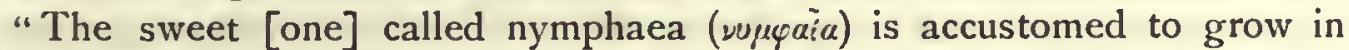
pools and marshes, as in the Orchomenian country, and Marathon, and the island of Crete. The Boeotians call it madonia, and eat the fruit. It bears large leaves upon (supra) the water; [these] ground and placed on wounds are said to stop blood. It is useful also as a drink for intestinal disorders." This has been generally accepted, I think correctly, to refer to $N y m$ phaea alba, the common white waterlily of Europe. Theophrastus also describes Nelumbo, under the name of xírкos.

A brief mention of the "lotus " of Egypt, evidently Nymphaea, occurs in the Historical Library of Diodorus Siculus, written about the beginning of our era. He says (Bk. 1, ch. 3) it grows in great plenty in the delta of the Nile, and is used for bread. He too speaks of Nelumbo, but under

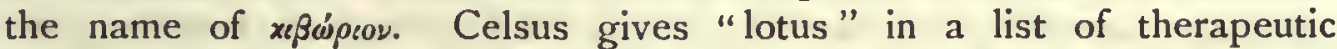
agents for "cooling the body." The word may not belong to the original manuscript, but may have been added in later copies. It is considered to stand for the Egyptian lotus as above.

Dioscorides, in his Materia Medica, devotes a chapter (I I2) in book

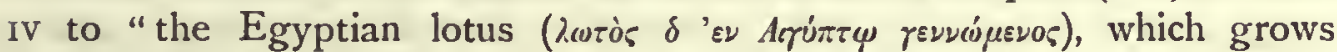
in plains flooded by the water" of the Nile. "The stem resembles that

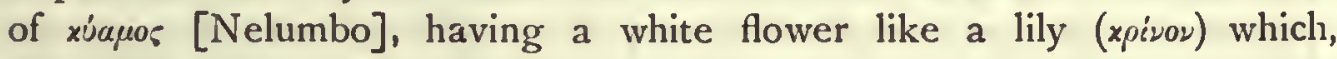
they say, opens at sunrise, and closes at sunset, and the head is altogether hidden under water, and again emerges at sunrise. The head is like a very large poppy; in it is seed (харло́ ; grana) like millet, which the Egyptians dry and beat into bread. It has a root like a quince, which is also eaten both raw and cooked; when cooked it resembles the yolk of an egg." The identity of this with our Nymphaea lotus L. can scarcely be doubted. We find a difficulty in that $N$. lotus is a nightbloomer, and therefore could not possibly be thought by those familiar with it to sink under water at night. But $N$. caerulea grows with $N$. lotus in Egypt, and is a day-bloomer, closing into a very insignificant bud by 
evening; its flowers, however, are not white, but pale blue. We think, however, that $N$. lotus is the one meant by Dioscorides, as its tubers are larger than those of $N$. caerulea, it fruits more freely, and the fruits when ripening are devoid of all the floral envelopes except the bases of the outer stamens, exposing a large poppy-like ovary. The fruit of $N$. caerulea is surrounded by its four sepals and four alternating sepaloid petals, so that its ovary, though equally poppy-like, remains hidden. The story of its behavior at night is a traveler's tale, enlarged upon, as we shall see, by Pliny, and copied many times afterward. Three other kinds of "lotus" are given in Dioscorides: one is the tree of Herodotus' Lotophagi; the other two are leguminous plants near to or part of our present genus Lotus. Nymphaea (vurqaí) appears in book III, chapter I38. He

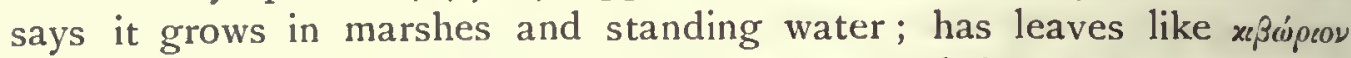
[Nelumbo], but smaller and more oblong, several from the same root, some floating and some submerged; flower white, like a lily (xpizov), with a bulb (xpoxivoss) in the middle. "But when done blooming, there comes a round black body of the shape of an apple or a poppy-head, which contains copious, black, crowded seed, of a glutinous taste. Stem

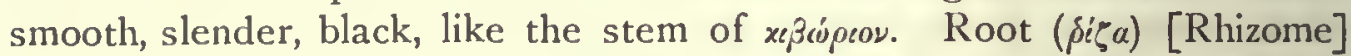
black, rough, like a club ( $\delta$ cyaioions) ; gathered in autumn." Dried and taken with wine, it is recommended for dysentery and bowel complaints ; it is also powerfully anaphrodisiac. ${ }^{1}$ For all these uses the seeds are also good. It is called Nymphaea because it "loves a watery place"; it is found plentifully $\left(\pi \circ \lambda \lambda \eta^{\prime}\right)$ in Elis in the river Anigros, and in Aliartia of Bœotia. This description all together is quite recognizable for Nymphaea alba; the black ovary is the only discrepancy. There is, continues Dioscorides, another nymphaea [which is called nymphona (

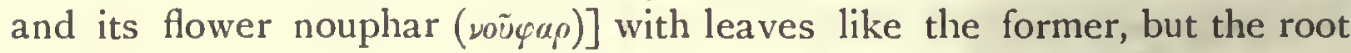
[rhizome] white and rough, flowers yellow, brilliant, resembling a rose. This can be no other than a species of Nuphar. He describes further, in book II, two kinds of xuraos, the Greek and the Egyptian; the former appears to be a kind of bean, the latter Nelumbo ; the fruit of this (which

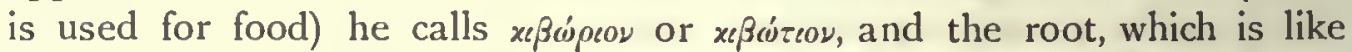
that of a cane, is also eaten both raw and cooked, and is called xoioxāoi $\alpha$.

Pliny in several places in his Natural History, uses the word "lotos" for four different plants, the herb lotos, the Egyptian lotos, a shrub lotos (perhaps the pomegranate) and the tree lotos. The fruit of the second of

1 "Eadem contra veneris insomnia bibitur, quae adimit : quin et aliquot diebus continuo pota, genitale flaccidum et enerve reddit." Edit. Sprengel, 1: 479. 
these (Bk. 22, chap. 2I) he calls "lotometra" and states that the Egyptian bakers knead the flour of .its seed with milk or water to make bread. He adds, to give the quaint English of Philemon Holland's free translation (p. I 25). "There is not any bread in the world (by report) more wholesome and lighter than this, so long as it is hot ; but being once cold, it is harder of digestion and becommeth weightie and ponderous." In book XIII (ch. I7) the "Egyptian lotus" (a Nymphaea) is described in almost the same words as those of Dioscorides: its occurrence and habitat, its poppy-like head, and seed resembling millet. He tells us that the Egyptians gather the heads, lay them in heaps until they putrefy, then wash the seeds clean, dry and grind them. Pliny repeats the story of the closing of the flower at sunset, stating only that it is covered with leaves until sunrise; also that the flower is white. But though he is more reserved in statement here than is Dioscorides, he goes farther in telling of the behavior of the "Egyptian lotus" in the Euphrates (chap. 18). There, he says, the flower is plunged beneath the water at evening, so deep that a man cannot reach any part of it with his hand; but after midnight it rises slowly, appearing above water again at sunrise. He tells us in addition that its root is covered with a black rind, and is good to eat, especially when boiled or roasted, and that it is excellent for fattening hogs. Nelumbo is mentioned by Pliny in two places under the names "colocasia," "cyamos" and Egyptian bean (faba). The description of Nymphaea in Bk. 25, ch. 7, reads much like that of Dioscorides. A few new features are introduced. The name and the plant, it is said, originated from a nymph who died of jealousy through love of Hercules ; hence the plant is called by some Heraclion; but by others it is called rhipsalos, for its club-like rhizome (radix). It grows in water and has broad, floating leaves. The other features of the plant, its names, localities, and uses, and the yellow Thessalian variety are exactly as given by Dioscorides, and the identities of all these are subject to the same doubts and assurances as those given in discussing that writer.

At that remarkable banquet imagined by Athenæus, the conversation turned on Alexandria, whereupon one of the feasters tells about the "lotus" which grows in the marshes near that city in summer; "it bears flowers of two colors, one like that of the rose, and it is the garlands woven of the flowers of this color which are properly called garlands of Antinous; but the other kind is called the lotus garland, being of a bluish (xuaveav) color" (Bk. I5, ch. 2 I). The first plant is probably Nelumbo, the second Nymphaea caerulea Sav.; we have here the first 
mention of Nelumbo under the name of lotus, and the earliest Latin or Greek record of a blue Egyptian lotus. Nelumbo is frequently mentioned elsewhere by Athenzus, once again under the name of lotus,

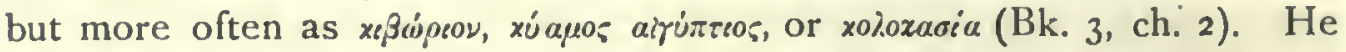
says, at variance with all other writers, that the Egyptians call this plant lotus, but quotes the other names from Nicander, Theophrastus, Diphilus the Siphnian, and Phylarchus.

Galenus adds nothing to the facts and theories of his predecessors concerning these plants. He recognizes three kinds of lotus (Bk. 7, ch. II), the herb, the tree and the Egyptian lotus (Nymphaea), and two kinds of Nymphaea (Bk. 7, ch. 13), one with black rhizomes and one with white; these correspond with Dioscorides' descriptions of Nymphaea alba and Nuphar. He simply mentions Nelumbo, under the name of faba Aegyptia (Bk. I, ch. 20).

From this time onward we find nothing of note for our science until it revived with the Revival of Learning. William Turner in I 548 gives this quaint note in his catalogue of "The Names of Herbes:"

"Nymphea is also named in greeke nymphaia \& madonais \& is called in english water Roses, \& some with the Potecaries cal it nenufar. The duch më cal thys herbe Seeblumen. Boeth the kyndes of water Roses growe in standyng waters."

Mr. Britten (cf. Turner, I 548, p. I 30) has identified "boeth the kyndes" as Nymphaea alba L. and Nuphar lutea Sm.

Three years later Fuchsius and Hieronymus Bock (Tragus) in Germany published their botanical classics. The former has a rude woodcut of the white waterlily with the Latin name Nymphaea candida

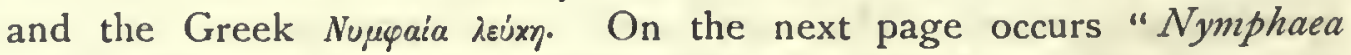
lutea," with a figure which identifies it with Nuphar.

Tragus goes into the subject much more extensively and shows evidences of personal observation. There are two kinds of "Seeblumen," the white and the yellow, of which the former is commoner. He compares the flower of this to a beautiful double (gefiult) lily or rose, with each petal shaped like one's thumb; and in the midst of the flower is a golden yellow sun (ein schöne goltgále Sonnen), and it is odorless. He describes the shape of the bud, and its green "outer leaves." The broad, round, disc-like foliage leaves, he says, are stiff and leathery, and grow on smooth hollow (lucken) stems. His figures are quite crude but recognizable, the "Weiss Seebluomen" as Nymphaea alba, the other 
as Nuphar. A long list of common names is given: Wasser Gilgen, Haarwurz, Haarstrang, Nenuphar in apothecary books, Clavus Veneris, Digitus Veneris, Alga palustris, Papaver palustre. The account of the medicinal virtues of these plants does not materially differ from those previously given.

Matthiolus, in his Commentary on Dioscorides (I 554), transcribes the chapter on Nymphaea from that writer with numerous slight verbal
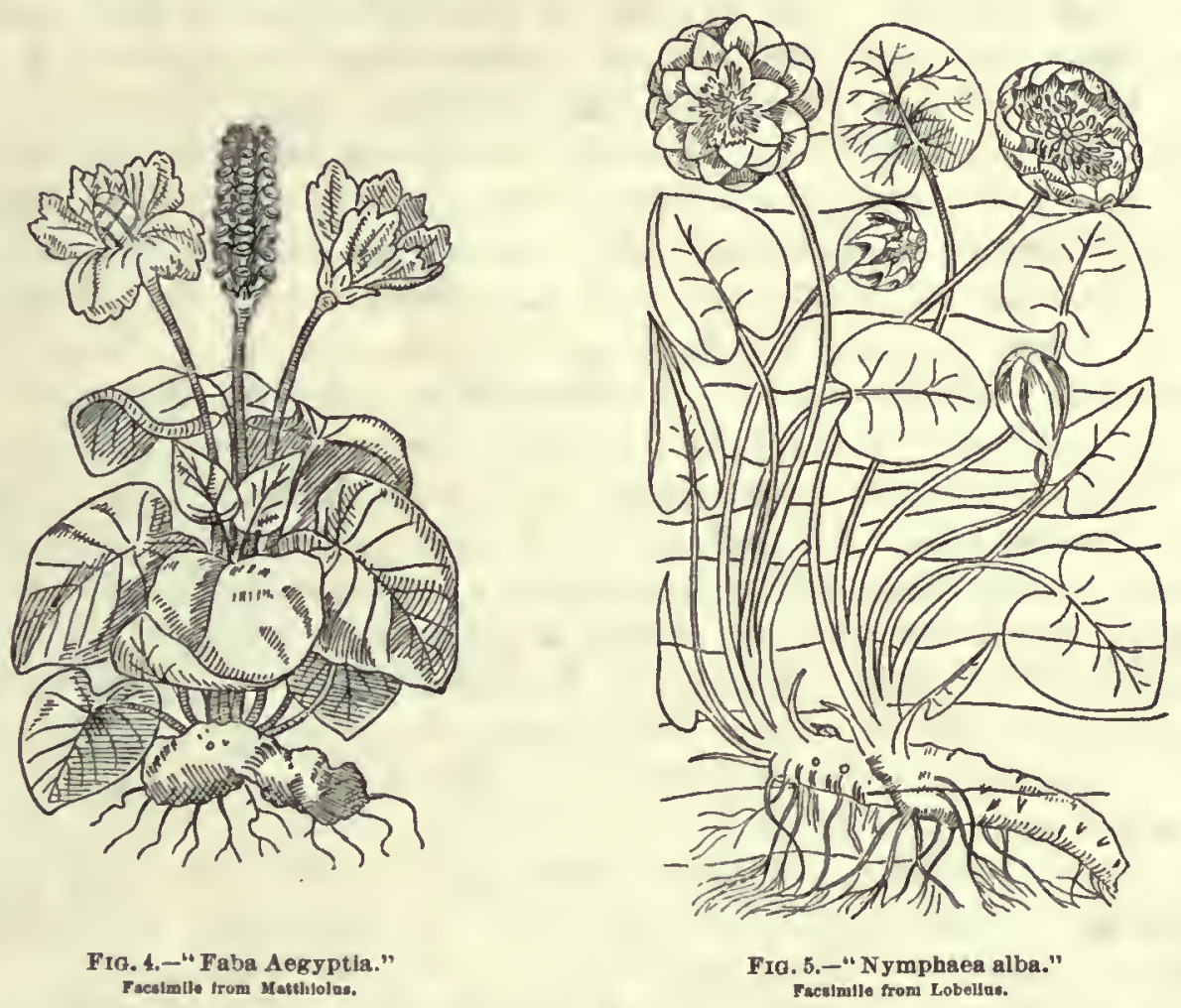

changes. He understands "Nymphaea" to signify our $N$. alba, and gives "Nymphaea altera," also called "blephara," for Nuphar. The two are figured side by side in rude but quite recognizable cuts; but these may have been inserted by C. Bauhin, whose notes were added to the original in the edition which I have seen. On the identity of the Egyptian Nymphaea and Nelumbo, Matthiolus was hopelessly at sea; for Nelumbo had been so long extinct in Egypt that nothing could be found there to correspond with the descriptions given by the classic writers. So, after much weighing of evidence, our author invented 
a unique figure (Fig. 4) to show what this confused plant must be-a figure which formed the basis of a heated discussion for the next three quarters of a century. We can only refer to this in passing, since Nelunbo, and Arum, and Colocasia are the genera most nearly concerned. Lobelius' "Observations of Plants" ( 576 ) figures two "Nymphaeas," $a l b a$ and lutea, and gives their medicinal virtues at length. The cuts are rude, but original and easily recognized (Fig. 5) as the species still bearing those specific names. In the "Adversaria Nova," Nymphaea lutea is given before alba, with most of the synonyms used by Tragus and in addition Nenuphar officinarum, plompen (Dutch), Escudetes del Rio and Higos del Rio (Spanish), Water lilie, blanc d'eau and Lis d'estang. From this time forward, waterlily is a term consistently used as a synonym for Nymphaea to the present day, except that in Devonshire, Eng., Iris pseud-acorus has shared the same common name (Friend, I 882). Nymphaea alba is not directly given any common name by Lobelius, but it is evident that some of those given above apply to it; he says it is sometimes called "major" to distinguish it from "N. alba minor," by which some small white flower, probably Limnanthemum, is designated. A "Nymphaea lutea minor Septentrionalium" is also figured ; it may be our Heteranthera. "Nymphaea," therefore, would seem to be definable as an aquatic plant with evident flowers and floating leaves; the idea represented by the word is acquiring a more distributed content. "Lotus Aegyptia" (Nymphaea lotus L.) is discussed on pages 385 and 386, but Lobelius is unable to interpret the descriptions given by the older writers, and regards the whole thing as a fabrication. He seems to have no idea of such a plant as Nelumbo.

Lyte's Herball (1578) ( $f d e$ Britten and Holland, 1879) gives a single name for the white and yellow waterlilies, viz., nenuphar. This name was also corrupted into " ninnyvers."

In 1589 , Petrus Bellonus published observations from Greece, Asia, Egypt, \&c.; he found nothing in Egypt to correspond with the old descriptions of Nelumbo, but found the word "colocasia" used for the root of an aroid which was used for food, as was already known by Matthiolus. So he concluded that Colocasia, Lotus, and Faba Aegyptia were synonyms, and made vain endeavors to interpret Herodotus, Theophrastus, Dioscorides and Pliny in harmony with this view.

A great beam of light was shed on the subject, however, by Alpinus (1592), who made a special study of the Egyptian lotus. Finding no sign of Nelumbo, but only nymphaeas and aroids in Egypt, he considered the 
ancient writers wrong in their synonymy ; colocasia, he said, was an aroid. "Lotus Aegyptia" he believed to be the white flower which, from its resemblance to the European waterlily, he had no hesitation in calling a "larger nymphaea"; in fact he regards it as practically identical with the species so familiar about Venice. For both have the poppy-like head, and seed like millet, and both, he said, retreat under water at sundown to emerge again in the early morning, "as is observed by everyone in the common nymphaea" (quae in communi nymphaea ab omnibus animadvertitur). Indeed he was surprised that Pliny and others thought this behavior strange in the Egyptian lotus. Both flowers and leaves are submerged at night, according to Alpinus, the flowers emerging first, at sunrise, and a little later all the leaves appear. Of course this does not really occur; but the flower of Nymphaea alba closes into a tight bud during the afternoon and is covered by the dull green sepals, to open again with the light of the next day; the disappearance of the leaves, however, must have been purely owing to darkness, and their reappearance after the flower must have been due to their darker color. Alpinus stated that the white Egyptian lotus was called by the Arabs "nuphar," and by the Hebrews "Arais el Nil." After the publication of the work just discussed, Alpinus received numerous tubers of the Egyptian lotus from a Venetian doctor in Cairo ; they were of the size of a walnut, ovate, with fibrous roots, blackish outside, yellowish within ; they were said to be eaten freely by the Egyptians, both raw and cooked; the sender also said that the plant resembled the lesser nymphaea $(N$. alba L.) except that the flowers were blue. "The which, if it be true, this is the lotus niloticus of Athenæus." Alpinus figures it with entire leaves, insuring its identity with $N$. caerulea Sav. At a still later date (1735 b), the same writer summed up the knowledge of the Egyptian lotus ("Lotus Aegyptia") in a "dissertation" on the subject. As synonyms are given Lotus niliacum, Nymphaea, and Nuphar Aegyptium. The flower and its stalk are called Arais el Nil, the leaf and petiole Bis el Nil, the root (tuber) Biarum. Four plates are devoted to it; one shows the whole plant, with its dentate leaves, ovoid tuber and the fruit devoid of floral leaves; another shows the calyx and fruit on a larger scale; the third shows two fully open flowers, and the fourth gives an enlarged view of a leaf and a tuber. The flower is described as having the four outer leaves green outside and white within, each with five to seven or more longitudinal nerves, spreading wide open when in bloom. Within these are about 12 smaller leaves [petals], pure white; then 25 to 40 long acute leaves [outer stamens], 
white below and yellow above; then a fourth series of slender yellow leaves [stamens] and a fifth series of almost capillary members [innermost stamens], followed by a row of narrow incurved bodies [carpellary styles]. At the middle is a small, hard globule, and a head containing the seed. The fruit is round like that of Nymphaea alba, with a green cortex, and seed like that of cabbage. The peduncles are hollow, and of the size of one's finger. The leaves are crenate (the crucial point of the description), of a dark green color, and so numerous as to cover the whole surface of the water; they die away in November, so that Alpinus considered the plant annual, in spite of the fact that it comes up again at the next flooding of the Nile. The root, he says, is ovate, of the size of a hen's egg, blackish outside, yellowish inside, and tastes at once sweetish and astringent. This excellent description of Nymphaea lotus deserves permanent recognition. It represents a masterly attempt to bring order out of the chaos which then existed, and that by the true scientific method of observation. Had subsequent descriptions been as well written, many of our difficulties in nomenclature would not have arisen.

We may mention here, following the chronological order, that Philemon Holland, in I60I, translates the word nymphaea used by Pliny as "Nemphar"; this name for the waterlily must have been more or less common, therefore, in England at that time.

Clusius in his earlier works (1576 and I60I) continues the fruitless discussion of the relations of Lotus, Faba Aegyptia and Colocasia. Concerning Lotus Aegyptia, however, he quotes at length from the valuable text of Alpinus; but, ignoring the latter's excellent illustrations, he copies the crude figure of the white waterlily from Matthiolus (in fact, the same block was evidently used in the printing), and introduces confusion by labeling it "Nymphaea alba. Lotus Aegyptia Alpini." Beside it appears Matthiolus' cut of Nuphar, marked "Nymphaea lutea major." "In 1605, however, he raised the cloud which obscured the Egyptian bean of classic writers by figuring and describing a fruit of Nelumbo, brought from Java by an intelligent sea-captain.

Dodonæus ( $158_{3}$ ) recognizes only two species of Nymphaea, namely alba and lutea. His figures of these are almost if not quite identical with those given by Lobelius, and his description and synonymy bear a striking resemblance to the text of Hieronymus Bock. The white species (candida), he says, has great, broad and nearly round, smooth, floating leaves on long, terete, smooth, porous petioles; flowers solitary, on similar stalks, composed of many oblong and acuminate leaves, in 
the midst of which are many yellow stamens. After the flower, a round head is produced, in which are very many black, shining seeds, like millet. The rhizomes are thick, nodular, black outside, white and spongy within, fastened in the mud by many fibrous roots. In addition to the synonyms given by Lobelius, Dodonæus tells us that Nymphaea is Nenuphar of the shops, and that Apuleius gives the Latin names "mater Herculania," "alga palustris," "clavum Veneris," “digitum Veneris," and the Gallic name Baditin. To these Dodonæus adds Wassermahnen and Haar-strang of the Germans. The medicinal powers of the herb are discussed and the subject is then dismissed without any reference to the Egyptian species.

Besler's magnificent folio (1613) illustrates in color three kinds of Nymphaea : $N$. alba major, $N$. alba minor, and $N$. lutea, known now as Nymphaea alba, $N$. candida, and Nuphar lutea respectively. The description of " $N$. alba major" is given with singular accuracy in many details : leaves broad, smooth, thick, green, cleft to the petiole, etc. ; radix spongy within, and marked with blackish scars (foliorum vestigiis), etc. In the figure, the characteristic round root-scars are very plain.

The material is now in hand for a satisfactory summing up of the knowledge of botany as determined by the progressive increase of accuracy and the widening horizon of science up to this time; and the summing up was duly made by Caspar Bauhin. In the Pinax (I623) he divides Nymphaea into two "genera," one with white flowers and black rhizome, the other with yellow flowers and white rhizome; the latter, called "Nymphaea lutea" includes Nuphar and some other types. The former, "Nymphaea alba," is divided into four species. The first of these, with its synonymy, is :

"Nymphaea alba major

Nenuphar album, Brunfelsius.

Nymphaea alba, Brunf. Matth. Ang. Dodon. Cord. hist. Lon. Ad. Lobel. Taber. Thal. Ger. Clus. hist.

Nymphaea candida, Trag. Fuch. Tur. Caes.

Nymphaea major alba, Lugd. Cast. Eyst.

Lotus Aegyptia, Alpini.'

The last synonym is unquestionably wrongly placed. The second species of Bauhin is "Nymphaea alba minor," being "Nymphaea parva, Matth." Whatever the plant may be, it is not a Nymphaea in the present sense; and the same may be said of the third and fourth species of Bauhin. The consideration reduces for our present purposes to a single species, in which, however, two, and possibly three, quite distinct plants are 
included, namely, the European species $N$. alba, and perhaps $N$. candida, and the Egyptian white lotus, $N$. lotus L. The blue Egyptian lotus, $N$. caerulea Sav., mentioned by Athenæus and Alpinus, is quite left out.

A unique volume is Gerard's "Herball or Generall Historie of Plantes" published in 1636. Of his five "Water Lillies" only the first would now be placed in the genus Nymphaea; this is "Nymphaea alba, White Water Lillie," given in the index of the work, however, as "N. alba major." The second species is "Nymphaea lutea," our Nuphar; the others have no relationship with the Nymphaeaceae. The figures of the first, second, fourth and fifth species were apparently printed from the same blocks as were those of Matthiolus, and the text is but an abbreviated tranislation of the same writer. The Egyptian lotus is not mentioned at all by Gerard.

Vesling, editing Alpinus in I640, recognized the difference between the European and Egyptian white waterlilies and discussed their relationships. He tells us also that the white lotus flower is woven into triumphal crowns.

In the same year Parkinson's fascinating “Theatrum" appeared; his archaic English is most entertaining. He gives a burning paragraph on the "Egyptian bean" question, having full knowledge of that plant (which we know as Nelumbo), and arraigning Matthiolus for his "false" and imaginary figure of it (Fig. 4). At no point does he refer to this plant as "lotus." In chapter 29 he gives "Nymphaea, the Water Lilly," with seven species:

I. N. alba major vulgaris, The great common white Water Lilly.

2. N. alba major Aegyptiaca sive Lotus Aegyptia, The great white Water Lilly of Egypt.

3. N. alba minor [Not a Nymphaea as now understood].

4. N. alba minima quae et Morsus ranae vocatur.

5. $N$. lutea major [Nuphar].

$\left.\begin{array}{l}\text { 6. N. minima lutea } \\ \text { 7. N. lutea flore minore }\end{array}\right\}$ [Not Nymphaea as now understood].

The first is of course our $N$. alba L.; it is illustrated by a copy of Lobel's figure (Fig. 5). The second is our $N$. lotus L., and is accompanied by Alpinus' figure of the whole plant. Referring to the resting period of this plant in winter, Parkinson suggests-perhaps in criticism of Alpinus-that the plant has been therefore "called annual, but I would call it restible."

A compilation of former observations with valuable comments, was made by Bodaeus à Stapel in the 1644 (Amsterdam) edition of Theophras- 
tus. He considered the word Nenuphar a corruption of the older Greek nouphar. But his description of the European waterlily is the valuable feature. The leaves, he says, are on long, terete, glabrous, porous peduncles, are approximately round, firm, almost coriaceous, for the most part floating on the water; upper surface smooth, distinctly veined beneath. Those which lie concealed below the water are thinner and softer. Flowers solitary, on stems like the petioles, made of many floral leaves, so that sometimes a single flower is composed of twenty-five to thirty or even forty leaves, each of the shape of one's thumb or a leaf of the greater Sedum. From the middle of the flower many yellow stamens project. Bud oblong, its outer leaves [sepals] purplish green. Flowers scentless, shining like the sun. Here, curiously enough, reappears the myth of its retreat below the water at evening and emergence at sunrise. The account continues: After the flower, there is produced a head like a poppy or round apple, with black shining seed, larger than millet. The rhizome (radix) is about as thick as one's arm, knotty, black outside, white and spongy within, odorless, tasteless, beset with and fastened in the mud by fibrous roots. Bodæus calls this plant "Nymphaea alba major." Two other varieties of "N. alba" and four of "N. lutea" are next described, but they are all outside our present genus Nymphaea and need not be considered here. At another place $N y$ mphaea lotus is fully treated under the name of "Lotus Aegyptia," giving all of Alpinus' figures. Bodæus thinks this plant should not be classed with Nymphaea on account of its bulbous root. He thus differs in opinion from Alpinus, and especially from C. Bauhin.

Piso (1648) gives us the earliest account of an American Nymphaea, in a Brazilian species. "Among those plants," he says, "which are common to Europe and the western world is Nymplaaea, called by the Brazilians $A g u a p e ́$, by the Portuguese Galvaon, which is noticed everywhere floating on the surface of pools and still waters. The leaves are similar to our Nymphaea, with a great network of veins beneath." The flower has a pleasant odor, and consists of four green sepals and about twelve narrowly oblong, acute, white petals. Its medicinal virtues are also detailed. Just what species is here referred to cannot be positively identified, nor does the crude figure accompanying assist. But from the character and number of the petals, and the fact that we know of but one white day-blooming waterlily in Brazil, we have but little hesitation in referring it, as did Caspary (1878), to $N$. ampla DC.

Bontius, whose accounts of the East Indies were bound in with Piso's 
of the West Indies in 1658 , devotes considerable space to "Nymphaea Indica flore purpureo"; the figure and description relate very clearly to Nelumbo and may be omitted here.

Another new feature is introduced by Flacourt (166I) in his " History of the Great Island of Madagascar." He found there a blue waterlily, which was considered a delicious food. It is called by the natives "Tantamou." Instead of being anaphrodisiac like the European species, this one provokes to excesses. The white waterlily, says Flacourt, is called in this country "Laze-Laze," and the yellow flowered one "Talifouc." The roots of all three are used for food. The identities of all of these are in the highest degree uncertain. The blue is probably $N$. capensis or $N$. madagascariensis. The white may be $N$. lotus, or a mere variety of the blue. The yellow one may be a Nuphar; at any rate, no yellow Nymphaea is known at present from that island.

Returning to the European flora, we may gather a few points from J. Bauhin's "Histoire des Plantes" (1670). Curiously enough he quotes the name Nymphaea alba minor, with the synonym $N$. parva Matth. from C. Bauhin, as signifying the European white waterlily, and adds a number of the common names given by Lobelius. The real identity of the plant is rendered certain by a crude picture. The peculiar mixing of the names remains unexplained.

Chabræus (1677) records five species of Nymphaea, viz.: $N$. alba vulgaris, $N$. lutea, N. minor lutea Lobelii, N. minor lutea flore fimbriato, $N$. alba minor. The last four would not now be classed in the genus Nymphaea at all. The figure of $N$. alba vulgaris, is an enlarged and very slightly modified copy from Fuchsius.

John Ray's "Catalogue of Plants of England" (1670) mentions five Nymphaeas, of which only the first, "Nymphaea alba," belongs in the genus as now constituted. The only information given in addition to the name is the words "In fuviis. Florem habet plenum." The "Methodus Plantarum" of the same author (1682) is especially interesting for its freedom from slavery to the classic writers. The twenty-fifth genus contains "Anomalous herbs and those of uncertain position"; the first section of these is headed "Anomalae Aquaticae," and the first of these is Nymphaea, plants with round to oblong, floating leaves, differing in their flowers. Three varieties are mentioned, of which " $N$. alba vulgaris" is the only true waterlily, the common white one of Europe. The "Historia Plantarum" (1688) follows the classification of the "Methodus" in general, but describes the European white water- 
lily as $N$. alba simply. In many points the description is only a repetition of earlier writers; the flowers are said to be odorless, with the outer leaves greenish as in Ornithogalum (ut Ornithogali). A "Nymphaea Brasiliensis," known to the natives as Aguapé, and described in nearly the same words as used by Piso, is given here, on the authority of Marggrav's observations, and classed as belonging to $N$. alba. A fifth species is added, $N$. alba major Aegyptiaca. The specific description of this refers to the "crenate leaves" which identify it with $N$. lotus L., and the statement is added, "flores ... semper supra superficiem aquae." The object of this addition comes out when in the succeeding paragraph the stories of Theophrastus, Pliny, and Alpinus are given regarding the retirement of the flower far under water at night, and the writer boldly concludes, "Nobis certe incredibilia videntur."

Jacobus Breynius ( 1680 ) is one of the few among the early botanists who considered new and foreign plants. His second Prodromus gives "Nymphaea flore coeruleo odoratissimo, Cap. bonae spei ; nobis," and "Nymphaea flore suave purpurascente Japonica; nobis." The former is doubtless $N$. capensis Thunb., the latter Nelumbo.

The magnificent "Flora Malabarica" of Van Rheede (1692) contains figures of a number of water plants. In vol. II, plates $26,27,28$ and 29 represent plants with floating leaves, all under the general Malabar name of Ambel. The first, called simply Ambel, is Nymphaea pubescens; the second, Cit-Ambel is the source of Willdenow's Nymphaea stellata, a blueflowered waterlily. The other two, Nedel-Ambel and Tsjeroa-Ambel are Limnanthemums. All are quite fairly recognizable from the engravings, at least as to their generic position. It is interesting to note that the natives of the Malabar coast classed Nymphaea and Limnanthemum under the same type or genus, just as did their European contemporaries. The text accompanying the plates refers chiefly to the medicinal properties of the plants.

In I696 Commelin published Latin names and synonymy for the species illustrated by Van Rheede. To Ambel he gave the title "Nymphaea indica, flore candido, folio in ambitu serrato," although he regarded it as identical with the Egyptian white lotus according to Parkinson, Alpinus, and Vesling. Cit-Ambel was dubbed "Nymphaea malabarica minor, folio serrato" and was a new species to European botany.

Perhaps the most magnificent and exhaustive botanical work of the pre-Linnæan period is the "Phytographia" of Plukenet (I69I-96), with its exquisite engravings and its several companion volumes of text. We 
cannot tell exactly what this writer understood by the term Nymphaea ; for of the four varieties figured in the Phytographia, one appears to be Trientalis, another is plainly Marsilia, a third is Nelumbo, and the fourth Limnanthemum. The genus is still more comprehensive in the "Amaltheum " (1705), including in addition to those above mentioned our $\mathrm{Nym}$ phaea alba and $N$. lotus as well as Nuphar, Hydrocharis, Podophyllum, and some others whose brief descriptions are unrecognizable. Several of these had been much more scientifically disposed of by earlier authors with whose writings Plukenet was fully conversant. In the "Mantissa" ( 1700$)$ Brasenia and Pistia are added as species of Nymphaea, additions which one can easily understand. Nymphaea capensis is also given under the name and on- the authority of Breynius as quoted above, but it is confused with Nelumbo. Finally an American terrestrial plant classed by previous writers as a Brassica, is here classed as a species of Nymphaea. The white Nymphaea or Laze-Laze of Flacourt is referred by Plukenet in the "Amaltheum" to his "Nymphaea Indiae" (Nelumbo). P'lukenet brings in no new information for our subject.

In 1 joy Sloane described a white flowered Nymphaea with the edges of the leaves "deeply cut," from the "Fresh River" in Jamaica; he says its leaves agree with the description of the white lotus of India, and hence he speaks of it as " $N$. Indica flore candido folio in ambitu scrrato" of Commelin. The identity must have been mistaken, since none of the Old World species are native in the new. Caspary has rightly identified this with $N$. ampla DC. In discussing the names, Sloan suggests that the Indian and Egyptian white lotus seem to him to differ very little; English botanists now rank them as one species. He also states, quoting authority, that his Jamaica waterlily was carried to the Indies by way of merchandise. Perhaps this is an attempt to explain its supposed identity with the Egyptian plant.

By all odds the best pre-Linnæan classification of plants, as is well known, was that of Tournefort ( 1700$)$. The waterlilies are placed in his Sixth Class, "herbs and suffruticose plants with rosaceous flowers." Nymphaea is the last (eleventh) genus in the fourth section of this class, while Nelumbo is separated from it as the first genus in section five. In this respect Tournefort came nearer our present ideas than Linnaeus, who made Nelumbo a species of Nymphaea. The genus Nymphaea is defined in the "Institutiones" as having a circle of many petals, and a pistil rising from the midst which forms a globose or conical multilocular fruit filled with many oblong seeds. The floral leaves and the fruit are putrescent, and 
the genus is "easily recognized" by the broad sub-rotund floating leaves. "Nenufar" is given as a generic synonym. Four spécies are named :

I. "Nymphaea alba, major C. B. Pin.," our $N$. alba.

2. "Nymphaea Americana, foliis circinatis, maximis, acute crenatis, subtus purpureis, flore albo Plum."

3. "Nymphaea Americana, foliis circinatis, minoribus, obtuse crenatis, subtus viridibus, flore albo Plum."

4. "Nymphaea lutea, major," our Nuphar luteum.

In vol. 2, p. I 37-8, the flowers, petals, ovary, fruit and seed of $N y m$ phaea alba and Nuphar are figured, with also a cross-section of the fruit of each. We are not prepared to settle the identity of Plumier's American species; it seems likely that No. 2 may be referred to $N$. ampla DC., and No. 3 to $N$. rudgeana Mey.; Caspary so placed them (1878). We cannot explain the absence of $N$. lotus from the list, unless it was meant to be included under the species $N$. alba major, as classed by C. Bauhin, who is quoted as authority for this name.

Finally Ludwig's ( 1 737) arrangement of the genera may be mentioned. He separated Nymphaea from Nelumbo, as did Tournefort, and described the former genus as having five sepals and many small petals; this is doubtless our genus Nuphar. He made an additional genus "Leuconymphaea" which has many petaloid stamens, and covers our present genus Nymphaea, as was recognized by Kuntze (1891) and MacMillan (I892).

The early plant anatomists seem to have neglected Nymphaea entirely. Grew and Malpighi make no mention of the genus. Vaillant in his essay on the structure of flowers ( 1717 ), refers to the "Grand Nenufar-blanc" as illustrating the condition where the stamens arise from the sides (reins) of the ovary. Older writers, as we have noted, referred occasionally to the "spongy" rhizomes and the "porous" petioles and peduncles. The Linnæan and post-Linnæan literature will be cited throughout the course of the present paper. 



\section{CHAPTER II.}

\section{STRUCTURE.}

The habits of waterlilies are too well known to need more than a brief statement here. These plants are found in the shallows of slow streams or still water all around the world. The long rhizomes of the Castalia group creep along in or upon the mud bottom of ponds or in a tangle of vegetation overlying this, in a depth of water from a few centimeters to as much as 5 or 6 meters, branching here and there, and dying off behind as they advance by apical growth. By far the greater number, however, have an erect, tuberous stem or caudex, which never acquires any considerable length, but stands with its growing apex about on a level with the mud in which its lower portion is buried. From the stem in every case a great many stout, fibrous roots pass downward and anchor the plant in place, while the leaves and flowers rise upward. The former lie flat upon the water surface, the upper side being dry and exposed to the air. Under some conditions the petioles may be strong enough to hold up the leaves and make them totally aerial. All of the species, at certain periods of growth (germination and beginning of each annual growing season), produce small, thin leaves which lead a submerged existence. The flowers of about half of the species open at the surface of the water and seem to float upon it, those of the other half are raised on strong peduncles some distance above the water level. Only in one or two species ( $N$. rudgeana, $N$. amazonum) is cleistogamy known to occur. The flowers in such cases never reach the air, or only do so for a few hours, after self-pollination has been effected. After anthesis the fertile flowers are drawn down into the water by movements of the peduncle, and here the seeds ripen. By means of a buoyant aril, the ripe seeds from the irregularly bursting fruits rise to the water-surface and are floated far and wide.

These peculiar conditions of life have impressed themselves strongly upon the forms and functions of the waterlilies. Manifold adaptations have arisen in every part of the plant. We shall discuss these in order in the succeeding pages, taking up first the gross morphology, then the finer anatomy of root, stem, leaf, and flower, and finally the physiology of the genus. 
THE ROOT.

The primary root in Nymphaeaceae is of short duration; in Nelumbo, indeed, it never becomes more than an embryonic rudiment. The entire root-system, therefore, of mature plants of this family is adventitious. The following description relates to conditions in mature Nymphaeas, the course of affairs at germination and immediately afterward being reserved for a later chapter. On digging out a well-grown rhizome of a waterlily, we find it beset by a great number of long, terete, white, spongy roots. In large tropical species ( $N$. caerulea, lotus, flavo-virens, zanzibariensis, capensis, and hybrids) these may be a centimeter or more in diameter, and they are nearly as large in strong specimens of $N$. alba; in $N$. odorata they measure usually 0.3 to $0.6 \mathrm{~cm}$. in diameter. Each root is decidedly contracted at its point of junction with the stem, but reaches its greatest diameter about $5 \mathrm{~cm}$. out, or less; thence it tapers almost imperceptibly to its apex 30 to 60 or $100 \mathrm{~cm}$. away.

In species with a short caudex (Apocarpiae; Lotos, Hydrocallis) these roots may be so numerous and close together as to be deformed at the base into prismatic shapes; in Eu-castalia the internodes are so elongated as to cause the roots to appear much more scattered. For the roots all arise from the bases of the petioles, or (in Eu-castalia) from an upraised cushion-like portion of the rhizome upon which also the petiole is inserted (Fig. 20). In $N$. flavo-virens and its hybrids a thick irregular excrescence remains after the decay of the petiole, projecting from the tuber a centimeter or more, on the lower side of which the roots are borne, to the number of 5 to 13 . In $N$. odorata 3 to 5 or 6 roots occupy a triangular area on the cushion behind each petiole; the apex of the triangle is farthest from the petiole and is occupied by the first formed root; this one is of medium size. Next to it is a second and much larger root, and the base of the triangular area is covered with a few much smaller ones. Some of the roots of young plants, and of adult specimens of $N$. flavo-virens, are transversely wrinkled in their upper parts, showing a contractile power. No co-ordinate branches are given off by the roots as a rule, but they are all clothed with a great number of slender rootlets, and the larger of these may again be beset with capillary branchlets; this arrangement may compensate for the total absence of root-hairs throughout the adult plants. A root-cap is present on the tip of every root and rootlet, often showing the long, thimble-like shape so frequent in water plants; it may be black or brown in color, but is frequently colorless or whitish on the smallest rootlets. 
The root-cap is said by Henslow (1892, p. 507-8) and Van Tieghem ( 1898 ) to resemble in structure that of monocotyls rather than dicotyls. In $N$. flavo-virens and $N$. caerulea, however, the tip of the root agrees exactly with the fourth type of structure given by De Bary (1884, p. I2),

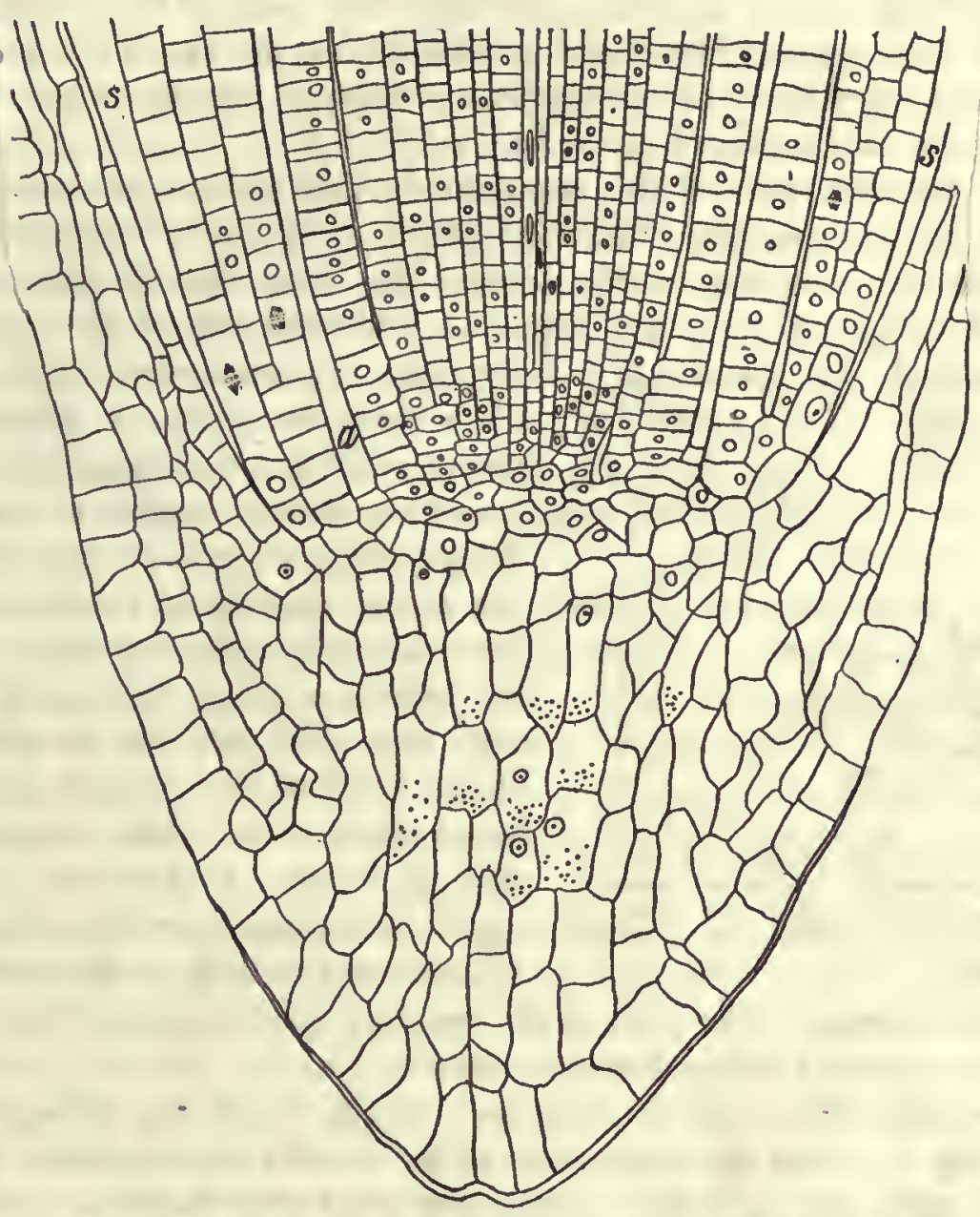

F1a. 6.-Lougitudinal seetion of root-tip of $N$. cacrulea. a, air-ennal; 8, space between root and upper portion of cap. From a photomlerograph.

i. e., there is a transverse layer of initial cells from which all of the tissues are developed (Fig. 6). Caspary and Nicolai assert that the cap continues to grow only for a very short period, after which no farther addition to it is made, though it is persistent, and not deciduous as in Nuphar (De Bary 1884, p. 4. 3 ). In a root of $N$. flavo-virens from a plant just breaking from a strong tuber, the cap is short-conical and rounded at apex, with 
long thimble-like prolongation around the root. Its outer surface is bounded by a distinct, smooth layer of cells, which are much larger than the underlying ones (cf. Fig. 6). At the apex these outer cells are columnar in shape and arrangement and are removed from the region of initial cells by I $2_{2}$ or 13 elongated elements (columella); they become nearly cubical opposite the initial region, where the cap is five to six cells thick, and elongated in the upper free portion of the cap, where for some distance this layer alone is present.

The relative size of the root-cap in this species is shown by the following measurements. The cap extends $0.035 \mathrm{~mm}$. beyond the initial cells, and $1.33 \mathrm{~mm}$. above this around the root; its diameter opposite the initials is $0.5 \mathrm{I} \mathrm{mm}$., the same as the diameter of the root above

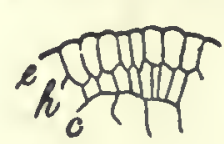

(a)

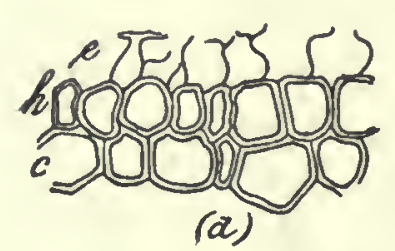

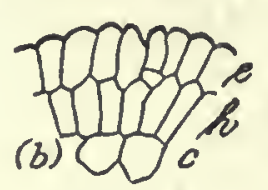

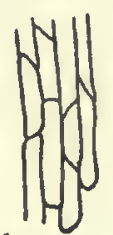

(c)

Fro. 7.-True and false epldermis of roots. $N$ marliacea chromatella. (a) from very young, (b) older, (d) mature root in traneverse section; (c) surface rlew of (b), $e$, epldermis, $h$, hypodermal layer, $c$, cortex. the cap. A somewhat larger root-tip of $N$. caerulea, (Fig. 6), taken from a young root of a mature plant, shows a structure exactly similar to that of $N$. flavo-virens; in one specimen, however, the apical portion of the cap had been worn away in irregular fashion so that the primitive outer layer of large clear cells is visible only on the sides. All of the cells of the cap are arranged in longitudinal rows. The peripheral portion of the cap is continuous with the upper, sheathing part, and is composed of narrower cells than those below the

body of the root. The root-meristem and root-cap are formed by a transverse row of cells as described above.

A regular epidermis of columnar cells is found near the apex of the roots (Fig. $7(a) e$ ); the outer walls of these cells are cutinized, but their partition walls are quite thin. They increase somewhat in size as the root enlarges, but their outer ends become rounded and somewhat drawn apart (Fig. $7(b) e$ ). In most of the species examined ( $N$. flava, tuberosa, odorata minor, marliacea-chromatella, lotus) they become almost cubical in shape (i. e., in cross section; they are elongated in the direction of the axis of the root), then are ruptured in their outer walls, the radial walls remaining as a black, irregular fringe on the surface of the root (Fig. 7 (d) $e)$, giving it a powdery appearance. In $N$. elegans $\times$ zanzibariensis, the epidermal cells become greatly flattened and epithelioid before rupturing. 
In all cases, however, the epidermis persists on the narrower portion of the root within about $2.5 \mathrm{~cm}$. of the rhizome. Its loss is the direct result of the great expansion of the root, caused by the enlarging and maturing of the air-canals.

Meanwhile the subjacent outermost layer of cortex has developed in an especial manner (see Fig. 7 h). At a very early stage this layer is composed of columnar cells closely resembling the epidermis at the same period. But as its cells become broader and more nearly cubical, the walls become collenchymatously thickened, as also do those of the next one or two layers below ( $N$. lotus, tuberosa, marliacea-chromatella). The outer walls of the hypodermal cells unite to form a fairly even surface, but the inner walls meet at various angles, owing to the varying depths of the cells. Thus an even hypodernal covering is formed in place of the lost epidermis.

The cortex may be divided into five layers : (I) the single hypodermal layer; (2) exo-cortex, a layer of from one to three or four tiers of closely packed cells without intercellular spaces; (3) medio-cortex, a tissue composed chiefly of large air-canals and constituting nine-tenths of the bulk of the root; (4) endo-cortex, consisting of one or two layers of cells closely set together, lying adjacent to (5) the endodermis (Figs. 8, 9).

The first of these layers has already been described. The exo-cortex is continuous, between the air-canals, with the medio-cortex. In $N$. odorata (Fig. 8) there are between the outermost air-canals and the hypodermis two series of cortical cells with thin walls and in size of lumen equal to or larger than the hypodermal cells. $N$. tuberosa and $N$. marliacea-chromatella have usually three series of cells in the exo-cortex; they are rounded, with collenchymatous walls, and larger by half than the hypodermal cells. The exo-cortex in $N$. lotus consists of a single row of cells (four or five near the base of a mature root), in $N$. flava of one or two rows. In $N$. elegans $\times$ zanzibariensis there are two or three series of cells which are thin-walled and three or four times as large in crosssection as the hypodermal cells; in longitudinal section, however, the hypodermal cells are much the longer, being about $0.025 \mathrm{~mm}$. long; the exo-cortical cells are only $0.0175 \mathrm{~mm}$. in length, and the cells of the mediocortex about $0.0076 \mathrm{~mm}$. N. flavo-virens, at least near the proximal end of the root, has five or six cell-layers in the exo-cortex.

The outstanding characteristic of the medio-cortex is the presence of large air-canals. These are elliptic or rounded or more or less hexagonal in cross-section, and run parallel throughout the length of the root, 
beginning in the meristem immediately back of the initial layer of cells Fig. 6 a). They appear to be without communication of any kind with

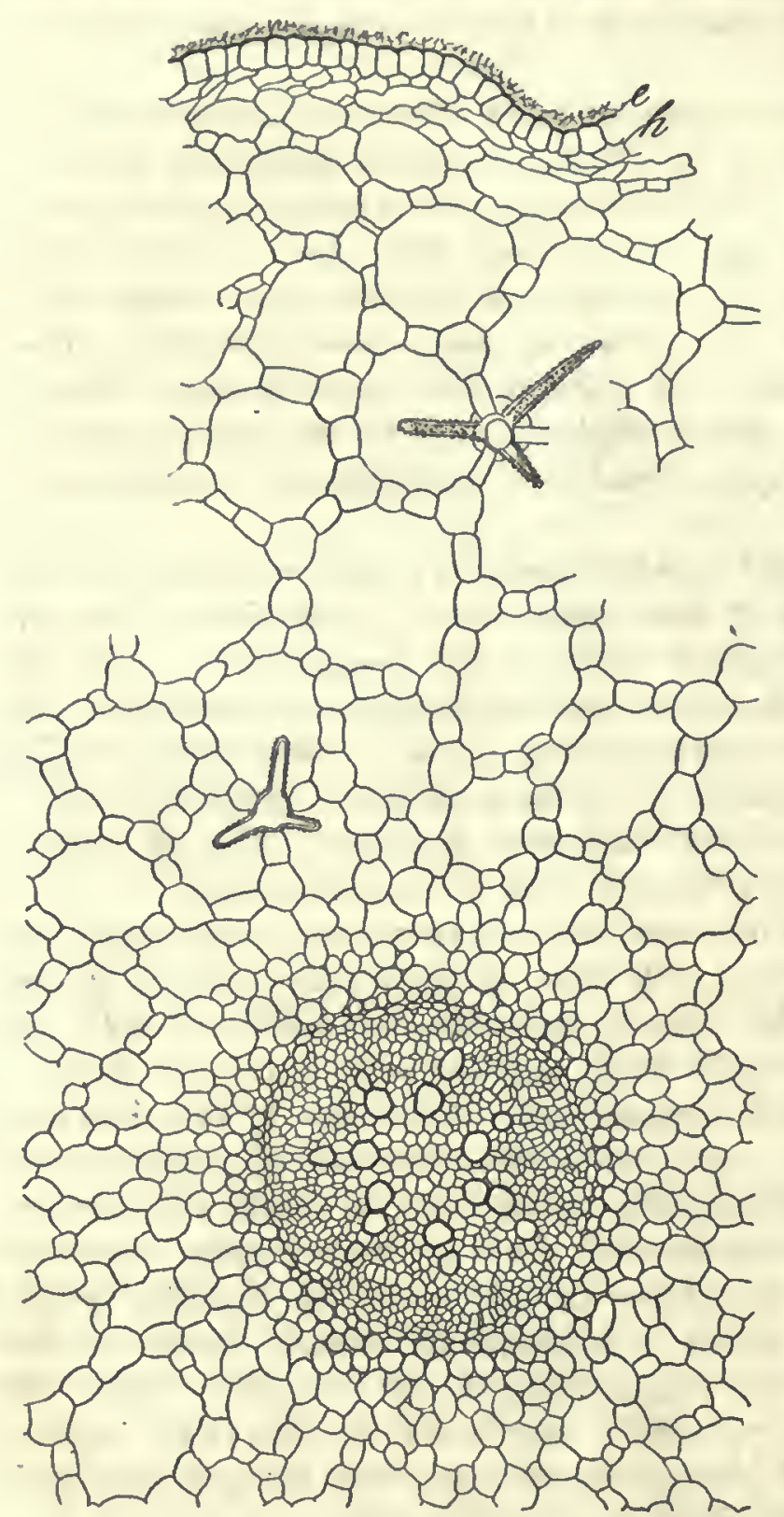

Fio. 8.-Root of $N$, odorata, transverse section. From photomicrograph; $e$, remnants of epldermis; $h$, false cpidermis. one another, i. e., the cells bounding them fit together without transverse intercellular spaces. $\bar{A}$ single perforation $0.0025 \mathrm{~mm}$. in diameter has been observed in the side wall of a canal in a root of $N$. tubcrosa, but this must for the present be considered exceptional. At more or less frequent intervals $(0.127 \mathrm{~mm}$. to $3.0 \mathrm{~mm}$. for $N$. tuberosa, $1.2 \mathrm{~mm}$. to $5 \mathrm{~mm}$. for $N$. elegans $\times$ zanzibaricnsis) diaphragms lie directly or obliquely across the canals. A diaphragm is a very thin plate of epithelioid cells (0.0076 mm. to $0.013 \mathrm{~mm}$. thick for $N$. tuberosa) with sinuous margins; the protuberances of the margins of the cells meet one another, leaving spaces between the sinuses (Fig. I 2 ). In $N$. lotus the cells are more even in outline, with large, round, intercellular spaces. 'Thus the passage of gases is left practically unimpeded. The walls of the canals are a single cell-layer thick, and bear stellate cells (idioblasts) here and there. In $N$. tuberosa these occur about $0.3^{2} \mathrm{~cm}$. apart on the average along each canal; in $N$. elegans $\times$ zanzibariensis they are 
two or three times as frequent, but somewhat more slender, and, though of nearly the same actual size, are much smaller in proportion to the size of the canals ; they are few in the root of $N$. flavo-virens, numerous in $N$. flava and $N$. odorata, very plentiful and of massive build in $N$. marliaceachromatella. Transverse sections show that they occur only in angles where three partition walls meet, and their arms project into the three adjoining canals (Fig. 8).

The canals vary in actual and relative size in the different species, but are always largest at the middle of the medio-cortex and smaller toward exoand endo-cortex. $N$. odorata (Fig. 8) has six or seven concentric rings of canals, i. e., that number can be counted along any radius of the root; they are all quite large and distinct. $\quad N$.tuberosa has seven to ten rows, very irregularly placed; the middle and outer ones are approximately circular in outline, those near the endo-cortex are greatly elongated radially, and the innermost and outermost ones are scarcely more than large intercellular spaces. N. flava and $N$. lotus have six or seven rows of rounded and quite regular canals in the main part of the root, becoming irregular in $N$. lotus near the stem. $N$. marliaceachromatella has nine rows, arranged

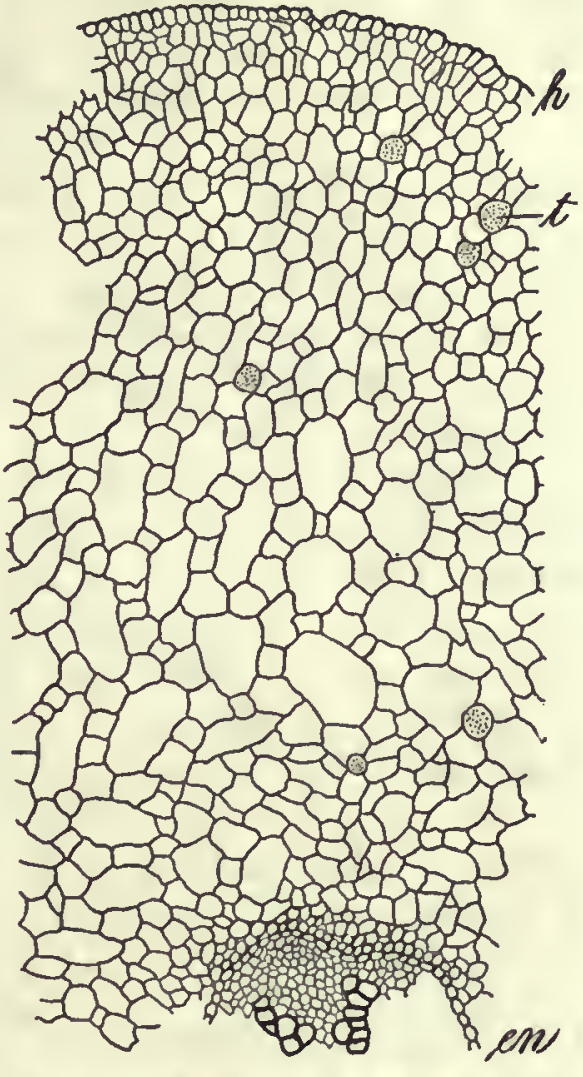

Fic. 9.-Contractile root of $N$. favo-virens, transverse section; $e n$, endodermis; $h$, false epidermis ; $t$, latex or tannin cell. much as in $N$. tuberosa; the radial elongation of the inner canals causes the partition walls in this region to look like radial bead-like strings of cells. $N$. elegans $\times$ zanzibariensis has eight or nine rows of large canals, each of a rounded-hexagonal shape; $N$. flavo-virens shows a similar structure in its nutritive roots.

The cells of the partition walls are nearly square in side view (longitudinal section). The angles of the canals are occupied mostly by rounded-hexagonal cells; three alternate sides of these face the canals, the other three are joined to the neighboring partition cells. Between two angle-cells is usually a single square or rectangular cell; but often 
this divides into two smaller ones. Occasionally the angle is formed not by a single cell but by three partition cells which meet at a point and are connected by beveled ends. In $N$. flavo-virens, $N$. tuberosa, and to some extent in $N$. marliacea-chromatella, all of these cells are greatly rounded out and turgescent, but their areas of union with one another (common wall) are narrow and bounded by slightly curved lines; in transverse sections these lines give the appearance of small tubular and branched cells lying between larger rounded cells; longitudinal sections reveal the true state of affairs. The contents of the medio-cortex cells may be very small indeed, as in $N$. flavo-virens and $N$. elegans $\times$ zanzibariensis, or there may be starch in the inner parts, as in $N$. tuberosa and $N$. marliaceachromatella, or the whole medio-cortex may be loaded with starch, as in $N$. flava. $\quad N$. marliacea-chromatella is intermediate in this respect between tuberosa and flava. The grains of starch are rounded and simple or elongate and double.

The endo-cortex is an ill-defined layer, most distinct in $N$. flava and $N$. elegans $\times$ zanzibariensis; in the former it consists of one or two cell-layers, in the latter of but one; it is composed of small cubical cells, and has rather large intercellular spaces, both between its own cells and between these and the endodermis on the one side and the medio-cortex on the other; it should not, perhaps, be separated in the description from the medio-cortex.

Bounding the cortical tissues on the inner side, an endodermis with thickened radial walls may always be recognized. Its circular outline is interrupted by occasional slight sinuosities; it is most evident in $N$. lotus, odorata (Fig. 8) and elegans $\times$ zanzibariensis, least so in $N$. flavo-

\begin{tabular}{|l|l|}
\hline \multicolumn{1}{|c|}{ Name. } & $\begin{array}{l}\text { No of rays } \\
\text { of xylem. }\end{array}$ \\
\hline N. odorata minor & 7 \\
N. ? & 8,8 \\
N. flava & 6,7 \\
N. lavo-virens $\times$ zanz. & 5 \\
N. elegans X zanz. & $7,7,7,7$ \\
N. caerulea X zanz. & 6,6 \\
N. tuberosa & 8 \\
N. caerulea & $6,7,7$ \\
N. lavo-virens & $5,7-8$ \\
N. atus & $6,6,9,4$ \\
N. rudgenum & 7,7 \\
N. marl.-chrom. & $7,8,8$ \\
\hline
\end{tabular}
virens and tuberosa. Its cells contain starch in $N$. flava and marliacea-chromatella.

A typical radial bundle system passes along the middle of the root. Its outermost cell-layer constitutes the pericambium. Against this the xylem and phloem patches abut; their number in different species is shown in the accompanying table.

In the center of the bundle an area of pith remains; this may extend over one-third of the diameter of the bundle in $N$. odorata and lotus, one-fourth in $N$. flava, tuberosa, and marliacea-chromatella, or one-sixth in $N$. elegans $\times$ zanzibariensis. In a general way this 
shows a greater amount of xylem tissue in species with a greater extent of leaf surface. The first-formed and smallest xylem tracheæ are in contact with the pericambium; one such trachea occurs in each xylem plate, and from it a single row of tracheæ continues radially inward. These are in direct contact with one another in $N$. tuberosa, elegans-zanzibariensis, flavovirens $\times$ anzibariensis, and sometimes in $N$. odorata; parenchyma cells may be interposed between them in $N$. marliacea $\times$ chromatella, lotus, and odorata; in $N$. flava the radial lines are quite irregular and difficult to follow, the tracheæ having much the appearance of being scattered throughout the parenchyma. Only spiral and spiro-reticulate tracheæ have been observed ( $N$. tuberosa, elegans $\times$ zanzibariensis). Large phloem patches with sieve-tubes and companion cells, but no fibers, lie between the xylem plates; they are rounded on the inner side and do not extend so far toward the center of the bundle as the xylem plates; that is, the innermost tracheæ project more deeply into the pith than do the inner boundaries of the phloem masses. All of the cells of the bundle appear polygonal and nearly isodiametric in transverse section, but even the parenchyma is much elongated in the direction of the axis of the root.

Contractile roots differ from the more numerous nutritive roots in that the xylem is less in quantity in the former, and the air-canals of the cortex are much smaller in proportion to the cells bounding them. In a root of an adult plant of $N$. flavo-virens (Fig. 9) taken up in October, the false epidermis and exo-cortex are apparently normal. The outer part of the medio-cortex is collapsed wherever a transverse wrinkle occurs, but it consists for the most part of comparatively dense tissue, in which the intercellular spaces are not larger than the surrounding cells. The vascular system is cut off from the cortex by a distinct endodermis. Each of the 5 to 9 xylem rays consists of a single line of trachex occupying about one-third of the diameter of the vascular cylinder. The pith in the center of the cylinder is sharply marked off from the surrounding tissues by an endodermis with very distinct radial thickenings. This occurrence of an intrafascicular endodermis seems very anomalous in a flowering plant, but was constantly found in contractile roots of adults of $N$. flavo-virens. In non-contractile roots of this species the xylem rays are often two cells wide, they extend farther toward the center of the vascular cylinder, and there is no inner endodermis. In none of the roots of other species was an inner endodermis found.

As stated before, a radial vascular bundle system traverses the entire 
length of each adventitious root. Branches are given off from it at right angles and pass straight out through the cortex to the side rootlets. Where the root joins the stem, the root-bundle passes in and bends sharply backward (away from the stem apex) and runs more or less obliquely into the plexus of bundles of the stem. In $N$. odorata the bundles of all of the roots from a single leaf-base unite in the peripheral region of the stem into one strong trunk (Fig. Io); the appearance of a pith in the midst of this trunk in N. alba candidissima gives rise to the "root-bearing stele" of Gwynne-Vaughan (1896 b). In $N$. lotus each root-bundle passes in separately and breaks up into a number of branches before joining the plexus of the stem. It is notable that there is no direct

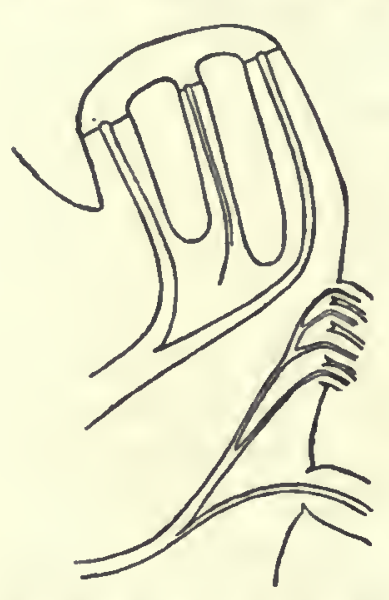

Fia. 10.- Vascular bundles of the roots of $N$. odorata. Longitudinal section of leaf-base. connection between the bundles of any leaf and the roots which spring from its base, close as their proximity is.

The innumerable small rootlets which cover the main roots seem to repeat entirely the structure of the latter. The vascular system (in $N$. elegans $\times$ zanzibariensis) is hexarch, with uniseriate pericambium and a tiny central pith; endodermis and endo-cortex are uniseriate and distinct; the meso-cortex has only one or two series of very small and irregular air-canals; hypodermis and epidermis occur as above described.

The rudiments of roots are laid down below the bases of the petioles at a very early period. In a strong rhizome of $N$. odorata a leaf bud less than $0.3 \mathrm{~cm}$. long, including the petiole, had four subtending roots already laid down in the tissues of the cushion just below it ; the posterior two of these had the root-cap well defined and had destroyed some of the overlying cortical cells of the stem. After this time, however, their development is very slow; at the base of a petiole over $8 \mathrm{~cm}$. long the root apices had just penetrated the epidermis, but were still concealed in the short pubescence of the leaf-cushion, No pericambial tissue has yet been distinguished in Nymphaeaceous stems for the source of adventitious. roots.

Reference has been made to cell-multiplication in the apex of growing roots, and to the early origin of the air-canals. These canals are at first surrounded by six cells. Between every two of these another cell is cut off, giving one at each angle of the canal, and one on each side (Fig. i $b$ ). 
The angle-cells are, in this stage, triangular and nearly equilateral (Fig. I I $a$ ); the lateral cells are narrow and brick-shaped, with their ends abutting on the canals. It is largely by the great extension of the lateral cells that the air-canals and the roots themselves increase in diameter; for the shortest side of the young cell becomes much the longest in maturity: meanwhile the angle-cells have expanded also, their three points becoming first rounded, then flattened, to give the cell its hexagonal shape (cf. Fig. 8 and II).

A diaphragm of an air-canal may be traced back (Fig. I 2) to a single lateral cell near the tip of the root; this extends out into the lumen of the canal, by distension of its wall, as a rounded papilla. The papilla is cut off, and soon divides longitudinally; each half then divides transversely, and again longitudinally. Thus by growth a plate of cells is formed, extending across the canal. As these cells enlarge, intercellular spaces are formed between them until the mature diaphragm is produced. Stellate cells develop from the angle-cells in the usual way, viz., Fra. 11.-Development of air-canals. Transverse section of root-tip of $N$. favoby extension of the $c$, cell divisions nearly completed; wall at several

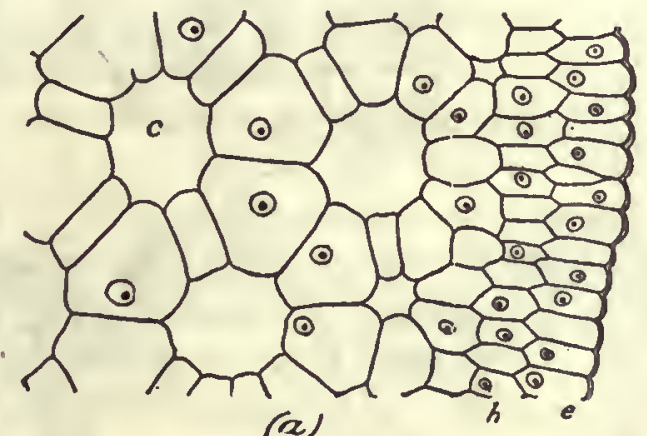

(a)

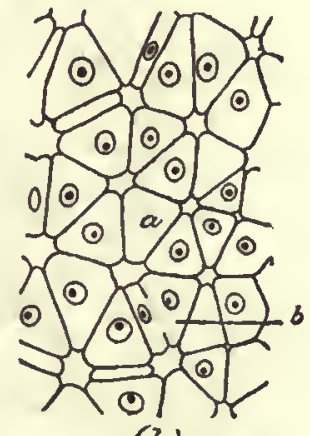

(b)

points, with subsequent thickening and deposition of crystals. This is exactly as described for Nuphar lutea by Trécul (1845).

Lateral rootlets take their origin while the root tissues are still very young, even within the root cap. They spring from the pericambial layer opposite each xylem ray, and make their exit in the usual way, but not until a considerable time after their inception; they do not occur in a mature state near to the root apex.

\section{THE STEM.}

Externally the stems of Nymphaeas offer some striking differences, which are at times characteristic of subgenera or even of species. Members of the Eu-castalia group have always a stout, spongy, horizontal rhizome which decays in its older parts as it elongates by apical growth. 
In $N$. tuberosa (var. parva Abbot) and $N$. odorata minor this may be only 5 to $10 \mathrm{~cm}$. long and 1.2 to $2 \mathrm{~cm}$. in diameter, but in the typical forms of these species it becomes 30,60 or even $100 \mathrm{~cm}$. long and $4 \mathrm{~cm}$. in diameter, while in the larger forms of $N$. alba and candida it may reach a diameter of $10 \mathrm{~cm}$. In general shape these rhizomes are terete, though the largest one I have seen ( $N$. alba candidissima) was somewhat flattened dorso-ventrally. In the American species they are of a dull whitish color, though this is nearly obscured by fine black hairs; in the European
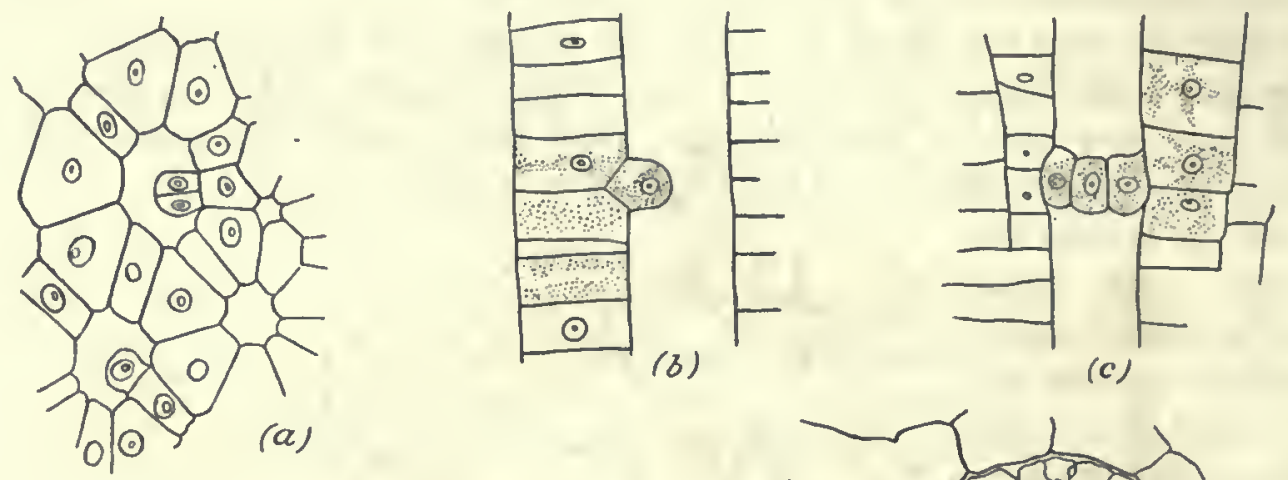

(c)
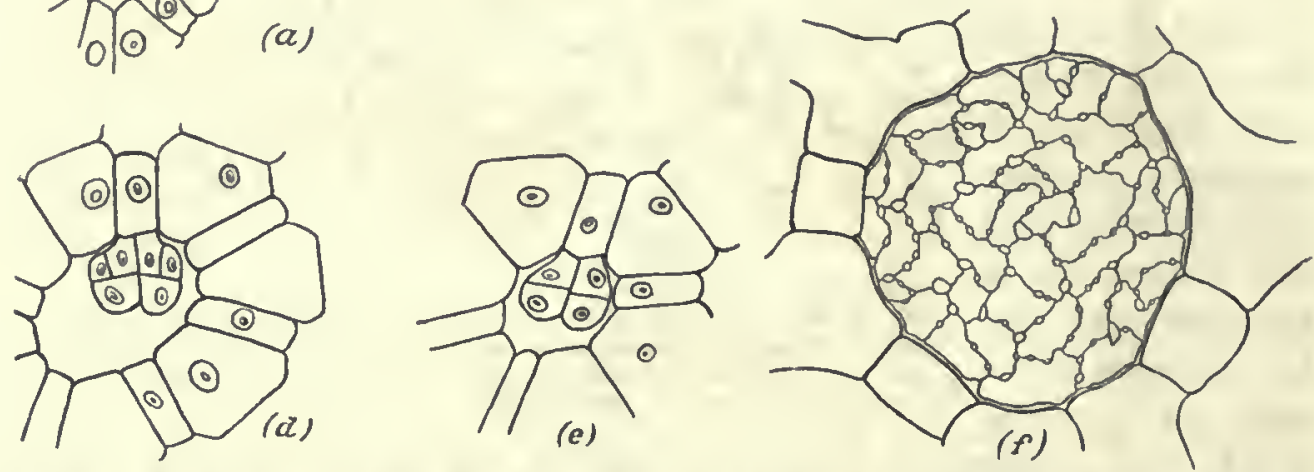

FIa. 12.-Diaphragms in the air-canals of roots ; $a, d, e$, early stages from transverse ; $b, c$, from longitudinal microtome sections of the root of $N$. favo-virens; $f$, mature diaphragm with beadlike Intercellular spaces from the root of $N$. elegans $\times$ zanzibartensis.

species the color is brownish or nearly black. All of the species of this group except $N$. tuberosa branch rather infrequently in their stems, and the branches are stout and attached to the main shoot by a broad base. In $N$. tuberosa, however, the rhizome (Fig. I3) is often crowded with short, tuber-like shoots from 1.2 to $8 \mathrm{~cm}$. long and 1.2 to $2 \mathrm{~cm}$. in diameter, attached to the parent axis by a short and very slender isthmus, sometimes only $0.3 \mathrm{~cm}$. in diameter. In external appearance these do not differ from the main rhizome, except in size and a darker color. One such tuber often has others, one, two, three or four, of nearly equal size, growing out from its sides and base, so that bunches of tubers are formed. Being light enough 
to float on water and easily detached from the parent plant and from one another by reason of the brittleness of the tissues of the isthmus, these tubers serve to distribute the plant widely. Waterlily leaves ("lily-pads") are eaten by large herbivorous animals (deer, \&c.), which wade about in the shallow water; these must detach numberless tubers and leave them floating about, as a person does when wading among them. Doubtless also wading birds, turtles, bull-frogs and many kinds of fish accomplish the same end. Special mention of the structure of these tubers will be made later.

Each of the Nymphaeas except the group just mentioned possesses a short, thick, erect caudex. Where this remains throughout the year

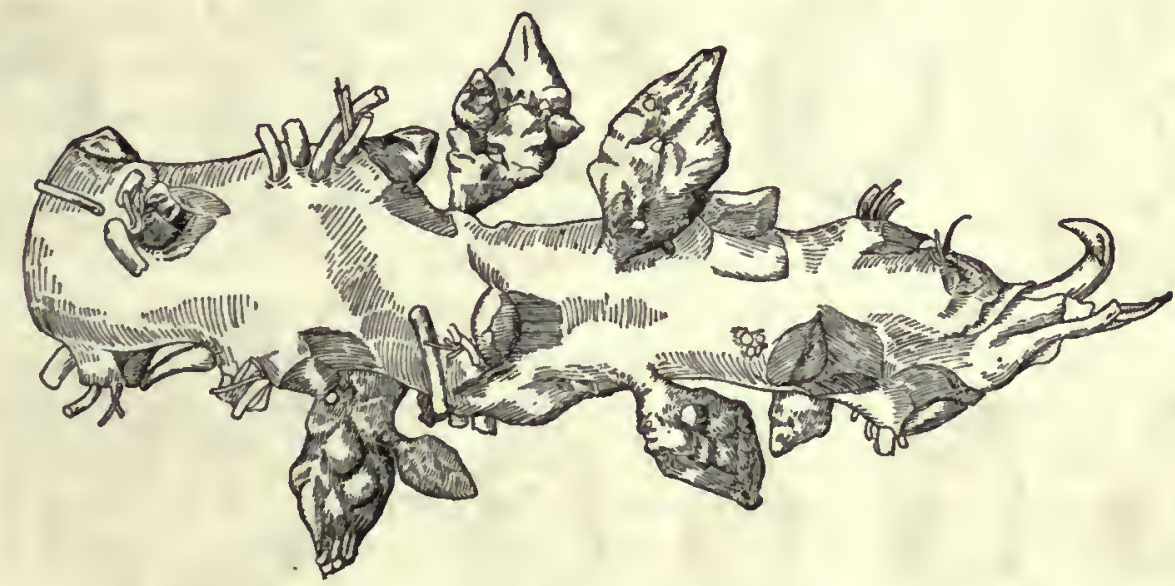

FIG. 13.-Rhizome of $N$. tuberasa. Natural size.

in a wet and more or less vegetative condition, it dies off in the lower part as it elongates above, about keeping pace in its elongation with the amount of sedimentation taking place around it. Such conditions habitually surround the Xanthanthae and Chamaenymphaeae, and these cannot otherwise survive. Species of the Hydrocallis group often have a like perennial growth, as also sometimes have the Lotos and apocarpous groups in cultivation. But the habit of all of the truly tropical members (Lotos, Hydrocallis, Apocarpiae) is to be dried off completely at one season of the year. In this case the large mature blooming plants die and rot away. $N$. flavo-virens alone, with some of its hybrids, is able to withdraw from vigorous flowering growth into a dry, resting tuber. Young plants, however, readily store away all of their nourishment in the caudex, which then forms a tuber from the size of a pea to that of a hen's egg (or much larger in $N$. flavo-virens). Such resting 
tubers are usually of an ellipsoid shape, or spheroidal in $N$. gigantea and elegans (Fig. 14). They are of a brownish black color, smooth and rounded in the lower half, but more or less acute above, because the apical region is protected by a dense upward growth of long fine hairs intermingled with dried and shriveled bases of petioles. These tubers live through the dry season without injury, and begin growth again in a characteristic manner on the return of sufficient moisture and heat. Mature stems of the types under discussion are, like the tubers, of an ellipsoid shape, and have grown in our Botanic Garden to a length of

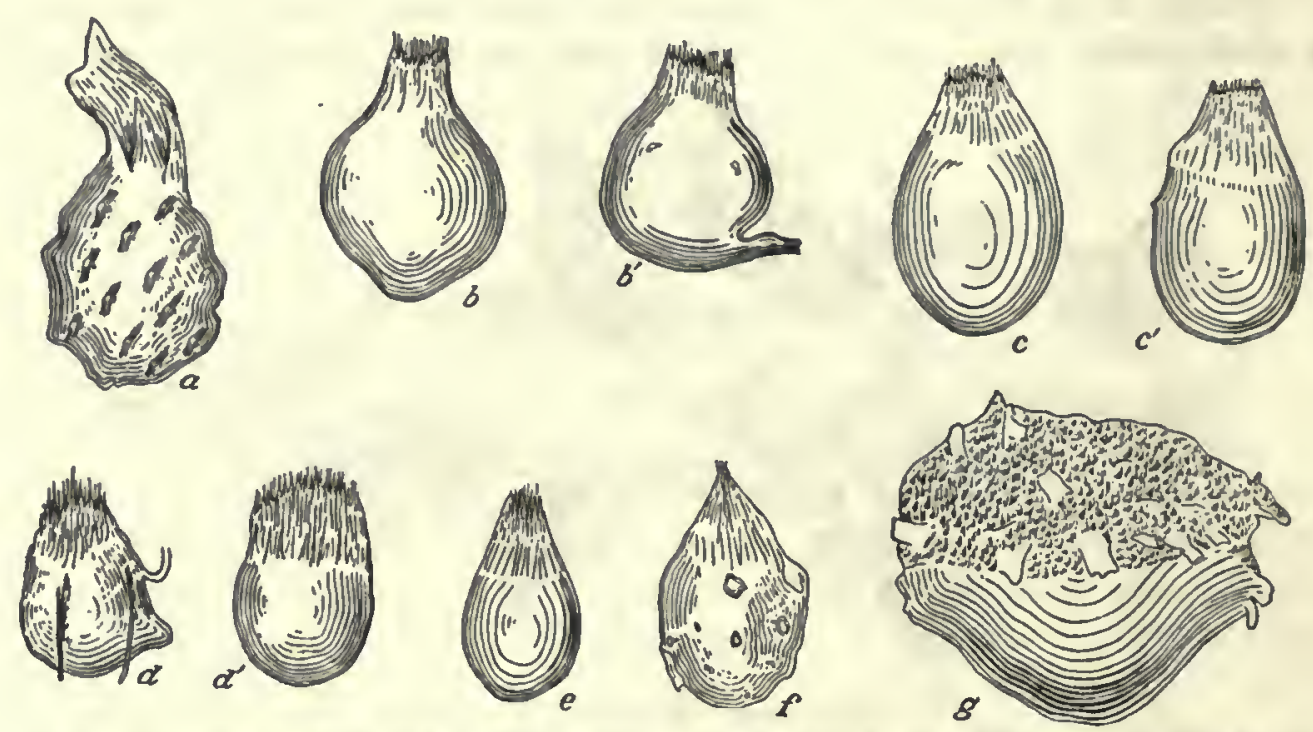

FI. 14 -Tubers: $a, N$, amazonum; $b, b^{\prime}, N$, gigantea, from two sldes 90 degrees apart; $c, c^{\prime}, N$. capensis, two specimens; $d, d^{\prime}, \boldsymbol{N}$. elegans, two specimens; $c_{1} \boldsymbol{N}$. zanzibariensis rosea; $f, \boldsymbol{N}$. lotus, seedling; $\boldsymbol{\sigma}, \boldsymbol{N}$. lotus, lateral tuber from mature plant. All natural slze.

$20 \mathrm{~cm}$., and a diameter of $10 \mathrm{~cm}$. in $N$. rubra var., 12.7 by $7.5 \mathrm{~cm}$. in $N$. dentata, caerulea and zanzibariensis; I have seen a resting tuber of N. Mrs. C. W. Ward (N. flavo-virens $\times$ zanzibariensis rosea) in the Dreer Nurseries which measured $2 \mathrm{I} \mathrm{cm}$. by $10 \mathrm{~cm}$. All of these are of a brownish black color. With us $N$. flava has not exceeded $7.6 \mathrm{~cm}$. long by $1.6 \mathrm{~cm}$. broad, and has a yellowish color, but Mrs. Treat (1877) records the length of an old caudex in the St. Johns River, Florida as $60 \mathrm{~cm}$., and diameter ro $\mathrm{cm}$. $N$. tetragona stem is rather slender, 7 to $12 \mathrm{~cm}$. long by $2.5 \mathrm{~cm}$. in diameter, and is of a blackish color; $N$. fennica is similar in appearance but stouter, $10 \mathrm{~cm}$. long by $3.75 \mathrm{~cm}$. in diameter.

No branching of the stem, that is, no development of vegetative buds, occurs in $N$. tetragona, and none in any of the apocarpous species 
(neglecting some hybrids), except in breaking out from the resting tuber. $N$. fennica may rarely fork, as one of our specimens shows. The Lotos and Hydrocallis species, however, give rise more or less freely to buds from the lower part of the stem, and these develop into young plants entangled among the roots and leaves of the parent. On the approach of winter, or the dry season, these lateral shoots harden off into resting tubers for the perennation of the plant. Tubers thus produced (in $N$. lotus) are very irregular in shape (Fig. I $4 g$ ), appearing knotty and gnarly, but they still show in their lower half a smooth surface, and on the upper parts a dense growth of long protective hairs intermingled with remains of dead petioles. A remarkable development of lateral shoots occurs in $N$. mexicana. Long stolons originate from the lower part of the stem, even in very young plants, and run horizontally just beneath the surface of the mud to form a new plant at a distance of 15 to $60 \mathrm{~cm}$. from the parent. No sooner has the young member established a few roots and leaves than it in turn sends out runners, and so on. Three or more such runners may be found attached to a single plant. Their minuter details will be described in another place. In autumn the ends of these runners develop a peculiar form of perennating stem (Fig. I5); it consists of an axis 1 to $1.6 \mathrm{~cm}$. long and $0.48 \mathrm{~cm}$. in diameter lying horizontally or obliquely in the soil ; on its upper surface is a continuous row of 3 to 6 small leaf buds, while from the under surface depends a bunch of thick, swollen, starch-laden roots $\mathrm{I}$ to $3.5 \mathrm{~cm}$. long and 0.3 to $0.6 \mathrm{~cm}$. in diameter; these lie crowded over each other somewhat in rows like bananas on a bunch; at the tip of each a flattened and distended root-cap remains.

A last type of stem exhibited by Nymphaea is that produced from resting tubers when they resume growth. From the center of the upper end of the tuber, in apocarpous species, a short, smooth, white stem (stolon), 0.16 to $0.3 \mathrm{~cm}$. in diameter, rises a centimeter or so, and at its summit a tuft of leaves and roots is formed; this may now be broken off and will grow into a perfect plant, while the tuber will repeat the process, if strong enough, as many as 8 or to times ( $N$. flavo-virens and hybrids). In Lotos species a much greater area of the tuber, in fact nearly all of its upper surface, develops a very large number of tiny shoots, crowded all over it. One, two, three or four of these start forward at nearly the same time and each develops a long internode 1.2 to 8 or $10 \mathrm{~cm}$. in length-a smooth, slender, white or reddish, often much curved stolon 0.16 to $0.3 \mathrm{~cm}$. in diameter-bearing a simple lanceolate or subulate bract 0.6 to $2.5 \mathrm{~cm}$. 
long at its summit. This is followed by a second internode, much shorter, 0.3 to $1.3 \mathrm{~cm}$. long, and this bears the tuft of leaves and roots which are the beginning of a new plant. If these shoots are detached, other shoots develop, and so on almost indefinitely, even from a tuber no bigger than the end of one's thumb.

Phyllotaxy in the Nymphaeas presents some peculiarities. As might be expected, forms with elongated rhizomes (Eu-castalia) have the simpler orders of leaf arrangement, and where dorso-ventrality appears leaf scars are only half as numerous on the lower as on the upper side. In $N$. tuberosa and odorata, the phyllotaxy seems to be as low as $\frac{2}{5}$ or $\frac{3}{8}$, and the internodes are $1.3 \mathrm{~cm}$. or more long. $N$. alba shows a much higher order, probably $\frac{8}{21}$ or $\frac{13}{3}$ (Raciborski 1894 ). But the erect tuberous
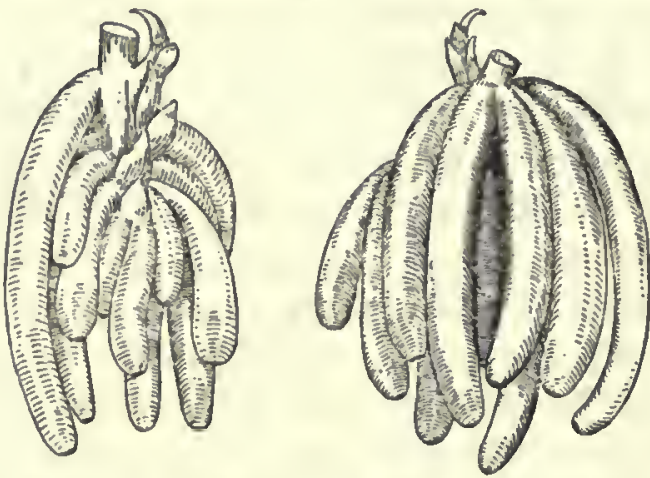

Fra. 15.-Perennatlng body of $\boldsymbol{N}$. mexicana. Seen from nearly opposite sldes. Natural slze. stems are so densely crowded with leaf attachments as to leave only narrow, sinuous lines of stem-surface visible; the order of the spirals I have not determined.

One can speak of a definite anthotaxy also in the genus Nymphaea, since a plant once in flower produces its bloom continuously until it dies. In $N$. gigantea the peduncular attachments form separate and distinct secondary. spirals alternating with two parallel spirals of leaves (Caspary, 1865). In other species the flowers occur in the place of leaves, as members of the leaf-spirals. In every case the peduncles arise entirely independently of any leaf axil and there is no visible trace of a bract. The relation of leaves and, flowers in the primary leaf-spirals is shown in the following series taken from Raciborski (I894). The numbers represent leaves, the letter $f$ stands for a flower. A rhizome of $N$. alba taken up in autumn gave I, $2,3,4,5,6,7,8,9$, IO, II, f, I2, I3, f, I 4, I 5, f, I6, I 7, f, I 8, I 9, f, 20, 2 I, f, 22, 23, 24, 25, 26, 27, 28, 29, f, 30, 3I, f, $32,33, \mathrm{f}, 34,35,36,37,38,39,40,4 \mathrm{I}, 42,43, \mathrm{f}, 44,45, \mathrm{f}, 46,47, \mathrm{f}$, $48,49, \mathrm{f}, 50,5 \mathrm{I}, \mathrm{f}, 52,53, \mathrm{f}, 54,55, \mathrm{f}, 56,57, \mathrm{f}, 58,59, \mathrm{f}, 60,6 \mathrm{I}, \mathrm{f}$, $62,63, f, 64$, \&c. ; the flowers up to 45 have already bloomed, the others would come out the next season. In $N$. zanzibariensis, a very floriferous species, leaf and flower alternate regularly after the plant once begins to bloom. " $N$. stellata" gave I, $2, \mathrm{f}, 3,4,5, \mathrm{f}, 6,7,8, \mathrm{f}, 9,10, \mathrm{I}, \mathrm{f}$, 
I 2, I 3, I $4, \mathrm{f}$, I 5, I 6, I $7, \mathrm{f}$, I 8, I $9,20, \mathrm{f}, 2 \mathrm{I}, 22,23, \mathrm{f}, 24,25,26, \mathrm{f}, \& \mathrm{c}$; the primary spiral seemed to be sometimes $\frac{8}{21}$, sometimes higher. $N$. rubra in the Münich garden (which Raciborski considered was more probably a hybrid) showed I, 2, f, 3, 4, 5, 6, f, 7, 8, f, 9, IO, I I, I 2, f, I 3, I 4, I 5, I6, f, I 7, I $8, \mathrm{f}$, I 9, 20, 2 I, 22, f, 23, 24, 25, 26, f, 27, 28, f, 29, 30, 3I, 32, f, 33, 34, 35, 36, f, 37, 38, f, 39, 40, 4I, 42, f, 43, 44, $45,46, f, 47,48, f, 49,50,5$ I, $52, f, 53,54,55,56, f, 57,58, f, 59,60$, $6 \mathrm{I}, 62, \mathrm{f}, \& \mathrm{c} .^{3}$

The structure of the stem in Nymphaeaceae has long been a puzzle, and for the most part still remains so. A transverse section of any vegetative stem of Nymphaea (Fig. I6) shows to the unaided eye three well-marked regions, viz., ( I) an outer wall of dense cellular tissue, about $0.16 \mathrm{~cm}$. thick, consisting of epidermis and exo-cortex, (2) a medio-cortex full of large lacunæ or air-spaces, (3) a dense central core traversed in every direction by vascular bundles. The second layer is traversed by numerous trabeculæ of denser tissue connecting the exo-cortex with the central core. The following description applies only to normal vegetative stems, not to stolons or resting tubers.

Microscopically examined, a well-marked epidermis is always present. In $N$. lotus and odorata (Fig. I 7) this is an irregular layer as to the level of the cells on the outer and inner sides, and as to their size, though they are approximately cubical in shape. The walls are equally thin on all sides.

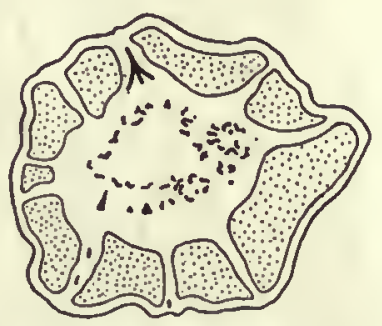

FIG. 16.-Rhizome of $N$. odor ata; transverse section of internode. Dotted portion represents the spongy medio-cortex; heavy lines are vascular bunales. Natural slze.

In $N$. flava the cells are much shallower than long or broad (about $2:$ I) and form a more even surface. With the exception of a very minute area at the growing point of the stem, its whole surface is covered with hairs. Where these first appear outside the naked area, every epidermal cell bears one. At a short distance back of this point, however, many of the epidermal cells undergo an oblique division, cutting off a wedge-shaped segment with its apex at the outer surface on one side of the cell, and a base nearly equal to half the base of the mother cell; the apex of the wedge widens out, and soon the new cell is cubical. A single cell thus comes to intervene between two formerly contiguous

\footnotetext{
'Raciborski's $N$. flava, having no runners, but an ordinary branching rhizome as in other Nymphaeas, was almost certainly $N$. odorata sulfurea $(N$. odorala $\times$ flava $)$ and not the true $N$. flava. His $N$. slellata was probably $N$. caerulea Sav.
} 
hairs. Such hairs are slender lines of terete cells, of almost even

\begin{tabular}{|l|r|}
\hline \multicolumn{1}{|c|}{ Bpecies. } & $\begin{array}{r}\text { Diameter of haira } \\
\text { at apex of stem. }\end{array}$ \\
\hline N. caerulea & $0.024-0.030 \mathrm{~mm}$. \\
N. tuberosa & $0.035 \mathrm{~mm}$. \\
N. lotus & $0.021-0.028 \mathrm{~mm}$. \\
N. flava & $0.021-0.033 \mathrm{~mm}$. \\
N. odorata & $0.028-0.033 \mathrm{~mm}$. \\
\hline
\end{tabular}
diameter throughout, but tapering at the apex, and attaining a length of $0.48 \mathrm{~cm}$. in $N$. caerulea, $0.6 \mathrm{~cm}$. in $N$. tuberosa, or $1 \mathrm{~cm}$. to $1.3 \mathrm{~cm}$. in $N$. lotus. The basal epidermal cell is cubical in shape, and if we represent its depth by unity, the lengths of the succeeding cells will be approximately 0.8 to $1.3,0.5$ to $2.2,2.2$ to 10 , and so on up to 15 or 20 times as long as broad. The relative and

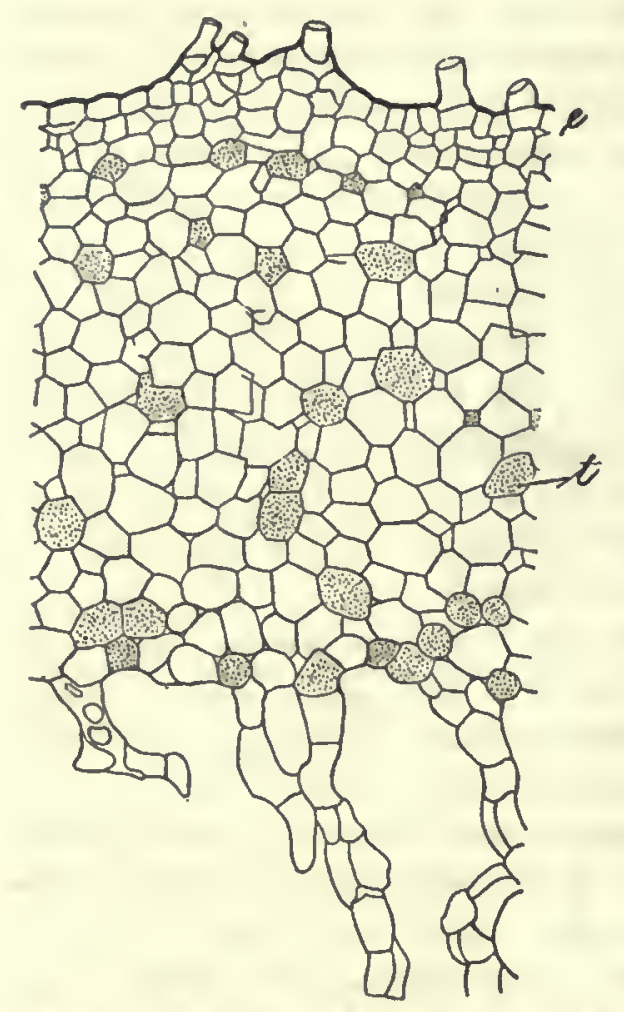

Fra. 17.-Microscopic section of rhizome of $N$. odorata; showing exo-cortex and 8 chaing of the spongy medio-cortex, $c$, epidermils; $t$, tannin (latex) cell. Camera fuclda sketch. actual diameters of these hairs in different species is shown in the accompanying table. In addition to these, hairs with thick multicellular base and slender shaft occur in $N$. tuberosa and lotus. The lower part of such a hair consists of 1 to 3 tiers of polygonal cells about one-third to one-half the diameter of the basal column of the hair; then follow 2 to 5 short cells in linear series, and finally a row of long cells as in the hairs first described. These complex hairs may arise from the simpler type by upgrowth of the tissues supporting them. Those of $N$. lotus are much larger than of $N$. tuberosa; indeed in the former species the surface of the stem is completely occupied by these hair-protuberances.

Much more sharply than in the root, we recognize in the stem three cortical regions (Figs. 16, 17, 18), an outer, dense, sub-epidermal layer 0.16 to 0.3 $\mathrm{cm}$. thick, a median spongy layer 0.6 to $2 \mathrm{~cm}$. thick, and an inner dense layer continuous with the parenchyma which makes up the central core of the stem. The spongy layer is not continuous, but is cut into irregular disconnected blocks by plate-like trabeculæ of dense tissue passing radially from outer to inner cortex. The cells of the outer cortex in $N$. odorata (Fig. 17) are nearly isodiametric, thin-walled, and contain 6 to 8 starch grains each; there are 12 to 14 layers of 
such cells, with occasionally a small intercellular space, and here and there a typical stellate cell many times as large as the cortical cells. In $N$. lotus the exo-cortex is 23 or 24 cells thick; each cell is ellipsoidal, the radial axis (with regard to the stem) being shortest, and the horizontal tangential axis longest. The walls appear thickened, and probably are colloid. There are no starch grains, no intercellular spaces and no stellate cells.

The relative amount of lacunar cortex is very different in the different types of stem. In the Castalia group it is quite prominent (Fig. 16), in the others rather insignificant; the following table shows the relation in five types examined. "Central core" includes endo-cortex and all within it.

\begin{tabular}{|l|l|l|l|}
\hline \multicolumn{1}{|c|}{ Spectes. } & Width of exo-cortex & Medio-cortex & Central core. \\
\cline { 1 - 2 } N. flava & $0.1 \mathrm{~cm}$. & $0.4 \mathrm{~cm}$. & $0.48 \mathrm{~cm}$. \\
N. tuberosa & 0.16 & 0.8 & 0.8 \\
N. Odorata & 0.13 & 0.3 & 1 \\
N. alba candidissima & 0.16 & 1 & $4.5 \times 3.8$ \\
N. lotus & 0.2 & 0.8 & 6.4 \\
\hline
\end{tabular}

In $N$. lotus (cf. Fig. $18 \mathrm{~m}$ ) the lacunar cortex might be said to occur in isolated patches of irregular shape around the periphery of the stem. The greater part of these regions is air space, and this is traversed in every direction by anastomosing chains of cells, after the manner of a loose, spongy parenchyma of a leaf. The cells are thin-walled, small, and nearly isodiametric in $N$. odorata and alba candidissima, and the chains may consist of one or more rows of these (Fig. I7), being sometimes rather plate-like; the nodes of the network are always multicellular. In $N$. lotus, on the contrary, the cells are three to four times longer than broad, or they may have a rounded body with slender arms reaching out to connect with neighboring cells.

The inner cortex and the tissue forming the groundwork of the central core of the stem alike consist of medium-sized spherical cells, containing numerous starch grains, and enclosing large intercellular spaces. There are about 25 cells radially outside the vascular region in $N$. alba candidissima, constituting the endo-cortex.- In $N$. lotus the endocortex may be $0.4 \mathrm{~cm}$. deep in a large stem, and consists of very many cell layers. The cells are wide apart, reaching out toward each other by short, narrow processes, and are surrounded by a large amount of air space; the tissue is of a whitish color. The cells and spaces are smaller, but otherwise it does not differ from parts of the brown medio-cortex. 
The endo-cortex contains some starch. The ground tissue of the central core of the stem consists of spherical cells with large intercellular spaces, as in $N$. alba candidissima, and is densely filled with starch, even in a large vegetative stem taken up in autumn and otherwise destined only to decay. In $N$. flava (Fig. 2I) the endo-cortex and ground-tissue are constituted as in $N$. alba-candidissima, but the cortex cells seem more crowded together than the central tissue of the core, and more densely laden with large starch grains. Stellate cells are occasional in the central core, and very plentiful in the cortex of this species.

The trabecula which cross the medio cortex (Fig. I6) are composed for the most part of tissue similar to the endo-cortex, but at the outer ends

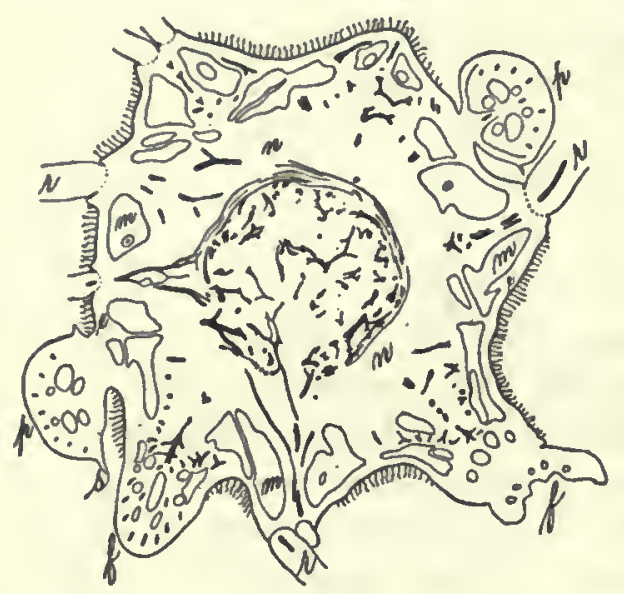

Fia. 18.-Caudex of $N$, caerulea; transverse section. Heavy lines represent vaseular tissue; $e$, exo-cortex; $f$, pedunele; $m$, medio-cortex; $n$, endocortex : $p$, petiole; $r$, root; $s$, stipule. Natural size. they gradually take on the characteristics of the exo-cortex. The number of trabecula in a cross-section is about 5 in $N$. flava, 7 or 8 in $N$. odorata, 8 in $N$. tuberosa, I 4 to 15 in a very large rhizome of $N$. alba candidissima, I 5 or I 6 in a large caudex of $N$. lotus.

On stripping off the exo-cortex of a stem of $N$. odorata, I found eight bands of trabecular tissue running longitudinally throughout the length of the portion studied, connected by transverse or oblique cross-trabeculæ at intervals of a half-inch or more. The petioles and peduncles are always situated over a longitudinal trabecula, in which the vascular bundles travel to join the central vascular plexus ; but these leaf and flower insertions stood in no discoverable relation to the transverse and oblique trabeculæ; in two cases carefully dissected there were no cross-trabecula near the insertion of the leaf. In $N$. flava slender trabeculæ divide the medio-cortex into fusiform areas, each lying with its longer axis horizontal and tangential to the stem; a leaf or flower or stolon stands over each such area, and a stout vertical trabecula crossing the short diameter of the area bears the central leaf trace to the vascular cylinder of the stem, while the lateral traces travel inward near the points of the fusiform area, surrounded by a thin layer of dense cortex. Caspary $(1857 b$ ) states that such a division of the spongy cortex into areas is common to Victoria, Euryale and Nymphaea. 
In waterlilies which are adapted to enduring a dry sẹason, the resting tubers differ markedly from the vegetative caudex. In the case of young seedling plants, which alone form resting tubers in most apocarpous species, the tuber acquires a smooth, corky bark on its lower parts. The leaf and root scars are obliterated by intrusion of cortical cells, which absorb the spiral thickenings of the xylem (Caspary, 1859) and give rise to several layers of typical cork. Although I have never found these in section to have the regularity of arrangement shown in some trees with a well-developed cork cambium (Ginkgo), I have often with my hands peeled off the bark from a living tuber, and found it to separate as smoothly as the bark of a willow twig in April. The interior tissues are dense and hard with their load of starch, and the vascular system remains intact except in its peripheral parts. The irregular lateral tubers produced upon the sides of large plants of the Lotos group seem to possess much less vascular tissue than the vegetative caudex and to have much more cortex, heavily laden with starch. The lacunar cortex is wholly absent from resting tubers, probably because, as in $N$. flavo-virens, the cork layer is formed inside the lacunar tissue, and all of this region dries or decays away.

In Eu-castalia and Chamaenymphaea, suberization $\begin{gathered}\text { Fra. 10.-Cork forma- } \\ \text { tion at base of root soar, }\end{gathered}$ takes place only over the scars of petioles, peduncles $N$. alba candidissima. and roots, and on the boundary of the living and dead tissues at the old decaying end of the stem. The root scars are healed over by a curved surface, concave on the outer side, in the middle of which the vascular bundle projects slightly. The cortical cells along this concave surface (which lies four or five cells farther in than the proximal ends of the air-canals of the root) undergo one to three parallel divisions (Fig. 19) to form the cork layer, and not until some time afterward do the adjoining root tissues decay away. I do not know how the vascular bundle of the root is closed. In $N$. alba candidissima, where the above facts were observed, the old rhizome, decaying at its posterior end, seems to have its epidermis shriveled and more or less disintegrated and its exo-cortex suberized in its cellwalls, but usually without cell-division. When this layer peels off, carrying with it the leaf scars, a rounded corky invagination or pouch is seen (Fig. 20 b) at the base of each main air-canal of the petioles and peduncles. The largest pouches extend inward a quarter of an inch, and point slightly backward; they are hollow, and wide open to the exterior, and are usually full of mud. The whole surface of the 
scar is suberized in a manner identical with that of the root. In one case (Fig. $20 \mathrm{c}$ ) the spiro-reticulate elements of a bundle in a leaf scar were closed by large thyloses from the neighboring parenchyma. Since but 3 to 5 , usually 3 , layers of cork are formed, the protection is only temporary; and when the water breaks through into the underlying tissues, a thin corky layer is thrown across the cortex in front of it, sometimes simply by modification of the cell-walls without division of their contents. Soon the water breaks through this, and again a partition is thrown across farther forward. So in the older parts of the stem, the plant keeps up a continually losing conflict with death, resulting in a gradually advancing decay of the tissues.

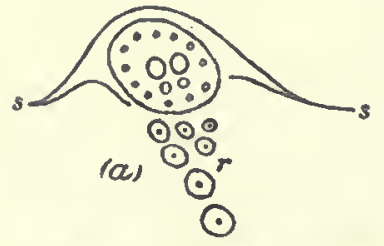

Fra. 20.-(a) Old leaf cushlon on rhlzome of $N$. alba canditisima, showlng base of petiole wlth alr-canals, Insertion of stlpule, 8 , and root scars, $r$; $(b)$ transverse section of $(a)$ through the two largest alr-canals; (c) thylosls closing splral vessel in old leaf scar.
In the outer, corky cells of the scars, and to a less extent in the inner ones, crystals are found. Some of these are irregular and rounded in outline, but most are beautifully rectangular, prismatic or tabular. The regular crystals may be transparent, homogeneous and sharp-angled, or they may be surrounded by a bunch of needles projecting from the middle line toward either end, or they may present much the appearance of bundles of raphides. Similar crystals and crystal masses are found in the suberized exocortex of the older parts of the stem. They are very resistant to reagents, and consist probably of calcium oxalate. They are often imbedded in masses of mucilage which becomes pinkish in chlor-zinc-iodide. The irregular, crystal-like bodies blacken with ferric chloride solution, and doubtless contain tannin. Throughout this research cork has been tested by its yellow color when treated directly with chlor-zinc-iodide, and by a blue color with the same reagent after boiling in potash solution and washing in hot alcohol (Meyer I898).

Before taking up the vascular system of the stem it will be of advantage to describe some special types of stem-structure. The remarkably developed stolons of $N$. flava and the lesser ones of $N$. lotus have the same general structure. Inside of a thin but cuticularized epidermis of small cubical cells, and about eight layers ( $N$. flava) of closely fitting cortical cells (two to three layers in $N$. rubra var.), the 
space is filled with longitudinal air-canals separated by partitions of a single cell-layer in thickness. Throughout the length of the stolon three to five vascular strands pass along, each surrounded by endodermis with the characteristic thickenings on the radial walls. Gwynne-Vaughan (1896, a, b) called these strands "steles," and considered the stolons polystelic. He states that the narrow isthmus connecting the tubers of $N$. tuberosa with the parent axis are similarly polystelic. I am not prepared to express an opinion upon the stelar nature of these strands, especially since the present idea of a "stele" seems to be of doubtful value, and, to say the least, needs more accurate definition. It will suffice to describe the appearance of the vascular strands in transverse section, and to mention their constituents. In $N$. flava a strand has at center a large, regular and thickly cuticularized air-canal, with two or three (usually three) projecting vascular lobes. Each lobe has one to three (sometimes none) spiral xylem cells next to the cells bounding the aircanal; the rest of the area consists of phloem, with large sieve-tubes and small companion cells. The vascular strands of $N$. rubra stolons have the large air-canal with only one or two vascular lobes.

In $N$. tuberosa the very short stolon resembles the rhizome in its epidermis and superficial hairs, and the large, starch-laden cells of the interior; these latter cells include very large intercellular spaces. There are about three vascular strands, bounded by endodermis. At the middle of each, or near one side, is a large group of spiral elements, corresponding in size and position to the air-canal in $N$. flava. A moderate amount of phloem lies about this, either concentrated in four phloem lobes, or half surrounding the xylem and bearing two or three lesser lobes, or completely surrounding the xylem and scarcely lobed. Two or three of these conditions are seen in a single section.

The vascular system of nymphaeaceous stems has always been described as consisting of scattered bundles (astelic), resembling monocotyledonous structure. In most cases this is about all that can be said (cf. Figs. 16, 18). Trécul (1845) studied the stem of Nuphar for a year with considerable success, but was far from being satisfied with his results. Nor do his researches shed much light upon the vascular structure of Nymphaea. Although we can not yet unravel the complicated network of tracheae and phloem strands, which seem to run in every imaginable direction and position throughout the inner tissues of the stem, some points are brought out by an examination of the stolons and young plants of $N$. rubra, and the general and nodal structure of $N$. flava. This latter 
species has an additional interest as representing probably the most primitive member of the syncarpous series.

In a transverse section of the caudex of $N$. flava (Fig. $2 \mathrm{I}$ ), one finds a pretty well marked cortex, a broad vascular ring with one to thrce leafgaps, and a well defined pith which is continuous with the cortex through the leaf-gaps. The vascular ring, however, presents a most peculiar

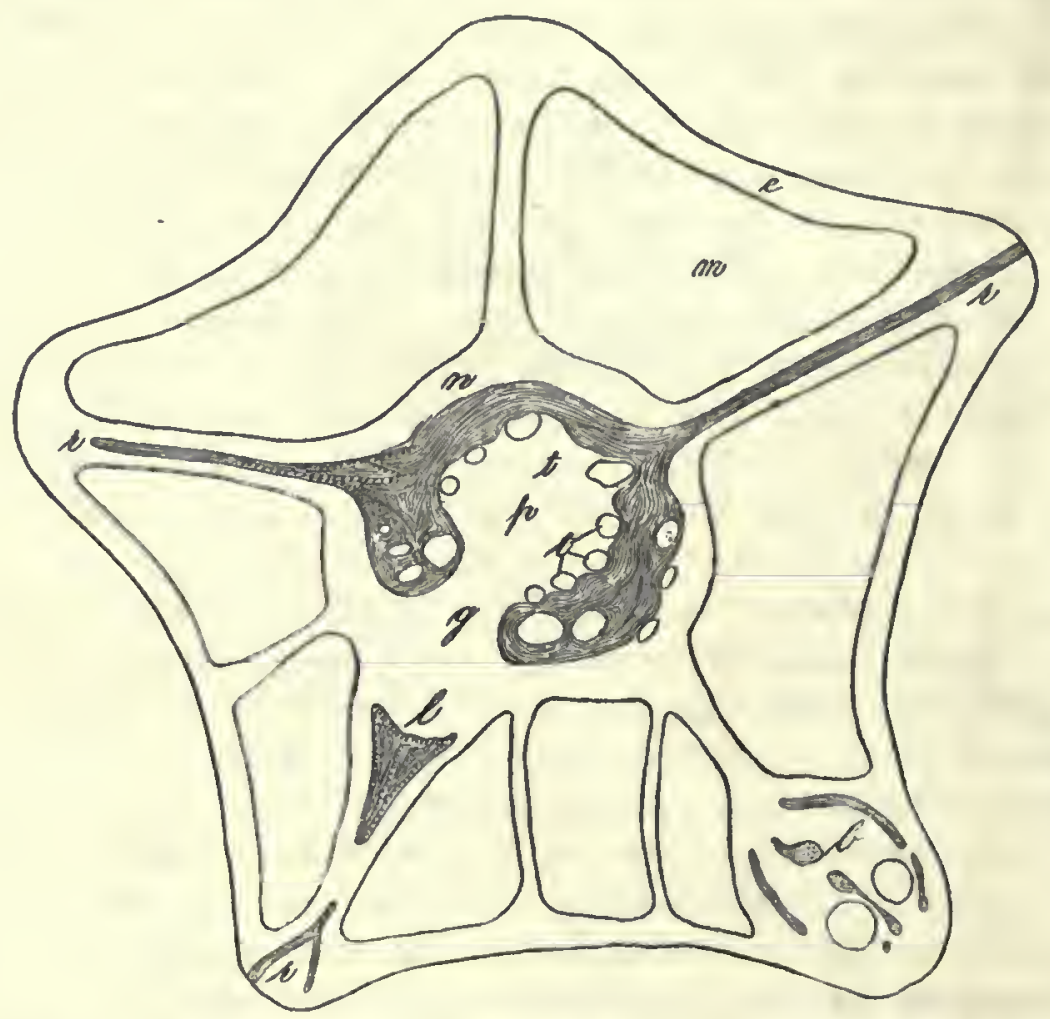

FIo. 21.-Transverse section of caudex of $N$. fava. $b$, base of leaf with bundles and air-canals; $e$, exocortex; $g$, leaf gap; $l$, point of branching of leaf trace; $m$, mediocortex: $n$, endocortex; $p$, pith (medulla); $r$, root trace; $t$, central leaf trace.

structure. Projecting slightly into the pith from the inside of the ring are seen seven or eight vascular bundles, $t$, of varying size, cut transversely, each with its phloem against the pith, and its xylem (of equal or greater amount) next to the vascular ring; these are the central leaf-traces. The greater part of the "ring" consists of horizontal or oblique elongated elements, mostly of phloem, but with some spiral tracheae; these are derived from root-traces and lateral leaf-traces. In this ring and sometimes on the outer side of it, next the cortex, are additional bundles 
cut transversely, with xylem inside and phloem next the cortex; their origin or end I was unable to learn. On the surface of the stem at each node or point of union of a petiole with the caudex, there is in $N$. flava a prominent conical projection, on the upper face of which the petiole is attached, and on the lower face the roots. Within the tissues of this projection the bundles from the attached roots unite into a single trace, and this passes horizontally through the cortex to the lower edge of the leaf-gap. A few cells join the vascular cylinder of the stem directly, but most of the trace is contained in two large lateral forks, one right and one left, which start almost horizontally into the vascular cylinder and could not be followed. The petiolar
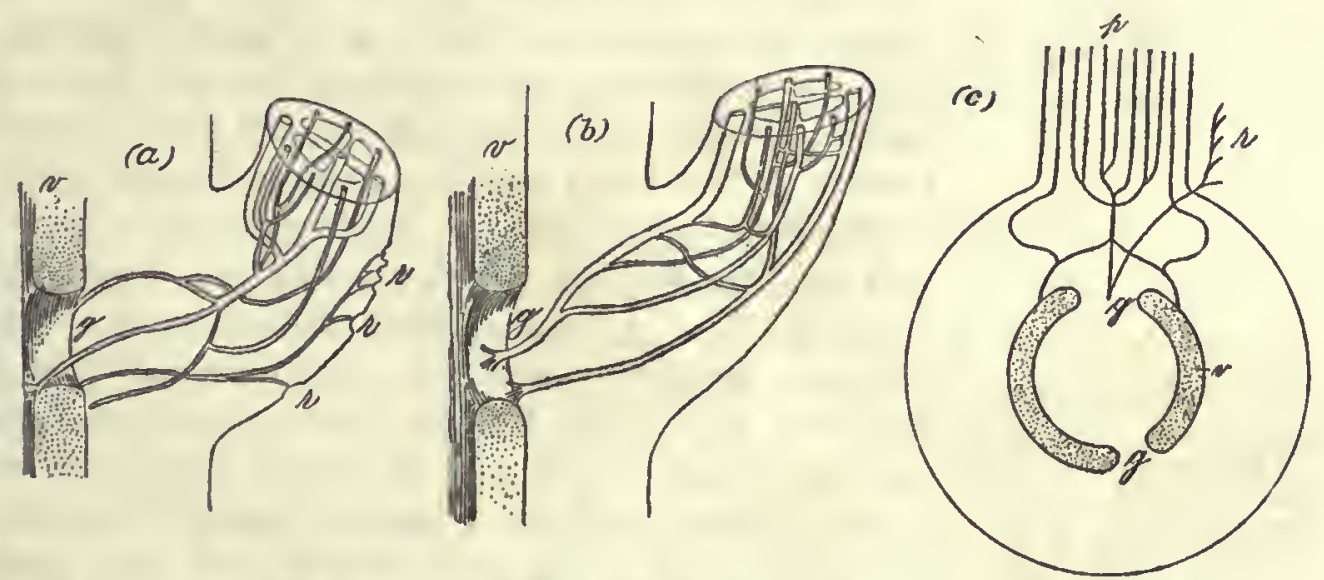

FIG. 22.-Course of vascular bundles at node of $N$ ymphaea fava. (a) base of petiole; (b) basc of peduncle; $a$, leaf gap; $r$, roots; $v$, vascular cylinder of ster, scmi-diagrammatic; (c) dingrammatic projectlon of $(a) ; p$, petiole.

bundles are nine in number, three in a median vertical plane, and six smaller lateral ones. Of the first three, one is anterior, one median, and one posterior. The others are right and left antero- and posterolateral, with one directly right and one left of the centre of the petiole. On entering the stem, the posterior and median bundles fuse, and are shortly joined by the anterior, the whole forming a large central leaf-trace. The right and left antero-lateral bundles are joined at about the same level as the above, by the directly right and left bundles, and the two fused bundles then join the central leaf-trace. This trace passes horizontally in through the cortex and comes in contact with the roottrace, then passes over the brink of the leaf-gap and turns sharply downward next to the pith, giving the appearance noted in the cross-section. About midway on its course through the cortex, the central leaf-trace 
gives off a strong branch to either side. Each branch passes about 45 degrees around the stem and then runs obliquely into the vascular cylinder. Meanwhile each has been joined near the middle of its course by a postero-lateral bundle from the petiole, which, on first entering the stem, bent sharply away from the other bundles and ran along horizontally in the exo-cortex to the corner of the leaf-area before turning inward. The whole is made reasonably clear by a glance at Fig. 22, (a), (c).

A very similar arrangement of bundles was found at the node of a stolon of $N$. rubra. It is usual in the Lotos group to find a slender

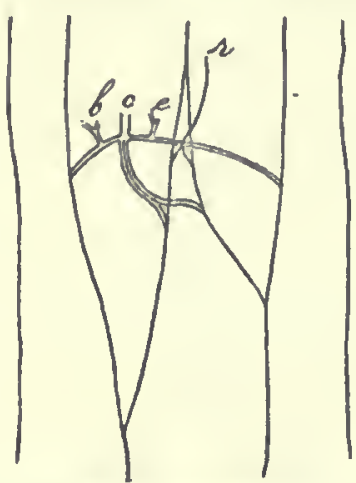

Fig. 23.-Vascular system of stolon of $N$. rubra? at a node; $b, e$, lateral leaf traces ; $c$, central leaf trace; $r$, root bundle.

The lower end is toward apical region of stolon. leaf a short distance below the young plant near the apex of the stolons. This is the only place in any Nymphaea, I believe, where a leaf can be found at sufficient distance from others to admit of simplicity in the arrangement of the bundles. At some distance below the leaf in question there are four bundles (steles of Gwynne-Vaughan) passing longitudinally in the stolon. Nearer the leaf one of these forks, making five bundles, nearly equidistant from one another (Fig. 23, upper end). Opposite the leafbase, the bundle on that side of the stolon divides into two parts which run almost in contact through the node. A single root is present here, and its trace, $r$, passes obliquely inward toward the space between the recently split bundle, and part joins each half. Three bundles enter the stolon from the leaf, a central, $c$, and two lateral, $b, e$. The central bundle passes in parallel to the roottrace, and a part joins each half of the split stem-bundle. Midway of its course inward, however, it gives off a large branch right and left and these join the next nearest stem-bundles on either side. Each lateral leaf-trace is joined by another small bundle (probably stipular) just within the stem tissues, and the two unite with the right and the left branches respectively of the central bundle. Above this leaf (below, in Fig. 23) the two parts of the split bundle move farther apart, and finally they fuse successively, each with its nearest neighbor, giving rise to five and then the original four bundles of the stolon. Shortly, however, these fused bundles again divide in making ready for the insertion of the next two leaves. The bundles from these leaves are in number and mutual relations identical with those of the first leaf; but the leaves here become crowded and the details of the course of the bundles 
can only be traced so far as to show that all of the four stolon-bundles are sooner or later joined by leaf-traces, and therefore that all of the bundles of the stem are common.

Concerning the origin and distribution of the bundles in the stolon of $N$. flava, we can only say that at the distal end of the stolon the vascular strands branch and anastomose, in fusing with leaf and root traces, to form the vascular cylinder or plexus of the new caudex. The strands of the stolon originate from the four sides of a ramular gap in the vascular system of the parent plant similar to a leaf-gap, and the stolons occur in the place of leaves in the leaf-spirals of the surface of the stem. The above evidently refers to a stolon with four vascular strands, which seems to be the normal number. I have examined one specimen with five strands, one central and four peripheral. In this the central strand fused with the lowest peripheral one before entering the parent stem, so that both passed in as a single strand over the brink of the ramular gap exactly like a central leaf-trace.

It would seem from these accounts that the bundles of the stolon are scarcely to be called steles, and that the behavior of the leaf-traces is more in line with dicotyledonous than with monocotyledonous structures. Prof. Nägeli remarked in 1857 (Caspary, I 857, b) that "of the five vascular bundles which enter each leaf in $N$. alba, the two lateral pairs in the interior of the stem go to the sides of the stem, but the middle one sends a branch inward to form a central strand, and only in this latter point does $N$. alba differ in structure from the characteristics of a dicotyledonous stem."

The relations of the bundles of the flower stalk in joining the stem have been most accurately worked out in $N$. flava. Seventeen longitudinal bundles were found in the peduncle, viz, a central bundle; four large ones 90 degrees apart around the periphery, of which one is anterior, one posterior, one right and one left; alternating with these are four smaller bundles, and eight tiny ones alternate with the last two sets. The last eight were not traced into the stem, but they doubtless unite with their larger neighbors at the base of the peduncle. Great variation exists in the details of the fusion and anastomosis of the remaining bundles, Fig. 22, (b). However, it seems constant for the four oblique bundles to

1 “_- dass von den 5 Gefässbündeln, die bei $N$. alba in jedes Blatt eintreten, die beiden seitlichen Paare im Innern des Stammes nach dessen Rande zugingen, das mittlere jedoch einen Zweig nach Innen entsende, um einen centralen Strang $z u$ bilden, und nur in diesem letzteren Punkte weiche der Bau von $N$. alba von dem Charakter des Dicotyledonenstammes ab." p. 79i-2. 
fuse with one or both of the adjacent large bundles, leaving, with the central one, five strong vascular trunks. Shortly the central and posterior trunks unite, leaving four, and then the anterior and right trunks unite, leaving but three traces. The left trunk may now join the fused right and anterior, or these may remain separate and pass to opposite sides of the gap in the vascular cylinder of the stem which is prepared to receive them. This gap is identical in size and shape with those for the leaves and stolons; since a peduncle is a form of stem, this should probably be called a ramular gap. The fused posterior and central trace passes in over the lower edge of the gap and turns downward after the manner of a central leaf-trace, with its phloem uppermost (innermost after turning downward). Some analogy between the bundles of peduncle and petiole would be desirable, but opinions on this would as yet be premature.

\section{THE LEAF.}

The three types of waterlily leaf mentioned on a previous page have been designated by Arcangeli $(1890, b)$ hydrophylls (idrofilli), aerophylls (aerofilli) and aerohydrophylls (aeridrofilli); the last includes all of those commonly seen and familiarly known as lily-pads. It will be more convenient, however, to speak in plain English of submerged or water leaves, aerial leaves and floating leaves. The aerial type is altogether exceptional. It occurs in $N$. odorata, alba, tuberosa, mexicana and marliacea-chromatella when the plants are much crowded, or in $N$. odorata minor where the rhizome is bedded in deep peat or sphagnum from which the surface water entirely dries away in summer. In the last case, specimens from Atco, N. J. have shown a few stomata on the under side of the leaf near the apex, and such leaves are always firmer and tougher in texture than floating leaves; but other than this no difference has been noted, and no further mention of them will be made.

Floating leaves are present in all Nymphaeas, excepting $N$. alba, when growing in deep, swift streams (which is a rare occurrence), and perhaps in $N$. amazonum submersa (Sagot, $188 \mathrm{I}$ ) and $N$. oxypetala. A mature flowering plant will have at one time from 4 of these in $N$. tetragona to 6 or 8 in $N$. odorata or 10 to 5 in the large tropical species. They are produced in rapid succession throughout the growing season, and after functioning for a few weeks, turn yellow and decay.

At the base of the petiole occur stipules of characteristic shapes (Fig. 24). In Castalia the two "stipules are inserted on the edge of the dilated pedestal of the leaf-stalk, and below the articulation of the latter; 
and are connate in one plate-like piece in front of the petiole. They are therefore intrapetiolar" (Lubbock, I 894). The insertion is usually a little oblique in Eu-castalia, the curved line of attachment extending farther back on one side of the petiole than on the other. The fused stipular plate persists for some time after the decay of the leaf. It is about $\mathbf{2 . 5}$ $\mathrm{cm}$. lon, more or less, and lies closely appressed to the rhizome; in general outline it is broadly oval, with emarginate apex. A shallow furrow exists along the line of fusion, into which the petiole fits, and from the ridges on either side of this the tissues taper out to an extremely thin margin. The stipular plate of $N$. flava is erect, lanceolate, $2.5 \mathrm{~cm}$. or more in length, thin, rounded at apex, and not persistent. In Brachyceras the stipules are fused at base, with distinct and more or less long-attenuate apices. The other subgenera have distinct, slightly unequal stipules, consisting each of a long ( 2.5 to $4 \mathrm{~cm}$.), narrow $(0.3 \mathrm{~cm}$.) wing, adnate to the side of the petiole, with free acuminate apex. In all cases the stipules are whitish or semitransparent, and soft in texture, and covered on both sides, but especially on the back, with deciduous mucilagehairs. Interspersed with these on the backs of the stipules in $N$. odorata and

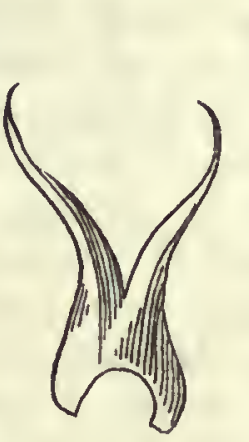

$\alpha$
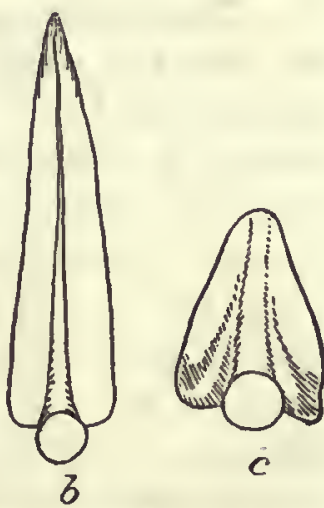

Fia. 24.-Stipules.

$a, N$. zanzibariensis $\times ; b, N$. fava; $c, N$. odorata. lotus are short fibrous hairs, one to three cells long in the shaft in the former species, much longer, but still few celled, in the latter. Both kinds of hair rest on similar bases of disc-like cells, as will be described shortly. I have observed no vascular supply to the adult stipules of $N$. lotus, but $N$. odorata has a principal vein running longitudinally in each ridge of the stipular plate, with about nine smaller ones parallel and nearer the margin. N. flava has also a midrib in each ridge, and may have one parallel vein outside of this. No others have been examined. The cellular structure is very simple. The epidermis of the two sides is continuous around the margins of the stipules, very even on its outer surface, but irregular and angular next to the parenchyma; it consists of more or less cubical cells in $N$. odorata and lotus, but in $N$. flava the cells are wider than deep and longer (in the direction of the length of the stipules) than wide. The interior is filled with nearly uniform, thin-walled cells, roundish or oval, with evident intercellular spaces in 
$N$.odorata and lotus, polygonal and with extremely minute intercellulars in $N$. Rava. In thickness this parenchyma reaches about eleven cells next to the petiole in $N$. lotus, tapering to one cell at the margin; $N$. flava has about 9 cells in thickness at the ridges; $N$. odorata has 16 cells at the ridges, and throughout its tissues are many very thin-walled, twopointed or variously forked idioblasts. Numerous small starch grains were observed in the parenchyma of a young stipule of $N$. lotus. In this species also the stipules are much more prominent when young than on mature leaves, lending weight to Lubbock's (1894) statement that they are throughout the genus of especial use in protecting the young leaves and flowers.

The petioles of Nymphaeas necessarily vary in length according to the depth of water in which the plant grows, being always long enough to allow the leaf some freedom in floating about; the range is therefore from a few centimeters to 5 or 6 meters, and that in the same species ( $N$. alba, odorata). In diameter the smallest are those of $N$. tetragona, $0.3 \mathrm{~cm}$. through, and the largest are found in $N$. lotus, $1.9 \mathrm{~cm}$. through. They vary very little from a cylindrical shape, being, near the ends, slightly flattened on the upper side. Of a uniform green in most species, many of the cells contain a blue-purple pigment in the blue-flowering species, or red-purple in the Lotos group; $N$. odorata has usually deep crimson-brown petioles, and in $N$. tuberosa they are quite characteristically marked with longitudinal brown stripes in the upper part. Always pubescent when young, the hairs persist only at the base in most species, but are permanent in the majority of the Lotos group, and in occasional specimens of $N$. odorata; Caspary (i 865) had such from New York State on which he founded his variety villosa, and we have cultivated such a plant, sent from Florida by Mr. Soar of Little River, in the Botanic Garden of the University of Pennsylvania. A plentiful growth of short filamentous algae on the petioles and under surfaces of leaves has been mistaken for pubescence by some writers.

Surface sections of the petiole reveal an epidermis composed of foursided cells arranged in fairly regular longitudinal rows, mostly with the longest dimension lengthwise of the petiole; the cross-walls are often oblique. At intervals of I or 2 to 15 or 20 cells, the rows are interrupted by circular, thick-walled cells, the bases of the hairs mentioned above. In the Castalia group, hair-bases seen to be most plentiful in $N$. odorata, though in all species they differ in number at different levels on the petioles. In transverse section, the epidermal cells vary in shape from 
slightly wider than deep to slightly deeper than wide. In $N$. nuberosa the latter shape occurs near each end of the petiole, while near the middle the cells are approximately square in section. The bases of the hairs, Fig. $25,(a),(b)$ are now seen to consist of a short epidermal cell whose inner end is about flush with its neighbors, surmounted by one or two shallow, disc-like cells which come up level with the outer surface. Two disc-like cells are constant in $N$. rubra and zanzibariensis $\times$ and occasional in $N$. tuberosa and amazonum, only one being found elsewhere. The disc-like cells are very shallow, one-third to one-fourth the depth of the epidermis in $N$. odorata and its varieties, but in other species they occupy about half
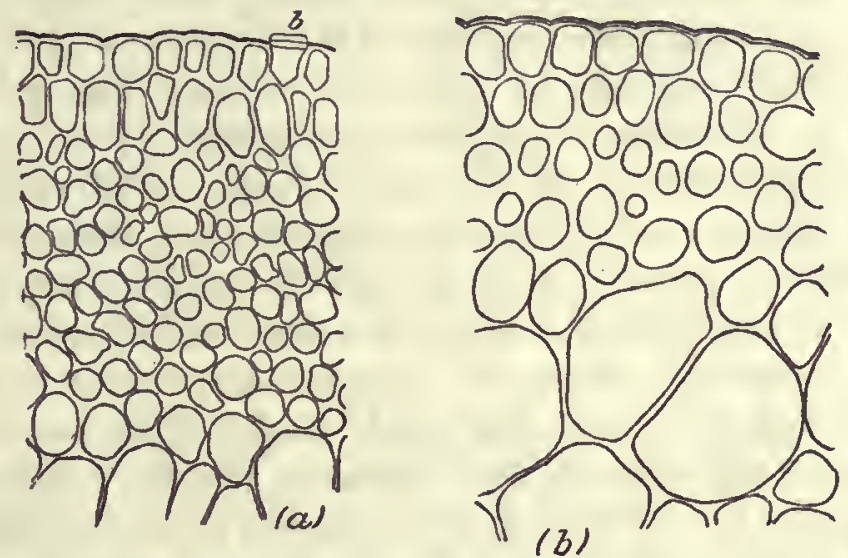

Fia. 25.-Collenchyma in pexioles.

(a) $N$. sturtevantii; (b) $N$. Aava ; $b$, basai cells of a hair.

the depth of the epidermis. A thick cuticle is always present, and was seen in $N$. tetragona to be distinctly lamellate.

Beneath the epidermis there is a single subepidermal layer, distinguishable in all but $N$. tetragona by its thin walls, and in $N$. rubra by the larger size and somewhat columnar arrangement of the cells. Under this layer is a zone of collenchyma (Fig. 25), whose cells remain of small or medium size but are followed internally by much larger fundamental cells in N. mexicana, flava, rubra, amazonum, and the middle parts of the petiole of $N$. zanzibariensis $\times$, but which become gradually larger inward and pass more or less insensibly into the fundamental tissue in $N$. odorata, tuberosa, tetragona and the lower part of petiole of $N$. zanzibariensis $\times$. This zone is about 3 cells wide in $N$. flava (a small petiole), 4 in $N$. tetragona, mexicana, amazonum, 5 or 6 in the upper and lower ends of $N$. tuberosa petiole and the middle of $N$. zanzibariensis $\times, 6$ or 7 in the middle of $N$. tuberosa, and 8 in $N$. odorata, rubra, and the two ends 
of $N$. zanzibarionsis $\times$. In $N$. tetragona the subepidermal layer is decidedly colloid, and in other species it may be slightly so in its inner walls. These colloid tissues are of the type usually described in textbooks for collenchyma; the thickenings are massed in the angles where three or more cells meet, sometimes from their great amount seeming to extend along the narrower sides. The appearance is often that of a group of round dull bodies (the cell-cavities) in a highly refractive but homogeneous medium; in less pronounced cases the likeness is more that of a network with large knots. In Müller's (1890) valuable classification of collenchyma, Nymphaea is cited as an example of his first class, "Cornercollenchyma" (Eckencollenchym), and as having the colloid matter sometimes convex and sometimes concave to the cell-lumen; the latter is most common, but the former may be seen in $N$. rubra. The greatest amount of thickening occurs about the middle of the colloid zone.

The remaining tissue of the petiole, designated already as fundamental tissue, consists of larger or smaller rounded, thin-walled cells, with large intercellular spaces; it is traversed longitudinally by numerous lysigenous air-canals and by vascular bundles. In $N$. odorata these cells are of fairly uniform size, but in $N$. rubra the cells bounding the air-canals, and those between the canals, are much smaller than those between the canal-region and the collenchyma. Many of the large fundamental cells are bi-nucleate, and in $N$. flava and $N$. zanzibariensis $\times$ contain starch.

For many years the air-canals of waterlily petioles and peduncles have attracted the attention of botanists on account of their large size and constant and characteristic arrangement. Thus Mackintosh (1876), Parlatore (188I) and Masters (1902, $a, b$ ), as well as Planchon, Caspary and others have written of them. Two principal types may be distinguished in petioles of mature plants; (I) that of Eu-castalia, with four nearly equal, large canals placed in a square near the middle of the petiole, two anterior and two posterior, and (2) that of Lotos, Hydrocallis and Xanthantha, with two greatly predominant canals and two lesser ones at each end of these (anterior and posterior). Other species, as shown in the diagrams (Fig. 26), approach one or other type more or less, or show intermediate conditions. Starting from such an arrangement as is shown in $N$. tetragona (I9) or gigantea (I I), we can easily imagine specialization leading in two directions to the well-marked types above mentioned. Each canal is bounded by an even layer of small cells, with walls slightly convex toward the canal, and is lined with a thick cuticular coating, whose function, if the researches of Barthélemy (1874) are of weight, is to aid in 

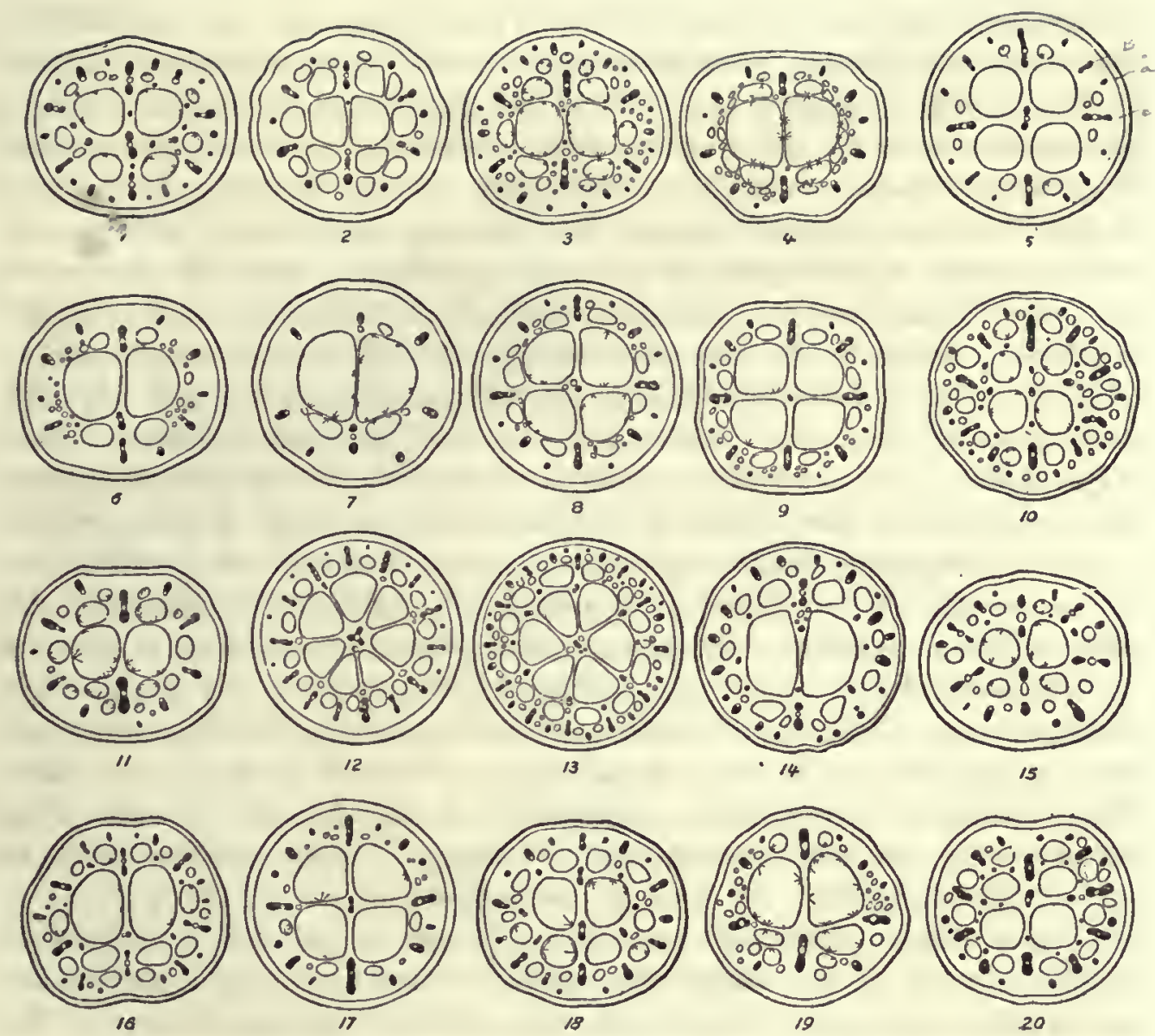

Fra. 26.-Sections of Petioles and Pedunclos.

\begin{tabular}{|c|c|c|c|c|}
\hline No. & Name. & Organ. & Dlstance from end. & $\begin{array}{l}\text { Natural size } \\
\text { (ccntimeters). }\end{array}$ \\
\hline 1 & N. odorata gigantea & petiole & $4 \mathrm{~cm}$. from leaf & $0.9 \times 0.64$ \\
\hline$\overline{2}$ & N. rudgeana & Ak $>$ & $7.8 \% " \omega$ & 0.48 \\
\hline 8 & N. amazonum & $" *$ & $1.8 \% "$ & $0.13 \times 0.48$ \\
\hline 4 & N. mexicana & " & $7.6 " 4 \quad 4$ & $0.48 \times 0.42$ \\
\hline$\&$ & N. odorata & peduncle & midway & 0.5 .5 \\
\hline$\frac{6}{7}$ & $\begin{array}{l}\text { N. odorata sulfurea (hybr.) } \\
\text { N. flava }\end{array}$ & petiolo & $9.6 \mathrm{~cm}$. from leaf & 0.47 \\
\hline 8 & $+\infty$ & peduncle & " flowor & $\mathbf{0 . 4 8}$ \\
\hline 9 & N. tetragona & "it & " " & 0.42 \\
\hline 10 & $\begin{array}{l}\text { N. zanzibariensis } \\
\text { N. gigantea }\end{array}$ & potiolo & 0.2 " " leat & 0.8 \\
\hline 12 & N. caerulea & pedunclo & “flower & 0.04 \\
\hline 13 & N. dontata? & notlolo & "\# " “ & 0.8 \\
\hline 15 & N. lotus? & peture & ".6 " & $0.85 \times 0.95$ \\
\hline in & N. caerulea & " & " " & 0.8 \\
\hline 17 & N. tuberosa & peduncle & $46 \mathrm{~cm}$. from rhizomo & 0.48 \\
\hline 19 & N. tetragona & petiole & 9.0 c. Irom „eax & $0.67 \times 0.48$ \\
\hline 20 & N. caeruloa $x$ & " & $9.6 \quad \cdots$ & 0.82 \\
\hline
\end{tabular}

Nos. 1, 2, 6, 7, 14, 16, 18, 18, 19 aro placed wlth ventral (upper) side uppormost. 
the exchange of gases between the air in the canals and the surrounding tissues. For, following Goebel (1893), it seems generally accepted that the air-spaces of aquatic plants are for the purpose of internal breathing ; and the researches of Lechartier ( 1867 ) as well as those cited by Goebel (1. c.) are in favor of this view. Such an internal cuticle can hardly be for protection in the same sense as this function is attributed to it on the outer surfaces of plants, though it might be simply a chemical product of the contact of air upon an otherwise unmodified living cell-wall. Similar arguments apply to the cuticular coatings on the surfaces of mesophyllcells where in contact with air, as in the air-chambers connected with the stomata in most plants. Russow (1884) and Mellinck (1886) regarded these coatings as intercellular protoplasm; but Kny (1900), working over the same ground very recently, considers the presence of living extracellular protoplasm in the large air-canals of water plants improbable; the writer favors this view for Nymphaea. Kohl (1889) found on the walls of the air-canals of $N$. alba small free crystals of calcium oxalate.

Between two adjacent air-canals there is often but a single layer of cells (e. g., N. fava, tetragona, and small leaves of rubra, amazonum, etc.); usually, however, the partitions are 2 to 6 or even 12 cells thick. The thickness varies slightly in different parts of the same petiole, since the canals taper a little at each end. The largest ones, at least, open at the proximal end into the lacunar mediocortex of the stem by pores in the end-wall; at the distal end they connect similarly with a mass of similar lacunar tissue which again makes communication with the aircanals of the veins of the leaf. At each of these points of opening the walls of the canals and the lacunar tissues are loaded with stellate idioblasts ; indeed, the lacunar tissue in $N$. flava, odorata and tuberosa seems to be little else than a tangled mass of such cells, with their arms interlacing in every direction. Diaphragms do not occur in the air-canals of the petioles and peduncles.

It will be well here to dispose of some matters relating to the internal hairs of Nymphaea. We have adopted for them the Sachsian term "idioblast" as used by Weiss (1878). ${ }^{1}$ Their common features are the great induration of the walls, and the presence of numberless small

\footnotetext{
"The earlier terms "pachycyst" of Caspary (1865), "pneumatocyst" of Planchon (1850, $e$ ) and "Knorpelzclle" of Hanstein, have never come into general use. Soleredcr's (I 898 ) "Sclcrenchymzelle" is a good term, but a little too broad. Ischirch (1889) has proposed the term "astrosclereide," but Arcangeli $(1890, a)$ rightly objects to this because so many forms are found in addition to the stellate-cell ; he therefore proposes "cladosclereide."
} 
more or less cubical or rhombohedral crystals of calcium oxalate embedded in the wall. Schenck (1884) states that the completed crystals are formed on the inside of the primary walls of the cell, followed in the usual way by deposits of layers of secondary thickening. Kohl (I 889) and Arcangeli (1890, a) support this view, in opposition to Molisch (1882) who thought the crystals were only partly embedded in the wall, and to Van Tieghem (Traité de Bot., I 2 ed., p. 644-5) who considers them to be simply incrustations and not crystals at all. That they are truly embedded is shown by the fact that a protuberance still remains after the salt is dissolved out by acid. Kohl (1. c.) gives a copious list of plants in which such " tertiary" calcium oxalate is found. Idioblasts are derived from ordinary young parenchyma cells ; these become distended on one or more sides into the air-canals or smaller intercellular spaces. In a narrow canal, the further extension of the cell takes place in two directions, resulting in a long, double-pointed (bipolar) idioblast, attached somewhere on one side. This type is very plentiful all through the petioles of the Eucastalia species; a row of such idioblasts occurs in these petioles next to or near the epidermis; a similar row was seen in $N$. zanzibariensis and in a hybrid of this near the leaf, but in no other species were they observed. If a cell bears two such elongated outgrowths, its shape resembles a long narrow $H$. But where the future idioblast lies next to a broad air-canal, it usually puts out several arms in different directions, giving the well-known stellate form; all possible shapes from the simple two-pointed fiber to a star with 8 or more arms may be found. These have been frequently observed and figured heretofore. They vary in number at different levels in the petiole. Thus, in $N$. tuberosa, near the rhizome the marginal ring of bipolar idioblasts numbered about i 8 , near the middle of the same petiole 100 , near the leaf 60 ; in $N$. odorata there were none at the rhizome, 60 to 70 midway, and 100 near the leaf; $N$. zanzibariensis $\times$ had about 100 near the leaf. A comparison of the number of idioblasts of all kinds in different species was made by counting those visible in a single field of the microscope (Leitz, oc. 2, obj. 3) at the center of the petiole (between the four main air-canals); the results are shown in the subjoined table. The varieties of $N$. odorata, viz, minor, rosea, and $N$. exquisita Hort., are like the type in this respect. $N$. flava and mexicana agree in having no bipolar idioblasts, but many small, shortarmed, stellate cells in the canals.

In addition to idioblasts, there are found rather plentifully (one every 6 to $5 \mathrm{~cm}$.) in the air-canals of petioles (and peduncles) of Apocarpiae, 
and less frequently in Lotos, irregular cell-masses projecting from the walls; these appear as whitish specks to the unaided eye, and are found to consist of numerous oval, thin-walled, turgid cells with one end free in the canal and the other attached. They develop from a single wall cell, much after the manner of the diaphragms of the canals of roots. Similar outgrowths were found by Mellinck (1886) filling up the air-

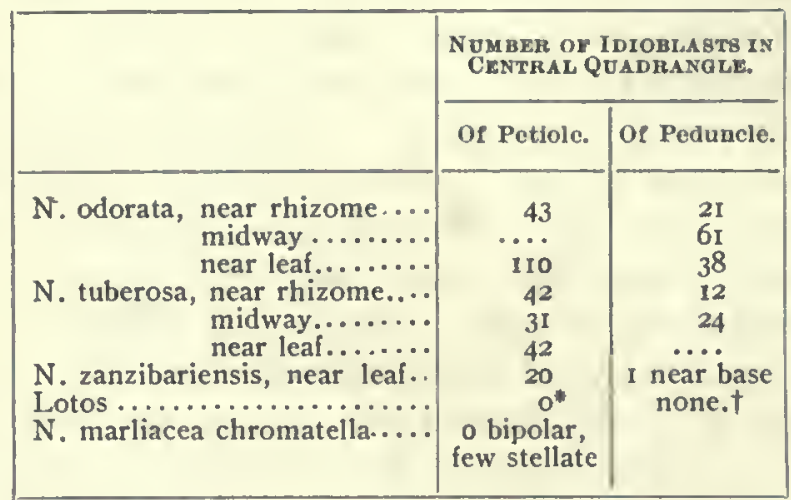

* 3 species and varieties examined. † 7 species and varieties examined.

spaces of petioles of $N$. alba which had been wounded as far in as the large air-canals. We shall speak of them hereafter as thyll-like bodies.

The course of the vascular bundles in the petiole is longitudinal and parallel from end to end. Their manner of entering the stem has already been referred to. In joining the leaf, all of the bundles are connected in the uppermost end of the petiole (or in the base of the leaf as one chooses to call it) by transverse commissures, forming a ring of vascular tissue parallel to the surface of the leaf. In Lotos this causes a circular swelling of striking prominence, which I have called the "collar"; it is less prominent in Apocarpiae, and not noticeable in the other groups. From this ring the primary veins radiate out into the leaf. In general, the bundles of the anterior and antero-lateral parts of the petiole supply the lobes of the leaf, the lateral and postero-lateral its sides, and the posterior and median form the midrib.

The arrangement of the vascular bundles in the petiole differs according to that of the air-canals and the size of the petiole, but follows an easily definable plan. Details may be gathered from the diagrams (Fig. 26). Where there are two main air-canals, we find a large doublebundle at each end of the partition between the canals, that is, in the median plane anteriorly and posteriorly, and two smaller bundles on each 
side of the canals equidistant from each other and from the former two. According to the size of the petiole there may be an additional, still smaller bundle in the middle of each space between the six just located;
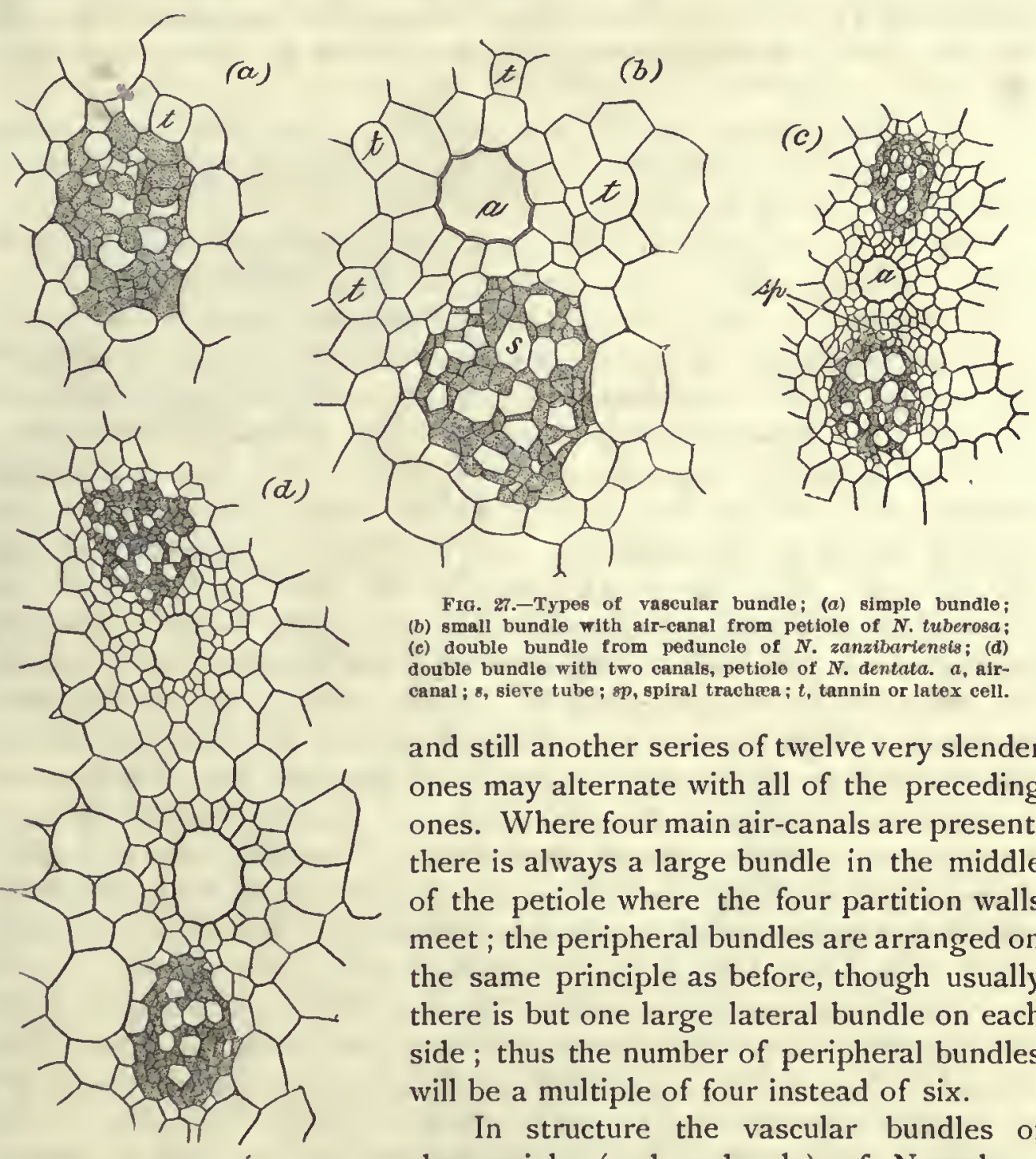

FIa. 27.-Types of vaseular bundle; (a) simple bundle: (b) small bundle with air-canal from petiole of $N$. tuberosa; (c) double bundle from peduncle of $N$. zanzibariensts; (d) double bundle with two canals, petiole of $N$. dentata. $a$, aircanal ; 8 , siere tube; $s p$, spiral trachsa; $t$, tannin or latex cell.

and still another series of twelve very slender ones may alternate with all of the preceding ones. Where four main air-canals are present, there is always a large bundle in the middle of the petiole where the four partition walls meet ; the peripheral bundles are arranged on the same principle as before, though usually there is but one large lateral bundle on each side; thus the number of peripheral bundles will be a multiple of four instead of six.

In structure the vascular bundles of the petiole (and peduncle) of Nymphaea show that extreme reduction of xylem which usually characterizes water plants. In the absence of any distinguishable endodermis, the bundles are sheathed by ordinary, large, fundamental cells; occasional intercellular spaces occur between these and the bundle-cells, but this is not common; the outer side of the sheathing-cells, however, joins with the 
surrounding fundamental tissue with the looseness common to that tissue. Three types of bundle may be distinguished:

(1) The smallest bundles, Fig. 27, (a), consist of a strand of phloem, with perhaps five or six sieve-tubes and a number of companion-cells, and on the inner (central) side there may or may not be one or two spiral elements.

(2) Medium-sized bundles, Fig. 27, (b), like the former but larger as to the amount of phloem, and accompanied on the inner side by a small but extremely regular and round air-canal.

(3) Still larger bundles, Fig. 27, (c), differing from (2) in having a phloem strand on the inner side of the air-canal as well as on the outer side; the inner strand is usually smaller than the outer.

Sometimes two air-canals intervene between the phloem strands, Fig. $27,(d)$, while in the center of a large petiole (or peduncle) there may be three phloem strands about a single air-canal. The four or six large peripheral bundles of the petiole usually have two phloem strands and one or two canals. These air-canals are quite small, scarcely visible to the naked eye, and are bounded by a very regular row of clear cells, whose walls next to the lumen of the canal are convex and strongly cuticularized. In very young petioles remnants of spiral elements may be seen in these canals, showing that they bear the same relation to the bundle as the well-known canals in the xylem of monocotyls, Zea mays, etc. Where the petiole joins the leaf several spirals are found at the sides of the canals, and these rapidly increase in number as we approach the collar until the canal is wholly obliterated, and there is, instead, a mass of spiral elements nearly or quite as large in cross-section as the phloem strands. The neat wall of the canal disappears pari passu with the encroachment of the spirals (cf. Caspary, 1858, p. $3^{82}, 3^{8} 5 ; 1888$, p. 2 ; Solereder, 1898$)$.

The lamina of the waterlily leaf (Fig. 28) varies in size from 5 to 7 $\mathrm{cm}$. in diameter in $N$. tetragona and odorata minor to $40 \mathrm{~cm}$. or $60 \mathrm{~cm}$. in the large tropical forms. It is cleft nearly to the center where the petiole is attached, and has been termed fissi-cordate. Nearly orbicular in most species, it is somewhat oval in $N$. caerulea, and decidedly so in $N$. elegans, pubescens, and tetragona. The margin is entire in Eu-castalia and Chamaenymphaea, slightly wavy at base in Xanthantha; in Hydrocallis and Brachyceras it varies from entire in $N$. amazonum and elegans to deeply sinuate in N. rudgeana, ampla, flavo-virens, capensis, and zanzibaricnsis; in $N$. gigantea and the Lotos group the leaves are sinuate-dentate, with 
wide rounded sinuses and sharp, almost acuminate teeth. The apex is usually rounded, but somewhat emarginate in $N$. caerulea and sometimes in $N$. odorata, especially the variety gigantea. In the sinuate-margined Apocarpiae, the tendency is for the apex to lie in a sinus, while in Lotos the midrib is continued out into one of the serrations. At base the two slobes may overlap or just touch or divaricate in the same plant or species, so that this feature is of very little systematic value. Near the petiole the lobes may be fused by their edges for a distance of 2.5 to $5 \mathrm{~cm}$. in Lotos, $1.3 \mathrm{~cm}$. in some Apocarpiae, or almost none in Castalia ; this causes the leaf to be more or less peltate, and the fused portion I have called the pelta (Fig. 28, $p$ ). At the apex of the lobes they tend to develop distinct points marking off the borders of the sinus (the space between the lobes) from the rest of the margin of the leaf; this point is acuminate and sharp in $N$. gigantea, capensis, and the Lotos group, obtuse but still produced and evident in Castalia, altogether absent and the lobes broadly rounded in $N$. amazonum. The thickness of the leaves of most species gives them a leathery feeling, but they are rather brittle

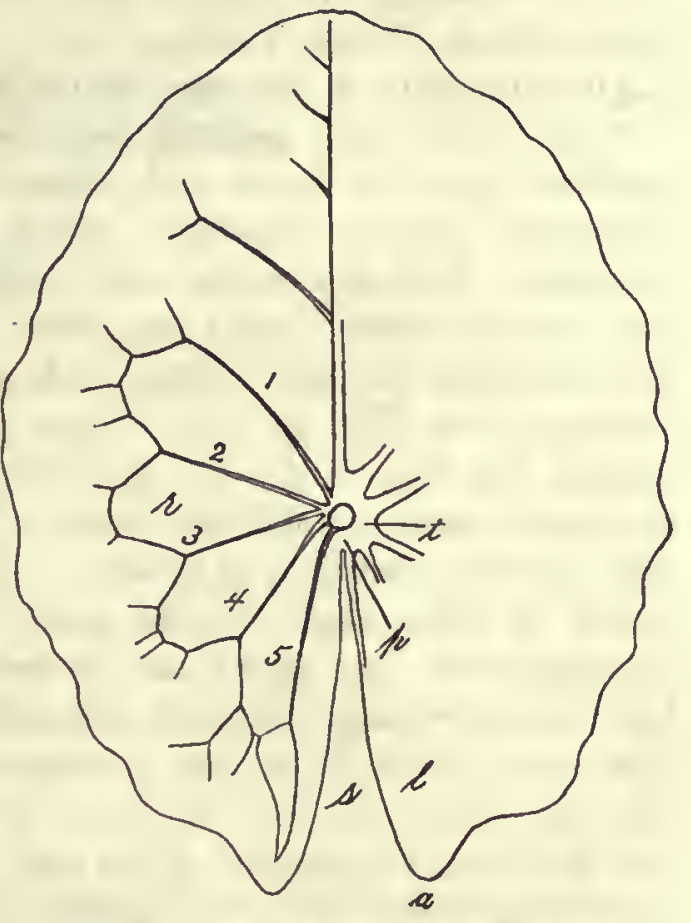

Fra. 28.-Leaf of N. Java, showing upper surface on right, lower surface on left half; $a$, angle of lobe; $l$, lobe; $p$, pelta; $r$, principal area; $s$ sinus; $t$, astomatic area; $1,2,8,4,5$, primary veins.

and easily torn. Mostly lying flat upon the water, we have exceptions in the crisped margins of $N$. Aavo-virens, capensis, zanzibariensis and the Lotos group. $N$. odorata gigantea often has the margin of the distal half of the leaf turned up at right angles to the water-surface to the height of 2 or $3 \mathrm{~cm}$., somewhat after the manner of Victoria. A rich chlorophyll-green is the usual color of the upper surface of the leaves. In $N$. flava, mexicana, tetragona, rubra-rosea, amazonum and zanzibariensis, however, there is more or less of brownish-red blotching, and in $N$. rubra the whole leaf is of a bronzy-red hue. The under surface of the leaf is quite different. Dull green in $N$. tuberosa, it is 
reddish to dark crimson-brown in $N$.odorata, alba, tetragona and flava, dull brownish in the Lotos group, and blue-purple in $N$. zanzibariensis and gigantea. Dark brownish or blackish blotches and specks mark the under surface in $N$. flava, caerulea, ampla, elegans and amazonum. The leaves are rolled inward from the sides (involute) in venation. They come up through the water in a more or less erect position, and only on reaching the surface does the lamina bend over at right angles to the petiole (Frank, 1872).

The venation, as inferred above, is in general palmate, but there is a distinct midrib with pinnate branching. The lowest pair of veins turn backward into the lobes, and others radiate out at various angles; it is sometimes difficult to decide whether the most anterior of these are distinct or branches of the midrib. Five ( $N$. flava, tetragona) to twelve $(N$. zanzibariensis) veins on either side of the midrib originate thus directly from the base of the leaf, and were called by Caspary (1865) primary veins (Fig. 28, I-5). They give off small branches along their course, but sooner or later fork into two nearly equal parts. A strong cross-vein soon connects the forks of adjacent veins, enclosing a distinct area between each pair of veins. The area whose long axis stands most nearly at right angles to the midrib was called by Caspary (1. c.) the principal area (Fig. $28, r$ ), and its length in relation to the radius of the leaf was used as a standard measurement in all of his taxonomic work. The vein below it is the principal vein (Fig. 28, 3). Beyond these primary areas there is a series of similar meshes, becoming rapidly smaller out to the margin of the leaf. Here the outer boundaries of the ultimate meshes make an irregular, submarginal vein in all but the Lotos group ; in these, three or four veinlets run together to a point in the apex of each tooth of the leaf-margin. Great variety exists in regard to the prominence of the veins on the under side of the leaves. In Castalia the veins are easily seen, but they are marked by very slight and gradual elevations of the leaf surface. In $N$. amazonum (Hydrocallis) the veins are prominent beneath as narrow, low, but quite abruptly raised lines. Among the Apocarpiae, $N$. gigantea has the veins quite abruptly raised above the leaf surface, and standing out as a prominent reticulum; $N$. zanzibariensis is similar save that the ultimate veinlets at the leaf margin do not project, and so we pass through $N$. flavo-virens to $N$. caerulea, in which the primary veins alone are markedly prominent, and the tertiary branches are raised very little if any above the leaf surface. The Lotos group, however, has an extremely prominent network of veins. The 
midrib near the base forms a ridge a centimeter high and 0.3 to $0.5 \mathrm{~cm}$. wide, with vertical, parallel sides and rounded summit. The primary veins are but little lower; the ultimate branches also, especially where they run out into the serrations, stand out like little cords. Thus by a system of underlying rafters the lamina is rendered firm and stiff. In the large leaves of Euryale and the gigantic foliage of Victoria this method of strengthening is carried to a remarkable degree of development.

In describing leaf-structure we may speak of $(\mathrm{I})$ the upper epidermis, (2) the palisade layer, (3) spongy parenchyma, (4) idioblasts, (5) veinstructure, (6) lower epidermis, and (7) external hairs.

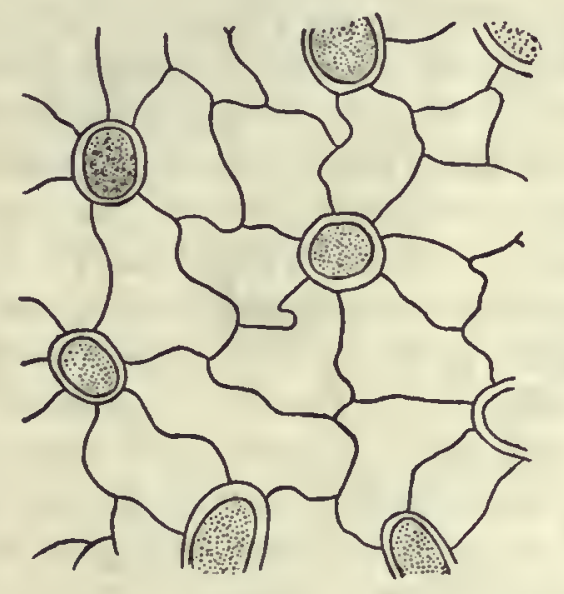

(a)

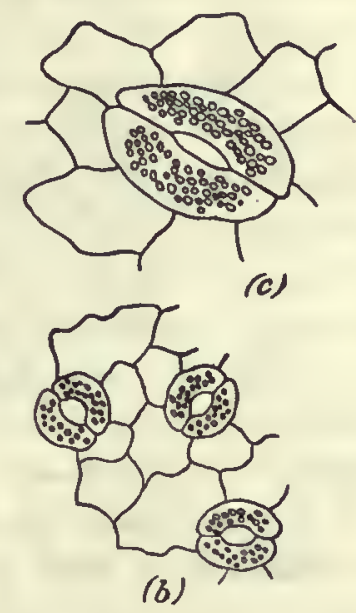

Fra. 29.-Epidermis of leaf, $\boldsymbol{N}$. tetragnna: $(a)$, lower epidermis with bases of hairs; (b), upper epidermis with average stomata; $(c)$, upper epldermis with very large stoma from margin of astomatic area.

The upper epidermis is perfectly smooth and even and somewhat cuticularized on its outer surface. The cells are square or polygonal and from 0.0127 to $0.0178 \mathrm{~mm}$. across (in eight species and varieties). Their outlines are quite wavy in $N$. flava, and mexicana, less so in $N$. tetragona and alba candidissima, and nearly straight in $N$. amazonum, odorata, tuberosa and zanzibariensis $X$. The cells vary in depth, but are about $0.01 \mathrm{~mm}$. deep in $N$. rubra and odorata, o.01 to $0.013 \mathrm{~mm}$. in $N$. tuberosa, 0.013 in $N$. amazonum, 0.01 to $0.0178 \mathrm{~mm}$. in $N$. tetragona, and 0.0178 to $0.02 \mathrm{~mm}$. in $N$. zanzibariensis $\times$. Stomata are present only on the upper surfaces of the floating leaves. They are usually small and round, Fig. 29, $(b)$, and separated from one another by two to three or four epidermal cells; their openings are comparatively large. The guard-cells stand on a level

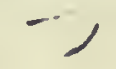


with the surrounding epidermis. The size is quite constant in the eight species studied, namely about $0.0176 \mathrm{~mm}$. in diameter ; those of $N$. tetragona, however, are slightly oval and 0.02 to $0.025 \mathrm{~mm}$. wide by 0.025 to $0.028 \mathrm{~mm}$. in length. The average number of stomata per square centimeter is, in round numbers, 340 for $N$. tetragona and odorata, 390 for $N$. tuberosa, 500 for $N$. zanzibariensis $\times, 530$ for $N$. mexicana, 720 for $N$. amazonum, 960 for $N$. alba candidissima, 1,000 for $N$. flava. Immediately over the insertion of the petiole there is an area totally devoid of stomata, Fig. $28,(t)$; it is of a rounded shape with a slender ${ }^{\circ}$ prolongation over

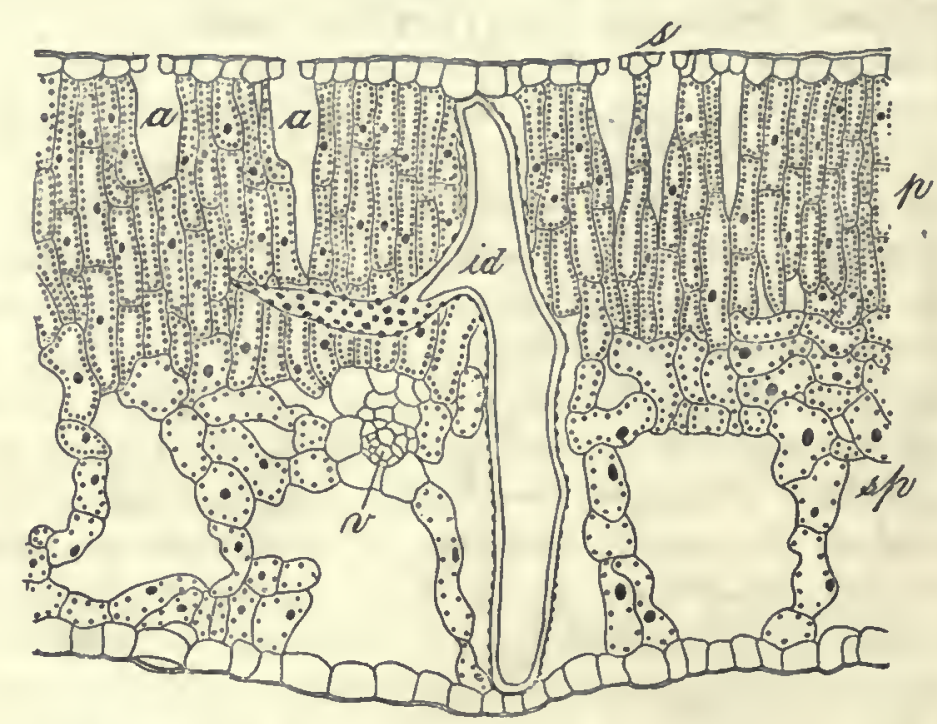

\footnotetext{
Fia. B0.-Leaf of $N$. rubra, vertical section; $a$, air chamber; ld, ldioblast;
} $p$, pallsade layer; 8 , stoma; $s p$, spongy parenchyma; $v$, a small vein.

each primary vein, and varies in size from $1.2 \mathrm{~cm}$. to $3.8 \mathrm{~cm}$. across. Here the epidermal cells are slightly larger than elsewhere. At the edge of this area the stomata are at first far apart and extremely large, Fig. $29,(c)$; in $N$. tetragona I found them 0.05 to $0.052 \mathrm{~mm}$. long by 0.038 to $0.045 \mathrm{~mm}$. wide, in $N$. alba candidissima $0.045 \mathrm{~mm}$. long by $0.038 \mathrm{~mm}$. wide, in $N$. odorata 0.043 to $0.045 \mathrm{~mm}$. long by 0.038 to $0.043 \mathrm{~mm}$. wide, in $N$. zanzibariensis $\times 0.038$ to $0.05 \mathrm{~mm}$. long by $0.031 \mathrm{~mm}$. wide, in $N$. amazonum 0.03 I to $0.038 \mathrm{~mm}$. long by 0.028 to $0.033 \mathrm{~mm}$. wide. From these exceptionally large dimensions the stomata rapidly become smaller at greater distances from the petiole, reaching the average size within the length of 0.5 to $0.7 \mathrm{~cm}$. A border of about $0.16 \mathrm{~cm}$. in width around the margin of the leaf is also devoid of stomata, but there is no increase in size of those nearest the margin. 
The palisade layer of waterlily leaves is very deep, and composed of parallel strings of cylindrical cells. Between these are long, narrow airchambers, opening through the stomata above, and connecting with the lacunae of the spongy mesophyll below. In $N$. tetragona the palisade layer is about $0.09 \mathrm{~mm}$. deep, in N. rubra (Fig. 30 ) 0.1 to $0.14 \mathrm{~mm}$. in depth, being in each cuse one-half the thickness of the whole mesophyll, and consisting of two to three series of long, narrow cells. In $N$. odorata the palisade occupies a little more than one-third of the thickness of the mesophyll and consists of five to seven series of cells with an aggregate depth of 0.14 to $0.15 \mathrm{~mm}$. In $N$. tuberosa there are four or five series of cells with a depth of about $0.16 \mathrm{~mm}$., or about one-half of the mesophyll. $N$. zanzibariensis $X$ has five series of cells, making about $0.14 \mathrm{~mm}$., or a little less than half the mesophyll; finally, $N$. amazonum has four series of cells, altogether about $0.14 \mathrm{~mm}$. deep, or half the depth of the mesophyll. Where the palisade layer is more than two cells thick, the uppermost ones are shorter than the rest, often but little longer than wide. Ameling ( 1893 , p. 189) gives $0.0166 \mathrm{~mm}$. as the average diameter of a cell of the palisade parenchyma of $N$. alba, and points out the interesting fact that this is exactly the same in a leaf $230 \mathrm{~mm}$. in diameter and in one only $95 \mathrm{~mm}$. across. In another table (p. 198) a leaf $190 \mathrm{~mm}$. across had the palisade cells $0.019 \mathrm{~mm}$. in diameter, and this is compared with a like measurement of $0.0197 \mathrm{~mm}$. in a leaf of Victoria regia $900 \mathrm{~mm}$. across. The close agreement in size of cells is striking. The lower ends of the strings of palisade cells rest against a very loose, irregular layer of mesophyll cells, the upper members of the spongy parenchyma (Fig. 30). They are large, thin-walled and turgid, and of the most varied forms; they connect with trabeculae or rods and plates of soft cells which pass vertically from this layer to the lower epidermis. Great air-chambers lying between the trabeculae occupy five-sixths of the space of the spongy layer. Bounding and supporting the lower epidermis in $N$. odorata, tuberosa, fava, marliacea chromatella, and zanzibariensis $X$ is a 1 to 3 seriate layer of smaller, fairly regular, and close-fitting parenchyma cells. This layer may be absent in N. rubra, amazonum, and tetragona, the air-spaces of the mesophyll being bounded below only by the epidermis. Immediately over the insertion of the petiole the mesophyll cells are nearly cubical, with walls evenly colloid-thickened, and without intercellular spaces.

A very striking feature of the mesophyll is the presence of innumerable idioblasts. In the spongy layer these are usually of the multipolar or stellate form. They project from every side into the air-spaces, and 
assume the most grotesque shapes; one might truly say that of the thousands one sees, no two are alike. Since most of the arms end freely in open cavities, as do those in the air-canals of the roots, petioles, and peduncles, it is impossible to assign to them any function of strengthening the tissues as Arcangeli (1890, a) suggested, although bipolar and $\mathrm{H}$ shaped idioblasts in leaves may have that use in a measure. Arcangeli's additional opinion that they serve as depositories for waste calcium oxalate seems to be a good one, although Kohl (1889) reverses the case and considers that in all such cases the salt is a by-product of the deposition of thickening carbohydrates on the cell-wall; he imagines that the glucose or dextrose is transported as a calcium compound. There are, however, great numbers of idioblasts in the leaf, of still another type, which seem to have a definite supporting office. These are cells of great size, with one end spread out in three or four lobes against the inner side of the upper epidermis; from this broad base a stout shaft runs down between the strings of palisade cells (Fig. 30, $i d$ ). Reaching the spongy parenchyma, it may break up at once into several radiating arms, or may continue straight on down to the lower epidermis and attach itself there by a narrow base; all imaginable intermediate conditions may be found. The walls of such idioblasts are extremely heavily thickened. In dried specimens these make prominences on the upper surface of the leaves, and since their number differs according to the species, they were used by Caspary (pachycysts, I 865 ) for systematic distinctions.

The veins which ramify copiously throughout the leaf present several interesting features. The midrib is marked by a line of modified parenchyma. In the palisade region this line is three to five cells wide. The cells are nearly cubical and very poor in chlorophyll; the upper ones have thickened walls. These grade off insensibly in to a plate of larger, closefitting parenchyma cells which runs through the leaf to the lower epidermis. There is a broad arc of corner-collenchyma just within the epidermis on the lower side of the rib. Embedded in the plate of parenchyma are the vascular bundles, and along its sides are two ( $N$. odorata) to several ( $N$. rubra, zanzibariensis $X)$ air-canals. Each vascular bundle is surrounded by a sheath of parenchyma cells much smaller than those of the neighboring tissue. Although a well-developed xylem of spiral tracheae and companion cells is present, it is less in amount than the phloem. Near the base of the midrib several types and positions of bundle are met with (Fig. 3I). In $N$. odorata there is shortly below the epidermis a tiny bundle, and just below this a much larger one, both with xylem above and 
phloem below. Under this is a double bundle with xylem in the middle and phloem above and below, then another double bundle, placed transversely, and finally a simple bundle with xylem uppermost. The lowest bundle is underlaid by a transverse band of thin yellowish collenchyma. Near the apex of the same midrib the lowest bundle with its band of collenhyma still persists; above it is an inverted simple bundle, and above this again, near the base of the palisade layer, is a simple bundle with normal orientation. Lateral bundles seem to arise along the midrib from the median double bundles, and as they go farther from the rib they swing round so as to present a normal orientation of xylem and phloem. At a point nearer the petiole than the section first described, the place of the transverse double bundle is taken by an irregular vascular mass,
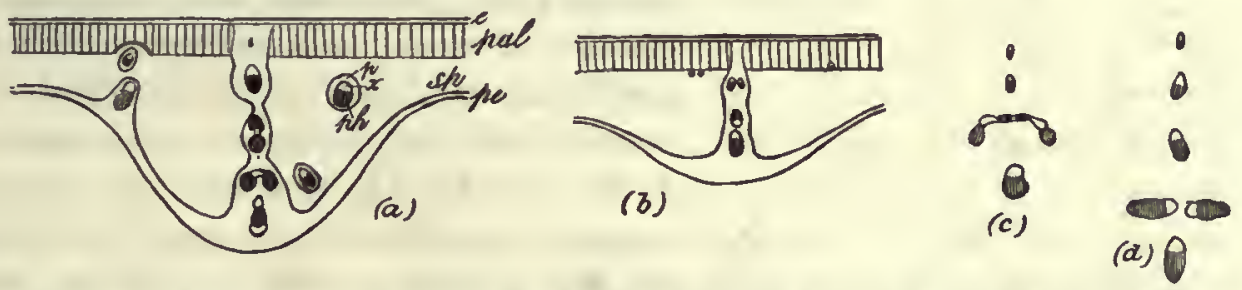

Fra. 31.-Arrangement of vascular bundles in veins of leaf: $(a)$ section near the base; $(b)$ near apex of midrib, $N$. odorata; (c), (d) from $N$. capensis $X ; \varepsilon$, upper epidermis; $p$, parenchyma; pal, palisade layer ; $p e$, lower epidermis and parenchyma; $p h$, phloem; $x p$, spongy parenchyma; $x, x y l e m$.

consisting of one or two xylem areas, each surrounded by two to four phloem lobes; each phloem lobe represents a bundle which emanates from the vascular collar, several of which fuse to form the transverse double bundle of the rib.

The primary veins are traversed by a lower large simple bundle with phloem below and xylem above, and a similar smaller bundle above this. In all of the lesser veins the orientation of bundle tissues is strictly normal. The lower curve of the vein also is lined within with corner-collenchyma, but there is no interruption in the palisade layer above; the bundle has a close sheath of small cells, and a wider investment of parenchyma. In all but the finest ramifications the veins lie nearer to the lower surface of the leaf and are made fast there by the continuity of their surrounding parenchyma with that which lines the lower epidermis; for there is such a lining layer near the veins, even in $N$. rubra. The smallest veins lie just beneath the palisade layer (Fig. 30, v), where the exchange of crude and elaborated materials takes place. I have not observed any free endings of veins ; anastomosis seems to be universal. 
The lower epidermis (Fig. 29, a) has been frequently referred to in previous pages. It is a perfectly continuous layer, 0.01 to $0.018 \mathrm{~mm}$. thick, quite smooth on the outer surface, and consisting for the most part of polygonal cells, many of which are about twice as long as broad (o.or $8 \times$ $0.036 \mathrm{~mm}$.). In these is located the pigment which colors the under side of the leaf. More or less plentifully interspersed with them are thickened circular cells (suberized, according to Schilling, 1894) representing the bases of hairs. Frequently the other epidermal cells are arranged around these in a radial manner. This caused Barthélemy (1874) to speak of them as pseudostomata, and he thought he could see in the center of some of them a small perforation. His opinion lacks confirmation.
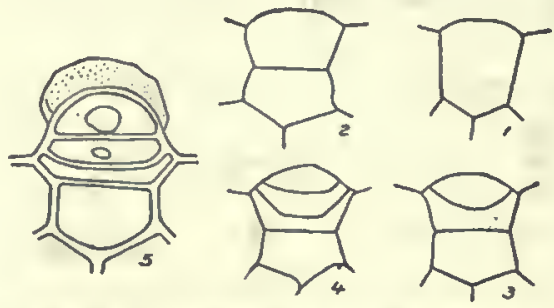

Fra. 32.-Development of mucliage hair of $N$. alba; $1-5$, successive stages. (After Schilling.)
The circular cells are about $0.02 \mathrm{~mm}$. across in $N$. flava, mexicana, amazonum, odorata, 0 . rosea, and tuberosa; 0.02 to $0.028 \mathrm{~mm}$. in $N$. zanzibariensis $\times$ and alba candidissima, and 0.025 to $0.029 \mathrm{~mm}$. in $N$. tetragona. Their relative number is shown by the following figures, representing the number visible in a single field of my microscope (Leitz, oc. 2, obj. 7):

N. flava 32, mexicana 19-20, amazonum 52, tetragona 21, odorata 36, o. rosea 34 , tuberosa 28 , rubra 46 . In the last-named species permanent hairs stand on many of these basal cells. Hofmeister in 1868 mentioned $N$. alba in company with Fagus, Salix, Quercus, \&c., as having hairy leaves only in the bud.

From what has already been said concerning the occurrence of basal cells of hairs in the epidermis of the petioles and lower leaf-surface, it will be seen that hair structures always occur on these parts at some time in their history; the main ribs of the leaves and their upper surface are alone totally devoid of them. On a leaf rudiment of $N$. flava a trifle over $0.16 \mathrm{~cm}$. long, some of these hairs are already complete, but others continue to develop, so that on a leaf three times as long all stages may still be found. A young epidermal cell swells outward beyond its neighbors and is cut in half by a transverse wall ; the outer cell continues to swell, and is soon divided by a wall which is strongly concave outward, making a terminal spherical cell (Fig. 32). A second concave wall may follow the first in the apical cell. Now, according to Schilling (1894), who investigated $N$. $a l b a$ and other aquatics, the cellulose walls of this cell become mucilaginized, the cuticle is ruptured, and the outer cell breaks down into a mass of 
mucilage. Cylindrical and clavate mucilage hairs are common in $N$. alba (Schilling, 1. c.), and appressed finger-like ones occur in N. rubra. They are shed as soon as the tissues of the leaf begin to elongate rapidly and become mature, being of use only to keep the developing organs embedded in a coat of slime. This phenomenon was noted by Irmisch in I 859. Subsequent to the development of mucilage hairs, or along with and among them, longer hairs are formed in most Nymphaeas. The early stages of these are exactly as just described; the apical cell, however, instead of remaining spherical, elongates and may undergo division

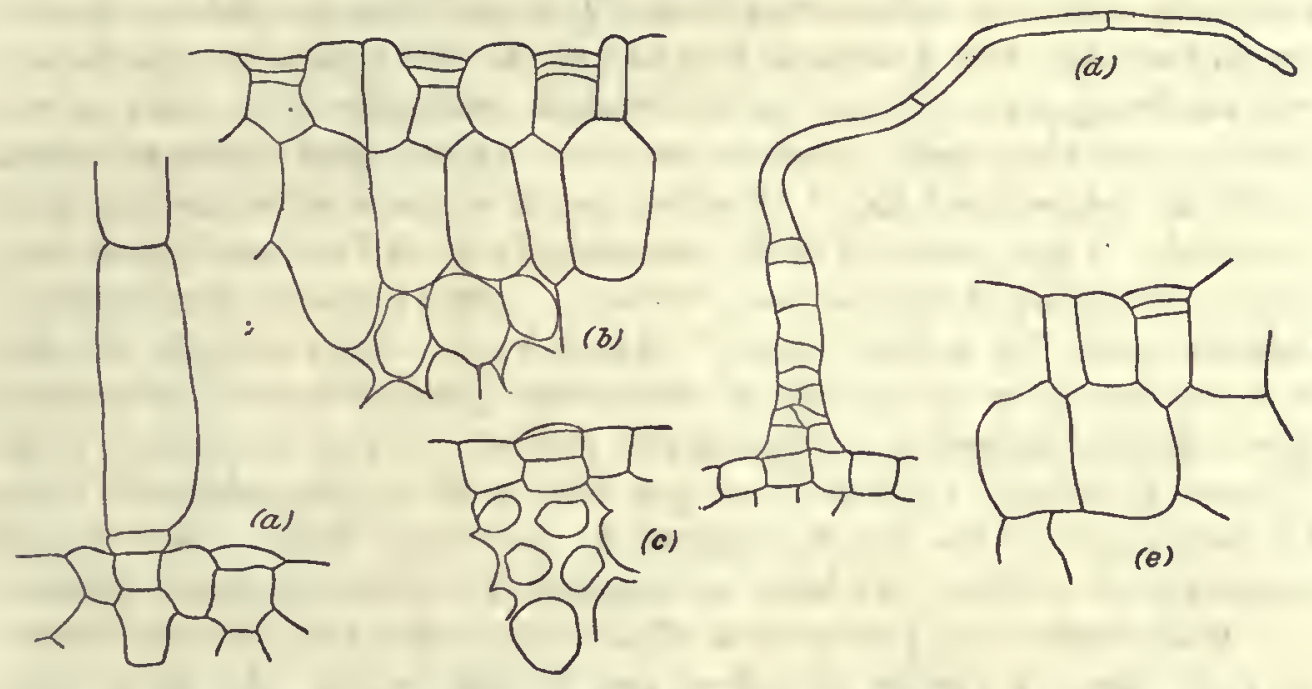

Fia. 33.-Hairs and halr bases: (a) on petiole of $N$. odorata; (b) on petiole of $N$. $r u b r a$, the shaft being shed: (c) on petiole of $N$. tetragona, showing also the collenchyma lmmediately below the epldermis: (d), (e), from rhizome of $N$. tuberosa.

into a number of cylindrical elements as in Eu-castalia. The terminal cell is bluntly rounded in Eu-castalia or acute in Lotos. These longer hairs are persistent all over in members of the Lotos group, but only at the bases of the petioles in Eu-castalia, and as a specially developed ring of long hairs at the summit of the petiole in $N$. amazonum. In Lotos the shaft of the hair is unicellular. Its base may be very much wider than the basal epidermal cells in the petiole of $N$. rubra and sturtevantii, or but little wider, as on the under side of the leaves of $N$. rubra. The hairs of the ring on $N$. amazonum consist of 12 to 15 cells, and reach a length of 0.48 $\mathrm{cm}$. Stahl (1888) considered the mucilage and other hairs as intended for protection against animals (snails, \&c.), and Goebel (1 893) suggested that they served to prevent contact of the young organs with one another in the bud; but Schilling (1894) regards them rather as useful in preventing 
the access of water to the embryonic tissues. The first idea could apply to the hairs on mature leaves as well as to the younger. It would be useless to assert that either purpose is unimportant.

In a few cases the leaves of Nymphaea have been viviparous. Planchon $(1852, c)$ records this for " $N$. stellata" (probably $N$. micrantha) as grown by Van Houtte. The plant came from English cultivators, with whom it had never shown this tendency. The new plant springs from the upper surface of the leaf just over the insertion of the petiole. "Already visible," says Planchon, "though very small on the young leaf, the axis but a tubercle with very rudimentary leaves, [the bud] remains almost stationary on the adult and functional leaf so long as this retains its connection with the living plant. If the leaf is detached artificially or by decay of the petiole, it puts out roots, develops its leaves rapidly, and seems to hasten to live an independent life." 1 Further details of the process have not been recorded. It was observed in $N$. micrantha Guill. \& Perr. and given thus in the description of the species: "Folia . . . inter lobos saepius bulbifera, bulbillis sphaericis pubescentibus." Hooker (1850) also records the fact in a few words in describing $N$. micrantha in the Botanical Magazine, where the leaf figured is viviparous, and Paxton $(1853, a)$ mentions it in his "Flower Garden." Lehmann $(1853, a)$ went so far as to establish a "Tribe III Bulbophyllon" for his $N$.vivipara, $N$. guineensis Thonn., and $N$. micrantha Guill. \& Perr. We have not considered these as specifically distinct.

Water-leaves are produced in all seedling Nymphaeas to the number of $2(N$. flava $)$ to I 5 or I 6 before any floating leaves. Of these more will be said in another chapter. In species which have dry resting tubers the first leaves produced on resuming growth are also entirely submerged. $N$. flavo-virens alone, with its huge tubers, is at times an exception to this rule; small tubers follow the rule. The perennating bodies of $N$. flava (doubtless also of $N$. mexicana) begin the growth of each bud with a few water-leaves, and the other Castalia species produce them either in late fall or early spring, or both. These members also lose their floating leaves and produce only water-leaves in unfavorable conditions ${ }^{2}$ of culture,

\footnotetext{
${ }^{1}$ Déja visibles, mais trés-petits sur la jeune feuille, pourvus d'un axe en forme de tubercule, mais avec des feuilles encore trés-rudimentaires, sur la feuille adulte et pleine de vie, ils restent presque stationnaires tant que la feuille tient à son pied nourricier. Qu'on détache artificiellement cet organe ou qu'il s'isole spontanément par la decomposition de son pétiole, aussi tôt le bourgeon pousse des racines, developpe rapidement ses feuilles et semble se hâter de vivre d'une vie indépendante. (Flore des Serres, $8:$ 285.)

'Bonnier (1890) found in several lakes of the Alps shoots of $N$. alba without floating leaves, but with an unusually large number of submerged leaves, "as is often seen in streams with rapid current."
} 
while the tuberous species in like circumstances lose all of their foliage and form tubers, from which they come out again first with water-leaves.

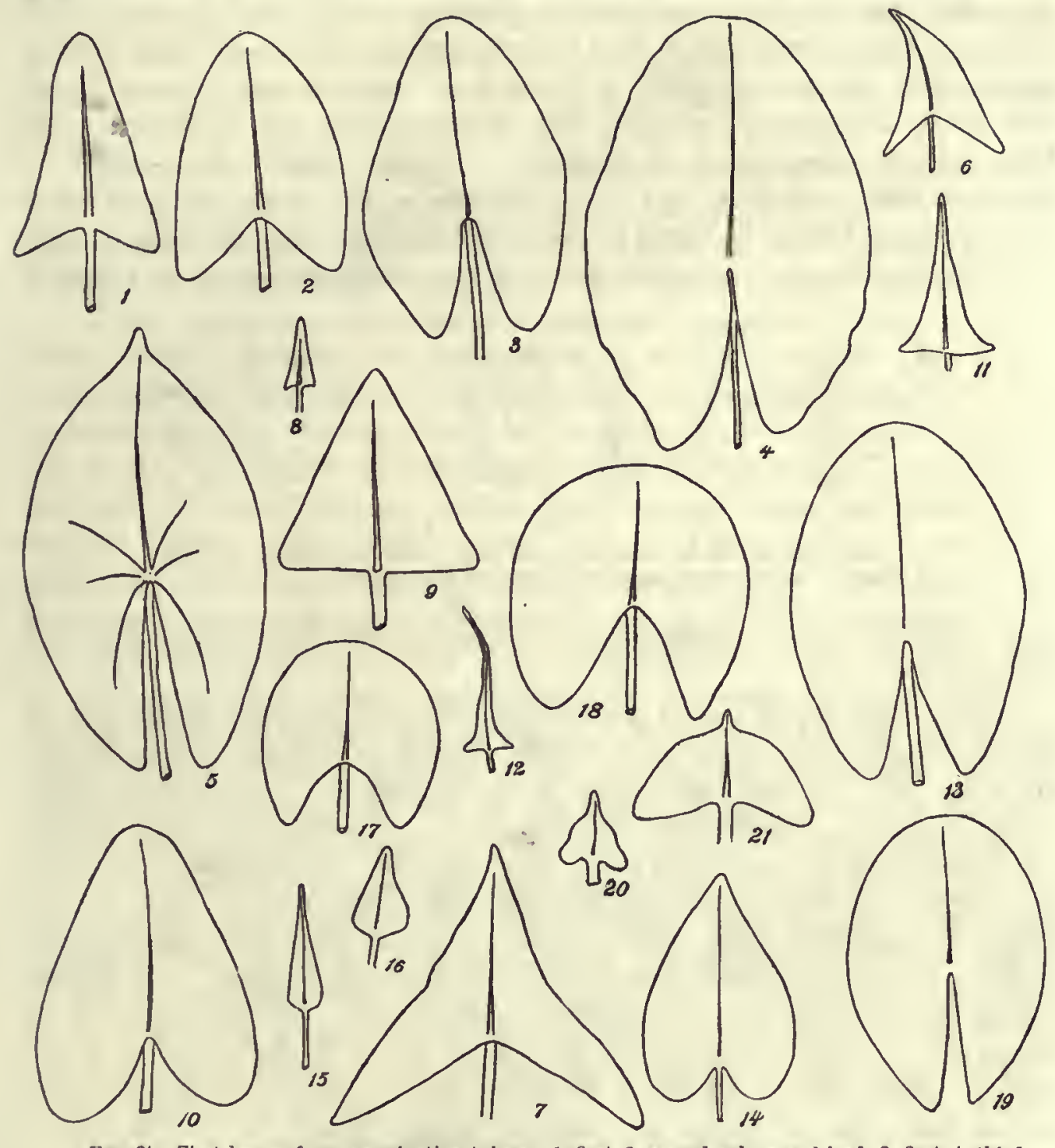

Fic. 84.-First leaves from germinating tubers: 1, first, 2, second submerged lcaf; 3 , first, 4, third floating leaf of $N$. ghountea; 5 , second floating, 6 , frst, 7 , second submerged leaf of $N$. flavo-virens; 8 , first, 9 , second, 10, third submerged leat of $N$. caerulea; 11,12 , first submergod leat from brood body of $\boldsymbol{N}$. mexicana and $\boldsymbol{N}$. Aava, respectively; 13 , second floating, 14, socond, 15, Arst submerged leaf of $N$. elegans; 16, first, 17 , second, 18 , third submeryed. 19, first floating leaf of $N$. zanzibariensts rosea; 20,21 first and second submerged leaves of N. "Mrs. C. W. Ward" (N. Aavo-virens $\times$ zanzibariensis). All natural sizo.

Wächter's (1897) observations on N. stellata, dentata, rubra, thermalis, and alba showed, by cutting off the roots or leaves from growing plants, that production of water-leaves could be induced by enfeebled nutrition, 
especially by lack of elaborated materials in the absence of mature foliage ; cutting off the roots had a much less marked effect. I have noted also in $N$. rubra that young shoots acquire floating leaves much sooner if left attached to the parent tuber than if early broken off and planted out. It seems quite certain, therefore, that the occurrence of water-leaves in fall and spring in Castalia is directly due to the cutting off of the leaves by frost, and the suspension of vitality in very cold water; and, except in the large and powerful tubers of $N$. flavo-virens, the young shoots of other species must gather strength in themselves before they are able to produce floating leaves. In other words, a leaf-rudiment will, up to a certain
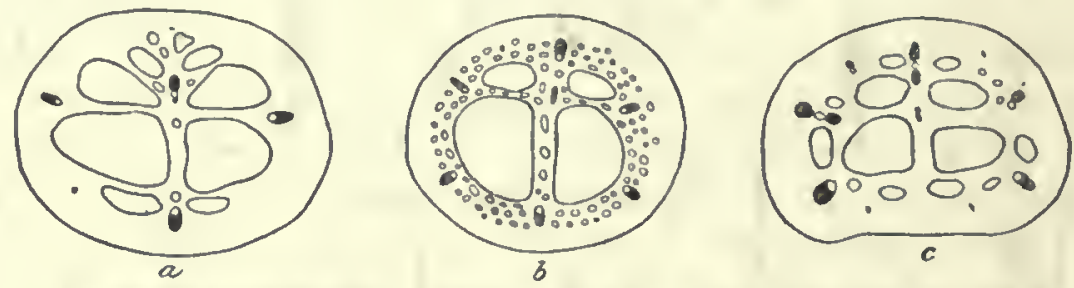

Fro. 85,-Transverse sections of petioles of water-leaves; $a, N$. rubra, from tuber: $b, N$. ortorata, from rhizome in spring; $c, N$. tuberosa, from tuber.

age, develop into a submerged or a floating leaf according to nutritive conditions.

Such submerged leaves as are now under discussion assume a more or less deltoid shape, varying to hastate (Lotos), cordate, or nearly orbicular (Fig. 34). Specific shapes, so far as known, are given in the taxonomic section. The petioles are usually 2.5 to 7 or $8 \mathrm{~cm}$. long, though sometimes longer, and rather stout in proportion. Structurally they show but slight differences from the petioles of floating leaves. The thickly cutinized epidermal cells contain many bright-green chloroplasts in the upper part of the petiole, where it is not covered by mud. The fundamental tissue, too, is rich in chlorophyll throughout. Its outer two to four layers are more or less colloid in the angles, but only slightly so at most ; here also chloroplasts are most plentiful. The arrangement of air-canals differs from that of petioles of floating leaves, but in the larger waterleaves this character approaches nearer and nearer to the typical arrangement for the species. The tendency in petioles of water-leaves is toward the condition with two main canals (Fig. 35) and a great many smaller ones around and between these, with partitions but one cell thick. This approaches the adult structure of $N$. flava and tetragona, and points also to a probable primitive state in which, like Nuphar and the roots of 
Nymphaea and Nuphar, the fundamental tissue of the petioles was traversed by innumerable small and equal canals. Specialization has enlarged some of these at the expense of others in Nymphaea, Euryale, and Victoria. The distribution of vascular bundles in petioles of waterleaves follows the plan laid down for floating leaves. Stellate cells occur in the air-canals, but no thyll-like bodies have been found.

The lamina is of a reddish color in Lotos and Eu-castalia, but is plain green in $N$. tetragona, fennica, and amazonum, and Apocarpiae. Its texture is extremely thin and fragile in Lotos, much firmer, though still very thin, in Castalia, Hydrocallis, and Apocarpiae. The upper epidermis is composed of rather larger, somewhat sinuous cells, and possesses a few stomata. Arcangeli noted stomata on water-leaves of $N$. alba in I $890(b)$, but Brand (1894) failed to find them, and considered Arcangeli's specimens to be arrested floating leaves. Wächter (1897) corroborated Arcangeli's observation by examining leaves in chloral hydrate, and extended the work to $N$. rubra, dentata, stellata, and thermalis, in all of which a few stomata were found on the upper surface of the leaves. The lower epidermis is like that of floating leaves. Great reduction has taken place, however, in the mesophyll. Arcangeli (l. c.) found the palisade layer in $N$. alba reduced to two strata of globular or ovoid cells, and Wächter found a single layer of crescent-shaped cells representing the palisade in $N$. rubra and thermalis. The spongy parenchyma is greatly reduced in quantity, and consists of loose cells with large intercellular spaces. Idioblasts are present, but few in number, and the vascular network is simple. The ordinary involute vernation is found in the water-leaves. They are, therefore, to be considered as reduced floating leaves, and no indication is offered of the wholly aerial habits which must have belonged to the distant ancestors of the Nymphaeaceae. Even the large aerial leaves of Nelumbo, from having stomata still restricted to the upper surface, must be considered as derived from floating leaves, and in no close relation to those of the probable terrestrial ancestors of the order.

\section{THE FLOWER, FRUIT, AND SFED.}

Few genera of plants offer such variety in size and color of flowers as is found among the waterlilies. The primitive yellow, but of a rich hue, is preserved in Xanthantha and the newly discovered $N$. sulfurea and stuhlmanni; white prevails in Castalia, varying to pink in $N$. fennica, odorata rosea, and alba rubra. All shades from pure white $(N$. dentata) to deep crimson $(N$. rubra) occur in the Lotos group, and from white 
( $N$. ampla) to pink ( $N$. versicolor) and royal blue ( $N$. zanzibariensis) in Apocarpiae. In Hydrocallis a creamy white prevails. Orange tints have been obtained in hybrids of $N$. flava and alba rubra $(N$. aurora, seignoreti). In size, $N$. tetragona, fennica, and odorata minor stand at one end of the line, with flowers 3.5 to $5 \mathrm{~cm}$. across, and at the other end are $N$. rubra, dentata, zanzibariensis, and gigantea, whose flowers measure $30 \mathrm{~cm}$. or more in diameter. There is, of course, great variation within a single species, according to the food supply and other conditions. Other general characters will be brought out in the following description of the flower and flower-stalk.

So close is the resemblance between petiole and peduncle in Nymphaea that we shall greatly abbreviate the present section by referring back to the previous one. The peduncles are always terete, and in color and presence or absence of pubescence are like the petioles of the same species (no brown stripes occur on the peduncles of $N$. tuberosa). In Eu-castalia the likeness extends to the length, diameter, and number of air-canals of the two organs. In Chamaenymphaea the likeness includes length and diameter. The same is true of Xanthantha when in deep water ; in shallow water, the peduncles are stouter. These species are also peculiar in that the upper part of the flower-stalk is somewhat fourfurrowed with shallow rounded grooves. In all other species the peduncles are I to $2.5 \mathrm{~cm}$. in diameter, and stiff enough to raise the massive flowers 5 to 30 or $40 \mathrm{~cm}$. above the water. The more slender peduncles of $N$. amazonum (Hydrocallis) are yet quite stiff and reach to or very little above the water surface. In exceptionally shallow water the same may be true for all of the Castalia group.

The epidermis presents nothing characteristic. It bears a large number of hair bases. Beneath it there is a single layer of thin-walled cells in $N$. dentata, rubra rosea, devoniensis, arnoldiana, and zanzibariensis. The inner wall of this layer is somewhat collenchymatous in $N$. zanzibariensis $\mathrm{X}$, marliacea chromatella, alba candidissima, and gladstoniana. Following this layer in the above-named forms, or including it in $N$. rubra, lotus, sturtevantii, caerulea, odorata, and tuberosa, there are 3 to I I layers of collenchyma as in the petiole. The character of the remaining tissue is also like that of the petioles. In Apocarpiae the cells contain a good deal of starch, but not so in Lotos and Eu-castalia. Four main air-canals traverse the peduncles of Castalia, but six is the standard number for the remaining groups; these numbers are subject to an occasional variation of one more or less, but much oftener of one more. The canals are equal 
and arranged symmetrically about the centre of the peduncle (Fig. 26). Outside of each of these are two rather prominent but much smaller canals, and in $N$. zanzibariensis each of these is followed by two more quite evident canals. Many smaller scattered ones are always present. Idioblasts are extremely scarce in the Lotos group, frequent in Apocarpiae, slentiful in Castalia ; fibrous (bipolar) idioblasts occur throughout the peduncle in Eu-castalia and around the periphery of the upper part in Brachyceras. Thyll-like masses of soft cells are frequent on the sides of the larger air-canals in Apocarpiae, occasional in Lotos, and not found in Castalia.

Vascular bundles are distributed on the same principle as in the petiole (Fig. 26). In the centre is a large double or triple bundle. Opposite each of the 4 or 6 main partitions there is a large double bundle, often with two well-formed air-canals in Apocarpiae and Castalia, but with the second canal a mere fissure without definite wall in Lotos. Midway between these bundles are smaller ones, and so on in several series, according to the size of the peduncle. Examples are shown in detail in the diagrams. The constituents of the bundles are exactly as described for petioles.

Just beneath the flower the peduncle widens out to form a receptacle for the insertion of the floral organs. This widening extends over about $1.3 \mathrm{~cm}$. in Lotos, making an inverted frustum of a cone with a slope of about $45^{\circ}$. In Apocarpiae, Hydrocallis, and Eu-castalia the transition is more sudden, almost like the limb of a salver-form corolla. The resulting receptacle is usually round, but in Chamaenymphaea its upper margin is square, with distinct and prominent angles. In Xanthantha there are four rounded prominences on the sides of the receptacle, with distinct grooves between; the grooves are continued down a short distance on the petiole, but they swell again quickly above, so that the receptacle is nearly round at the line of insertion of the sepals. The color of the receptacle is usually like the peduncle, but paler. Within the upper part of this region the vascular bundles of the peduncle unite into an extremely complex horizontal network, from which bundles are separated out for the floral organs. The complexity of this anastomosis is too great to admit of any definition or unraveling as yet.

The flower proper has four sepals, of which one is anterior and outer. The two lateral sepals are covered on one edge by the anterior one, and on their posterior sides they overlap the posterior sepal. At times three or five sepals may occur. I have seen the smaller number in $N$. rubra 
and the larger in $N$. elegans, and Eichler $\left(1878,2: 183^{-186}\right)$ records both numbers for $N$. alba. A trimerous flower of $N$. ampla was the type of Gaudichaud's $N$. trisepala. Hexamerous and heptamerous flowers are known. When five sepals occur, two stand in place of one in the posterior position; when only three are present, the posterior one is lacking (Payer, 1857; Eichler, 1. c.).

The number of petals varies from 7 ( $N$. tetragona) to 33 ( $N$. capensis). The 4 outermost are largest and alternate with the sepals; over each interval between these, i. e., opposite each sepal, is a pair of smaller petals, making a whorl of 8 . This seems to be followed in Brachyceras and Lotos by another alternating whorl of 8 . Of this row usually only 4 or 5 are present in $N$. caerulea, while an additional row is found more or

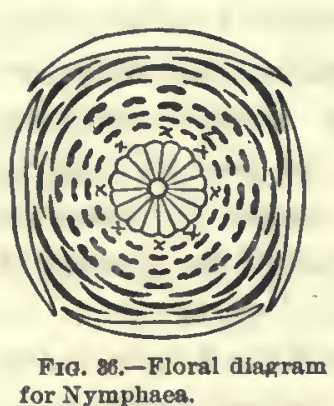
less complete in $N$. capensis and zanzibariensis. In Hydrocallis the petals are all regularly arranged in alternating whorls of 4 . Here, also, the outermost stamens follow in one or two whorls of 4 ; then come one or two whorls of 8 , the first of which has two members over each interspace between the preceding 4 ; within this it is impossible to make out any order. The stamens of the Lotos group follow on in more or less definite whorls of 8 , and the same may frequently be seen in Brachyceras. In old flowers of $N$. caerulea, long after inflorescence, when the organs are spread apart by the growth of the ripening ovary, I have several times found the stamens arranged in 16 vertical lines, with mostly 4 stamens in each line. The whorled arrangement is not distinct in Castalia, and Eichler (1. c.) states for $N$. alba that there are 4 petals alternate with the sepals, and 4 alternate with these, i. e., over the sepals. These 8 are the beginning points for oblique lines of successively smaller petals, rising right and left with equal inclination. Each series has, on the average, four members. The inclination of the spirals is such that each successive petal stands over the space between two neighbors, so that in all 16 vertical rows of 2 petals each are formed. The arrangement of the stamens was not made out. The inner petals and stamens are inserted at various levels up the sides of the ovary (receptacle). There is a narrow, naked zone between the petals and stamens in Lotos and Anecphya, but in other genera the two sets of organs are in continuous series, except in some forms of $N$. candida and tetragona. The carpels are always in a circle in the middle of the flower, abutting against a central prolongation of the floral axis. 
We will now take up some details relating to the individual floral organs. The line of insertion of the sepals is usually smooth and rounded; but in $N$. candida the bases of the sepals are slightly produced downward, and in $N$. fennica the sepals make a sharp, clean-cut angle with the receptacle. The general shape of the sepals is ovate. They are always greenish and chlorophylloid outside, and soft and petaloid inside; the margins which are covered in the bud are wholly petaloid. Specific details of shape, size, color, and texture are given in the taxonomic portion of this paper. The epidermis of the outside of the sepals has a very smooth surface, and consists of irregularly polygonal cells in surface view, nearly square in section. Bases of mucilage hairs are frequent in $N$. tuberosa and plentiful in $N$.odorata. In the latter species, also, stomata are present. They begin at or just below the middle of the sepal and are more plentiful toward the apex and are a little larger than those of the leaf (0.015 by $0.015 \mathrm{~mm}$.). The cells of the inner epidermis are rounded and prominent on the exposed side, of approximately rectangular shape, and shallower than those of the back of the sepal. Here also rounded cells like the bases of mucilage hairs are frequent, but no stomata. The parenchyma of the sepal is traversed longitudinally by vascular bundles and in the lower parts by air-canals. Inside the outer epidermis there are in $N$. zanzibariensis $\times$ about 8 tiers of close-fitting, nearly spherical cells containing chlorophyll; they become gradually larger from without inward. Then follow 1 or 2 flattened cells and a vascular bundle, or, between the bundles, 2 to 4 flattened cells and an air-canal. About 5 roundish cells intervene between the air-canals and the inner epidermis. At the apex of the sepals the structure differs from this only in the absence of air-canals. Just within the epidermis on each side two or three layers of cells are feebly collenchymatous, but most noticeably so on the inner side of the sepal. The air-canals in this hybrid are rather large, round or oval, and arranged in a single row between the middle of the parenchyma and the inner epidermis. The partitions between them are two or three to several cells thick. The vascular bundles have a well-developed protoxylem, and at some distance from this, in the larger ones, a small air-canal. There is a row of larger bundles about the middle of the parenchyma and a row of smaller ones between the air-canals and the inner epidermis, with still others between the canals. Many stellate idioblasts project into the air-canals, but none was found elsewhere in these sepals. Thyll-like ingrowths also occur. One of these consisted of but two dense clavate cells, another had a multicellular base surmounted 
by a crown of ovate cells with dense granular contents. Intermediate forms were seen.

In $N$. odorata the sepal is quite thick at the base, but very thin above. In the basal region there are about 12 tiers of cells between the outer epidermis and the air-canals, of which the first 4 or 5 are slightly collenchymatous. They are all rounded in outline and become gradually larger from without inward. ' Among them are very many bipolar idioblasts lying lengthwise of the sepal. The air-canals are very numerous and irregular in shape and size. They are separated by partitions only one cell thick, and occupy a zone about as thick as the denser parenchyma just described. Great numbers of idioblasts of irregularly stellate forms occur here. Between this zone and the inner epidermis there is a zone of about 6 layers of parenchyma. A single irregular row of vascular bundles traverses the partitions between the air-canals. They have well-developed protoxylem and, in all the larger ones, an air-canal. The same structure is continued in the apex of the sepal, but with fewer tiers of cells and much smaller air-passages. Nearly all of the parenchyma cells contain chloroplasts, especially the two or three outer layers, where the cells are crowded together and polygonal in outline.

A section near the middle of the sepal of $N$. tuberosa shows a still more leaf-like arrangement. Within the outer epidermis are two to four layers of round cells with large intercellular spaces and containing many chloroplasts. Then comes a zone 3 to 5 times wider than the first, made up of branching lines of cells and large intercellular spaces. Through this zone the vascular bundles travel, accompanied by one or two layers of close-fitting parenchyma. Phloem and xylem are well represented, but no air-canal was seen. The orientation of the bundles is normal in all parts of the flower. Stellate idioblasts are plentiful in the air-chambers. The inner epidermis is backed by a single continuous layer of rounded cells. Near the apex of the sepal the air-chambers are quite small, the intervening partitions are multicellular, and idioblasts much fewer. The total thickness of the sepal, however, may be greater than at the middle.

Most of the general features of the petals have been already mentioned, and specific details are sufficiently covered in the chapter on taxonomy. The outer four petals are usually of about the size and shape of the sepals. They are thicker at base than elsewhere, and are traversed by a number of longitudinal veins which divide up into a fine network in the upper half or two-thirds of the petal. There may be some longitudinal air-canals in the basal parts. No distinction of blade and claw occurs, but 
the oval to lanceolate lamina tapers gently to a comparatively broad insertion. Where the petals are brightly colored, the lower parts are usually paler, and often yellowish, even in blue flowers. The margins of the petals, as of the sepals, are always entire and are of softer texture than the sepals. The inner ones are shorter and narrower than the outer.

The structure of the basal and sepaloid portions of the outer petals of $N$. odorata is exactly like that of the sepals, even to the presence of large stomata on the back. The softer parts of these petals, and all of the inner ones, are much thinner. The epidermis of both surfaces is like the inner epidermis of the sepals, and has numerous hair-bases. Parallel and anastomosing veins traverse the parenchyma, accompanied in the middle line by idioblasts of varied shapes, but without air-canals.

The stamens are quite characteristic in the different groups of waterlilies. In Castalia, especially $N$. alba, all gradations are found, from inner petals with a callous yellow tip or with one or two tiny anther cells, to stamens with petaloid base and a small but perfect anther, and so on to the innermost stamens, where the anther is large and thick and broader than the filament. $\quad N$. amazonum shows similar but more rapid gradations ; the innermost filaments are filiform and the anthers narrowly linear. In $N$. gigantea, however, all of the filaments are slender, and anthers narrow. Lotos also shows no gradation from petal to stamen, but the outer filaments are as much as half an inch wide at base; their insertion is wide and somewhat decurrent at the sides. The anther is broad and ligulate, with blunt, round apex. The inner stamens are shorter and narrower, ligulate in shape, and not decurrent. In all of the foregoing groups the connective is not continued above the anther cells more than as a limiting border to the anther, with the exception of the outermost stamens of $N$. gigantea, which bear a tiny subulate tip. In Brachyceras, however, there is a prominent prolongation of the connective at the apex of a large number of the outer stamens. This is least in $N$. elegans $(0.08 \mathrm{~cm}$.$) , small$ in $N$. flavo-virens, but may reach nearly $1.3 \mathrm{~cm}$. in length in $N$. zanzibariensis. In this group, also, transitional forms between petal and stamen are sometimes seen. The outer filaments are ovate, often shorter than the lanceolate or linear anthers; these grade by slow degrees into the innermost stamens, which are short and slender and without appendage. In all species the outer stamens are colored like the petals, excepting the yellow anther cells in Castalia and Apocarpiae and the reddish-brown anthers of some Lotos species. The innermost stamens are wholly yellow in all but $N$. rubra, where the reddish-brown color persists. 
The structure of the filament resembles that of the inner petals. The epidermis bears hair-bases, the parenclyyma is made of soft, rounded cells, and air-spaces are present. There are one to three or more longitudinal vascular bundles. The mature anther is covered by a single layer of square cells, a little deeper than wide, with thickened inner and lateral walls; the outer wall is unthickened. The anther cells are parallel and introrse, with longitudinal dehiscence (Fig. 37, $a, b$ ). In Lotos and Brachyceras the division between the two loculi of each cell is
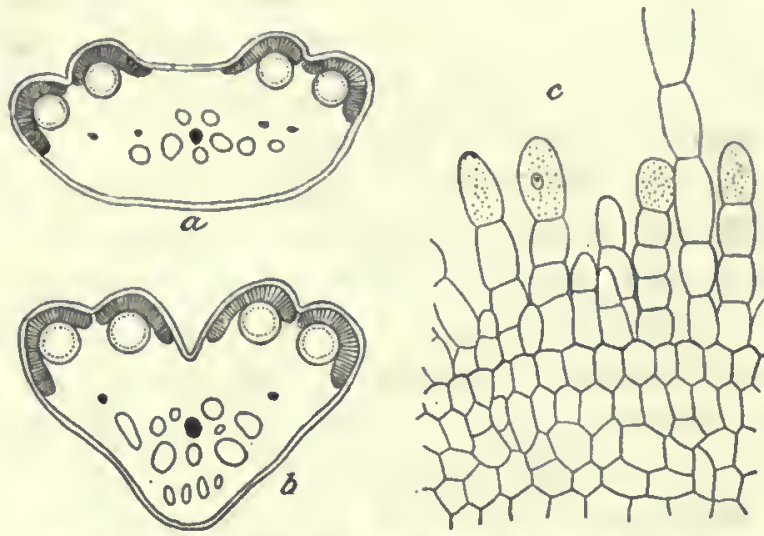

Fia. 37- $a, b$, transrerse sections of anther of $\boldsymbol{N}$, flava near base and near apex, respectively; $c$, vertical sectlon of stigma, showing papillae, $N$. tuberosa. All after Chiffot. quite evident after dehiscence, as the pollen dust remaining after most has been shed lies in two pairs of grooves on the inner face of the anther. Chifflot (1902) has recently made a minute study of sporophyll structure in Nymphaeaceae, including nine species of Nymphaea. He finds slight differences in the venation of the stamens. He sums up his work (which I have not had tirne to verify) in a classification based on the distribution of idioblasts ("sclérites") and stomata in the stamen, and of idioblasts in the carpels (1. c., p. 280). We quote this in translation. The names are correct and mostly well chosen, unless in the case of " $N$. blanda." The material of this came from the Kew Herbarium, where $N$. rudgeana occurs under the name of $N$. blanda, and is much more plentiful.

\section{SYNCARPIAE :}

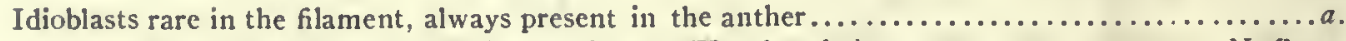

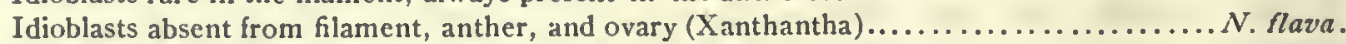

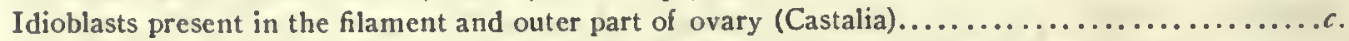
a. Stomata present on upper epidermis of filament (Lotos). Idioblasts absent from mesophyll of ovary, present in carpellary styles .................... thermalis.

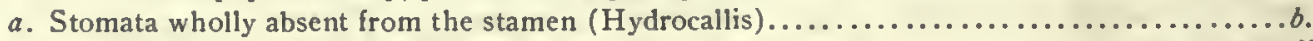

$b$. Idioblasts of but one kind, present in filament and anther.................. "N. blanda."

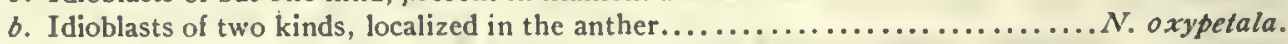

$c$. Idioblasts absent from the anther, but numerous in the carpellary rays..................

$c$. Idioblasts present in anther, rare in carpellary ray $\ldots \ldots \ldots \ldots \ldots \ldots \ldots \ldots . \ldots \ldots$. $t$ berosa.

d. Stomata absent from whole stamen..................................... alba.

d. Stomata present at base of loculi on both faces of filament. $N$. pygmaea $[=N$. tetragona $]$. 
Apocarpiae :

Idioblasts rare in the filament, always present in the anther. Stomata absent from all the surface of the filament (Brachyceras). Idioblasts absent from all parts of the mesophyll of the ovary and carpellary styles.................... caerulea.

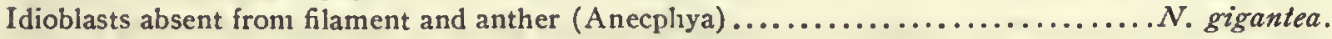

The dry microspores (pollen grains) of $N$. alba are oval and deeply folded is, on one side (Kerner, 1895, fig. 218 ); in Brachyceras (Fig. 38, b-e) they are spheroid, with greatly flattened poles, or, in $N$. capensis, lenticular, and the edges may be folded under from three sides. Fischer (I890) speaks of them as folded in (eingefaltet) in $N$. dentata, lotus, rubra, and $a l b a$, the infolded half being separated from the other by an equatorial line. Along this line the exine separates in germination. The exine on the infolded half is thinner and smoother than on the other half, and has parallel to the equatorial line a ring of similar thickness and sculpture to the outer half (Fischer, 1. c.). In water the grains become spherical in a

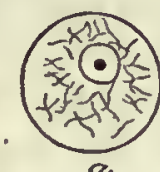

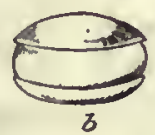

6

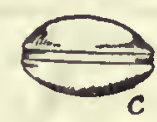

Fre. 88-Pollen : $a$, young grain of $N$. favo-virens; $b-c, N$. caerilea: $b$, just matured; $e$, nearly dry; $i$, $e$, as shed from the anther, seen from opposite sides.

few minutes, and along the equatorial line in $N$. capensis, caerulea, zanzibariensis, and hybrids the two halves of the exine separate slightly; they seem to be too small to cover the whole swollen grain. In pollen of $N$. odorata mounted in glycerine jelly, some grains have the exine caps still touching at one edge, but wide apart at the other, while some are equidistant all round, and some are unbroken. Fine rods, points, and granules cover the exine in Eu-castalia, and one-half of it in $N$. tetragona and flava (Caspary, I865; I888). It is smooth in Brachyceras, and, according to Caspary (11. c.), in Anecphya, Lotos, and Hydrocallis. Fischer (1890), however, found it granulate (körnig-walzig) in N. rubra and dentata, and smooth in $N$. lotzs, and I have found it smooth in $N$. mexicana. In germination Caspary frequently refers to an operculum, and in one place (I888) to the "smaller half" of the exine; but the two parts which I have noticed in Brachyceras and $N$. odorata are practically equal, and Fischer speaks simply of two pieces (zwei Stücke) in $N$. alba, and elsewhere of the two "halves" of the exine. The term "operculum" is therefore misleading.

The pistil is composed of 5 to 35 carpels, the number being extremely variable for any one species. They are placed radially round a central 
prolongation of the floral axis and are immersed in the excavated receptacle with about half of the ventral suture exposed above and the other half fused with the central axis. The back of each carpel is more or less prolonged above the receptacle (except in $N$. gigantea) into a stylar process. We shall speak of this as a carpellary style (Fig. 39, c). The exposed portions of the ventral sutures are connivent or united into a broad, round disc, cup, or funnel, the whole surface of which is stigmatic. At the center of this the floral axis projects as a process (Fig. 39, a) which is ovoid or nearly spherical in Eu-castalia, narrowly ovate in $N$. tetragona, linear and rounded in $\mathrm{X}$ anthantha, linear and acute in Hydrocallis, broadly conical and obtuse in Lotos and Apocarpiae. It is of a dull white color.

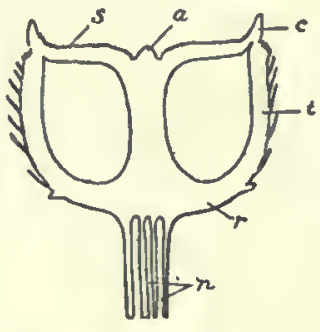

FIG. 39.

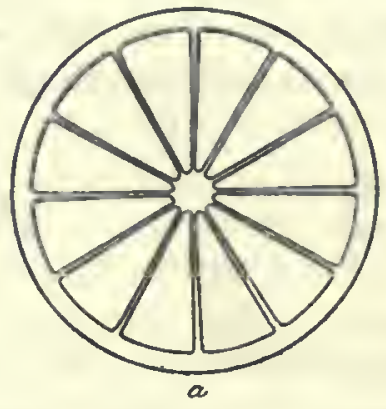

FIG. 40

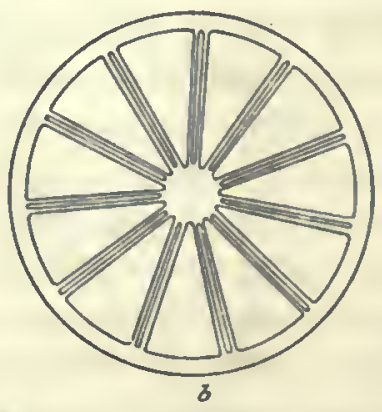

rengry style;

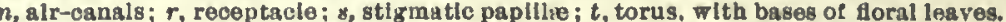

FiG. 10.-Diagram of ovary in transverse section: $a$, syncarpous; $b$, apocarpous.

The stigmatic surface (Fig. 39, s), is usually yellow and densely papillose. The papillae completely cover the upper surface of the small rounded dorsal projections of the carpels of $N$. gigantea, and in other species they extend for a short distance up on the inner face of the carpellary styles. The styles themselves are, as indicated, wanting in $N$. gigantea. In Brachyceras they are short, stiff, orange-colored bodies, grading from mere points in $N$. elegans to erect processes in $N$. flavo-virens or stout, incurved bodies $0.6 \mathrm{~cm}$. long in $N$. zanzibariensis. In Xanthantha and Chamaenymphaea they are more or less ligulate, and stand out horizontally in the basal part.In Eu-castalia and Lotos they are 0.6 to $1.3 \mathrm{~cm}$. long, ligulate and flexible, and in Hydrocallis of about the same length, slender and terete below, with a large clavate end.

In the structure of the ovary Caspary (1865) was first to recognize two fundamentally different types. In most of the old group Cyanea of De Candolle and Planchon he found the walls between the cells of the ovary 
are composed of two distinct lamellae, which easily fall apart along their smooth surfaces of contact. In all other species there is no such division in the walls, but the tissues in each partition are perfectly continuous. The first group was called on this account Lytopleura (iúros free, $\pi$ k̇euod, side), with the definition "carpella toto latere libera tantum externe ad dorsum, et interne ad processum axilem coniunctum enata." The remaining group was called Symphytopleura ( $\sigma u \mu \varphi v \tau^{\prime}{ }_{5}$, connate), and defined "carpella toto latere coniunctum enata." It seems desirable, however, to get rid of names as far as possible, so we have adopted the simple descriptive terms "apocarpous" and "syncarpous" for the two groups. It is valuable to keep in mind that apocarpy occurs in a large group of Nymphaeas, as the Cabombeae and Nelumboneae are all apocarpous. The dehiscence of the fruit of Nuphar, $N$. flava, and the fossil Anœectomeria into separate carpels suggests a recent apocarpous ancestry.

The absence of any definite placenta in Nymphaea has long been a subject of remark. The ovules are attached in large numbers all over the walls of the ovary cells, both lateral and dorsal. They are anatropous, and, at the time of flowering, are suspended on the funiculi with the micropyle upward. The cells of the ovary are oval in side view, wedge-shaped in transverse section, and are filled with a stiff, colorless mucilage.

Externally the ovary (or receptacle) is densely covered with fibrous and mucilaginous hairs. Those of the first type are few and early deciduous in $N$. zanzibariensis $\mathrm{X}$, but plentiful in the other species examined; they are plainly visible in the Lotos group. The longest I noted in $N$. odorata was $0.34 \mathrm{~mm}$., and in $N .0$. minor $0.66 \mathrm{~mm}$., composed of two shaftcells; the longest in $N$. tuberosa was $0.3 \mathrm{~mm}$., with three shaft-cells ; in $N$. zanzibariensis $\times 0.25 \mathrm{~mm}$., five-sixths of its apical part being a single cell. The epidermis is about O. $5 \mathrm{~mm}$. thick, composed mostly of cubical cells. Within this is a layer of dense tissue about $0.34 \mathrm{~mm}$. thick, of small polyhedral cells with very minute intercellular spaces, followed by a loose, spongy tissue with very large air-spaces. In $N$. zanzibariensis $\times$ the airspace in the latter zone barely exceeds the cellular tissue in volume and there are no idioblasts. In $N$. tuberosa and odorata the air-space greatly preponderates, and in the latter stellate cells abound. The spongy layer is much narrower and idioblasts very scarce in $N$. odorata minor. The epidermis bounding the ovary cells is backed by a single continuous layer of soft parenchyma cells. In Syncarpiae this layer and the lacunar perenchyma are alone present between the epidermal layers in the partitions of the ovary. In Apocarpiae the condition is very different. The line of 
division between the carpels lies in the middle of each partition and extends from a point in the wall of the ovary a little farther in than the back of the ovary cells to a point in the central axis distinctly farther in than the inner edge of the cells. On each side of this line is a smooth face of square or columnar epidermal cells; the two sides are in contact. This epidermis is backed by two layers of closely packed rectangular cells; then comes a line of open spongy tissue, then a single layer of parenclyma supporting the epidermis which lines the cells of the ovary.

This epidermis is composed of short columnar cells of highly glandular nature; each one bulges out into the cavity with a round, turgid end. They doubtless secrete the mucilage which fills the ovary. The axis of the ovary is composed of spherical cells with large intercellular spaces in $N$. zanzibariensis $\times$; in Eu-castalia ( $N$. alba candidissima, odorata, tuberosa) the spaces are so large that the cells are drawn out into several broad arms. Many stellate idioblasts were present in $N$. odorata. In the upper parts the tissues of the axis become solid. The process in which it terminates is firm and composed of thin-walled parenchyma; the cells are often slightly elongated and arranged in rows bending from the center out to the periphery. A regular epidermis of small cubical cells covers the process.

The stigma is marked with a number of narrow radiating furrows, one between every two carpels and one along the ventral suture of each. Indeed, the ventral sutures are scarcely closed and are easily torn apart. The stigmatic papillae (Fig. $37, c$ ) are crowded as close as they can stand and consist of rows of 2 to 8 short cylindrical cells. The terminal one is rounded and contains large, oily-looking bodies. In Hydrocallis the cells separate from one another and the stigma is covered with a moist, powdery mass of oily-looking cells, some of which remain attached to each other in strings.

The carpellary styles have numerous mucilage hairs on the epidermis and are made up internally of spherical cells loosely laid together. On the clavate apex of the styles of $N$. amazonum, the epidermis has a slightly corrugated cuticle, and the cells contain a pink-purple pigment.

The vascular system of the ovary presents certain regular features. From the complicated plexus in the base of the receptacle the immediate connections have not been worked out, but sooner or later there is separated a ring of bundles which ascend with numerous branchings and anastomoses in and just outside of the lacunar tissue of the ovary wall, and a ring which ascend in the central axis near the edges of the cells of the ovary. In $N$. odorata another bundle passes up the centre of the axis 
to terminate in the axile process. From the bundles of the outer ring branches are given off to the petals and stamens on the one side and to the walls and partitions of the ovary and ultimately to the ovules on the other. Finally, a bundle extends into each carpellary style. In Syncarpiae the bundles of the inner ring, like those of the outer, are irregularly placed with regard to the carpels, and they seem to unite among themselves by oblique branches; but in Apocarpiae there are one or two bundles in the inner edge of each carpel, and these are separated from neighboring ones by the divisions between the carpels. The inner bundles branch copiously into the partitions between the cells of the ovary in order to connect with the ovules. The bundles are so oriented as to bring xylem next to the ovary cells and phloem away from these, that is, normally with regard to the carpel itself. Consequently the bundles of the outer ring have xylem on the axial side, but the inner ring has phloem toward the axis. In the partitions the bundles nearest one cell have their xylem next to that cell; since those on the other side of the partition are similarly arranged, the two sets have their phloem sides turned toward one another. The central axile bundle of $N$. odorata has one or two spiral tracheæ with phloem all round, but especially thick on two opposite sides. Some peculiar vascular bundles occur in the ovary wall. The largest bundles of this type have an outer mass of phloem, then a band of xylem; this is followed by a band of small-celled parenchyma, and this by another xylem band equal to the former. These are comparable with the smaller veins of the leaves where two bundles stand one above the other; in the ovary the phloem of the upper bundle is suppressed and the intervening parenchyma reduced.

The fruit of a waterlily is technically a berry. The outer wall of the ovary remains firm, but its inner tissues become soft and mealy, i. e., the cells easily separate from one another. The ovary-cells are filled with a greater or lesser number of hard spheroid or ovoid seeds embedded in mucilage, and each surrounded with an aril. Dehiscence is irregular; the fruit simply bursts open by the growth of the arils and swelling of the mucilage. In $N$. flava, however, there is a decided tendency for the carpels to separate, still containing the seeds. The ripening of the fruit takes place under water, during which time various changes occur in the floral leaves. In Castalia these completely rot away, leaving only small scars. In Lotos about half an inch of the bases of the outer stamens remains attached to the fruit. In $N$. amazomum the sepals persist and the other parts of the flower may be only partly decayed. In Brachyceras 
the sepals and outer four petals remain and become stiff and turgid and develop a good deal of additional chlorophyll. The fruits of $N$. tetragona and flava are small ( 2 to $2.5 \mathrm{~cm}$. long), and the persistent carpellary styles form only an insignificant crown around the top. In Eu-castalia the stigma grows very little if any after anthesis, but is about half as wide as the diameter of the spheroid fruit. But in Brachyceras and Lotos, where the fruits become 8 to $12 \mathrm{~cm}$. across, the stigma keeps pace with the growth of the rest of the pistil, so that the fruit has much the same shape as the ovary of the flower.

The seeds of waterlilies offer marked characteristics which are often of great systematic value. They were made an object of special study by Weberbauer (1894), from whose valuable paper many of the following details, especially regarding $N$. alba, are taken. Some important species, however, e. g., $N$. tetragona and flava, did not come under his notice. The largest seeds are those of Xanthantha and Anecphya, then $N$. tetragona, followed by $N$. tuberosa, candida, alba, and odorata; those of Lotos and Brachyceras are considerably smaller than the preceding; the smallest are found in Hydrocallis. They vary in number inversely as the size. $N$. flava may have only seven perfect seeds to a fruit, or one to three per carpel ; $N$. tuberosa has sixty to seventy, while $N$. lotus, mbra, caerulea, capensis, zanzibariensis, and amazonum have thousands. They are nearly globular in N. flava, flavo-virens, elegans, and amazonum, and ellipsoid in the rest. The micropylar end is always slightly pointed, and in Eu-castalia and Chamaenymphaea the raphe forms a gentle swelling along one side. In Castalia the color of the seed is usually greenish black, but brown is the regular color in $N$. tuberosa. Dark brownish-olive tints are found in all others that I have seen, except $N$. amazonum, which is reddish brown, covered with silvery hairs.

The micropyle and hilum lie near together at one end of the seed. The character of the surface, whether smooth or ridged or hairy, can best be discussed in describing the microscopic details of structure.

The aril which is attached to the ripe seed is a bell-shaped outgrowth of the funiculus. It is whitish and translucent, mucilaginous, and holds between its two coats tiny air bubbles. It is much shorter than the seed in $N$. tuberosa, a little longer than the seed in $N$. odorata (Fig. 4I, a), lotus, caerulea, capensis, zanzibariensis, and amazonum, but in these the seed is visible at the open end of the aril. In $N$. alba (Weberbauer) and gladstoniana the seed is completely inclosed and hidden by the aril, while the aril of $N$. flava is a large, wrinkled bag, big enough, if stretched out, to 
cover two seeds with ease. Its cells (Fig. 4I, c-e) are tubular and stretched out in the direction of its growth, thin-walled, and somewhat pointed. In $N$. flava they are about three times longer and wider than in $N$. odorata and caerulea. The inner layer of cells adheres closely to the seed, and its cells are much smaller than those of the outer layer. The walls are supplied with fine pores (Weberbauer). The aril serves, by its mucilage and inclosed air, to float the seed for a short time; it drops the seed in the course of a few hours ( $N$. tuberosa) or a day or so ( $N$. caerulea), partly by being bursted and torn through absorption of water, partly by decay (Fig. 4r, b).

The seed proper is protected by a firm shell consisting of two parts, the outer a single layer of thick-walled, close-fitting cells, the inner a

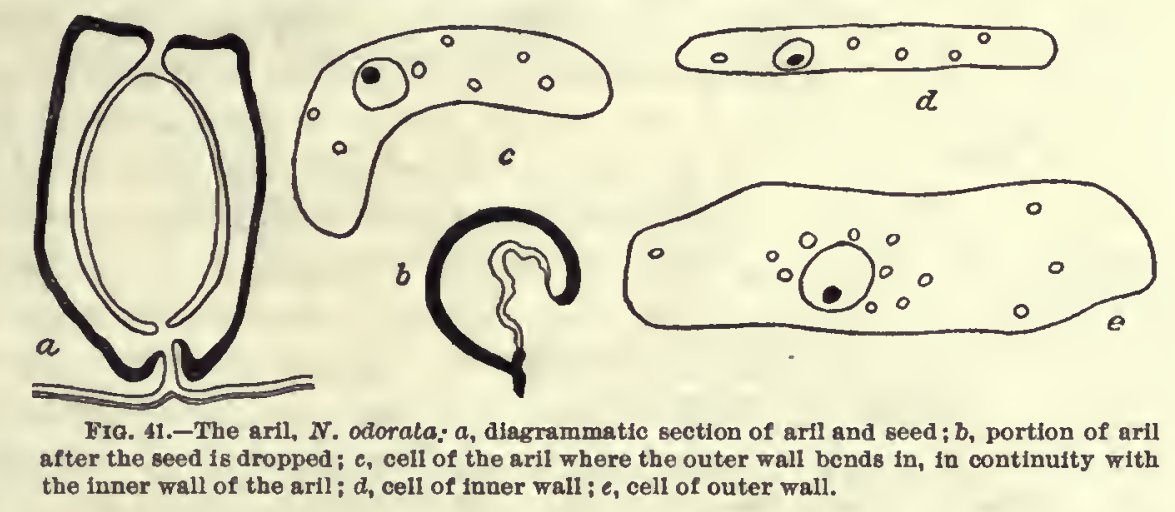

few layers of thick-walled, but loosely placed cells. The latter layer is of the same thickness as the former; its cells are much flattened tangentially and contain large tangential air-spaces; the walls are lignified, with the exception of a thin layer next to the lumen. The cells of the outer layer are also strongly compressed tangentially (except in $N$. flava). On account of the great induration, which is thickest on the outer wall, they have but a small lumen (Fig. 42). The walls are penetrated by porecanals. They are composed of lignin, excepting a thin layer of cellulose next to the lumen and an outer thin cuticula which projects inward along the boundaries of the cells. In the cells there are (in $N$. alba) bluish-green granules which give color to the seed. In surface view the outer cells are arranged in longitudinal rows, and, except at the micropylar end, they have very sinuous walls. Over the raphe the cells are elongated in the direction of the rows, but elsewhere at right angles to the rows. At the micropylar end of the seed the cells of the hard (outer) layer are nearly square and in rows, but interrupted over the hilum, which lies (in $N$. alba) about 
three cells from the micropyle. At the hilum the thick-walled cells of the inner seed coat are rounder and more closely packed than elsewhere.

Based on the examination of the seeds of about twenty species of Nymphaea, Weberbauer distinguished four types of testa, as follows:

(1) Surface bare, smooth, and shining: N. alba, candida, tuberosa, odorata.

(2) Bare, with longitudinal ridges; adjacent edges of rows of cells are alternately raised up or level; the ridges may be interrupted at middle of seed (N. rubra (Fig. 42, a), pubescens).

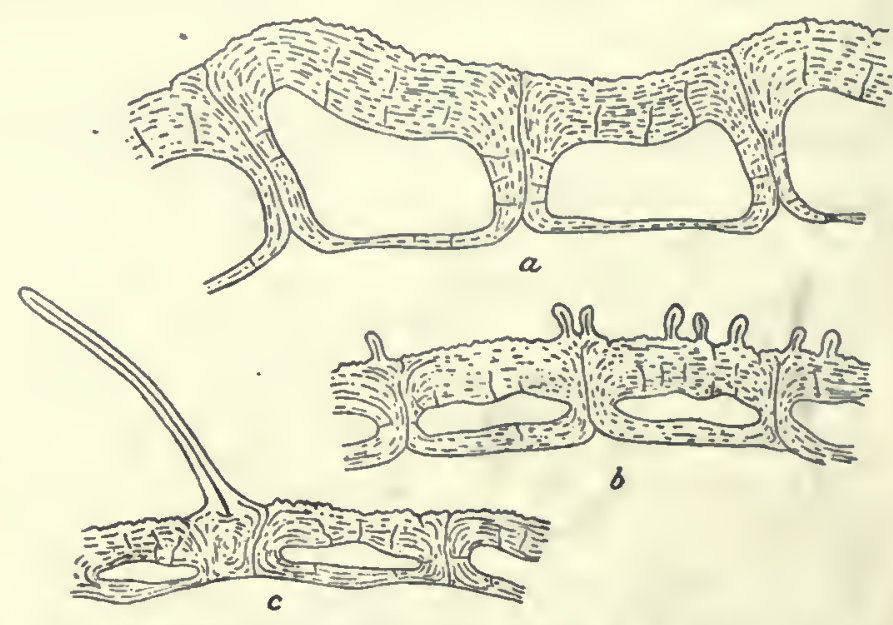

Fid. 42.-Sectlons of outer cell layer of testa: $a, N$. rubra;,$N$. Aavovirens ("N. gracilis" Weborb.) ;,$N$. stellata. After Webcrbauer.

(3) The seed bears longitudinal rows of hairs in the position of the ridges of the second type; the rows may be similarly interrupted ( $N$. blanda, amazonum, gigantea, caernlea, stcllata (Fig. 42, c), capensis, ampla, madagascariensis); $N$. lotus, thermalis, and dentata are only slightly hairy and show transitions to the second type.

(4) Both longitudinal and transverse cell walls have short papillar outgrowths ( $N$. flavo-virens, Fig. 42, b).

Differences occur in the degree of flattening of the outer cells and thickening of the walls, as also in the number of hairs and character of the surface under them. In $N$. thermalis the amount of thickening is less than in other Lotos species, and in N. gigantea the outer walls of the cells are scarcely thicker than the lateral and inner walls. In $N$. rubra. the cells are but little compressed. $N$. amazonum has a dull, roughened surface beneath the hairs, but in " $N$. blanda" (probably $N$. rudgeana) this is very smooth and shiny and the hairs are bent at the tip. $N$. ampla 
and madagascariensis show an inclination to the formation of ridges as in the second type, with a reduction of the hairs.

The outer coat of $N$. flava is peculiar in several points. It is covered with long, slender, appressed hairs just visible to the naked eye, springing from all sides of the cells. It thus combines the characters of the third and fourth types of Weberbauer. The cells are extremely wavy superficially, and so irregular in shape as to render the longitudinal rows obscure. They differ from those of all other species investigated in being nearly twice as deep as wide. A great amount of induration of the outer walls leaves the lumen as a small pear-shaped space at the inner end of the cell. This is a striking approach toward the narrow columnar structure of the hard layer of Victoria and other genera of Nymphaeaceae. I find that $N$. tetragona belongs plainly to the first type of seed coat according to Weberbauer, and $N$. elegans to the fourth type.

The inner seed coat is pressed to a thin layer, except at the tip of the nucellus. The walls are thickened on the inner side, but as it approaches the micropyle the thickening extends up the side walls,

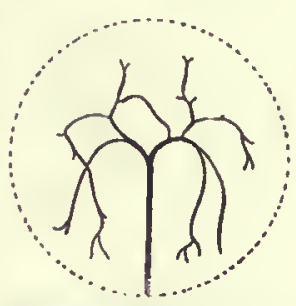

FIG. 43.-1)istribution of vascular bundles from the chalaza, in seed coat of $N$. alba. After Chifflot. until at the micropyle only the outer walls are unthickened. With this thickening there is an increase in the height and sinuosity of the side walls. The micropyle is closed by slightly thickened rounded cells and a layer of thinner cells overlying the inner coat (cf. Fig. 44). A vascular bundle passes along the raphe, and spreads in the seed coat irregularly (Fig. 43), as figured by Chifflot (1902).

Nine-tenths of the space of the seed is occupied by perisperm (nucellar tissue). This consists of large, thin-walled polyhedral cells (Fig. $44, p)$, densely packed with starch. The outermost cells of the nucellus are shriveled and compressed together into a thin membrane, which is thickest between the embryo and the seed coat. The outer food-storing cells are small and somewhat flattened, but in most of the nucellar tissue they are elongated and disposed somewhat in lines (Leitungsbahnen of Weberbauer) running obliquely upward toward an air-space beneath the embryo. The central axis of the seed is filled with looser, thin, elongated starch-laden cells. The nuclei of the cells, where distinct, are pressed over against one wall. The starch is in simple or compound granules, and these, in $N$. gladstoniana and odorata, are aggregated into spherical masses. The grains are very small, and the spherical masses are not 
larger than single grains of some plants. Each spherule is surrounded by a pellicle of protoplasm, and a network of the same substance ramifies among the constituent granules. This type of aggregation exists in a less perfect condition in $N$. flava, but was not seen elsewhere. In $N$. odorata stained sections of the perisperm show a network of

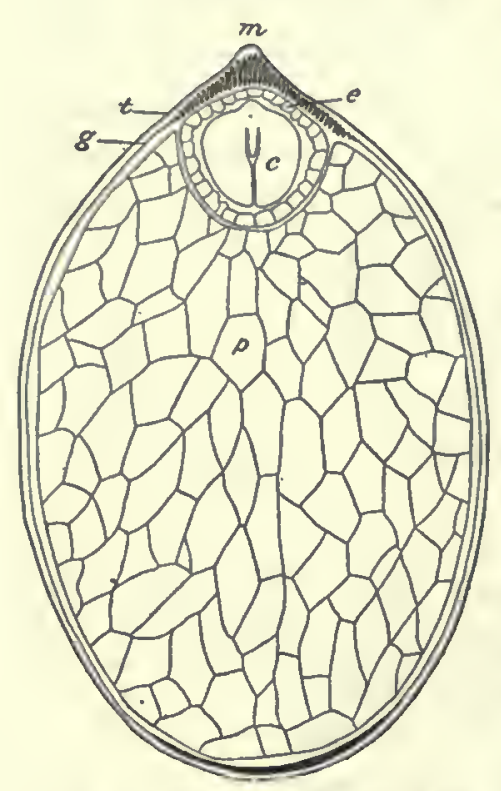

Fia. 44.-Longitudinal section of seed: $c$ cotyledon; $c_{4}$ endosperm; $g$, tegmen: $m$, micropyle ; $p$, perisperm; $t$, testa. thicker plasma strands between the starch spherules near the middle of each cell.

In the micropylar end of the seed a small lenticular or globose space (Fig. 44) is occupied by the endosperm and embryo. The former is a single layer of cubical cells (e) inclosing the latter. The endosperm cells are thin-walled, but Weberbauer was able to find the walls covered with pits so that the thicker portions formed a fine network. They have moderate nuclei, and contain a rich supply of proteids and oil, but no starch. Over the radicle the endosperm is very thin and poor in contents. The embryo has two equal, fleshy, hemispherical cotyledons, excavated on the inner side to receive the plumule. Between their symmetrical bases is the tiny caulicle, and a slight prominence at the end of this is the radicle. Foodstoring tissue of isodiametric cells and elongated conducting cells are distinguishable; an axial strand of the latter is found in the caulicle, with a branch into each cotyledon. No starch is found in the embryo, but it is richly supplied in all its parts with oil and protein. In a crushed embryo of $N$. flava the oil globules run together in considerable drops which stain easily with alcannin. The plumule consists of two rounded papillæ, the leaf rudiments, placed transversely to the cotyledons. One of these is about four times as large in volume as the other. 


\section{CHAP'TER III.}

\section{DEVELOPMENT.}

\section{ORGANOGENY AND EMBRYOLOGY.}

If it were not for the long hairs which clothe the apex of the stem of Nymphaea, there could hardly be a more favorable object for the study of the development of the organs of a mature plant. We cut off the broad tip of a rhizome of $N$. alba, odorata, or tuberosa $\mathrm{I} \mathrm{cm}$. back and pin it down to the wax bottom of a dissecting pan. Then with the aid of a dissecting microscope the larger leaves and their stipules are cut away. The hairs may be pulled out with fine forceps. This is the most difficult part of the task. Finally one discovers that the stem apex is slightly basinshaped. At the center is a very minute elevation, the growing point, and around it the rudiments of leaves and flowers are arranged in spiral order.

The figures of leaf development given by Payer (1857) for $N$. alba are equally applicable to $N$. odorata, and would need but little alteration for N. rubra. I have examined the last two by dissection, and have studied $N$. caerulea, odorata, and flava briefly in serial microtome section. The youngest rudiments at the stem apex are mere rounded papillæ, without indication of their future destiny. They gradually elongate and on reaching a length of $0.08 \mathrm{~cm}$. the foliar or floral character becomes evident. The leaf rudiment (cf. Pl. II, I-7) takes on a more and more conical form, while the floral rudiment remains broad and rounded and develops the anterior sepal. A leaf of N. rubra var., $0.16 \mathrm{~cm}$. long, is about three-quarters as wide at base, and tapers to a rounded apex; on the inner face a broad triangular depression is sharply marked off by two lateral ridges which are continuous over the apex and curve inward a little below, ending about one-fifth of the length of the rudiment above its base. Below this is the petiole; the upper part is the lamina. The rudiment becomes longer and more acute, and the lateral ridges become slightly rolled inward until in a leaf $0.3 \mathrm{~cm}$. long the former triangular depression has become a narrow groove, rounded above. At the base of the petiole there is now on either side a narrow rounded auricle, three times as long as 
broad, placed so that one end touches the rhizome and the other is a very short distance above. These are the stipules. In a leaf $0.64 \mathrm{~cm}$. long the lamina is still more than twice the length of the petiole; the inrolled sides now meet in the median line and the veins are prominent. The lobes of the leaf extend down along the front of the petiole and are slightly divaricate. The petiole is about as broad as long and somewhat contracted at each end. The stipules a re slightly larger and more nearly vertical. The coating of hairs on petiole, stipules, and lamina is well developed, and the swollen collar at the base of the leaf is becoming evident. Subsequent development is, to outward appearances, chiefly a matter of size, except with regard to the stipules. On a leaf of $N$. rubra whose petiole is already more than $5 \mathrm{~cm}$. long these form lunate auricles, with nearly vertical line of attachment to the petiole, and a lobe extending upward a short distance above the line of insertion. Such a stipule is about one-third as wide as the diameter of the petiole and twice as long as wide. After this it decreases in proportionate width, while greatly elongating to reach the mature form. In $N$. odorata (Pl. II) and $N$. alba the young leaf rudiment, less than $0.16 \mathrm{~cm}$. in length, is more rounded and less acute than in $N$. rubra and the stipules are quite different. About the time the flattening of the inner side of the rudiment to form the lamina occurs, two elongated ridges appear, one on either side of the base of the leaf, extending along toward each other just in front of the rudimentary petiole. The adjacent ends soon meet in the median line and the beginning of the stipular plate of the Castalia group is evident. Being shorter in the median line than at the sides, its outline is obcordate. As the whole ridge grows higher, it overtops its leaf at the length of about $0.3 \mathrm{~cm}$., and on either side of the middle line an S-shaped fold occurs, which throws the median part of the stipules away from the leaf, or, to state it otherwise, forms a groove into which the leaf fits. A great thickening along these folds makes two strong keels on the inner side of the stipule. Later this broad plate elongates to the typical adult form. A leaf rudiment of $N$. odorata $0.3 \mathrm{~cm}$. long had downward pointing hairs covering the back of the lamina and the petiole, but on the next younger leaf these were present only on the lamina.

The formation of the principal air-canals takes place at an extremely early period. The first beginning of separation of the cells was seen in $N$. caenulea in a rudiment $0.5 \mathrm{~mm}$. long. The canals were seen with the naked eye in a leaf rudiment of $N$. flava about I mim. long; the bounding walls were composed of columnar cells. At $1.6 \mathrm{~mm}$. long all of the canals are indicated. In the smaller leaf the fusion of the three main bundles 


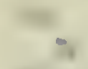

15 



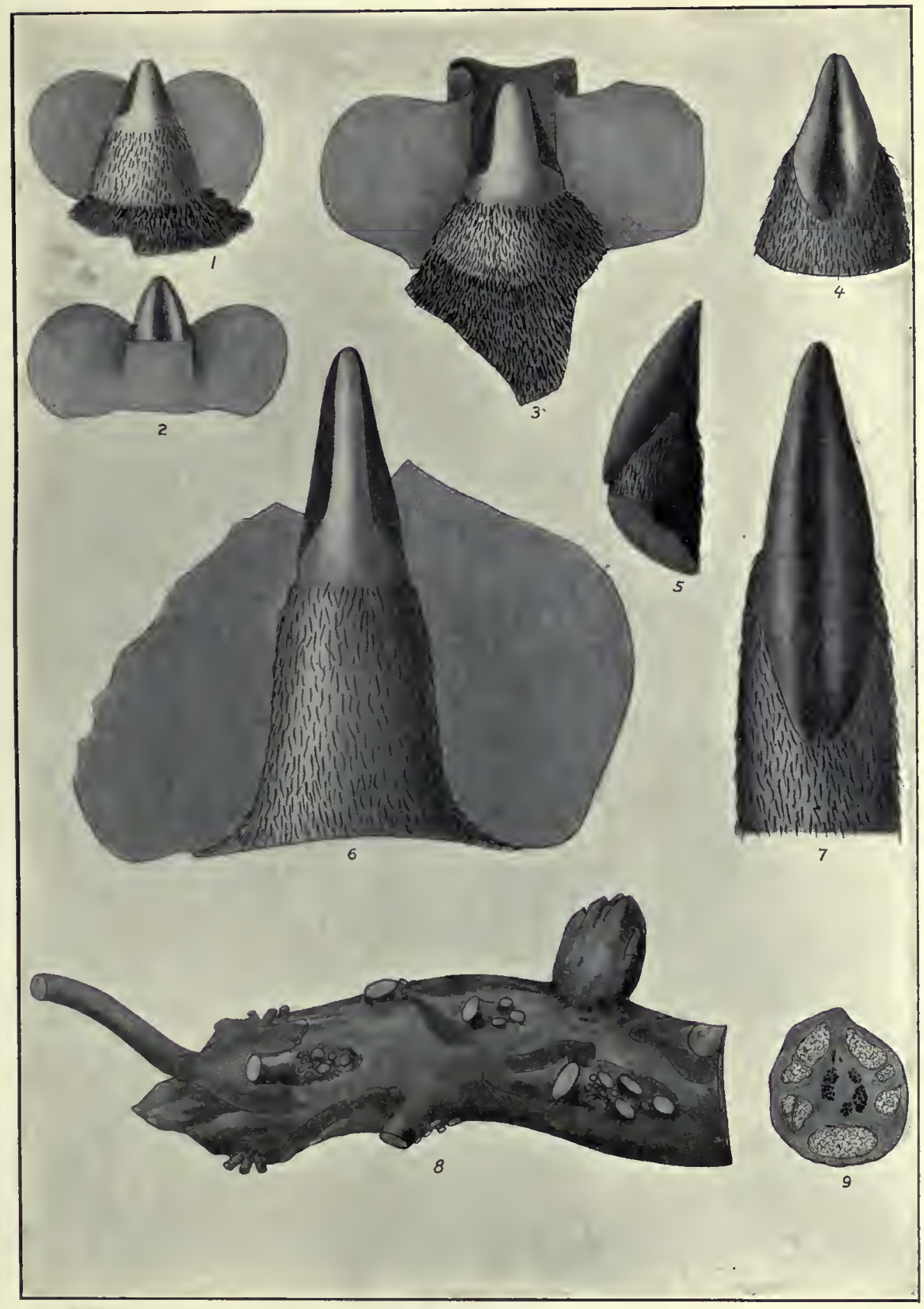

A. KORONEKI DEL

NYMPHAEA ODORATA.

1-7, development of leaf and stipules; 1,2 , front and back views of the same rudiment; 3 , older; 4,5 , front and side views of one rudiment; 6,7 , front and back views; 8 , rhizome with roots and leaves trimmed off, natural size; 9 , transverse section of rhizome, natural size. 

from the petiole to a single trace and the separation of this again into the central and two lateral traces was seen. The bundles were chiefly composed of procambial cells, though some spirals were present in the three branches within the inner fork. The lamina of the older leaf mentioned had elongated cells along the lines of the veins, but the parenchyma was almost totally undifferentiated and was without intercellular spaces. A leaf of $N$. tuberosa richardsoni whose lamina and petiole are each $1.3 \mathrm{~cm}$. long has the air-canals well developed along the midrib. Between the veins the mesophyll consists of five layers of cubical cells arranged in vertical lines from the upper to the lower epidermis. The layer next to each epidermis is continuous, but between the vertical rows in the three middle layers long intercellular spaces are present. Idioblasts are already present near the midrib. A leaf of $N$. odorata with lamina $2.5 \mathrm{~cm}$. long and petiole $3.2 \mathrm{~cm}$. has the air-chambers of the mesophyll well marked off by plates of cells; the palisade consists of a single layer of dense cubical cells, underlaid by two or three layers of flat cells elongated parallel to the surface of the leaf; the mucilage hairs are large and functional. When the lamina is $8 \mathrm{~cm}$. long the palisade still consists of a single cell-layer; the big idioblasts have not yet appeared. Stoma-mother-cells are present in full number and nearly mature size ; some, indeed, have just divided to form the guard cells. They are round, granular, and highly refractive. The maturation of the stomata occurs only a day or two before the leaf finally expands. Caspary $(1854 ; 1858)$, in announcing first the apical growth of leaves, showed that this apical growth continues longer in Nymphaea than in other plants, and that the margin of the leaf in all Nymphaeaceae is the latest part to complete its development.

The tissues of the stem begin to differentiate within $0.25 \mathrm{~mm}$. of the point of apical growth. No plerome is at any time distinguishable. The lacunar cortex acquires intercellular spaces while all of the tissues are still meristematic, and the early establishment of desmogen strands, adventitious roots, and external hairs has already been referred to.

Concerning the development of the flower, we are able to corroborate the work of Payer (1857) and Goebel (1886) on N. alba by observations on $N$. caerulea and lotus, and to add some details. The discussion of important morphological problems will be deferred whenever possible until the observed facts are set forth. The earliest rudiment of a flower that I have seen was a smooth, thimble-shaped upgrowth at the stem apex in $N$. caerulea. On such a papilla, according to Payer, there appears in $N$. alba the rudiment of the anterior sepal; then the two lateral sepals 
arise on the sides, and later the posterior sepal. Hence comes their peculiar astivation. Four papilla next appear alternate with the sepals. 'They arise simultaneously, grow rapidly, and are always larger than the inner floral organs, which originate later. They are at the base of a hemispherical receptacle whose surface, naked hitherto, becomes covered little by little from base to summit with a number of new papillæ. These are arranged in ten vertical rows, one abutting on each petal, one on each lateral sepal, and two on the posterior and anterior sepals. The lowest ones soon flatten out and become petals; the uppermost become typical stamens; between these two sets one finds all gradations from stamen to petal. The stamen rudiments, however, do not cover the whole receptacle. A bare space remains at the summit, around the edges of which a row of papillæ appears. These (the carpels) become horse-shoe shaped, and their inner edges join, making a sinuous line. The sinuosities extend somewhat toward the center, and a thick process of the receptacle grows up to fill the central space, closing the ovary-cells. Now the sepals and the four outer petals remain stationary, as it were, while the rest of the receptacle elongates, carrying with it the carpels, stamens, and inner petals. Thus the ovary comes to be inferior with regard to the stamens and inner petals while the outer petals and the sepals have an inferior insertion. There is no fusion of the floral leaves outside the carpels with the ovary or receptacle, as Koehne (fide Goebel) believed.

According to this account from Payer, the ovary would bear the carpels at its summit, and its lower parts would be of axial origin. Goebel (1. c.) noted this difficulty and showed that before the carpels are mapped out there is a hollowing of the receptacle as is common in inferior ovaries. From the edge of the axial excavation, but reaching to the bottom of it, arise the carpel-rudiments. They are never free from the receptacle on the outer side. The whole wall of the ovary-cells, however, is of carpellary origin, and no part is formed from the vegetative apex of the flower stalk. Our own observations on $N$. caerulea and lotus support Goebel's view.

In $N$. lotus the time relations of the origin of the outer floral organs differ slightly from that given by Payer. In the apex of a large flowering plant we found three rudimentary flowers of successive ages and sizes, in all of which only the anterior and lateral sepal-rudiments were present (Fig. 45, a, b). This shows that these organs originate much earlier than those farther in. The anterior sepal was much larger than the others, and was inserted considerably farther down. In such a rudiment one could hardly speak of a peduncle, for this sepal seemed almost sessile on the 
parent stem. The next older flower noted (Fig. 45, c) had a broad papilla representing the posterior sepal, a rounded one for the right antero-lateral petal and a partly formed papilla for the left antero-lateral petal. The right petal was about half as large as the posterior sepal, and this was about half as large as a lateral sepal, and this again half as large as the anterior sepal. The next flower had the two anterior petals about equally developed. The remaining organs (except the carpels) originate one by one; two postero-lateral petals come next, then four petals opposite the sepals; then four opposite the first petals. The exact order of these was not determined (Fig. 45, d). In early stages the bud exceeds the peduncle in length, but after the total length of the two reaches $2.5 \mathrm{~cm}$. the peduncle begins to exceed the bud. Previous to this stage the anterior and lateral
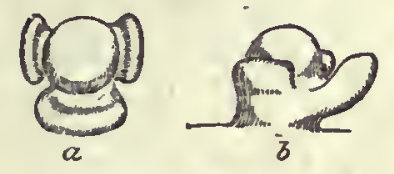

Fia. 45.-Development of flower, $N$. lotus var.; $a$, end view; $b$, side vlew of
rery early stage: $c$, with rudiments of sepals and two anterior petals; $d$, sepals,
two whorls of petals, and one member of tho next whorl laid down.

sepals alone cover the bud; later they are pushed apart and the posterior sepal is exposed. The carpels are rather late to develop. In a bud $\mathbf{I ~} \mathrm{cm}$. long they resemble little folded leaves, fused half way up the back with the hollowed receptacle, but open along the ventral suture, and, even in $N$. lotus, wholly free from each other.

The above facts throw light on several questions, and first upon the kind of inflorescence found in Nymphaea. It will be remembered that the flowers stand in place of leaves on the stem, but without any subtending bract. Payer says the case is very simple: Each flower arises in the axil of a leaf, but on account of crowding in the bud, the flower comes to be at some distance from its leaf, and it requires some experience ("il faut quelque habitude") to find the leaf to which a given flower belongs. Schumann (1894) maintains the same view and cites the case of Victoria, in which there are parallel spirals of leaves and flowers on the stem, and at the apex each leaf has a flower to its left as they originate. Raciborski (1894) opposes this with the theory that the bract is entirely suppressed in Nymphaea and Victoria. This better accords with the exact location of the flowers in the leaf spirals; and in Nuphar there is at times, if not always, a rudimentary bract subtending the young flowers. Eichler (1875), however, 
on the authority of Caspary and Braun (in personal letters), reluctantly accepts the belief that the flowers are axillary, but the bract and bracteoles are carried up on the summit of the peduncle as anterior and lateral sepals. The argument for this has been based largely upon the uncertain ground of teratology. Planchon $(1850, e)$ figured a flower of $N$. caerulea "whose peduncle showed accidentally [at the lower end] three spatulate bracts, with petioles wavy here and there on the margins as the sepals are at base."* Caspary (fide Eichler) found in the same species a flower with the anterior sepal at the base of the peduncle as a ribbon-shaped bract, the lateral sepals also pushed down, and the posterior sepal in its proper place. This was followed by four sepals in a whorl, placed diagonally like the second whorl of a normal flower. Caspary found similar cases in $N$. alba, gigantea, rubra, and hybrids of $N$. caerulea and capensis. My own observations on the development of the flower of $N$. lotus fully substantiate Caspary's view, and, I may say, completely turned me from an opponent to an adherent of his theory. The low insertion of the rudiment of the outer sepal and its very early appearance, followed at once by the two lateral sepals, are convincing. This also explains the peculiar relations of the sepals in the bud; on any other theory, except a blank displacement, the anterior sepal should be, like the posterior, covered by the lateral sepals.

It remains, however, to explain the presence of a single posterior sepal and the oblique position of the next four floral leaves. Caspary and Braun looked upon the single sepal as an "Ergänzungsblatt." But if the floral diagram of Nuphar as given by Baillon (3:82) can be depended on, in which the outermost of the five sepals is posterior and the petals "are inserted along a spiral," we have the most perfect starting point for the development of the flower of Nymphaea. The outermost sepal of Nuphar homologizes with the posterior sepal of Nymphaea, and a very slight shifting of the remaining four sepals away from the median anterior line gives them the oblique position of the four outer petals of Nymphaea. The strongly sepaloid character of these petals, especially in Brachyceras, indicates such an origin. As to the inner petals, from the acycly of Nuphar, Nymphaea shows a continually increasing tendency to cyclic symmetry. In $N$. lotus the rudiments of all of the floral leaves (excepting the three outer sepals) arise in series, one after another, but Payer's account of $N$. alba places the four outer petals in a whorl, and the inner

\footnotetext{
* _- dont le pédoncule offre accidentellement trois bractées spathulées, à pétiole ondulé ça-et-là sur les bords, comme les sépales le sont à leur base.
} 
petals and the stamens in alternating whorls of five; probably this plant should be worked over anew. In the mature flower the cyclic arrangement is least evident in Castalia and but little more so in Lotos; but, as stated, in old flowers of Brachyceras, and open flowers of Hydrocallis it seems to prevail in all of the parts (cf. Fig. 36). Probably cyclic arrangement is always to be considered as derived from acyclic, and Nymphaea seems to be in the transition stage. For such flowers the term hemicyclic or spirocyclic (Engler, 1898 ) is best. It goes beyond the truth to place Nymphaeaceae among acyclic orders as Goebel did (I887, p. 412).

While still maintaining that the terms sepal and petal as commonly used for waterlilies are physiologically correct, the morphological value of the petals must be considered. We have shown that the anterior sepal represents the bract, the lateral sepals the bracteoles, and the inner sepal with the four outer petals the primitive sepals. For the last homology I am indebted to a suggestion from my instructor, Dr. John W. Harshberger. In development no distinction can be made between the rudiments of the remaining petals and the stamens, while in $N$. alba the four outer petals do have a distinct and simultaneous origin. Payer, therefore, pointed out, and rightly so, that the inner petals are really modified stamens, and the waterlilies are habitually double flowers in the same sense as roses, almonds, etc., are doubled in cultivation. This at once explains and is supported by the extremely variable number of petals and the occurrence of transitional forms between petal and stamen. It seems probable, however, that in last analysis all petals are modified stamens, and in Lotos and Anecphya, where a naked space occurs between the insertion of stamens and petals, and intermediate forms rarely if ever occur, the distinction between the two classes of organs is being rapidly drawn, and the homology is more distant than in Castalia. The fixation of definitive petal and stamen characters upon the floral rudiments is taking place before our eyes in the genus Nymphaea. It is striking, but on second thought only natural, to find this kind of specialization going on alongside of the change from spiral to cyclic symmetry. The two phenomena are but manifestations of the same law of adaptation and differentiation in form and function.

After the stamen rudiment is established it grows considerably before the archesporium appears. It has been claimed that the anther cells are at first extrorse and are pushed around to the inner side by uneven growth of the connective. In $N$. lotus, at least, this is not the case. Two pairs of archesporial lines are differentiated in the substance of the anther, 
each consisting of a single straight row of cells. They are removed four or five cells from the inner epidermis and seven to twelve cells from the outer epidermis, and between each pair of lines eight cells intervene. The cells immediately surrounding the archesporia take on a more or less concentric arrangement, and the development goes on in the usual way for flowering plants. In $N$. caerulea the outer stamens develop slightly in advance of the inner ones; where the former are $1.3 \mathrm{~cm}$. long and the spore-mother-cells are already separate from one another and becoming rounded off, the mother-cells of the inner stamens form a continuous tissue.

The ovules originate after the ovary has attained a considerable size, say $0.5 \mathrm{~cm}$. in diameter in $N$. caerulea. At first a tiny rounded column

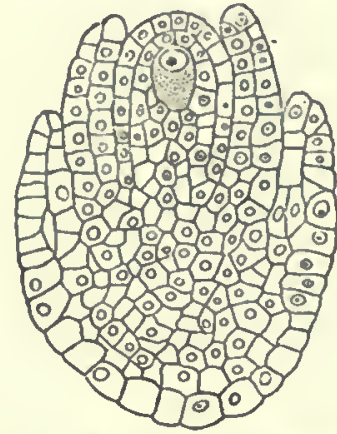

Fig. 46.-Orule of $\boldsymbol{N}$. odorata, from a half-grown bud, showiug archesporlum. From a photomicrograph.

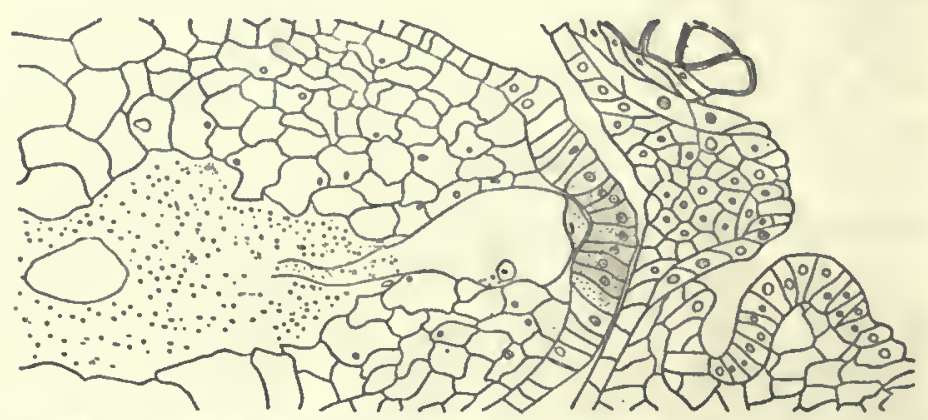

Fra. 47.-Embryo sac of $\boldsymbol{N}$. odorata ; Iongitudinal section of ovuie at time of flowering. From a photomicrograph.

projects into the enlarging ovary cell. This swells at the end into a knob, an integument of two cell-layers grows up around the knob, and then a second integument outside the first. When the inner integument has reached the height of the nucellus, the outer one is about half as high (cf. Fig. 46). Meanwhile the knob has turned over at right angles to the supporting column in its change toward anatropy. A large archesporial cell is now visible at the apex of the nucellus, covered by a layer of cells. The archesporial cell presents five times as large a surface in longitudinal section as the surrounding cells; its nucleus is as large as an entire cell of the nucellus, is rather poor in contents, and has a single dense nucleolus. Its further development has been described for $N$. odorata by Cook (I902). According to his account, a tapetal cell is cut off at the outer end of the archesporial cell (cf. Fig. 46), and from the former several tapetal cells arise by a variable series of divisions. Three potential megaspores are next cut off from the mother-cell. These rapidly degenerate, leaving a 
single large megaspore. This cell elongates to form the embryo-sac. Returning to the stage in which only the archesporial cell is found, we note an elongation of cells in the center of the funiculus which foreshadows the vascular bundle. This was seen in an ovary of $N$. odorata $0.6 \mathrm{~cm}$. in diameter; the ovules were just visible to the naked eye. In an anther from the same flower the microspores are formed, but have not received the chatracteristic markings on the exine; the tapetum appears as a layer of disintegrated matter around the walls of the anther cell ; the thickenings are not yet laid down in the anther wall. After this the ovule rapidly grows to its mature form. The outer integument becomes three cells thick and loses its protoplasm, while the inner integument consists of two layers, of which the inner alone remains richly protoplasmic. The nucellus consists of many cells arranged in radial rows; the outer ones are tangentially flattened, the central ones rounded. The raphe is prominent and is traversed by a slender vascular bundle with a spiral trachæa on the side next to the nucellus. The funiculus is covered at base with a glandular epidermis like that of the ovary, but the glandular cells end at a sharp line near the seed, beyond which the epidermis is plain and smooth. Between the epidermis and the vascular bundle the round parenchyma cells enclose large intercellular spaces. The embryo-sac (Fig. 47) is prominent as a clear area below the micropyle, and is shaped like a flask with the neck extending down into the axis of the seed. The ratio of the diameter of the body and neck of the flask is as 5 to I in $N$. odorata and zanzibariensis, but in $N$. lotus the whole ovule is longer and narrower, and the embryo-sac is lanceolate in longitudinal section, with rounded ends. A single layer of columnar nucellar cells covers its outer end.

A day or two before the flower opens the egg apparatus is complete. 'The embryo-sac is slightly narrowed at the micropylar end, where it is covered, as before, with one layer of columnar cells. In this upper part of the sac three similar cells are crowded, two above and one below. The rest of the sac is lined already by a few cells around the sides, visible only in my preparations as compressed nuclei. Hofmeister (1858) doubtless referred to the same thing in Nuphar, "whose embryo-sac," he says, " even before fecundation shows clearly a cellular wall" (Zellstoffhaut). A pair of nuclei indistinctly seen in the extreme end of the narrow inner part of the sac in $N$. odorata doubtless represent the antipodal cells; a single cell with very large nucleolus occupies the same position in $N$.zanzibariensis. The outer integument now consists of two (or near the raphe three) layers 
of slightly flattened cells, poor in contents. The inner integument has both of its layers very thin, and the outer one nearly empty.

Dahmen (1892) critically exanined the funiculus of the ovules of Nymphaea. Since the so-called aril originates as a swelling on the funiculus before fecundation occurs, he considers that it is not an aril in the usual sense, restricting the use of the term to outgrowths which occur when the seed is ripening. The distinction, however, is extremely unimportant, especially as the aril of Nymphaea does not reach maturity until the seed is ripe, and most of its growth occurs after the seed has attained its full size. In $N$. lotus Dahmen noted two swollen zones on the funiculus near the ovule, but only one in $N$. rosea (quid?) and zanzibariensis. The epidermis of the funiculus has slightly thickened walls; within it is a thin-walled parenchyma and a vascular bundle with phloem and a little xylem. "The bundle has no connection with the aril. Small round starch grains are found temporarily in the parenchyma, epidermis, and phloem. Intercellular spaces occur only in the arillar swellings according to Dahmen, but I find them plentifully elsewhere in $N$. odorata. The tissues are all filled with mucilage, which is only precipitated by strong alcohol. The protoplasm is dull yellowish. Asparagin occurs in the funiculi, but no sugar was found.

Unfortunately we cannot accurately trace all of these tissues to their mature state, but the changes are not important in any part except the embryo-sac. The early stages were worked out by Hofmeister (1858) in Nuphar luteum and advena, which differ from Nymphaea in that the narrow inner part of the embryo-sac is much longer, and extends after fecundation to the chalaza; an axial tube remains open even in the mature seed (Weberbauer, 1894). In Nuphar there are three cells at the top of the embryo-sac, two upper synergidæ and an ovum below. About the time of fecundation a transverse wall divides the narrow part of the embryo sac from the upper wide part, and the latter is soon filled by two or three endosperm cells. The fertilized ovum now divides transversely, and a suspensor of one to five cells is formed above the embryo. The observations of Mr. Cook (1902) on $N$. odorata seem to be corroborated up to the first cell-wall laid down in the embryo-sac. His views on the development of the embryo, however, which he considers to be monocotyledonous and without suspensor, are totally at variance with my own preparations. I cannot imagine that his interpretations are correct. This portion of $\mathrm{Mr}$. Cook's paper is based chiefly on Nuphar advena, in which Caspary's drawings (in $\mathrm{Hb}$. Berlin) seem also to indicate the absence of a suspensor. 
The earliest fertilized ovule of Nymphaea that I have seen is of $N$. lotus, and has already reached nearly its mature size. The integuments are considerably hardened, and the perisperm is loaded with starch. A broad space at the micropylar end of the seed is occupied by the endosperm, the cells of which are very thin and watery (Fig. 48,a). A distinct layer of perisperm still bounds the endosperm on the side next to the seed ceat. From a point near the micropyle a row of three cells projects into the endosperm, representing the embryo. An older seed of the same species shows the endosperm occupying an approximately spherical space, somewhat pointed above and flattened below; its cells are large and

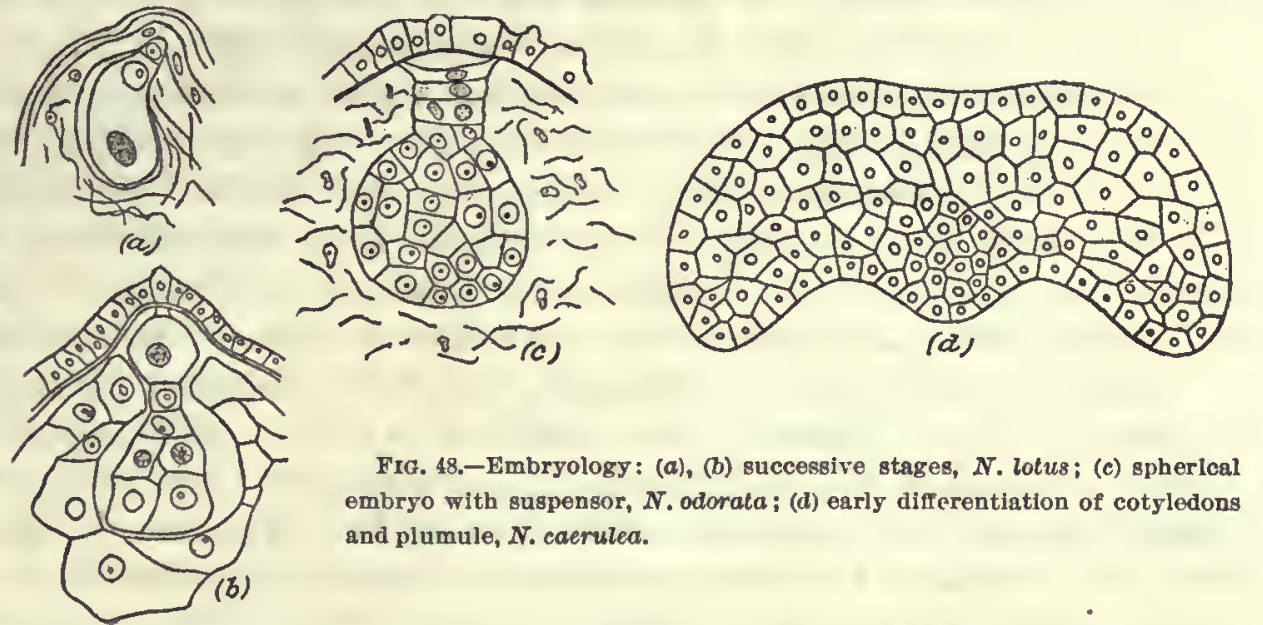

distinctly nucleate, but very thin walled and poor in contents. The embryo (Fig. 48, b) consists of a line of three suspensor cells and a terminal knob of probably eight cells (four in longitudinal section). The uppermost suspensor cell is hexagonal, the others square (in section). After this the endosperm enlarges very little. As the embryo encroaches upon it, the outer cells become denser and more regular until they reach the mature condition, and the inner ones' are crushed to a thin layer of remnants between the permanent outer layer and the cotyledons. The embryo proper (cf. Conard, 1902) becomes accurately spherical as it enlarges, until it consists of some hundreds of cells (Fig. 48,c). Then the lower end becomes flattened by reason of the outgrowth of cells on each side of the lower pole. In section the embryo now appears triangular and almost equilateral. The two lobes increase symmetrically and form the two equal cotyledons. At first these spread out nearly horizontally (Fig. 48, $d$ ), while in the middle between them a slight cone-like papilla 
represents the plumule, and a similar prominence opposite (next to the suspensor) is the radicle. Subsequently the cotyledons spread round the walls of the endosperm and fill up all of the limited space available, while between them the two leaf-rudiments of the plumule are differentiated.

\section{GERMINATION AND EARLY GROWTH.}

Corresponding with the habits of life of the various species of $\mathrm{Nym}$ phaea are certain requirements for the proper growth of seedlings. Seeds of the Eu-castalia group quickly lose the power of germination if dried; in nature only those which are, by chance freshets, stranded hopelessly above the normal water level ever become dry. $N$. tetragona can withstand drought fairly well. Seeds from Kashmir communicated by Mr. Wm. Gollan, of Saharanpur, India, germinated quite well, but of several sendings received in the early spring of successive years from Japan, only one seed has ever sprouted. The former were sent to us directly after they were gathered, while the latter have doubtless been kept in a seed-house since the previous summer. Seeds of the Lotos and Brachyceras group can withstand a great deal of drought; they are accustomed to it; but they are kept much more successfully, as Caspary (1877) recommended, packed in clay and air dried. Under these conditions a considerable amount of moisture is retained, even when the mass appears to be perfectly dry. $N$. zanzibariensis was introduced into Europe from Zanzibar by seeds packed in chalk; and of a box of seeds of $N$. dentata, mingled with soil, received last summer (190I) from Jamaica, nearly every one sown germinated. In all of the Castalia group the seeds should be kept in bottles of water. It was thus, also, that Victoria regia was successfully carried to England after a long series of costly failures.

For germination the seeds of waterlilies need to be submerged in 5 to $30 \mathrm{~cm}$. of water. Those of the Castalia group prefer a temperature of $15^{\circ}$ to $18^{\circ} \mathrm{R}$., but the tropical species do best at $23^{\circ} \mathrm{R}$. (Siber, 1883). A very irregular length of time is required. Of a quantity of $N$. elegans $\times$ zanzibariensis seeds sown as soon as collected, a large number came up in two weeks ; after more than a year some earth from this pot chanced to be placed in a warmer tank, and numerous new and vigorous seedlings appeared. In the Dreer Gardens at Riverton, N. J., I have seen flowering plants of $N$. caerulea which came up spontaneously out of doors where two years previously that species had been grown; the seeds had lain dormant over all one summer. In this case Mr. Tricker informed me that the bottom of the pond had been dug over each spring. Probably the 
seeds were buried in the first digging and brought to the surface in the second. In midsummer $N$. zanzibariensis seeds will germinate quickly after maturing, and the bags of seed must be gathered as soon as the fruit bursts; but in the summer of 1900 numerous seedlings of this plant sprang up in the pond of the Botanic Garden (University of Pennsylvania) and blossomed before frost; they must have come from seed ripened in the previous autumn. Mr. Waters (1886) gives an interesting account of the germination of $N$. odorata. Seeds gathered in the fall of 1883 were sown at once in an aquarium kept in a living room with north light. In March, 1884 , many were germinating. In June, I 885, the vessel was placed where it received direct skylight with sun for an hour at noon; a half dozen new plants appeared in August. In the fall they were returned to the living room, and about Christmas another seed had germinated. From February to April, 1886, four others sprouted; these had therefore lain dormant for about two and a half years, although they were constantly in conditions which would permit germination.

The general features of a seedling Nymphaea were noted by Tittmann in 1821 . Treviranus, Caspary, Klebs, Goebel, and others have since remarked upon or figured such seedlings. The first visible evidence of life in the seed is the loosening of an operculum at the apex (Fig. 49, 8, o). This is a conical body bearing the micropyle and hilum; its edge is ragged by reason of the sinuous margins of the cells of the testa. The operculum is pushed aside by the protruding embryo and its wrappings, and lies on these at one side near the edge of the opening from which it was torn. The seed coat is also rent with short longitudinal fissures, dividing the lip of the aperture first formed into numerous acute teeth (Fig. 49, 8). As the embryo emerges it is covered by a white sheath produced by the swelling and straightening out of the overlying "rumpled up" portion of the inner seed coat; this protects it from the sharp and ragged edges of the testa. The cotyledons remain permanently within the seed and show no changes in the inner parts except in the emptying of the cells. It is by the elongation of the bases of the cotyledons into a kind of petioles that the radicle and plumule are passively carried out of the seed. These cotyledonary petioles also curve geotropically downward until the caulicle is in a vertical position, and then they cease to grow (Fig. 49, 3, 4).

Through all this time the plumule and radicle have remained dormant, but now both start into activity, the former very rapidly. The hypocotyl does not elongate at all. The epicotyl and first leaf shoot upward as a slender subulate body (Fig. 49, 3,4). The elongation of the epicotyl 


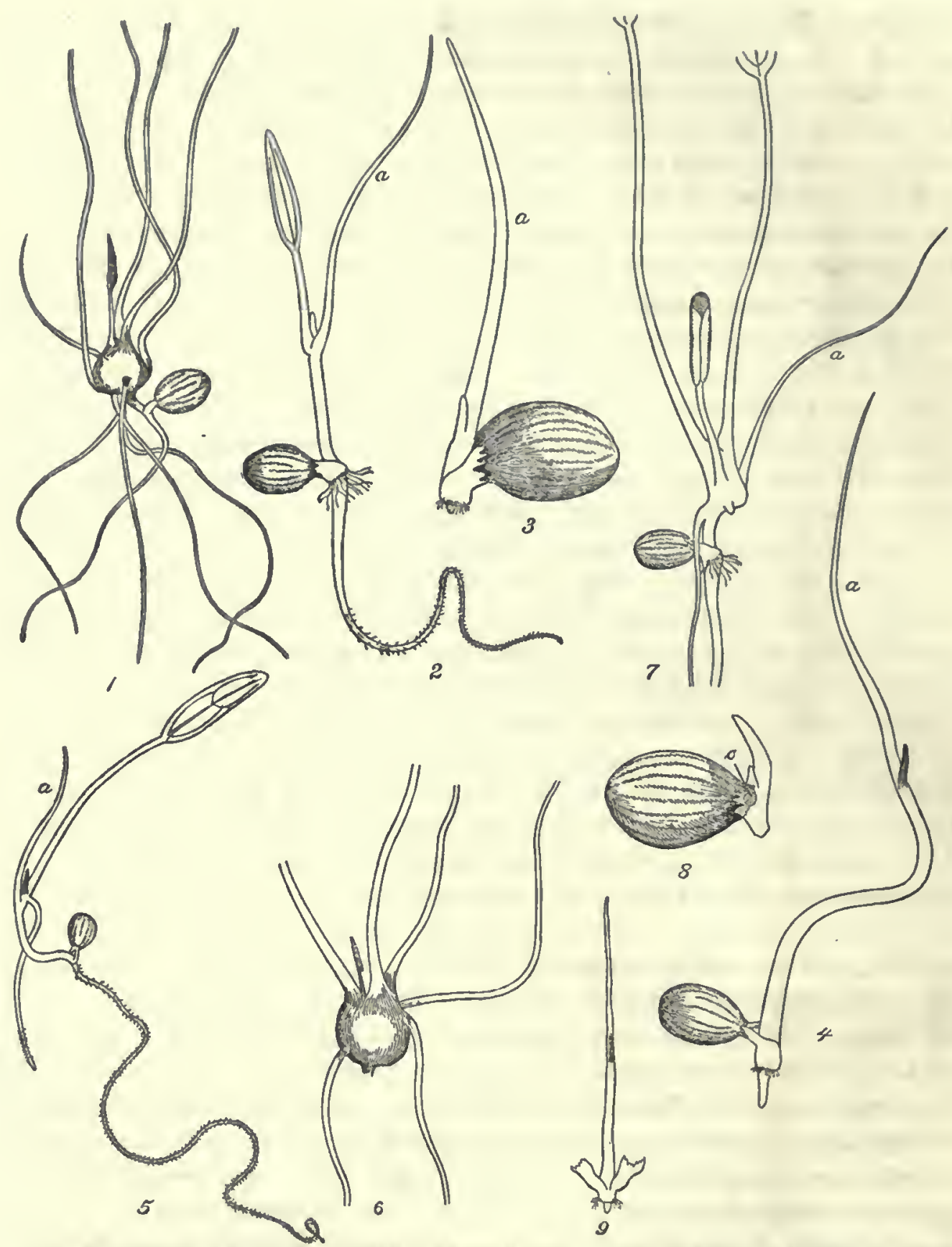

Fia. 19.-Seedlings or a hybrid Nymphaea of the J.otos group. 1, tuber formation at summit of epleotyl well advanced. 2, the flrst broad icaf expanded, the primary root, with root hairs, mature. 3 , the flrst (fliform) leaf nearly mature, and rhizolds springing from cotyledon. 4, a slightiy older piant, from a geed which was burled more deeply in carth; the epicotyl is muen eiongated. 6 , first secondary root. 6 , small ripening tuber : epicotyl rotted off. 7 , beginning of second secondary root and third broad leaf (4th leaf). 8, soon after germination; the tegmen (dotted) extends beyond the hard seed coat, bearing the dotached opereulum. 9, plantlet of same are as 8, with eotyledons broken off from their petioles. $a$, first (flliform) leaf; 0 , opereulum. 
depends upon the depth to which the seeds are buried; it reaches up just to the surface of the soil. If they are uncovered at the bottom of the water, the epicotyl is scarcely visible (Fig. 49, 3); if is about as long as the width of the cotyledonary petioles. In other circumstances this internode may be $2.5 \mathrm{~cm}$. long $(2,4,5)$. The stimulus which effects this difference is light. Seeds of $N$. gladstoniana and flava grown in glass bottles of water in the dark sent out very long epicotyls reaching far above the layer of seeds in the bottom of the bottle. The first leaf produced by the seedling is a slender awl-shaped object, like a spear of grass (Tricker, 1897); it looks like a prolongation of the epicotyl (Fig. 49, (a); the boundary between the two is marked by a tiny rudiment of the next leaf. While these changes are going on in the plumule, a large tuft of root-hairs is formed on a broad prominence at the base of each cotyledonary petiole. These hairs serve to anchor the plantlet to the substratum and doubtless to absorb some food during the inactivity of the radicle (Goebel, 1893). After the subulate leaf has nearly reached maturity, and the second leaf-rudiment is swelling, the radicle begins to elongate (Fig. $49,4)$. Hitherto it has been a tiny papilla between the bases of the cotyledons, but it soon grows out into a primary root 5 or 8 centimeters long (5).

The second leaf of the plantlet arises opposite the first and develops a petiole and an ovate to linear lamina $(2,5)$. At its base a single adventitious root comes out and descends into the earth; it only becomes evident after the leaf is nearly mature (5). Subsequent leaves are broader and broader in the lamina, becoming deltoid in Lotos and cordate to nearly orbicular in Brachyceras (cf. Fig. 50). Several of them remain on short petioles and are typically aquatic, but finally small floating leaves are sent up. Each one bears one or more adventitious roots at the base. The petioles of all the earlier leaves are winged and clasping at the base; no stipules are developed until later.

The plantlet being thus pretty well established, the primary root ceases to function and soon dies away. As the nutriment is baled out from the seed, the central portions of the cotyledons are first emptied, then their outer parts, and then the endosperm. Finally the solution of the perisperm begins at the end next to the embryo and works steadily back until the supply is exhausted. The nutriment furnished to the young plant, therefore, is at first highly proteinaceous, and at the last wholly carbohydrate. The cotyleclons remain of the same size as before germination, or very nearly so. When the seed has been emptied of its food, the epicotyl shrivels and dies as the primary root did before it (Fig. 49, I, 6). 
The internodes above the epicotyl are not developed, but the stem gradually thickens and enlarges into a miniature tuber. In nearly all of the genus the plant is now essentially mature; it needs only to enlarge. But in Eu-castalia a marked change takes place. The internodes after a time
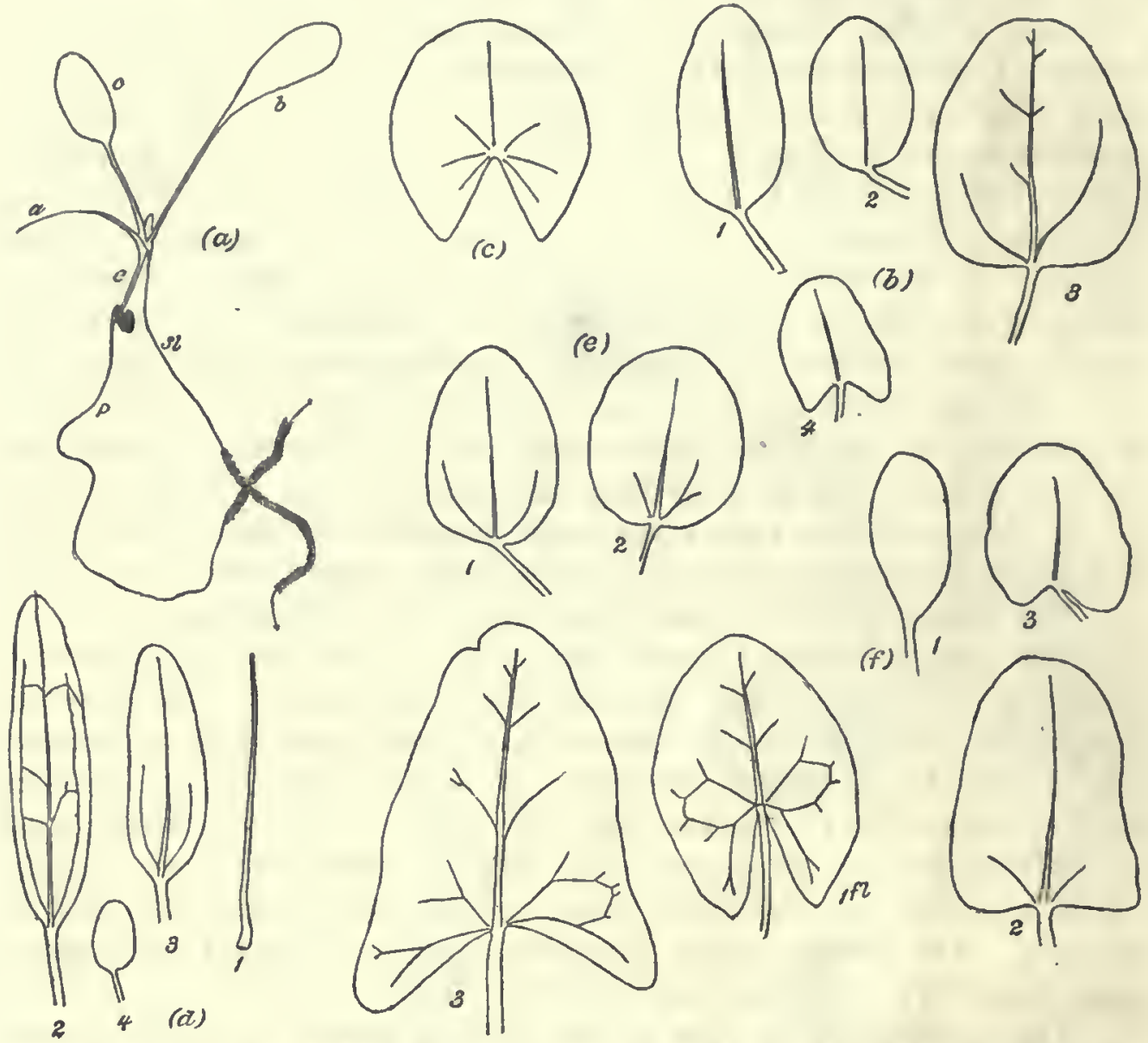

FIa. 50 -Seedling lcaves: (a), $N$ amazonum; $a$ first leaf; $b$ sccond (first broad) leaf; $c$, third leaf ; $e$, eplcotyl; $p$, primary root; 8 , first secondary root; $(b), N$. caerulea; $1,2,8,4$, first and following broad leaves; (c), first floating leat, N. odorata gioantea; $(d), N$. lotus var., $1,2,3,4$, first and following leaves, the list very young: (e), $N$. zanzlbariensis; $1,2,8$, first and following broad loares; $(f), N$. tetrayona, 1, 2, 3, first and following broad submerged leaves; $1 \pi$, first floating leaf. Twice natural size.

regularly, but slightly, elongate, and the stem suddenly becomes plagiotropic; thus a tiny horizontal rhizome is produced. From this point onward maturity is simply a matter of size.

In structure the characteristic features of the order are evident at a very tender age. While the primary root is still a mere papilla, the rootcap consists of a single layer of cells, and behind it are three to four close 
layers of meristem cells ; immediately back of these, large intercellular spaces abound. 'The epidermis of the primary and early adventitious roots differs from all mature rootage in having a copious supply of roothairs (Fig. 49, 2, 5). It will be recalled that root-hairs are generally said to be wholly lacking in Nymphaea, Nuphar, Euryale, and Victoria. As we have observed them in $N$. dentata, lotus, caerulea, zanzibariensis, amazonum, elegans, odorata, capensis, and hybrids, they are doubtless universal in the genus. On one occasion also they were found on early roots of a plant springing from a tuber of $N$. caerulea. Victoria lacks them even on the primary root. The epidermal cells of the early roots (in $N$. dentata) are long and rectangular in surface view, and about as deep as wide; where root-hairs occur, however, they spring from cubical cells. No shedding of epidermis occurs in these roots. The root-cap is long and thimble-shaped.

Inside the epidermis there are in the primary root about six layers of thin-walled cortex cells and a small (diarch?) vascular bundle. The adventitious roots are like this, but successively larger. In the earliest of these the diarch bundle is quite plain and is surrounded by a distinct endodermis; the two xylem patches are continuous across the middle of the bundle. The appearance of the central vascular strand of the hypocotyl and lower part of the epicotyl is exactly the same as this, but it is described here as "two opposite bundles with their xylems confluent" (cf. Gwynne-Vaughan, 1897). A short process of procambial cells extends toward the base of each cotyledon, but no vascular tissue extends into them. They are composed of elongated thin-walled cells, and have a rather narrow insertion. The bundles of the stem are turned with their sides toward the cotyledons, i. e., a line connecting the bases of the cotyledons would pass through the confluent xylem and between the phloem masses. Higher up in the epicotyl the two bundles become more distinct, and each, instead of being semicircular in section, is nearly round; the xylems are still in contact, though torn asunder to leave an irregular aircanal in the middle. The first two leaves are placed opposite the phloems of the two bundles and at their point of insertion the vascular system spreads out toward them on each side. In close succession the bundles of the first adventitious root, the acicular leaf, the first broad leaf, and the second root and broad leaf join the widened portion of the system, with anastomoses across from bundle to bundle. Each of the above-named organs has a single bundle. No central strands exist above this, but the bundles spread out through the now fleshy stem on their way to the various organs. The communication from vessel to vessel which easily 
occurs in ordinary plants by reason of their proximity is made possible in these thick stems with widely separated bundles by the profusion of crossbranches. Gwynne-Vaughan (1897) noticed in the center of the young stem of $N$. zanzibariensis a cylinder of meristem tissue suggesting a stele, in which later desmogen strands were differentiated. He evidently considered this as furnishing a kind of transition from the "monostelic" epicotyl to the "astelic" stem.

The epidermis of all parts of the plant above the cotyledons, excepting the upper surface of the leaves, is supplied with mucilage hairs. In $N$. flava these are so numerous on the acicular leaf as to make a plainly visible coating of jelly all over it, as is seen on petioles of Brasenia. The

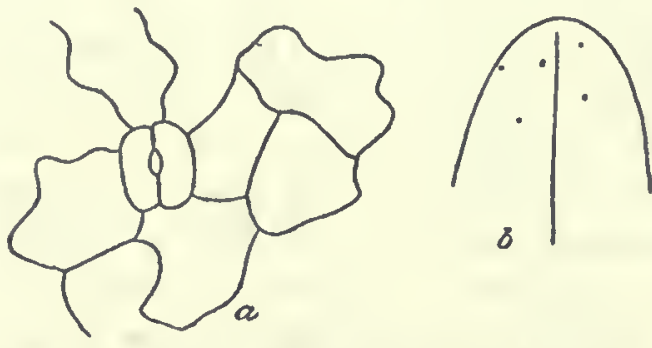

Fic. 51.-First broad (submerged) leaf of $N$. lotus seedling: $a$, stoma in upper epidermis; $b$, portion of tip of leaf, showing distribution of stomata by dots. hair-bases remain on the full-grown parts as in mature plants. The inner tissues are very loose throughout. In the epicotyl the intercellular spaces are often as large as the rounded cortex cells. The acicular leaf is similarly constructed. The first broad leaf of $N$. dentata has four well-developed air-canals in the petiole; the second has six canals, which are at first of almost equal size. The lamina of these leaves is extremely thin and fragile. Stomata are found scattered over the upper surface in $N$. lotus (Fig. 5 I), caerulea, elegans, amazomum, zanzibariensis, and capensis, but I failed to discover any in $N$. odorata or rubra; probably the observation is at fault, for they are at best rather difficult to see. The best success was had with material fixed in chrom-acetic acid and mounted in balsam; probably Wächter's (1897) chloral hydrate method would prove equally effective. The palisade-layer of these leaves is reduced to a single layer of hemispherical cells against the upper epidermis. Between these and the lower epidermis there are branching partitions two cells high, enclosing large air-spaces (Constantin, 1886). The venation is very simple.

Between the bases of the second and third leaves a few long protective hairs appear as on the adult stem-apex. The young stem is at first devoid of lacunar tissue; its fundamental parenchyma consists of rounded cells in which starch is rapidly deposited. From this time on the plant is in a position to go into a state of rest on any emergency. 


\section{CHAP'TER IV.}

\section{PHYSIOLOGY.}

Special observations on the physiology of waterlilies are not numerous. That such plants have the usual "senses of direction"-geotropism and heliotropism-goes without saying. The primary and adventitious roots are all alike highly sensitive to gravitation at first, but the latter soon become more or less passive and run obliquely downward, while the secondary and tertiary roots ramify throughout the soil from its surface to a depth of $30 \mathrm{~cm}$. or more. The peculiar type of root spoken of on a previous page as "contractile" exhibits a striking physiological adaptation. Such roots have been found only on young plants of the Lotos and apociarpous groups, excepting $N$. flavo-virens, in which adults also have contractile roots. In all of the plants mentioned, however, resting tubers are produced at the close of the season. The object evidently is to draw these tubers well down into the earth for protection against drought and herbivorous animals. For the adult plants, with the one exception named, perish when the flowering season is over, and consequently are not supplied with any special contractile organs. $N$. flavo-virens $\times$ zanzibariensis bears a few contractile roots on the lower part of the tuber of adult plants. This hybrid usually has persistent tubers as in $N$. flavo-virens; its contractile roots, however, show none of the peculiar structure which characterizes those of $N$. flavo-virens. As a rule it is the lowest (oldest) root from each of the older leaf-bases which is contractile; in $N$. lotus one or two upper roots occasionally contract. This lowest root is strongly geotropic, while the others are rather feebly so. It also persists in a living condition after all of its companion roots have completely rotted away. After contraction it becomes fusiform in shape. The greater density of the cortex in contractile roots indicates that this is the layer where contraction takes place, probably, as Rimbach (1902) has shown for liliaceous plants, by shortening and widening of the cells. Thus we see a strong differentiation, apparently greatest in $N$. flavo-virens, into nutritive and mechanical roots.

In stems the great density of tissue in all but the Castalia group, and especially in resting tubers, has already been shown. This is distinctly related to the storage of starch which takes place so largely in such plants. 
I know of no experiments upon the geotropism of stems outside of the Eu-castalia group. Among these plagiotropism is very pronounced. A stem of $N$. odorata $3 \mathrm{~cm}$. in diameter and $10 \mathrm{~cm}$. long planted upright in a pot in early spring had turned its apex to a horizontal position by mid-summer.

Young petioles and peduncles of different species turn through $90^{\circ}$ in the course of twenty-four hours if placed in a horizontal position. This tendency is, of course, well developed in all species. The leaf-stalks and flower-stalks, however, are often so slender that their positions are mostly passive, except at the ends. The buds in Castalia, and the leaves in all species, by their buoyancy make their way to the surface of the water unless opposed by other forces. We have already noted that the leaf in coming up through the water has its midrib in a straight line with the petiole, and on reaching the air the petiole bends over at the top nearly at right angles to the lamina (Frank, I872). That this is not a purely passive condition is shown by the stiffness and turgidity of the organs. Also, when plants are moved close together or placed in small tanks, where the upper parts of the petioles are thrown out of their former directions, they bend the lamina down until it is more or less submerged. In the course of twenty-four hours, however, the leaf is again lying flat upon the water surface. A corresponding bending has taken place in the upper part of the petiole. This bending may be due simply to readjustments of a mechanical kind in the elastic collenchyma of the petiole, or it may be the result of a distinctly vital action. In the latter case it is related to the phenomena next to be described.

It has been noted that the "length of the petioles and peduncles depends upon the depth of the water in which the plant is growing." Not only is this true for plants in different localities, but a given plant, if moved from shallow into deeper water, where all of its leaves are submerged a few centimeters, will be found on the following day with all its leaves floating in the normal manner. Plants moved from deep to shallow water need no adjustment except in the angle between the petiole and lamina ; but leaves produced afterward have petioles only long enough for the new conditions. Now, it is certain that throughout the life of a leaf its petiole is continually growing longer, even though the water level remains constant. This is necessary in order to make room for the new leaves which are rising in succession from the center of the plant. One need only look at a large plant of any tropical Nymphaea as grown in gardens to be convinced of this. We see an area ten or twelve feet in 
diameter covered with the foliage from a single well-grown specimen. If the gardeners have not been too careful we see that the outer border of this ring is occupied by yellow and decaying leaves on very long petioles. Within these comes a zone of large green and shining healthy leaves, then smaller tender ones, and, at the center, one or two are only partly unrolled from the bud. The rate of elongation of a petiole of $N$. rubra detached from the parent plant was $2.5 \mathrm{~cm}$. per day. This, with perhaps a certain amount of stretching of the collenchyma and softer tissues, may account for the rise of leaves on plants moved from shallow to deeper water, but it does not reach the case of adjustment from deep to shallow water. Frank (1872) investigated the causes of this phenomenon, giving especial attention to Hydrocharis morsus-ranae, and concluded that gravitation (as expressed by water pressure) and light, though not the causes, are used by the plant as signs by which to measure how much it has yet to accomplish before a growing organ has reached its most advantageous position ("Gravitation und Licht sind nicht die Erreger jener Wachsthumsformen, sondern die Pflanze bedient sich ihrer nur als Merkmale, an denen sie abmisst, wieviel sie noch zu leisten hat, bis das durch Wachsthum zu richtende Glied seine vortheilhafteste Lage erreicht hat." p. 85). The expression is an excellent one, even if the "signs" are insufficient. For is it not so with all stimuli and all organisms? No external stimulus is in itself a final cause of any physiological action; that is, the irritability of protoplasm is the indispensable condition of all vital functions. Karsten (1888), experimenting on Hydrocharis and Ranunculus sceleratus, showed the insufficiency of Frank's explanation, and proved that it is the oxygen of the air which inhibits the growth of the petioles as soon as the leaf-blade reaches the surface of the water ("--dass es der Sauerstoff der Atmosphäre ist, welche bei den Schwimmblättern jene constatirte Hemmung im Wachsthum ihrer Stiele bewirkt, sobald sie die Wasseroberfläche erreichen." p. 577). In Nymphaea, however, the inhibiting influence of the air still permits the slow elongation of the petioles by which the older leaves are moved farther and farther away from the center of growth.

Once spread out upon the water surface, the leaves are subjected to the stress of currents in air and water. Jahn (1896) pointed out four requirements for such foliage: (1) lightness and firmness of lamina; (2) the greatest possible amount of surface ; $(3)$ insertion of petiole at center of leaf; (4) the petiole must make a large angle with the lamina. The first is attained by the great amount of air space, and in Lotos and Apocarpiae by the girder-like veins. But in strong winds the leaves are often 
raised up at one edge or blown completely wrong side up. The toughness of the lamina prevents its tearing. Breadth of leaf surface is carried to its ultimate extent in the circular leaves. The larger the leaves the less easily they will be overturned, and a further need will be appreciated when it is noted that waterlilies must have all of their foliage in one plane; a distribution in space of three dimensions is not available to them. That the rounded outline has been acquired by a backward extension of the basal lobes of the leaf is due to the third condition. A round lamina with marginal attachment of the petiole is quite a possible thing. But if such a leaf were to exert any tension upon its anchorage, the effect would be to submerge the basal portion. The central attachment obviates this difficulty; and peltation is a further advance toward the same end. Various other adaptations of the plant in irritable response to its peculiar environment have been referred to in previous pages. A number of interesting activities of the floral parts will be described shortly.

The nutritive relations of waterlilies have not been specially worked out. They require a large amount of nitrogenous food, as every cultivator can testify, but prefer it in the form of nitrates rather than ammonia: Excess of calcium, as in limestone waters, is not beneficial. Doubtless these substances are absorbed with water by the roots directly, since no root-hairs are present. And the importance of the roots is shown by the great reduction in vigor of plants when moved from one pot to another, though they soon regain their strength. Wächter (1897) has shown, however, that complete removal of the roots is less injurious than removal of the leaves. Water is also absorbed elsewhere than at the roots. A leaf of $N$. rubra $35 \mathrm{~cm}$. across, severed from the parent plant and left floating in the water, with the end of the petiole tied to a stick above the water level, not only remained apparently healthy for three days, but grew $1.3 \mathrm{~cm}$. in diameter, and its petiole elongated $6.3 \mathrm{~cm}$. Whether or not this leaf was transpiring moisture through the stomata I cannot say; but that a large amount of transpiration occurs from waterlily leaves was shown by a small tank in my father's garden. This was a water-tight iron vessel four feet square, and the surface was almost completely covered with leaves so that very little free cvaporation could occur. After every clear summer day it was necessary to add one to three buckets of water to keep the level constant. So reduced is the xylem in the petioles that one questions how and where any sap can ascend. Some have thought the small air-canals in the vascular bundles are filled with liquid, but we find no evidence of this. But, in a leaf placed with the end of the petiole in 
watery eosin, the phloem portions of the bundles were stained as though the coloring matter had traveled up in them. The whole subject of the course of water in aquatic plants needs investigation.

Respiration is to be looked upon as causing some of the most characteristic structures of water plants, namely the air-canals. In August, 1867, Lechartier experimented on $N$. alba as it grew naturally in the rivers. He found that on cutting off a leaf just below the water surface a flow of gas takes place from the air-canals of the petiole. This flow continues throughout the day, ceases at dark ( $7 \mathrm{p} . \mathrm{m}$.), and begins again the next morning (8.30 a. m.). It may continue even against a pressure of $26 \mathrm{~cm}$. of water, and after all of the leaves have been cut off the plant. In one instance $220 \mathrm{cc}$. was collected from a single petiole in an afternoon, and in another $262 \mathrm{cc}$. The total amount of gas from a single plant was I,028 cc. in fifty-three hours. In these plants all of the leaves were submerged during the experiments. A plant with several floating leaves was next used. A petiole was cut off near the leaf, and when held I $\mathrm{cm}$. below the water surface no gas came out; when raised in a closed inverted tube of water $10 \mathrm{~cm}$. above the surface of the river, the flow amounted to $600 \mathrm{cc}$. in fifteen minutes. This gas was tested in portions of $60 \mathrm{cc}$. collected successively, and at three times of day, as follows :

The first, fifth, and tenth portions of air contained-

\begin{tabular}{|c|c|c|c|c|c|c|c|c|}
\hline & \multicolumn{3}{|c|}{$\Delta \mathrm{T} 6.30 \mathrm{A.} \mathrm{M}$. } & \multicolumn{3}{|c|}{$\Delta T 11.30$ A. M. } & \multicolumn{2}{|c|}{ AT 2.30 P. แ. } \\
\hline & I. & v. & $\mathbf{x}$. & I. & v. & $\mathbf{x}$. & I. & v. \\
\hline $\begin{array}{c}\mathrm{CO}_{2} \\
\mathrm{O} . \\
\mathrm{N} .\end{array}$ & $\begin{array}{l}\text { I } \\
7 \cdot 7 \\
91 \cdot 3\end{array}$ & $\begin{array}{c}3 \\
8.1 \\
88.9\end{array}$ & $\begin{array}{r}2.5 \\
8.2 \\
89.3\end{array}$ & $\begin{array}{c}0.5 \\
9 \\
90.5\end{array}$ & $\begin{array}{r}2.5 \\
9.7 \\
87.8\end{array}$ & $\begin{array}{r}2.4 \\
9 \cdot 7 \\
87.9\end{array}$ & $\begin{array}{r}0.5 \\
16.8 \\
82.7\end{array}$ & $\begin{array}{c}2 \\
10 \cdot 7 \\
87 \cdot 3\end{array}$ \\
\hline & 100 & 100 & 100 & 100 & 100 & 100 & 100 & 100 \\
\hline
\end{tabular}

From these figures it appears that the air drawn out last at each period $(\mathrm{V}, \mathrm{X})$, and therefore probably from the stem and roots of the plant, contains more carbon dioxide than that in the petiole, and that the oxygen content of the inclosed air increases greatly while the plant is exposed to sunlight. At best, though, the proportion of oxygen present is much less than in atmospheric air. It appears also from the first experiments that the gases are not necessarily, if at all, derived directly from the air. Barthélemy (1874) attempted to repeat Lechartier's work, but found that the flow of gas diminished rapidly after the first gush; he 
therefore believed the flow to be due to a higher pressure in the plant than outside. He agreed with Lechartier in believing that there is a movement of gases in the air-canals of Nymphaeaceae toward the leaf, to make exit through the stomata, and concluded that stomata in general are for the exit rather than for the entrance of gases. Goebel's (1893) experiment seems to differ from these. On a dull autumn day petioles of N. rubra and stellata (?) were cut off under mercury near the water surface and held as nearly as possible erect. The smaller intercellular spaces became in every case injected with mercury up to the lamina, even in pieces $60 \mathrm{~cm}$. long. This would indicate a considerable negative pressure. Recognizing the positive pressure as noticed by Sachs (though without mention of Lechartier or Barthélemy), Goebel concludes that when the amount of assimilation is slight there is a rarefaction of air in the canals caused by the continuance of respiration; but when assimilation is active, part of the oxygen is given off into the intercellular spaces, and reaches the air-canals and finally extends to the rhizome and root. This view at once harmonizes the observed phenomena and explains the presence of the air-canals. It is the more plausible when we consider the peaty soil in which our waterlilies grow and the general absence of free oxygen in submerged muddy material.

Since the behavior of the flowers has for its object the successful reproduction of the species, and since there is in this connection a very distinct series of movements and activities, the whole relation of these parts has been reserved to this point, although there would be good reason to take them up under the head of irritability. The rise of the flower bud from the rhizome to the surface of the water takes place in the same manner as that of the leaf, and the peduncle must be regulated in length by the same stimuli that regulate the petiole; it is even capable, in Castalia, of a slight elongation if the water level rises after the flower first comes into bloom. A peculiar adaptation occurs, on the other hand, in plants of any species, when grown in very shallow water, say 10 to $15 \mathrm{~cm}$. This often occurs in our gardens, where we have the tropical kinds as near to the surface as possible in order to keep them warm. Now, the flower bud is first pushed out from the apex of the plant in a very immature state, and it is to finish its development as it is rising through the water. In very shallow water, therefore, it reaches the surface when it is by no means ready to be exposed to the air. The situation is recognized at once by the plant, and the peduncle bends to one side and becomes S-shaped 
(Fig. 52); thus the bud maintains its erect position and is kept submerged. Then in due time, the bud having matured and the peduncle having reached a suitable length, the latter straightens up and lifts the former into the proper position for opening. In $N$. flavo-virens, where I have noticed this most plainly, the flower stands about a foot above the water.

The opening of the flower occurs at a particular time of day for each species:of Nymphaea. Indeed, we have attempted in the accompanying

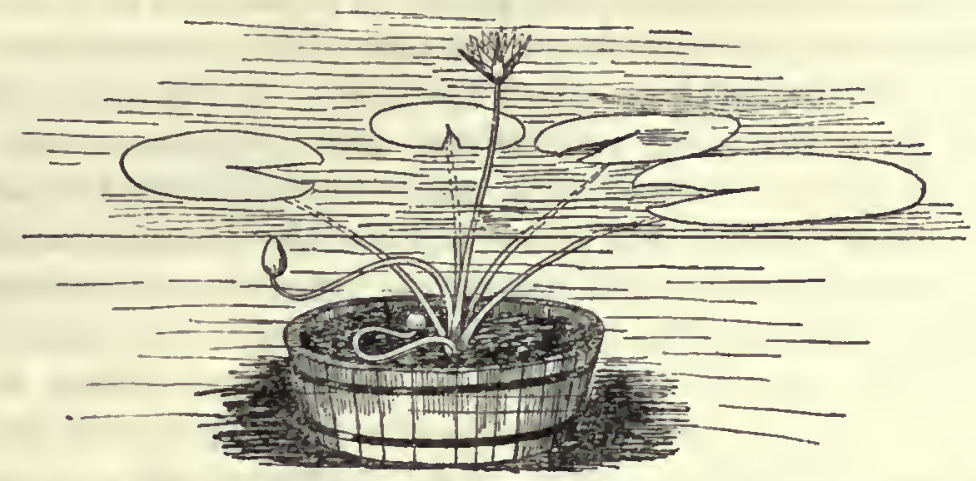

FiG. 52.-A strong-growing waterilly in shallow water.

list * to imitate Linnaeus's floral clock in this genus alone. After remaining open a few minutes ( $N$. amazonum) or hours, the flower closes at a certain time, and this is repeated on two $(N$. flava) or three $(N$. odorata, caerulea, etc.) to six or seven $(N$. gigantea) successive days. This is the foundation on which was based the statement of Pliny and others that the flowers retreat under water at night. The process of opening and closing usually occupies nearly an hour. On its first day the flower always opens

* Floral clock for the latitude of Philadelphia $\left(40^{\circ} \mathrm{N}\right.$.).

\begin{tabular}{|c|c|c|c|}
\hline $\begin{array}{l}3-1 \mathrm{~s} . \mathrm{m} . \\
-5\end{array}$ & $\begin{array}{l}\text { N. amazonum (new flower) opens. } \\
\text { N. amazonum (old flower) opens wide. }\end{array}$ & $12-1$ p. m. & $\begin{array}{l}\text { N. odorata, tuberosa, caerulea, and ele- } \\
\text { gans close. }\end{array}$ \\
\hline 6- 6 & N. amazonum closes; N. marilacea car- & $1-2$ & N. alba candidissima closes. \\
\hline \multirow{3}{*}{$a-7$} & $\begin{array}{l}\text { nea opens. } \\
\text { N. alba candidissima and odorata minor }\end{array}$ & $2-$ & $\begin{array}{l}\text { N. elegans } \times \text { zanzibariensis and marliacea } \\
\text { chromatella close. }\end{array}$ \\
\hline & open. & $3-4$ & N. mexicana closes. \\
\hline & $\begin{array}{l}\text { N. graclls and elegans } x \text { zanzibartengis } \\
\text { open. }\end{array}$ & $4-8\}$ & $\begin{array}{l}\text { N. capensis Xzanzibariensis closes. } \\
\text { N. tetragona, gracilis, and Pennsylvania }\end{array}$ \\
\hline \multirow[t]{2}{*}{$7-8$} & $\begin{array}{l}\text { N. elegans, capensis, and caerulea } \times \text { zan- } \\
\text { zibarlensis open. } \\
\text { N. caerulea, marliacea chromatella, and }\end{array}$ & $5-6$ & $\begin{array}{l}\text { ciose. } \\
\text { N. capensis, zanzibariensis, and zanzi- } \\
\text { barlensisx close. }\end{array}$ \\
\hline & tuberosa open. & b- & \\
\hline $8-8$ & $\begin{array}{l}\text { N. marliacea chromatella (new flower) } \\
\text { opeas. }\end{array}$ & $7-8$ & $\begin{array}{l}\text { N. dentata and omarana open. } \\
\text { N. amazonum (old flower) opens sepals. }\end{array}$ \\
\hline $2-10$ & $\begin{array}{l}\text { N. capensis Xzanzibarlensis opens. } \\
\text { N. zanzibariensis X opens. }\end{array}$ & $8-8$ & $\begin{array}{l}\text { N. rubra, rubra rosea, and devoniensis } \\
\text { open. }\end{array}$ \\
\hline \multirow[t]{2}{*}{$10-11$} & N. mexicana opens. & & \\
\hline & $\begin{array}{l}\text { N. rubra and rubra rosea close. } \\
\text { N. tetragona and zanzibariensis open }\end{array}$ & $\left.\begin{array}{l}10-11 \\
11-12\end{array}\right\}$ & N. rud \\
\hline & N. omarana closes. & & \\
\hline
\end{tabular}


about an hour later than on subsequent days, closes earlier, and spreads but half as wide. An exception to this must be made for $N$. amazonum, whose very peculiar habits are detailed in the description of the species. $N$. rudgeana has also shown a very short nocturnal period of opening. Observations on other Hydrocallis species would undoubtedly yield interesting results. The characteristics of each species, so far as known, are given in the taxonomic chapter.

The stimulus to these actions is to be attributed, in diurnal species at least, wholly to light. If plucked and taken into a room they rapidly close, even though the normal time has not come. On the following morning, however, they reopen even in a very dimly lighted room. Subsequent movements of the cut flower soon become irregular, and it finally ceases to move. This is probably due to the death of the protoplasm in the sensitive or motor centers, though the flower may remain open without wilting for some days. That light is the normal stimulus is also shown by the earlier opening of the flowers in more northern latitudes. Thus Kerner (1 895) gives $7 \mathrm{a} . \mathrm{m}$. as the time for opening of $N$. alba at Upsala, and 8 to 9 a. $\mathrm{m}$. at Innsbruck, $13^{\circ}$ farther south. Heat seems to have no effect upon the Eu-castalia group in ordinary atmospheric quantities; for the time of opening and closing remains the same on days and nights when the mercury is continually above $80^{\circ} \mathrm{F}$. and on cool, cloudy days when the temperature does not rise above $65^{\circ} \mathrm{F}$. In tropical species as grown out of doors in our climate heat does have a marked effect. One evening in I 900 , when the mercury registered about $95^{\circ} \mathrm{F} ., N_{\text {. }}$ zanzibariensis remained open nearly an hour later than usual; and in autumn, when the night temperature reaches $40^{\circ} \mathrm{F}$. and the plants are looking the worse for wear, the diurnal tropical species become very irregular and open but a little way. The conclusion to be drawn is that the plant itself must be in a certain condition of health or tonicity to enable its parts to perform their functions. The effect of heat is essentially systemic rather than local. In Lotos it seems likely that heat may have a more distinct influence upon the flowers, but it is still obscure. They do not close until the heat of the sun is making itself felt, but on exceedingly hot nights they open to perfection, and on much cooler days they close at the usual time. But when the cold of autumn injures the plants, they sometimes remain open two or three days and nights continuously. On one occasion at Riverton, N. J., I saw about sixty large flowers of this type cut in the morning and placed in jars of water in a shaded glass house; they closed very slowly and incompletely. We must conclude, therefore, that light is again the 
principal stimulus, causing in these closure, in other species opening, of the flower. The difference in effect is paralleled in positive and negative heliotropism and positive and negative geotropism. The influence of different colors of light has never been tried. Chemical stimuli were used by Tassi (1884). He found that flowers of $N$. alba and other plants were unable to perform their movements under the influence of anæsthetics, and in şome plants the color changed.

The large and showy flowers of waterlilies are in many ways designed for the visits of insects. The colors are mostly conspicuous and attractive. $N$. caerulea is comparatively insignificant; and $N$. rubra makes very little showing at night, but in the early morning it is magnificent. $N$. rudgeana, according to Caspary ( 1878 ), is often cleistogamous. The possibility of such a thing is suggested by its regular occurrence in Euryale; and $N$. amazonum, with its odd habits, may well be considered as approaching the same condition. Certain it is that close pollination occurs regularly in this species. In cold weather, too, the flowers of $N$. amazonum seem to be fertilized without ever rising to the water surface. The occurrence of similar irregular cleistogamy in $N$. rudgeana may have been due to unnatural conditions. Observations are totally lacking on Hydrocallis species in their native haunts.

In Castalia and Apocarpiae the flowers have a sweet ethereal odor. This is richest and most delicious in $N$. odorata, faint in $N$. tetragona, scarcely perceptible and only present on the first day of opening in $N$. alba. The Lotos and Hydrocallis groups have very little odor; in the latter it is pleasant and ethereal, but in the former it is dull and rather offensive. The flowers are always pistillate on the first day of opening, and the stigmatic cup is filled nearly to overflowing with a large quantity of slightly sweetened water. This is excreted by the stigma itself and by the axile process. The stamens at this time stand erect around the stigma, leaving a narrow vertical pit in the center of the flower, bounded all over the sides by the still closed anthers of stamens of different lengths. All the stamens are stiff in Lotos, but in Castalia the innermost filaments are very slender and flexible, scarcely able to hold up the heavy anthers. The carpellary styles also stand erect. In flowers of the second and later days the stigma is quite dry and the papillae shriveled (in $N$. odorata and tuberosa; Robertson, r889), though in $N$. alba, according to Schulz (r890) still receptive. The carpellary styles, when long enough, have bent inward over the stigma until they lie horizontally or point downward, and the inner stamens meet in the middle so as more or less to hide the pistil. The 
stamens now dehisce. Where the flower is open only for two days, as in Xanthantha, all of the stamens dehisce on the second day, but the outer ones precede the inner by a few hours. In the rest of Castalia the inner stamens dehisce on the second day of opening; they do not completely cover the entrance to the stigma from above, but they hang over far enough to drop their pollen upon it, and sometimes close fertilization occurs. In Brachyceras, as a rule, the entrance to the pistil is totally obstructed on the second day by the inner stamens, and the outer ones are dehiscing; subsequently the inner stamens bend outward and dehisce until, on the last day, the passage to the stigma is wide open again. In spite of this, $N$. caerulea and stellata are said by Caspary (1877) to be capable of self-pollination, the latter while still in the bud. The stiff stamens of the-Lotos group dehisce simultaneously on the second day, and undergo no considerable change of position.

The exact manner of effecting cross-pollination and the insects concerned are unknown for the Lotos group, but the white and light-pink varieties are extremely fertile when grown out of doors in the vicinity of Philadelphia. The agency of insects in Hydrocallis is likewise undetermined. $N$. alba is, in the opinion of Delpino, fertilized by scarabaeid beetles (Cetoniae and Glaphyridae); he regards Nymphaea and Victoria as especially adapted for beetles. Kirchner, in his "Flora von Stuttgart," page 275, mentions "flower-beetles" as visitors (fide Müller, 1883, p. 93 ; Schulz, I890), and Picciola found Donacia (a chrysomelid beetle) abundantly. But Schulz found $N$. alba perfectly fertile with its own pollen, and considered that the flies and beetles which visit it always cause close fertilization. $N$. tuberosa is visited by small mining bees (Andrenidae), flower-flies, and beetles (Robertson, I 889 ), and $N$. odorata by Halictus and others. In our own experience, mining bees and flower-flies are the only insects found. They are drowned in large numbers in the stigmatic fluid, and are found in the closed flowers after anthesis. In a single bloom of $N$. capensis $\times$ zanzibariensis I once counted thirty-two little bees! Bacon (1874) noticed dead insects in $N$. odorata and supposed that they were caught by the closing of the flower; Delpino attributed their death to the heavy odor of the flower, and Planchon to the accumulation of carbon dioxide in the floral cup (fide Robertson). But Robertson is undoubtedly correct in considering it simply a case of drowning. The course of events is about thus: The insects which visit the flowers are in search of the copious pollen; no true nectar is secreted. The earliest flowers to open each day are the older ones, in which pollen is plentiful and the stigma is dry. The insects fly 
from flower to flower in safety gathering their loads. When an hour later the new flowers open with their receptive stigmas, the insects are well dusted over. Coming to the narrow opening of the new flower, they rush in with confident haste; but reaching the slender inner stamens, these bend down under the weight, and the visitor is dropped into the pool of liquid in the stigmatic basin. As he struggles to get out by crawling up the styles, he must again lay hold of the treacherous inner stamens, and be again let down into the water. Thus pollen is washed off the bee into the fluid, and the need of the plant is met; it is a matter of strength and endurance on the part of the visitor whether or not he gets out alive. When the stigmatic fluid is absorbed, the pollen grains settle down among the papillæe and are in a position to germinate. In some species a considerable amount of heat is evolved in the newly opened flower, but never in anything like the quantity found in Victoria regia.

On the last day of opening the flower begins to sink back into the water again. In Hydrocallis it takes but 2 to 5 hours for the closed flower to become totally submerged; in $N$. odorata it requires 6 to I 2 hours, and the flower remains nearly wide open. In Lotos and Brachyceras also the flower often sinks while still open, but on its last day it has already moved down near to the water surface, and is not totally submerged until i 2 to 20 hours later. The submergence of the flower is due to active, even powerful, movements of the peduncle, and occurs most pronouncedly in fertilized flowers. Infertile flowers scarcely get below the surface of the water, and then quickly disintegrate; sometimes the peduncle decays before the floral parts, showing how great is the transmitted effect of fertilization. Under the most favorable circumstances only about half of the ovules proceed with development to form mature seeds, but the presence of Io or I 2 fertile ovules in each cell of such fecund species as $N$. lotus or caerulea is sufficient to stimulate the movements of the peduncle. In Lotos the peduncle simply bends over and carries the flower down, and the ripening fruit lies on its side. In $N$. amazonum there is a double curve, so that the ripening fruit is upright. But in other species more or less of spiral coiling accompanies the bending. The stout peduncles of Brachyceras descend in the same manner as $N$. amazonum, but there is in addition a strong curving of the lower half of the peduncle to the right or left. The result is that we find the fruits near the bottom of the water, I 5 to $35 \mathrm{~cm}$. away from the crown of the plant and on the opposite side from the point of insertion of the fruit-stalk. $N$. flava in shallow water (15 cm.) makes the same kind of a bend; as the stalk is more slender, the bends are sharper and the 
fruit is pressed close against the mud. N.tetragona resembles $N$. flava in these respects. In deep water (I to 5 meters) $N$. flava, odorata, alba, and tuberosa carry the spiral turning to its highest development. From a few centimeters above the rhizome to within a few centimeters of the flower, the peduncle is coiled into a close helix from 2 to 8 centimeters in diameter, and with 2 to 8 or ro turns; thus the fruit is drawn down within about half a meter of the bottom of the water, and often quite into the mass of algx and other vegetation overlying the mud. Just such an adaptation has given the specific name to Vallisneria spiralis. Besides removing the fruit from the drying influence of the air, the purpose of these movements is doubtless twofold: First, to hide the fruit from the many aerial, aquatic, and amphibious animals which might feed upon it, for the majority of such creatures get their food at the surface rather than in the depths of the water; secondly, to reduce the danger of the fruits being broken off, as would easily occur with the long, slender peduncles of Castalia. 


\title{
CHAPTER V.
}

\author{
TAXONOMY.' \\ Genus NYMPHAEA (Linn.) J. E. Smith.
}

Generic diagnosis-Sepals 4 (rarely 3 or 5 ), inferior. Petals many ( 2 to 40 ), multiseriate, the lowest alternate with the sepals. Stamens many ( 20 to 700 ), multiseriate, inserted above the petals on the upraised torus which surrounds the carpels; outer filaments broader, often petaloid; innermost slender or filiform; anthers introrse, bilocular. Carpels many ( 8 to 35 ), sunk in the cup-shaped, fleshy receptacle, fused dorsally with it, and produced above it into shorter or longer processes, the carpellary styles (except in Sec. Anecphya); margins of carpels fused centrally with the floral axis, which extends above them as a short axile process. Stigma broad, concave, radiate. Ovules very many, anatropous, pendulous from the sides of the ovary cells. ' Fruit a spongy berry, ripening under water and bursting irregularly. Seeds with a floating sac-like aril, open at the apex; endosperm very small; perisperm copious. Embryo small, straight.

Aquatic herbs with perennial elongated or tuberous rhizome, rooting in mud at the bottom of ponds, streams, etc.; leaves floating, ovate to orbicular, fissi-cordate, 5 to $60 \mathrm{~cm}$. in diameter ; flowers solitary, showy, floating or raised above the water on stiff scapes, 2.5 to $30 \mathrm{~cm}$. in diameter, white, blue, red, or yellow, in all shades.

Founded by Smith on $N$. alba $\mathrm{L}$.

Nymphaca, Tournefort 1700 , in part. Linnaeus 1753, in part.

Nymphaea, J. E. Smith 1809 . DeCandolle $1821 b$, 1824. Planchon $1853 b$. Lehmann $1853 a$. Caspary 1855, 1865, etc. Bentham \& Hooker 1862. Gray, etc. Not Salisbury I806a.

Caslalia, Salisbury $1806 a$. Greene $1887 a$ and $b$, I888. Britten $1888 a$. Lawson I889. Britton \& Brown 1897 .

Leuconymphaca, Ludwig 1737. Kuntze 1891. MacMillan I892.

Nymphea, Rafinesque 1830.

1 This chapter, together with most of the bibliography at the end of Chapter VIII, was submitted to the University of Pennsylvania in partial fulfillment of the requirements for the degree of Doctor of Philosophy, May I, I90I. At that time I had placed the members of the Lotos group in a single species, $N$. lotus. The separation of these into three distinct species, the fusion of $N$. flava and $N$. mexicana, the addition of some African species, and the substitution of " $N$. Alavovirens" for "N. gracilis" are the only material changes made since that time. A few citations and measurements have been added in several species. 
In order to present a tabular view of species and subgenera the following synopsis and key are inserted. The genus Nymphaea divides readily into two main divisions, which are subdivided into five subgenera.

Group I. Nymphaeae apocarpiae. Subgenus (1) Anecphya. (2) Brachyceras.

Group II. Nymphaeae syncarpiae. Subgenus (3) Castalia. (4) Lotos. (5) Hydrocallis.

\section{Analytic Key.}

Carpels free at sides, i. e., walls between ovary cells double (Fig. 40) (Nymphaeae

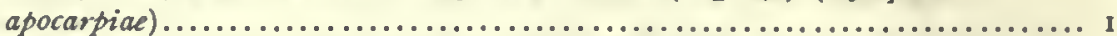

Carpels fused at sides, i. e., walls between ovary cells single (Fig. 40) (Nymphaeae

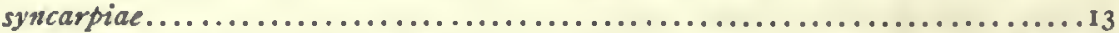

1. Carpellary styles wanting; stamens unappendaged (Anecphya) .................... gigantea

1. Carpellary styles present, thick and fleshy; stamens appendaged (Brachyceras) ............ 2

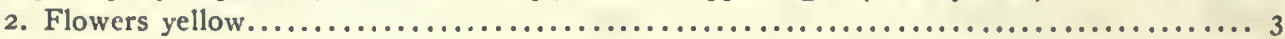

2. Flowers never yellow............................................. 4

3. Leaves 4 to $6 \mathrm{~cm}$. across; veins inconspicuous....................... sulfurea

3. Leaves 20 to $25 \mathrm{~cm}$. across; veins very prominent.................. stuhlmannii

4. Leaves entire or nearly so............................................

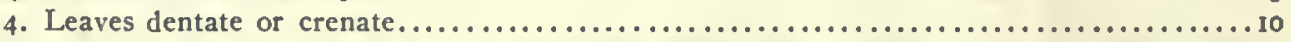

5. Leaves narrowly elliptic (twice as long as broad), blotched .................... ovalifolia

5. Leaves ovate or orbicular............................................... 6

6. American species; flowers pale violet................................. elegans

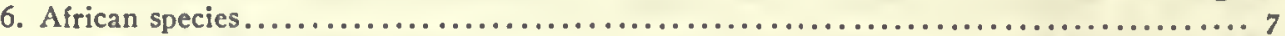

7. Mature leaves bulbilliferous................................... micrantha

7. Not bulbilliferous................................................. 8

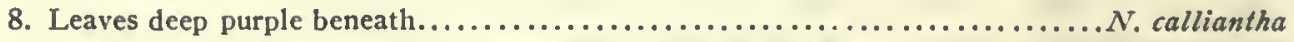

8. Leaves green or purplish-green beneath, spotted with black.................... 9

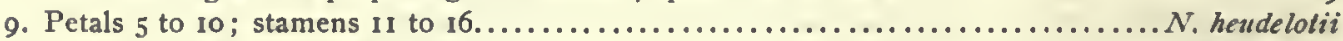

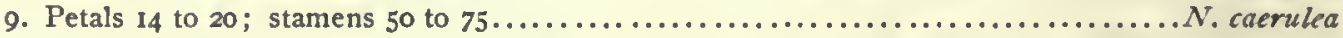

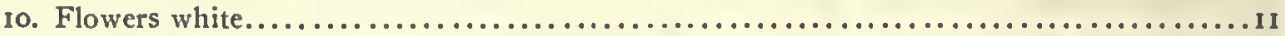

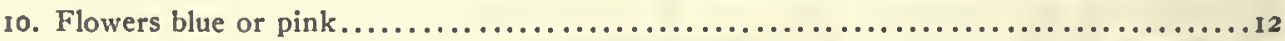

II. Petals narrow, acute; leaves pure green beneatl.................... flavo-virens

II. Petals elliptic, obtuse; leaves black-spotted beneath................... ampla

12. Petals 20 to 30 ; stamens 150 to $275 \ldots \ldots \ldots \ldots \ldots \ldots \ldots \ldots \ldots \ldots \ldots \ldots \ldots \ldots \ldots$. capensis

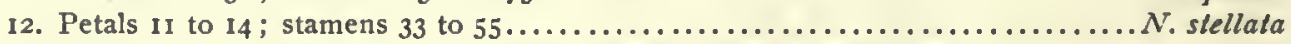

13. Sepals prominently veined; styles linear; leaves spinose-dentate (Lotos)............... I4

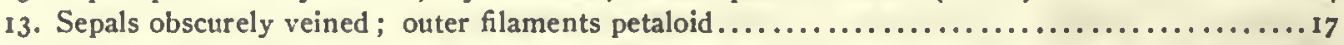

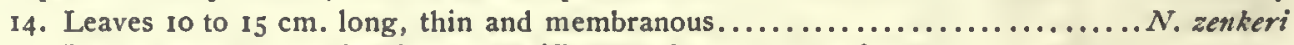

14. Leaves 20 to $25 \mathrm{~cm}$. in diameter, stiff; venation very prominent................. I5

15. Flowers red; leaves bronzy.................................... rubra

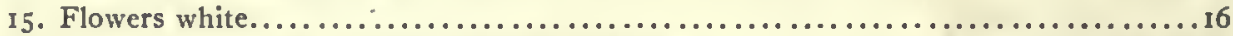

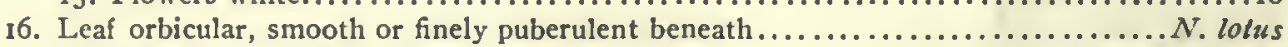

16. Leaf ovate, densely pubescent beneath............................ pubescens

17. Styles clavate; flowers nocturnal (Hydrocallis) $\ldots \ldots \ldots \ldots \ldots \ldots \ldots \ldots \ldots \ldots \ldots \ldots \ldots \ldots \ldots \ldots \ldots$

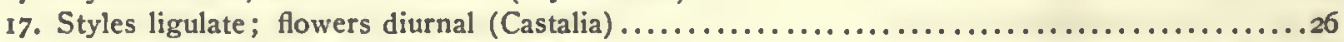

18. Sepals and petals long acuminate...................................... oxypetala

18. Sepals and petals acute or obtuse.........................................

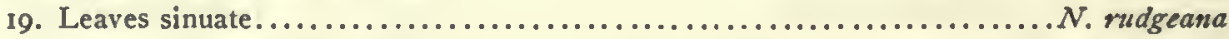

19. Leaves entire....................................................

20. Petiole bearing a ring of long hairs at top........................... amazonum

20. No ring of hairs at top of petiole........................................... 


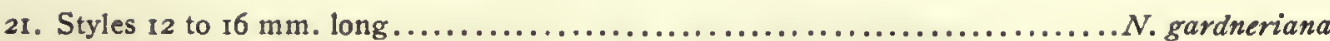

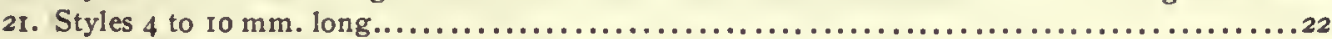

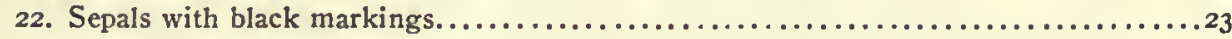

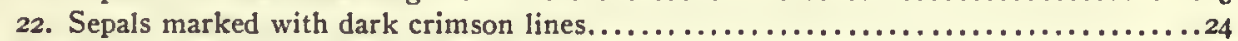

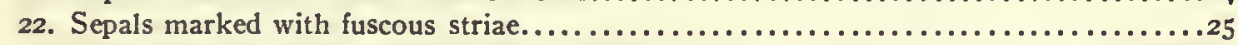

23. Spots few, large; leaves large, broadly peltate................. lasiophylla

23. Spots few, linear; leaves small, narrowly peltate................ tenerinervia

24. Leaves green above and below................................... blanda

24. Leaves marked beneath with dark purple forked and branching lines....N. jamesoniana

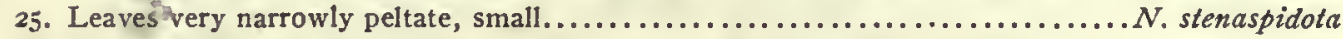

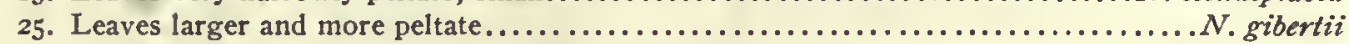

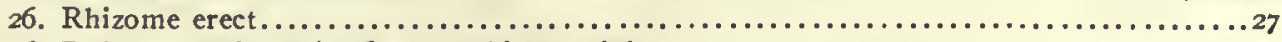

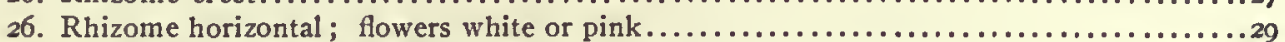

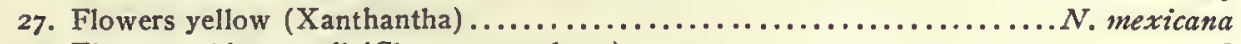

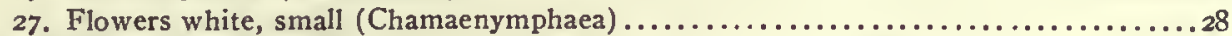

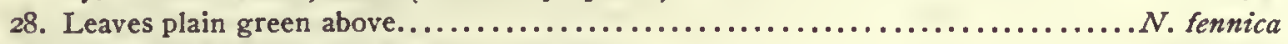

28. Leaves more or less blotched with brown.................................... tragona

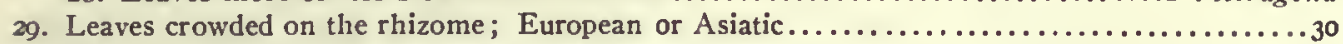

29. Leaves scattered on the rhizome; American.......................................

30. Line of attachment of sepals to receptacle sharply angular..................... candida

30. Line of attachment of sepals rounded...................................... alba

31. Petals spatulate; rhizome tuberiferous........................... tuberosa

3I. Petals elliptic; rhizome not tuberiferous.......................... odorata

Group 1. NYMPHAEAE APOCARPIAE (=Lytopleura Casp. 1865, 1878, In88).

Carpels free from one another at the sides, fused along part of the suture with the axis of the flower, and dorsally with the perigynous torus. Tropical species with diurnal flowers ranging in color from blue through pink to white, raised 7 to $30 \mathrm{~cm}$. above the water, on stiff peduncles. Venation of sepals inconspicuous. Outermost stamens first to dehisce, innermost last. Principal air-canals in the peduncle 6 (5 to 7 ), in the petiole 2 ; idioblasts very few; multicellular ingrowths rather frequent in the air-canals. Rhizomes erect, tuberous, drying off in the resting season. Plants glabrous throughout, except on the apical portion of the tuber and the base of the petioles and peduncles.

\section{Subgenus I. ANECPHYA Casp. 1865, 1888.}

Carpellary styles absent. Stamens, very many, with narrow filaments and short, curved anthers, without appendage, or simply mucronate, inserted very densely at the summit of the torus around the stigmatic disc, the outermost being at some distance from the insertion of the innermost petals. Seeds larger than in the next section. Flowers appearing subtended each by two leaves, i. e., there are on the rhizome oblique series of flower bases alternating with two series of leaves. One species, in Australia and New Guinea.

Sec. Cyanea, Planchon $1852 b, 1853 b$ (in part).

Sec. Appendiculatae, trib. Cyananthos, Lehmann 1853 a (in part).

Sec. Inappendiculatae, trib. Castalia, Lehm. 1853 a (in part). 


\section{Nymphaea gigantea Hook. (Plate III.)}

\section{Dingnosis.-See under subgenus Anecphya.}

Nymphaea gigantea, W. J. Hooker $1852 a$, fid. original specimen in hb. Kew. Planchon $1851 b$, $1852 d, 1853 b$. Rev. Hortic. $1852 b$. Lehmann 1853 $a$. Paxton 1853 d. F. Müller I861, 1862. Bentham \& Müller 1863. Caspary 1865. Garden I883b. G. \& F. 1893a, with good half-tone. Tricker 1897. Moenkemyer 1897. G. C. 1900. Conard 1901 a. Not seen: Lemaire 1853; Duchartre 1858; A. G. I894, I897.

Castalia stellaris, Salisbury $1806 b$ (in note to tab. 14, referring to specimen collected by Banks at Endeavor River).

Castalia gigantea, Britten 1888 a. Lawson 1889.

Victoria Fitzroyana, Hort. (fide Hooker, 1. c.).

DESCRIPTION.-Flower 6 to $30 \mathrm{~cm}$. in diameter (12.5 to $19 \mathrm{~cm}$. as cultivated about Philadelphia; $30 \mathrm{~cm}$. in the type specimen, dried), opening for 7 days from 9 a. $\mathrm{m}$. to 7 p. m. (Casp. 1865), inodorous. - Bud ovoid, rounded at apex.-Peduncle terete, rather slender ( $\mathrm{I}$ to $2.5 \mathrm{~cm}$. in diameter), tapering upward, smooth, light green, rising Io to $35 \mathrm{~cm}$. ( 18 inches, Robinson 1865 ) above the water; air-canals as in group Apocarpiae (figured by Hooker $1852 a$, as petiole).-Receptacle short, small, dark green.-Sepals 4, oval or elliptic, rounded at the apex, breadth:length $=1: 2.5$ to 3 (average); persistent in fruit. Anterior (outermost) sepal pure green without, with a few biackish lines and dots; margins blue-purple above, shading to carmine-purple at point of attachment. Posterior (innermost) sepal with a broad green area in middle of back; a wide border ( 3 to $5 \mathrm{~mm}$.) around apex and sides, narrowing to the base of the sepal, covered by the lateral sepals in the bud, of a dark royal-purple color in apical part, shading to sky blue at sides and carmine-purple at base. Lateral sepals with one side covered, and similar in coloring to posterior sepal. Five strong veins and several smaller ones visible at base of each sepal. Inside of sepals sky blue, shading to royal purple at apex, dark blue on lateral margins, and carmine purple below.-Petals 18 to 5I, longer than the sepals and not entirely covered by these after the first day of opening; outermost petals obovate, obtuse, narrowed at base, deeply concave, not at all sepaloid, outside sky blue, shading to royal purple at apex and base, similar in color, but paler, within. Intermediate petal obovate to spatulate, rounded at apex, tapering at base, colored like outer petals, but paler throughout; innermost petal oblanceolate, rounded at apex, tapering to the base, pale whitish blue, tinged pure blue at apex and base. All of the petals thin and fragile, finely I to 7 nerved, satiny and crumpled like chiffon, fading in color on later days of opening.-Stamens 367 to 745 , incurved at summit through an arc of $45^{\circ}$ to $90^{\circ}$, half as long as the petals, separated from these by a wide interval and inserted densely on the upper part of the ovary. Anthers briglit yellow, about 75 outer ones bearing a short, thin, acute apical appendage (or all unappendaged, Casp. 1865). Filaments paler yellow; Io or 12 outermost ones broader than their anthers; all the rest are nearly or quite thread-like and longer than their anthers. "Outermost anthers first to open, innermost last. Pollen smooth" (Casp. 1865).-Carpels 12 to 20, quite distinct from one another and rather easily separated from the receptacle, stigmatic over all their upper free surfaces; carpellary styles wanting. Ovules large, few in number.-Seed "large, 
$3-1590$

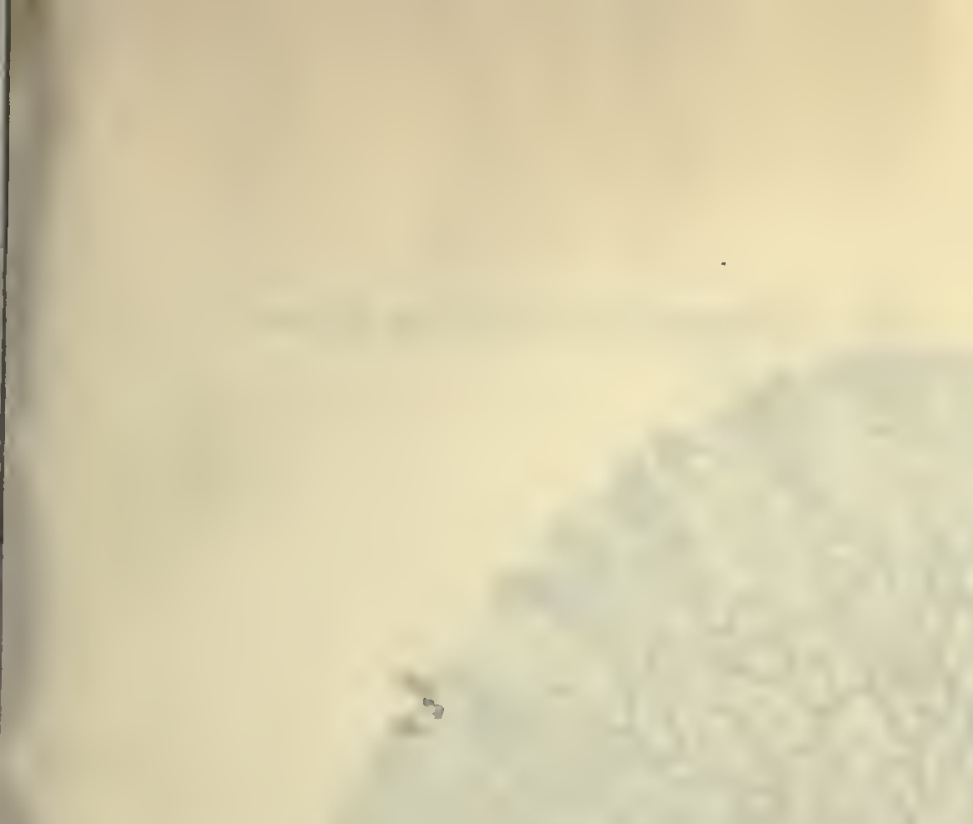





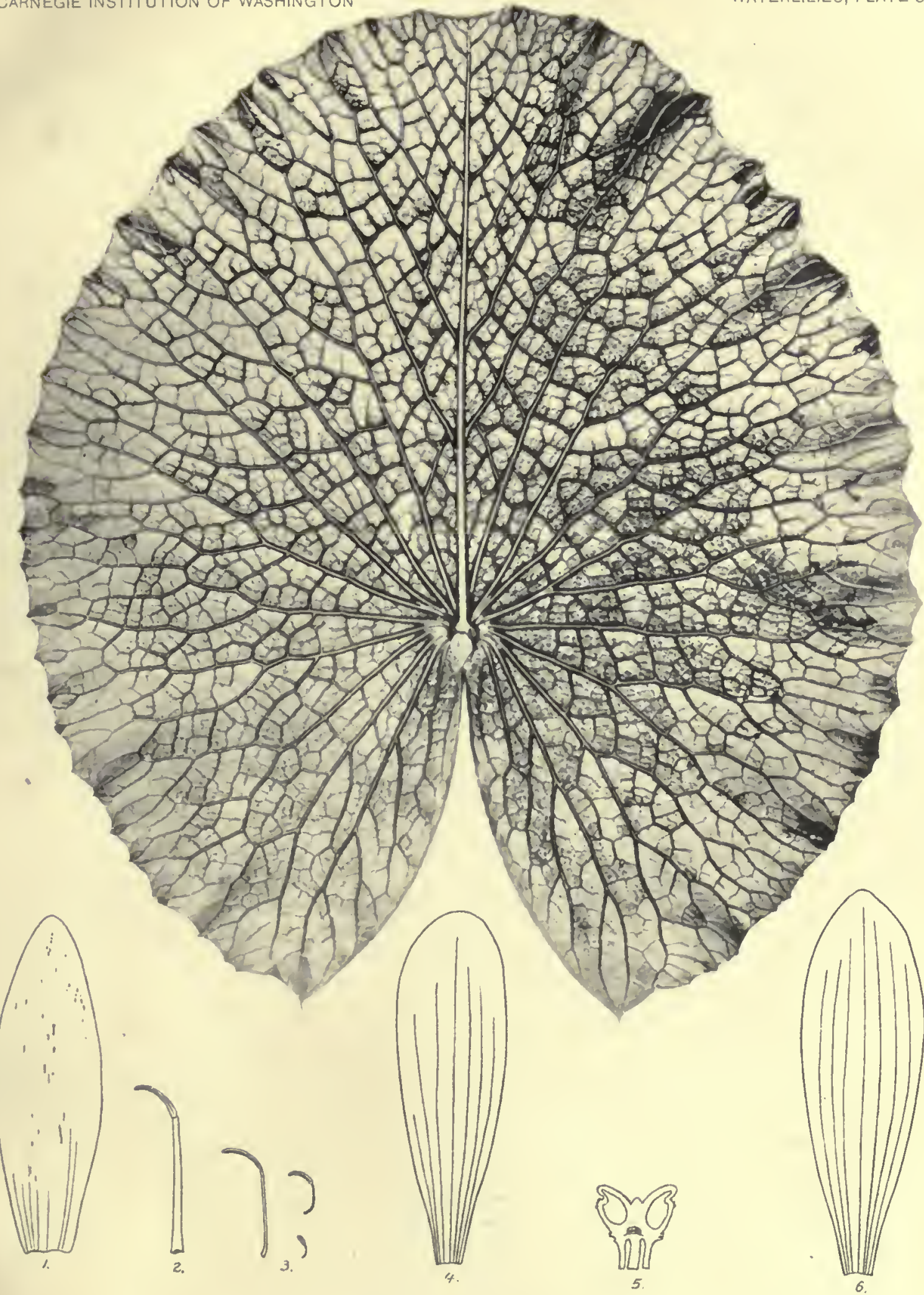



dark colored, ellipsoid, apiculate, usually covered with interrupted longitudinal lines of hairs" (Casp. 1865). (See table of measurements of flowers, below.)

Submerged leaves from sprouting tuber (Fig. 34) 2 or 3, entire, green.above, reddish beneath. First leaf triangular-hastate, with rounded apex and angles, and nearly straight sides; sinus very broad and shallow. Second leaf ovate-sagittate, broadly rounded at apex; sinus broadly triangular, lobes narrowly rounded. First floating leaf ovate, with deep open sinus and rounded apex and lobes; margin slightly irregularwavy. Secont and third leaves similar, with narrower sinus and margins distinctly sinuate-dentate on outer side of lobes; first two dull green beneath, third suffused with purplish blue, and with a few blackish spots.

Leaf of mature plant very narrowly peltate, crbicular-ovate or elliptic, $60 \mathrm{~cm}$. or less in diameter, breadth: length $=1: 1.4$; margin flat or slightly wavy, sharply dentate; teeth short, acute (or obtuse, Casp. 1865 and Mrs. Rowan's paintings), $2.5 \mathrm{~cm}$. apart and $0.6 \mathrm{~cm}$. long; upper surface green and veiny, minutely elevate-punctate; under surface glabrous, brownish pink when young, becoming Tyrian purple when full grown. Veins prominently reticulated on under side of leaf; primary nerves 9 or to on each side; length of priacipal area: length of radius of leaf $=I: I .33$. Depth of sinus $=0.37$ of length of leaf ; margins entire, touching or slightly overlapping within, then curving out, becoming 7.5 to $15 \mathrm{~cm}$. apart at periphery of leaf; angles produced into a fine subulate tooth.-Petiole smooth, terete, 60 to $150 \mathrm{~cm}$. long, witt 2 large air-canals, 2 smaller ones before and behind these, and a surrounding ring of Io still smaller ones; 2 double bundles anteriorly and posteriorly, with a peripheral ring of I I bundles.-Stipules absent, but petiole winged at base, the wings gradually vanishing above.

Rhizome (tuber) ovoid; small ones (Fig. I4) nearly spherical, I.6 to $1.75 \mathrm{~cm}$. in diameter, contracted above, the vegetative bud springing abruptly from the rounded summit; larger tubers with prominent leaf-bases. Each flower subtended by two leaves, the peduncular scars on the rhizome forming an oblique series alternating with two series of leaf-scars (Casp. 1865).

Measurements of Flower from University of Pennsylvania Botanic Garden, igoo (in cm).

\begin{tabular}{|c|c|c|c|c|c|c|c|c|}
\hline \multicolumn{2}{|c|}{ Sерага. } & \multicolumn{2}{|c|}{ Petatas. } & \multicolumn{5}{|c|}{ Stamens. } \\
\hline Length. & Breadth. & Length. & Breadth. & $\begin{array}{l}\text { Length of } \\
\text { Filament. }\end{array}$ & $\begin{array}{l}\text { Length of } \\
\text { Anther. }\end{array}$ & $\begin{array}{l}\text { Width of } \\
\text { Filament. }\end{array}$ & $\begin{array}{l}\text { Width of } \\
\text { Anther. }\end{array}$ & $\begin{array}{l}\text { Length of } \\
\text { Appendage. }\end{array}$ \\
\hline $\begin{array}{c}7 \\
\text { (outer.) } \\
7 \\
\text { (inner.) }\end{array}$ & $\begin{array}{l}2.2 \\
2.4\end{array}$ & $\begin{array}{c}8 \\
\text { (outer.) } \\
7.3 \\
\text { (median.) } \\
6.7 \\
\text { (inner.) }\end{array}$ & $\begin{array}{l}2.6 \\
2.2 \\
1.6\end{array}$ & $\begin{array}{l}2.55 \\
1.9 \\
1.45 \\
0.33\end{array}$ & $\begin{array}{l}\text { I.I5 } \\
0.95 \\
0.65 \\
0.3\end{array}$ & $\begin{array}{l}0.25 \\
0.075 \\
0.04 \\
0.025\end{array}$ & $\begin{array}{l}0.16 \\
0.08 \\
0.08 \\
0.04\end{array}$ & $\begin{array}{l}0.16 \\
0.075 \\
0 \\
0\end{array}$ \\
\hline
\end{tabular}


Measurements of Leaves (in ca.).

\begin{tabular}{|c|c|c|c|c|c|}
\hline & $\begin{array}{l}\text { Length of } \\
\text { Midrlb. }\end{array}$ & $\begin{array}{l}\text { Length } \\
\text { from Apex } \\
\text { to Angle. }\end{array}$ & $\begin{array}{l}\text { Depth of } \\
\text { Sinus. }\end{array}$ & $\begin{array}{l}\text { Width of } \\
\text { Leaf. }\end{array}$ & $\begin{array}{l}\text { Width of } \\
\text { Sinus. }\end{array}$ \\
\hline First submerged ${ }^{*} \ldots \ldots \ldots \ldots \ldots \ldots$ & 2.4 & 2.87 & 0.5 & 1.9 & 1.9 \\
\hline Second submerged *............ & 2.23 & 3.2 & 0.8 & 2.8 & 1.9 \\
\hline First floating ${ }^{*} . . . \ldots \ldots \ldots . . . . .$. & 2.55 & 4 & 1.6 & 2.5 & 1.12 \\
\hline 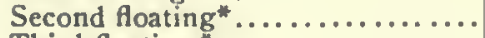 & 2.87 & 5.1 & 1.9 & 3.2 & 1.42 \\
\hline 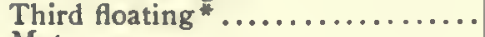 & 3.2 & 4.8 & 2.23 & 3.5 & 1.3 \\
\hline 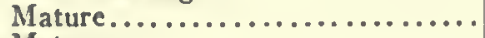 & ...... & 38.2 & ..... & 30.6 & ...... \\
\hline 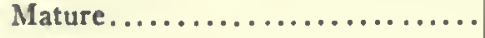 & ...... & 46 & $\ldots \ldots$ & 40 & ...... \\
\hline
\end{tabular}

- From a small tuber.

Geographic Distribution.-Australia and New Guinea. "Lakes and marshes throughout tropical Australia" (Benth. \& Müll. I863). "At river mouths in S. Australia," Schomburgk 1875. "Moreton Bay, Queensland; Clarence River, N. S. W.," Benth \& Müll., 1. c. Papua, Müll. 1875. "New Guinea, coll. Zippel ; Endeavor River, coll. Banks," Casp. 1865. Rockhampton, E. Australia, coll. A. Dietrich, in hb. Berlin. King's Creek, Queensland. coll. Müller, in hb. Munich.

Type collected by Bidwill, No. 39, at Wide Bay, Queensland, in hbb. Kew, Berlin.

Forma alba-with white flowers. Benth. \& Müll., l. c.

Forma rosea-with pink flowers. Benth. \& Müll., 1. c.

Notes.-Introduced into England in 1852, and fruited by Van Houtte (Ghent) in 1855. Flowered in open air, in heated water, at Glasnevin (Dublin) in 1865. Frequent in cultivation in America, flowering freely out of doors all summer. Tubers are said to germinate better in deep water, i. e., about $60 \mathrm{~cm}$; but this is not necessary if good bottom heat is furnished.

Var. violacea (Lehm.) new comb. (Plate I, Frontispiece.)

Smaller than the type. Flower 12 to $15 \mathrm{~cm}$. in diameter. Bud conical-ovoid, acute. Sepals coriaceous, ovate to oblong, tapering above with nearly straight sides to the obtuse apex; outer surface dark green more or less densely marked with interrupted heavier and lighter black lines; inner surface pale. Petals many, rich violet, slightly shorter than the sepals; outer ones larger, obovate oblong, tapering above. Stamens very many, much shorter than the corolla; appendage obsolete. Carpels about Io.

Leaves subovate, repand, light green above, deep purple beneath; petiole to apex 9 to II $\mathrm{cm}$. ; width II.5 to $12.7 \mathrm{~cm}$. ; lobes $6.4 \mathrm{~cm}$. long, obtuse; primary nerves Io to 12 ; veins numerous, reticulate, prominent beneath, green. Sinus margins curved, open at periphery. mann.)

Rhizome cylindrical, the size of one's little finger. (Details mostly from Leh-

Nymphaea violacea, Lehmann $1853 a$, fid. original specimens coll. John Macgillivray, Oct. 10, 1848, Cape York, Voyage of the Rattlesnake, Botany, 4ro, in hb. Kew.

N. Banksii, Cunn., fid. original specimen, coll. A. Cunningham, June, 1819, Endeavor River, N. E. Australia, in hb. Kew. 
N. serrata, Müller, fid. original specimen, coll. F.. Müller, July 15, 1855, Arnheim's Land, Australia, in hb. Kew.

N. repanda, Müller, fid. original specimen, coll. F. Müller, July 16, 1856, Arnheim's Land; also Head of Sturt's Creek, Australia; both in hb. Kew.

N. versicolor, Müller, fid. original specimen, coll. F. Müller, July I5, 1856, Arnheim's Land, Australia, in hb. Kew. Not Roxb. I809.

N. stellata, Müller I86I, fid. original specimens, sent by F. Müller from Rockingham Bay, Queensland, in hb. Munich; from Escape Cliffs, N. Australia, coll. W. Halls, in hb. Kew; from Barron River, Queensland, coll. W. Sayer, in hb. Paris; also in hb. British Museum. Not Willd. 1797.

N. Brownii, F. M. Bailey, I899, fid. original specimen in hb. British Museum.

Geographic Distribution.-Queensland, Arnheim's Land, Australia.

Nores.-Caspary considered this merely a small form of $N$. gigantea; but the paintings of both types made by Mrs. Rowan in the native habitat, which I saw at the Philadelphia Museum, April 16, 1901, show the marked peculiarities cited above, which certainly entitle the plant to varietal rank. Mrs. Rowan considers it a very distinct type, and says it is restricted to the Cape York Peninsula, a region practically uninhabited by white people. We are especially fortunate in having opportunity to reproduce Mrs. Rowan's painting from the original, which is now the property of the University of Pennsylvania. Examination of the European collections gave fully conclusive evidence on the rank of this form. (Cf. also its synonymy.)

Subgenus 2. BRACHYCERAS Casp. 1865, 1878, 1888 .

Carpellary styles present, short, stiff, and fleshy. Stamens numerous, following the petals in order on the torus directly or without much interval; exterior anthers long, more or less strongly appendaged with a process of the connective, the corresponding filaments being flat and more or less expanded. Seed smaller. Twelve species of world-wide distribution in the tropics.

Cyanea and part of Lotos DC. $1821 b$.

Cyanea (mostly) Planchon $1852 b, 1853 b$.

Section I. Appendiculatae Lehmann $1853 a$ (in part).

\section{Nymphaea elegans Hook. (Plate IV; Fig. 53.)}

Leaves entire or slightly wavy at base, narrowly peltate, broadly ovate to ovateorbicular; under surface dark purple; about $18 \mathrm{~cm}$. long. Flower 7 to $13 \mathrm{~cm}$. in diameter, pale violet, open from 8 a. m. to I p. m. Buds ovate. Sepals marked with black lines and dots. Petals 12 to 20 , ovate, obtuse. Stamens about 100, stout, yellow; appendage minute; filaments narrow.

Nymphaea elegans, Hooker I85I, fid. original specimen, cultivated at Kew, from Texas, in hb. Kew. Revue Horticole 1851 b. Paxton $1853 b$. Sterns 1888 . Tricker I897. Conard 1901 $a$. Castalia elegans, Greene I888. Lawson 1889. Rose 1895 . Nymphaea Mexicana, Gray 185o. Not Zucc. 1832.

DESCRIPTION.-Flower 7 to $\mathrm{I} 3 \mathrm{~cm}$. in diameter, open widely on three successive days from 8 a. m. to I p. m.; odor sweet, moderately strong. $-B$ ud ovate, obtuse or rounded at apex.-Peduncle terete, slender, stiff, rising 12 to $18 \mathrm{~cm}$. above the water, 
reddish brown, with 5 or 6 main air-canals, each with two very small canals outside. -Receptacle very narrow, sloping.-Sepals 4 (or sometimes 5) lanceolate, breadth: length $=1: 3.4$ to 3.6 , obtuse or sub-acute; outer surface dark green, marked with fine brownish-black lines and dots, especially near the margins; 9 longitudinal veins visible by looking through the sepal at a light; inner surface dull greenish-white.-Petals 13 to 24 , lanceolate, tapering to base and apex, breadth:length $=1: 3.7$ in outermost petals, crowded on lower part of torus. Outer surface of outermost petal sepaloid

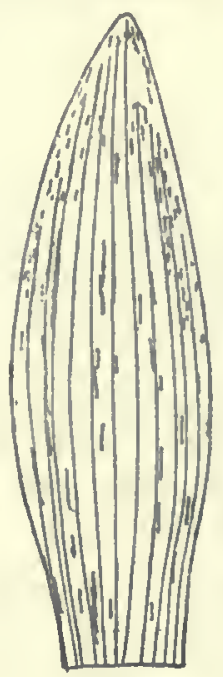

a

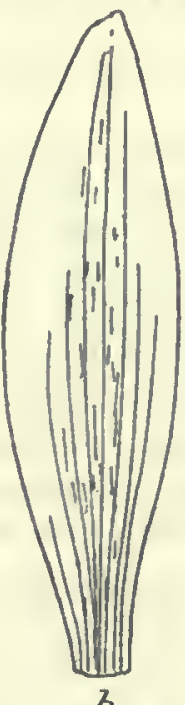

b

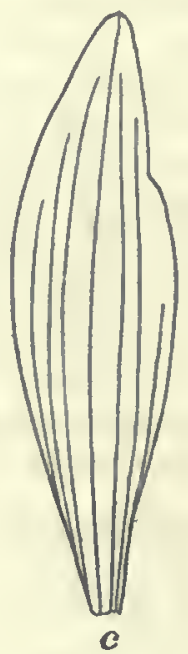

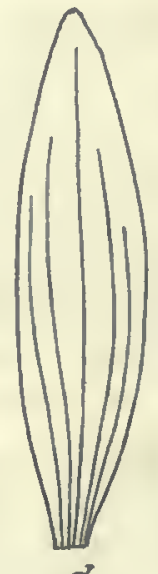

$d$
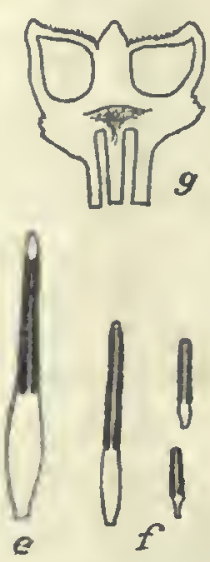

Fra. B3.-Nymphaea elegans; $a$, sepal; $b$, petal of outermost whorl; $c$, petal of second whorl: $d$, petal of Innermost whorl; $e$, outer stamen; $f$, succossively smaller stamens; $g$, vertical section of ovary. Natural size.

Floral Organs.

\begin{tabular}{|r|r|r|r|r|}
\hline & No. & No. & No. & No.* \\
\cline { 1 - 2 } & & & \\
\hline Sepals ... & 4 & 5 & 5 & 4 \\
Petals ... & 21 & 20 & 24 & 13 \\
Stamens. & 145 & II 8 & 139 & $\ldots$. \\
Carpels .. & 22 & 22 & 25 & I5 \\
\hline Total .... & 192 & I65 & I93 & $\ldots$ \\
\hline
\end{tabular}

* Small flower, early in season.

in midline, green, with blackish lines and dots, with 5 strong veins visible on looking through; edges and inner surface pale violet, nearly white, fading to dull whitish on lower third of petal. Second row of petals a little shorter than first, pale violet above, nearly white in lower half, 5-veined. Innermost petal narrowly lanceolate, colored like second series, but very pale.-Stamens 80 to 145, stout, yellow, about one-half the length of the petals, inserted around the top of the ovary, leaving a bare space above the petal insertions; appendages very small, only present on the outer stamens. Outermost filament narrowly elliptic, slightly broader than anther; innermost tapering 




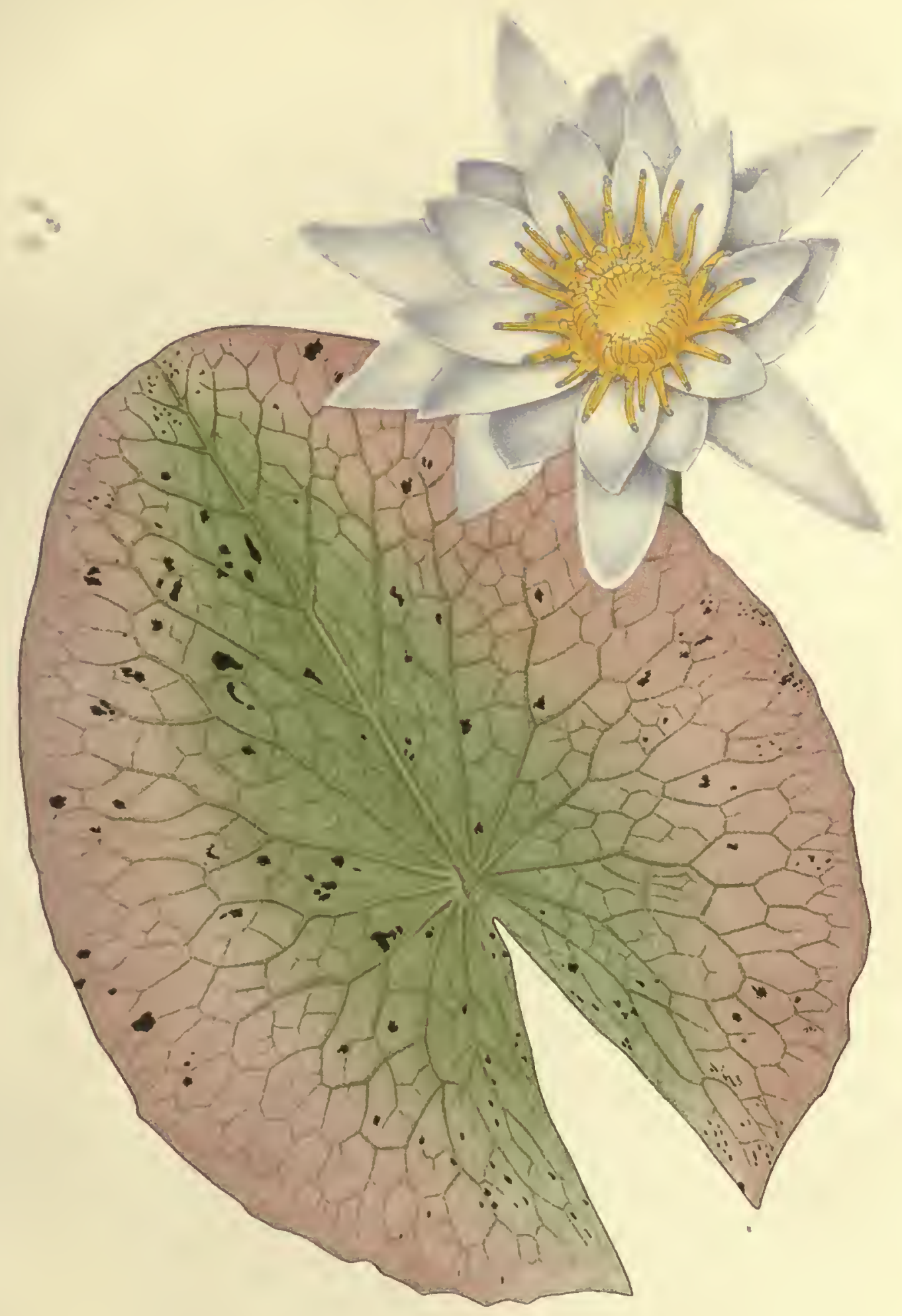

NYMPHAEA ELEGANS. 

from the width of the anther at top of filament to about one-half as wide at base. All of the anthers longer than the filaments. (See measurements at end of description.) - Ovary nearly hemispherical, with a naked ring on the sides between petals and stamens.-Carpels 15 to 25 ; styles yellow, erect, minute, $0.8 \mathrm{~mm}$. long, a little broader than high, acute, the tip projecting as a very small point beyond and above the broadly rounded and centrally grooved stigmatic ray. Stigma more or less curved funnel-shape, with large central depression, in which the slender, conical, acute axile process stinds free. Diameter of stigma $0.8 \mathrm{~cm}$.; depth of depression $0.3 \mathrm{~cm}$.; height of axile process $0.2 \mathrm{~cm}$. - Fruit rounded, much depressed, cheese-shaped, $3.2 \mathrm{~cm}$. in diameter by $2.2 \mathrm{~cm}$. high, to $3.5 \mathrm{~cm}$. in diameter by $1.9 \mathrm{~cm}$. high, of a pale greenish color, subtended by the persistent sepals, contracted above to the low crown of hard, inwardlydirected styles; stigma basin-shaped, about $1.6 \mathrm{~cm}$. in diameter, black, radially striatesulcate; axile process broadly conical and obtuse. -Seeds nearly globose, about $0.13 \mathrm{~cm}$. in diameter, mucronate at hilum by persistence of a portion of the funiculus, dull olive green, smooth, with rather strong raphe. Aril about as long as the seed, and closely investing it.

Germination may occur immediately on ripening of seed, or after a period of drought. First leaf of seedling filiform, I. 6 to $2.8 \mathrm{~cm}$. long. Second leaf ovate, narrowed above, obtuse, $1.12 \mathrm{~cm}$. long by $0.48 \mathrm{~cm}$. wide, rounded at base; petiole $0.8 \mathrm{~cm}$. long. Third leaf like second, but with slightly cordate base. Fourth leaf broader and more cordate at base. Fifth leaf broadly ovate, cordate, with rounded apex and basal lobes.

First submerged leaf from small tuber (Fig. 34) narrowly triangular, acute at apex; base truncate with rounded angles. Second leaf typically cordate, acute. First three floating leaves entire, ovate, broadest about midway of length, with rather wide sinus; apex broadly rounded, angles rounded; first two leaves green on both sides, third green above, purplish beneath. Fourth floating leaf speckled above with small brownish blotches, under surface brownish red with a number of fine darker specks; margin wavy on outside of lobes.

Measurements of Leaves from Small Tuber (in CM.).

\begin{tabular}{|c|c|c|c|c|c|}
\hline & $\begin{array}{l}\text { Length of } \\
\text { Midrib. }\end{array}$ & $\begin{array}{l}\text { Length } \\
\text { from } \\
\text { Apex to } \\
\text { Angle. }\end{array}$ & $\begin{array}{l}\text { Depth of } \\
\text { Sinus. }\end{array}$ & $\begin{array}{l}\text { Width of } \\
\text { Leaf. }\end{array}$ & $\begin{array}{l}\text { Width of } \\
\text { Sinus. }\end{array}$ \\
\hline 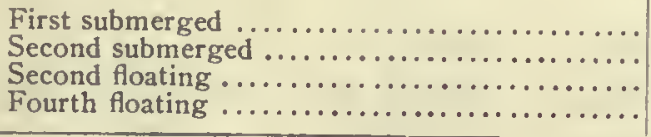 & $\begin{array}{c}\text { I.6 } \\
2.5 \\
2.6 \\
\ldots \ldots\end{array}$ & $\begin{array}{l}1.55 \\
2.9 \\
4.5 \\
5.7\end{array}$ & $\begin{array}{l}0 \\
0.45 \\
1.9 \\
2.55\end{array}$ & $\begin{array}{l}0.5 \\
1.9 \\
3.0 \\
4.15\end{array}$ & 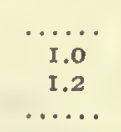 \\
\hline
\end{tabular}

Leaf of mature plant broadly oval, or at times nearly orbicular; breadth : length = I : I. 3 ; usual length I 5 to $18 \mathrm{~cm}$., peltate by 0.6 to $2.0 \mathrm{~cm}$., of rather thin texture, entire in upper half, very gently sinuate-dentate in basal half; apex rounded. Upper surface dark green, with small blackish-purple markings when young; under surface bright purplish-red with frequent blue-purple spots, greenish along the midline. Veins prominent out to the sixth grade; principal nerves 6 to 8 on each side; length of principal area : radius of leaf $=1: 1.76 .-$ Sinus open, depth : length of leaf $=1: 3$ 
(approx.), margins straight or slightly concave, converging toward the periphery; angles about $3.2 \mathrm{~cm}$. apart, tapering, acute.-Petiole slender, light brown, attached to the lamina by a slender "collar"; principal air-canals 4, two larger and two smaller; stellate cells numerous on walls of larger canals.

Rhizome (tuber) erect, ovoid, black, thickly covered with leaf scars, about $7.5 \mathrm{~cm}$. long by $3.5 \mathrm{~cm}$. thick, ripening early in the fall. No stolons formed in vegetative period. Small tubers (Fig. I4), I.2 to $1.35 \mathrm{~cm}$. in diameter, spherical-ovoid, smooth in lower half, tapering above to the scaly-woolly vegetative end.

Measurements in centimeters.

\begin{tabular}{|c|c|c|c|c|c|c|c|c|c|}
\hline \multicolumn{5}{|c|}{ STAYENg or FLOWER A." } & \multicolumn{2}{|c|}{ SEPALS. } & \multicolumn{3}{|c|}{ Pmats. } \\
\hline $\begin{array}{c}\text { Tetal } \\
\text { Length. }\end{array}$ & $\begin{array}{l}\text { Width of } \\
\text { Fliament. }\end{array}$ & $\begin{array}{l}\text { Length of } \\
\text { Anther and } \\
\text { A ppendago. }\end{array}$ & $\begin{array}{l}\text { Width of } \\
\text { Auther. }\end{array}$ & $\begin{array}{c}\text { Length of } \\
\text { Appen- } \\
\text { dage. }\end{array}$ & Length. & WIdth. & Length. & Wldth. & Remarks. \\
\hline $\mathbf{1} .75$ & 0.2 & 0.9 & 0.16 & 0.08 & 3.8 & 1.1 & 3.5 & 0.9 & Outer. $a$ \\
\hline 1.42 & 0.16 & 0.8 & 0.13 & 0.04 & a3.8 & $a 0.96$ & $3 \cdot 3$ & 0.9 & Median. a \\
\hline I. I3 & 0.13 & 0.47 & 0.13 & 0 & 3.65 & I. I & 3.2 & 0.8 & Inner. $a$ \\
\hline 0.95 & 0.1 & 0.64 & 0.13 & 0 & 3.8 & 0.96 & & & \\
\hline 0.64 & 0.06 & 0.48 & 0.13 & o & 2.9 & 0.8 & & & \\
\hline
\end{tabular}

- Beasurements in this table and those marked $a$ in adjoining tables are from the same flewer.

Geographic Distribution.-Texas, Mexico to Guatemala, chiefly in warm lowlands. "Near head of Leona River" (Gray I850); Waco, Texas (Sterns I888) ; Rio Grande, El Paso, Texas (Coulter I890); Guatemala (Smith I893); Tamaulipas, Vera Cruz, and Mazatlan, Mexico; Brownsville, Texas (coll. Pringle, Flora of Texas, 1888 , No. 1955). Also coll. Berlandier, No. 2402, June, 1834, at Palo Alto, Rio de las Mines, Mexico, in hbb. Kew, Paris, and No. 972 in hb. Berlin; coll. Hartweg, Mexico, No. 1972 in hb. Paris and 1592 in hb. Delessert.

Notes.-Types collected by Dr. C. Wright on Leona River in June, 1849, and sent to A. Gray, and thence with seeds to Hooker, who raised plants and described the species from them. It was rediscovered in 1887 by $M$ isses Trimble and Wright at the Waco locality in eastern-central Texas.

The flower is beautiful and delicately colored; the plant grows easily and blooms and fruits profusely.

\section{Nymphaea ampla (Salisb.) DC. (Plate V.)}

Leaves 15 to $40 \mathrm{~cm}$. in diameter, sub-orbicular, narrowly peltate, sinuate or nearly entire, with small black spots above and below, at least when young; under surface red-purple; lobes acute. Flowers white, 7 to $13 \mathrm{~cm}$. in diameter; sepals ovate-lanceolate, obtuse or somewhat acute, marked with blackish lines; petals 7 to 21 , lanceovate, obtuse; stamens 30 to I9o, yellow, outermost ones much longer than innermost.

Castalia ampla, Salisbury $1806 a, 1806 b$.

Nymphaea ampla, DC. 1821 b, 1824 (fid. leaf of original specimen, in hb. British Museum). Sprengel 1825. Don 1831. Macfadyen 1837. Schomburgk 1848. Gray 1850. Planchon $1853 b$. Grisebach 1864. Caspary 1878. Garden 18836 . Watson 1883 . Hemsley I888. Pringle I890. Gray, etc., I895. Conard, Ig01 $a$. 
$=$

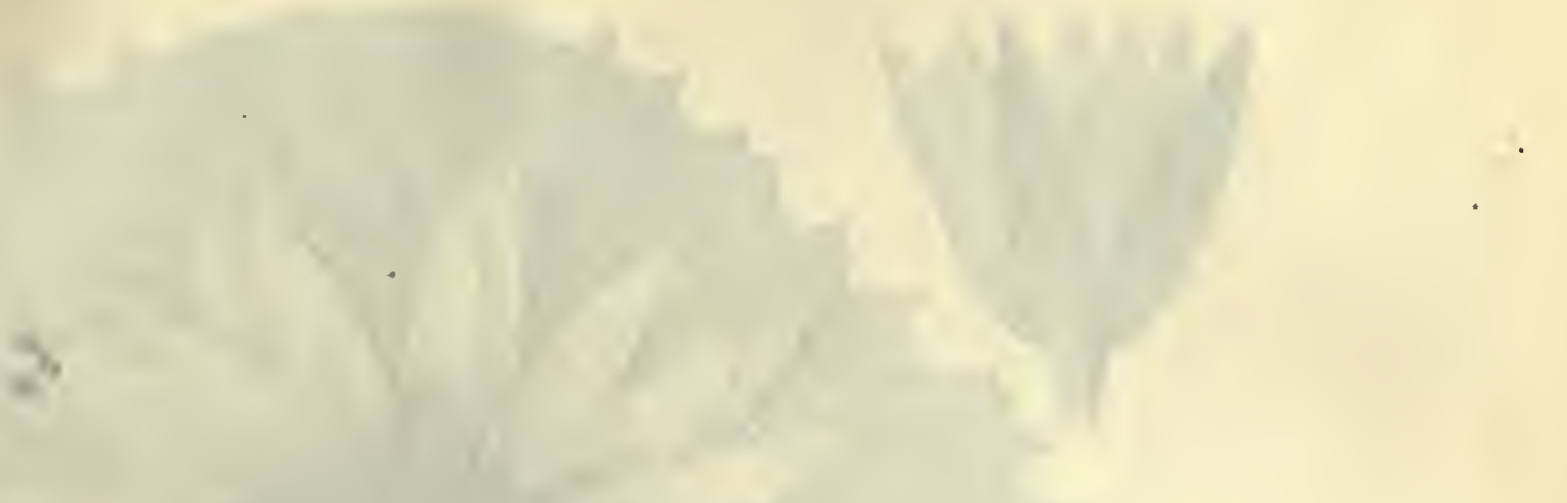




\section{.}

(1)

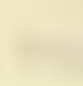

10 (1)

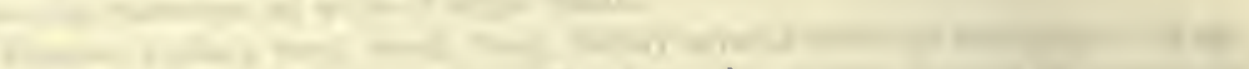
, (n)

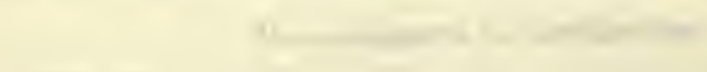

$$
\text { - } 10
$$

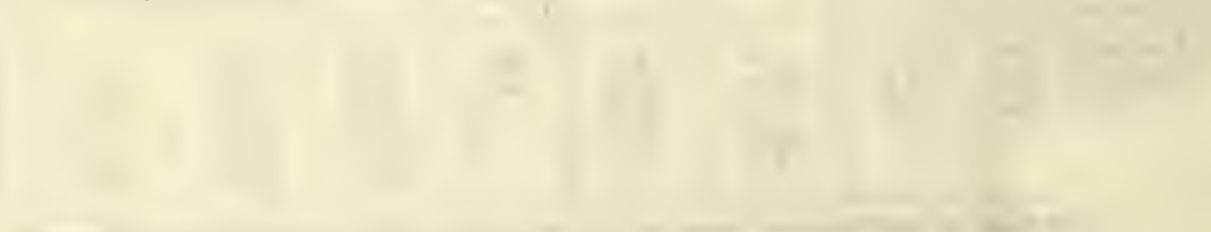

(n)

(1)

1

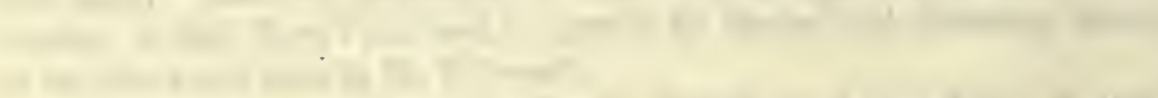

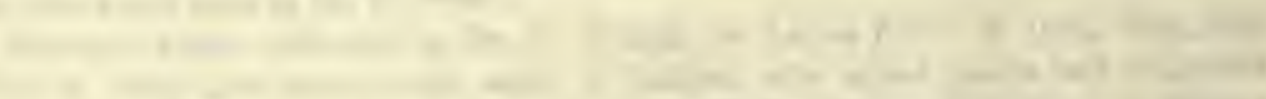

.

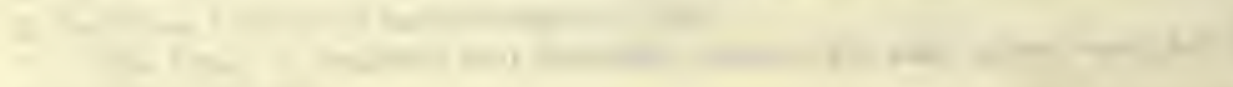

$(20)$

$1=0$

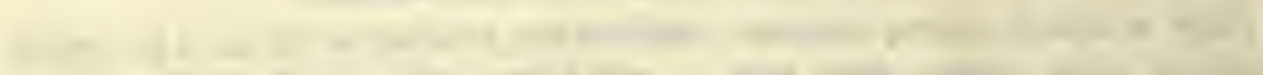
(1)

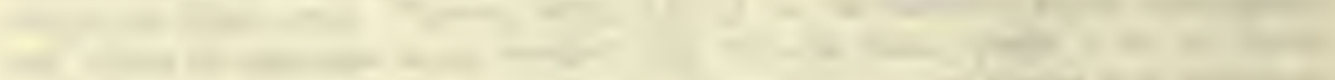
10

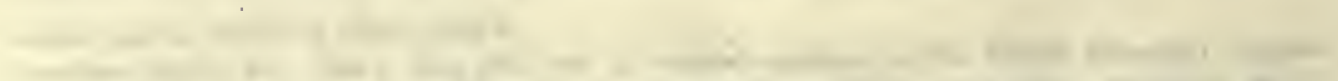

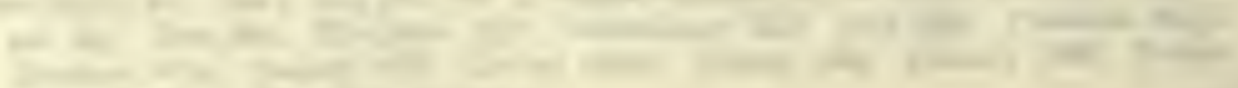
10 
CARNEGIE INSTITUTION OF WASHINGTON

WATERLILIES, PLATE 5

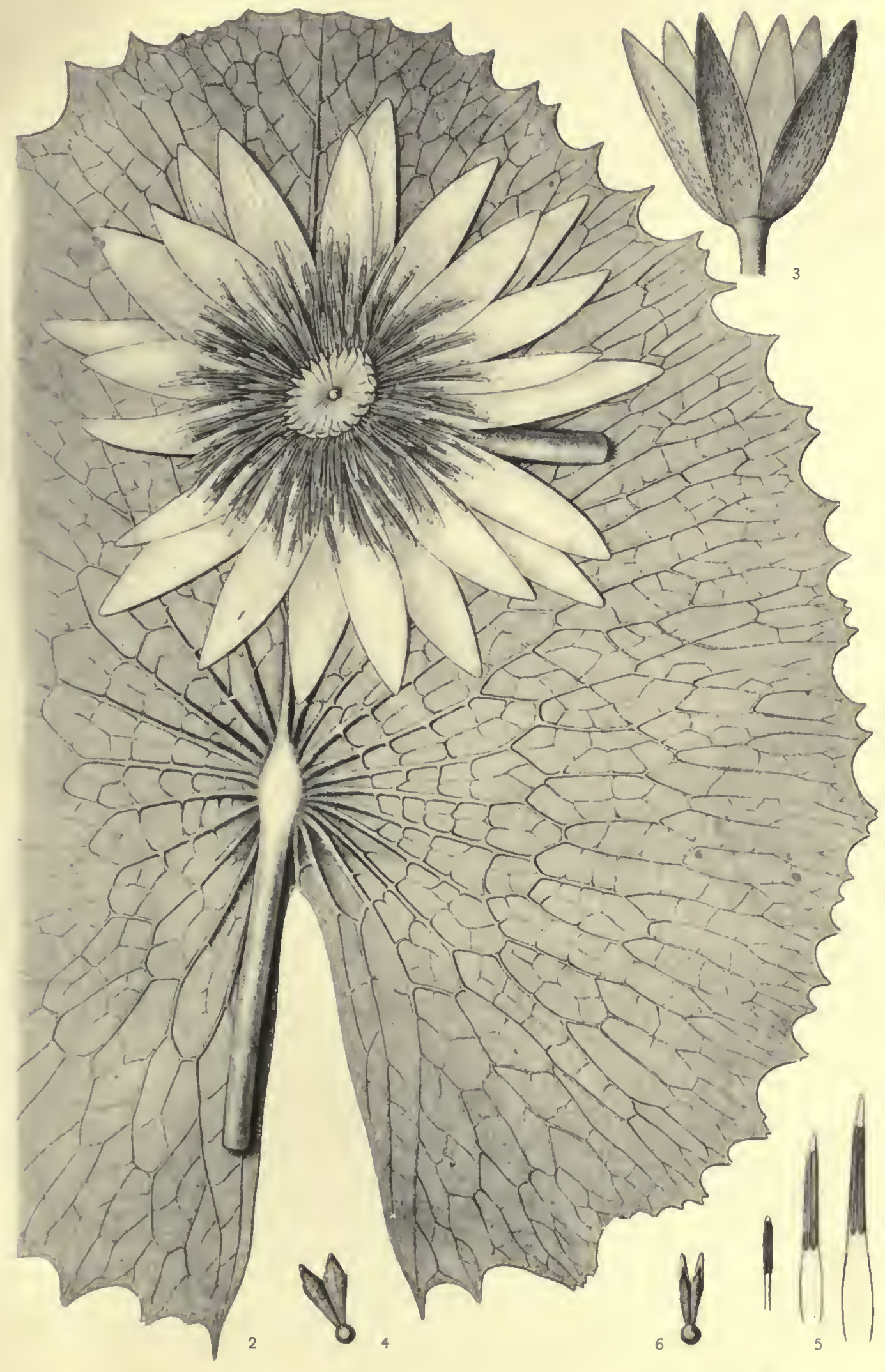

NYMPHAEA AMPLA. 

N. Lotus, Linn. 1762 (the American plant). Aublet 1775. Willdenow 1797. Loudon 1855.

$N$. Candolleana, Lehmann $1853 a$, as to the leaf ( $f d$. original specimen from hb. Lehmann now in hb. Berlin). Flower is of $N$. rudgeana.

N. foliis circinnatis maximis, Burmann 1759.

N. ampla var. Plumieri, Planchon 18536 . Grisebach 1857. Caspary 1878.

N. trisepala Gaudich.? fid. Eichler 1878.

DESCRIPTION.-Flowers white, 9 to $13 \mathrm{~cm}$. across.-Sepals 4, coriaceous, narrowly oblong, breadth: length $=I: 2.3$ to 5.8 (average of $5 \mathrm{I}$ sepals from 43 flowers $=$ I : 3.6, Cisp. I878), obtuse, acute or acuminate, outer surface green, marked with short blackish lines.-Petals 7 to $2 \mathrm{I}$, the outermost tinged yellowish-green.-Stamens 30 to I90, outermost much longer than innermost; anthers appendiculate.-Carpels I4 to 23 ; styles short-conical, gradually narrowed or abruptly apiculate-acuminate, acute, subacute, or obtuse, breadth: length $=I: I .5$ on the average, $=I: I$ to 2.5 in extremes; axile process rounded, breadth: length $=\mathrm{I}: 0.09$ on the average, $=\mathrm{I}: 0.3$ to 2.0 in extremes; stigma extending out on styles in short, rounded or rarely acute rays._Seed sub-globose-elliptic, about I $\mathrm{mm}$. long, with longitudinal rows of hairs.-Leaves large, narrowly peltate ( 3 to $3 \mathrm{I} \mathrm{mm}$.; average $10 \mathrm{~mm}$.), sub-orbicular, 15 to $40 \mathrm{~cm}$. in diameter, sinuate or nearly entire, green above; with small black spots; under surface red-purple; veins prominent, principal nerves 5 to I4 (average IO) on each side of leaf; length of principal area : radius of leaf $=\mathrm{I}: 2$.

Geographic Distribution.-Tropical and sub-tropical America, from $26^{\circ} \mathrm{N}$. in Texas, through the Antilles, to $8^{\circ} \mathrm{S}$. in Brazil ; Fort Clark and Spofford, Texas (Plank 1896). Lampasas, Mexico. Neuvo Leon; Lakes between Ocuiltzapotlan and Famulte de las Sabanas; Lagunas de Macultepec (very large specimen, coll. J. N. Rovirosa, I889, in hb. Acad. Nat. Sci. Phila., with petals $9.5 \mathrm{~cm}$. long and leaf $56 \mathrm{~cm}$. long by $48 \mathrm{~cm}$. wide). Mexico, coll. Houston, No. I731, in hb. British Museum.

\begin{tabular}{|c|c|}
\hline \multicolumn{2}{|c|}{ SePal Dimengions. } \\
\hline Breadth. & Length. \\
\hline $\mathrm{cm}$. & $\mathrm{cm}$. \\
0.9 & 2.6 \\
2.9 & 9.2 \\
2.4 & 9.4 \\
\hline
\end{tabular}
Springs and streams near Monterey, Mexico (Pringle, Plant. Mex., I889, No. 258I). La Paila, New Granada. St. Domingo island. Vera Cruz, Hazienda de Mamulique, Hazienda de Tamatoc, Laguna Verde, Mexico (Casp. 1878). Aguada del Labach, Yucatan, coll. Schottmüller, No. 528, in hb. British Museum; also Gaumer, No. 428, in hb. Boissier. Cuba; St. Miragoane; Alligator Pond, Jamaica; Rio Ulna, Honduras; Belize, Honduras, coll. J. Robertson, Dec. 27, 1889, No. 20, in hb. British Museum. Hog Island, Bahamas, coll. Eggers, No. 408I. Martinique, coll. Plee, in hb. Paris. Guatemala (Smith I89I, I893) fid. original specimen in hb. Kew. Encruzilhada, near Pernambuco, Brazil, coll. H. Schenck, Herb. Brazil, No. 4I 52, in hb. Berlin, and coll. Gardner, No. 9I5, near Alinda, in hb. Kew. Demarara, British Guiana, coll. Parker, in hb. Kew. Trinidad, coll. Fendler, No. 207, in hb. Kew. St. Vincent, south end, coll. Smith, No. I708, in hb. Kew. Prov. Quito, Peru, coll. Hartweg, No. I592, in hb. Boissier.

NOTES.-In the arrangement of this species we have followed Caspary as closely as possible; he examined the type material in nearly all of the European collections. DeCandolle's type specimen consists of a leaf of this species with a flower of $N$. rudgeana Mey. 
The true species (var. Plumieri Planch., etc.) is of powerful growth, but has not yet been introduced into cultivation. We have discarded the varietal name in this and in other species, allowing the specific name alone to stand for the form originally described.

Var. speciosa (Mart. \& Zucc.) Casp.

Of medium size; stamens 42 to 129 ; leaves less coriaceous, margins more or less repand-sinuate or dentate, with obtuse teeth; nerves slightly prominent beneath; lobes divergent, overlapping or approximate. Tuber sub-globose.

N. speciosa Martius \& Zuccarini I832, fid. original specimen, coll. Martius, in aquis S. Christoph., Prov. Rio de Janeiro, Brazil, in hb. Munich, in sched. No. 28.

N. ampla, Hooker I849.

N. ampla $\beta$ Hoakeri, Planchon 1853 b.

N. ampla $\gamma$ Salzmanni, Planchon $1853 b$ (flower).

$N$. trapeealifalia, Lehmann 1853 a (flower), fid. original specin:en in hb. Berlin. Leaf is of $N$. rudgeana.

N. nervasa, Lehmann $1853 a$, from hb. Steudel, fid. Casp. and original specimen in hb. Berlin.

N. ampla var. speciosa, Caspary 1878 .

N. Leibaldiana, Lehmann $1853 a$, as to the American plant in hb. Vienna, fid. Caspary 1878. Specimens "ex herb. Lehm." in hbb. Kew and Bcrlin are from Africa, and appear to be $N$. copensis.

N. gracilis, Zuccarini $1832 a, b$, fid. original specimens (2 sheets) coll. Karwinski, Aug. I827, "ex lacu Mexicano," in hb. Munich. Coll. Pringle, Plant. Mex. 189I, State of Jalisco, No. $389 \mathrm{~g}$. N. undulata, Lehmann 1853 a, fid. original specimens, coll. Galeotti, No. 4846 ( 4840 in Kew), Nov., 1840, "lacs près Oaxaca, Mexico," ex hb. Lehmann in hbb. Berlin, Kew. Hemsley I888.

Geographic Distribution.-Tropical America from $19^{\circ}$ N. to $23^{\circ} \mathrm{S}$. Valley of Mexico (Karwinski) ; Oaxaca, Mexico (Galeotti) ; Guadalajara (Pringle). Caguas, Porto Rico, coll. P. Sintenis, No. 2577, Sept. 5, 1885. St. Domingo, coll. Poiteau, 1802, in hb. Delessert. Jamaica; Nevis; St. Croix; Lebanon in Antigua; Maracaibo; La Paila in New Granada; Merida; Demerara in British Guiana; Kaw River in French Guiana; Pernambuco, Santa Cruz, St. Christophe, Para, Rio de Janeiro, Cabo Frio, Capocabana, and Bahia in Brazil (Caspary 1878).

Notes.-This is the form cultivated in Europe as $N$. ampla, sent to Kew from Jamaica by Macfadyen in 1847 or 1848 , and to Caspary from Caracas by Dr. Ernst in 1869 .

Specimens from St. Christophe and Maracaibo have the lobes of the leaf widely divergent; those cultivated in Europe' from Jamaica stock have the lobes touching; nearly all the others in collections have an open but very narrow sinus.

The type specimens of $N$. ampla $\gamma$ Salzmanni Planch. and $N$. tropaeolifolia Lehm. consist each of a flower of this variety with a leaf of N. rudgeana Mey. (Casp. 1878).

Var. pulchella (DC.) Casp.

Flowers of medium to small size; stamens 30 to 50 ; margin of leaves sub-entire or slightly repand-sinuate; veins slender, scarcely prominent.

N. pulchella, DC. $1821 b$, fd. original specimens, without data, in hb. DeCandolle, but marked coll. Pavon, at Guayaquil (DC. ms.) in hbb. Paris and British Museum. Planchon $1853 b$. Lehmann $1853 a$.

N. lineata, St. Hilaire 1833 , fid. Caspary 1878 , and original specimen in hb. Paris.

N. ampla var. pulchella, Caspary 1878 . 
Geographic Distribution.-South America, from $2^{\circ}$ to $23^{\circ} \mathrm{S}$. Guaniva, Porto Rico, coll. Sintenis, No. 3662, det. Caspary, in hbb. Berlin, Kew, Munich. Guayaquil, Peru; Province of Rio de Janeiro (between Sitio de Paulista and Sitio do Porier), Brazil (Caspary 1878 ).

\section{Nymphaea fiavo-virens Lehmann. (Plate VI; Fig. 54.)}

Leaves sub-orbicular, 30 to $45 \mathrm{~cm}$. in diameter, narrowly peltate, deeply and irregulatly sinuate or nearly entire, plain green on both sides; angle of lobes rounded. Flowers white, 10 to $15 \mathrm{~cm}$. in diameter; sepals pure green, or with 2 or 3 scattered short black lines near the margins; petals 16 to 20, narrow, acuminate; stamens about 60 , deep yellow; outermost filaments short, broad, petaloid; anthers with a yellowishwhite appendage.

Nymphaea flavo-virens, Lehmann $1852 b, 1854$, fid. specimens from the Hamburg Botanic Garden, I864, in hb. Kew, and from hb. Lehmann in hb. Berlin. Hooker Igor, fid. original specimen in hb. Kew, cult. in Kew Garden.

N. gracilis Hort. Watson I887? G. \& F. I894 b. Tricker I897. Conard I901 a. Not Zuccarini 1832 a. N. mexicana Hort, not Zuccarini 1832, fd. Hooker, l. c.

DESCRIPTION.-Flowers Io to $15 \mathrm{~cm}$. in diameter, open from early morning to 5 or 6 p. m., sweet scented, resembling Convallaria majalis.-Peduncle terete, slender, glabrous, tapering upward, rising 20 to $30 \mathrm{~cm}$. above water, with 6 small main aircanals and 12 secondary ones, all with thick partitions between.-Sepals 4, lanceolate, tapering to an acute apex, $8.3 \mathrm{~cm}$. long by 2 to $2.4 \mathrm{~cm}$. wide, green and obscurely nerved outside, sometimes with a few scattered short black lines; inner surface whitePetals 18 or 19 , of firm texture, outermost opening nearly horizontally, about as long as the sepals, narrowly lanceolate, acute, breadth:length $=I: 5.6$ to 6.1 ( $=1.27 \mathrm{~cm}$.: $7.8 \mathrm{~cm}$. ; and $1.4 \mathrm{~cm} .: 8.3 \mathrm{~cm}$.). Outermost petal greenish-white outside, with 2 or 3 reddish lineolæ. Inner petals smaller, pure white.-Stamens about 60 ( 56 to $6 \mathrm{r})$, yellow ; outer ones longer, with short, broad, petaloid filaments, and appendages of medium length, stout, light yellow in color.-Carpels 12 to 15 ; styles short, stout, fleshy, orangeyellow, becoming elongated and incurved in fruit.-Fruit nearly globose, $2.2 \mathrm{~cm}$. in diameter by $2.87 \mathrm{~cm}$. high, crowned by the small circle of styles $(1.9 \mathrm{~cm}$. in diameter at base, outside measurement), and slightly depressed, basin-like stigmatic disc; axile process broadly conical with rounded apex, about twice as wide as high. Cells of berry oval, about $1.9 \mathrm{~cm}$. high by $0.95 \mathrm{~cm}$. wide radially. Seed nearly spherical, with insignificant raphe, about $0.2 \mathrm{~cm}$. in diameter.

\begin{tabular}{|c|c|c|c|c|}
\hline \multicolumn{3}{|c|}{ Floral Organs. } & \multicolumn{2}{|c|}{ Mature Leaves. } \\
\hline Organs. & No. & No. & Length. & Breadth. \\
\hline 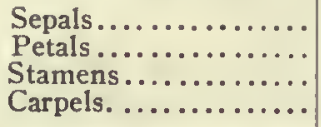 & $\begin{array}{l}4 \\
18 \\
60 \\
15\end{array}$ & $\begin{array}{r}4 \\
19 \\
56 \\
15\end{array}$ & $\begin{array}{l}\mathrm{cm} . \\
43.3 \\
46.0 \\
46.3\end{array}$ & $\begin{array}{l}\mathrm{cm} . \\
38.9 \\
40.0 \\
42.7\end{array}$ \\
\hline
\end{tabular}


Submerged leaves from small tuber 2 or 3 ; first one ovate, acute, or oftener triangular-hastate with acute apex and angles; second leaf much larger, angles slightly rounded, lobes long and narrow, widely diverging, thin and crisped or even twisted. First floating leaf ovate, abruptly acuminate, broadest opposite the insertion of the petiole, slightly crenulate; sinus deep, margins straight or slightly curved, slightly divergent or touching or overlapping, angles narrowly rounded; upper surface green with a few brown blotches, especially near the margin; under surface green, blotched with brown.

Leaf of mature plant narrowly peltate ( 1.2 to $1.9 \mathrm{~cm}$.), orbicular-ovate, 30 to $45 \mathrm{~cm}$. in diameter, deeply and irregularly sinuate-dentate, with obtuse or rounded teeth

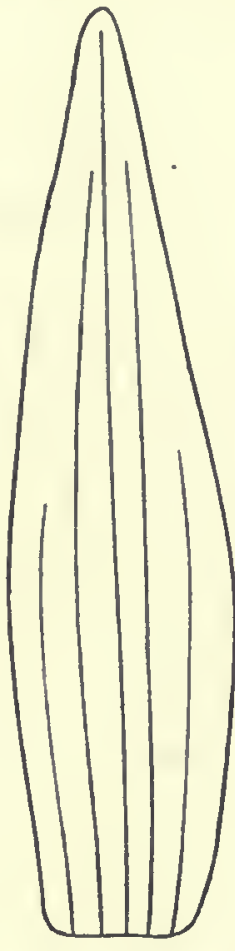

a

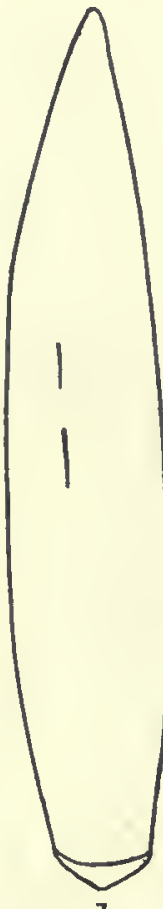

6
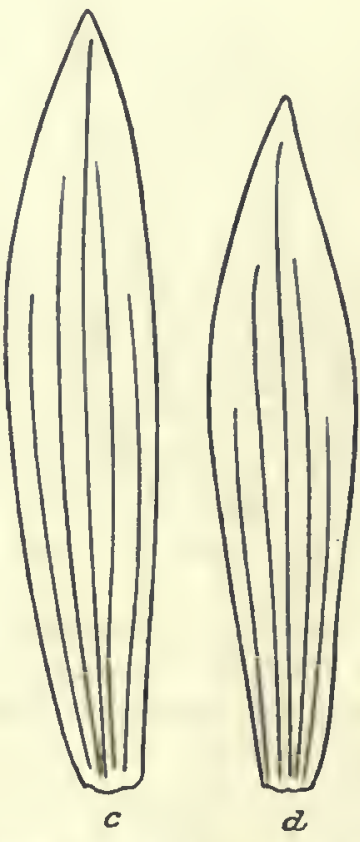
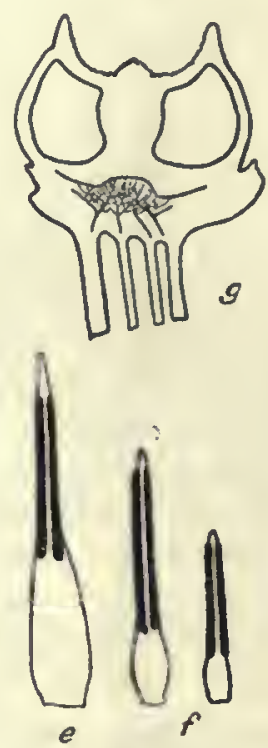

FIG. 3t.-Nymphaea Ravo-virens: $a$, sepal; $b$, petal of outermost whorl; $c$, petal of second whorl; $d$, petal of third whorl; e, outer stamen; $f$, inner stamens; $g$, vertical section of ovary. Natural size.

$1.2 \mathrm{~cm}$. long and $2 \mathrm{~cm}$. apart, rarely nearly entire; pea-green above, paler below; veins prominent beneath, primary nerves 7 to 9 on each side; length of principal area: radius of leaf $=I: I .6$ to $I .75$. - Sinus, depth: length of leaf $=I: 2.5$ to 2.8 ; margins more or less convex, divergent or overlapping; angles rounded.-Petiole terete, $1.2 \mathrm{~cm}$. in diameter, 60 to $150 \mathrm{~cm}$. long.

Rhizome (tuber) erect, stout, $3.8 \mathrm{~cm}$. long by $2.9 \mathrm{~cm}$. thick to $21 \mathrm{~cm}$. long by Io $\mathrm{cm}$. thick (!), brownish-black, very rough with projecting leaf cushions, each capped by the dried base of the petiole and marked on the under side with root scars; upper 


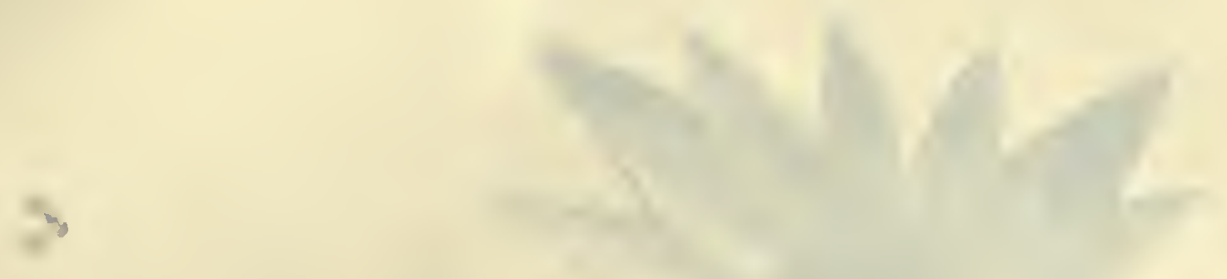

.

, 


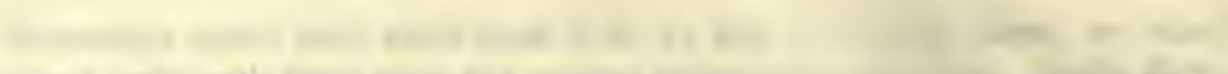

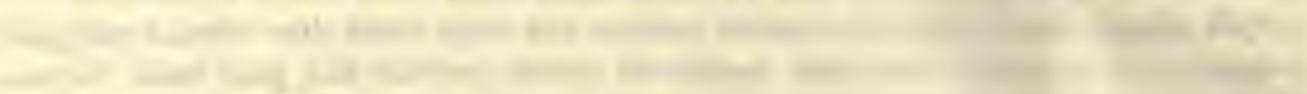

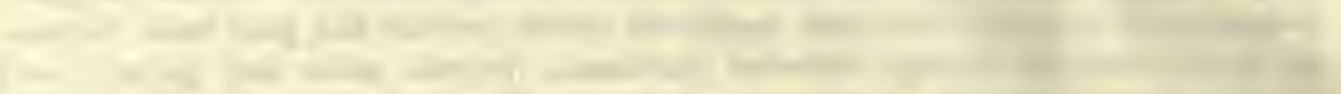

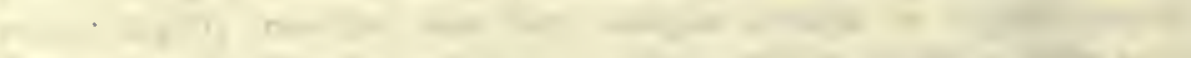

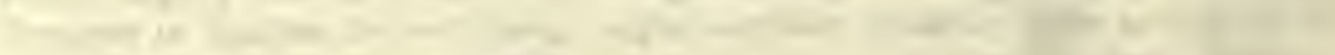

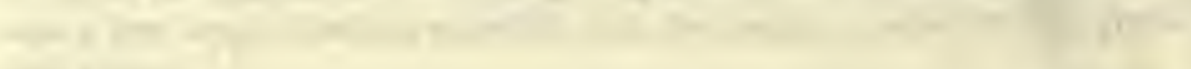

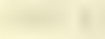

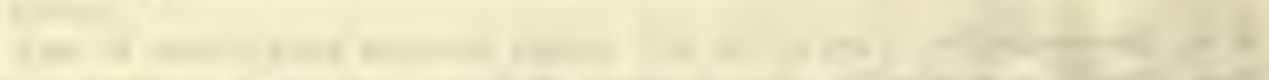
10

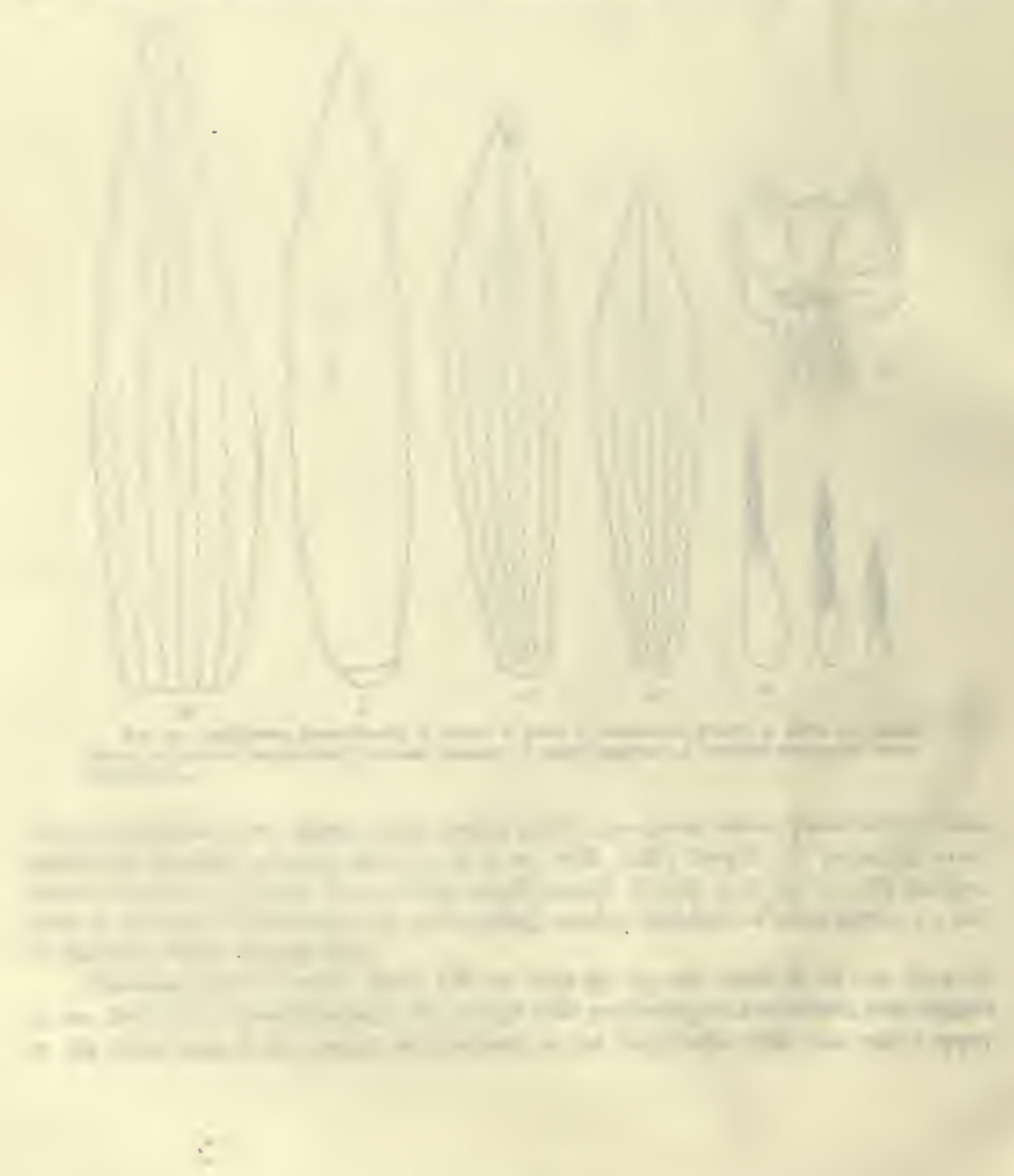




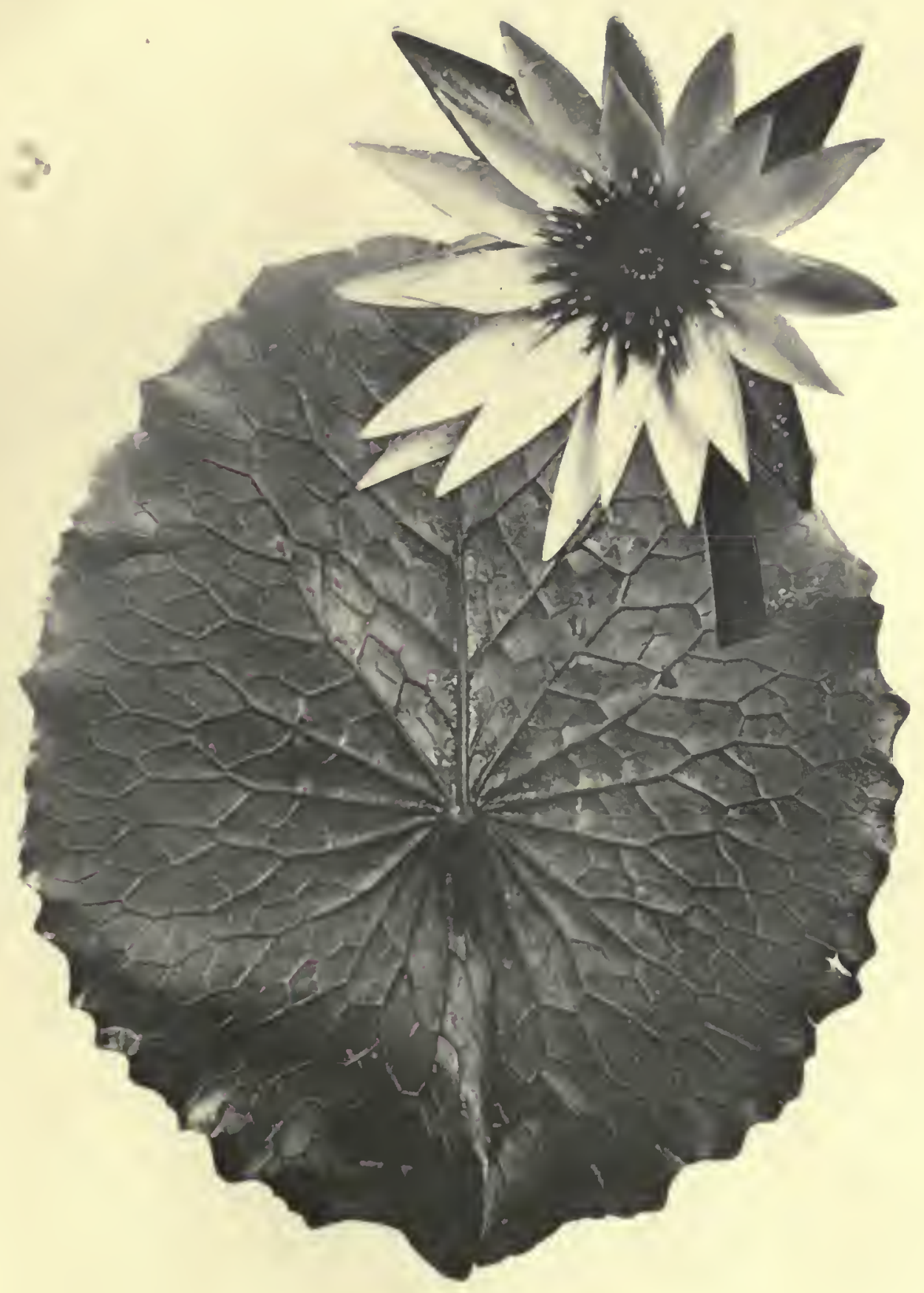

NYMPHAEA FLAVOVIRENS. 
. 
quarter of tuber clothed with long light brown hairs, above which the stout soft leafrudiments may project visibly even in the dried state. Phyllotaxy of a high order, but the leaf scars are 1.2 to $1.9 \mathrm{~cm}$. apart, and by their dry projecting habit give the tuber somewhat the appearance of a rough pine-cone.

Measurements of Leaves from Small Tuber, in Centimeters.

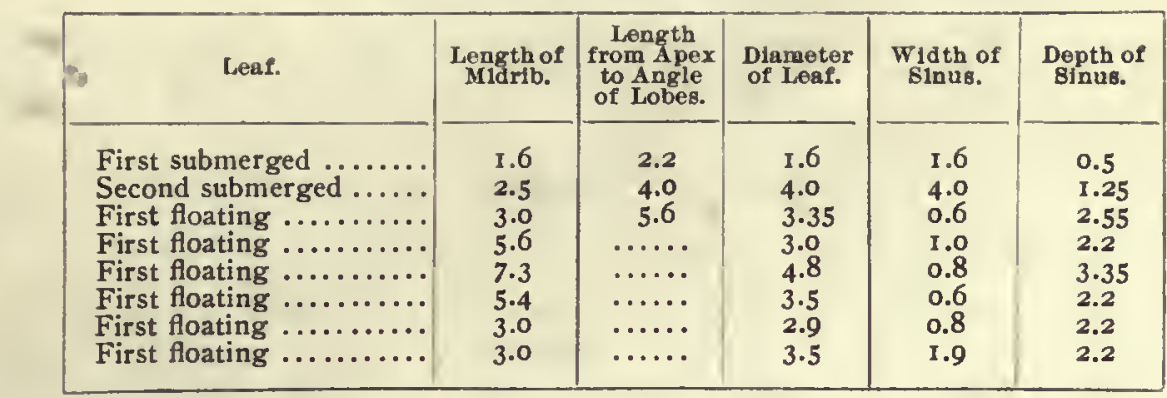

Geographic Distribution.-Uncertain.

Notes.-This species has been known for ten years in American gardens as $N$. gracilis. An examination of Zuccarini's types shows this name to be mistaken, while the plants agree well with the types of $N$. flavo-virens both of Lehmann and Hooker. Concerning its original home there is some doubt. Lehmann's type in hb. Kew is marked "Hort. Bot. Hamburg 1864, ex hb. Reichenbach fil." The plant figured in the Botanical Magazine was grown at Kew from stock received in 1892 from W. N. Pike, Floral Park, N. Y., under the name of N. mexicana. The present stock in American gardens was collected by Mr. C. G. Pringle and introduced by Mr. E. D. Sturtevant, then of Bordentown, N. J., previous to I894 (G. \& F. I894 b). Of Mr. Pringle's Plantae Mexicanae, No. $389 \mathrm{I}$ is labeled "Nymphaea gracilis Zucc.," and agrees well with the types. Concerning the herbarium specimens and the living plants, however, Mr. Pringle writes as follows under date of September I8, I904 (received while the present chapter was in press): "No. 3891 of my Plantae Mexicanae was collected in an artificial pond near the station of El Castillo some fifteen miles east of Guadalajara; and from the same station I gathered, at the end of the season, when they were lying dry on the surface of the soil and resembling pine cones (the water of the pond had then been drawn off) the tubers which I suppose were supplied to Dr. Sturtevant through my associate, Mr. F. H. Horsford, of Charlotte, Vermont. I am sure of these facts." In G. \& F. 3:415 (1890) Mr. Pringle writes: "Nymphaea gracilis I only know in the region drained by the Lerma, yet this is a wide region, extending from Aguas Calientes and San Luis Potosi on the north to near the City of Mexico on the east and south and to beyond Guadalajara on the west." Is $N$. flavo-virens Lehm. merely a cultivated form of $N$. gracilis Zucc. (=N. ampla DC.)?

This is a robust species, and very resistant in the resting state. It hybridizes very readily with pollen of $N$.zanzibariensis, from which cross beautiful garden varieties have arisen and been named in several places, e. g. N. Astraea, N. Greyae, N. mauvii, $N$. Wm. Stone, N. Mrs. C. W. Ward, N. gracilis azurea, N. g. purpurea, N. g. rosea perfecta, N. g. rubra. 


\section{Nymphaea stellata Willdenow.}

Leaves elliptic-orbicular, rather broadly peltate; margin irregularly sinuate; lobes obtuse; upper surface green; pink or blue-violet beneath. Flower 5 to $12 \mathrm{~cm}$. across, pale blue (varying to pink or white), open from 8 a. m. to 2 p. m. Buds ovate; sepals with minute blackish dots. Petals II to I4, dull white at base; stamens 33 to 54; appendage blue, anthers and filaments pale yellowish.

Nymphaea stellata, Willdenow 1797. Andrews tab. 330. Aiton 1811. DeCandolle 1821 $b, 1824$. Wight \& Arnott I834. Planchon $1853 b$. Rev. Hortic., 1854a, 1855 b, col. plate. Caspary 1865 in part; 1877 . Conard 1901 a.

Castalia stellaris, Salisbury 1806 a.

N. malabarica, Poiret, in Lamarck 1802 , fid. original specimen coll. Sonnerat, Isle de France, from hb. Lamarck, in hb. Paris.

N. stellata var. parvifora, Hooker \& Thomson, 1855.

DEsCription.-Flowers small, 5 to $13 \mathrm{~cm}$. across, open on three successive days from $8 \mathrm{a}$. m. to 2.p. m., nearly odorless. $-B u d$ oblong, ovate, rounded at apex.Peduncle terete, slender, rising well above the water-surface.-Sepals 4 , oblong, subovate-triangular, breadth: length $=\mathrm{I}: 2.8$ to 3.5 , margins nearly straight toward the apex; outer surface light green, uniform or marked with minute dark purplish lines; inner surface bluish-white.-Petals to to 16 , lanceolate, acute, shorter than the sepals, pale blue above, yellowish-white at base.-Stamens 33 to 54, with small blue appendage; anthers and filaments pale yellow.-Carpels Io to I7; styles short-triangular, usually apiculate, obtuse; breadth:length $=\mathrm{I}: \mathrm{I}$ to $\mathrm{I} .5$; stigmatic ray terminating on the style in a short obtuse triangle, breadth : length $=\mathrm{I}: 0.5$ to 0.7 . Stigma slightly concave. - Seed elliptic globose, diameter: length $=0.8: 0.9 \mathrm{~mm} . ;=0.8: 1.0 \mathrm{~mm}$. , gray.

Leaf of adult plant rather broadly peltate; breadth of pelta: depth of sinus $=\mathrm{I}$ : 6 to Io; outline sub-orbicular-elliptic, 12 to $15 \mathrm{~cm}$. in diameter, irregularly sinuaterepand, or subentire, rounded or slightly retuse at apex; upper surface bright green, sometimes faintly brownish blotched; under surface purplish to deep blue-violet, with green veins. Primary veins 9 to I I on each side of leaf; length of principal area: radius of leaf = I:I.4 to $1.6 .-$ Sinus deep, usually open; margins nearly straight; angles slightly produced, acute or obtuse.-Rhizome ovoid.

Geographic Distribution.-Southern and southeastern Asia and neighboring islands, Java, Borneo, and the Philippines. Malabar, Tanjore in India (Hainan, coll. C. M. \& A. Henry, No. 8382).

Var. cyanea (Roxburgh) Hooker \& Thomson.

Flowers of medium size, blue, with faint odor or none.

Nymphaea cyanea, Roxburgh 1824. Wight \& Arnott 1834.

N. stellata $\beta$, Sims 1819 . Planchon $1853 b$.

Var. versicolor (Roxburgh) Hooker \& Thomson. (Plate VII.)

Flowers of medium size, pink; stamens numerous. Leaves sinuate, pink beneath, marked above and below with pustules $\mathrm{I}$ to $2 \mathrm{~mm}$. in diameter.

Nymphaea versicolor, Roxburgh, in Sims 1809. Roxburgh 1814, 1824. Planchon $1853 b$.

$N$. punctata, Edgeworth $1845=N$. Edgeworthii Lehmann $1852 b$, fid. original specimen, coll. $M$. P. Edgeworth, 1844, Sadhoura, India, in hb. Kew. Not N. punctata Kar. \& Kir. I841? 


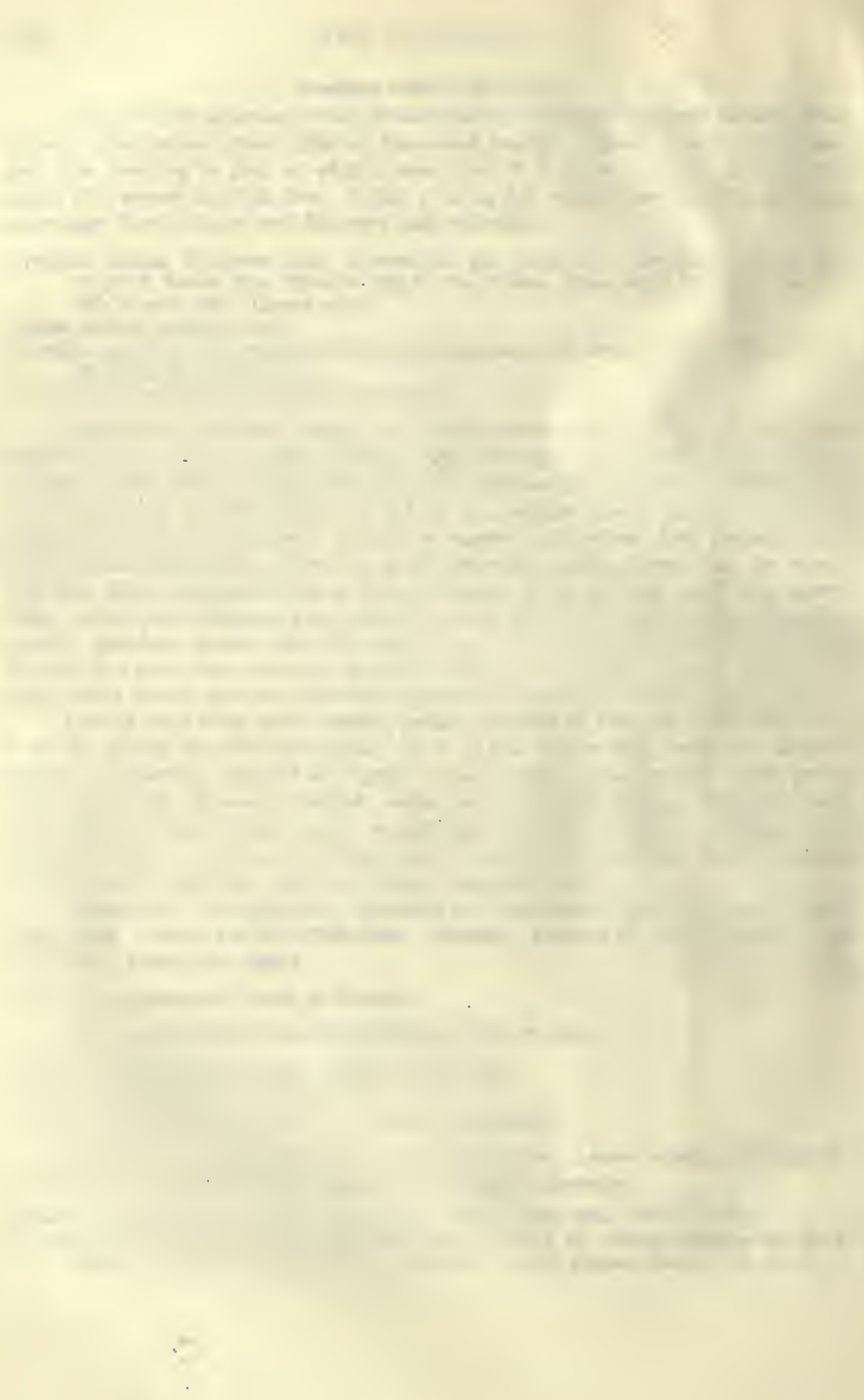




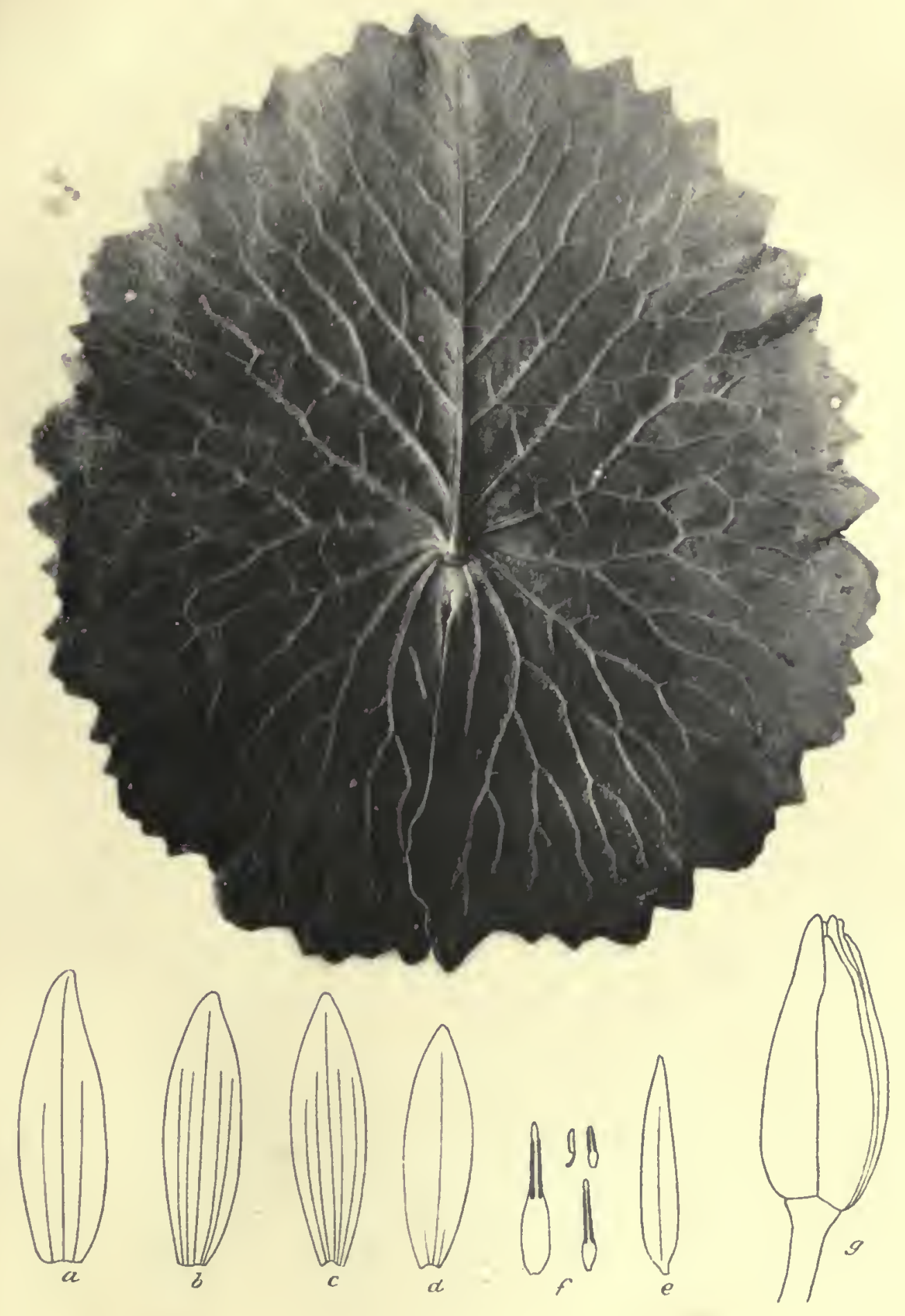

NYMPHEEA STELLATA VERSICOLOR. . 

N. rhodantha, Lehmann $1853 a$, fid. specimen coll. Cumming, No. 702, "in insulis Philippin.," from hb. Lehm. marked in the handwriting of Lehmann, in hb. Berlin.

N. Hookeriana, Lehmann I853a, fid. original specimen marked in handwriting of Lehmann, coll. Hooker \& Thomson, Dec. 19, I850, at Noapolly, Bengal, from hb. Lehm. in hbb. Berlin, Kew. $N$. bella, Lehmann $1853 a$, as to the flower; leaf is of $N$. pubescens, fid. original specimen from hb. Lehm. in hb. Berlin.

Nores.-Hooker \& Thomson record, and the herbaria bear them out, that no sharp line could be drawn between the varieties of this species as it occurs in India, but they were certainly wrong in including the African plants. The three extreme Indian forms are themselves fairly recognizable. The margin of the leaf may be almost entire. The pustules so evident on the leaf of our $N$. versicolor cultivated from seeds sent by Mr. Gollan of Saharanpur, India, may be present at times in the other varieties. Our plant also had a great number of bulbils on the caudex, as shown in several herbarium specimens both of blue and pink forms.

Willdenow's description was based solely on the figure and text of Van Rlieede's Flora Malabarica II:53, tab. 27 , and was very brief: "N. foliis integerrimis, lobis divaricatis, acutis, calyce tetraphyllo petalis acutis longiore." Andrews figured the plant in color and later Sims gave a rather larger form than that of Andrews. Planchon figures a plant evidently identical with that of Andrews and Van Rheede, and Caspary (1877) places its description clearly in parallel columns with the allied forms $N$. caerulea, capensis, and zanzibariensis. Of these it comes much nearest to $N$. caerulea, but is plainly distinct. I have been unable to find it in American gardens.

The flowers of this species, according to Caspary (I877), are regularly self-pollinated, often while still in the bud; it refused to cross with $N$. caerulea under Caspary's management.

Rose-colored and white varieties of $N$. stellata sent from Canara to Caspary by the missionary Zeigler in 1869 were long cultivated in the botanic garden at Königsberg.

\section{Nymphaea caerulea Savigny. (Plate VIII; Fig. 55.)}

Leaves entire or slightly wavy at base, orbicular or ovate-orbicular, narrowly peltate, becoming 30 to $40 \mathrm{~cm}$. in diameter; green above; under surface green with small dark purple spots, purplish all round near margin. Flowers 7 to $15 \mathrm{~cm}$. across, open from 7.30 a. m. to $12 \mathrm{~m}$. Buds conical. Sepals thickly marked with black lines and dots. Petals 14 to 20 , lanceolate, light blue above, lower half dull white. Stamens 50 to 73 ; appendage long $(0.5 \mathrm{~cm}$. on outermost stamens), slender, pale blue.

Nymphaea caerulea, Savigny I802, fid. original specimens coll. Delile, I798, near Cairo. Ventenat I803. Delile 1813. DeCandolle $1821 b$. Planchon $1851 a, 1853 b$. Caspary 1877. Wildeman \& Dur. I900. Conard I90I $a$.

N. stellata, Caspary 1865 in part, 1873. Boissier 1867 , I888. Oliver I868; and of many authors and collectors. Not Willdenow 1797 .

N. maculata, Schum. \& Thonn. 1829, fid. original specimens from Copenhagen, kindly loaned by the curator of the herbarium. Welwitsch ms. in hb. Paris.

$N$. poecila, Lehmann $1853 a$, fid. original specimens from hb. Lehmann seen in hb. Berlin.

N. scutifolia, Tricker 1897. Not Castalia scutifolia, Salisbury 1806 a.

$N$. discolor, Lehmann $1853 a=N$. caerulea, Kotschy MS. (see note).

Casialia stellaris, Salisbury $1806 b$ (in part).

C. caerulea, Tratinnick I822. 
DESCRIPTION.-Flowers 7 to $17 \mathrm{~cm}$. across, light blue, with a faint and characteristic sweet odor, open on 3 days from 7.30 a. $\mathrm{m}$. to $12 \mathrm{~m}$. (4 days, 8 a. $\mathrm{m}$. to $2 \mathrm{p} . \mathrm{m}$. Casp. 1877).-Bud distinctly conical, with straight sides, obtuse, abruptly contracted below to the receptacle, $7 \mathrm{~cm}$. long by $2.5 \mathrm{~cm}$. in diameter at base.-Receptacle nearly three times as wide as peduncle, spreading out at about $45^{\circ}$ from the vertical, pale purplish green.-Peduncle terete, 0.6 to $0.8 \mathrm{~cm}$. in diameter, 18 to $38 \mathrm{~cm}$. long, most slender about $1.25 \mathrm{~cm}$. below flower, smooth, dull brownish-green; main air-canals 6 , surrounded by a circle of 12 smaller ones.-Sepals 4, broadly lanceolate, breadth: length $=1: 2.8$ to 4.7 , the sides nearly straight in upper two-thirds, somewhat converging below to the broad base; apex rounded. Outer surface dark green, thickly flecked with purplish-black dots and lines most dense near margins of sepal and midway of length; the green ground-color assumes a yellowish tint near base of sepal. Seven
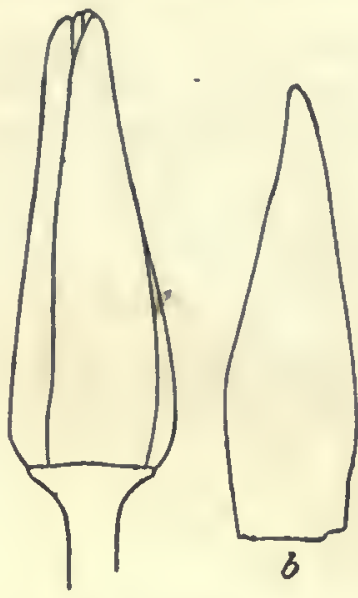

a
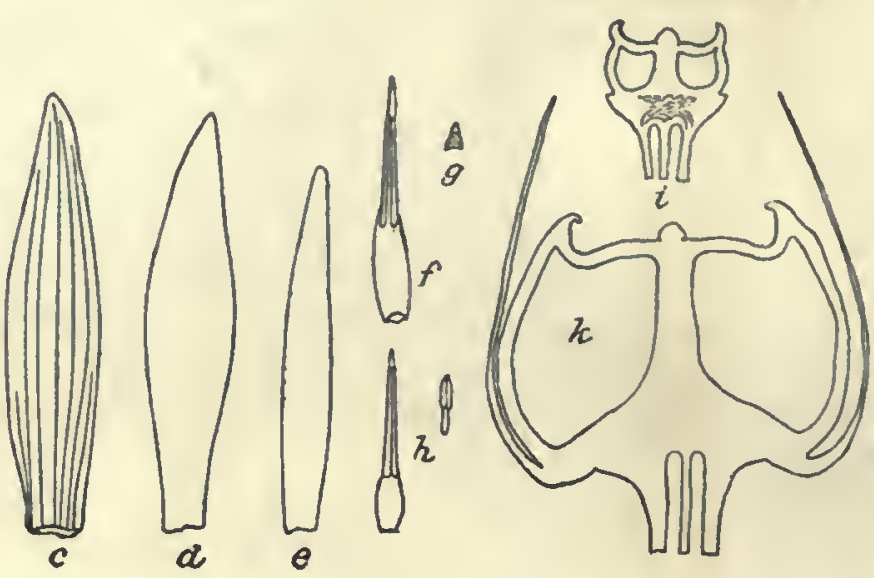

FIa. 35 -Nymphaca caerulea: $a$, closed flower; $b$, sepal; $c, d$, $c$, outer, medlan, and inner petals; $f, h$, stamens; $\sigma$, carpellary style viewed en face; $i$, vertlcal section of ovary; $k$, vertical section of fruit. Reduced about one-half.

longitudinal veins can be seen by looking through the sepal at the light. Inner surface dull white, tinged blue on midline near apex, greenish and veiny and semi-translucent in lowest three-quarters of length.-Petals 12 to 20 , of moderately firm texture, opening about $30^{\circ}$ above horizontal, about as long as the sepals. They stand in 3 series: first, a whorl of 4 , alternate with the sepals; second, a whorl of 8 , one on each side of each outer petal; third, a whorl of 8 alternate with the second, but usually imperfect, consisting of only 2 to 5 petals on one side of the flower, rendering it so far unsymmetrical. Outermost petal narrowly elliptic-lanceolate, obtuse, with rather broad insertion ( $0.8 \mathrm{~cm}$. in Flower No. 3, see table of measurements), not at all concave; outer surface colored on lower half and on the midline dark green with black spots exactly like the sepals; one-third of width at margin on each side, above, colored pale blue; inner surface white on lower half, becoming translucent and 7 -veined at base, shading above to a pale sky-blue at apex and on upper margins. Petals of second whorl shorter than those of the first, rhombic-lanceolate, narrowed at apex and base, 5-veined 


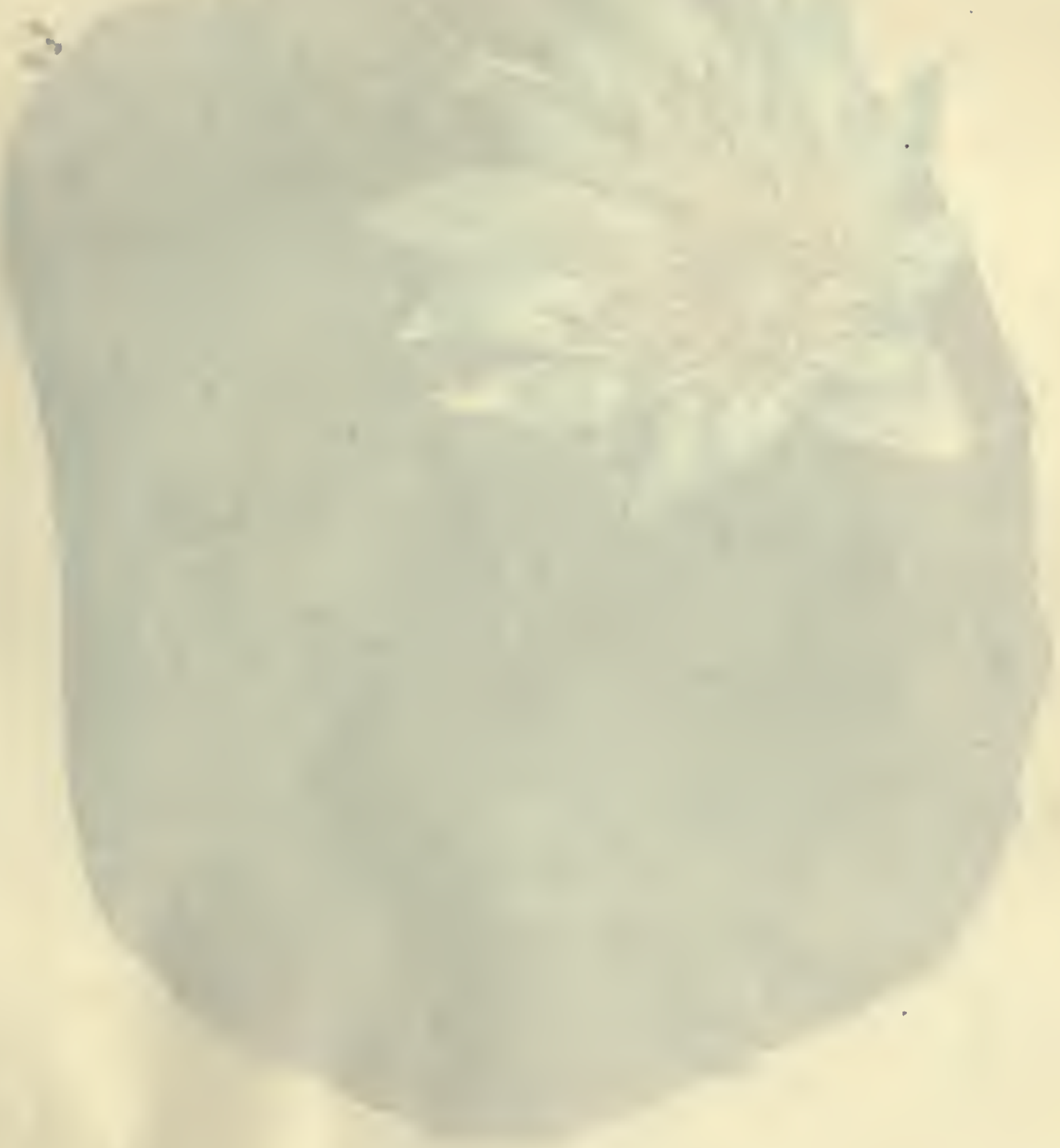





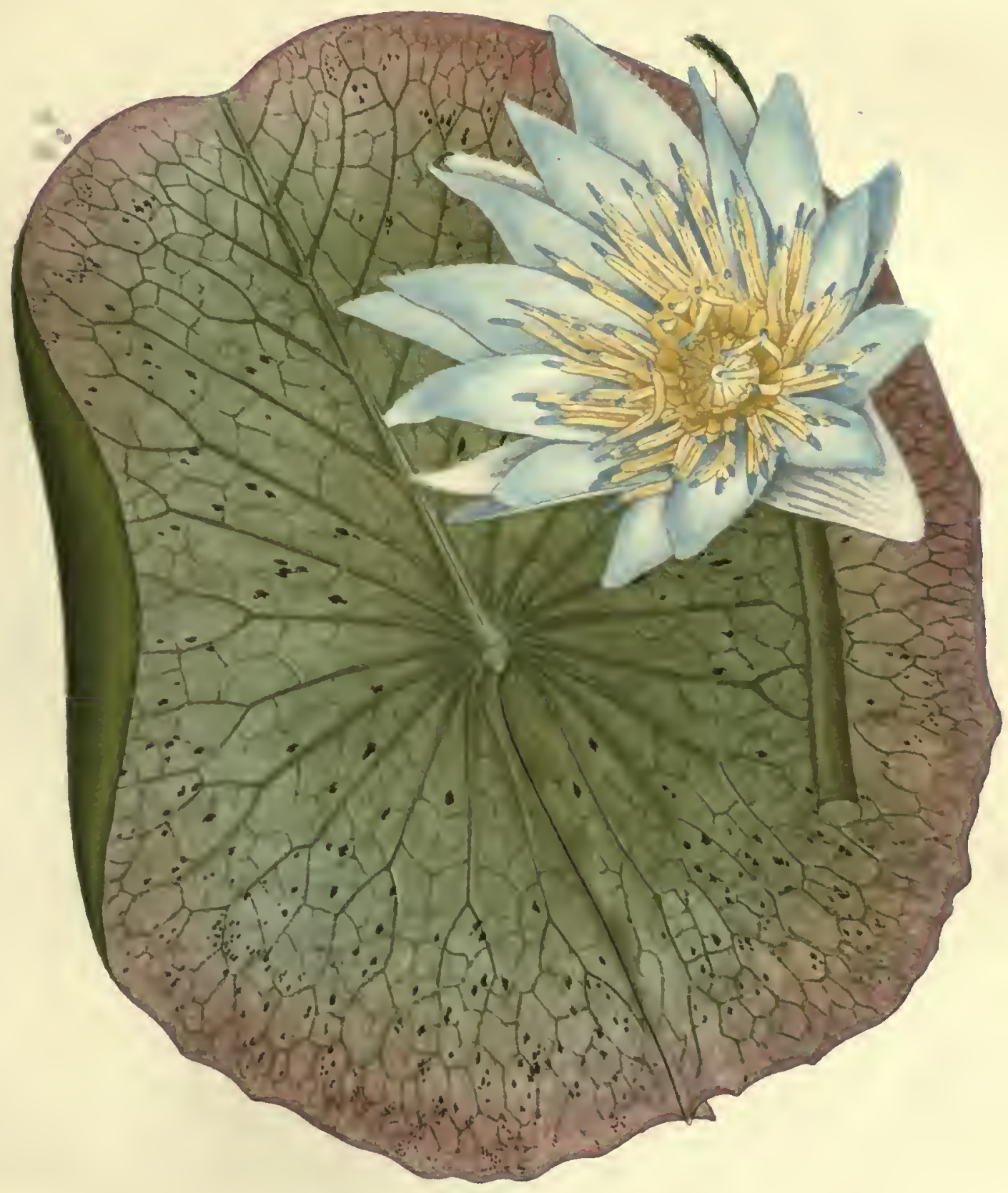



below, white on the lower third, pale blue above, pure sky-blue at apex, the blue and white shading together insensibly, the latter predominating in two-thirds of length on inner surface of petal. Petal of third (innermost) whorl linear-lanceolate, obtuse, blue at apex; outer surface with white margins in lower three-fourths of length, the blue continuing half way down the midline; on inner surface, white prevails on lower fivesevenths of length.-Stamens 50 to 73 , sometimes appearing inserted without order, sometimes indistinctly spiral, often in about 16 vertical ranks of 3 to 5 stamens each. Outermest stamens with short and rather broad filaments and long acuminate anther with two long, nearly parallel anther cells and proportionately long, acute, 3 -angled appendage, one angle pointing inward; blue at tip and half-way down, yellowish-white below. Median stamen has short, broadly elliptic filament, very long parallel anther cells, and short appendage; anther and filament bright yellow, only the appendage blue. Innermost stamen bright yellow all over, short, stout; anther broader and longer than filament; no appendage.-Ovary nearly hemispherical (e. g., I.9 cm. in diameter by $0.95 \mathrm{~cm}$. high; $0.4 \mathrm{~cm}$. by $0.24 \mathrm{~cm}$.). - Carpels $\mathrm{I} 4$ to $2 \mathrm{I}$; styles short $(0.3 \mathrm{~cm}$. long by $0.08 \mathrm{~cm}$. in diameter), fleshy, nearly erect, subacute, concave inward, all alike, pure yellow, papillose up to about $0.08 \mathrm{~cm}$. from apex, the papillose area ending roundly. Stigma nearly flat, bending upward on the styles, yellow. Axile process rising abruptly from the stigma, broader than high (height : breadth $=\mathrm{I}: \mathrm{I} .5 ;=0.24 \mathrm{~cm}$.: $0.38 \mathrm{~cm}$.) and somewhat conical in shape, with obtuse tip, of a whitish color.-Fruit large, round ( 4.5 to $6.4 \mathrm{~cm}$. in diameter by 2.5 to $3.8 \mathrm{~cm}$. high), truncate above, with deep radiating fissures between the carpels, flattened or even excavated beneath around the peduncle, of a pale green color, becoming translucent and brownish, crowned with the hard, slightly enlarged styles, and surrounded by the sepals and outer 4 petals, all of which are dark green and spotted as in the flower. The peduncle makes a large, rude spiral turn, holding the fruit still erect but with its base nearly or quite resting on the earth.-Seed ellipsoidal, acuminate at the hilum, $0.17 \mathrm{~cm}$. long by $0.12 \mathrm{~cm}$. in diameter, dull olive brown; surface marked with about 14 interrupted longitudinal lines of minute hairs; raphe evident, not prominent. Aril longer than the seed.

Germination may take place immediately on ripening, or the seeds will withstand drying over winter. First leaf of seedling filiform, 1.6 to $1.9 \mathrm{~cm}$. long. Second leaf broadly elliptic on a petiole about $2.5 \mathrm{~cm}$. long; blade about $1.27 \mathrm{~cm}$. long by $0.6 \mathrm{~cm}$. wide. Third leaf broader and shorter. Fourth leaf deltoid-ovate with rounded angles and apex, and truncate base; lamina $1.6 \mathrm{~cm}$. long by $1.27 \mathrm{~cm}$. wide at base ; later leaves finally deltoid-cordate, with rounded apex and angles, and rather deep sinus. First floating leaves nearly orbicular, 2.5 to $3.8 \mathrm{~cm}$. in diameter, entire; sinus deep with straight and touching margins; under surface marked with irregular blackish spots.

First leaves from tuber submerged, 2 or 3 on each shoot; the first one may have a minutely denticulate margin, I cm. long by $0.3 \mathrm{~cm}$. wide ; or, more commonly, the lamina is entire, broadly deltoid, $3.2 \mathrm{~cm}$. long by $3.2 \mathrm{~cm}$. wide at base, with rounded angles, and petiole 2.5 to $3.8 \mathrm{~cm}$. long. A third one may be produced, of oval shape, fissi cordate, with deep open sinus and rounded apex, $3.8 \mathrm{~cm}$. long by $2.9 \mathrm{~cm}$. wide. First floating leaves from tuber like those of seedling, but larger; perfectly entire.

Leaf of mature plant very narrowly peltate ( $1: 14$ to I6, Casp. 1877), ovateorbicular to orbicular, 30 to $40 \mathrm{~cm}$. in diameter $(33 \mathrm{~cm}$. long by $30.6 \mathrm{~cm}$. wide), soft, 
thin and quickly withering, slightly wavy or sinuate in the basal half, apex slightly emarginate, dark green and obscurely veiny above, color darker over insertion of petiole. Under surface paler green, with numerous small dark purple blotches, which are larger near the midrib than at the periphery; margins purplish, shading from dark redpurple at the extreme edge to green, the transition taking place in the course of about I $\mathrm{cm}$. near sinus angles, in about $2.5 \mathrm{~cm}$. at apex of leaf. Veins prominent out to the fifth grade; primary nerves 6 to Io on each side of leaf. Petiole attached by quite a strong "collar." Length of principal area : radius of leaf $=\mathrm{I}: \mathrm{I} .3$ to $\mathrm{I} .7$. - Simus usually closed; depth: length of leaf $=\mathrm{I}: 2.7(=\mathrm{I} 3.5 \mathrm{~cm} .: 35.7 \mathrm{~cm}$. $)$; margins doubly curved, convex and overlapping above, separating about $2.5 \mathrm{~cm}$. from periphery of leaf and becoming parallel; angles subacute, slightly produced, about $0.6 \mathrm{~cm}$. apart.-Petiole terete, or flattened near the leaf, about $0.6 \mathrm{~cm}$. in diameter, dull brownish-green; with 2 larger upper air-canals, and 2 smaller ones below, and a ring of 12 still smaller ones outside.-Stipules smooth, fused at base, short, distant above, acuminate, very acute; I.9 to $2.2 \mathrm{~cm}$. long, $1.3 \mathrm{~cm}$. wide at base; free portion I.I to $1.6 \mathrm{~cm}$. long, $0.5 \mathrm{~cm}$. wide; tips 0.9 to $1.2 \mathrm{~cm}$. apart.

Rhizome (tuber) erect, thick, ovoid, 2.5 to $7.5 \mathrm{~cm}$. long by 2 to $6.4 \mathrm{~cm}$. in diameter, blackish, apex protected by leaf-bases and long fine hairs. Phyllotaxy of a very high order, the leaf-bases completely covering the larger rhizomes, leaving only about $0.3 \mathrm{~cm}$. around each one. Roots springing from the bases of the petioles. Offsets formed only when the tuber breaks out from the dried state; 2 or 3 shoots may come from one tuber; the stolon is terminal, very short, the point of origin of new leaves remaining within the coating of long hairs.

\begin{tabular}{|c|c|c|c|c|c|c|c|c|c|}
\hline \multirow[b]{2}{*}{$\begin{array}{l}\text { Sepals....... } \\
\text { Petals ....... } \\
\text { Stamens..... } \\
\text { Carpels.... . }\end{array}$} & \multicolumn{7}{|c|}{ Number of Floral Organs. } & \multirow{2}{*}{$\begin{array}{c}\text { Ideal. } \\
4 \\
20 \\
64 \\
16\end{array}$} & \multirow{2}{*}{ 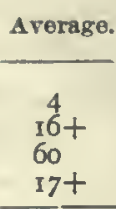 } \\
\hline & $\begin{array}{r}4 \\
17 \\
61 \\
17\end{array}$ & $\begin{array}{r}4 \\
14 \\
50 \\
15\end{array}$ & $\begin{array}{r}4 \\
16 \\
58 \\
16\end{array}$ & $\begin{array}{r}4 \\
20 \\
57 \\
20\end{array}$ & $\begin{array}{r}4 \\
16 \\
69 \\
17\end{array}$ & $\begin{array}{l}4 \\
16 \\
73 \\
21\end{array}$ & $\begin{array}{r}4 \\
14 \\
52 \\
15\end{array}$ & & \\
\hline Totals..... & 99 & 83 & 94 & IOI & 104 & II 4 & 85 & 104 & $97+$ \\
\hline
\end{tabular}

Measurements of Sepals.

\begin{tabular}{|c|c|c|}
\hline Flower. & Length. & Breadth. \\
\hline & $\mathrm{cm}$. & $\mathrm{cm}$. \\
Flower 1.... & 6.8 & 1.9 \\
Flower $2 \ldots .$. & 6.2 & 1.75 \\
Flower $3 \ldots .$. & 7.0 & 1.9 \\
Flower 4..... & $\left\{\begin{array}{l}8.6 \\
8.8\end{array}\right.$ & 2.6 \\
8.8 & 2.9 \\
\hline
\end{tabular}


Measurements of Petals (in centimeters).

\begin{tabular}{|c|c|c|c|c|c|c|c|c|c|c|c|}
\hline \multirow{2}{*}{\multicolumn{2}{|c|}{ Flower 1.}} & \multirow{2}{*}{\multicolumn{2}{|c|}{ Flower 8.}} & \multicolumn{6}{|c|}{ Flower 4.} & \multirow{2}{*}{\multicolumn{2}{|c|}{ Flower 8.}} \\
\hline & & & & \multicolumn{2}{|c|}{ Outermost Whorl. } & \multicolumn{2}{|c|}{ Second Whorl. } & \multicolumn{2}{|c|}{$\begin{array}{l}\text { Innermost (Im- } \\
\text { perfect) Whorl. }\end{array}$} & & \\
\hline Length. & Breadth. & Length. & Breadth. & Length. & Breadth. & Length. & Breadth. & Longth. & Breadth. & Length. & Breadth. \\
\hline $\begin{array}{l}6.7 \\
6.4 \\
6.2 \\
5.7 \\
5.6\end{array}$ & $\begin{array}{l}1.4 \\
1.35 \\
1.2 \\
0.8 \\
0.7\end{array}$ & $\begin{array}{l}6.5 \\
6.3\end{array}$ & $\begin{array}{c}o \mathrm{I} \cdot 4 \\
m \mathrm{I} \cdot 3\end{array}$ & $\begin{array}{l}8.45 \\
8.45 \\
8.3 \\
8.45\end{array}$ & $\begin{array}{r}2.0 \\
1.8 \\
i 2.0 \\
1.9\end{array}$ & $\begin{array}{l}7.8 \\
8.0 \\
8.0 \\
7.8 \\
7.65 \\
7.65 \\
7.65 \\
7.65\end{array}$ & $\begin{array}{l}2.9 \\
2.8 \\
2.8 \\
2.8 \\
2.0 \\
2.0 \\
2.0 \\
1.9\end{array}$ & $\begin{array}{l}7.3 \\
7.3 \\
7.2 \\
7.0\end{array}$ & $\begin{array}{l}1.75 \\
1.5 \\
1.75 \\
1.3\end{array}$ & $\begin{array}{l}5.9 \\
5.6 \\
5.4 \\
5.26 \\
4.95\end{array}$ & $\begin{array}{c}o \mathrm{I} .4 \\
m \mathrm{I} .4 \\
m \mathrm{I} . \mathrm{I} \\
i 0.8 \\
i 0.7\end{array}$ \\
\hline
\end{tabular}

$i=$ inner. $m=$ median. $\quad 0=$ outer.

Measurements of Stamens (in centimeters).

\begin{tabular}{|c|c|c|c|c|c|}
\hline Flower. & Total Length. & $\begin{array}{l}\text { Breadth of } \\
\text { Ftlament. }\end{array}$ & $\begin{array}{l}\text { Length of } \\
\text { Anther Colls. }\end{array}$ & $\begin{array}{l}\text { Breadth of } \\
\text { Anther. }\end{array}$ & $\begin{array}{c}\text { Length of } \\
\text { Appendage. }\end{array}$ \\
\hline $\begin{array}{l}\text { Flower I.... } \\
\text { Flower } 3 \ldots . .\end{array}$ & $\begin{array}{l}3.75 \\
2.7 \\
1.4 \\
0.88 \\
3.7 \\
2.7 \\
0.88 \\
3.5 \\
2.1 \\
1.12\end{array}$ & $\begin{array}{l}0.56 \\
0.4 \\
0.16 \\
0.13 \\
0.56 \\
0.48 \\
0.13 \\
0.48 \\
0.32 \\
0.16\end{array}$ & $\begin{array}{l}1.6 \\
1.6 \\
0.8 \\
0.48 \\
1.6 \\
1.6 \\
0.48 \\
1.6 \\
1.42 \\
0.72\end{array}$ & $\begin{array}{l}0.32 \\
0.24 \\
0.16 \\
0.16 \\
0.32 \\
0.24 \\
0.16 \\
0.32 \\
0.24 \\
0.21\end{array}$ & $\begin{array}{l}0.5 \\
0.3 \\
0.08 \\
0 \\
0.56 \\
0.24 \\
0 \\
0.48 \\
0.16 \\
0.04\end{array}$ \\
\hline
\end{tabular}

Geographic Distribution.-Northern and Central Africa. Cairo, Savigny i802. Damietta and Rosetta, coll. Schweinfurth. Guinea, Schum. \& Thonn. Nubia, Kotschy (see note). Sona Gungu (Distr. of Cataracts), Congo, Wild. \& Dur., 1900. Angola, Welwitsch. Omkenen, Kordofan, coll. Dr. Hendur, No. 890, in hb. Berlin. Cyrenaica, coll. M. Pacho, I826, in hb. Paris.

Var. albifiora, Caspary.

Flowers white; sepals without black spots.

Nymphaea caerulea var. albiflora, Caspary 1877.

N. abbreviata, Guill. \& Perr. 1830 .

$N$. ampla, Kotschy MS. $=N$. nubica, Lehmann (see Note). Not N. ampla, DC. I82 $b$.

Geographic Distribution.-With the type. Rare. Damietta, Egypt, coll. Sieber, fid. Caspary 1877. Egypt, coll. Schweinfurth, 1885, in hb. British Museum. Central Africa, coll. Schweinfurth, No. 2329, in hb. Berlin. Kounoun, Cape Verde, coll. Perrottet, 1831 , in hb. Delessert.

NorE. - The name of this species has had a varied application, as is shown by the synonymy of this and the preceding and following plants. The cause lies partly in 
the close resemblance of $N$. caerulea and $N$. stcllata, and partly in the fact that these and $N$. capensis were introduced into cultivation near the same time, and the descriptive character of the name caerulea made it equally applicable to all. The geographical proximity of this and $N$. capensis may have added to the confusion. Indeed, examination of herbarium material shows that $N$. caerulea is connected by intermediate forms with $N$. micrantha on the west and $N$. capensis on the south. We have not been able to secure living material of $N$. micrantha, but the capensis type is very easily distinguished from the present species. Their hybrid ( $N$. pulcherrima Tricker) is entirely sterile. Other related forms are discussed in their proper places. Many botanists have included all the blue waterlilies of Africa and Asia under the name of $N$. stellata, as did Hooker \& Thoms. (I855) ; Caspary, ten years later, separated off N. capensis, and in 1877 gave exact descriptions of four species in parallel columns; he stated that his old arrangement (1865) needed complete revision, but unfortunately this work was left undone.

The Kotschy collection from Nubia has long been a stumbling block to students of Nymphaea. They are marked No. I66 N. caerulca Sav. and No. I67 N. ampla DC.- "Kotschyi Iter Nubicum. In stagnibus pluvialibus ad radices eurontas montis Cordofani, Arasch Cool, Jan. 5, I84I, d. Oct. 12, 1839." The first is represented in hbb. Kew, Paris, Boiss., Deless., and Berlin. It was marked by Caspary " $N$. capensis Thunb." The Boissier specimen has narrower petals and fewer stamens than the type of capensis; the Berlin specimens differ between themselves-one flower has spotted sepals, and the leaf gently sinuate; another has leaves typical of $N$. caerulea but no spots on the sepal. No. I67 was marked "N. caerulea Sav." by Caspary in hb. Boiss., with the addition of "var. albida" in hb. Paris. The leaf is gently sinuate in the Kew, Deiessert, and one Paris specimen. It is also represented in hbb. Berlin and Boissier. The leaf may or may not have black spots and some purple coloration beneath. The flower resembles that of $N$. caerulea, but was evidently white, and in the Kew specimen, at least, the outer stamen is provided with an unusually long, lanceolate appendage. The two plants seem strikingly intermediate between $N$. capensis and $N$. caerulea. No. 167 is the type of Lehmann's $N$. nubica.

Self-fertilization occurs regularly in this species.

Reference to the importance of $N$. caerulea as the Blue Lotus, the lotus par excellence of Egypt, has been made in Chapter I.

\section{Nymphaea micrantha Guillemin \& Perrottet. (Plate IX.)}

Leaves small, round-cordate, peltate, entire, petiolate; petioles very long, slender; lobes divaricate, acuminate; under surface reddish, marked with violet-black dots; upper surface glabrous, pale green, in mature plants bulbiferous at the summit of the petiole; stigmatic rays $\mathbf{I}$.

N. micrantha, Guillemin \& Perrottet 1830. Hooker 1850. Paxton 1853 a.

N. caerulea, Guillemin \& Perrottet 1830. Not Savigny ISoz.

$N$. caerulea var. albida, Guillemin \& Perrottet $1830=N$. micrantha, Hook.

N. rufescens, Guillemin \& Perrottet 1830.

$N$. stellata var. bulbillifera, Planchon 1852 c. Not $N$. stellata, Willdenow 1797.

$N$. vivipara, Lehmann $\mathrm{I} 852 a, b, \mathrm{I} 853 a, \mathrm{I} 854$.

N. guineensis, Schumacher \& Thonning 1829, fid. Chifflot 1902. 


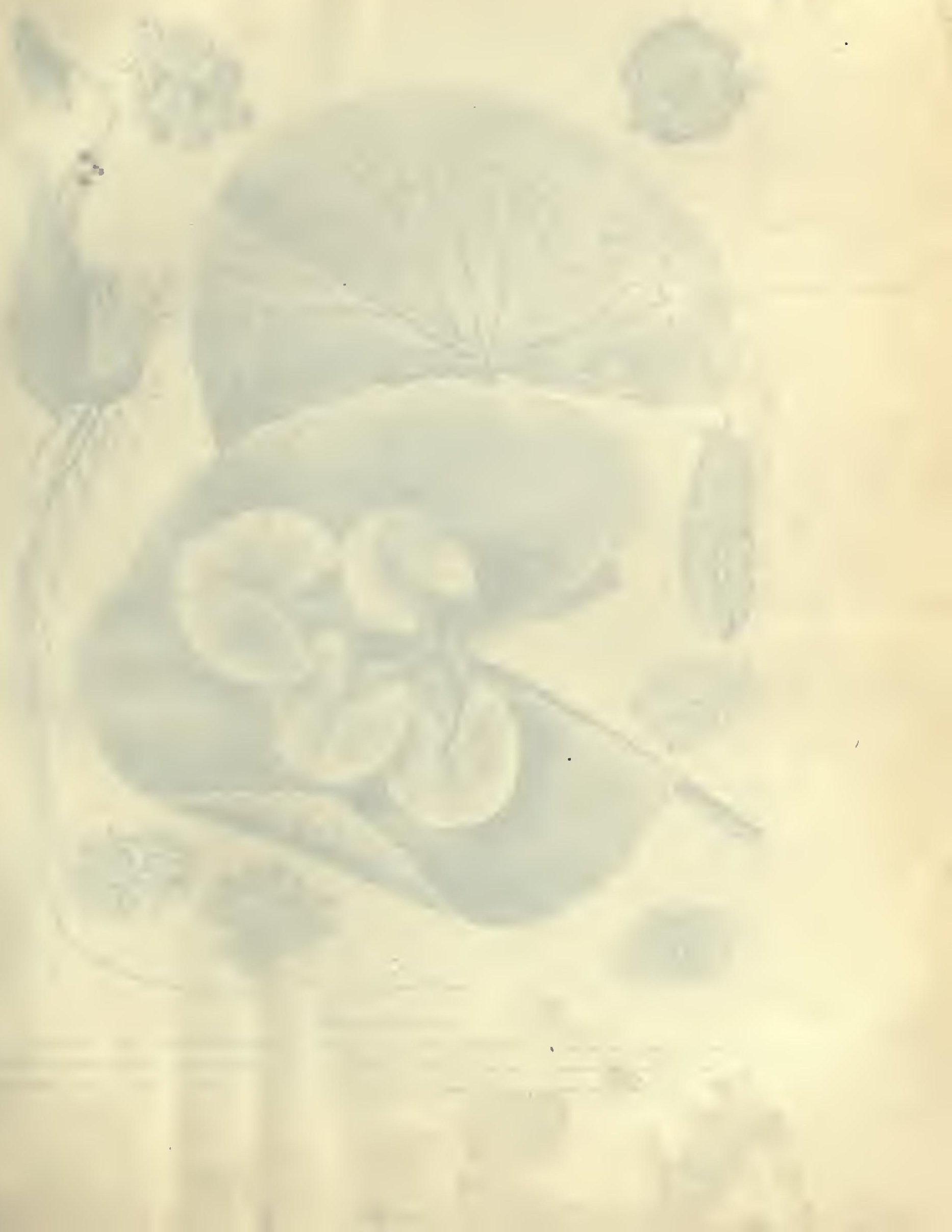





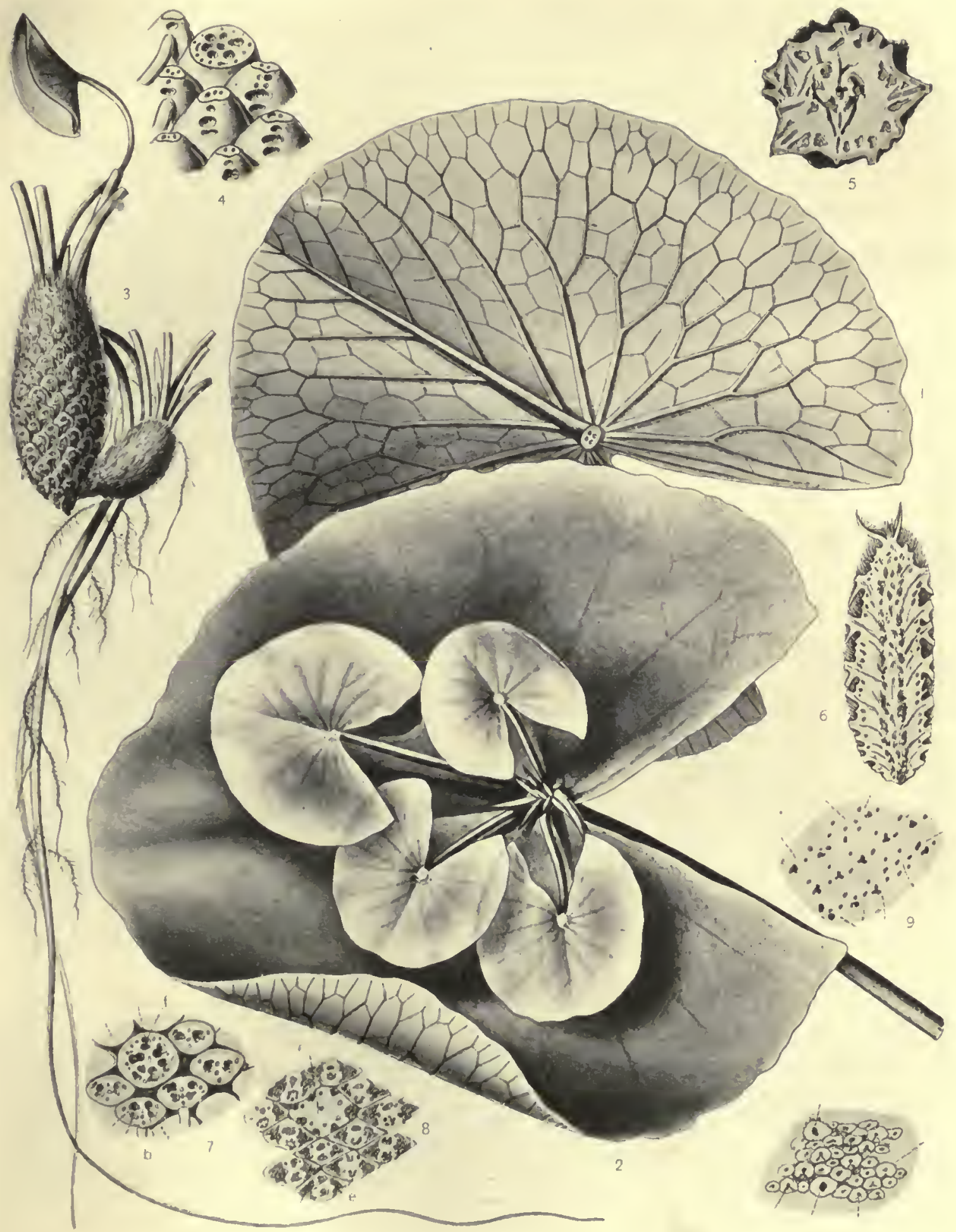

NYMPHEA MICRANTHA.

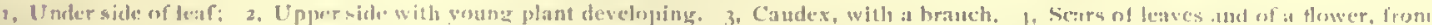

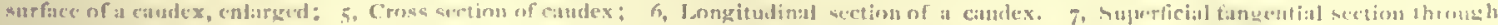



DESCRIPTION.-Sepals 5, narrow, lanceolate, acuminate, with violet dots.-Petals IO, I.3 to $5 \mathrm{~cm}$. long, a little shorter than the sepals, lanceolate, narrow, blue to white. -Stamens numerous; filaments whitish, narrow at base; anthers of various lengths, twice as long as the filaments; appendage short, conic-terete-Ovary round. Seeds very numerous, very small, blackish.-Leaves $7.6 \mathrm{~cm}$. long, $5.1 \mathrm{~cm}$. wide (in the type). - Rhizomes clustered, with soft tawny wool around the bases of the petioles; roots very long.

Geographic Distribution.-West Coast of Africa. In swamps of the peninsula of Cape Verde, near n'Batal; in the Galam region; in the kingdom of Cayor, etc. Flowers almost all the year.

Types.-Coll. Perrottet, I83o, in hbb. Delessert, Kew, DeCandolle. Also coll. E. Holub, Eastern Bamangwato territory, Bechuanaland.

NoTES.-The most striking difference between this and $N$. caerulea Sav. lies in the viviparous habit. Chifflot (I9O2) states, and Planchon's description indicates, that this character does not appear until the second year of the plant's growth. The first year it has nearly white flowers, and corresponds to $N$. guineensis Sch. \& Th.; the second year bulbils appear, but the flowers are small and pale, and the plant corresponds to N. micrantha Guill. \& Perr. Only in the third year, according to Chifflot, does the plant acquire its definite morphological characters.

We do not find either in the specimens or descriptions of Guillemin \& Perrottet any important differences between the several viviparous forms they enumerate. $N$. rufescens is a larger plant; sepal $7.6 \mathrm{~cm}$. long, petals 18 to 20 , stamens very numerous with petaloid filament; carpels 18 to 20 ; leaves I2 to $25 \mathrm{~cm}$. in diameter, more or less spotted beneath, primary veins 12 to 20, prominent; coll. Perrottet, I830, Senegal, seen in hbb. Delessert, Boissier, DeCandolle; also coll. Roger, Dec., 1823, Senegambia, in hb. Kew (with the note "Les graines servent de nourriture aux nègres"); also coll. Buchholz, Eliva Sonanga, Cape Lopez, West Africa, in hb. Berlin. N. caerulea Guill. \& Perr. has "leaves strongly peltate, impunctate, red beneath, lobes long, free, acute"; types coll. Perrottet, I831, Senegal, in hbb. Delessert, Kew; also coll. Leprieur, Sept., I821, " in paludosis prope Ngalete, regio Cago, Senegambia," in hb. Delessert; also coll. C. Barter, Baikie's Niger Expedition, No. 7064, 1858, at Nupe, in hb. Paris. $N$. caerulea var. albida Guill. \& Perr. has larger flowers than the type, with narrow lanceolate petals, nearly white; types coll. Perrottet, Walo, Senegambia, in hb. Delessert; also coll. Leprieur in same district in hb. Delessert. This is apparently identical with $N$. micrantha Hook. Caspary's "N. micrantha Hook." (notes and herbarium, now in hb. Berlin) has an orbicular leaf with wide sinus and obtuse lobes, with or without black spots beneath; petals ovate, white, 3.8 to $4.5 \mathrm{~cm}$. long. This plant was much used by Caspary in hybridization, giving well-marked intermediates with the closely allied $N$. caerulea Sav. (seen in hbb. Kew, British Museum, Berlin).

\section{Nymphaea heudelotii Planchon. (Fig. 56.)}

Flowers small, 2.8 to $5.1 \mathrm{~cm}$. in diameter. Sepals lance-ovate, with black spots outside. Petals 5 to IO, lanceolate, acute, bluish-white. Stamens II to I6; anthers much longer than the filaments. Carpels 4 to Io. Leaves almost or quite entire, ovate 
or orbicular, cleft nearly to the petiole, 2.5 to $8.2 \mathrm{~cm}$. long, reddish beneath, with black specks. Seed smooth.

N. Heudelotii, Planchon $1853 b$, according to the original specimen.

$N$. pseudo-pygmaea, Lehmann $1853 a$, according to the original specimen in hb. Kew, which consists of a submerged leaf, with flower and fruit, much dilapidated, coll. Ileudelot and communicated by hb. Paris.

DESCRIPTION.-Planchon gives the following: Dwarf, glabrous; floating leaves cordate-suborbiculate, very narrowly peltate, with the sinus narrow and nearly closed

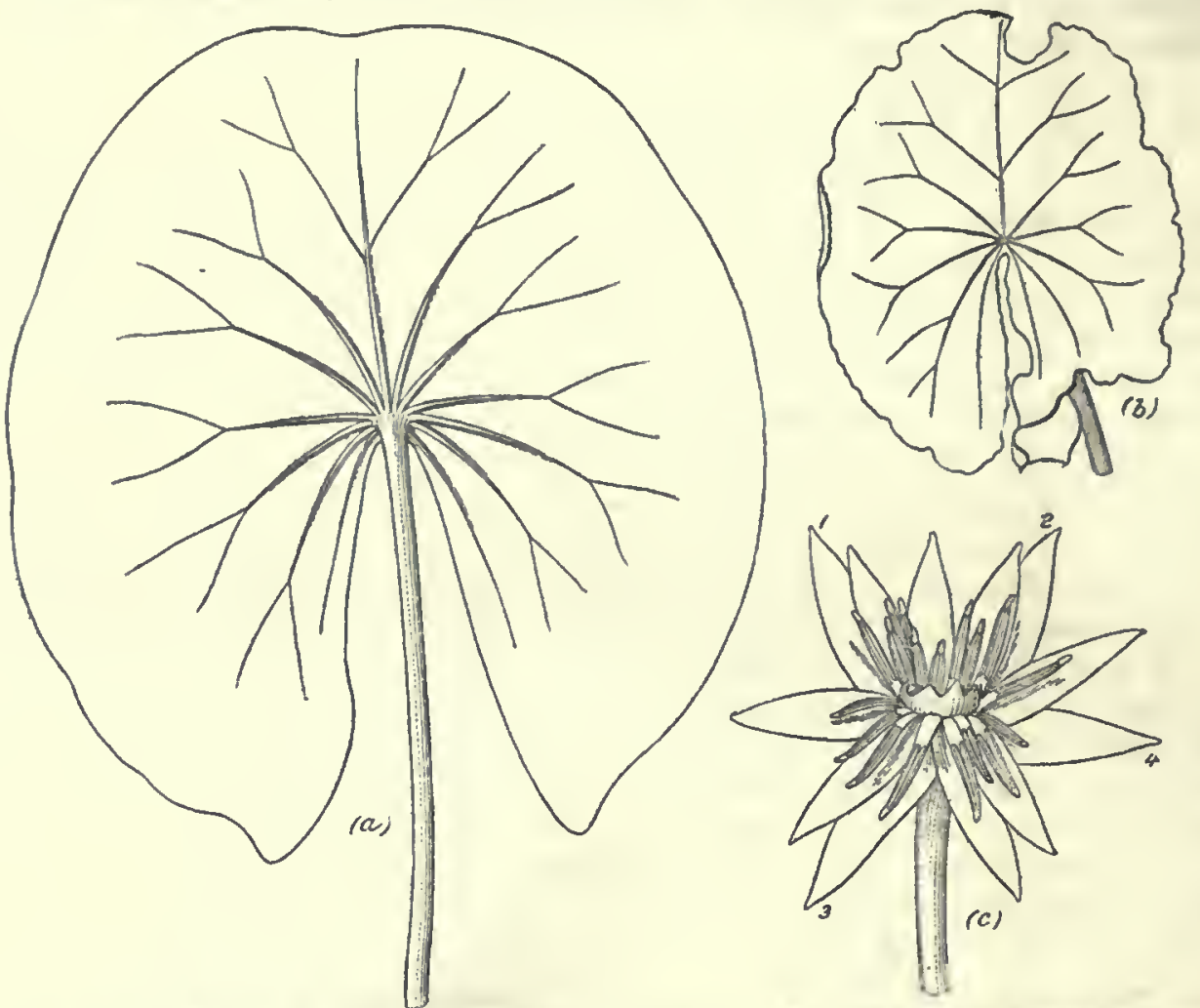

FIG. 56.-Nymphaea heudelotll: $(a)$, (b), leaves; (c), flower; $1,2,8,4$, sepals. From a drawing of the types in the notes of $\mathbf{R}$. Caspary, now in hb. Berlin, by kind permission of the Directors. Natural size.

(in the membranous submerged leaves wide open) ; margin slightly repand; under surface purplish, violet spotted. Flowers small; sepals ovate at base, becoming rather long attenuate, with violet lines outside; petals 5 to 8 , bluish, appendiculate, anthers five to six times longer than the rather broader filaments; rays of the stigma 8 to ro, short, triangular, acute. Fruit globose, shorter than the calyx; seed elliptic-globose, smooth (not costate).

Geographic Distribution.-Senegambia, in shallow flowing streams; Fouta Dhiallon.

Types.-Coll. Heudelot, No. 844, in 1837, seen in hbb. Delessert, Berlin, and Kew. In hb. Kew I saw another specimen consisting of a half-closed flower and two frag- 
mentary leaves, coll. Sierra Leone Boundary Commission, Dec. 22, 1891, in "small streams, Luseniga, Samu." In hb. Berlin is a specimen, coll. Alex. V. Mechow's Exped., No. 480, Jan., I880, at Malange, West Africa, marked N. stellata; also coll. Pogge, No. 559, Jan. 2, "aui der Ueberschwemmung ausgesetzten Stellen am Lulua," and No. 558, Nov. 21, I88I, "Wassertümpel in der Campine am Lulua"; also. coll. Schweinfurth, No. 2329, Oct. 30, 1869, "Land der Djue: Gr. Scriba Ghattes in der Sumpfsteppe im Wasser; Bl. reinweiss."

Var. năa new var. (Fig. 57.)

Sepals 4, lanceolate, obtuse, $I .2$ to $2 \mathrm{~cm}$. long by about $0.32 \mathrm{~cm}$. wide, green outside, with small and distinct or large and diffuse black spots; nearly white within. Petals 7 to Io, lanceolate, acute, shorter than the sepals, I.5 to $\mathrm{I} .7 \mathrm{~cm}$. long, $4 \mathrm{~mm}$. wide, white. Stamens II to I4, yellow, with very short appendage, all nearly alike and about half as long as the petals, apparently in two series. Stigma of 5 to 6 broad carpels, with short, broad styles. Fruit nearly globose, surrounded by all of the floral parts. Seed gray-green, ellipsoid, $1.3 \mathrm{~mm}$. long, $0.88 \mathrm{~mm}$. in diameter.
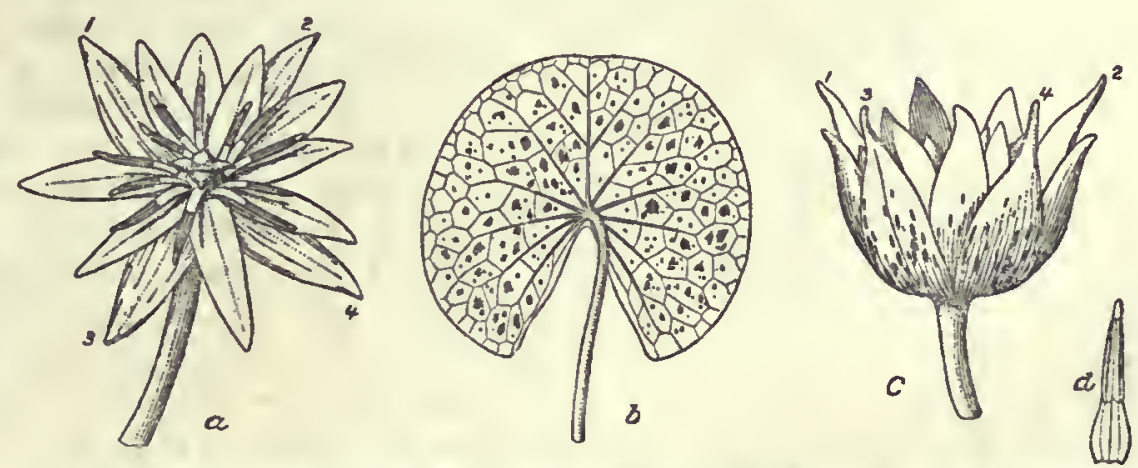

FrG. 57.-Nymphaea heudelotii nana: $a$, open flower, $1,2,8$, 4 , sepals; $b$, under side of leaf: $c$, flower pressed ou one side showing outside of sepals; $d$, stamen; twice natural size. Drawn by J. Pohl from specimens of Baum's No. 655 in hb. Berlin, by kind permission of the directors.

Leaves orbicular, 2 to $3.1 \mathrm{~cm}$. in diameter; pelta $1 \mathrm{~mm}$.; entire, green above, red beneath, with black specks, somewhat coriaceous; primary veins 5 to 6 , depressed; length of principal area: length of radius $=3: 4$; sinus margins straight, diverging, lobes rounded.

Plant glabrous throughout; petioles and peduncles very slender, ${ }_{5} 5$ to $36 \mathrm{~cm}$. long. Caudex an ovoid or globose tuber.

N. Guineensis, Gilg 1903. Baum 1902. Not Sch. \& Th. I829.

Distribution ANd Types.-Coll. H. Baum, No. 655, Jan. I7, I900, KuneneZambesi Expedition, “am linken Longa-Ufer bei Minnesera, I250 m. ü. M., in flachen sumpfigen Gräben, selten." "Eine Miniatur-Nymphaea mit weissen wohlriechenden, höchstens die Grösse eines Markstückes erreichenden Blüten." Seen in hbb. Berlin, Delessert, British Museum, Kew, Munich. 
Notes.-On comparing Mr. Baum's specimens with the originals of $N$. guincensis Schumacher \& Thonning, kindly sent to me at Berlin by the directors of the Museum of Copenhagen, Professor Gilg fully agreed that his former identification of the two was mistaken. Whether the Baum specimens should have specific rank must remain at present a matter of opinion; they are the most divergent forms yet known of a series of African waterlilies leading by slight gradations up to $N$. caerulca Sav. No

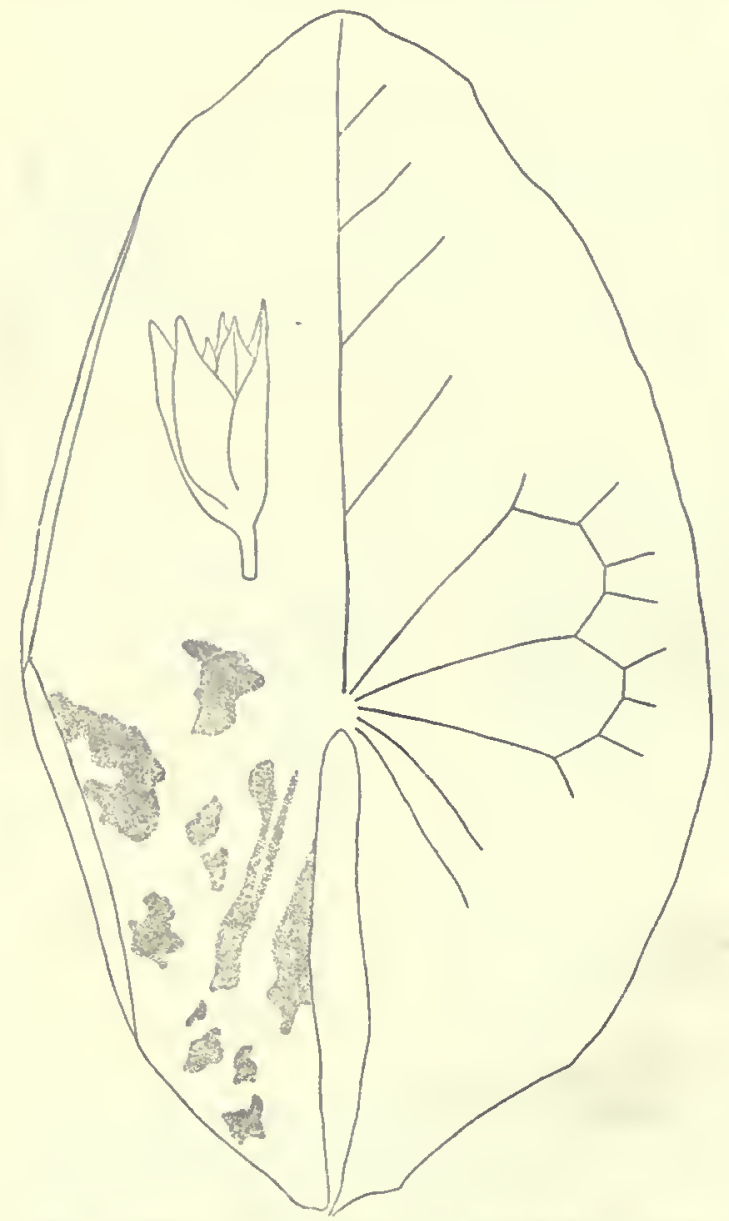

Fia. 58.-Numphaca ovalffolia: leaf and flower. Under side of leaf on right, showing veins. Upper side of leaf on left, with blotches shaded in on lower half; folded over at margin. One-half natural size. From a tracing of the original specimen of $\mathrm{B} 6 \mathrm{hm}$, in hb. Berlin. one could doubt that the two extremes are specifically distinct. The Mechow specimen, No. 480 cited above, differs from Baum's No. 655 in having larger flowers ( $5 \mathrm{~cm}$. in diameter), sepals 1.7 to $2.8 \mathrm{~cm}$. long, stamens two-thirds as long as the petals, leaves 3.8 to $4.5 \mathrm{~cm}$. across, with big blotches of brown above; length of principal area : length of radius $=2: 3$. Pogge's No. 559 has the flower like Baum's 655, the leaf $2 \mathrm{~cm}$. across, blotched brown above, dull dark green beneath. Schweinfurth's No. 2329 has blotched leaves $5 \mathrm{~cm}$. across, flower $5 \mathrm{~cm}$. in diameter, stamens 25, a little more than half as long as the petals. Pogge's $55^{8}$ has leaves 5.7 to $7.6 \mathrm{~cm}$. across, and sepal $3.2 \mathrm{~cm}$. long (poor specimen). Next to this come Planchon's types of $N$. heudelotii. On the other hand, $N$. micrantha Guill. \& Perr. seems to differ from $N$. heudelotii Planch. chiefly in being viviparous.

Nymphaea ovalifolia new sp. (Fig. 58.)

Leaf narrowly elliptic, $25 \mathrm{~cm}$. long by $14.7 \mathrm{~cm}$. wide, with large irregular brown blotches above; sinus Io $\mathrm{cm}$. deep, sides nearly parallel, lobes acute, pelta $0.3 \mathrm{~cm}$. wide. Primary veins about 6 ; principal area $2.5 \mathrm{~cm}$. wide by $5.7 \mathrm{~cm}$. long. Under surface plain green.

Flowers deep blue ("himmelblau"), closed in dull weather. Sepals and petals acuminate, without dark spots; sepal $4 \mathrm{~cm}$. long by $\mathrm{I} .3 \mathrm{~cm}$. wide.

Distribution and Types.-Coll. C. Böhm, No. 92, March, I882, Deutsche Expedition nach Ost-Afrika, in the Wala River, Ugally, in hb. Berlin. With this may be classed a specimen, coll. F. Stuhlmann, No.48I, July 27, I890, Expedition Emin Pasha, at Palla Bay, marked " $N$. stcllata var. alba," in hb. Berlin. 
NoTE.-Although a single imperfect specimen affords but a feeble foundation for a species, the peculiarities of this one require us to give it separate consideration. A name therefore seems necessary.

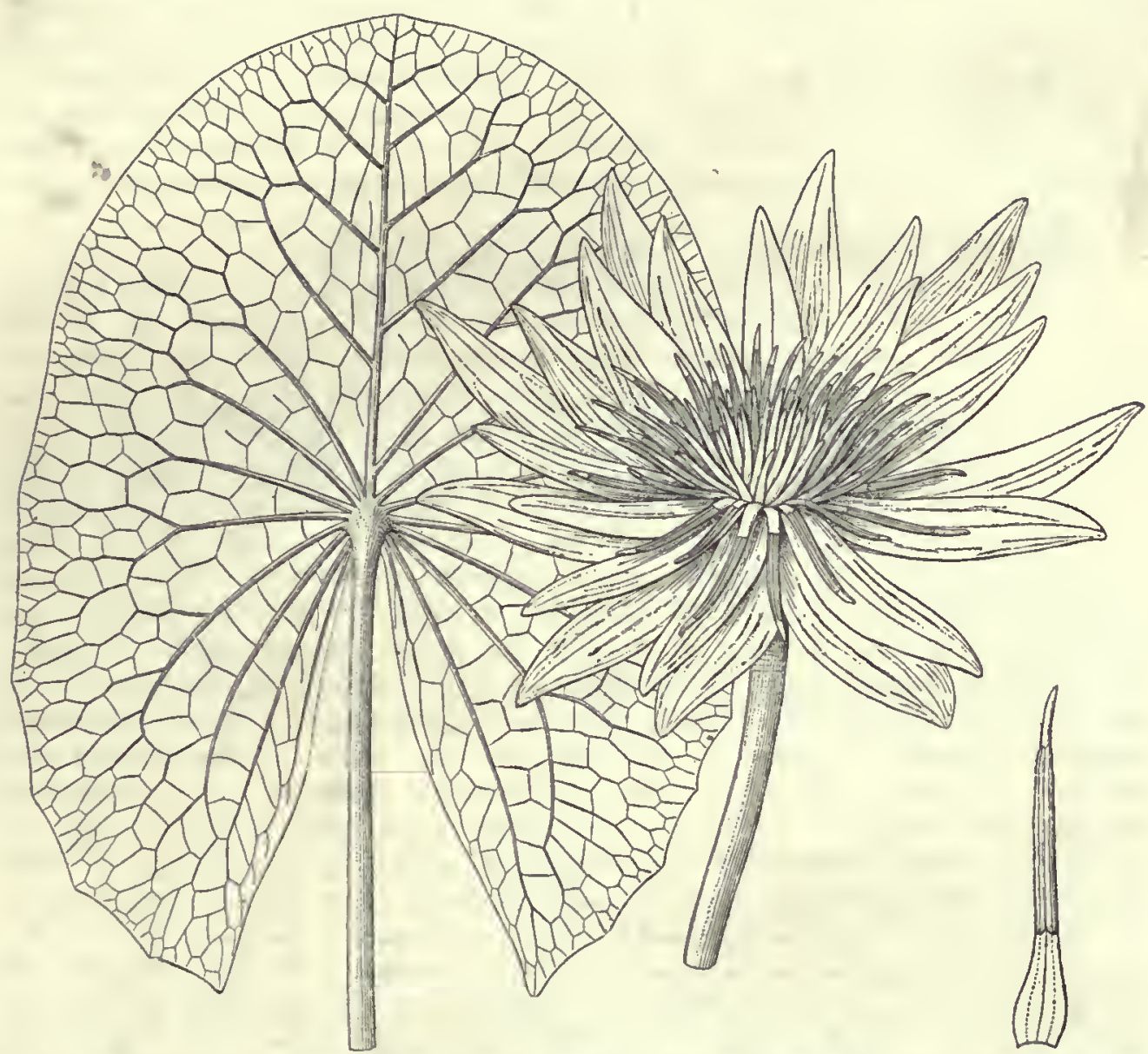

FIa. 59.-Nymphaea calliantha: Flower and under side of leaf, reduced three-sevenths. Outer stamen, enlarged one-seventh. Drawn by J. Pohl, from Baum's No. 395 in hb. Berlin.

Nymphaea calliantha Conard. (Fig. 59.)

Flowers ro to $15 \mathrm{~cm}$. in diameter, pink, violet purple, or light blue; sepals green outside, with black spots near the margin, lanceolate. Leaf entire, ovate-orbicular, cleft nearly to the petiole, purplish to deep royal purple beneath.

$N$. caerulea, Gilg 1903. Not Savigny 1802.

N. calliantha, Conard 1903 .

DESCRIPTION.-Sepals 4, lanceolate, $7 \mathrm{~cm}$. long by $1.7 \mathrm{~cm}$. wide, acute, outer surface dull green with a few black spots near the margin, covered margins tinted red; inner surface bright rose pink on upper 1.5 to $2 \mathrm{~cm}$., shading to white below.-Petals 
I7, lanceolate; outer one $1.7 \mathrm{~cm}$. wide, sepaloid on back, its margins petaloid; whitish below, shading pink in upper two-thirds, to decided rose pink in uppermost $\mathrm{I} \mathrm{cm}$.; inner surface white in lower three-fourths, becoming rose pink at apex, and on margins for I to $2 \mathrm{~cm}$. below apex; inner petals white. Stamens about roo, yellow; outermost stamen has filament $4 \mathrm{~mm}$. wide, $8 \mathrm{~mm}$. long, anther $2.5 \mathrm{~mm}$. wide at base, I9 $\mathrm{mm}$. long, appendage $6 \mathrm{~mm}$. long, I $\mathrm{mm}$. wide at base, subacute. Stigma? - Fruit?Leaf ovate-orbicular, entire, 13 to $28 \mathrm{~cm}$. long by 9 to $23 \mathrm{~cm}$. wide, pelta $0.5 \mathrm{~cm}$., green above. Under surface purplish on margin, shading to green in the space of 3 to $4 \mathrm{~cm}$., spotless. Primary veins 8 on each side, length of principal area: radius $=7.7 \mathrm{~cm}$.: $10.2 \mathrm{~cm}$.

Geographic Distribution.-Central and Southwest Africa.

Types.-Coll. H. Baum, Reise nach Süd-West Afrika, Kunene-Zambesi Expedition, No. 395, Nov. 9, I899, " am Kubango unterh. der Kueio, I I20 m. ü. M." Native name "Amavu." In hbb. Delessert, Berlin, British Museum. Gilg (1903) adds, evidently quoting Baum, "Blüthen weissblau. * * * Blätter sehr dünn." The pink color seen in the herbaria may therefore be due to changes in drying, as some other specimens in this collection had undergone the same change. Professor Gilg also considers Höpfner's No. 36 from Mossamedes (in hb. Berlin) to be identical with Baum's 395. A specimen in hb. Kew, coll. F. D. \& E. J. Lugard, Sept., I8g6, Botletle River, Ngamiland, Tropical Africa, appears to be the same, as also one, coll. W. P. Johnson, Lake Nyassa, in hb. Kew. Baum's No. 208, Oct. 4, I899, " an ruhigen Stellen im Okachitanda bei Kassinga, I290 m. ü M., am Uferrand und in Einbuchtungen des Flusses, auch in der Mundung und in Pfannen hinter Kassinga " (Gilg 1903), has smaller leaf and flower, but more numerous floral organs. Leaf $16 \mathrm{~cm}$. long by $13.5 \mathrm{~cm}$. wide; under surface deep red-purple. Petals 20 to 26 , stamens I 5 or more. In hbb. Berlin, Delessert, British Museum. No. 396 of Baum, from the same locality as 395 , is smaller than the latter, but doubtless of the same species. Flowers rose color; petals II to I4, 4 to $4.5 \mathrm{~cm}$. long; stamens more than 50. Leaves very dark purple beneath. In hbb. Delessert, Berlin. Professor Gilg ( 1903 ) considers Fischer's No. 4 (in hb. Berlin) from the African lake region between Magu and Kagehi to be identical with the foregoing. We place here also a specimen in hb. Kew, coll. A. Carson, I89I, at Karonga, Nyassa, having flowers Io $\mathrm{cm}$. across, deep blue; petals elliptic-lanceolate, stamens stout; leaf oval, $14 \mathrm{~cm}$. long by $10 \mathrm{~cm}$. wide, lobes acute, overlapping, margins wavy in lower half, under surface dark red-purple.

Var. tenuis Conard.

Leaves nearly orbicular, 7.5 to $10 \mathrm{~cm}$. long by 7 to $8.6 \mathrm{~cm}$. wide, green above, dull dark purple beneath; primary veins 6 ; length of principal area : radius $=3.2 \mathrm{~cm} .: 3.8$ $\mathrm{cm}$; sinus lobes slightly diverging or overlapping, obtuse, margins nearly straight.

Flower 9 to $13 \mathrm{~cm}$. across; petals and sepals very narrow (e. g., sepal $5.75 \mathrm{~cm}$. by I cm.; petals $5.4 \mathrm{~cm}$. by $0.8 \mathrm{~cm}$., $5.1 \mathrm{~cm}$. by $0.85 \mathrm{~cm}$.). Sepals 4 , green outside, with numerous black spots; margin red-purple; inside white. Petals I4 to I7, 3.5 to $5.4 \mathrm{~cm}$. long, white or pale blue, rounded at apex. Stamens 33 or more, slender, yellow, the outermost with filament $3 \mathrm{~mm}$. wide and I $\mathrm{cm}$. long, anther $7 \mathrm{~mm}$. long, appendage 7 $\mathrm{mm}$. long; innermost stamen with filament $3 \mathrm{~mm}$. long and $0.8 \mathrm{~mm}$. wide, anther $3 \mathrm{~mm}$. long and $1.3 \mathrm{~mm}$. wide, appendage $1.25 \mathrm{~mm}$. long. Carpels Io. 
N. caerulea, Gilg 1903. Not Savigny 1802.

N. calliantha var. tenuis, Conard 1903.

Distribution and Types.-Coll. H. Baum, No. 771, March 10, I900, " an ruhigen Stellen in der Kuito-Niederung zwischen Kutue und Sobi, I 200 m. ü. M." in hbb. Delessert, Berlin. Professor Gilg unites with this form Pogge's No. 560 from the "Baschilangebiet" and Buchner's No. 88 from the "Malangebiet"; I prefer to class No. 88 with $N$. heudelotii, but I have no notes on Pogge's No. 560. Both are in hb. Berlin

Notes.-This species is distinct enough, we believe, from the nearest relative, $N$. caerulea. The color of the under side of the leaf, and the peculiar long narrow area between the two primary veins nearest the sinus, are easily noted characteristics. It should prove a valuable acquisition for the water-garden.

\section{Nymphaea capensis Thunberg. (Plate X; Fig. 60.)}

Leaves large, nearly orbicular, deeply sinuate; angles produced, acuminate; green on both sides. Flowers bright blue, large, open from 7 a. m. to 4 p. m. Buds ovate. Sepals pure green, spotless. Petals 20 to 30 , elliptic. Stamens about I50, appendaged.

Nymphaea capensis, Thunberg 1800 , fid. original specimens, coll. Burmann, No. 49I, from hb. Thunb. in hbb. Delessert, DeCandolle. Harvey 1838. Lehmann 1853a. Caspary 1865, 1877. Conard $1901 a$.

N. caerulea, Andrews, tab. 197. Kerner 1795. Dryander I801, fd. original specimens in hb. British Museum. Aiton 1811. Spach 1846. Tricker 1897, and others. Not Savigny 1802.

Castalia scutifolia, Salisbury $1806 a$ and $b$.

$N$. scutifolia, DeCandolle $1821 b, 1824$, fid. original specimen from hb. Thunb. in hb. DeCandolle. Planchon $1850 c, 1853 b$. Paxton $1853 c$.

N. cyanea Hort. fid. Paxton, 1. c.

N. Berneriana, Planchon $1852 b$; $1853 a, b$; fd. original specimens, coll. Bernier, No. I58, I835, "Nord de Madagascar," in hbb. Delessert, Paris.

N. Emirnensis, Planchon $1852 b$; $1853 a, b$; fd. original specimens coll. Bojer, " in ubisque paludosis in provinc. Emirna, insula Madagascar," in hbb. Paris, DeCandolle.

$N$. Leiboldiana, Lehmann $1853 a$, as to the African plant, fid. specimens from hb. Lehmann in hbb. Kew, Berlin.

N. Petersiana, Klotsch I862, fid. original specimen, coll. Peters, Feb. 8, I848, Mozambique, in hb. Berlin.

N. stellata var. macrantha, Gilg MS., fid. specimens coll. F. Wilms, Flora Africae Australis, No. Io, Dec., I883, Distr. Middelberg, Transvaal, in hb. Berlin, and No. 13, July, 1884, Distr. Lydenburg, "zwischen Spitzkop und dem Komatifusse," in hbb. Kew, British Museum, Berlin. Not. N. stellata, Willdenow 1797.

N. stellata of Cape collectors and (in part) of many botanists. Not Willdenow I797.

DESCRIPTION.-Flower I 5 to $20 \mathrm{~cm}$. across, opening on 4 successive days from 7 a. m. to 4 p. m. ( 5 days, 7 a. m. to I p. m.; 5 a. m. to 3 p. m. Caspary 1877), sweet scented.-Bud narrowly ovate, pure green.-Peduncle terete, $60 \mathrm{~cm}$. long, rising $22 \mathrm{~cm}$. above water; green; 0.8 to $\mathrm{I} .3 \mathrm{~cm}$. in diameter, main air canals 6 , surrounded by $\mathrm{I} 2$ smaller ones, and these by 24 very small ones.-Receptacle yellowish.-Sepals 4, narrowly wedge-ovate, breadth: length $=I: 2.4$ to 4.3 , tapering above to a rounded apex, opening to about $30^{\circ}$ above horizontal; thick and fleshy in texture; outer surface deep 
green toward apex, paler and yellowish in lower third, and on margins; that part of margin which is covered in the bud is white with a bluish tinge; inner surface greenishwhite, tinged with blue above, pale green in lower quarter; obscurely many nerved (I8 to 19 ) at base. Persistent in fruit.-Petals 21 to 38 ( 15 to 27 , Casp. 1877) of rather thin texture, shorter than the sepals, all plane (i. e., not concave). Outermost petal elliptic-lanceolate, tapering at base, obtuse at apex; outer surface rich sky-blue above, lower third greenish in midline, with nearly white margins; 5-veined; inner surface rich sky-blue above, shading to nearly white in lower third, and then to yellowish at the base. Inner petals successively shorter and narrower, colored like the outermost except-

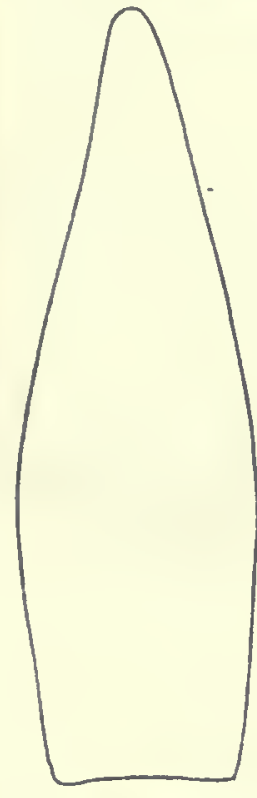

a

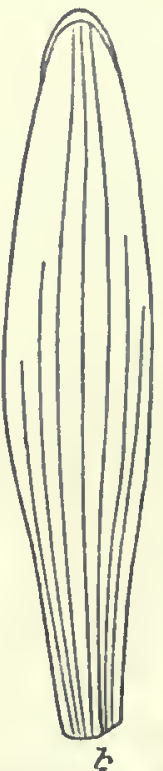

द
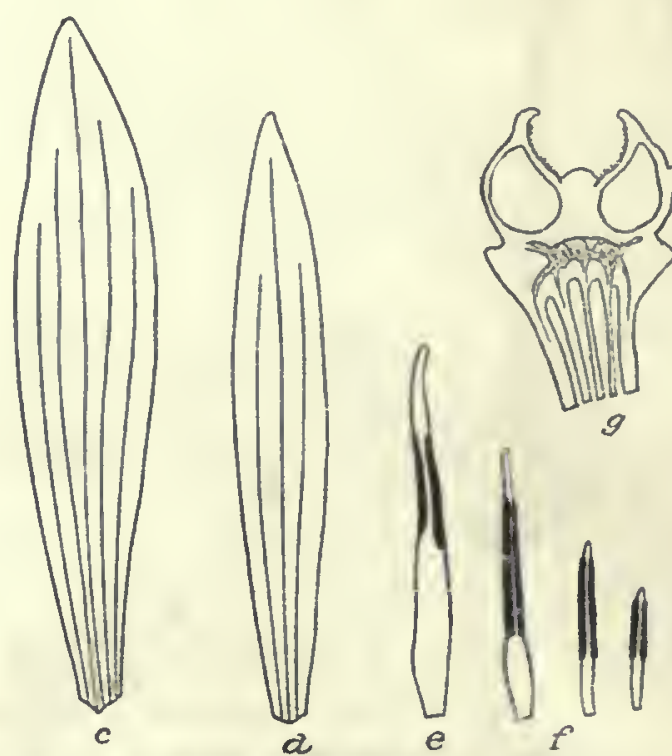

$f^{2}$

Fra. 60.- Nymphaea capensis: $a$, sepal; $b$, outermost petal, hooded at apex; $c$, median petal $d$, innermost petal ; $e, f$, outer and inner stamens; $g$, vertical section of ovary. Natural size.

ing the green color on the back. Inner 3 series of petals acute; innermost sometimes narrowly long-acuminate, simulating a stamen.-Stamens I20 to 225 ( 82 to 243, Casp. 1877), the outermost about half as long as the petals. Anthers all longer than the filaments; appendages obtusely triangular, long on outer stamens, becoming obsolete only on the innermost. Outer filaments broadly elliptic, much wider (3 times) than anther; inner-median filaments about as wide as the anthers; innermost filaments narrower than the anthers. Appendages always blue, like the petals; filaments yellow throughout; backs of the outer anthers (connectives) shading from blue above through deep blue-purple to yellow at base. Inner stamens yellow throughout. Just outside of the ring of carpellary styles there often appear short filiform yellow processes, which evidently represent stamens reduced by crowding and lack of nourishment.-Ovary about $2 \mathrm{~cm}$. in diameter.-Carpels 24 to 3 I (I2 to 47 , Casp. 1877); styles stout, oblong to linear-lanceolate (breadth: length $=I: 2$ to 5.5 ), fleslyy, pure 
5 

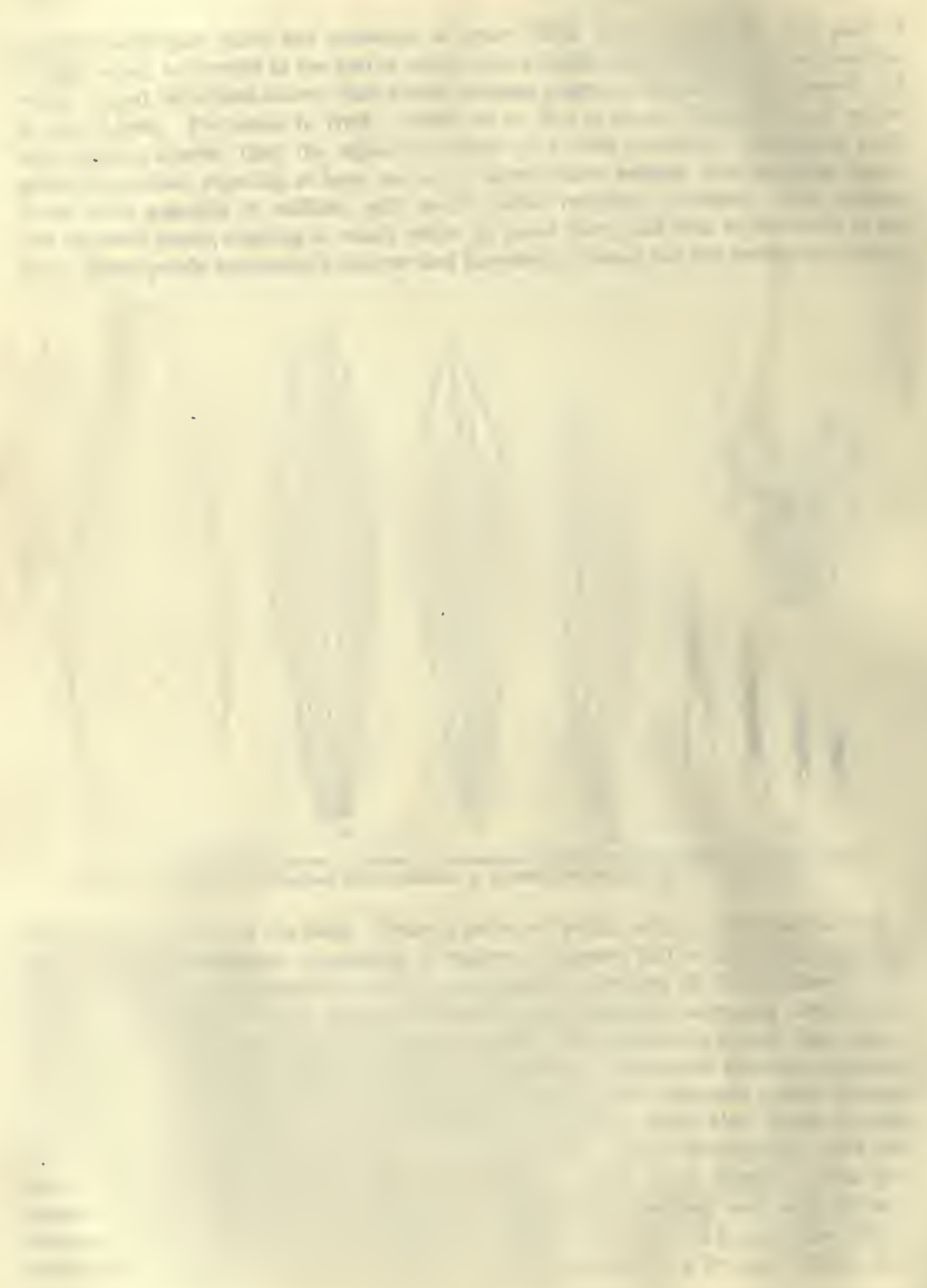


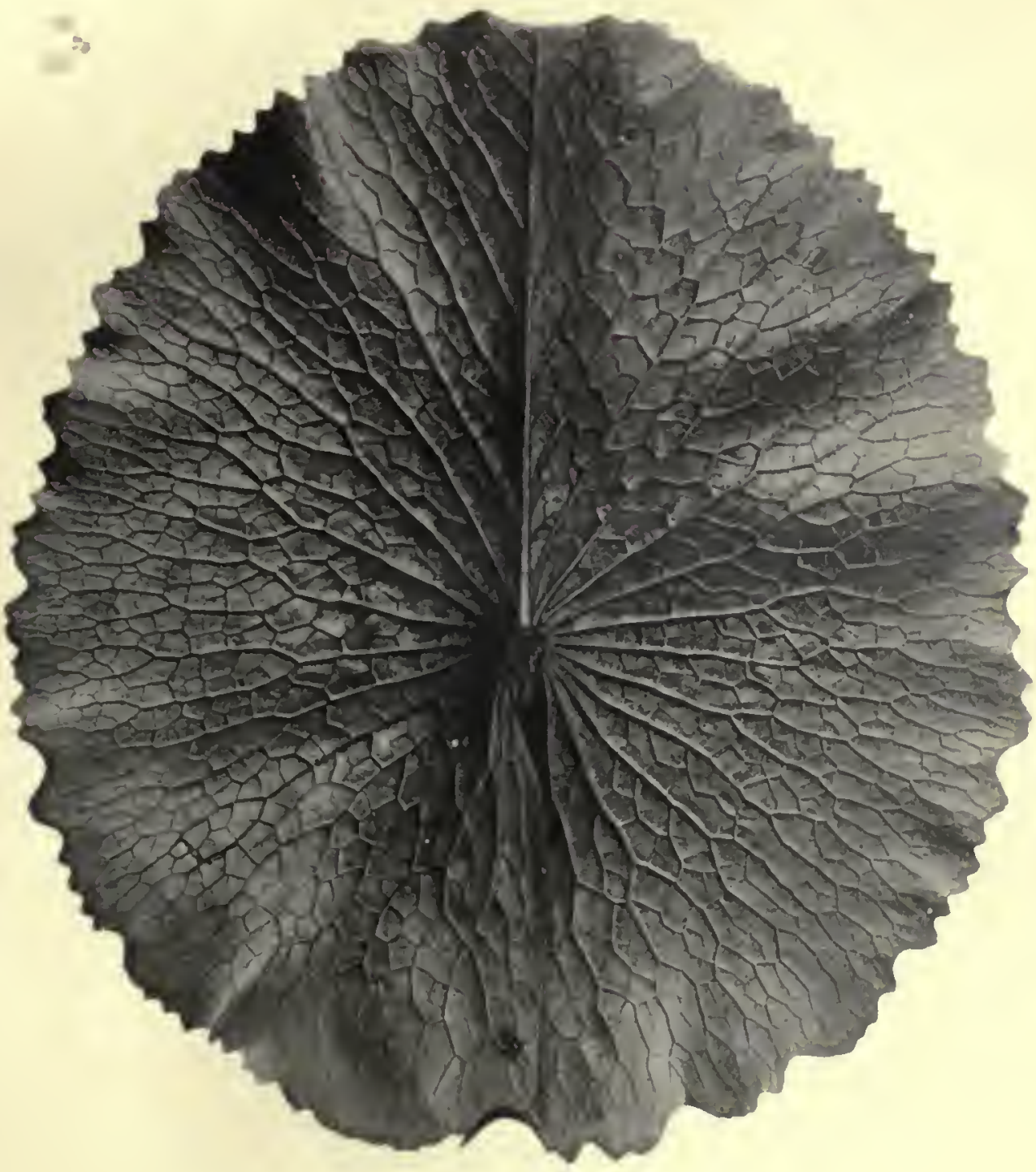

NYMPHEA CAPENSIS. 

yellow, rounded at apex, $0.64 \mathrm{~cm}$. long on back, $0.16 \mathrm{~cm}$. wide at base. Stigmatic rays extending up two-thirds of the length of the styles, and ending at an acute angle but with rounded apex. Axile process conical, white, translucent.-Fruit depressed spheroidal, $5.7 \mathrm{~cm}$. in diameter by $3.6 \mathrm{~cm}$. high, crowned with the comparatively long $(0.64 \mathrm{~cm}$.) obtuse incurved styles; stigma concave.-Seed ellipsoidal to nearly globose, $0.16 \mathrm{~cm}$. by $0.1 \mathrm{~cm}$. (average) (0.15 by 0.11 ; 0.16 by 0.09 ; 0.17 by O.II), acuminate at hilum, dull dark olive-brown, with about 18 interrupted longitudinal lines of rather long hairs, giving the seeds a rough appearance to the naked eye, and making them roll about irregularly.

Germination immediate or after drying off. First leaf of seedling filiform, I.75 to $2 \mathrm{~cm}$. long. Second leaf elliptic, I.I cm. long by $0.46 \mathrm{~cm}$. wide, rounded at both ends. Third leaf broadly elliptic, $I . I \mathrm{~cm}$. long by $0.64 \mathrm{~cm}$. wide, rounded at apex, abruptly rounded at base. Late submerged leaf nearly orbicular, entire, deeply cordate, broadly rounded at apex, lobes rounded, diverging $30^{\circ}$ to $40^{\circ}$; length of leaf 2.4 $\mathrm{cm}$., width $2.2 \mathrm{~cm}$., depth of sinus I cm., petiole stout, about $I .3 \mathrm{~cm}$. long by $0.08 \mathrm{~cm}$. thick.

Germinating tuber produces 3 or 4 submerged leaves. First leaf broadly triangular with rounded angles and truncate base; second leaf ovate-cordate, apex abruptly short-acuminate, sides parallel in lower half, sinus about $80^{\circ}$ open, with straight margins and rounded angles; third leaf cordate-ovate, with rounded apex and lobes, sinus deep and wide, open about $45^{\circ}$; fourth leaf similar to third, but with acute angles and margin a little wavy on outside of lobes. First floating leaf coriaceous, orbicularovate, narrowly peltate $(0.25 \mathrm{~cm}$.), margin slightly wavy in lower half, excavated on outer side of angles of lobes; apex rounded; sinus deep, narrow, margins convex, touching above, angles obtuse or subacute.

Leaf of mature plant narrowly peltate (I.3 to $\mathrm{I} .6 \mathrm{~cm}$.), orbicular or orbicularovate, 25 to $40 \mathrm{~cm}$. in diameter, thin and soft in texture, doubly or trebly sinuate dentate, somewhat crisped, teeth mostly rounded, sometimes angular and obtuse, depressions between teeth 0.3 to $1.3 \mathrm{~cm}$. deep; apex of leaf rounded. Upper surface bright green, depressed-veiny, somewhat brown-spotted when young; astomatic area large, paler in color, umbonate over the insertion of the petiole. Stomata very many and small on most of the lamina, larger and scattered at margins of astomatic area. Under surface pea-green, veins all prominent, Io to 12 on each side; length of principal area: radius of leaf $=I$ : I.I to 2.0.-Sinus, depth: length of leaf $=I: I$ to 1.16 , margins overlapping above, diverging toward periphery, angles produced, acuminate, awntipped.-Petiole terete, dark green, about $\mathrm{I} \mathrm{cm}$. in diameter, 60 to $150 \mathrm{~cm}$. long, with 4 main air-canals, 2 larger and 2 smaller, and to small ones surrounding these; transverse section near the leaf shows several large thickened fibers in the parenchyma and around the periphery; stellate cells very few, with short, thick rays. Both of these types of cell diminish in prominence further down the petiole. Base of petiole finely puberulent.-Stipules partly adnate.

Rhizome (tuber) ovoid; small ones distinctly egg-shaped, smooth in lower twothirds of length, tapering above to the bud, $2.5 \mathrm{~cm}$. long by 1.5 to 1.6 in diameter; older ones clothed with long, dark silky hairs and thickly beset with leaf-bases; producing no offsets during active growth. Roots spring from the bases of the petioles. 
Geographic Distribution.-South and East Africa; Madagascar; Comorro Islands. Zeekoevley, Promontory of the Cape of Good Hope, and Zwartkops river at Uitenhage, Thunberg 1800 . Port Natal, Pretoria, L'oldstrom; Hopefield, Delagoa Bay, Albany, Semliki Valley; Zanzibar, Island of Nossi-bé; Island of Johanna, Comorro. Tananarivo; Province of Emirna, Madagascar.

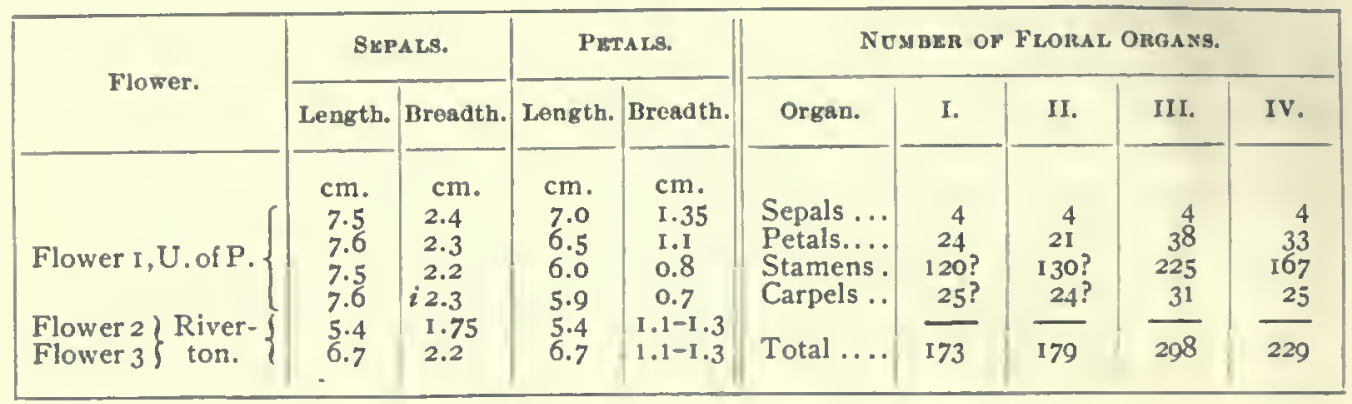

$i=$ lnner.

Mature Leaf Measurements.

\begin{tabular}{|c|c|}
\hline Breadth. & Length. \\
\cline { 2 - 2 } & \\
\cline { 2 - 2 } $\mathrm{cm}$. & $\mathrm{cm}$. \\
32.5 & 38.9 \\
$3 \mathrm{I} .2$ & 35.7 \\
30.6 & 35.7 \\
\hline
\end{tabular}

Stamen Measurements (in centimeters).

\begin{tabular}{|c|c|c|c|c|}
\hline $\begin{array}{l}\text { Total } \\
\text { Length. }\end{array}$ & $\begin{array}{l}\text { Width of } \\
\text { Fllament. }\end{array}$ & $\begin{array}{l}\text { Length of } \\
\text { Anther } \\
\text { Cells. }\end{array}$ & $\begin{array}{l}\text { Wldth of } \\
\text { Anther. }\end{array}$ & $\begin{array}{l}\text { Length of } \\
\text { Appendage. }\end{array}$ \\
\hline 3.35 & 0.4 & ... & $\ldots$ & $\cdots$ \\
\hline 2.2 & 0.16 & ... & .... & .... \\
\hline I.I & 0.15 & .... & $\ldots$ & .... \\
\hline 3.7 & 0.6 & 1.6 & 0.2 & 0.5 \\
\hline 3.2 & 0.3 & 1.75 & 0.2 & 0.35 \\
\hline 2.5 & 0.3 & 1.6 & 0.16 & 0.24 \\
\hline 2.2 & 0.2 & I. 4 & 0.16 & 0.16 \\
\hline I.6 & 0.16 & 1.0 & 0.16 & 0.16 \\
\hline
\end{tabular}

Leaves from Small Tuber (centimeters).

\begin{tabular}{|c|c|c|c|c|c|}
\hline Leaf. & $\begin{array}{l}\text { Length of } \\
\text { Midrlb. }\end{array}$ & $\begin{array}{l}\text { Length, } \\
\text { Apex } \\
\text { to Angle. }\end{array}$ & Wldth. & $\begin{array}{c}\text { Slnus } \\
\text { Depth. }\end{array}$ & $\begin{array}{c}\text { Slnus } \\
\text { Wldth. }\end{array}$ \\
\hline First submerged $\ldots \ldots \ldots \ldots \ldots \ldots \ldots$ & $1 \cdot 3$ & I. 4 & I.3 & 0 & 0 \\
\hline Second submerged................... & 1.6 & 2.8 & 1.8 & 0.8 & I. 5 \\
\hline Third submerged $\ldots \ldots \ldots \ldots \ldots \ldots \ldots \ldots$ & 2.5 & 3.9 & 2.9 & 1.4 & I.9 \\
\hline Fourth submerged.................. & 3.1 & 5.5 & 4.4 & $2 \cdot 3$ & 2.1 \\
\hline 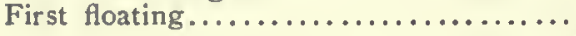 & $3 \cdot 4$ & 6. I & 5.0 & 2.4 & I.I \\
\hline
\end{tabular}

Notes.-The description of Thunberg is so brief that it is no wonder his name was long neglected. It reads as follows: " $\mathrm{N}$. foliis subpeltatis cordatis orbiculatis integris, petalis lanceolatis calyce aequalibus." "Foliis integris" is only true of young leaves. The synonymy given above will show how far this species has been confused with the Egyptian $N$. caerulea. It is generally known in gardens at present as $N$. scutifolia, sometimes as $N$. caerulea.

Planchon says of $N$. berneriana that the filaments are much broader and appendage longer than in $N$. capensis, and $N$. emirnensis had the filaments shorter than in 
capensis; after examining the types, beside much other material from South Africa and Madagascar in the European herbaria, we can see no basis for a separation of these forms.

N. capensis grows easily and flowers and fruits freely. Caspary ( 1877$)$ considered it incapable of self-pollination, but it produced much seed in the Botanic Garden of the University of Pennsylvania (1900), though it had usually but one flower open at a time.

Introduced at Kew by F. Masson about I792, carried from the Cape in H. M. S. "Gorgon," Captain Parker.

Var. madagascariensis (DC.) new comb.

"Leaves narrowly peltate, 5.1 to $6.3 \mathrm{~cm}$. in diameter, obtusely sinuate, impunctate, glabrous, lobes divaricate. Flowers blue. Sepals 4, green outside, oblong, subobtuse, $2.1 \mathrm{~cm}$. long. Petals 8 , obleng, subacute, 4 inner ones smaller. Stamens 8 to I2, shorter than the petals. Carpels 8 to I2. Rhizome small, sub-spherical." (DeCandolle, 1821 $b, 1824$ ). A small form of $N$. capensis.

Nymphaea madagascariensis, DeCandolle 1821 b, 1824. Planchon 1853 b. Not Caspary 1880.

Geographic Distribution.-Madagascar.

TyPeS.-Coll. Brugière, Madagascar, I8or, in hb. DeCandolle. Other specimens coll. Bernier, No. I59, "étangs à Ling-raton," in hb. Paris; coll. Pervillé, No. 677, Feb., I84I, Ambongo, Madagascar, in hb. Paris; coll. Perrottet, I820, Madagascar; in hb. Paris; coll. Chapelin, Madagascar, in hb. Paris; coll. Boivin, I847-52, Madagascar, in hb. Paris.

Notes.-Caspary (I880) regarded DeCandolle's type as a dwarf, of which the larger specimens of Perrotte乞, Goudot, and Rutenberg were more perfect forms. We recognize, with Caspary, that our knowledge of Mascarene Nymphaeas is extremely deficient, but it has seemed best to include all the larger ones in $N$. capensis, and to recognize these smaller ones simply as dwarfs of that species. This view is supported by the known capacity of the species, and especially of the var. zanzibariensis, to develop small flowers when in limited quarters. A study of living plants can alone settle the question.

\section{Var. zanzibariensis (Casp.) new comb. ${ }^{1}$ (Plate XI; Fig. 6r.)}

Leaves large, somewhat peltate, nearly orbicular, closely and irregularly sinuatedentate; sinus closed, angles not produced; under surface more or less suffused violet. Flower large, open from i I a. m. to 5 p. m. Sepals green, spotless, margins purple, inner surface deep purplish-blue. Petals 18 to 24 , oblong, obtuse, deep blue (light blue or rosy in varieties). Stamens very many ( 136 to 242 ), appendages and back of outer anthers deep blue, shading to carmine-purple (in the type).

Nymphaea zanzibariensis, Caspary 1877 , fid. original specimens from hb. Casp. in hbb. Berlin, Kew, Munich; 1882. André 1882. Moenkemyer 1897. Tricker 1897. Conard I901 $a$.

N. stellata var. zanzibariensis, Hooker 1885. Rev. Hortic. I897. Not N. stellata, Willdenow 1797.

\footnotetext{
${ }^{1}$ Referred to in the text, for the sake of brevity, as "N. zanzibariensis."
} 
Description.-Flowers 15 to $25 \mathrm{~cm}$. across (25 to 250 nm., Casp. 1877), opening on 3 to 5 successive days from II a. $\mathrm{m}$. to $5 \mathrm{p}$. m.; highly fragrant; number of floral organs 175 to 300 , average about 220. - Bud rather broad, oblong-ovate, obtuse or rounded at apex.-Peduncle stout, rising to to $20 \mathrm{~cm}$. above the water, with 6 main air-canals.-Receptacle rather long, swollen, with sloping sides.-Sepals 4, oblongovate, breadth: length $=1: 2.3$ to 3.0 , obtuse, opening about $15^{\circ}$ above horizontal ; margins gently curved toward the apex; outer surface dark green, often shaded with reddish-brown in upper three-quarters; uncovered margins deep carmine-brown, covered margins shading from carmine-brown to deep violet; inner surface deep purplish-blue above, shading to yellowish-green at base. Innermost sepal narrowest, with broad (12 mm.) covered margins. Outer surface of sepals with 7 principal veins ( 5 in small

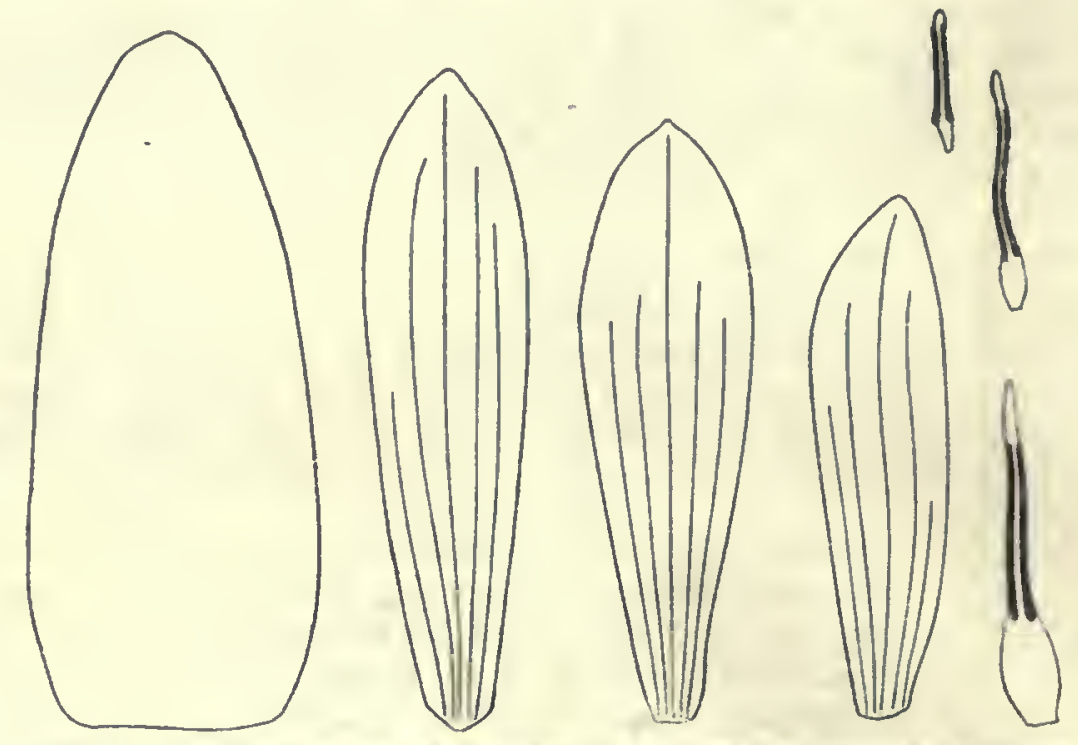

Fia. 61.-Nymphaea capensis zanztbariensts: Sepals, petals, and stamens of sueeessive serles, slightly reduced.

flowers); alternate with these are 8 more slender nerves. Inner surface slows the veins as darker lines, there being 32 or more at base of each sepal.-Peials 16 to 24 , long obovate, the outer obtuse, innermost acute, all rich deep blue above, with obscure darker veins, shading through carmine-purple to whitish at the point of attachment to the torus. The outer 4 stand in a whorl alternate with the sepals; all, or only the outer 2, carmine-brown on the back just above the base. Second whorl consists of 8 smaller petals, alternate by twos with the sepals. A third whorl of 8 still smaller petals follows, alternating with the second, but often only the anterior and lateral ones are developed. A few petals of a fourth whorl, alternate with the third, may be present, even when the third is not fully developed. All of the petals, except those of the fourth whorl, have 5 principal nerves, visible on the outer side.-Stamens I 26 to 242 according to size of flower, slightly shorter than the petals; appendage and inner side of outer anthers deep blue, back of anthers deep carmine-purple, giving way to light yellow on the long-elliptic filament. Inner filaments inverted wedge-shape. In very large 


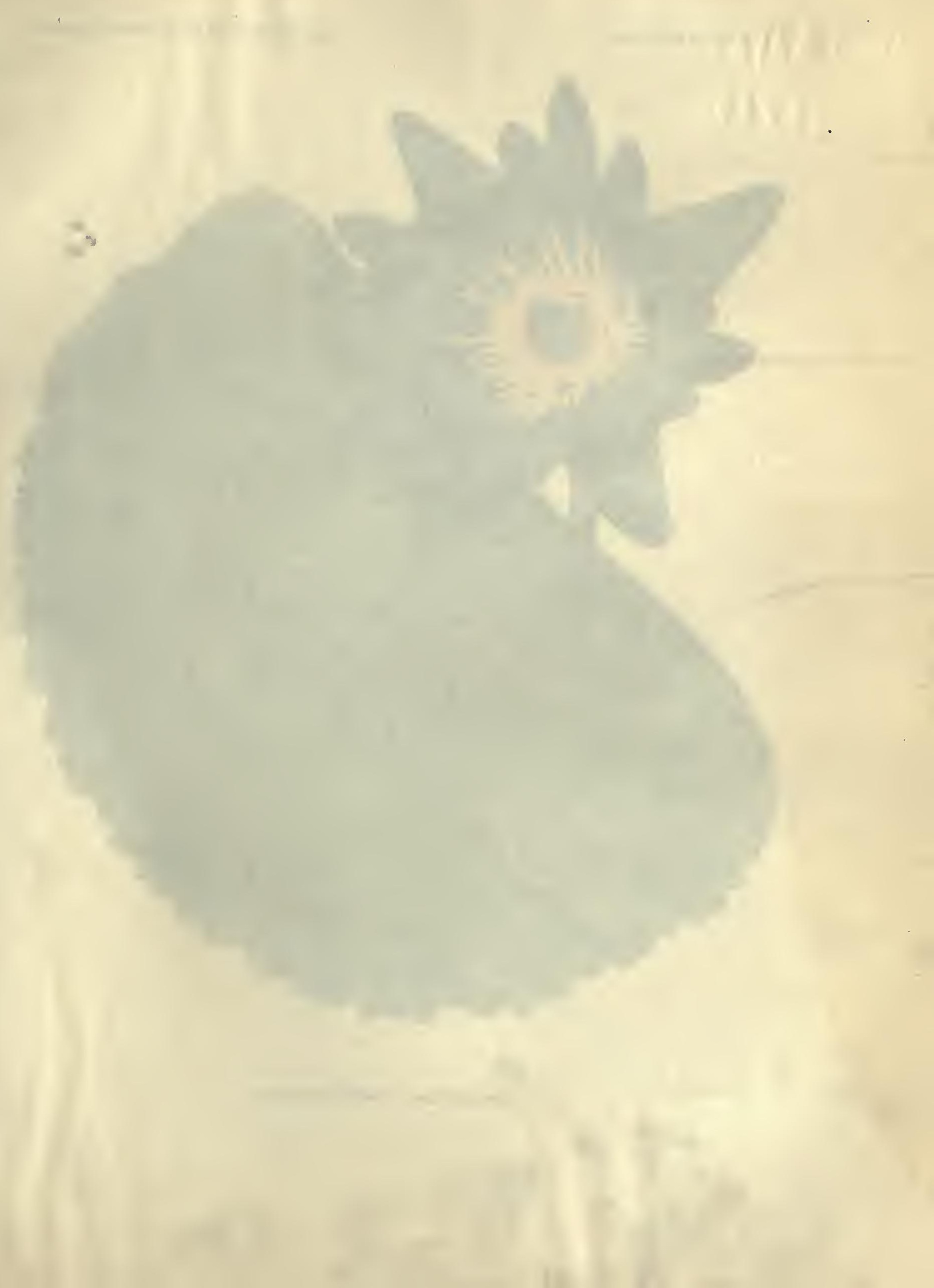




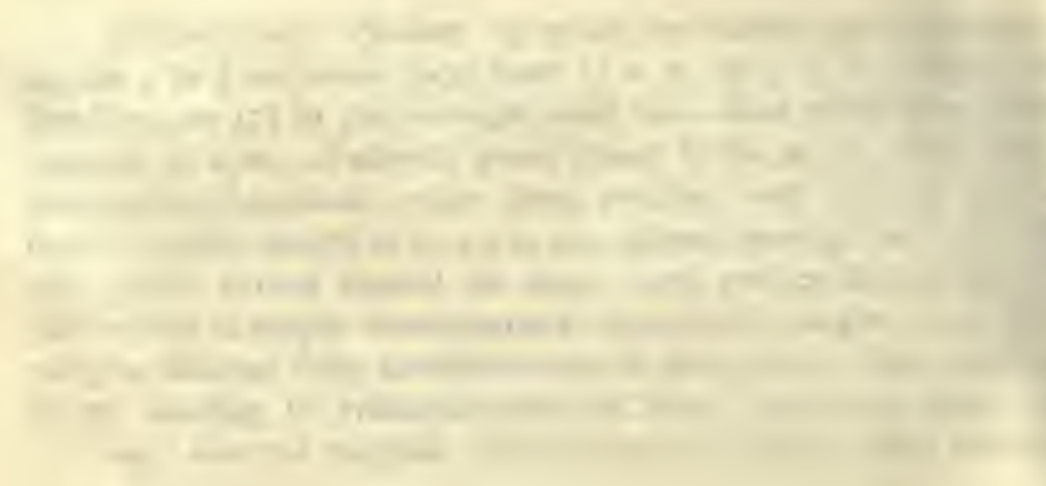

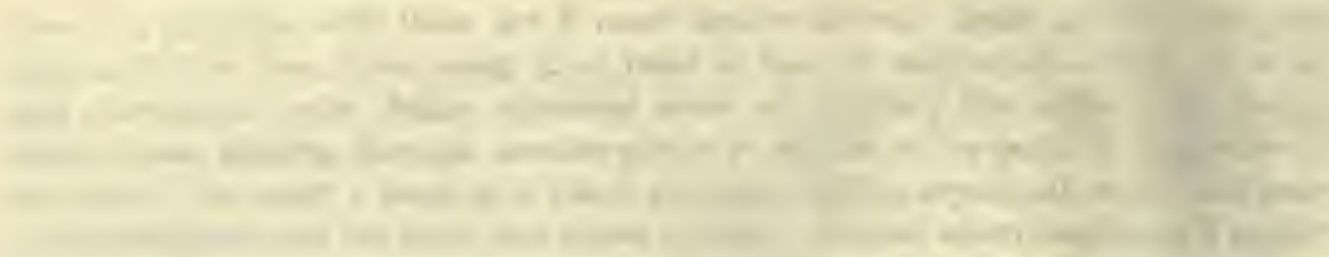

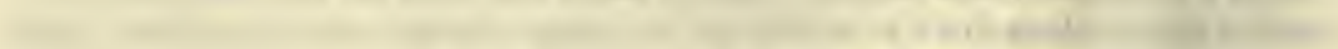
2. 10

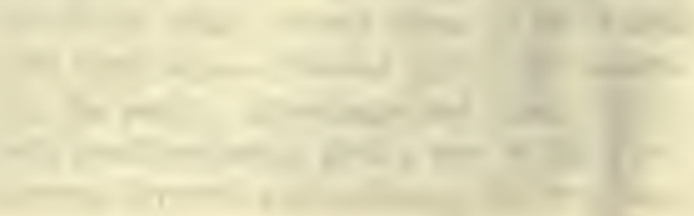




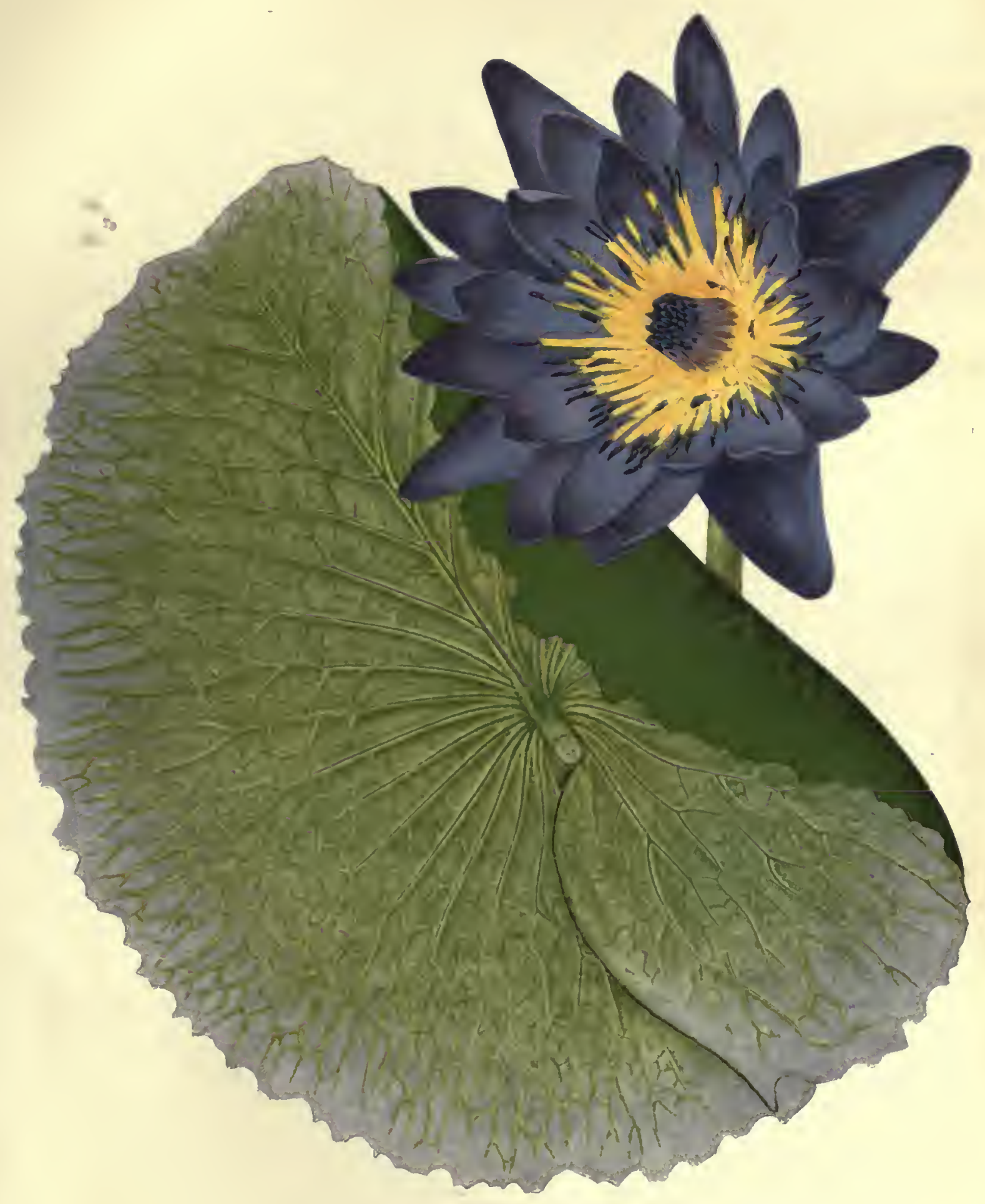



flowers the carmine-purple on the back of the outermost anthers extends down to the middle of the filament; the inner side of the filament is also suffused with blue above. Pollen yellow to the naked eye, colorless under the microscope with transmitted light; grains flattened-spherical, smooth, with large nucleus. Appendage of outermost stamens lanceolate, about 7 times as long as broad, with a swelling on inner side which grows to a keel on median stamens, and on innermost stamens the appendage is thicker than wide. Anthers bent inward, making an angle with the filament.-Carpels 15 to $3 \mathrm{I}$; styles triangular, breadth : length $=\mathrm{I}: 2.5$ to 2.8 , tapering above, acute, straight and erect on first day of opening, afterward bending gradually inward until in fruit they are hook-shaped. Stigma yellow, its rays short, triangular--Fruit yellowish, depressedspherical, $56 \mathrm{~mm}$. high by $67 \mathrm{~mm}$. in diameter, covered by the enlarged, thick and leathery sepals, containing several thousand seeds.-Seed dull brown, elliptic, rather long, with papillæ at one end; diameter: length $=0.75 \mathrm{~mm} .: 1.2 \mathrm{~mm}$.; $=0.8 \mathrm{~mm}$.: I.45 mm., with - 5 to 24 interrupted rows of short hairs, the rows at one end often alternate with those at the other.

Germination immediate, or after drying. First leaf of seedling filiform. Second leaf broadly ovate, sub-acute, rather abrupt at base, $I .3 \mathrm{~cm}$. long by $0.8 \mathrm{~cm}$. wide. Third leaf orbicular-ovate, truncate near its junction with the petiole, I.I $\mathrm{cm}$. long by $1.0 \mathrm{~cm}$. wide. Fourth leaf round-reniform, with shallow, rounded sinus and rounded lobes, $1.6 \mathrm{~cm}$. long by $\mathrm{I} .4 \mathrm{~cm}$. wide. Late submerged leaf orbicular, fissi-cordate, $3.8 \mathrm{~cm}$. long by $3.5 \mathrm{~cm}$. wide, entire, rounded at apex; sinus $1.9 \mathrm{~cm}$. deep, margins convex, divergent, angles rounded. First floating leaves orbicular, 2 to $2.5 \mathrm{~cm}$. in diameter, entire; sinus deep, closed, its margins straight and touching, angles meeting and completing the circular outline of the leaf; upper surface more or less thickly blotched with irregular reddish-brown spots; under surface pale green, with a distinct violet tinge all around near the margins. The later leaves have less and less of brown spotting above, and gradually acquire the characteristic margin and color beneath

Measurements.

\begin{tabular}{|c|c|c|}
\hline \multicolumn{3}{|c|}{ Sepals. } \\
\hline Source of Data. & Length. & Width. \\
\hline $\begin{array}{l}\text { Caspary, } 1882 . . .\{ \\
\text { Riverton flowers }\left\{\begin{array}{l}1 \\
2\end{array}\right.\end{array}$ & $\begin{array}{l}\mathrm{cm} . \\
8.2 \\
8.4 \\
8.4 \\
8.4 \\
6.0 \\
6.85\end{array}$ & $\begin{array}{l}\mathrm{cm} . \\
3.7 \\
3.8 \\
3.7 \\
3.0 \\
2.5 \\
2.4\end{array}$ \\
\hline \multicolumn{3}{|c|}{ Petals. } \\
\hline Riverton flowers $\left\{\begin{array}{l}\mathrm{I} \\
2\end{array}\right.$ & $\begin{array}{l}5.7 \\
6.5\end{array}$ & $\begin{array}{l}1.3 \\
1.3\end{array}$ \\
\hline
\end{tabular}
as the plant approaches maturity.

Submerged leaves from sprouting tuber 2 or 3. First leaf deltoid, with straight sides and curved base; apex acute. Second leaf broadly orbicular-cordate, with broad, open, rounded sinus and narrowly rounded angles. Third leaf similar to second, larger, with narrower, more acute sinus. First floating leaf orbicular to orbicular-ovate, entire, blotched more or less densely with red-brown above, under surface red on a green ground. (This paragraph describes the growth from a small tuber of the rosea form.)

Leaf of mature plant 15 to $60 \mathrm{~cm}$. in diameter, circular or slightly elliptic, narrowly peltate, length of pelta: depth of sinus $=1: 9$ to 17 ; texture rather firm and 
leathery; margin coarsely and irregularly sinuate-dentate, the teeth mostly angular and obtuse, the larger sinuses as much as $\mathrm{I} .3 \mathrm{~cm}$. deep. Upper surface green, faintly brownblotched when young; under surface suffused violet or even dark purple; veins prominent, primary nerves to to 12 on each side; length of principal area: radius of leaf $=\mathrm{I}$ : I.I to 1.7.-Sinus, depth: length of leaf $=\mathrm{I}: 2$ to 2.9 , margins convex, more or less widely overlapping, or oftener touching and both curled upward, forming a raised keel I.3 to $2.5 \mathrm{~cm}$. high in place of the sinus; angles forming an acute tooth in series with the marginal serration of the leaf, but lying within the circle described by the leaf-margin.-Stipules fused at base, long-lanceolate, tapering, acuminate.

Rhizome ovate or cylindric-ovate, rather stout, protected by long hairs at summit, smooth below when dry; producing no offsets during vegetative season.

Measurements of Leaves.

\begin{tabular}{|c|c|c|c|c|c|c|}
\hline Leal. & Length. & Breadth. & $\begin{array}{l}\text { Length of } \\
\text { Lobes. }\end{array}$ & $\begin{array}{l}\text { Length of } \\
\text { Pelta. }\end{array}$ & $\begin{array}{c}\text { Length of } \\
\text { Princlpal } \\
\text { Area. }\end{array}$ & $\begin{array}{l}\text { Number } \\
\text { of Veins. }\end{array}$ \\
\hline 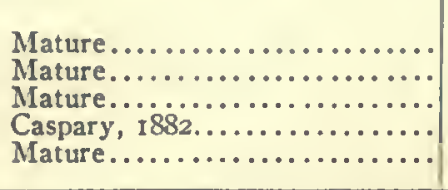 & $\begin{array}{l}\mathrm{cm} . \\
36.3 \\
31.2 \\
37.3 \\
60 \\
34.4\end{array}$ & $\begin{array}{l}\mathrm{cm} . \\
33 \\
33 \\
34.4 \\
60 \\
\ldots .\end{array}$ & $\begin{array}{l}\mathrm{cm} . \\
15.3 \\
14.7 \\
12.7 \\
\ldots \ldots \\
\ldots \ldots\end{array}$ & $\begin{array}{l}\mathrm{cm} . \\
1.6 \\
1.6 \\
1.3 \\
1.0 \\
1.9\end{array}$ & $\begin{array}{r}\mathrm{cm} . \\
9.6 \\
\mathrm{II.I} \\
\mathrm{II} . \mathrm{I} \\
\ldots \ldots \\
\ldots\end{array}$ & $\begin{array}{l}10 \\
11 \\
10 \\
\cdots \\
\cdots\end{array}$ \\
\hline \multirow{2}{*}{\multicolumn{2}{|c|}{ Leaf (small tuber of var. rosea). }} & \multirow{2}{*}{$\begin{array}{l}\text { Length of } \\
\text { Midrib. }\end{array}$} & \multirow{2}{*}{$\begin{array}{c}\text { Length } \\
\text { from } \Delta \text { pex } \\
\text { to Angle. }\end{array}$} & \multirow{2}{*}{ Width. } & \multicolumn{2}{|c|}{ Sinus. } \\
\hline & & & & & Depth. & Width. \\
\hline $\begin{array}{l}\text { First submerged } \ldots \ldots \ldots \ldots \ldots \ldots \\
\text { Second submerged } \ldots \ldots \ldots \ldots \ldots \\
\text { Third submerged } \ldots \ldots \ldots \ldots \ldots \ldots \\
\text { First floating } \ldots \ldots \ldots \ldots \ldots \ldots \ldots \\
\text { First floating } \ldots \ldots \ldots \ldots \ldots \ldots \ldots\end{array}$ & $\begin{array}{l}\cdots \ldots \ldots \\
\ldots \ldots \ldots \\
\ldots \ldots \ldots \\
\ldots \ldots \ldots \\
\ldots \ldots \ldots\end{array}$ & $\begin{array}{l}\mathrm{cm} \\
1.15 \\
1.5 \\
1.75 \\
2.0 \\
1.65\end{array}$ & $\begin{array}{l}\mathrm{cm} \\
1.0 \\
2.45 \\
3.25 \\
2.0 \\
3.0\end{array}$ & $\begin{array}{l}\mathrm{cm} \\
0.75 \\
2.2 \\
2.9 \\
2.7 \\
2.5\end{array}$ & $\begin{array}{l}\mathrm{cm} . \\
0 \\
0.8 \\
1.4 \\
1.7 \\
1.4\end{array}$ & $\begin{array}{l}\mathrm{cm} \\
0 \\
1.5 \\
1.8 \\
0.5 \\
1.0\end{array}$ \\
\hline
\end{tabular}

Geographic Distribution.-The island and toivn of Zanzibar, in permanent rainpools (Caspary 1877 ).

NoTES.-Seeds of this species were received by Caspary from J. M. Hildebrandt in the middle of April, I874, packed in chalk. Planted in water at $22^{\circ} \mathrm{R}$, they germinated freely in about two months, and in 1875 seven strong plants came into flower; these were the types on which the species was established. In herbaria, however, it is almost indistinguishable from $N$. capensis, and they form fertile crosses; we have therefore reduced this one to varietal rank. It hybridizes readily with all the members of the Brachyceras group.

Seeds developed late in the season will withstand the winters of Philadelphia and vicinity, germinate spontaneously, and form blooming plants the following summer; but the flowers are produced too late to ripen seed for the succeeding season. The same is true of $N$. caerulea, whose seeds have lain two years before developing plants. Planted in small pots, $N$. zanzibariensis will produce perfect flowers of any desired size down to 2.5 to $3 \mathrm{~cm}$. in diameter. 


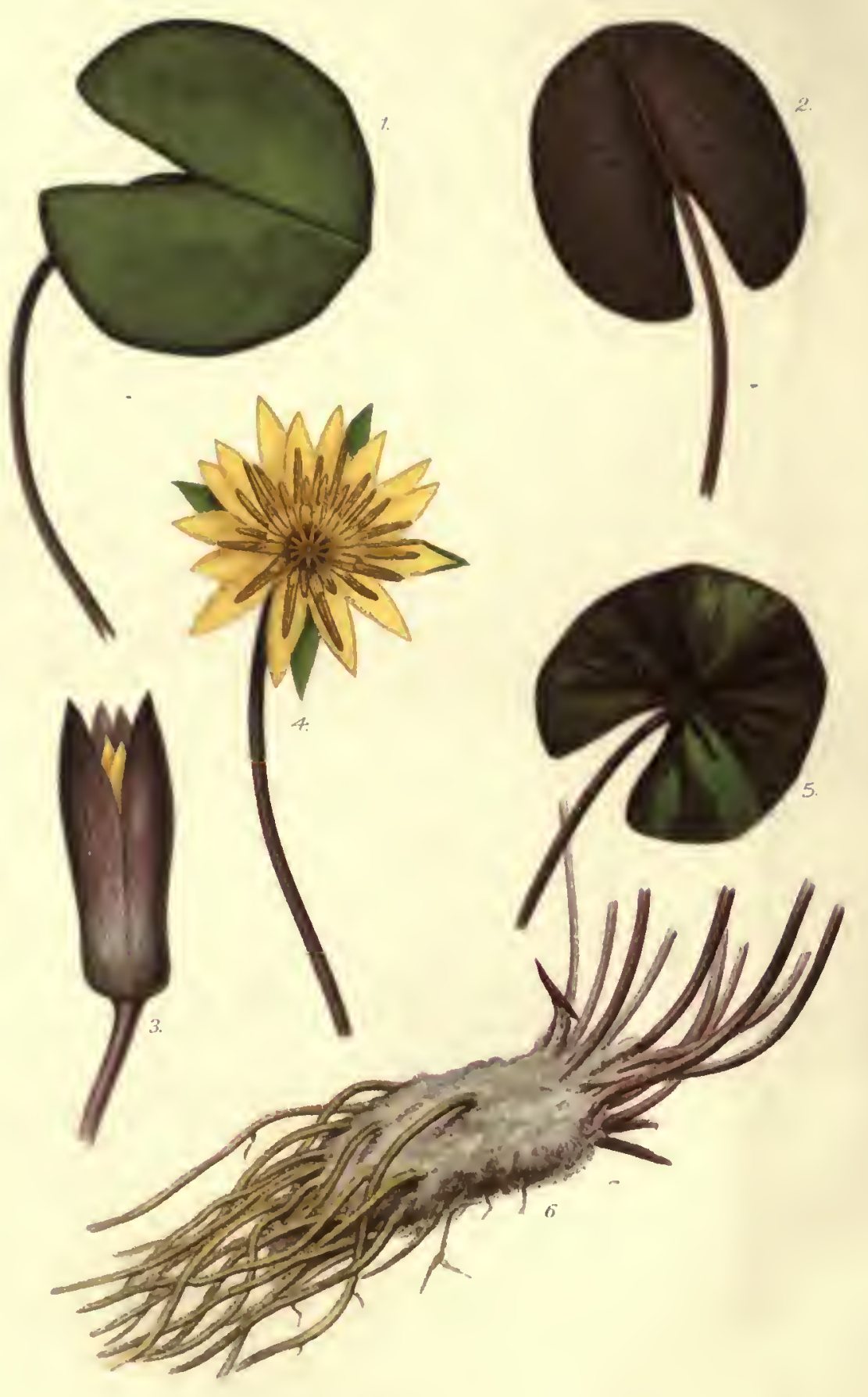

NYMPHEA SULFUREA. 


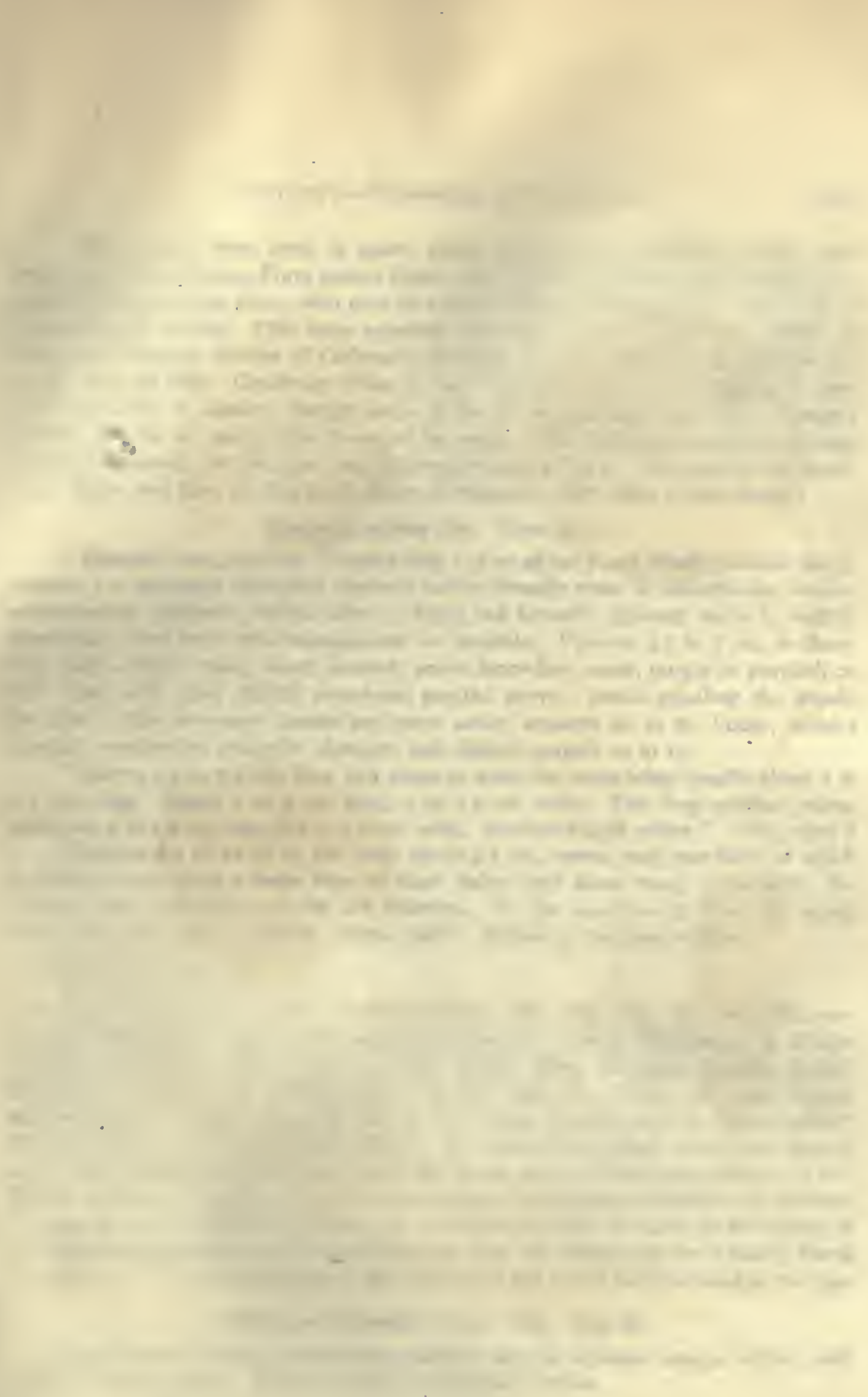




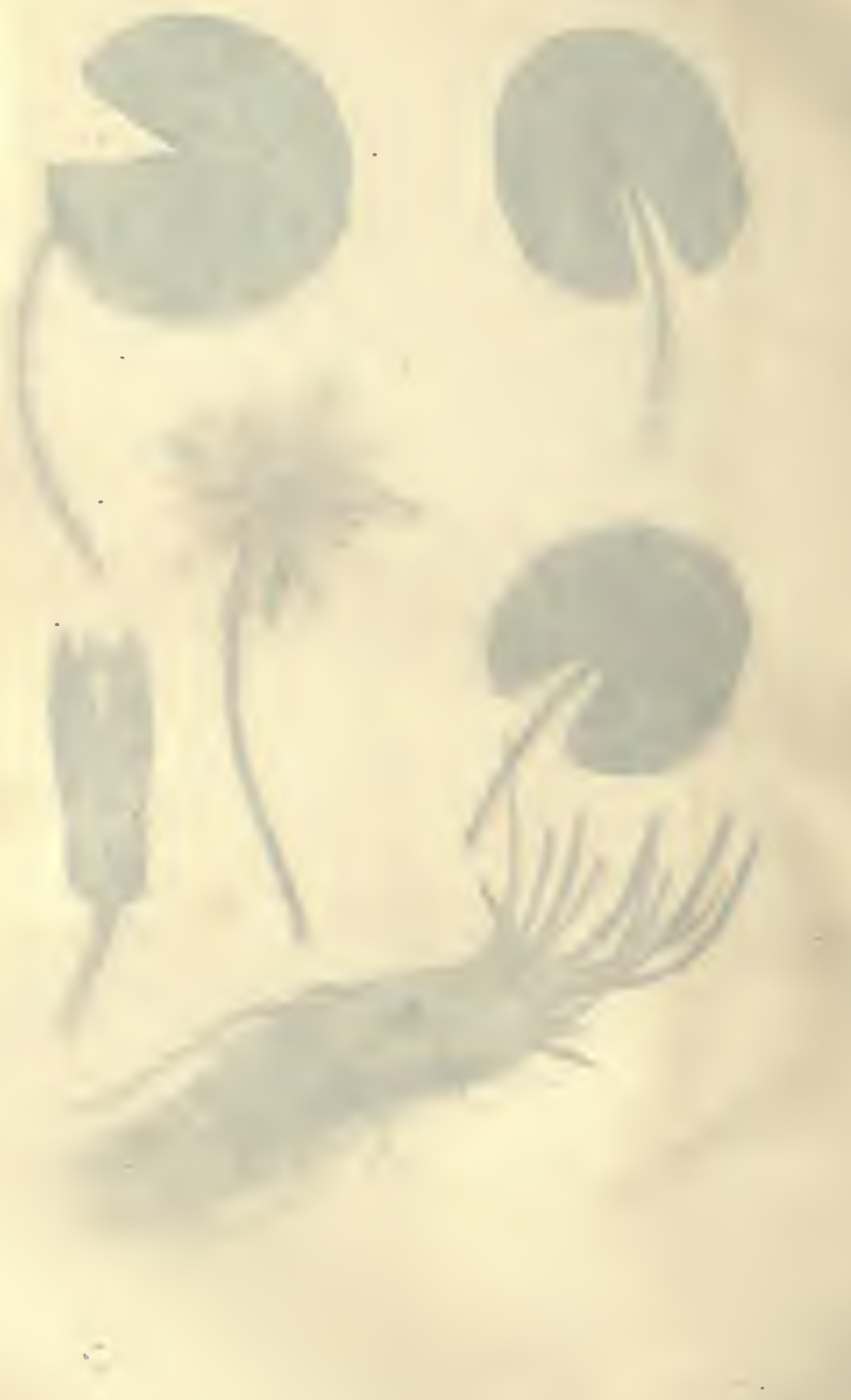


When raised from seed, it sports freely into the two following forms, with numerous intermediates: Form azurea Hort., with light blue flowers, sepals lacking the purple shadings; form rosea, with pink or reddish flowers, sepals green, under side of leaves shaded reddish. This form appeared first with Herr L. Graebener (I887) in I884 in the Botanic Garden of Carlsruhe, although the first published description was by W. Siber in 1887 . Graebener claims to have obtained it at will by crossing $N$. zanzibariensis with $N$. dentata, though many of the hybrid seedlings came blue. Caspary did not, nor do we, accept this theory of its origin. The experiment needs to be successfully repeated, but we have not had opportunity to try it. [Cf. also Revue Horticole, I890 $a$, and Rev. de l'horticult. belge et étrangère, I890, May I (not seen).]

\section{Nymphaea sulfurea Gilg. (Plate XII.)}

"Rhizome stout, conical. Petioles long [ 38 to $46 \mathrm{~cm}$.] and slender ; leaves deeply cordate, i. e. narrowly triangular excised; outline broadly ovate or suborbicular, entire; subcoriaceous, glabrous, reddish above, [deep] red beneath; primary veins 6 , slightly prominent, outer veins sub-inconspicuous or invisible. Flowers 4.5 to $7 \mathrm{~cm}$. in diameter, deep sulphur color, sweet scented; sepals lanceolate, acute, purple or purplish on both sides, with many slightly prominent parallel nerves; petals equaling the sepals, but often a little narrower, shorter and more acute; stamens 40 to 50 , linear; anthers elongate, connective evidently elongate and dilated; carpels I2 to I4.

"Leaves 4.5 to $5.5 \mathrm{~cm}$. long and about as wide, the sinus being usually about I to I. $5 \mathrm{~cm}$. deep. Sepals 2 to $3 \mathrm{~cm}$. long, I to $1.5 \mathrm{~cm}$. wide. The deep sulphur yellow petals are 2 to $2.8 \mathrm{~cm}$. long, 0.7 to $1.2 \mathrm{~cm}$. wide. Anthers bright yellow." (Gilg, Ig03.)

Rhizome 6.4 to 12 or $15 \mathrm{~cm}$. long, about $2.5 \mathrm{~cm}$. across, only one-third of which is flesh, the rest being a dense layer of black hairs; leaf bases many, prominent; the rhizome was evidently erect but not tuberous. In the specimen at Kew the sepals are copper-red outside, greenish-yellow inside. Petals I3, cadmium-yellow.

\section{N. sulfurea, Gilg r 1903 .}

Distribution And Types.-Coll. H. Baum, No. 657, Jan. I7, 1900, KuneneSambesi-Expedition, "am linken Longa Ufer bei der Imbala, Minnesera, in flachen sumpfigen Gräben," altitude I,250 m., in hbb. Berlin, Kew, Delessert, Munich, British Museum. Also No. 325, October, I899, "in der Nähe des Kuebe, in einem Bache, welche in einem Sumpfe entspringt und in den Kuebe mündet, nicht im Kuebe selbst," altitude $\mathrm{I}, \mathrm{I} 5 \mathrm{O} \mathrm{m}$., in hbb. Delessert, Berlin; this number has larger leaves and flowers and broader petals than the former, with the leaves plain reddish-brown above; in No. 657 the leaves are blotched all over the upper surface with large reddish-brown blotches. No. 325 is mentioned first in Gilg's text, and appears, from the color of the leaves, to be especially designated in the description (our first two paragraphs are a nearly literal translation); in case of separation of the forms, No. 325 would have to stand as the type.

\section{Nymphaea stuhlmannii (Scliw.) Gilg. (Fig. 62.)}

Sepals yellowish green, petals bright sulphur yellow, stamens orange yellow, with sulphur yellow anther. Stigma orange. Receptacle brown.

$N$. lotus var. stuhlmannii, Schweinfurth in Engler 1895 .

N. stuhlmannii, Gilg roo3. 
Description.-Flowers io to $15 \mathrm{~cm}$. across, sweet scented ("duftet sehr aromatiscli"). Sepals 4, obovate, broadly rounded above, with numerous longitudinal veins, $8.3 \mathrm{~cm}$. long by $2.5 \mathrm{~cm}$. wide. Petals about 22, broadly obovate, with one to several longitudinal veins. Stamens about 125, stout and thick, all appendaged, the innermost very shortly so. Carpels about 23 ; stigma shallow, flat. Leaf orbicular-ovate, entire, $2 \mathrm{I} \mathrm{cm}$. wide by $25.5 \mathrm{~cm}$. long; sinus margins nearly straiglit, lobes diverging, obtuse; green on both sides; veins prominent; primary veins 7 ; principal area $7 \mathrm{~cm}$. long.

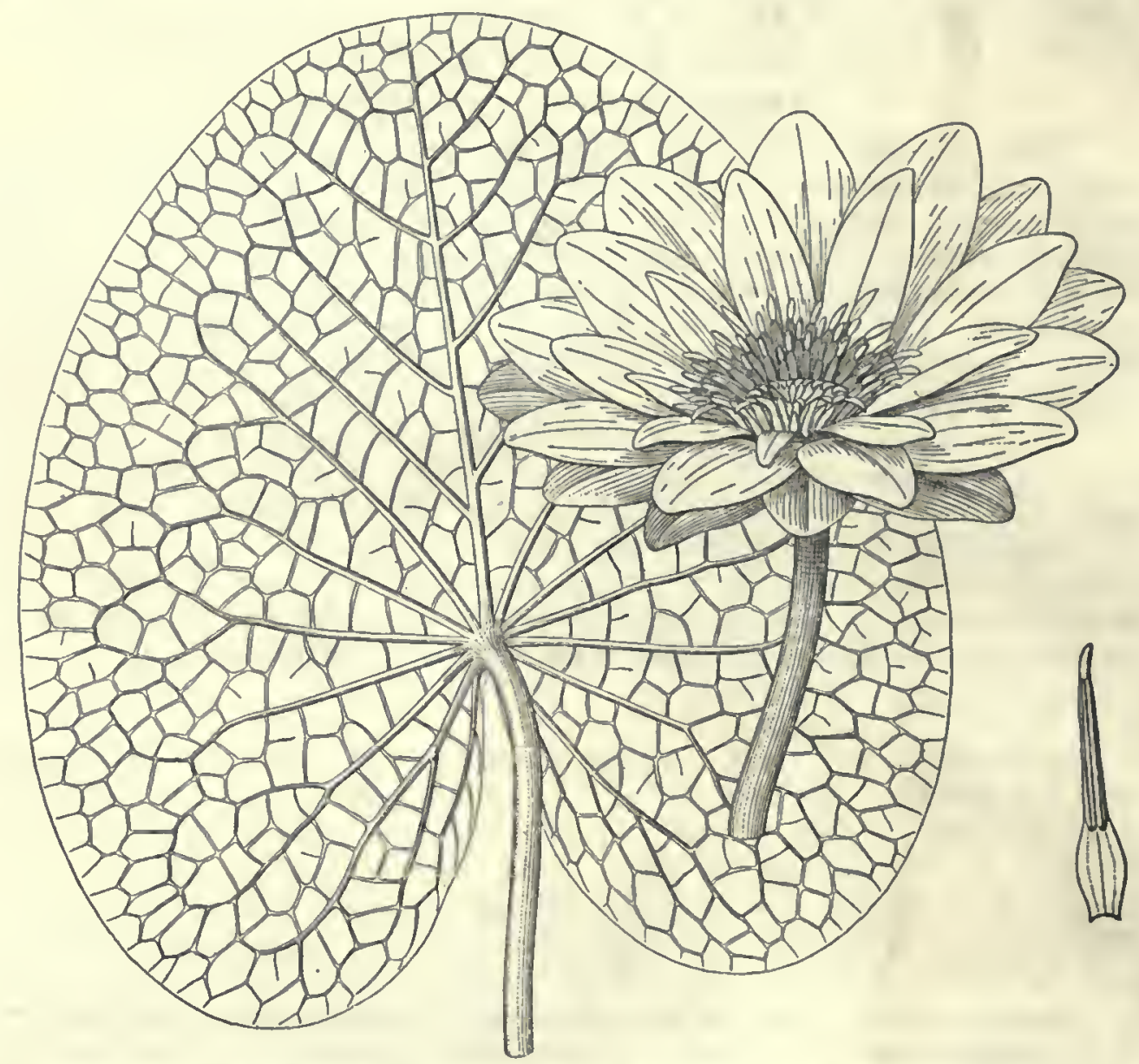

F19. 62,-Nymphnea stuhmannii: Flowor, under sido of leaf, and outer stamen. Drawn by J. Pohl, from the type in hb. Borlin, by kind permission of tho Diroctors. Roducod one-half; stamen natural size.

Distribution and Type.-Coll. Stuhlmann, No. 410, July 16, I890, at "Uniamweni, Gunda mkali, bei Bibisande," Africa, altitude I,200 m., in hb. Berlin.

Notes.-A single sheet of this plant exists in the Berlin collection; it has one leaf, two separate open halves of a large flower, and one small wrinkled flower-enough to show that a splendid garden plant is yet to be introduced. 
Group II. NYMPHAEAE SYNCARPIAE (SYMPHYTOPLEURA, Casp. 1865, 1878, 1888).

Carpels completely fused with one another at the sides; attached also to the axis of the flower and to the torus as in Group I. Stamens not appendiculate. Flowers white, rose, purple or yellow, never blue; nocturnal or diurnal.

\section{Subgenus 3. CASTALIA DC. 1821 .}

Flowers diurnal, usually floating. Sepals not evidently veined. Stamens inserted in series with the petals and grading into them in size and shape; innermost stamens with narrow filaments. Styles linear, more or less ligulate. Leaves entire or sinuate or crenulate, never sharply dentate. Rhizomes not protected against drought, but lying dormant in cold weather. Plant glabrous except on the rhizome and bases of petioles and peduncles. Seed smooth. Seven species, found in all of the North Tenperate Zone, except the Pacific Slope of North America.

Castalia and part of Lotos, Planchon $1852 b, 1853 b$.

Sec. II. Inappendiculatae, trib. III. Castalia (in part), Lehmann 1853 a. Castalia and Xanthantha, Caspary 1888.

\section{A. XANTHANTHA CASPaRy 1888.}

Flowers yellow, opening near noon and closing in the late afternoon. Outermost stamens first to dehisce. Pollen smooth. Seed very large. Floating leaves sinuate, more or less blotched with reddish brown. Principal air-canals in peduncle 4 , in petiole 2; idioblasts in course of petioles and peduncles stellate only. Rhizomes erect, short, giving rise to numerous long stolons or runners which propagate the plant very widely during summer, but produce in autumn on geotropic stolons characteristic brood-bodies, consisting of a row of buds and a cluster of short fleshy roots (resembling those of Limnanthemum). One species, native in Florida, Southern Texas, and Mexico.

Nymphaea mexicana Zuccarini. (Plate XIII; Figs. 63, 64)

Flowers 6 to $13 \mathrm{~cm}$. in diameter, bright yellow; sepals and petals elliptic, ovate to lanceolate, acute or rather obtuse. Receptacle with four swollen ridges. Leaves floating or aerial, orbicular to ovate, narrowly peltate, nearly entire or denticulate-wavy, Io to $18 \mathrm{~cm}$. in diameter, with the petiole inserted much nearer the lobes than the apex; upper surface blotched with brown, at least when young; lower surface deep purple or purplish-green (green in aerial leaves), with small blackish spots."

Nymphaea mexicana, Zuccarini $1832 a$ and $b$, fid. original specimens, coll. Karwinski, Sept., 1827, "aus dem See bei Mexico," in hb. Munich. Planchon 1853b. Hemsley 1888 . Pringle 1800. Gerard 1890 $b$; 1891. Plank 1896? Tricker 1897. Conard 1901 a. Not Gray 1850.

N. flava, Leitner 1838. Gray 1876, fid. original specimens. Treat 1877. Meehan 1880. Chapman 1883. Carrière 1884. Hooker 1887 , fid. original spccimen in hb. Kew. Gray, etc, 1895 .

Tricker 1897. Conard 1901 $a$.

N. lutea, Treat 1877 . Not Linn. 1753.

Castalia flava, Greene 1888.

${ }^{1}$ Referred to in the text as "N. flava" wherever the material used was from Florida plants directly or in cultivation. 
N. planchonii, Caspary MS. (fower) in hb. Berlin. This specimen bears several marks: (I) coll. "Poeppig, No. 3033, 1832, Colufer Amazon, Nymphaea hepatica"; (2) "No. 10 Nymphaea [obtusiloba striken out] tussilagifolia Lehm." in Lehmann's handwriting; (3) "Nymphaea (flore partim rubro, partim favo). In lacu chalcensi prope Yotla (sit. Mexico), I4 Mayi, G. Andrieux, Plant. Mex. exsicc. No. 54r." The leaf is of N. rudgeano, the flower is of $N$. mexicana. No. 54I of Andrieux in hb. Paris is N. mexicana.

DESCRIPTION.-Flowers floating, or raised 5 to $12 \mathrm{~cm}$. above the water when in shallow places, 7 to Io $\mathrm{cm}$. in diameter, open from II a. $\mathrm{m}$. to $4 \mathrm{p}$. m., with faint odor of a tea-rose or odorless.-Peduncle terete, 3 to $6 \mathrm{~mm}$. in diameter, 16 to $150 \mathrm{~cm}$. long. -Receptacle four-sided, the corners broadly rounded and prominent, the sides slightly grooved; two of the corner-ridges are larger than the alternate two.-Sepals 4, elliptic to lance-ovate, obtuse, length : width $=4.5 \mathrm{~cm} .: 1.3 \mathrm{~cm}$.; outer surface green with pale brownish margins; seven longitudinal veins visible by looking through the sepal at a

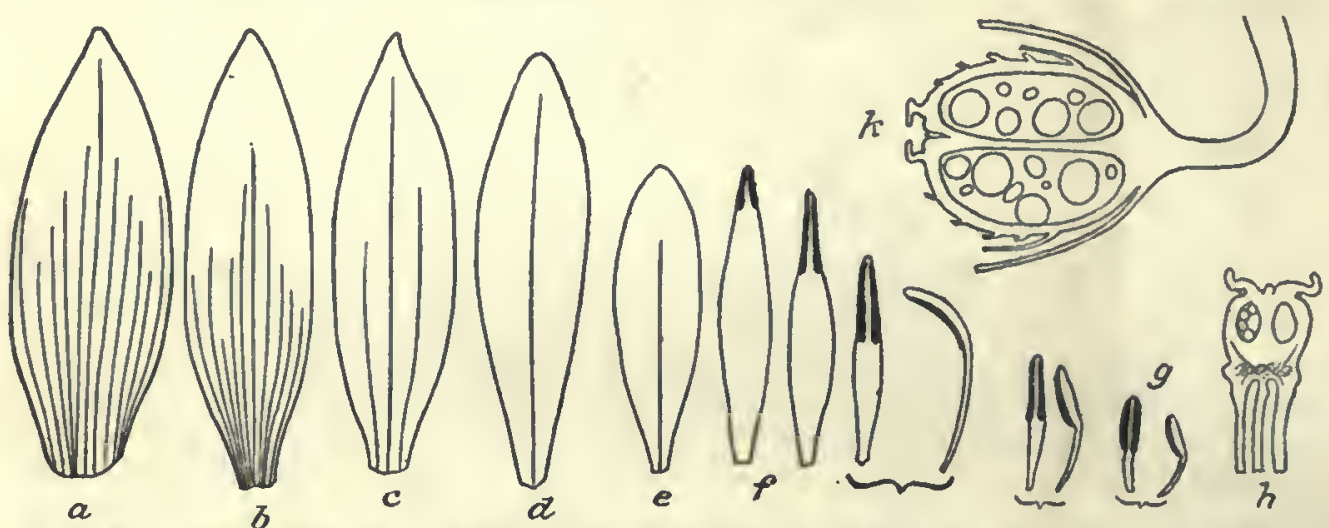

Fra. 68. - Nymphaea mexicana : $a$, sepal ; $b-e$, successive petals; $f, g$, stamens; $h$, section of ovary; $k$, section of fruit. $a-h$ from Mexican (?) plants, cult. at Riverton, N. J.; $k$, from Florida plant, in the Botanic Garden, Untversity of Pennsylvania. Six-sevenths natural size.

strong light; inner surface yellow; opening to about $15^{\circ}$ above horizontal._Petals I 2 to 23 , outermost of the size and shape of the sepals or somewhat narrower, obtuse or acute, slightly purplish without. Inner ones narrowly obovate, rounded at apex.Stamens about 50, stout, golden yellow, grading inward from petaloid to typical stamens. Innermost stamens short, anther about as long as or shorter than its filament and of the same width. Back of anthers convex, face deeply grooved between the anther cells. Pollen smooth.-Carpels 7 to I0; styles short, fleshy, with a deep furrow on the inner face. Stigma deeply curved-funnel-shape, the papillose rays ending roundly on the base of the styles; each ray with a short longitudinal median fissure (the suture). Axile process small, rounded, in the bottom of the narrow central pit of the stigma. -Fruit spherical in Texan specimens, ovoid in those from Florida, $2.5 \mathrm{~cm}$. in diameter, crowned with the small stigma $0.6 \mathrm{~cm}$. in diameter.-Seeds globose, very large, 0.48 $\mathrm{cm}$. in diameter, very finely appressed-hairy, dull greenish-black.

Submerged leaves from brood-body I to 3 , narrowly hastate, acuminate. First floating leaves ovate to orbicular-ovate, much blotched above with reddish-brown; sinus slightly open, or overlapping; margin entire in apical portion, sinuate below, especially at angles; under surface green, tinged with reddish-brown, with a few blackish specks. 



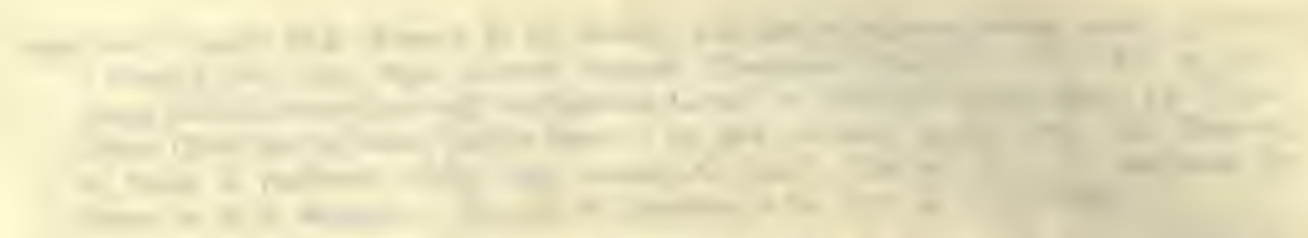

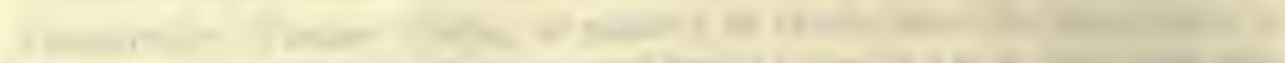

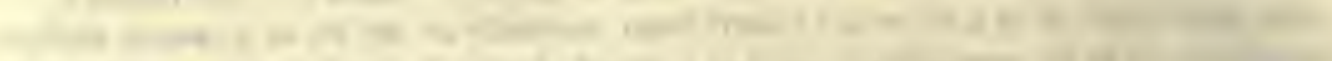

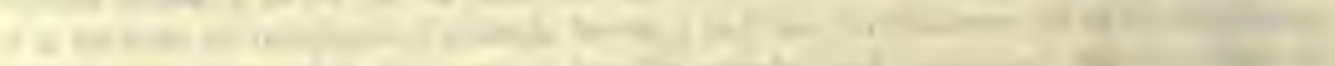

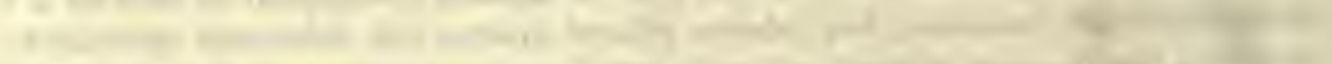

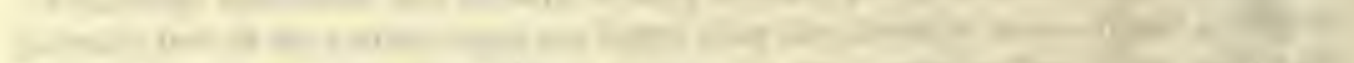

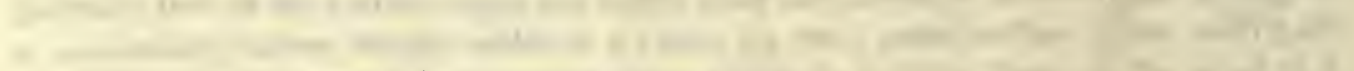
.

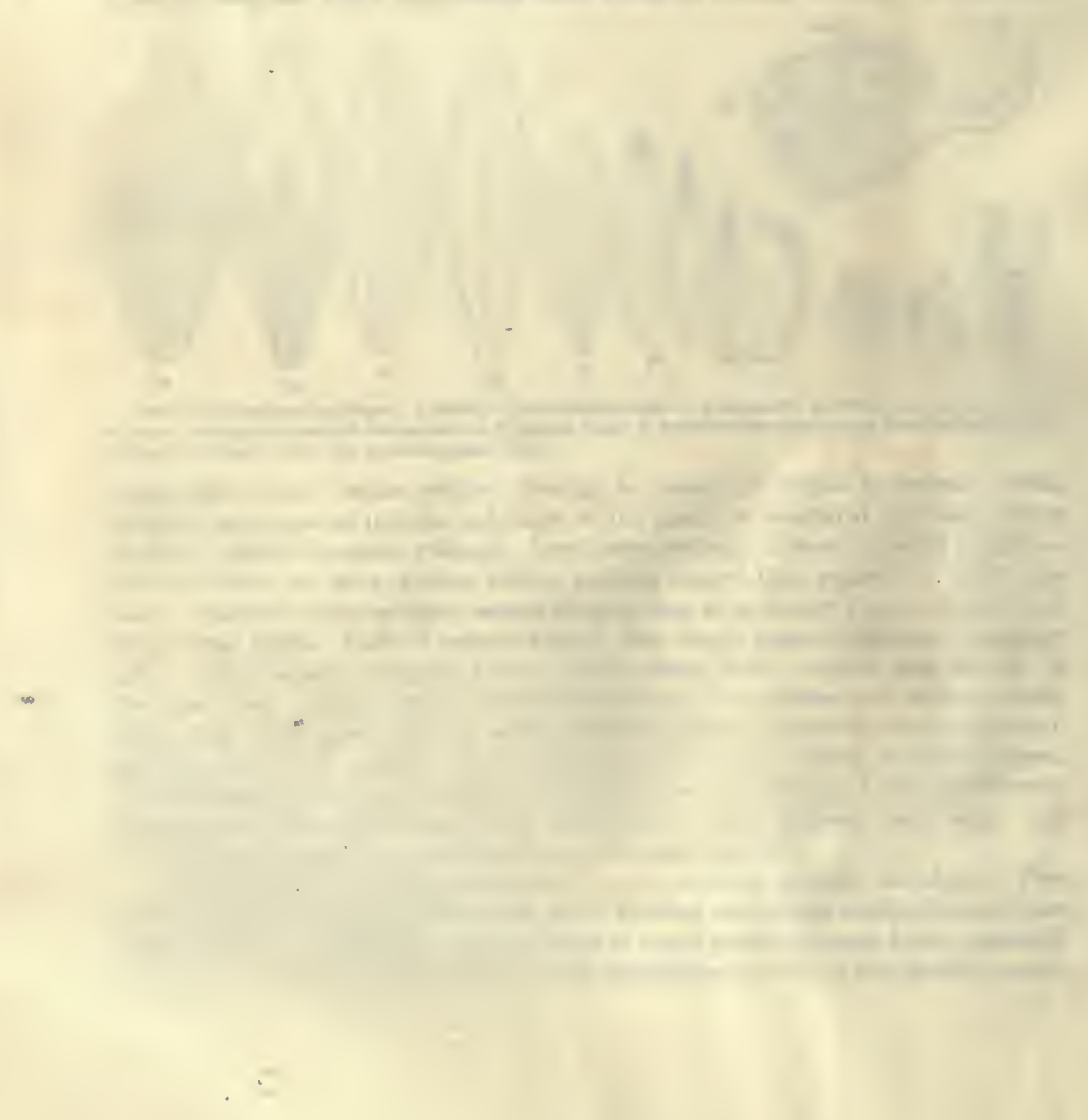




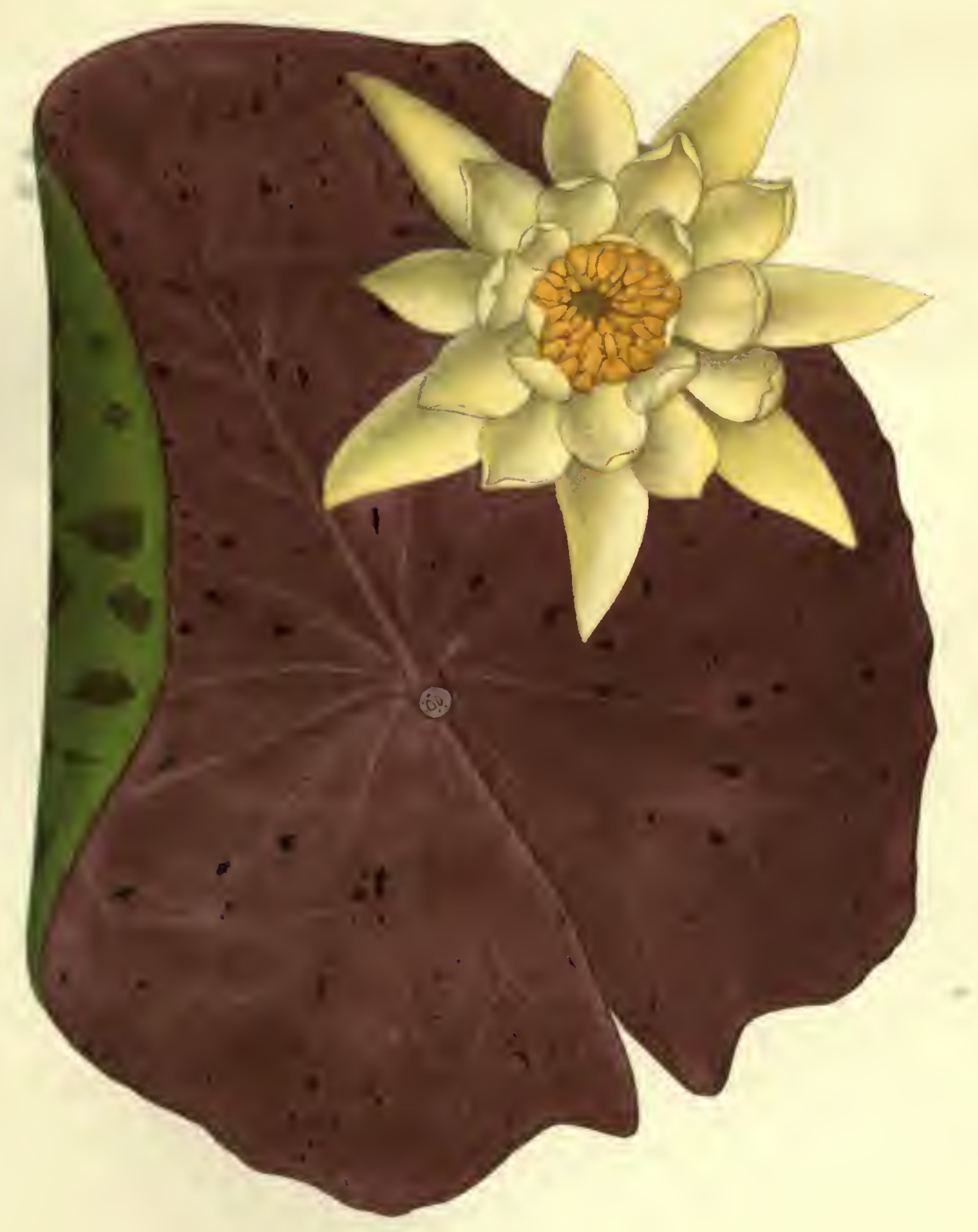



Leaves of mature plant floating, or aerial and 7 to $12 \mathrm{~cm}$. above the water, broadly ovate to orbicular, evidently peltate, entire, or more commonly sinuate or crenulate-wavy at base, becoming entire or slightly emarginate at apex; green above, with brown mottlings, at least on the floating leaves; under surface deep purplish-red, often becoming greenish, marked with small blackish dots. Primary veins scarcely visible, 5 to Io on each side, depressed from the second fork outward.-Sinus short, depth: length of leaf $=\mathrm{I}: 2.6$ to 2.8 ; margins nearly straight, slightly separated or overlapping; angles slightly or evidently produced, obtuse or somewhat acute, made prominent by a deep concavity of the margin of the leaf on outer side of lobe. The aerial leaves may become concave above by the overlapping of the sinus margins.-Petiole with two main air-canals placed transversely, and two smaller ones placed anteriorly and posteriorly; stellate cells small, numerous, short armed.-Stipules fused into a single entire lanceolate organ, thin, membranaceous and translucent; apex rounded; $3.3 \mathrm{~cm}$. long by $0.8 \mathrm{~cm}$. wide, standing erect and clasping the younger leaves; smooth, and uniform in thickness.

Rhizome erect $(1.9 \mathrm{~cm}$. long by $\mathrm{I} .4 \mathrm{~cm}$. thick), becoming as much as $30 \mathrm{~cm}$. long and 5 to $6 \mathrm{~cm}$. thick (Treat I877), densely covered between the leaf bases with long, light-colored hairs, and on the sides marked with large, projecting, spirally arranged leaf cushions, which are about $0.64 \mathrm{~cm}$. apart from center to center. From the upper part of the rhizome naked
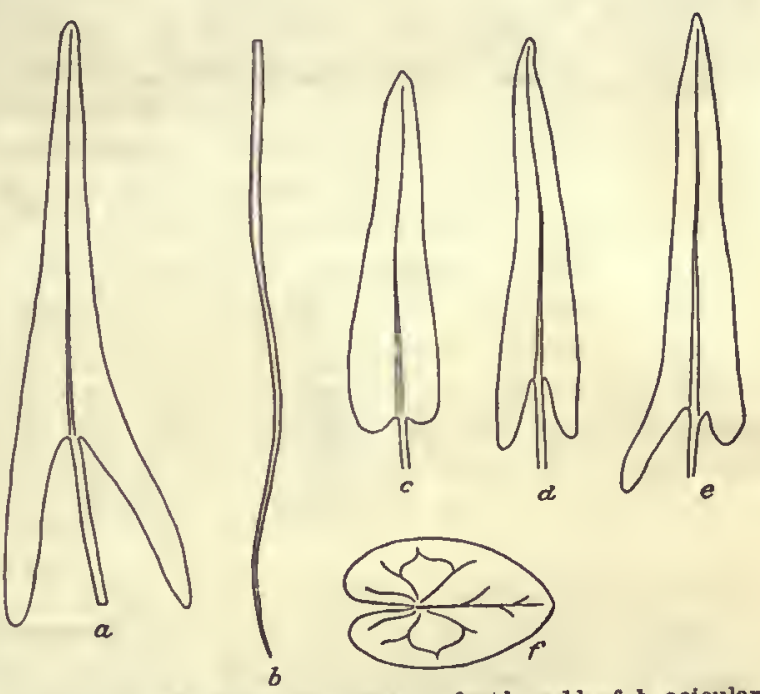

FIa. 64.-Nymphaea mexicana : $a$, first broad leaf, $b$, acicular leaf of seedling; $c, d, e$, submerged leaves of seedlings; $f$, trst floating leaf of seedling. Florida stock. Natural size. stolons 0.5 to $1.0 \mathrm{~cm}$. in diameter are given off; these pass along under the mud in which the plant grows for a distance of 15 or $20 \mathrm{~cm}$. to I meter, when the terminal bud turns upward and forms a new plant; in a few weeks the new plant again sends out runners, and the connection with the parent stem dies away. In autumn the stolons become geotropic and bury their tips $20 \mathrm{~cm}$. or more in the mud, and there form brood-bodies. A brood-body consists of an axis $2.5 \mathrm{~cm}$. long, with a row of 3 to 6 or 7 upward pointing buds on one side, and a cluster of about a dozen or more fleshy roots 1.3 to $3.8 \mathrm{~cm}$. long and 0.4 to $0.48 \mathrm{~cm}$. in diameter hanging down like a "hand " of bananas on the other side. In spring, the uppermost bud sends up a naked stolon at whose summit leaves spring up as noted above; roots spring from the bases of these leaves, and soon an independent plant is formed. If the first bud is broken off, the second sprouts, and so on; probably the second and lower buds would sprout sooner or later in any case, so long as the food supply in the fleshy roots was not used up. 
The Waterililies.

Mrasurements of Floral Parts in centimeters.

\begin{tabular}{|c|c|c|c|c|c|c|c|c|c|c|}
\hline \multicolumn{2}{|c|}{ BEPALS. } & \multicolumn{2}{|c|}{ Petals. } & \multicolumn{6}{|c|}{ STAMENS. } & \multirow[b]{2}{*}{ Ilemark. } \\
\hline Length. & Breadth. & Length. & Breadth. & $\begin{array}{c}\text { Total } \\
\text { Length. }\end{array}$ & $\begin{array}{l}\text { Longth } \\
\text { of Fila- } \\
\text { ment. }\end{array}$ & $\begin{array}{l}\text { Breadth } \\
\text { of Fila- } \\
\text { ment. }\end{array}$ & $\begin{array}{l}\text { Length } \\
\text { of } \\
\text { Anthor. }\end{array}$ & $\begin{array}{l}\text { Breadth } \\
\text { of } \\
\text { Anther. }\end{array}$ & $\begin{array}{l}\text { Longth } \\
\text { of Appen- } \\
\text { dage. }\end{array}$ & \\
\hline$i 5$ & 1.9 & o 4.5 & 1.5 & .... & 2.55 & 0.64 & (a) & (a) & (a) & ) \\
\hline$l 4.8$ & 1.75 & 4.5 & 1.4 & $\ldots$ & 1.5 & 0.3 & (a) & (a) & (a) & \\
\hline$r 4.8$ & 1.75 & 3.7 & I. 3 & 1.6 & 0.8 & 0.16 & 0.8 & 0.23 & 0 & Une \\
\hline ... & $\ldots$ & $i 3.2$ & 0.95 & 1.12 & 0.48 & 0.10 & 0.6 & 0.16 & 0 & Hower. \\
\hline$\cdots$ & $\cdots$ & $\ldots$ & ... & 0.86 & 0.4 & 0.16 & $0.4^{8}$ & 0.24 & 0 & \\
\hline 4.8 & 1.6 & .... & .... & ... & ... & ... & $\ldots$ & ... & ... & \\
\hline $4 \cdot 5$ & R. 1.6 & $\ldots$. & ... & $\ldots$ & ... & $\ldots$ & ... & $\cdots$ & $\ldots$ & \\
\hline 3.0 & I.3 & .... & .... & $\ldots$ & ... & $\ldots$ & ... & ... & $\ldots$ & \\
\hline 5.4 & H.1.9 & $\cdots$ & $\cdots$ & $\ldots$ & $\cdots$ & $\cdots$ & $\cdots$ & $\cdots$ & $\cdots$ & \\
\hline
\end{tabular}

1R.= Riverton plant. $\quad H_{0}=$ Harshberger's plant. $\quad i=$ innermost. $\quad l=$ left. $\quad r=$ right. $\quad o=$ outormost. $(a)=$ withered.

Number of Floral Parts.

\begin{tabular}{|c|c|c|}
\hline Floral Parts. & I. & II. \\
\hline $\begin{array}{l}\text { Sepals.......... } \\
\text { Petals ........... } \\
\text { Stamens....... } \\
\text { Carpels......... }\end{array}$ & $\begin{array}{r}4 \\
26 \\
60 \\
9\end{array}$ & 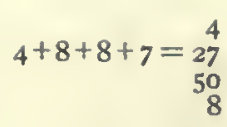 \\
\hline Total......... & 99 & 89 \\
\hline
\end{tabular}

Leaf Measurements.

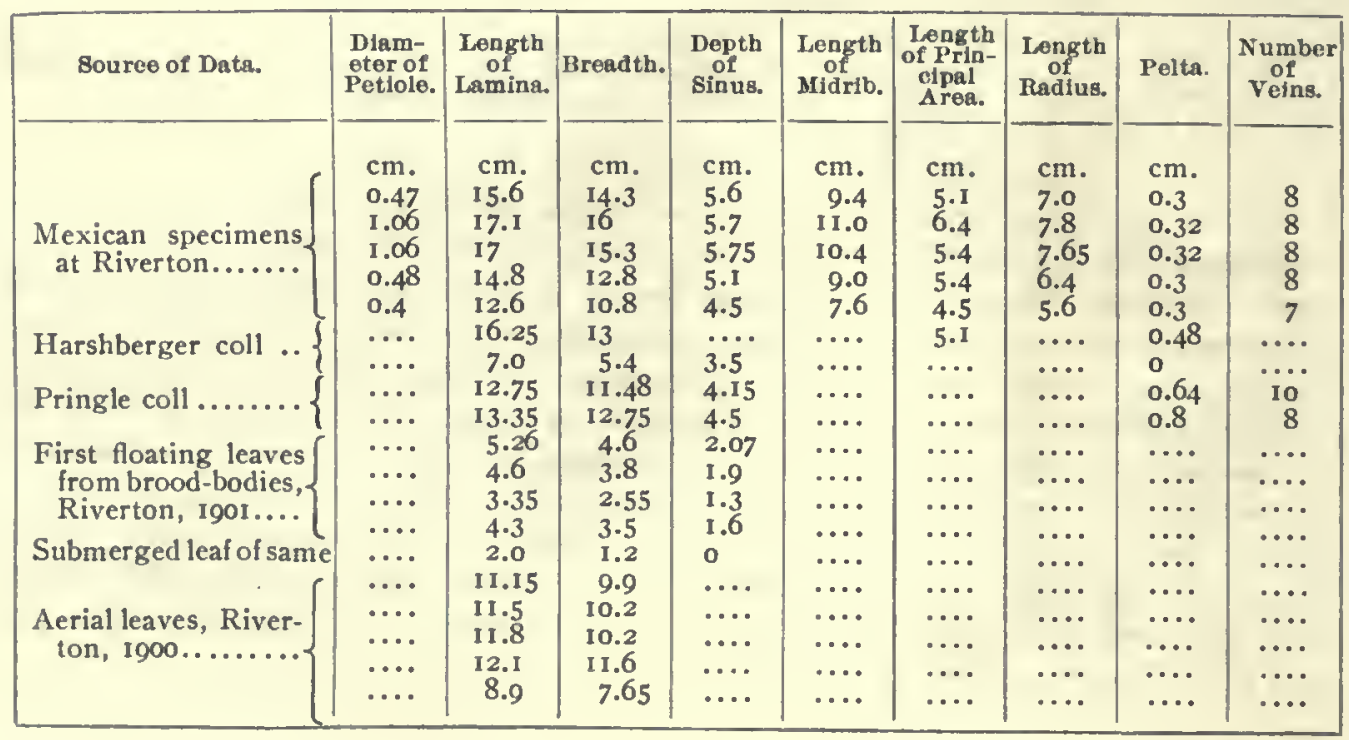


Geographic Distribution.-Florida, Texas, and Mexico. "Lagoons of the lower Rio Grande southward to the Valley of Mexico, and westward to the valley of the Lerma, State of Jalisco" (Pringle I890). Lake Xochimilcho, Valley of Mexico, coll. J. W. Harshberger. Brownsville, Texas, coll. Pringle, Flora of Texas, I888, No. 1956. In Florida: St. Johns River, from Jacksonville southward for 40 miles (Treat, 1877, fid. original specimens); Curtis, North American Plants, No. Ior $a$ and Second Distribution No. 4815. Miami River; Prairie Creek (both in lib. Acad. Nat. Sci. Phila.). Little River, coll. Dr. J. M. Macfarlane, cult. in Botanic Garden, Univ. of Pennsyivania. Reservoir Pond, Palm Beach, coll. Mr. Thomas. Also coll. Rugel, "ad f. Alachua, Florida or." July, 1848, in hb. British Museum.

Notes.-Zuccarini's description of $N$. mexicana ascribes white flowers to it, whereas the leaf agrees with that given above. Examination of the types leaves no doubt as to the identity of the plants now so familiar in cultivation; the white color must have been purely a guess, as Professor Radlkofer suggested to me. The dried specimens are brown like the average herbarium specimens of the European waterlily.

Our conclusion to unite the Florida and the Mexican plants comes only after prolonged consideration and comparison, and it is to be regretted that the very suggestive name $N$. flava has to be abandoned. It has seemed to us that the leaves of the Mexican plant are thicker and rounder, with less of purple coloration beneath. The floral leaves also are a little broader than those of the Florida plants. A fruit on Pringle's No. 1956 in hb. Acad. Nat. Sci. Phila. seems to have been nearly spherical, while the fruits of the Florida plants in our garden were ovoid. We have not been able to secure living plants direct from any Mexican locality. The Prairie Creek specimens, collected by Garber in 1878 , have leaves more nearly orbicular than those from other Florida localities; this is probably because they grew in shallow water. We see in cultivation like variations from this cause.

The name $N$. flava Leitner rested on the floral decorations and name on Audubon's plate of the great white swan; the leaves accompanying the yellow flowers are evidently those of a Nuphar. Excepting Rugel's unrecognized specimen, the species was known only by that plate until Dr. Edw. Palmer in 1874 sent a dried specimen to Harvard, with a statement of its yellow color. Mrs. Treat, however, in 1876 , again discovered the plant, and made it known by sending ample material both fresh and dried to Harvard ; from there it was sent to Kew, where it flowered first in July, 1882.

\section{B. Chamaenymphaea Planchon 1853 .}

Flowers white or rosy, opening near noon and closing in the late afternoon. Innermost stamens first to delisce. Pollen aculeate or tuberculate. Seed of medium size. Leaves entire, obovate to oval. Principal air-canals in peduncle 4, in petiole 2; idioblasts stellate only. Rhizome erect, short, entirely without offsets (at least in $N$. tetragona). Native of the North Temperate Zone, especially in China and Japan.

\section{Nymphaea tetragona Georgi. (Plate XIV; Fig. 65.)}

Flower small, 2.5 to $5 \mathrm{~cm}$. across, white, with a small number of floral parts; receptacle distinctly tetragonal. Leaves ovate, small ( 2.5 to $12 \mathrm{~cm}$. long), green above with brown blotches when young, under surface dull red; sinus open, lobes acute. Petiole with 2 main air-canals. Rhizome erect, covered with projecting leaf-scars. 
Nymphaea tetragona, Georgi 1775 , fid. original specimen from hb. Pallas, in hb. British Museum; 1800. Caspary 1865. Robinson 1896. Conard 1901 $a$.

N. tetrogononthos, Pallas MS., in Sims 1813 , fid. specimen cited above.

N. pygmoea, Aiton 1811. Sims 1813. Smith 1819. DeCandolle 1821 b, 1824. Sprengel 1825. Don 1831. Ledebour 1842. Turczaninow 1842. Planchon $1852 b ; 1853 a$ and $b$. Lehmann 1853 a. Hooker \& Thomson 1855. Loudon 1855. Hooker 1872. Garden 1883b. Tricker I897. Moenkemyer 1897 .

N. foliis cordatis integerrimis and $N$. alba minor, Gmelin 1769.

N. pygmaea alba, Hort, Gerard 1890 a?

Castalia pygmaea, Salisbury 1806 b.

C. Leibergi, Morong 1888, fid. original specimens. G. \& F. 1888.

C. odorata var. minor, Macoun I891 (in part) fid. specimen coll. J. M. Macoun, July 17, 1886, No. 94 from hb. Geol. and Nat. Hist. Survey, Canada, in hb. British Museum. Not N. odorata var. minor Sims 1814 .

C. tetragona, Lawson 1889. Britton \& Brown 1897.

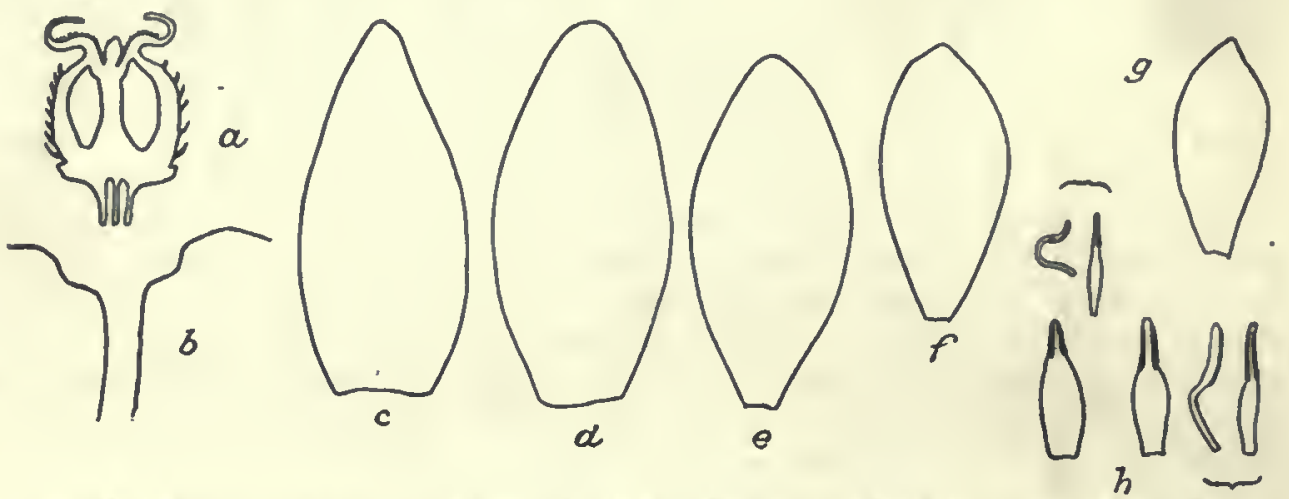

FIG. 65.- Nymphaea tetragona: $a$, section of ovary; $b$, section of receptacle; $c$, outer, $d$, Inner sepal ; $e$, outer, $f$, median, $g$, fnnermost petal; $h$, stamens. Natural size.

Description.-Flower floating, 3.3 to $7.6 \mathrm{~cm}$. across, open on 3 or 4 days from noon until 5 p. m., sweet-scented (or odorless, Britton \& Brown 1897).-Peduncle slender, 0.3 to $0.4 \mathrm{~cm}$. in diameter, terete, to to $30 \mathrm{~cm}$. long, with 4 main air-canals. Receptacle enlarging abruptly from the scape, distinctly tetragonal, with rounded angles, green.-Sepals 4 , ovate to oblong-ovate or broadly lanceolate, breadth : length $=$ I: I.I6 to $3.6 \mathrm{I}$, obtuse or slightly acute; opening horizontally or less, putrescent in fruit; green and veinless outside, white within; when dry, marked outside with short elevated lines.-Petals 8 to 17 , rather thin, pure white (or faintly striped with purple lines, Morong 1888), about as long as the sepals, oblong, obovate or broadly lanceolate, or oblong-elliptic, apex obtuse or somewhat acute, narrowed toward the base, grading into the stamens.-Stamens about 40, with golden yellow anthers, shorter than the petals (stamens 12 to 16 in the American plant, in 3 or 4 rows, running up the ovary about half way, Morong I888); outer stamens shorter than median ones; outermost filaments elliptic or obovate to lanceolate-oblong, very broad, narrowed toward the base (inserted up to the summit of the ovary, Casp. 1865; Turcz. 1842); outermost anthers shorter than median and inner, cells diverging below, sometimes only one cell developed. Median stamen with filament as in outer, but narrower; cells of anther parallel. Innermost stamens very short, filaments slender, cells 


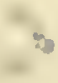





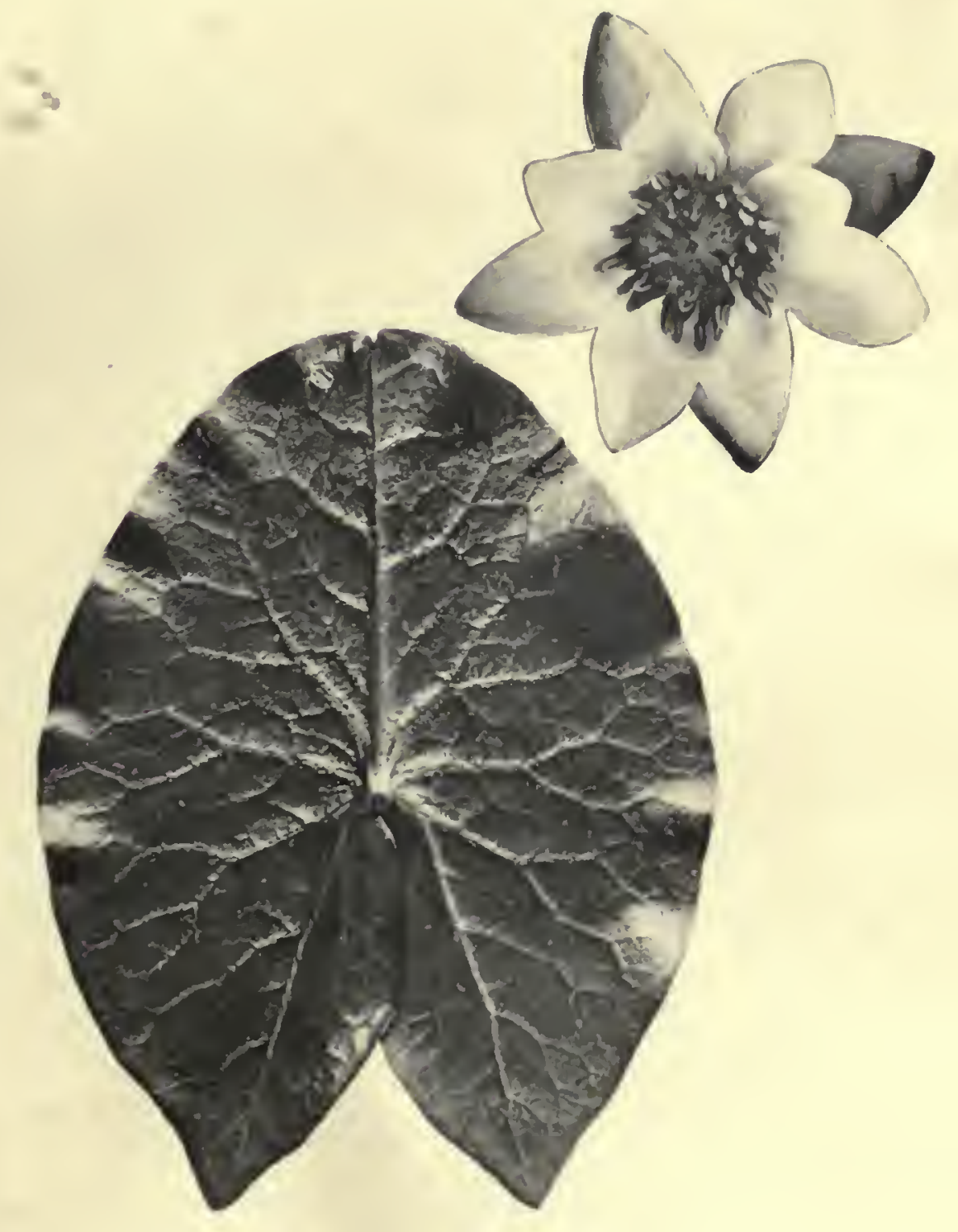

NYMPHAEA TETRAGONA. 

of anthers as in median stamens.-Pollen yellow, finely tuberculate, operculum smooth; diameter 0.03 to $0.04 \mathrm{~mm}$., average $0.034 \mathrm{~mm}$.-Carpels 6 to 8 (4 to I2, as hitherto described) ; styles thin, subcoriaceous, ovate or oblong-elliptic, short and blunt, breadth: length $=\mathrm{I}: \mathrm{I} .25$ to 3 , concave; stigmatic area extending on their bases as an upraised cushion, ending obtusely. Stigma little or not at all depressed.-Fruit spherical, naked, green, crowned with the small stigma.-Seed large, 0.3 to $0.2 \mathrm{~cm}$. long by 0.16 to $0.17 \mathrm{~cm}$. in diameter, dark brown, smooth.

Seeds which germinate in late summer form small plants, and at approach of winter, hse their leaves and retire into a small tuber. These germinate, producing first a series of submerged leaves, then small floating leaves as follows: Submerged leaves broadly bbovate, rounded at apex, thin, pale green; sinus deep, margins nearly straight near the petiole and parallel or diverging or slightly overlapping, curved outward below to the broadly rounded lobes. First floating leaf obovate-oblong, rounded at apex; sinus overlapping, lobes narrow, rounded at angles, suggesting rabbit-ears; green above with a brown line around margin; under surface greenish-red, densely marked with fine bright red marblings.

Leaf of mature plant cleft to the petiole, more or less coriaceous, broadly oblong, ovate or elliptic, 5 to $10 \mathrm{~cm}$. long by 3.3 to $7.6 \mathrm{~cm}$. wide, entire, rounded at apex (rarely emarginate, Casp. I865), dark green above, more or less mottled (at least when young) with reddish-brown; under surface green to dull red; primary veins 5 or 6 on each side of leaf, sunk in the tissues; length of principal area: radius of leaf $=\mathrm{I}: \mathrm{I} .5$ to $I .9$ (average I: I.3).-Sinus depth: length of leaf $=I: I .8$ to 2.2 (average $I: 2$ ), lobes unequal, margins nearly straight or slightly convex, touching, or diverging and I.9 to $3.8 \mathrm{~cm}$. apart at periphery, angles more or less produced, rounded to sub-acute or rarely acuminate. Astomatic area very small; stomata larger and not so crowded as in Eu-castalia, scattered toward the point of insertion of the petiole; cells of upper epidermis large.-Petiole smooth, terete, very slender, 0.24 to $0.4 \mathrm{~cm}$. in diameter, Io to $30 \mathrm{~cm}$. long, with 4 main air-canals, 2 larger and 2 smaller, with 4 still smaller ones anteriorly and posteriorly, and one on each side; 2 double bundles are present ( $\mathrm{I}$ anterior and I posterior) with 3 or 4 smaller ones on either side; stellate cells projecting into the 6 larger air-canals, rays very slender, long, densely covered with small crystals, quite brittle.-Stipules oblong-ovate or Measurements of Sepals (AFTER CASPary, 1865). elongate-triangular, acute, not at all keeled.

Rhizome erect, 7 to $15 \mathrm{~cm}$. long, blackish, covered with long hairs ( $\mathrm{I} .3 \mathrm{~cm}$. long) ; apex covered with leaf-bases and stipules. Entirely without branches or offsets.

Leaves from Small Seedling-Tuber (in centimeters).

\begin{tabular}{|c|c|c|c|c|c|}
\hline \multirow[b]{2}{*}{ Leaf. } & \multirow[b]{2}{*}{ Length. } & \multirow[b]{2}{*}{ Breadth. } & \multirow{2}{*}{$\begin{array}{l}\text { Depth of } \\
\text { 8inus. }\end{array}$} & \multicolumn{2}{|c|}{ Width of Sinus. } \\
\hline & & & & $\begin{array}{l}\text { Half- } \\
\text { way up. }\end{array}$ & At Angles. \\
\hline Submerged $\ldots \ldots \ldots \ldots \ldots \ldots \ldots \ldots \ldots \ldots \ldots$ & 4.8 & 3.35 & 2.55 & o.16 & I.I \\
\hline 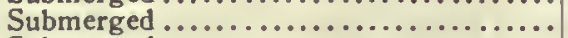 & I. 4 & I.I & 0.8 & 0.08 & 0.3 \\
\hline 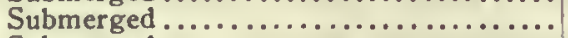 & 3.2 & 2.1 & I. 6 & & 0.6 \\
\hline 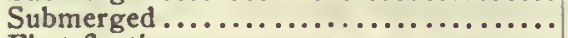 & $3 \cdot 5$ & 2.4 & I. 75 & (a) & 0.3 \\
\hline 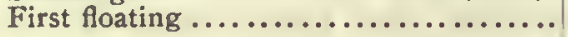 & 3.7 & 2.4 & 1.9 & (a) & 0.6 \\
\hline
\end{tabular}

a Overlapping. 
Geographic Distribution.-Eastern Europe, Asia and North America, south to Australia. Russia (Baikal region), Georgi 1775 . Khasia Hills, and marshes at Nonkreem, alt. 5,600 ft., India, Hook. \& Thom. I855, fid. specimens coll. Hooker, Duthie, Stewart, etc. N. Queensland, Australia, Müller I887? Siberia, Gmelin I 769. Common in China and Japan, fid. numerous specimens. Granite Station, Kootenai County, Idaho, U. S. A., coll. Leiberg, Heller and the writer. Misinaibi River and along Severn River, Canada (Ontario), Macoun I89I.

Notes.-Caspary (1865), from whom the measurements in the text were mostly taken, divides the species thus:

I. Lata: Sepals and petals shorter and broader, outermost petals slightly exceeding the sepals; depth of sinus less than half the length of the leaf. Leaves not spotted. Pollen smaller. Found in eastern and northern Asia.

II. Angusta: Sepals and petals longer and narrower; depth of sinus equal to or exceeding half the length of the leaf; pollen larger. This varies into ( $\mathrm{I}$ ) orientalis, outermost petals a little shorter than the sepals; lobes of leaves long-produced, rarely acuminate; leaves not spotted. China and Japan. (2) indica, outermost petals slightly exceeding the sepals; lobes of leaves long-produced, tapering and acuminate; leaves usually brown-spotted above. Northern India (Nonkreem). Georgi's specimens are of the broader sepaled type. Those with narrower petals and sepals may deserve varietal rank as var. angusta Casp.

The American plant, from its small number of stamens and their insertion below the summit of the torus, may deserve the rank of a variety.

$N$. tetragona was introduced into England from China in 1805 by the East India Company, in the ship "Winchelsea," Capt. Campbell. It is hardy in our climate. Being of small size it is suitable for aquaria.

The seeds are used for food in Japan, and the leaf buds are also eaten, dressed with vinegar (Rein I886).

Nymphaea acutiloba, DC. I82I, is of uncertain identity, but as it came from China it is probably $N$. tetragona Georgi.

Nymphaea fennica Mela.

Flower cup-shaped, small, 3.8 to $6.9 \mathrm{~cm}$. across, white or rosy; receptacle large, square, sloping upward, with a keel running from the peduncle to each corner; sepals forming a sharp angle at their line of insertion. Petiole with 2 main air-canals.

Nymphaea fennica, Mela I897, fid. specimens coll. A. J. Mela, in hb. Univ. of Penna. G. C. 1899.

DesCription (taken from Mela's paper)._Flozver cup-shaped, small.-Bud short ovate, square at base, constricted just above the base, then rounded and rapidly drawn in to the acute apex.-Receptacle characteristic, very broad; breadth of receptacle : length of sepals $=6 \mathrm{~mm} .: 14 \mathrm{~mm}$. (small flower) $;=9 \mathrm{~mm} .: 19 \mathrm{~mm}$. (medium) $;=12$ $\mathrm{mm} .: 25 \mathrm{~mm}$. (large flower). Looking at the receptacle with the apex of the bud turned away, the surface slopes gently, roof-like, from the top of the peduncle, with a low, narrow keel running to each angle. Edges of receptacle not projecting downward as in $N$. candida, but plane beneath, making a sharp angle on the side. In fruit the receptacle is a little wider than the berry and calyx, these being completely hidden 
when the fruit is viewed from beneath.-Sepals elliptic-ovate, a little contracted below the apex, often very broad; length: breadth $=3: 2$ ( 18 to $19 \mathrm{~mm}$.: 12 to $13 \mathrm{~mm}$.); calyx somewhat contracted just above its origin, so that the edges of the receptacle, which are sharp-angled outwardly, appear to project.-Petals ro to i 5 , very concave, and crowded, with apex directed upward so that the corolla is cup-shaped; lanceolate or narrowly-lanceolate.-Stamens about 50. Anthers very short and broad (3 mm. long by $\mathrm{I} \mathrm{mm}$. wide) ; filaments petaloid, with broad, elliptic, deep yellow blade and strongly contracted, whitish claw; blade often with I to 3 longitudinal folds, with I or 2 transverse folls between blade and claw.-Stigma 5 to 9 rayed, with yellow, often violettipped, styles. Stigmatic surface usually (not always) deep violet, with generally $3^{-}$ pointed rays.-Fruit broad conical-ovate, broadest at base, but not so broad as the receptacle which forms a square disc, whose edges (and especially the corners) extend noticeably beyond the circumference of the fruit; the calyx persists as a 4 -sided pyramid surrounding the fruit.

Leaf small, 7 to $12 \mathrm{~cm}$. long by 5 to $9 \mathrm{~cm}$. wide, elliptic-cordate; lobes acute or obtuse, margins overlapping or approaching or more or less wide apart $(3 \mathrm{~cm}$.). Primary veins of the lobes usually divergent, even when the lobes overlap, though they are sometimes parallel or even converging.-Petiole slightly flattened, with 2 large air-canals.

Rhizome erect, 5 to $10 \mathrm{~cm}$. long, about $2.5 \mathrm{~cm}$. in diameter, conical at apex, covered with long black hairs. One of our specimens has two equal branches.

Geographic Distribution.-Middle and East Finland, mostly in small forest ponds, sometimes in running water, from the shallows to a depth of I or 2 meters, often accompanied by large and small forms of $N$. candida. Found also in Southern Finland. (Cf. specimens coll. Lönnbohm, Aug., I898, No. 360I, "locus classicus," in several herbaria.)

Notes.-The receptacle and air-canals of petiole place this species in near relation to $N$. tetragona; in several other respects it approaches $N$. candida semiaperta. One is inclined to suggest that $N$. tetragona of China shades off through the Siberian forms into $N$. fennica, this then runs into $N$. candida, and it again into $N$. alba of Germany and England. A careful review of these forms, in the living state by cultivation and hybridization, as also in histological details, is highly desirable.

The seeds of $N$. fennica have not as yet been described.

Numerous stations for this species throughout Finland are given in Mela's paper. Red-flowered specimens occur "im See Keskimmainen im Kirchspiel Lapinlahti," and in Pieni Musto and Jäläjärvi.

Through the kindness of Mr. Mela, we have a fine series of specimens of $N$. fennica; of several rhizomes sent to us alive, only one survives, and it has never bloomed.

\section{C. edCastalia Planchon $1853 b$.}

Flowers white or rosy to deep carmine, opening in early morning, closing from noon to mid-afternoon. Innermost stamens first to dehisce. Pollen aculeate or tuberculate. Seed of medium size. Leaves entire, nearly orbicular, of solid color above. Principal air-canals in peduncle 4 , in petiole 4 ; thickened bipolar idioblasts more or less numerous in the tissues of leaf and flower stalks, this type of cell being absent 
from other syncarpous members of the genus. Rhizome horizontal, long and creeping, more or less branched. North temperate zone, south to Algeria, Cashmir, and British Guiana.

\section{Nymphaea candida Presl. (Plate XV; Fig. 66.)}

Leaves floating, crowded on the rhizome, phyllotaxy about 13 on 34 ; lowest pair of veins on under side of leaf (veins of the lobes) curved toward one another. Flower odorless, white, 6.4 to $7.6 \mathrm{~cm}$. across. Line of insertion of the sepals angular, projecting downward. All of the filaments broader than the anthers. Ovary much contracted and destitute of stamens immediately below the stigmas. Fruit ovoid, seed large.

Nymphaea condida, Presl 1822, fid. specimens coll. Topitz, Flora exsiccata austro-hungarica, No. 1282, "in stagno Egersee ad pagum Sonnberg prope urbem Gratzen (locus classicus)." Reichenbach 1845 . Planchon $1853 \mathrm{~b}$. Schuchardt 1853. Celakovsky 1867 . Caspary 1879. Grisebach 1882. Gerard 1892. Tricker 1897. Moenkemyer 1897. Conard 1901 $a$.

N. alba, Linnaeus $1753 ; 1762$ (in part), and other European authors.

$N$. alba oocarpa, Caspary $1855=N$. alba oligostigma Casp. $1863 ; 1865$.

N. biradiata, Sommerauer 1833, fid. specimens coll. Sommerauer, in Tricbnersee in Styria in hbb. Paris, Boissier, and coll. Wettstein, Flora exsiccata austro-hungarica, No. 1281. Coll. Statzer in I. Dörfler's Herb. Norm., No. 3502; coll. Keller in Magnier, Fl. select. exsicc. No. 3453; coll. F. G. Strobl, "in aquis stagnantibus: Triebner-vel Gaishornsee vallis Paltinae (locus classicus)." Reichenbach I845. Fries 1846. Planchon $1853 \mathrm{~b}$. Schuchardt 1853.

N. semiaperta, Klinggraeff 1848, fid. F. Schulz, Herb. Norm. nov. ser. Cent. 3, No. 207, and specimen coll. Caspary, Aug. 9, 1859, near Königsberg, in hb. Boissier. Schuchardt 1853.

N. neglecta, Hausleutner 1850, fid. specimen coll. R. Fritz, July, 1870, in a pond near Rybnick, Ober-Schlesien, in hb. Berlin.

N. Kosteletzkyi, Palliardi MS., fid. Lehmann $1852 b$, and specimens sent by Palliardi to Lehmann, from hb. Lehmann in hbb. Kew, Berlin. Schuchardt 1853.

N. pauciradiata, Bunge, in Meyer \& Bunge $1829=N$. alba Patrin, fid. Meyer \& Bunge, 1. c; fid. specimens coll. Ledebour, 1845 , in the Altai region, in hbb. Paris, Munich.

$N$. intermedia, Weiker, in Reichenbach 1842.

N. Basniniana, Turczaninow 1842 , fid. specimens sent by Turczaninow from hb. St. Petersburg, in hbb. Kew, Boissier, DeCandolle $=N$. bashiniana, Steudel 1841 .

$N$. Cachemiriana, Cambessedes in Jacquemont 1844 , fid. original specimens in hb. Paris $=N$. alba var. Kashmiriana, Hook. \& Thoms. 1855. Hooker 1872.

N. punctata, Kar. \& Kir. 1842, fid. Casp. 1879, from Semenow 1854, and specimens coll. Kar. \& Kir. "in Songoriae lacubus prope fluvium Lapsa," in hbb. Berlin, Paris, DeCandolle.

N. alba, L. var. minor DC., fid. specimen coll. Fischer, 1819, in hb. DeCandolle. Besler 1613, cf. Flora 1833. Schuchardt $1853 .=N$. minor Reichenbach $1842 ; 1845 .=N$. permixta, Boreau 1859.

N. Milletii, Boreau 1859, fid. specimen coll. Ed. Longeron, June I2, I86I, Maine et Loire (locus classicus?) in hb. British Museum.

N. Wenselii, Maack in litt., fid. plate from Ruprecht 1859, in hb. British Museum.

DESCRIPTION.-Flower floating, 6 to $13 \mathrm{~cm}$. in diameter.-Sepals 4 (or 5) oblong or ovate-oblong $(3.8 \mathrm{~cm}$. long by $1.3 \mathrm{~cm}$. wide), narrowed at apex, acute or obtuse, about 7-veined, green outside, white within.-Petals 12 to 20 , white, oblong to oblong-lanceolate, obtuse or somewhat acute, 7-nerved, outer ones nearly as long as the sepals.Stamens 32 to 70 , shorter than in $N$. alba, grading inward from the petals, orangeyellow; filaments lanceolate (outer) to linear-lanceolate (inner), long acuminate, never narrower than the anthers, usually inserted only on the sides, not on the summit, of 
the ovary. Pollen granulate with smooth operculum, larger than in N. alba.-Ovary ovate or roundish, usually contracted and destitute of stamen insertions below the stigma.-Carpels 5 to I4; styles linear, flattened, breadth: length $=I: I .5$ to 2.5 ; apex rounded or somewhat acute. Stigma concave, yellow, red or violet, the rays terminating usually in 3 teeth (a central and two lateral) on the base of each style. Axile process slender.-Fruit ovoid or spherical; in the former case, narrowed below the stigma, which stands as it were on a short thick column surmounting the berry; greenish or reddish; subtended by the persistent sepals; diameter 1.9 to $4.4 \mathrm{~cm}$.-Seed larger than in $N$. albw, ellipsoid, brownish, $0.3 \mathrm{~cm}$. long; aril longer than the seed.

Leaf cleft at base to the petiole, sub-orbicular to oval, 1o or I2 to $30 \mathrm{~cm}$. long and $25 \mathrm{~cm}$. wide, entire.-Simus, depth: length of leaf $=\mathbf{1}: 2.5$; lobes nearly equal, inner margins curved, overlapping a little above, and spreading out toward periphery of leaf (or straight, and parallel or touching); angles more or less acute. Veins on under surface of leaf prominent, the lowest pair (i. e., those running into the lobes) curved, and, if produced, would cross, inclosing an oval area. -Petiole terete, smooth.

Rhizome stout, $5 \mathrm{~cm}$. or more in diameter, horizontal, with strong lateral roots, but often without sidebranches; apex surrounded by petioles, peduncles and stipules. Phyllotaxy about 13 on 34 with very short internodes; the surface of the rhizome may almost be said to consist of large leaf-cushions.

Geographic Distribution.Northern and arctic Europe and Asia, south to the mountains of Germany and the Himalayas. Krumme-

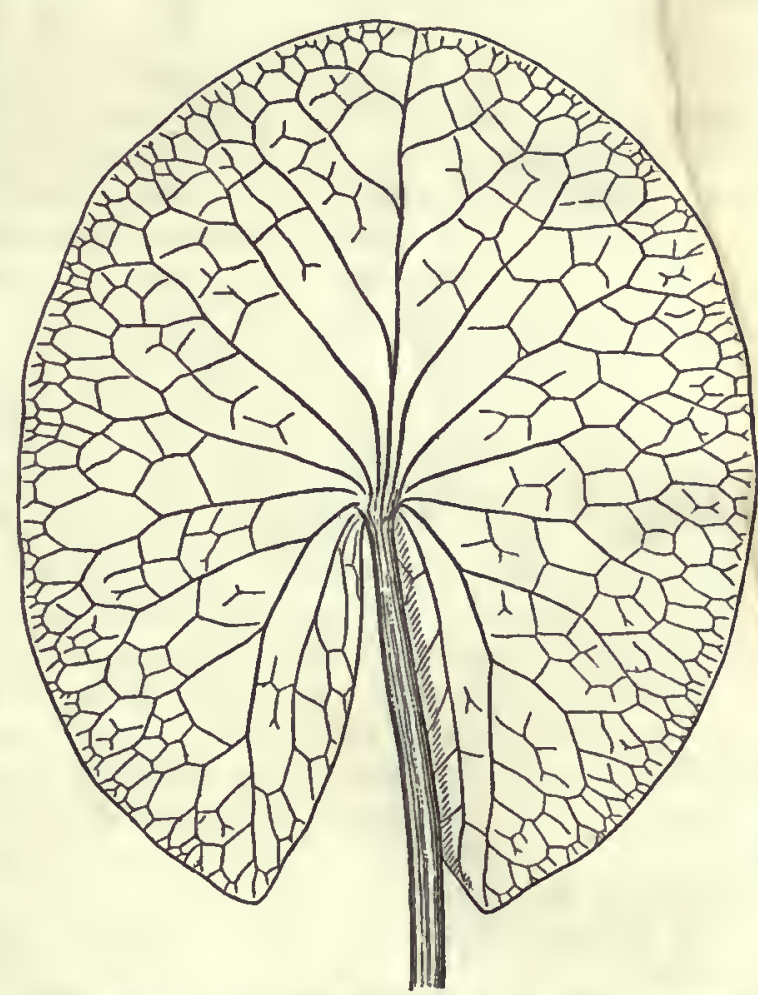

Fia.66.-Nymphaea candida: Under stde of leaf of specimen in hb. British Museum, from the classlo locality (Flora exsiccata austro-hungarica, No. 1282), by courtesy of the Directors. P. Highley, del. Reduced one-quarter.

\section{See, near Grubno, in West Prus-}

sia (Caspary 1884). Canton St. Gallen, in Switzerland (Gremli 1882). Lojo in Poland (Lindberg 1881 ). Herjedalen in Sweden (Behm I887). Far north in Finland (Saelan 1879). Egersee, near Gratzen, in Austria (Kerner 1886). Königgrätz, in Bohemia (Hansgirg 1880). Vésztö, in Hungary (Borbás 188I). Ascends 500 meters in southern Bavaria (Schenck 1885). East slopes of Urals (Cler 1873). Triebnersee, Palatinathal, Austria (Kerner 1886). Bohemia, in ponds and ditches (Presl 1822). Austro-Hungary (Leopoldskron, coll. Stohl), Flora exsiccata austro-hungarica, 
No. 1283. Franzensbrunn: 3 Nomenteiche, coll. Caspary, Aug. 25, 1855, in hb. Kew. Lakes of the Vosges near Sembach, Bavaria, coll. Koch, July 20, I859. Hammertcich near Falkenberg, Obcr-Schlesicn, fid. specimen in hb. Kew. Teplitz in Bohemia, coll. Winkler, 1853, in hbb. Boissier, DeCandolle. Near Stockholm, Sweden, coll. Ljogruen, I845, in hbb. Munich, DeCandolle. Lithuania, coll. E. Rudominówna, in hb. Kew. Neusattel near Ellnbogen, coll. Caspary \& Ortman, 1855, in hb. Kew. Schwarzsee near Kitzbühel, Tyrol, coll. Traunsteiner, No. I608, marked "N. alba," in libb. Boissicr, Paris. Lakcs of the Baikal region, Siberia, coll. Fischer, 1836 , in hb. Paris. Cashmere Lake, coll. J. E. Winterbottom, May 13, 1847, and coll. Falconer, both marked "N. alba" in hb. Kew.

Notes.-The species varies widely as indicated above in the description, and as may be inferred from the lengthy synonymy. Presl's distinctions were not widcly known, or were lost sight of by most botanists. He separated $N$. candida from $N$. alba largely on account of the absence of stamens from the summit of the ovary. The sanc namc had been used for a Europcan white waterlily by Tragus, Fuchs, Caesalpinus and others. N. pauciradiata was characterized by its small flowers and few carpels ( 8 to 9). $N$. biradiata was noticed on account of the blood-red star on the stigma. N. basniniana was separated from $N$. alba on account of having oval leaves instead of round, and its small number (9) of carpels. N. cachemiriana has also only 7 to 8 carpels; the original description is quite complete. N. semiaperta has as its outstanding trait the fact that even at noonday the flowers remain only half open. $N$. neglecta was marked off from alba by its small oval fruit, few rayed stigma, and the converging course of the lowest pair of veins of the leaf; from candida in having petals longer than the calyx, and ovary only one-third bare, instead of two-thirds as in Presl's candida; from semiaperta by smallness of ovary and color of stigma. It is interesting to notice how various observers have been impressed witl differcnt features of the plant as they appear more or less exaggerated in certain localities.

Probably the best disposition of the case is that of Caspary in 1879 , when he first granted specific recognition to this group of forms. His paper of 1855 placed these plants in variety oocarpa of $N$. alba, with the following divisions:

N. alba var. oocarpa.

E. angustata-styles longer and narrower; Königswerth in Bohemia.

F. semiaperta-styles shorter; flower opening one half.

a. erythrocarpa-fruit reddish $(=N$. semiaperta and biradiata)

G. aperta:

b. chlorocarpa-fruit greenish (=N. neglecta)
a. erythrocarpa ( $=N$. kosteletzkyi and cubogermen, from Franzensbrumn)
( $=N$. candida Presl from Pardubitz in Bohemia)
b. chlorocarpa ( $=N$. candida Ortm. from Ellnbogen, Bohemia) (=N. candida Presl from Pardubitz, Bohemia)

The name oocarpa was changed by the author to oligostigma in 1863 , and finally, on discovering that crosses between $N$. alba oocarpa and $N$. alba sphaerocarpa were true hybrids, with imperfect sexual apparatus, the two were made distinct species, and the following disposition of the one in hand was given, with a few, mostly Swedish, localities. 
N. candida Presl.

Var. I. oocarpa; fruit ovoid, ligher than broad.

I. aperta; sepals and petals opening to form an obtuse angle.

A. xanthostigna; stigma yellow. Nerike; Fagertärn; E. Prussia; Königsberg; a few lakes in West Prussia.

B. erythrostigma; stigma more or less dark crimson, especially near apices of stigmatic rays. Södcrmanland and Norbotten.

a. erythrocarpa. Norbotten.

b. chlorocarpa. Norbotten.

2. Semiaperta; sepals and petals forming an acute angle when open; fl. campanulate. Prussia, east of the Weichsel, and Bohemia.

Erythrocarpa and chlorocarpa, $N$. biradiata and $N$. semiaperta.

Var. II. sphacroides; fruit spheroidal, broader than tall.

I. aperta; sepals and petals opening to form an obtuse angle.

A. erythrocarpa. Norbotten.

B. chlorocarpa. Norbotten.

2. scmiaperta; sepals and petals forming an acutc angle when open; f. campanulate.

A. erythrocarpa. Norbotten; Prussia.

B. chlorocarpa. Prussia.

$N$. alba $\times$ candida occurs in East Prussia at Neuhausen near Königsberg, near Goldap, and elsewhere (Caspary 1879). Sernander (1894) clains to have found a red variety of $N$. candida in Fagertärn, Sweden.

Nymphaea nitida, Sims I8I I $a$, with entire, suborbicular leaves, with obtuse lobes; flowers white, cup-shaped, may belong here. Its habitat is unknown, and it has not recently been positively identified anywhere. The figure of the Botanical Magazine was "drawn at Mr. Vere's garden" in Kensington-Gore, Mr. Anderson, gardener. A specimen exists in hb. Caspary (now Berlin), which was presented by Prof. M. T. Masters in 1854 from the botanic garden of Oxford. Here it was received in 1840 from Kent, whither it came directly from Anderson. This specimen appears to belong to $N$. candida as lere defined.

\section{Nymphaea alba (L.) Presl.}

Leaves nearly orbicular, floating, red when very young, 1o to $30 \mathrm{~cm}$. in diameter, crowded on the rhizome, phyllotaxy about 13 on 34; lowest pair of veins straight and diverging. Flower odorless, pure white (in the type), Io to $12 \mathrm{~cm}$. across, opening fully. Line of insertion of sepals rounded, not prominent. Stamens covering the ovary to the summit. Filaments of inmost stamens not wider than the anthers. Axile process spherical. Fruit more or less spherical, seed small.

Nymphaca alba, Linnaeus 1753 , fid. original specimen in hb. Linnacus, without data; 1762 (in part). Willdenow 1797 (in part). Aiton I789; I8II (in part). Smith I800; I809 (in part), and all writers previous to 1822 , and many since.

N. alba, Presl 1822. Reichenbach 1845 . Hentze I848 $a ; 1852 a, b$. Schuchardt 1853. Caspary I879. De Halácsy 1900. Conard I901 $a$.

N. alba melocarpa, Caspary $1855=N$. alba polystigma Casp. 1863 .

N. Aesopii, Orphanides MS. in Boissier I888; fid. specimens coll. T. G. Orphanides, Flora Graeca exsiccata, No. I05I (hb. Orphanid., No. 264) Feb., I862, "ad lacu Baldovo supra Vodena Macedoniae," in hbb. Paris, Boissier.

N. Dioscoridis, Heldr. MS., in Boissier I888; fid. specimens coll. Heldreich, Herbar. Flor. Hellenic., May 23, 1878, at "Aetolia: in lacu Lysimachion," in hb. Boissier. 
N. venusta, Hentze $1848 b$; $1852 a$, fid. specimens coll. Hentze from hb. Lehmann, in hbb. Kew, Berlin.

N. rolundifolia, Hentze $1848 b ; 1852 a$, fid. specimens coll. Hentze, from hbb. Lehmann and Caspary, in hbb. Kew, Eerlin.

$N$. erythrocarpa, Hentze $1852 b=N$. alba Hentze $1848 a ; 1852 a$, fid. specimen coll. Hentze, from hb. Lehmann, in hb. Berlin.

N. parvifiora, Hentze $1848 b$; $1852 a$, fid. specimens coll. Hentze, from hb. Lehmann, in hbb. Kew, Berlin.

N. splendens, Hentze $1848 a$; $1852 a$, fid. specimens coll. Hentze, from hb. Lehmann, in hbb. Kew, Berlin.

N. wrceolata, Hentze $1848 b ; 1852 a$, fid. specimen from hb. Lehmann, in hb. Berlin.

N. alba var. intermedia Gave 1892; fid. original specimen coll. P. Gave, June 30, 1891, St. André, Haute Savoie.

Castalia speciosa, Salisbury, 1806 a. Britten 1888 a.

C. alba, Woodville \& Wood 1806. Link 1831. Greene 1888. Lawson 1889.

DESCRIPTION.-Flozver floating, 7 to $15 \mathrm{~cm}$. in diameter, open on 4 days from 7 a. m. to 4 p. m. (7 a. m. Upsala; 8 a. m. Innsbruck, Kerner 1895), ( 5 p. m. Schulz 1890 ), faintly sweet-scented on first day of opening, odorless afterward.-Peduncle terete.-Recepfacle rounded along the line of insertion of the sepals.-Sepals 4 (rarely 3 or 5. Eichler 1875 ) oblong or ovate, obtuse or somewhat acute, smooth, opening out horizontally or more, putrescent in fruit, green mostly shaded with reddish-brown outside, whitish or pale reddish within, stiff, obscurcly 7 -nerved.-Petals I2 to 24 , of rather firm texture, outermost opening horizontally, grading inward in size, shape and position to the stamens. Outermost petals about as long as the calyx, lanceolate to oblong, or ovate, obtuse, white, often striped with green, gray, or reddish on the back-Stamens 64 to 100 or more, covering the torus to its summit, innermost first to ripen. Outer ones 15 to $17 \mathrm{~mm}$. long, innermost 4 to $5 \mathrm{~mm}$. long. Anthers sulphur-yellow to orange-yellow, sickel slraped with the convexity inward, inserted at an angle with the filament, the angle being slight in the outer stamens, reaching $90^{\circ}$ in the innermost; lines of dehiscence facing inward and downward; outermost anthers 10 to $12 \mathrm{~mm}$. long, innermost about 3 mm. Filaments curved, convex side outward, bringing the anthers over the niddle of the flower; outer filaments white, petaloid; innermost filament fliform, yellow, narrower than the anther. Pollen aculeate, operculum smooth; 0.035 diameter.-Oevry slightly contracted below the stigma, corered with stamens to the sunmit. - Carpols $S$ to 24 (mean $=12$ to 20 ); styles fleshy, triangular-ovate, roended at apex, more or less concare and I to 5 sulcate on inner side, sclphur yellow, often tinted orange. Stigmatic area scarcely produced above to the bases of the strles, eading acutely. Stigma more or less deeply depressed, basin or funael shape, sulpheryellow. Axile process conical, acute, yellowish-white-Frwsis slobose or depressedglobose, crowned with the styles, which are bent sharply inward. Inser wall of frcit cells whitish, spongy; tissues steen or blood-red. Ripe fruit rellowish-greea cutside, dcrnid of floral leaves - Serd 3 num lans by $2 \mathrm{~mm}$ in diameter, ellipsoidal or oroid, dark olive green, smocth; raphe evident. Anil ixchaing the seed, cpea at eod cpposite hilum, and with irregular margin.

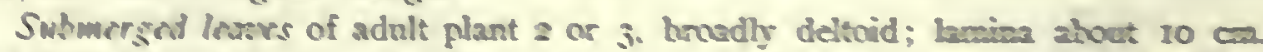
acnes, with storiath on upper epidermis; petiole $10 \mathrm{~cm}$ long: leares protoced in iall, or in unfaromatle conditions (CF. Areangeli I\$ 100 ) 
Mafure foofing loof cincular or ronnd-ovate, entire or slightly enarginate at apex, somewhat leatliery, usually dark green above, paler in astomatic area and over primary veins; yellowish-green or reddish beneath; reddish or even dark red when very young; marginal line brownish-red. - Sinus reaching to the petiole, open or closed, nuargins curved, or rarely nearly straight, separated, touching or overlapping; angles obtuse. Veins of the lobes, if produced, diverging.-Stipules large, lanceolate, narrowly cmarginate, bicarinate, entirely free, far overreaching the apex of the rhizome.

Rhizonic horizontal, often very thick ( 5 to $8 \mathrm{~cm}$.), becoming 90 to $\mathrm{I} 20 \mathrm{~cm}$. long, black, with prominent leaf cushions. Apex protected by the long stipules and the usual long fine hairs. Phyllotaxy of a high order, about I3 on 34. Branches few, stout, strongly attached.

Geographic Distributiox. - Europe and Northern Africa. Great Britain (Smith I800, etc.). Denmark, France, Gerniany, Italy, Spain, Greece. Algeria (Planchon $1853 b$ ). Sweden. E. g. Heldreich, Herbar. Graecum Norm., No. I I06, coll. in "Euboea Septentrionalis : in stagnis Suvala ad cumen Tympanon in Telethrii." Steinitz, Flora exsiccata Austro-Hungar., No. 2056, " Hungaria : in aquis stagnantibus prope Rakos in ditione Pestinensi." C. Scholz, No. 775 of A. Callier: Flora Silesiaca exsiccata, Editio 1895, "Guhrau: Wald bei Gabel." Lignier, No. 3452 in Magnier, Fl. select. exsicc., I893-4, "Loir-et-cher: Villeherviers, étang au Glandier."

NotEs.-This is the Nymphaea par

\begin{tabular}{|c|c|} 
Size of Leaves. \\
\hline Length. & Width. \\
\hline $\mathrm{cm}$. & $\mathrm{cni}$. \\
27 & 24.9 \\
27 & 25.5 \\
35.1 & 30.6 \\
37 & 34.4 \\
36.4 & 31.2 \\
34.4 & 29.3 \\
$9.5-23$ & $9.5-23$ \\
\hline
\end{tabular}

Size of Fruit.

\begin{tabular}{|c|c|}
\hline Helght. & Diameter. \\
\hline $\mathrm{cm}$. & $\mathrm{cm}$. \\
3.8 & 4.0 \\
3.2 & 3.5 \\
\hline
\end{tabular}
excellence of the classic botanists. It has a wide distribution and varies much in size of leaf and flower, as well as in the color of all the parts, and the shape of the fruit. Hentze (1848-52) distinguished several varieties which so fully retained their characteristics in cultivation and in propagation from seed that he regarded them as practically of specific rank. N. splcndens was so named for its orange-yellow instead of sulphur-yellow stamens, and was collected in ponds in "Reinhardswalde in Niederhessen" and between Beberbeck and Hombressen. $N$. urceolata was characterized by the deeply urceolate stigma; collected between Rödelheim and Bockenheim, and at Bergen near Frankfurt a. M.; also at Darmstadt ("grossen Wog"), Buchrainweihern near Heissenstamm, and Bulau near Hanau. $N$. vcunsta, with many (24) petals and (90) stamens, and a cup-shaped flower, secmed especially showy; collected in the so-called "Grosse Judenteiche" at Gosslar in the Harz. N. rotundifolia was named for the shape of its leaves; collected near Heringen, “Kleinensee im Werra-Thal." Hentze's typical N. alba came from Sweden (Upsala). $N$. erythrocarpa was characterized by the blood-red tissues of the interior of the fruit, and came from "Bremerhafen, aus dem Lande Hadeln." $N$. parviflora was distinguished by its small flowers ( 7 to Io $\mathrm{cm}$. across, the others being to to $15 \mathrm{~cm}$.), accom- 
panied by leaves of the ustal size; it was collected at two stations near Lich. All of these were supported by numbers of specimens in all stages of flower and fruit.

In Greece, $N$. aesopii of Macedonia was separated off by Orphanides on account of its huge size, and $N$. dioscoridis from Lake Lysimachia in Aetolia for its smallness.

Caspary began his work on waterlilies by reviewing this species. $\mathrm{He}$ rightly maintained that the smallness or largeness of the plant is not a safe guide to classification, but that there were other characteristics of a more profound and constant nature on which divisions could be founded. Accordingly in 1855 he gave the following arrangement :

N. alba.

I. melocaria.

A. depressa.

a. chlorocarpa $=N$. venisia Htze.

$=N$. rotundifolia Htze.

b. erythrocarpa $=N$. erythrocarpa Htze.

B. circuinvallata.

C. sphaerocarpa.

a. chlorocarpa.

a. Aava $=N$. parviflora $\mathrm{H}$ tze.

$=N$. alba Htze.

$\beta$. splendens $=N$. splendens Htze.

b. erythrocarpa.

D. urceolata $=N$. urceolata Htze.

II. Oocarpa (see under $N$. candida Presl).

In 1863 Caspary changed the main headings, substituting I. Polystigma and II. Oligostigma in the above table. Finally in 1879 , as referred to under $N$. candida, he raised the tivo varieties to specific rank under the names of $N$. alba (L.) Presl and $N$. candida Presl, dividing the former species and giving a few localities, thus:

N. alba.

I. sphoerocarpa. Fruit subglobose.

1. platystigma. Stigma more than half the diameter of the fruit (commonest form).

A. chlorocarpa. Fruit green (widely distributed).

a. flava. Stamens sulphur color.

b. splendens. Stamens orange.

B. erythrocarpa. Fruit more or less suffused crimson.

a. vulgaris. Petals white, or outer ones pale rosy.

b. rosea. Petals and stamens deep crimson $=N$. alba and rosea Hartm. Handb. Skand. Fl., 1864, p. 76.

2. cngystigmo. Stigma, measured from the backs of the processes, equal to or less than half the diameter of the fruit (rare); Wcst Prussia, near Danzig.

II. depressa. Fruit depressed-globose; alt. : lat. $=2: 3$ to $5: 6$.

1. chlorocarpa-hcre and there in Germany.

2. erythrocarpo-here and there in Germany.

III. urccolato. Stigma deeply infundibuliform in fruit, sunk in to middle of fruit-in Germany, very rare. Chlorocarpa and erythrocarpa.

IV. oviformis. Fruit ovoid; upper one-fourth to one-third of height destitute of filaments-in soine lakes of West Prussia. 


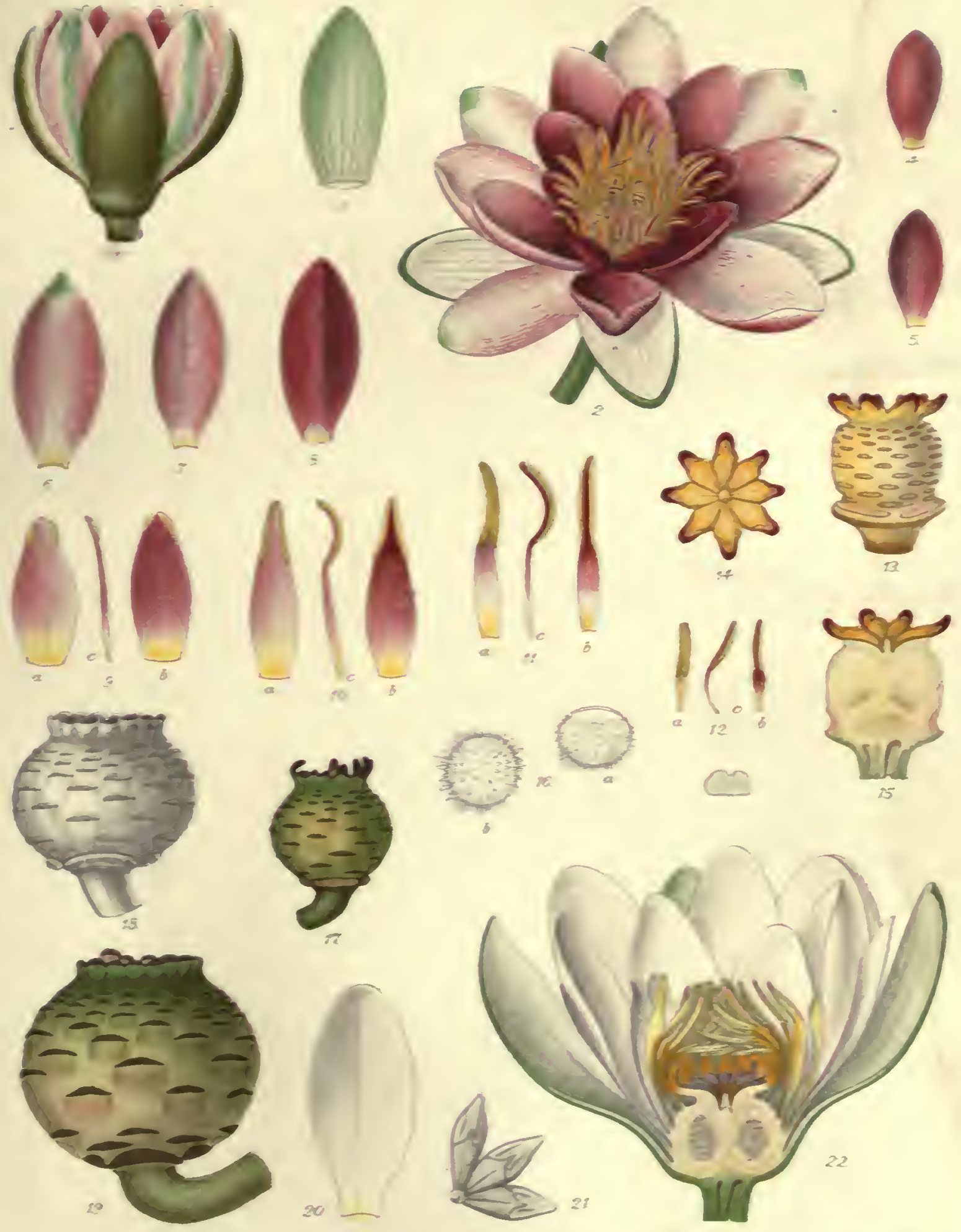

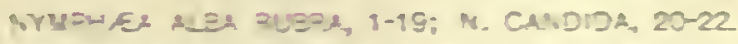

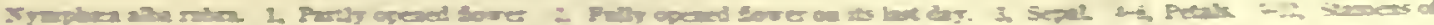

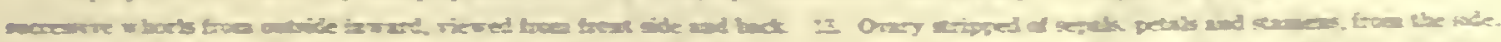

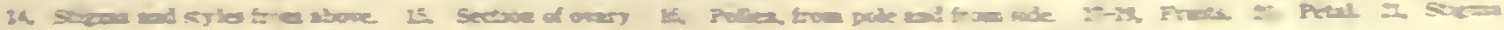

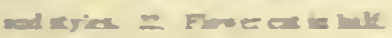



In all of these varieties, both larger and smaller forms occur. This division has been adopted by some botanists, but is dccidcdly too cumbrous for practical use. We have therefore inscrted the most important variety and the only one requiring special notice, namely, the pink Swedish waterlily, under its usual name, Nymphaea alba var. rubra.

Var. rubra, Lönnroth. (Plate XV.)

Outermost petals rosy, intcrmediate intensely rosy, innermost deep carmine-red; anthers and stigma yellow; filaments and styles orange to deep red-brown. Variable in depth and purity of color, deepening on second and third days of flowering.

Nymphaca alba var. rubra, Lönnroth 1856. Liebman \& Lange 1874. Garden 1879. Hooker 1884, fid. original specimen from Kew Garden, in hb. Kew. André 1884 .

N. alba var. rosea, Hartman. Trimen 1872. Masters 1878. Hemsley 1879. Tricker 1897. Conard $1901 a$.

N. alba sphaerocarpa platystigma erythrocarpa rosea, Caspary 1879.

N. alba sphaerocarpa rubra, Caspary $187 \mathrm{I}$.

$N$. alba var., Fries, 1858 .

N. alba var. purpurea, Fries MS. in Herb. Norm., fid. specimen, coll. T. G. Gjöbel, "Nerica, in lacu Fagertärn, par. Hammar," in hb. Kew.

N. sphaerocarpa, Carrière 1878. Tricker 1897 .

N. sphaerocarpa var. rubra, Duchartre 1877.

N. Caspary, Carrière 1879 b (N. Caspari Carrière $1880 ; N$. Casparyi Carrière 1888).

Description.-Flowers 7 to $15 \mathrm{~cm}$. in diameter, opening pale pink, changing to rose-pink or even deep red, often with a bluish cast; the color appears as linings on a white or pink ground.-Petals narrower than in the type, obtuse or rounded.Rhizomes strong, branching as in the type.

Geographic Distribution.-Lake Fayer (Fagertärn) in the Parish of Hammar, Nerike, Sweden, collected by B. E. Kjellmark in July, 1856 .

NOTES.-Introduced by Caspary in $187 \mathrm{I}$ and later by Froebel of Zurich, and sold in England in 1878 at $£_{5}$ per root. Requires cool weather and water, and is difficult of cultivation, at least in this country. Flowered first in America by Mr. Hovey of Boston, and later by Wm. Tricker at Dongan Hills, N. J. It was received by Caspary in 1863, and in the Botanic Garden of Königsberg was found to produce' highly fertile crosses with the type ( $N$. alba sphaerocarpa); a close relationship was thus proven.

E. Fries, in a letter to the "Botanische Zeitung," published in 1858 (p. 73), refers to this as a Nymphaea with rosy-purple flowers, giving to its native pond in Nerike, the name of "Fagersjo," "the beautiful lake." He considered it only a form of $N$. alba.

Carrière writes in $\mathbf{1} 888$ of a $N$. casparyi alba, as a new seedling from $N$. casparyi; the description is peculiar; but if it refers to a white form, it can be no less than a return to the typical color.

\section{Nymphaea odorata Ait. (Fig. 67.)}

Rhizome horizontal, with few stout persistent branches. Phyllotaxy about 2 on 5, with long internodes $(2$ to $5 \mathrm{~cm}$.). Petioles even greenish-purple. Leaves orbicular, usually purplish beneath, coriaceous; sinus open or closed. Flower very sweet 
sccnted, opening early ( 6 a. m.) ; sepals usually purplish-green or purple (pure green in var. giganlea). Sced of medium size.

Nymphaca odorata, Aiton 1789 , fid. original specimen in hb. British Museum, from Kew Garden (excluding Siberian plant); 1811. Willdenow 1797; 1816. Sims 18056 . Andrews tab. 297. Pursli 1814. Nuttall 1818. Smith 1819. DeCandolle $1821 b ; 1824$. Rafinesque 1830 . Planchon 1853 b. Loudon 1855. Caspary 1855; 1865. Mechan 1880. Wood 1880. Gray 1889. Gray, etc., 1895. Tricker 1897. Conard $1901 a$.

N. alba, Limaeus 1753 (the North American plant). Walter 1788. Michaux 1803, fid. specimen from hb. Michx., in lib. Paris.

N. alba canadensis, Graham in Jameson Edinb. rev. str. 1. journ., vol. 8, p. 386, 1826 (not seen).

N. alba fore pleno odorata, Gronovius 1762.

Castalia pudica, Salisbury 1806 a. Britten 1888 a.

C. odorata, Woodville \& Wood 1806. Greene 1888. Branner \& Coville 1888. Lawson 1889. Britton 1889 a. Britton, etc., 1894 . Britton \& Brown 1897 .

DesCription.-Flowers usually floating, 7 to 12 or $15 \mathrm{~cm}$. across, opening on 3 or 4 successive days from $6 \mathrm{a} . \mathrm{m}$. to $12 \mathrm{~m}$., with a strong, sweet, characteristic odor. -Buds of two forms, the one slender, conical, rounded at apex, the other ovoid.Peduncle terete, grcenish-purple, usually slender and weak ( 0.3 to $0.5 \mathrm{~cm}$. in diameter); in the case of strong crowded plants in shallow water $(30 \mathrm{~cm}$. or less), the peduncles may be rigid and bear the flowers $15 \mathrm{~cm}$. above the water (Sugar Hollow Pond, Danbury, Conn.). In fruit the peduncle coils into a close spiral (or loose if peduncle is very stout), bent to right or left, or both ways in one peduncle; coils 5 to 9 , about 2.5 $\mathrm{cm}$. in diameter. Air-canals as in Sec. Castalia.-Receptacle slort, round, scarcely evident, horizontal.-Sepals 4, ovate to lance-ovate, rounded at apex, narrowed at base, putrescent after flowering. Outside green, more or less shaded with reddish-brown or red, covered margins nearly white; veinless; inside greenish-white-Petals 23 to 32 (average 27), smaller than the sepals; outer ones ovate to elliptic-lanceolate, slightly concave, apex obtuse or rounded, narrowed at base, pure white, spreading out as much as $15^{\circ}$ below the horizontal. Median petal slightly obovate, obtuse at apex, wedgeshaped at base. Inner pctal broadly ob-lanceolate, obtuse, sides curved and tapering at base. Outermost staminode ob-lanceolate, acute, with one short anther cell.-Stamens 55 to 106 (average 79) inserted in direct series with the petals; innermost ripen first, outermost last. Filaments of all dimensions from staminodes to filiform threads, the innermost being more slender than their anthers, which are bent inward at right angles. Anthers curved, concave outward, placed obliquely so that the apex stands over the point of attachment or nearer the center of the flower; anthers largest in intermediate stamens. Pollen grains sphcrical, thickly beset with longer and shorter rods and lumps, alike from all the stamens, rupturing in germination by a large circular cap which is rough like the other parts of the grain.-Carpels 13 to 25 (average I7), with short linear styles, $0.64 \mathrm{~cm}$. long by $0.16 \mathrm{~cm}$. wide, which are erect on the first day of opening, later strongly incurved over the stigmatic disc. The latter is basin-shaped, shallow, but of varying depth. Stigmatic surface continued out on the styles one-half of their length or less, then narrowed suddenly and finally ending acuminately. Axile process nearly spherical, pointed at top, much narrowed at point of attachment.-Ovules many, small.-Seed ovoid, of medium size, $0.23 \mathrm{~cm}$. long by $0.16 \mathrm{~cm}$. in diameter, dark olive color, smooth, shining; aril one-fourth longer than the seed. 


\section{TaXoNomy-NymphaEA ODORATA.}

The seeds of $N$. odorata may germinate immediately after escaping from the fruit, or may remain dormant in cold water until the following spring; the first is probably the case with fruits ripened before September I, the second with those

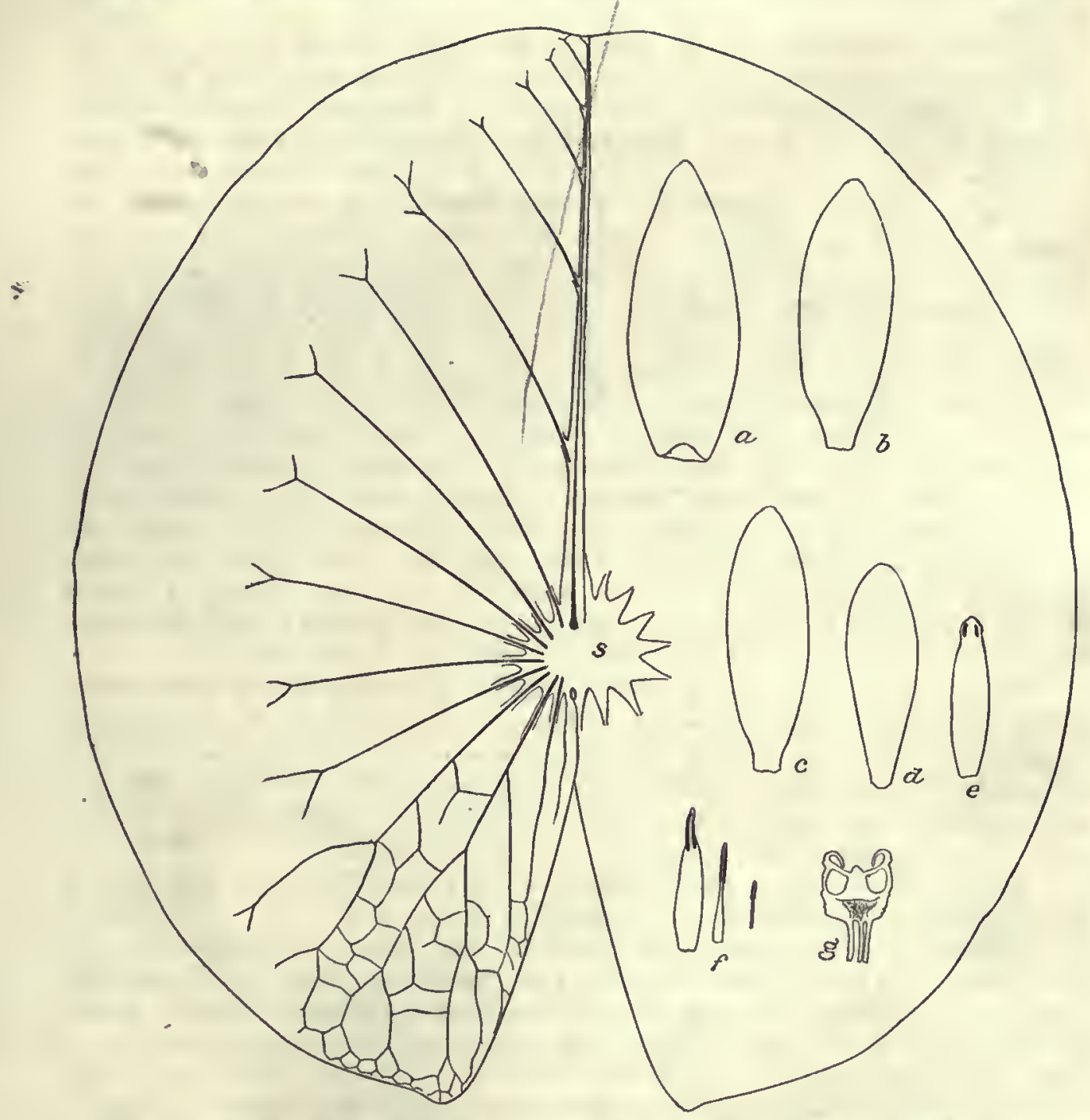

F1a. 67.-Nymphaca odorata: Under side of leaf on left; upper surface on right; $a$, sepal; $b$-d, outer,

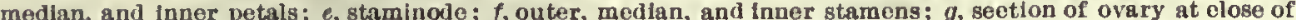
flowering period; 8, astomatie area. Natural slze of leaf $20.9 \mathrm{em}$. $\times 22.6 \mathrm{em}$.; all redueod proportionately.

ripened later. In both cases probably the first floating leaves are thrown up in the summer after the seed was formed. I found great numbers of seedlings (var. minor) in a pond south of Marlton, N. J., August 30, 1900, with only submerged leaves. The first leaf is filiform, about $1.6 \mathrm{~cm}$. long. The second is elliptic-oblong. Intermediate 
leaves are ovate, cordate, rounded at apex, with rounded basal lobes and sinus. Late submerged leaves are sagittate-cordate, with deep narrow sinus; are stiff in texture, bright emerald green, and stand erect or semi-erect, I.I2 to $1.42 \mathrm{~cm}$. long by 0.8 to 1.0 $\mathrm{cm}$. wide.

Leaf of mature plant nearly orbicular, fissi-cordate, never peltate, entire or slightly emarginate at apex, 12 to $25 \mathrm{~cm}$. in diameter, smooth and dark green above, veins not evident; under side pustulate or spongy in appearance, smooth or slightly pubescent (?), varying in color from dark dull purplish-red to green tinged with red in the lateral regions. Veins evident but not prominent beneath, the whole lamina being thickened about them. Primary veins 8 to 9 on each side of leaf. Length of principal area: length of radius of leaf $=1: 1.12$ to $1.2(=7.6 \mathrm{~cm} .: 8.6$ $\mathrm{cm} . ;=6.4: 7.6 \mathrm{~cm}$.). Depth of sinus less than one-half the length of the leaf (I:2.5, average); margins straight or gently curved, touching, or spreading as much as $30^{\circ}$; angles obtuse, not at all produced.-Petiole terete, slender, smooth or slightly pubescent (always pubescent or hirsute when young, and at base in maturity), 30 to $180 \mathrm{~cm}$. long, reddish-green to dark purplish-red, with 4 main air-canals and 2 to 4 smaller ones. Idioblasts very numerous, about 150 to 200 in central quadrangle one centimeter below leaf; many bipolar idioblasts in the smaller intercellular spaces, and a ring of thickened fibers around periphery.-Stipules fused into a broadly wedgeshaped, thin, white and semi-transparent scale, closely appressed to the rhizome, with two-cleft apex and slightly decurrent, oblique base; outer surface pubescent, smooth next to the rhizome; length I.3 to $2 \mathrm{~cm}$, width 1.2 to $1.4 \mathrm{~cm}$.; bearing a shallow rounded furrow next to the petiole, with 2 longitudinal sub-median keels, $0.3 \mathrm{~cm}$. apart beneath.

Rhizome stout, 2.25 to $3.2 \mathrm{~cm}$. thick and 30 to $100 \mathrm{~cm}$. long, pale in color, covered with a dense, short, black pubescence. Hairs of two types, one larger and stouter, of comparatively short, iso-diametric cells, the others much more numerous, slender, composed of few elongated cells; all with 2 or 3 discoid basal cells. Interior dull white with a pinkish tinge. Apex rounded, clothed with stipules and long fine hairs. Branches stout, few. in number, their attachment 1.3 to $2 \mathrm{~cm}$. in diameter.

Geographic Distribution.-Common in the Eastern United States; north to Nova Scotia and Manitoba, south to Virginia and Arkansas.

Notes.-Introduced into Europe (England) in 1786 , by Wm. Hamilton. In I80I it was "far less common" there than $N$. caerulea, and was considered a tencier piant; was well known in Europe in 1850; was cultivated in McMahon's garden in Philadelphia in 1830 (Harshberger 1899), and appears in American trade-lists in 1883 and probably earlier.

Flower from June to October; fruit July to October. The roots were found to be uninjured by drying away of the water in the fall at State College, Pa. (Buckhout I891); the plant was also seen blooming well in the absence of water at Baury's Lay, Buzzards Bay, R. I. (Sturtevant I889). The plants which I have regarded as types grow at Bristol, Pa., in a mill-pond. 
Number of Floral Organs.

\begin{tabular}{|c|c|c|c|c|c|c|c|c|c|c|c|c|c|c|c|c|}
\hline Organs. & I. & II. & III. & IV. & v. & VI. & VII. & VIII. & IX. & x. & $\mathbf{X I}$. & XII. & XIIr. & XIV. & $\mathrm{XV}$. & Average. \\
\hline Sepals...... & 4 & 4 & 4 & 4 & 4 & 4 & 4 & 4 & 4 & 4 & 4 & 4 & 4 & 4 & 4 & 4 \\
\hline Petals...... & 32 & 25 & 27 & 29 & 27 & 30 & 30 & 32 & 26 & 24 & 24 & 24 & 25 & 23 & $3 I$ & $27+$ \\
\hline Staminodes. & I & I & 2 & 0 & 7 & .. & 4 & 4 & .. & 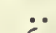 & 5 & $\cdots$ & 3 & & $\mathbf{I}$ & . \\
\hline Stamens.... & 87 & - & 96 & 75 & 106 & 76 & 70 & 100 & 72 & 69 & 69 & 55 & 70 & 66 & 71 & $79+$ \\
\hline Carpels .... & 19 & 14 & 16 & 16 & 23 & ig & 24 & 25 & 14 & 13 & 15 & 13 & 18 & 14 & 17 & $17+$ \\
\hline Total..... & 143 & $\cdots$ & 145 & 124 & 167 & 129 & 132 & 165 & 116 & 110 & 117 & 96 & 120 & 107 & 124 & $127+$ \\
\hline
\end{tabular}

Measurements (in centimeters).

\begin{tabular}{|c|c|c|c|c|c|}
\hline \multicolumn{2}{|c|}{ SEPALS. } & \multicolumn{4}{|c|}{ STA MREN8. } \\
\hline Length. & Breadth. & Length. & $\begin{array}{l}\text { Width of } \\
\text { Filament. }\end{array}$ & $\begin{array}{l}\text { Length of } \\
\text { Anther. }\end{array}$ & $\begin{array}{l}\text { Width of } \\
\text { Anther. }\end{array}$ \\
\hline $\begin{array}{l}5 \cdot 9 \\
7 \cdot 5 \\
\end{array}$ & $\begin{array}{l}2.5 \\
2.1\end{array}$ & $\begin{array}{l}4.15 \\
3.8\end{array}$ & $\begin{array}{l}1.3 \\
0.9\end{array}$ & $\begin{array}{l}0.95 \\
1.42\end{array}$ & $\begin{array}{c}\text { st } 0.95 \\
0.6\end{array}$ \\
\hline \multicolumn{2}{|c|}{ Pretals. } & $3 \cdot 5$ & 0.6 & I. 42 & 0.24 \\
\hline $\begin{array}{l}5.9 \\
6.3 \\
5.4 \\
5.1\end{array}$ & $\begin{array}{cl}0 & 2.2 \\
0 & 1.8 \\
m & 1.9 \\
i & 1.75\end{array}$ & $\begin{array}{l}3.5 \\
2.55 \\
1.9 \\
0.95\end{array}$ & $\begin{array}{l}0.5 \\
0.16 \\
0.03\end{array}$ & $\begin{array}{l}0.95 \\
0.8 \\
0.48\end{array}$ & $\begin{array}{l}0.16 \\
0.08 \\
0.04\end{array}$ \\
\hline
\end{tabular}

$0=$ outer.

$i=$ inner.

$m=$ median.

$s t=$ staminode.

Var. minor Sims. (Fig. 68.)

Whole plant one-quarter to one-half the size of the type, with more of red coloration on sepals and under side of leaves.

Nymphaea odorata var. minor, Sims i814. Britton I889a. Gray 1889. A. G. I893. Tricker I897. Conard igor $a$.

N. minor, DeCandolle 1821 $b$. Donn I831. Not Reichenbach 1842; 1845.

$N$. odorata var. parviflora, Rafinesque 1830 .

$N$. odorata var. rubella, Rafinesque 1830 .

DESCRIPTION.-Flowers 5 to $9 \mathrm{~cm}$. across (I.3 cm., G. \& F. I894a).-Buds broadly or narrowly ovate, $3.3 \mathrm{~cm}$. long by $2.07 \mathrm{~cm}$. in diameter to $2.9 \mathrm{~cm}$. long by $\mathrm{I} .3$ $\mathrm{cm}$. in diameter.-Peduncle dark reddish-brown, 0.24 to $0.32 \mathrm{~cm}$. in diameter, to to $50 \mathrm{~cm}$. long, only half supporting the flower even when the plant has no water around it, as sometimes happens in summer.-Receptacle green, rounded-quadrilateral, diameter $0.64 \mathrm{~cm}$. - Sepals dark brownish-green or pure green, red or whitish on the margins, nearly white at base, greenish-white within, obscurely 7 -nerved, especially visible within; breadth : length $=I: 2.8$ to 2.5 - Petals 17 to 24 , sometimes marked with pink when old.-Stamens 37 to 68.-Carpels ro to 16; papillose area more or less continued out on the styles, which vary greatly in length and width, even in the same flower.-Ovary nearly spherical, 0.8 to $1.12 \mathrm{~cm}$. in diameter by 0.5 to $0.63 \mathrm{~cm}$. high.Axile process round, translucent, whitish, its top rising above the level of the bases of the styles, i. e., in a very shallow stigmatic basin.

Leaves deep red beneath (or green when aerial), lobes usually diverging; diameter 5 to $\mathrm{I} 3 \mathrm{~cm}$. ( $4 \mathrm{~cm}$., G. \& F. 1894 a.) -Petioles like the peduncles.-Stipules $\mathrm{I} .3 \mathrm{~cm}$. 
long by $1.3 \mathrm{~cm}$. wide, bifid, otherwise like those of the type.-Rhizome 1.3 to $1.9 \mathrm{~cm}$. in diameter, densely covered with long black hairs; yellowish in cross-section.

\section{MEASUREMENTS}

Diameter of flowers $8.9 \mathrm{~cm}$. ; $8.3 \mathrm{~cm} . ; 7.9 \mathrm{~cm} . ; 6.7 \mathrm{~cm} . ; 5.7 \mathrm{~cm}$.

Carpellary styles $0.4 \mathrm{~cm}$. long, $0.08 \mathrm{~cm}$. wide, continuation of stigma $0.13 \mathrm{~cm}$. long.

GEograpific Distribution.-Shallow water in cold bogs and sandy soil, occurring with the type, but chiefly on the Atlantic Slope. The commonest form in New Jersey.

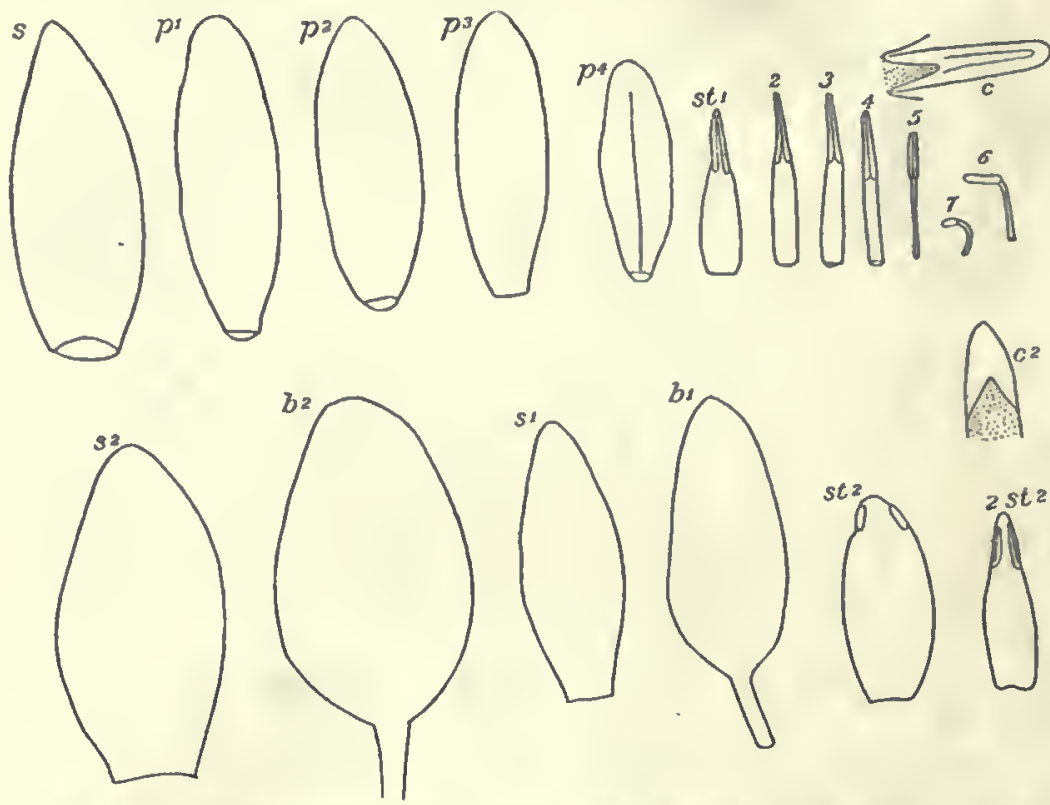

Fra. 68-Nymphaca odorata minor: Upper row of flgures from one flewer of the narrew ferm; 8 , sepal; $p 1,2,8,4$, successivo pctals ; st 1-7, suecessive stamens ; $c$, carpellary style, with stigmatic surface detted; $82, b 2$, sepal and bud of the broader form; $81, b 1$, sepal and bud of the narrew ferm. st 2 , staminode; 2 st 2 , cuter stamen; $c 2$, carpellary style, all of the broader form. Natural size, except carpellary styles, which are enlarged.

Number of Floral. Organs.

\begin{tabular}{|c|c|c|c|c|c|c|c|c|c|c|c|c|c|c|c|c|}
\hline \multirow{2}{*}{ ORGAN. } & \multicolumn{3}{|c|}{ MaILTON, N.J. } & \multicolumn{13}{|c|}{ RAQUETTE LAKE, N. Y. } \\
\hline & I. & II. & III. & I. & II. & III. & IV. & v. & VI. & VII. & VIII. & IX. & $\mathbf{X}$ & $\mathbf{X I}$. & XII. & XIII. \\
\hline Sepals ........ & 4 & 4 & 4 & 4 & 4 & 4 & 4 & 4 & 4 & 4 & 4 & 4 & 4 & 4 & 4 & 4 \\
\hline Petals ........ & 24 & 22 & 17 & 27 & 27 & 27 & 24 & 30 & 25 & 25 & 24 & 27 & 27 & 28 & 25 & 19 \\
\hline Stamens...... & 68 & 51 & 37 & 64 & 65 & .. & 67 & 69 & 60 & 67 & st 4 & st i & 66 & 77 & 68 & 69 \\
\hline Carpels ....... & 16 & 12 & 10 & 14 & 18 & $\therefore$ & 14 & 15 & 14 & 14 & .. & .. & 14 & 14 & 13 & 17 \\
\hline Total ....... & 112 & 89 & 68 & 109 & 114 & -. & 109 & 118 & 103 & 110 & .. & .. & III & 123 & 110 & 109 \\
\hline
\end{tabular}

Notes.-Specimens of this variety were found at Atco, N. J., in 1900, growing in sphagnum and peat where no water was visible; the leaves in this case were aerial, 


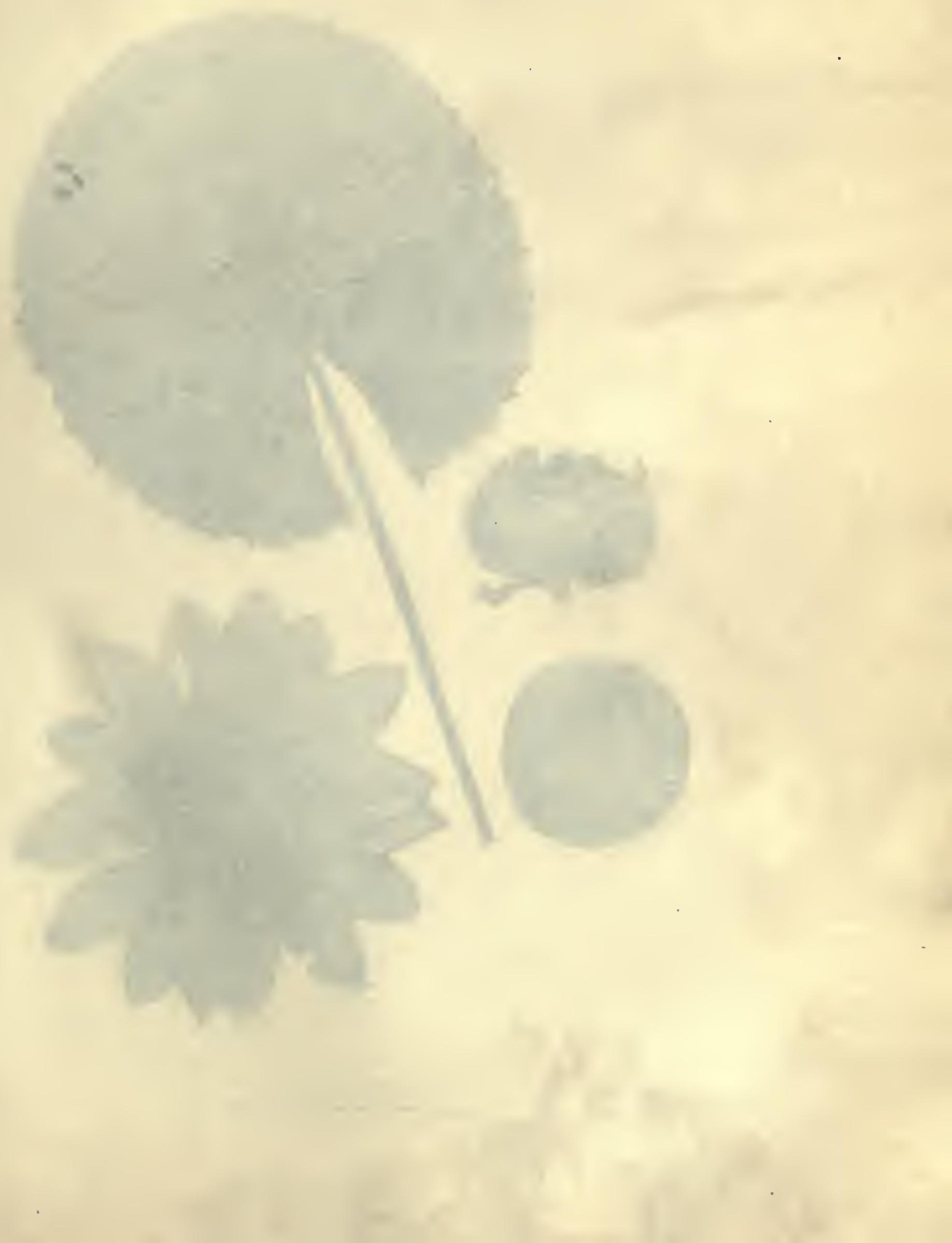





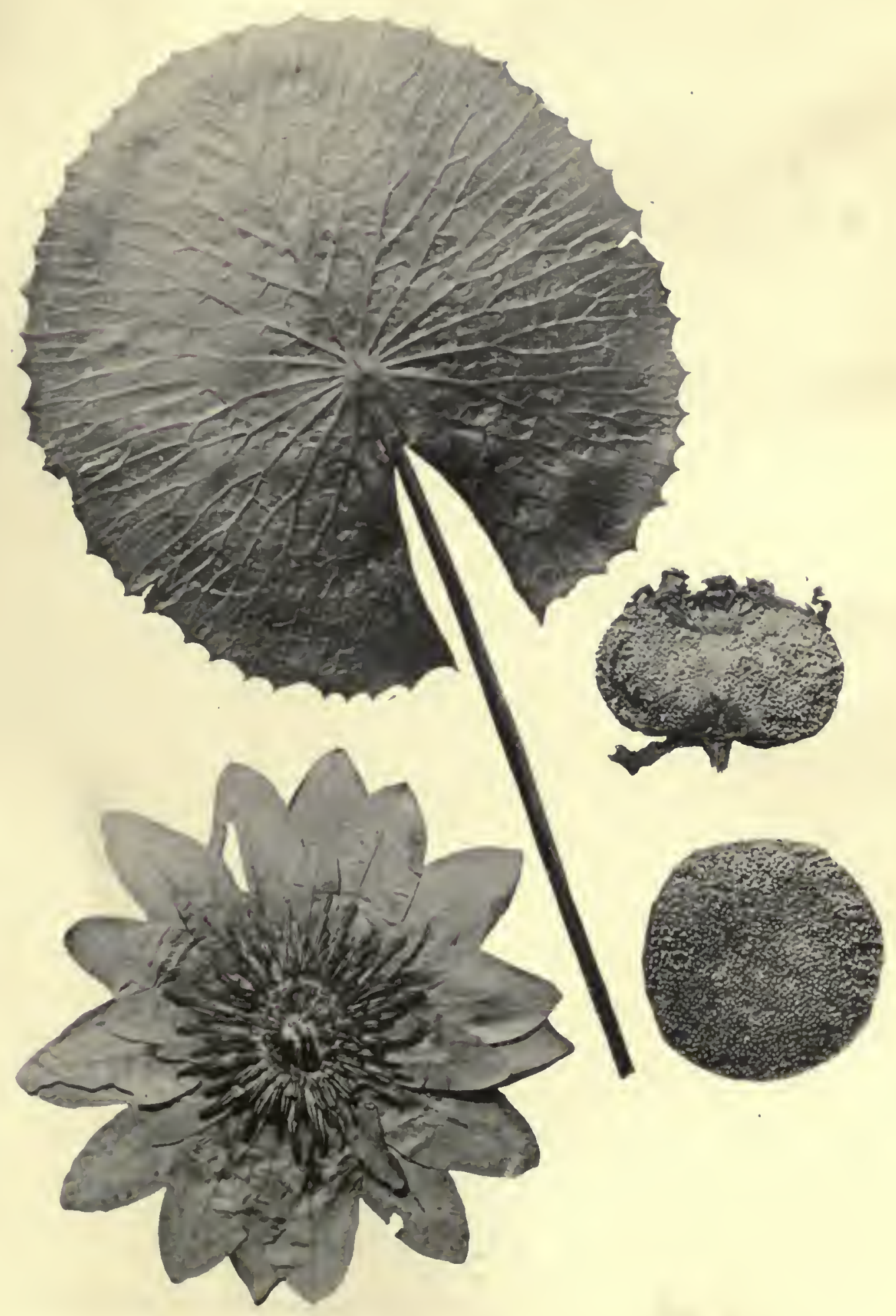



and had stomata on the back near the apical region. Such leaves were 5 to $10 \mathrm{~cm}$. in diameter, mostly or entirely green beneath. The petioles were green or purplishgreen and had two large upper air-canals and two smaller lower ones, with no others visible to the unaided eye. The thickened idioblasts were very numerous, probably giving the necessary stiffness to the petiole.

Measurements of Flower I, Marlton, N. J.

\begin{tabular}{|c|c|c|c|c|c|c|}
\hline \multicolumn{2}{|c|}{ SEPAL8. } & \multicolumn{2}{|c|}{ Petals. } & \multicolumn{3}{|c|}{ STAMENS. } \\
\hline Length. & Width. & Length. & Width. & Length. & Width. & $\begin{array}{l}\text { Length of } \\
\text { Anther. }\end{array}$ \\
\hline $\begin{array}{c}\mathrm{cm} . \\
3 \cdot 5 \\
3 \cdot 5 \\
\ldots \ldots \\
\ldots \ldots \\
\ldots \ldots \\
\ldots \ldots\end{array}$ & $\begin{array}{l}\mathrm{cm} . \\
\mathrm{I} \cdot 35 \\
\mathrm{I} .35 \\
\ldots \ldots \\
\ldots \ldots \\
\ldots \ldots \\
\ldots \ldots\end{array}$ & $\begin{array}{l}\mathrm{cm} . \\
3 \cdot 35 \\
3 \cdot 0 \\
3 \cdot 0 \\
2.3 \\
\ldots \ldots \\
\ldots \\
\ldots\end{array}$ & $\begin{array}{l}\text { cm. } \\
\text { I.12 } \\
\text { I.15 } \\
0.8 \\
0.55 \\
\ldots \ldots \\
\ldots \ldots\end{array}$ & $\begin{array}{l}\text { cm. } \\
\text { I.75 } \\
1.75 \\
1.75 \\
1.6 \\
1.42 \\
1.12 \\
0.48\end{array}$ & $\begin{array}{l}\mathrm{cm} . \\
0.4 \\
0.24 \\
0.21 \\
0.10 \\
0.08 \\
0.08 \\
0.04\end{array}$ & $\begin{array}{l}\mathrm{cm} . \\
0.64 \\
0.7 \\
0.8 \\
0.64 \\
0.48 \\
0.48 \\
0.16\end{array}$ \\
\hline \multicolumn{7}{|c|}{ FLower II, MarLton, N. J. } \\
\hline $\begin{array}{r}\mathrm{cm} . \\
3.7 \\
3.5 \\
3.5 \\
3.5 \\
\ldots \ldots \\
\ldots \ldots \\
\ldots\end{array}$ & $\begin{array}{l}\mathrm{cm} . \\
\mathrm{I} .75 i \\
\mathrm{I} .75 \\
\mathrm{I} .75 \\
\mathrm{I} .75 \\
\ldots \ldots \\
\ldots \ldots \\
\ldots\end{array}$ & $\begin{array}{l}\mathrm{cm} . \\
3.35 \\
3.2 \\
3.2 \\
3.0 \\
2.86 \\
\\
2.4 \\
\text { st } 2.07\end{array}$ & $\begin{array}{l}\text { cm. } \\
I .42 \\
I .6 \\
1.42 \\
I .42 \\
I .42 \\
I .12 \\
0.8\end{array}$ & $\begin{array}{l}\mathrm{cm} . \\
1.92 \\
1.9 \\
1.75 \\
1.6 \\
1.6 \\
1.12 \\
0.8\end{array}$ & $\begin{array}{l}\mathrm{cm} . \\
0.48 \\
0.5 \\
0.4 \\
0.21 \\
0.16 \\
0.08 \\
0.04\end{array}$ & $\begin{array}{l}\mathrm{cm} . \\
0.48 \\
\ldots . \\
\cdots .6 \\
0.64 \\
\cdots .48 \\
0.48\end{array}$ \\
\hline \multicolumn{7}{|c|}{ Flower III, Marlton, N. J. } \\
\hline $\begin{array}{l}\mathrm{cm} . \\
2.87 \\
2.87 \\
\ldots \ldots \\
\ldots \ldots \\
\ldots \ldots\end{array}$ & $\begin{array}{l}\mathrm{cm} . \\
\mathrm{I.04} \\
\mathrm{I} . \mathrm{I} 2 \\
\ldots \ldots \\
\ldots \ldots\end{array}$ & $\begin{array}{l}\mathrm{cm} . \\
2.87 \\
2.8 \\
2.8 \\
2.55 \\
2.4\end{array}$ & $\begin{array}{l}\mathrm{cm} . \\
\mathrm{I} .04 \\
\mathrm{I} . \mathrm{I} 2 \\
0.95 \\
0.8 \\
0.4\end{array}$ & $\begin{array}{l}\mathrm{cm} . \\
\mathrm{I.75} \\
0.64 \\
\ldots \ldots \\
\ldots \ldots\end{array}$ & $\begin{array}{l}\mathrm{cm} . \\
0.32 \\
0.04 \\
\ldots \ldots \\
\ldots \ldots\end{array}$ & $\begin{array}{l}\mathrm{cm} . \\
0.48 \\
0.3 \\
\ldots \ldots \\
\ldots \ldots\end{array}$ \\
\hline
\end{tabular}

$$
i=\text { Inner. } \quad \text { st }=\text { Staminode. }
$$

Measurements of Specimens from Raquette Lake, N. Y.

\begin{tabular}{|c|c|c|c|c|c|c|c|c|c|c|c|}
\hline \multicolumn{2}{|c|}{ Sepazb. } & \multicolumn{4}{|c|}{ STAMKNS. } & \multicolumn{6}{|c|}{ LEA Yeg. } \\
\hline Length. & Width. & Length. & Width. & $\begin{array}{c}\text { Length } \\
\text { of } \\
\text { Anther. }\end{array}$ & $\begin{array}{c}\text { Width } \\
\text { of } \\
\text { Anther. }\end{array}$ & Length. & Width. & $\begin{array}{c}\text { Number } \\
\text { of } \\
\text { Velns. }\end{array}$ & $\begin{array}{l}\text { Princi- } \\
\text { pal Area. }\end{array}$ & Radhus. & $\begin{array}{l}\text { Depth } \\
\text { of } \\
\text { Sinus. }\end{array}$ \\
\hline $\begin{array}{l}\mathrm{cm} . \\
4.5\end{array}$ & $\begin{array}{c}\mathrm{cm} . \\
\mathrm{I} .9\end{array}$ & $\begin{array}{l}\mathrm{cm} . \\
2.55\end{array}$ & $\begin{array}{l}\mathrm{cm} . \\
0.64\end{array}$ & $\begin{array}{l}\text { cm. } \\
0.95\end{array}$ & $\begin{array}{l}\mathrm{cm} . \\
0.4\end{array}$ & $\begin{array}{l}\mathrm{cm} . \\
\text { I I } 8\end{array}$ & $\begin{array}{l}\mathrm{cm} . \\
\text { II. }\end{array}$ & 6 & $\begin{array}{l}\mathrm{cm} . \\
4.15\end{array}$ & $\begin{array}{c}\mathrm{cm} . \\
5.9\end{array}$ & $\begin{array}{l}\mathrm{cm} . \\
4.8\end{array}$ \\
\hline 4.5 & 1.6 & 2.55 & 0.5 & 0.95 & 0.5 & I5. 3 & 13.7 & 7 & 5.4 & 6.4 & 6.0 \\
\hline 4.15 & 1.6 & 2.23 & o. I6 & 0.64 & 0.08 & 13.I & 12.4 & 7 & 5.2 & 5.4 & $5 . I$ \\
\hline 3.7 & I. 6 & I. 3 & 0.05 & 0.50 & 0.05 & 14.3 & I 3.1 & 6 & 4.8 & 6.7 & 5.4 \\
\hline
\end{tabular}


Plants from Raquette Lake, N. Y., differ a little from the New Jersey form; the leaves tend more to an ovate shape, with overlapping sinus and slightly produced lobes; in 30 to $180 \mathrm{~cm}$. of water. The flowers have a slightly larger number of organs.

Introduced into England by Pursh as $N$. odorata rosea in 1812.

Var. rosea Pursh.

Flowers of medium size, 8 to $10 \mathrm{~cm}$. across, deep pink, or red; when closed, after once blooming, the sepals remain spread out horizontal on the water. Leaves $12 \mathrm{~cm}$. in diameter, deep crimson beneath, dark purplish-green above; primary veins about 7 on each side; length of principal area: radius of leaf $=I: 1.2$ to 1.26 ; sinus open, angles somewhat produced.

Nymphaca odorata var. rosea, Pursh 1814, fid. specimen coll. Pursh 1808, in Bass and Wading Rivers, in hb. Kew. Garden $1883 b$. Tricker 1897. Conard 1901 $a$.

$N$. odorata minor floribus roseis, Hooker $188_{3}$, marked $N$. odorata var. rubra on the type in hb. Kew; raised in Kew Garden from plants sent by A. Gray.

$N$. rosea, Rafinesque 1830 . Donn 1831 .

$N$. sanguinea, Donn 1831 ?

Castalia odorata forma rosea, Britton $1889 a ; 1890$. Millspaugh 1893 .

C. odorata rosea, Britton, etc., 1894 . Britton \& Brown 1897.

$N$. odorata rubra, Rev. Hortic. I88I $b$. Wittmack Ill. Gartenztg., I882, p. 367.

Grographic Distribution.-Cape Cod; Barnstable, Mass. (Gray r889); Lancaster, Mass. Cape May County, N. J.; Woodstown, Salem County, N. J.; Manchester, Ocean County, N. J. (Britton I $889 a$ ). Buffalo, Putnam County, W. Va. (Millspaugh 1893). Rare and local.

NotES.-Millspaugh gives the following remarkable account of the Buffalo station: "On a plat of low bottom land near Buffalo, Putnam County, W. Va., the plough turns up a large number of small tubers each season that the soil is cultivated. These planted in tubs produce, much to the astonishment of the neighborhood, beautiful deeppink waterlilies. How long this bottom has been drained is not known, but the evidence adduced by the fact above stated of the existence of a pond here, certainly over a century ago, is very interesting, as is also the light thrown upon the distribution of this pretty form of waterlily."

The plants in cultivation are said to have sprung from a single original specimen.

Var. gigantea Tricker. (Fig. 69.)

Distinguished by large size in all its parts. Flowers less odorous than in the type; sepals mostly green. Leaves turned up around apical part of margin.

N. odorata var. giganica, Tricker 1897. Conard I901 a.

N. reniformis, Walter 1788? DeCandolle I821 $b$. Donn I83I. Not Gray I889.

Castalia reniformis, Nash 1895 , fid. original specimens.

C. tuberosa, Lloyd \& Tracy 1901? MacCarthy 1885?

$N$. odorata var. chlorhiza, Rafinesque 1830 ?

$N$. spiralis, Rafinesque 1830 (excluding synonyms).

N. Maximiliani, Lehmann 1853 a, as to the fower; leaf is of $N$. tenerinervia; fid. specimen from hb. Lehmann in hb. Berlin.

N. Parkeriana, Lehmann 1853 a; 1854. Watson 1894. Conard I901 a. Fid. specimens coll. Parker in British Guiana, from hb. Lchmann in hbb. Kew, Berlin.

N. Pringlci, Rose MS., coll. Pringle, Plante Mexicanæ 1896 , No. 6464 , from Lake Xochimilcho $=N$. Iussilagifolia, Pringle isg7? 
Description.-Flowers floating, io to $15 \mathrm{~cm}$. in diameter, closed before $2 \mathrm{p.} \mathrm{m}$.; odor dull or absent.-Peduncles terete, rather stout, 8 to $10 \mathrm{~mm}$. in diameter, in fruit showing about 3 spiral turns 3.9 to $5 \mathrm{~cm}$. in diameter.-Sepals narrowly ovate, rounded at apex, breadth: length $=1: 2.4$; outer surface green.-Petals 24 to $3 \mathrm{I}$ (average of 13 flowers, 27.6), ovate or obovate, broadly rounded at apex, tapering at base, all alike in shape, pure white, outermost petals very faintly tinged with purple on the back near the base; shorter than the sepals; breadth: length $=1: 2.9$. - Stamens 69 to I 20 (average of 9 flowers, 90.5).-Carpels 15 to 23 (average of 9 flowers, 17.7); styles long, flat, thin, bunding strongly inward after anthesis; papillose ray ending bluntly far below the tip of the style.-Fruit depressed globose, reddish around the bases of the styles when nearly ripe.-Secds as in the type, dark olive brown, smooth, $0.224 \mathrm{~cm}$. long by 0.155 $\mathrm{cm}$. in diameter, inclosed in the aril.

Mature leaves $40 \mathrm{~cm}$. in diameter ( 15 to $60 \mathrm{~cm}$., Nash 1895), apical margin and part of sides turned up for 2 to $5 \mathrm{~cm}$., somewhat as in Victoria; upper surface dark green; green beneath, with only a very faint tinge of purplish near the margin of some leaves (bright red, Tricker 1897).-Veins, especially the midrib, prominent, 9 on each side; principal area : radius of leaf $=$ I : r.2.-Sinus open, margins curved; angles obtuse, very little or not at all
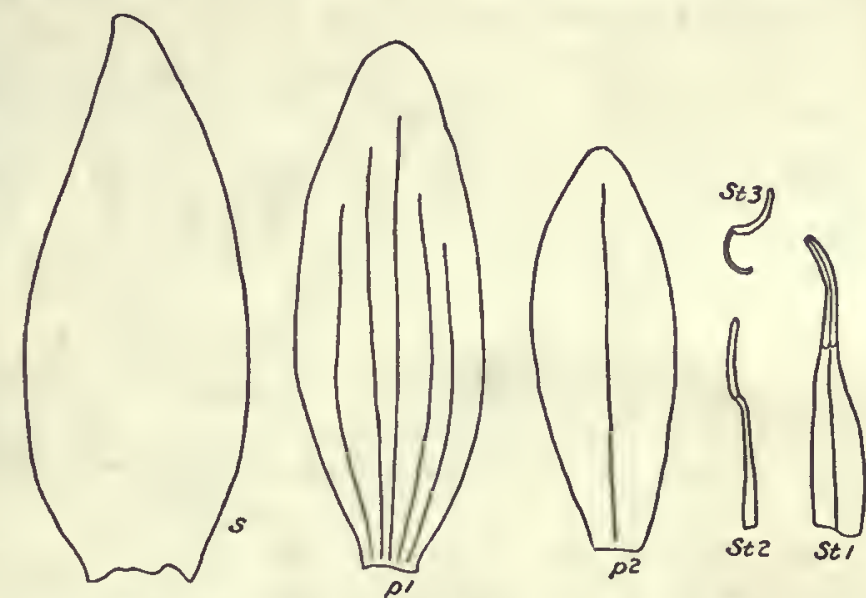

Fra. 09.-Nymphaea odorata gigantea: 8 , sepal; $p 1, p 2$, outer and median petals; st 1,2,3, outer, median, and inner stamens. Natural size. produced.-Petioles stout, plain green.

Rhizomes stout, clothed with short dark hairs; yellowish-white inside; ieaves scattered, about $2.5 \mathrm{~cm}$. apart. Branches few and stoutly attached.

Geographic Distribution.-Southeastern United States; Delaware to Florida and Lotisiana; Cuba; Mexico; British Guiana. E. g. C. Wright, Plantæ Cubenses, No. 1856, coll. at Nueva Felipina, Cuba. R. M. Harper, No. 1212, Cane Water Pond, Decatur County, Ga. Nash, Pl. Cent Penins. Florida, No. I153, vicinity of Eustis. Curtiss, No. 6672, Lake Como, Fla.

Notes.-The plants which $I$ have taken as types of this variety came from the Delaware and Chesapeake Canal at the railroad bridge, 2 miles west of St. George's City, Del. Here it grows in water from 60 to $120 \mathrm{~cm}$. deep; in Lake Ella, Florida, it grows from the shallows of the shore out to a depth of 3 to 5 meters (Nash 1895).

If Walter's $N$. reniformis can be identified with any known plant, this must be the one; but there is nothing but its geographical range by which to verify it, as no type exists in the Walter herbarium in hb. British Museum. His description is as follows: "N. reniformis, foliis reniformibus, corollis polypetalis, loculis mono- 
spermis." If we accept the last two words as binding, the name cannot apply to any species of the present genus Nymphaea, but rather to Nelumbo, as was understood by Rafinesque (1830). It seems best, therefore, as Caspary already advised (I865), to discard the name entirely. Gray was certainly wrong in applying it to $N$. twberosa, a species which does not exist in the region covered by Walter's Flora. In choosing a name, therefore, we have discarded the suggestion of Mr. Nash, and accepted the established and expressive name which the plant bears in gardens. Britton \& Brown (1897) are certainly right in pronouncing this plant distinct from $N$. tuberosa Paine, as is shown by the absence of tubers and the small size of the seeds. In these respects, however, as well as in the great number of idioblasts in the petioles, and the behavior in germination and thereafter, it is in agreement with $N$. odorata. An interesting parallelism exists in the European $N$. alba, of which gigantic varieties occur in the warm and sunny climate of Greece.

Number of Floral Organs.

\begin{tabular}{|l|r|r|r|r|r|r|r|r|r|r|r|r|r|r|r|r|}
\hline Sepals... & 4 & 4 & 4 & 4 & 4 & 4 & 4 & 4 & 4 & 4 & 4 & 4 & 4 & 4 \\
Petals... & 27 & 28 & 24 & 29 & 28 & 28 & 28 & 27 & 26 & 28 & 26 & 24 & 31 & 29 \\
Stamens. & 80 & 108 & $\ldots$ & 108 & 69 & 89 & 79 & $\ldots$ & 73 & 89 & $\ldots$ & $\ldots$ & $\ldots$ & 120 & $\ldots$ \\
Carpels.. & 16 & 18 & $\ldots$ & 19 & 16 & 19 & 17 & $\ldots$ & 17 & 15 & $\ldots$ & $\ldots$ & $\ldots$ \\
\hline Total.... & 127 & 158 & $\ldots$ & 160 & 117 & 140 & 128 & $\ldots$ & 120 & 136 & $\ldots$ & $\ldots$ & $\ldots$ & 176 \\
\hline
\end{tabular}

MEASUREMENTS.

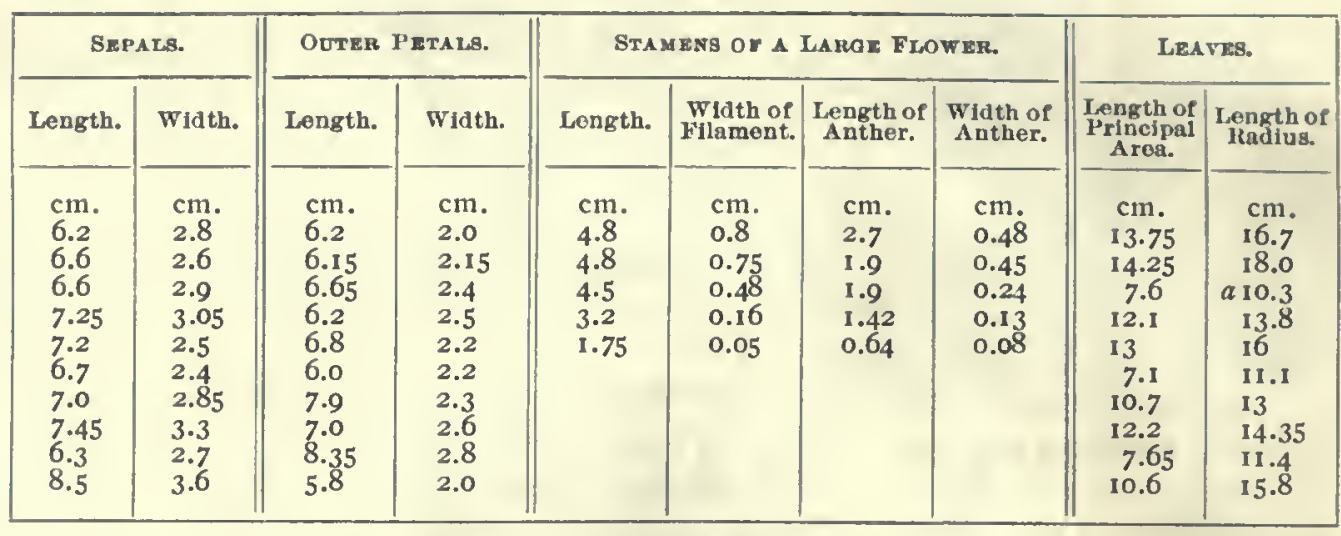

$a=$ Young leaf.

The flowers of this variety are visited by Halictus pectoralis 9 , in Florida (Robertson 1889).

Caspary makes varieties of Nymphaea odorata based on the character of the petiole, "I Glabra," "II Villosa," and "villossissima"; the first was based on the collections of Pursh, probably our type and var. minor; the second rested on specimens from Texas in several European herbaria, and may be nearly our var. gigantea; the third was collected by Paine in Hidden Lake, Herkimer county, N. Y. The classification is of a very doubtful character, since the hairiness depends wholly upon the age of the petiole, the hairs being always present in the young state, but always shed sooner or later. 




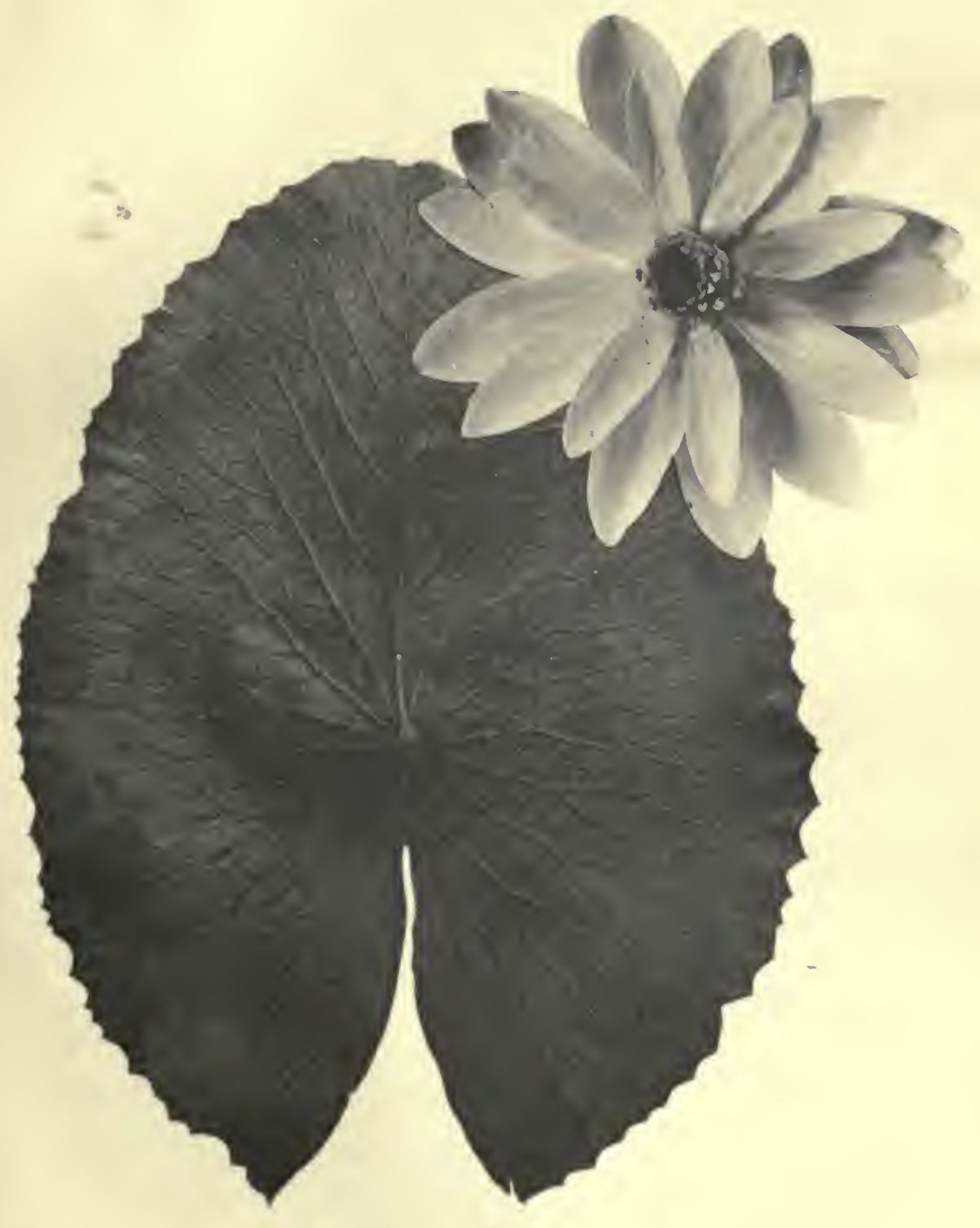

NYMPHAEA PUBESCENS. 

Nymphaea tuberosa Paine. (Figs. 70, 71, 72.)

Rhizome horizontal, with many, often compound, slenderly attached tuber-like branches. Phyllotaxy 2 on 5, with long internodcs. Petioles green, with longitudinal brozun stripes above. Leaves orbicular, pure green beneath; sinus usually narrow, angles slightly produccd. Flowers scentless or nearly so, opening about $8 \mathrm{a}$. m.; sepals pure green; petals obovate to oblanceolate, pure dazzling white, often deflexed. Sced large.

Nymphan tubcrosa, Paine 1865 , fid. specinen coll. Paine on S. shore of Lake Ontario, from hb. A.

Gray, in hb. Kew. Hooker 1881. Garden 1882; 1897. Gray, Manual ed. 5. Caspary 1888. Sargent 1888. Tricker 1897 . Conard $1901 a$.

N. reniformis, Gray 1889. Not Walter 1788, etc.

N. maculata, Rafinesque 1830 .

N. alba, Nuttall 1818. Not Linn., etc.

N. blanda, Hort. (in some American gardens). Tricker 1897. Not Meyer 1818.

$N$. tuberosa maxima, Hort. Conard Igor $a$.

N. tuberosa var. parva, Abbott 1888 .

Leuconymphaea reniformis, MacMillan 1892 .

Castalia reniformis, Branner \& Coville 1888.

C. tuberosa, Greene 1888 . Britton 1889 a. Lawson 1889. Hitchcock 1890 . Britton \& Brown 1897.
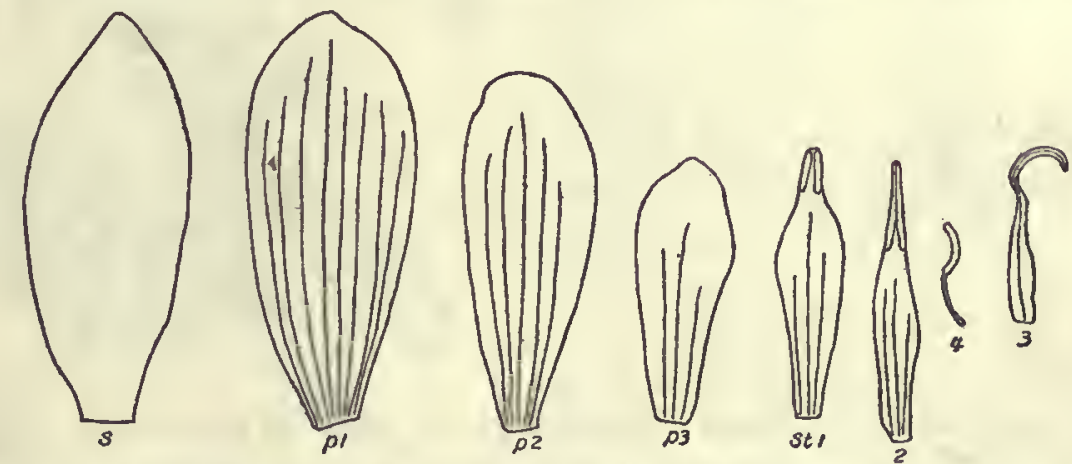

FIG. 70.-Nymphaea tuberosa: $s$, sepal ; $p 1, p 2, p 3$, successive petals; st 1-4, suecessive stamens. Natural sizc.

DesCRiPTION.-Flower io to $23 \mathrm{~cm}$. across, floating, or when crowded and in shallow water raised 10 to $15 \mathrm{~cm}$. above the surface. Open 3 or 4 days ( 2 or 3 , Sargent I888) from 8 a. m. to I p. m. (2 or 3 p. m., Sargent, 1. c.) ; odorless (or with a faint odor of apples, Gray 1889).-Peduncle tercte, stout, 0.5 to $0.9 \mathrm{~cm}$. in diameter, greèn, forming in fruit, in the lower portion, about 3 close spirals $6 \mathrm{~cm}$. in diameter, the upper portion only slightly bent; $30 \mathrm{~cm}$. to 2 meters long; air-canals as in $N$. odorata. -Sepals 4, often becoming reflexcd to the peduncle in flower, putresccnt; pure green outside, rounded at apex.-Petals all pure white, obovate or almost spatulate, concave, rounded at apex, wedge-shaped at base, outer ones reflexed in flower, gradually smaller inward but retaining the spatulate or obovate shape.-Stamens as in $N$. odorata.Carpels about 14; axile process globular.-Fruit depressed globose, bare of all floral parts, $3.2 \mathrm{~cm}$. in diameter by $2.2 \mathrm{~cm}$. high.-Seeds few (I57 in a fruit), large, dark olive-brown, smooth, with very prominent raphe; $0.44 \mathrm{~cm}$. long by $0.28 \mathrm{~cm}$. in diametcr. Aril about as long as the seed, or shorter, not stipitate. 
The germinating tuber produces at first 3 or 4 thin and fragile submerged leaves. The first is broadly deltoid, rounded or emarginate at apex, truncate at base, 2.9 to $3.8 \mathrm{~cm}$. wide at base by 1.6 to $1.9 \mathrm{em}$. long on a slender petiole 7 to $12 \mathrm{~cm}$. long. The second is similar to the first or may be mueh larger, somewhat drawn in at the petiole, approaching a hastate shape, $6.4 \mathrm{~cm}$. wide by $3.8 \mathrm{em}$. long. Third and fourth leaves liastate, rounded at apex, $5.4 \mathrm{~cm}$. wide at base by $6.4 \mathrm{~cm}$. long, the sinus 1.9 en. deep. The first floating leaf is orbicular-ovate, entire, with rounded apex, open, straight narrow sinus with lobes produeed and aeuminate, 5.7 to $7.6 \mathrm{~cm}$. in diameter. By degrees the mature foliage is attained.

Leaf of mature plant floating, or sometimes borne 2 to $7 \mathrm{~cm}$. above the water, eleft to the petiole, less leathery in texture than in $N$. odorata, orbieular, 12 to $38 \mathrm{~cm}$.

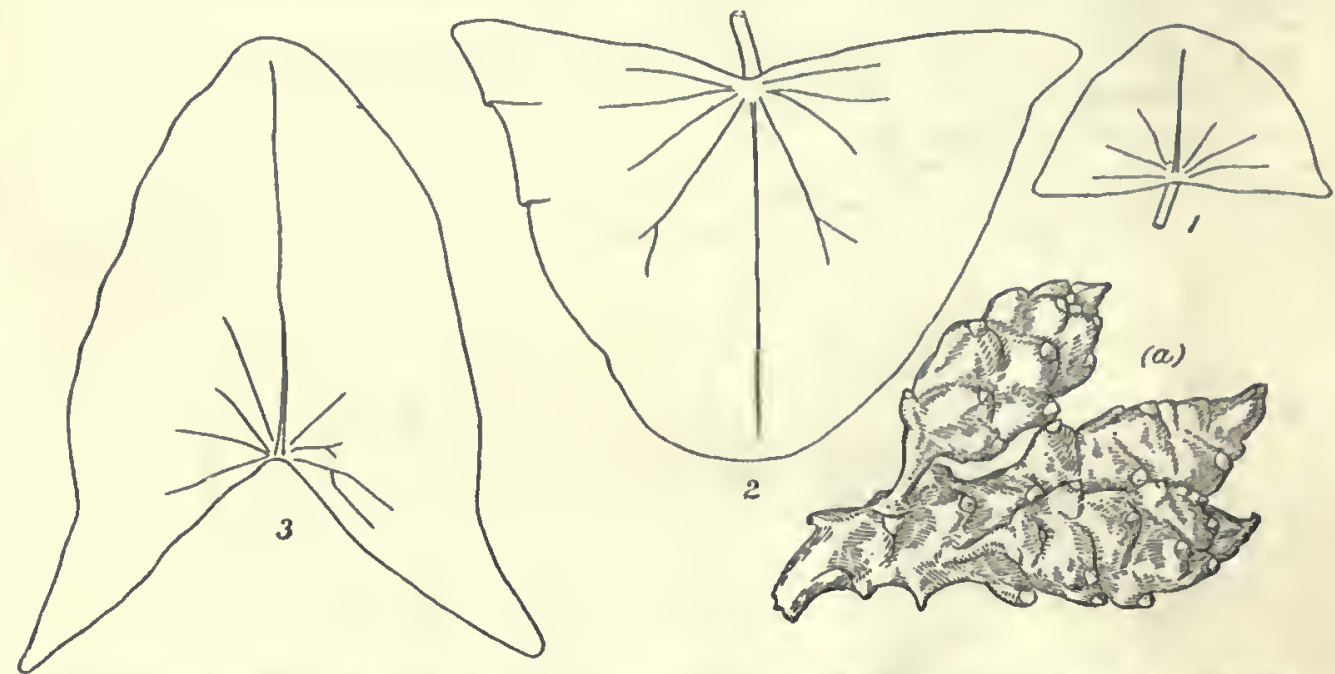

Fıa. 71.-Nymphaea tuberosa: (a) group of tubers; 1, 2, 3, first, second, and third submerged leaves from sprouting tuber. Natural size.

aeross, entire, or slightly eurved outward at apex, smooth, bright green and somewhat veiny above (purplish and shiny when very young), darker in color over the point of insertion of the petiole. Under surface mostly smooth, pitted toward the center (sometimes pubeseent, Britton \& Brown, 1. e.), always green at maturity, slightly purplish toward margins when young; veins rather prominent, 7 to 13 on each side; length of principal area : radius of leaf $=1: 1.6$. Sinus depth: length of leaf $=$ I: 2.3 , open or elosed, nuargins gently eurved, touching at proximal end, 3.2 to $6.4 \mathrm{~cm}$. wide at periphery of leaf, angles short-aeuminate, abrupt on outer side, obtuse at point.-Petiole pubeseent when very young, smooth at maturity, terete or a little flattened ventrally, with I or 2 longitudinal ridges, $30 \mathrm{~cm}$. to $2 \mathrm{~m}$. long, 0.6 to $0.9 \mathrm{~cm}$. in diameter; 4 main air-canals surrounded by 12 smaller ones; idioblasts in very sinall number, about 40 in eentral quadrangle $1 \mathrm{em}$. below leaf. Color green, with I2 to 24 longitudinal brown stripes due to pigment dissolved in subepidermal tissue, running from near the leaf downivard I or $2 \mathrm{dm}$. or even the whole length of the petiole; about one-half of the stripes are broader and more prominent than the rest.- 
Stipules fused, whitish, appressed, broadly triangular, slightly emarginate, with a swelling near the base, $1.4 \mathrm{~cm}$. long by $1.4 \mathrm{~cm}$. wide.

Rhizome horizontal, stout, 2.5 to $5 \mathrm{~cm}$. in diameter, $10 \mathrm{~cm}$. to $90 \mathrm{~cm}$. long; color pale, almost obscured by fine dark hairs; apex protected by stipules and long fine hairs. Phyllotaxy 2 on 5 , becoming less evident on older parts; leaves 2 to $2.5 \mathrm{~cm}$. apart. Roots 8 or more from one leafbase. Branches numerous, 2.5 to 7 or $10 \mathrm{~cm}$. apart ; originating with strong connection ( $1.12 \mathrm{~cm}$. in diameter) with parent rhizome, but the attachment later becomes very slender $(0.3$ to 0.8 $\mathrm{cm}$.) so that the pieces easily break off, forming the so-called tubers. Mature tubers 2.2 to 6 or $8 \mathrm{~cm}$. long by 1.3 to $1.9 \mathrm{~cm}$. thick, occurring singly or in groups of 2 to 5 from an originally single shoot. They are loaded with starch, and show the usual rhizome structure; they spring from any point without any visible order on the parent stem; the connecting isthmus shows (in transverse section) 3 vascular bundles with central xylem, embedded in a mass of large-celled, loose, starch-laden parenchyma.

Grographic Distribution. -North and west of the Appalachian Mountains in North America : Lake Champlain, west through the Great Lakes to Minnesota, south to Arkansas. Very rare on the Atlantic Slope. Lake Hopatcong, New Jersey, fid. specimens cultivated at

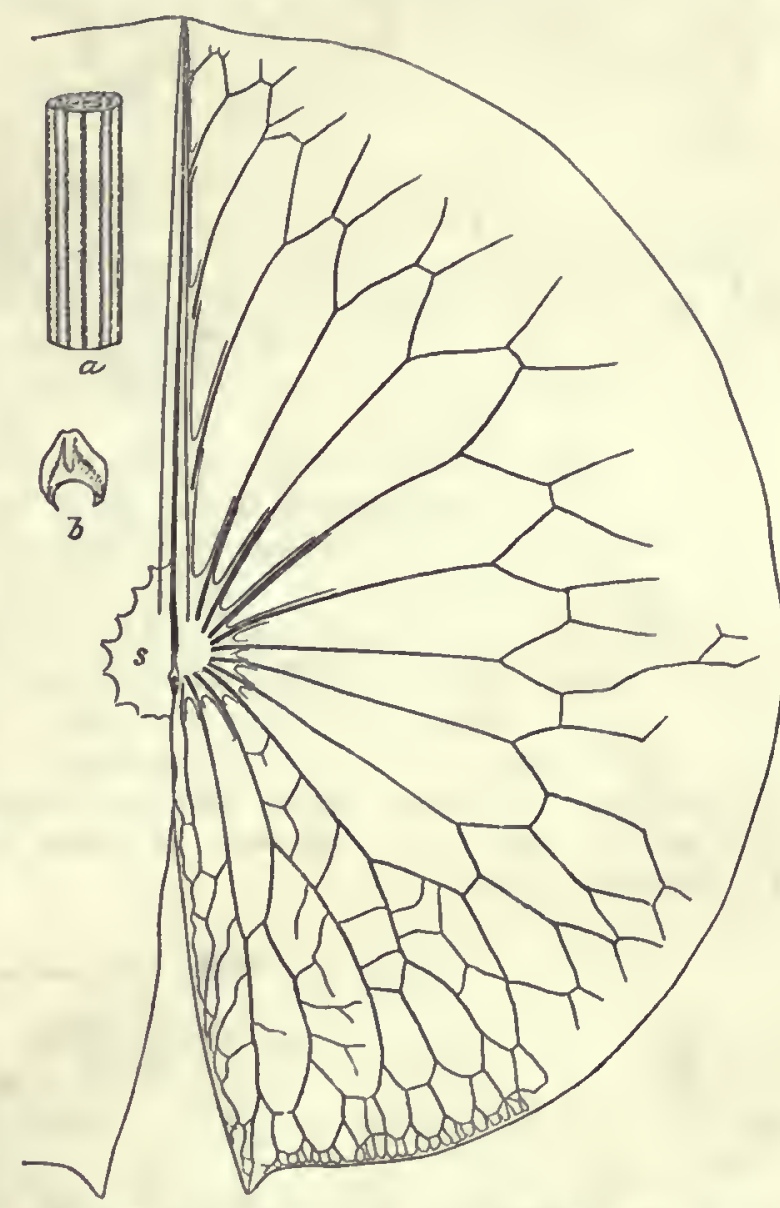

Fra. 72.-Nymphaea tuberosa. Undor side of leaf on right, upper slde on loft; $s$, astomatlc area; $a$, potiole, showing stripes; $b$, stipule. Natural size of leaf $24.5 \mathrm{cn}$. long; stlpule reduced proportionately. Petiole enlarged.

Riverton. Poeatquissing Creek,

Mercer County, N. J. (Abbott 1888, and our own collections). Meadville, Pa. (Britton \& Brown 1897). Raquette River, New York (Prentiss in Bull. 'Torr. Bot. Cl., 10: 4345). Ontario, Canada (Britton 1889 b). Grosse Isle, mouth of Detroit River (Campbell, Bull. Torr. Bot. Cl., I3: 93-94, 1886). Southeastern Minnesota (Wheeler 1900). Ames, Iowa (Hitchcock 1890). Swamps near Little Rock, Ark. (Branner \& Coville 1888).

NoTES.-A smaller variety from Lake Hopatcong, N. J., is known in gardens 
as $N$. odorata maxima ( $N$. tuberosa maxima (Hort.) Conard $1901 a$ ) ; it has leaves 7 to I $5 \mathrm{~cm}$. in diameter; margin of leaf a little drawn in at the sinus; lobes overlapping; angles acuminatc. Petiole pubescent, with a few faint longitudinal stripes. Rlizome somewhat tuberifcrous. Flowcr medium to large, cup-shaped, with the fragrance of $N$. odorata; sepals pure green outside, petals pure white like the type; rarely produces seed. This may be a natural hybrid with $N$. odorata, since that species is common in New Jersey, and Dr. Abbott has rcported a dininutivc but otherwise typical form of $N$. tuberosa under the name of $N$. $t$. var. parva from near Trenton, N. J.

A pink odorless waterlily found at Painesville, Ohio, may be a variety of this (Beardslee 1877).

Nymphaca tubcrosa is a very strong grower; when one wades among the plants, great numbers of the tubers are detached, and float to the surface of the water; thus the plants are distributed and will in short time take complete possession of a small pond. Gray (1889) speaks of the tubers as "spontaneously detaching "; we have seen no way for this to occur; it seems more likely that they are naturally broken off by wading animals (deer, ctc.) which feed on the leaves of Nymphaeas, as also by frogs, turtles, and even by fish.

At the margin of the astomatic area on the leaves, the stomata are large, oval or round, and scattered, immersed in shallow pits; those of the rest of the lamina are small, round and crowded. Stomata are absent from a narrow margin all round the leaf and along the sinus.

Flower, June to September. Fruit, July to October.

According to Robertson (1889) the flowers are visited by Hymenoptcra: Andrenidae: (1) Agapostcmon radiatus Say $9 ;$ (2) A. nigricans F. \&; $(3,4)$ Halictus spp. ; (5) H. pectoralis Sm. $\$$; (6) H. occidentalis Cress. $\%$; (7) H. coriaceus Sm. + ; (8) Prosopis sp. 9. Diptera: Syrphidae: (9) Helophilus divisus Lw. (10) H. latifrons Lw. Bombyliidae: (II) Spamopolius fulvus Wied. Coleoptera: Rhipiphoridae: (12) Rhipiphorus limbatus F.

\section{Subgenus 4. LOTOS, DeCandolle I821 (in part).}

Flowers nocturnal, raised on stout peduncles io to $30 \mathrm{~cm}$. above the water. Sepals with 7 to 13 conspicuous and prominent veins. Stamens inserted at some distance above the petals, all flat and more or less ligulate, rounded at apex, dehiscing simultaneously. Pollen smooth. Styles linear, ligulate. Leaves sinuate-dentate with acute sub-spinous teeth. Petioles, peduncles, and under side of leaves more or less pubescent. Main air-canals in peduncles 6 ( 5 to 7 ), in petioles 2 ; idioblasts and multicellular ingrowths absent. Rhizome tuberous, erect, ovoid, drying off in the resting season. Seed rather small, with interrupted longitudinal lines of short hairs. Four species native to the tropics of the Old World, from Senegambia to the Philippine Islands, extending north to Hungary (two isolated localities) and south to Madagascar.

Lotos, Planchon 1853 b. Caspary 1865; 1888.

Sec. II. Inappendiculatae trib. I Lotos (in part) and trib. II Chamaelotos (in part), Lehmaun 1853 a. 


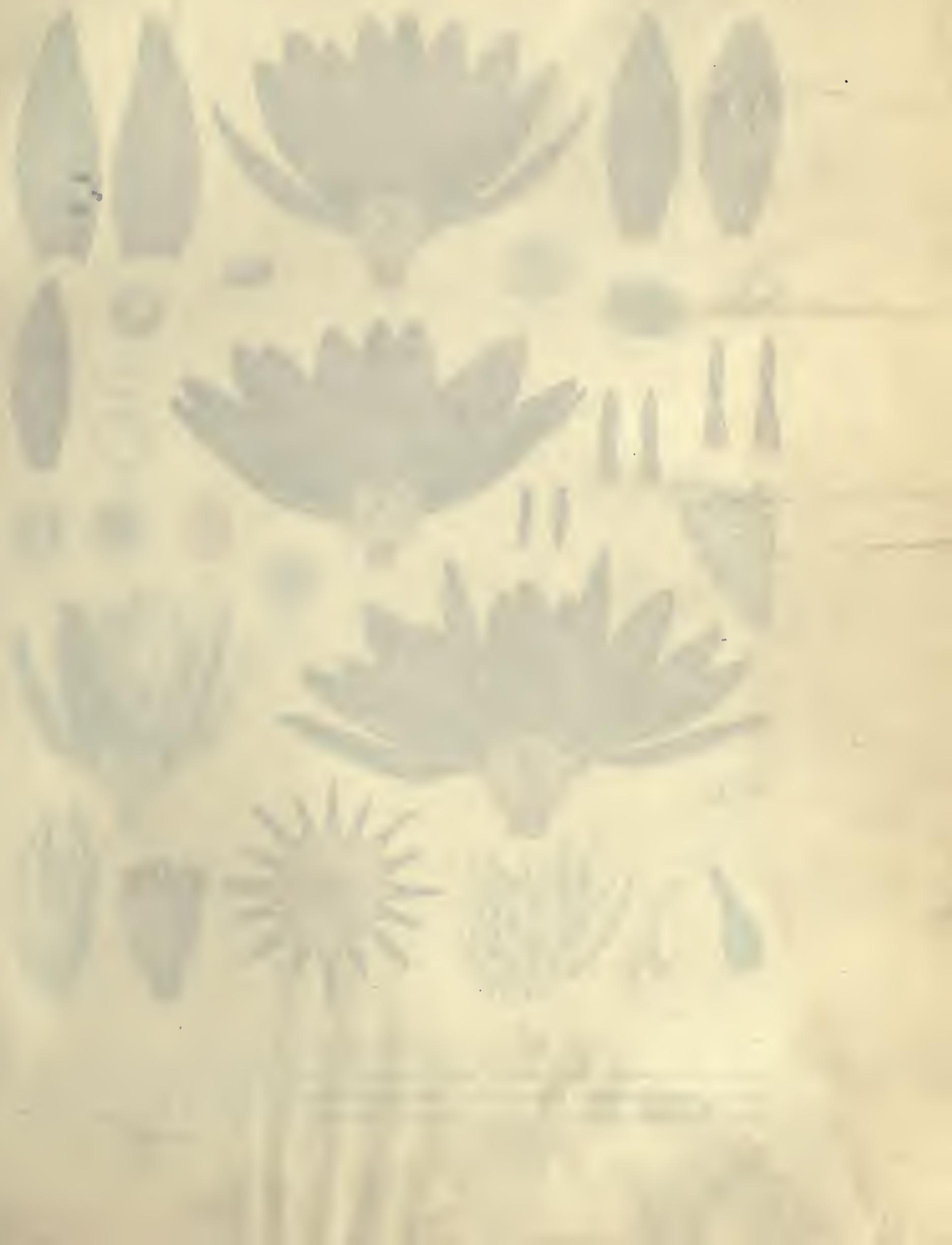





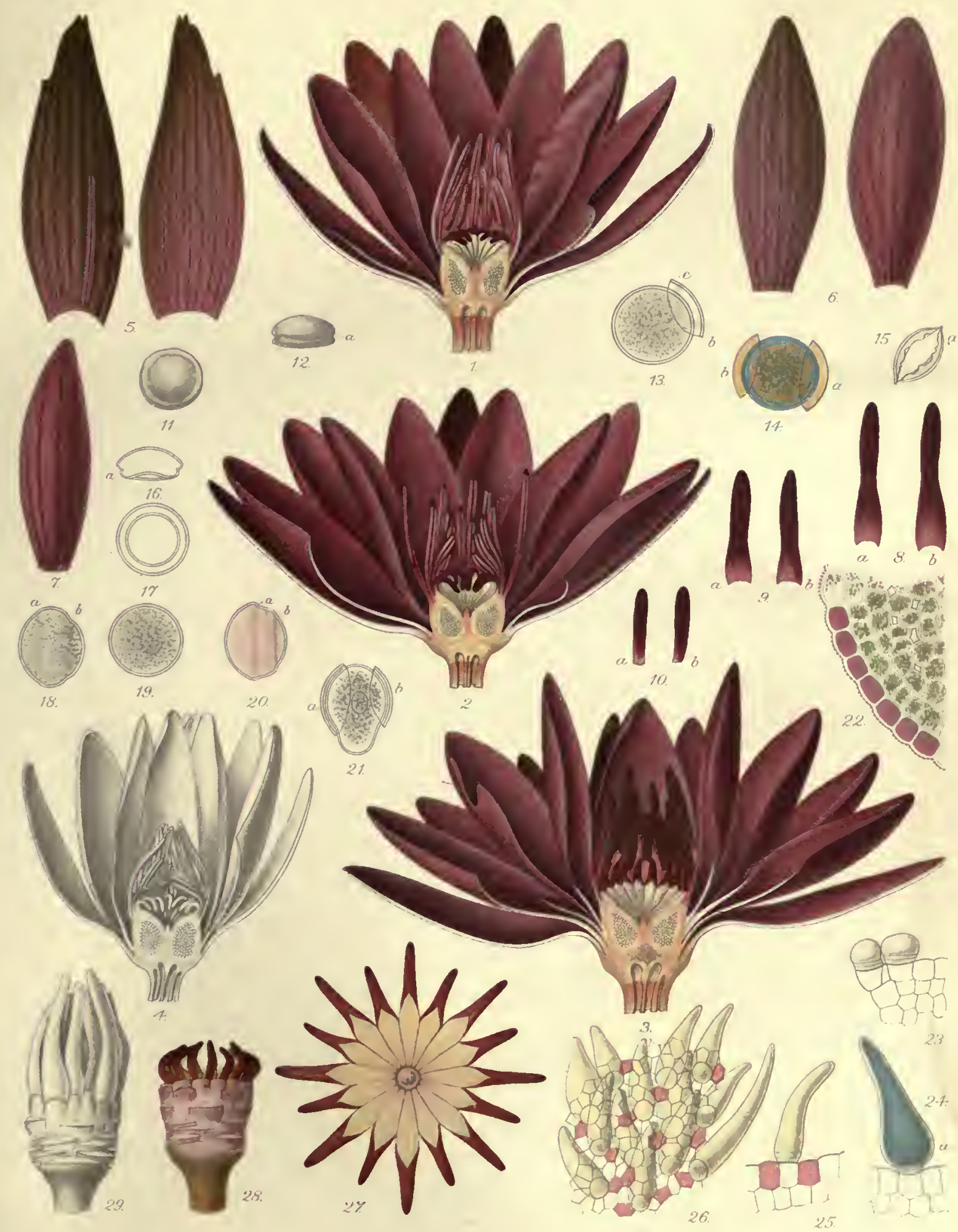

NYMPHAEA RUBRA.

1-4, Vertical sections of flowers in different phases of inflorescence. 5. Sepals, 6-7 Petals. 8.10, Outer median and inner stamens from front and back. 11, 12, 15, 16, 17, 18, 19, 20, aspects of mature pollen. 13, 14, 21, phases of germination of nollea. 22, Transverse section of style. 23-26, Hai
the side. 29, Ovary auil stamens. 

Notes.-The following species differ chiefly in color of leaf and flower, in shape of leaf, and in production of seed. It is stated in Hooker \& Thomson (1855) that all gradations in color occur in India from the white to the deep-red forms; they therefore united them into one species, $N$. lotus L., with three varieties: a. Lotus; leavcs orbicular or relliform, densely pubescent beneath; lobes divergent or approximate; flowers ample, red, rosy or white. $\beta$. cordifolia; leaves cordate-ovate, densely pubescent beneath; lobes divergent; flowers of medium size, white or carneous. $\gamma$. pubescens; leaves puberulent or pubescent beneath; flowers smaller, white, rosy or red. These cliaracters are wholly unreliable in cultivation, whercas the color relations come pretty true to seed, and are usually reproduced precisely from the tuber. Caspary's (I865) division of the species into var. lata with sepals ovate to ovate-oblong, petals white or rosy, filaments yellow; var. angusta, with sepals mostly oblong-lanceolate, petals white, inner filaments with a purple spot; var. oblonga, with sepals mostly oblong, rarely oblong-lanccolate, petals white, rosy or purple, is also unsatisfactory. There seems to be no constant morphological difference on which to base a classification. In $\mathrm{I} 888$, however, Caspary speaks of $N$. lotus, pubescens, and rubra as distinct species. This opinion may have been founded on the rclations of hybrids, of which many arc in cultivation. But the evidence from this source is not conclusive. For example, the hybrid $N$.omarana has bronzy green leaves and large flowcrs with petals

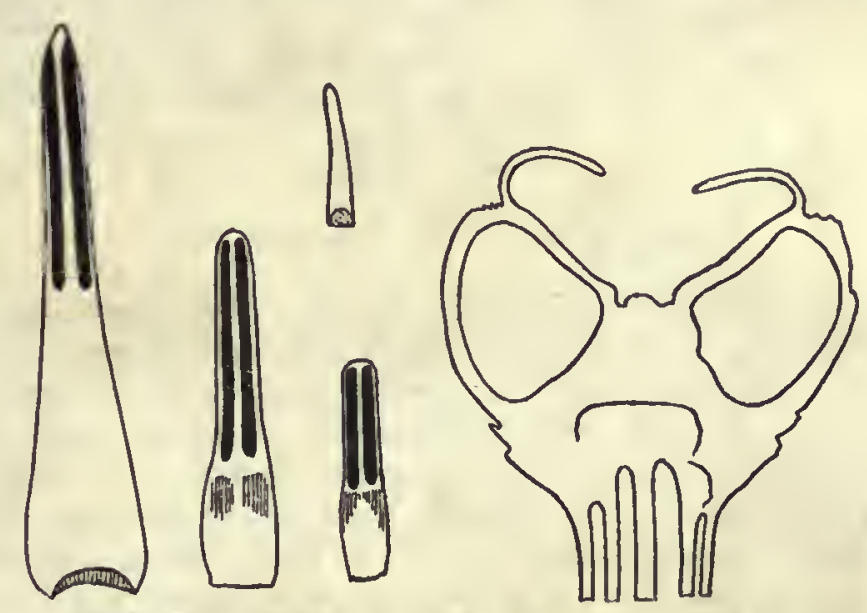

FIG. 73.-Floral organs of the Lotos group. Outer, median and inner stamens; carpellary style; vertical section of ovary. Natural size. From a white flowered garden form.

pinkish-red with a nearly white streak up the middle, and the floral leaves open out horizontally; it shows plainly the blending of its $N$. lotus and $N$. rubra parentage; it bears seed, however, much more freely than $N$. rubra, but less freely than $N$. lotus. Its exact parentage is stated to be $N$. lotus $\times N$. sturtevantii; the latter is a seedling from $N$. devoniensis, raised without crossing, according to Mr. Sturtevant, but it gives evidence of $N$. lotus parentage. $N$. devoniensis was at first considered to be a hybrid of $N$. lotus and $N$. rubra, but it shows no evidence of white parentage, and is probably not of hybrid origin, and Hooker \& Thomson claim to have found it common in India; it very rarely produces seed, however, a character which it seems to have inherited in exaggerated form from its red parent. Whatever else may be inferred from these facts, certain it is that crossing of these forms does not induce sterility, but rather that fertility increases the nearer the mixed progeny approaches to the highly fertile $N$. lotus. From what we have seen, however, there secms sufficient reason to consider $N$. lotus, pubescens, and rubra quite distinct. 
Nymphaea lotus (Linnaeus) Willdenow. (Plate XVI.)

Flowers usually large, white or tinged pink on backs of outer petals; stamens yellow. Fruits numerous, depressed-spherical, truncate above, yellowish-green. Seeds brown, shining, with very fine meridional ridges.

Nymphaca lotus, Linnaeus 1753 (excluding Indian and American plants), fid. original specimen in hb. Linnaeus, now at Linn. Soc. London. Hooker \& Thomson 1855 (in part). Miquel 1859 (in part). Caspary 1865 (in part). Boissier 1867 (in part).

N. lotus, Willdenow 1797. Savigny 1802. Waldstein \& Kitaibel 1802. Andrcws tab. 391. Sims 1805a. Aiton 1811. Delile 1813. Sprengel 1817. DeCandolle 1821 $b$; 1824. Guillemin \& Perrottet 1830. Planchon $1852 b$. Lehmann $1853 a$. Simkovics 1883. Caspary 1888 . Tricker 1897. Moenkemyer 1897. Conard I901 $a$.

N. lotus a Aegyptia, Planchon 1853 b.

N. aegyptiaca, Opiz Naturalientausch (fid. Steudel 184I; Casp. 1865.)

$N$. thermalis, DeCandolle $1821 b ; 1824$, fid. specimen coll. Kitaibel at Grosswardein, 1815 , in hb. DeCandolle.- Reichenbach 1845. Lehmann $1853 a$. Planchon $1851 c ; 1853 b$.

$N$. dentata, Schumacher \& Thonning 1829 , fid. specimcns "ded. Sehum." from hb. Lehmann in hb. Berlin; no types of this exist at Copenhagen, fid. Prof. E. Warming. Walpers 1842. Hooker 1846. Planehon 1850 a. Rev. Horticole 1851 a. Loudon 1855. Tricker 1897.

$N$. Ortgiesiana, Planchon $1852 e$, fid. specimen sent by J. E. Planchon Feb. 4,1853 , in hb. Kew.

Castalia mystica, Salisbury 1806 .

C. lotus, Woodville \& Wood 1806 . Tratinnick 1822 .

DESCRIPTION.-Flowers 15 to $25 \mathrm{~cm}$. across, open on 4 successive nights from $7.30 \mathrm{p} . \mathrm{m}$. to II a. m., the sepals and petals all standing out horizontally, and stamens all erect; nearly odorless.-Buds ovate, obtuse.-Peduncle stout, pubescent, 0.6 to 2.0 $\mathrm{cm}$. in diameter, with usually 6 main air-canals, surrounded by 12 smaller ones; no spiral bending in fruit.-Receptacle conical, about twice as wide as upper part of peduncle-Sepals 4, broadly ovate ( $10.8 \mathrm{~cm}$. long by $5.1 \mathrm{~cm}$. wide), rounded at apex, pure green on back, white at base, with Io to 16 creamy white, prominent veins; covered margins and inside white-Petals 19 or 20 , oval, broadly rounded at apex, tapering slightly at base, longer than the sepals; texture rather thick and firm; 4 outermost petals green along middle of back, otherwise white, or tinged with pink or purplish; inner petals shorter and narrower, never stamenodial.-Stamens about half as long as the petals, yellow; outer ones with broad, persistent filament having a lunate, semi-decurrent insertion on the torus; inner filaments slightly wider than the anthers, with or without a dark purplish-brown spot on upper part; outer anthers shorter than their filaments; inner anthers as long as, or slightly longer than the filaments.-Ovary finely pubescent.-Carpcls about 30; styles yellow, tinged purplish-brown on the back, becoming incurved over the stigma in fruit; stigma funnel-shaped; axile process short, cylindric, rounded.-Fruit large, 6 to $9 \mathrm{~cm}$. in diameter, with copious seeds; stigma funnel-shaped; calyx and enlarged outer filaments persistent. Seed $1.36 \mathrm{~mm}$. by 1.07 $\mathrm{mm}$. to $1.44 \mathrm{~mm}$. by $1.09 \mathrm{~mm}$., with interrupted longitudinal lines of hairs ; aril inclosing the seed.

Germination may occur immediately after ripening of the seed, or better after a period of drought. First leaf filiform, 1.6 to $1.9 \mathrm{~cm}$. long. Second leaf linear to linear-ovate, rounded at apex, tapering at base, 1.9 to $2.2 \mathrm{~cm}$. long by $0.48 \mathrm{~cm}$. wide; petiole slender, about $1.3 \mathrm{~cm}$. long. Third leaf narrowly ovate with abruptly tapering 


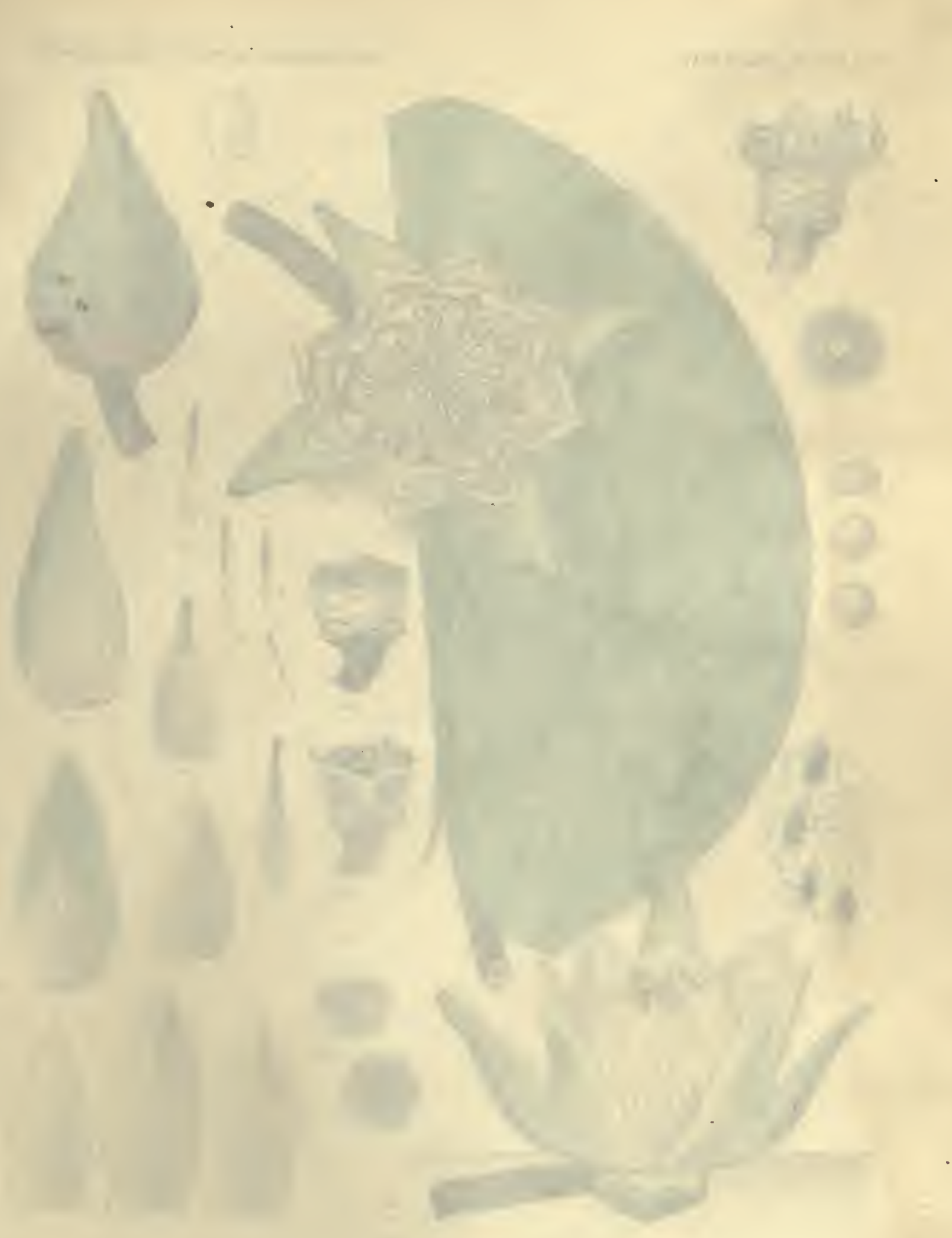

西 



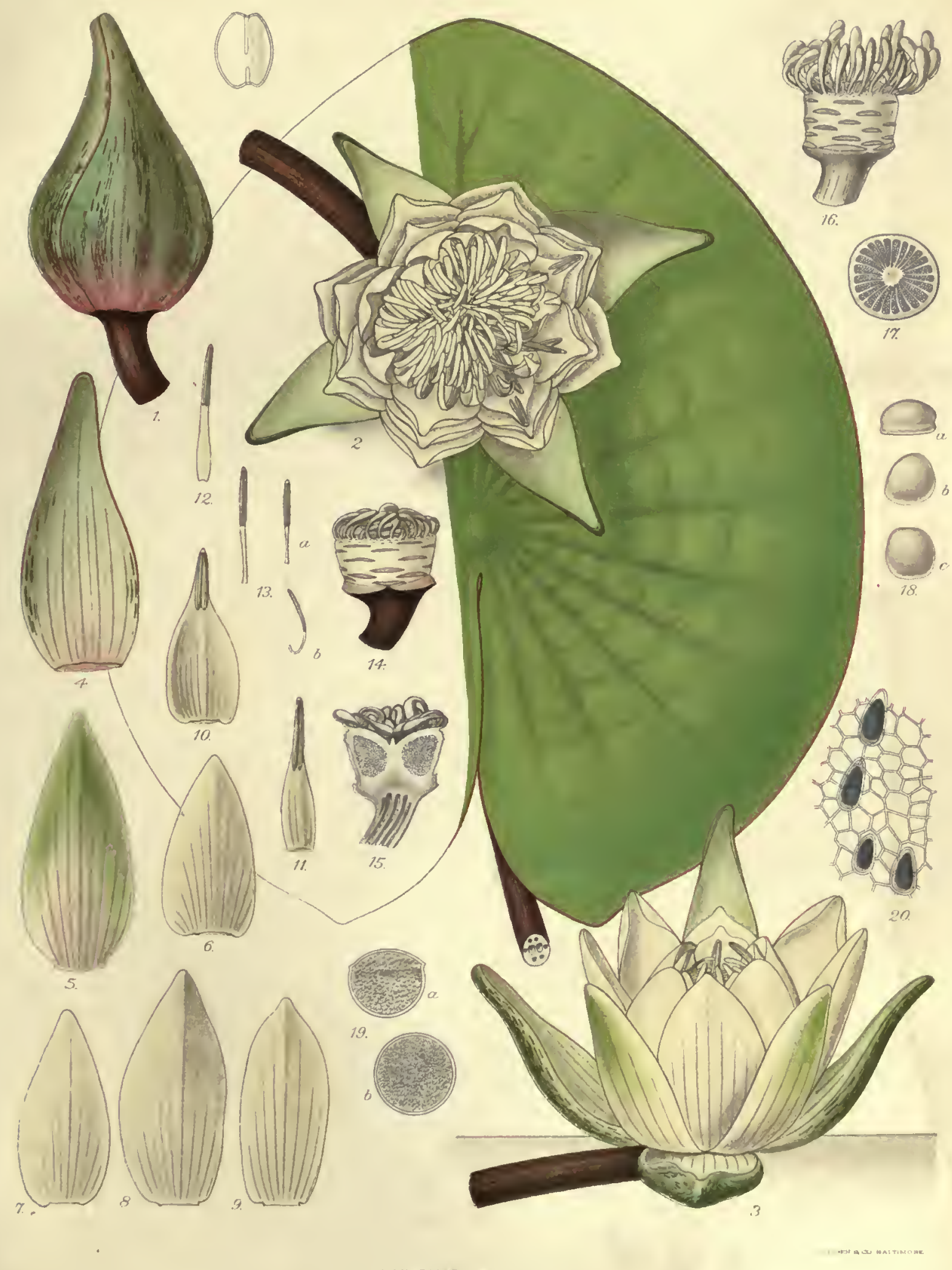

NYMPHAEA AMAZONUM

1, Bud. 2, Eully open tlowet. 3, Half open flower on surface of water, 4, Sepal, 5-9, Petals, 10-13, Stamens. 14-17, Views of ovary and carpellary styles. 18, 19, Pollen. 20, Finidermis of ovary. 

base, I. $6 \mathrm{~cm}$. long by $0.64 \mathrm{~cm}$. wide. Fourth leaf ovate, $1.6 \mathrm{~cm}$. long by $0.95 \mathrm{~cm}$. wide, broadest and nearly truncate at base, the sides nearly parallel below, curving in above the middle to the rounded apex. Fifth leaf cordate-ovate, with rounded apex and lobes, I.68 cm. long by $1.04 \mathrm{~cm}$. wide, sinus $0.16 \mathrm{~cm}$. deep (cf. Lubbock I892).

The germinating tuber gives rise, all over its apical region, to a large number of slender stolons about $2.5 \mathrm{~cm}$. long and 0.08 to $0.16 \mathrm{~cm}$. in diameter, with a lanceolate, acute, translucent bract 0.6 to $1.2 \mathrm{~cm}$. long on the basal portion, and an apical center of vegetation, from which about three submerged leaves are first formed, varying greatly in size according to the supply of nourishment. The first leaf may have a petiole $3.8 \mathrm{~cm}$. long, bearing a filiform midrib $\mathrm{I} .3 \mathrm{~cm}$. long with a minute protuberance on either side at base representing the lamina; or the lamina may be expanded as a linear terminal lobe with a shorter linear lobe on either side of the rounded

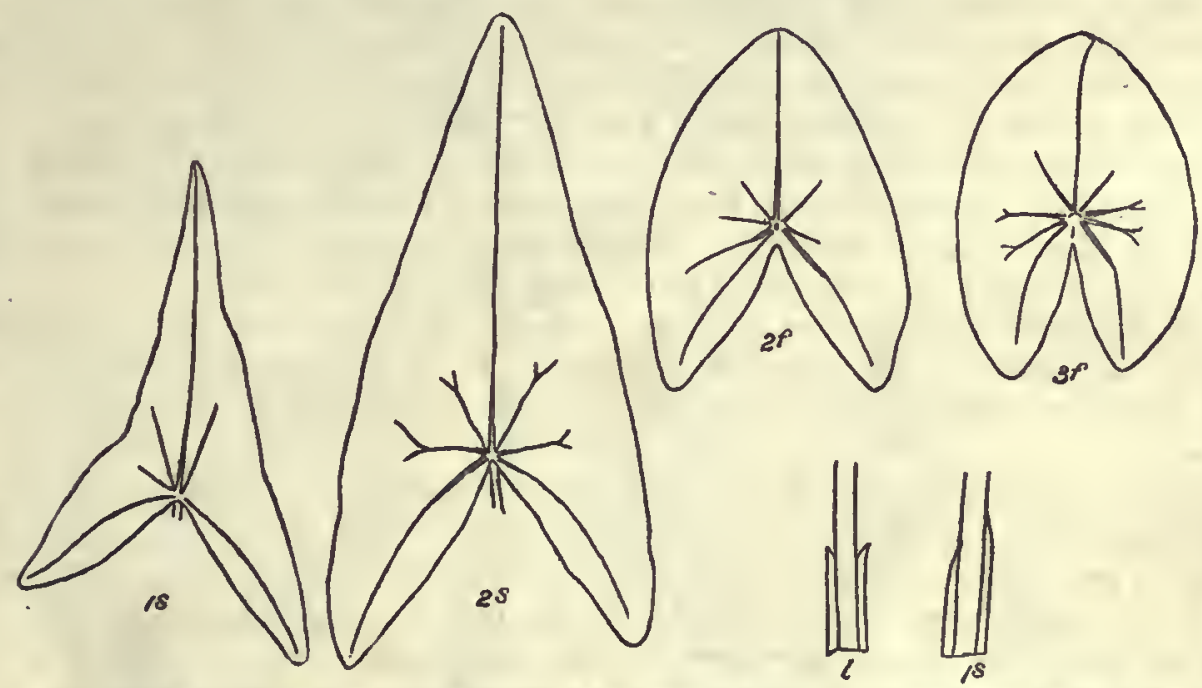

Fia. 74. Early leaves of the Lotos group, from germinating tuber of $N$. devoniensis Hort.: 18, iamina and stipules of first submerged leaf; $2 s$, lamina, $l$, stipules, of second submerged leaf ; $2 f, 8 f$, second and third floating leaves. Lamina natural size. Stipules enlarged.

base. The second submerged leaf is deltoid, with rounded angles and broad, shallow, rounded sinus. The third leaf is broadly deltoid, with deeper sinus. All three appear at first of a reddish color, later becoming green; their texture is very soft and thin, and margins entire. The first floating leaves vary much in size according to foodsupply, but are entire, oval, deeply cordate, with rounded apex and lobes; length: breadth = I.5: I (about); gradually leaves of a more circular outline are produced, and when practically round the dentation appears, at first very faintly, slowly reaching the adult form in the older leaves.

Leaf of mature plant distinctly peltate ( 2 to $5 \mathrm{~cm}$.), orbicular, 20 to $50 \mathrm{~cm}$. in diameter, subspinose-dentate and more or less wavy at margin, the teeth being sharp and brown-tipped, situated on the crests of the vertical undulations of the margin, I. 3 to $5.0 \mathrm{~cm}$. apart, with curved sinuses. Texture very firm and stiff by reason of the large prominent veins of the under surface; primary veins about 9 on either side 
sinuate-dentate; thin and membranaceous; younger ones glabrous, adult or sub-adult leaves glabrous above, densely pilose beneatl with very short hairs; veins slightly prominent above, manifestly so beneath; venation loose, conspicuous; flowers 5 to 7 $\mathrm{cm}$. in diameter, 'white'; sepals 4 , ovate-lanceolate, acute, whitish within, light green outside; petals 7 to 8 , smaller than the sepals, and becoming decidedly smaller and narrower inward; stamens 35 to 45 , broadly linear; anthers rather short, connective scarcely produced; carpels several.

"Leaf to to $15 \mathrm{~cm}$. long, 9 to $13 \mathrm{~cm}$. wide; the sinus is about 2 to $4 \mathrm{~cm}$. wide at base of lobes. The sepals are 2.5 to $3 \mathrm{~cm}$. long, 7 to $10 \mathrm{~mm}$. wide; the petals decrease in size inward down to $2 \mathrm{~cm}$. long and $4 \mathrm{~mm}$. wide. The outermost stamens are about $2 \mathrm{~cm}$. long and $3 \mathrm{~mm}$. wide at base, anthers $7 \mathrm{~mm}$. long by $2 \mathrm{~mm}$. wide." (E. Gilg.)

N. Zenkeri, Gilg, in herbaria.

Geograpitic Distribution.- "Cameroon: Bipindi, in slowly flowing brooks and in streams of the Lokundje at Bequanohe. Coll. Zenker, No. 2130. Flower in July." (E. Gilg.)

Notes.-Finding this species labeled by Professor Gilg in several European herbaria, but there being as yet no published description, we were favored by the Berlin professor with the above description from his own pen, based on the specimens in the Royal Herbarium. We have gladly inserted it therefore, translated verbatim from the Latin and German in which it was communicated.

\section{Nymphaea pubescens Willdenow. (Plate XVII.)}

Flowers small, white; stamens yellow. Leaves small, ovate, dark green. Fruits numerous, nearly spherical, contracted above, dark green. Seed spherical-ovoid, brownish-olive, shining, nearly smooth.

Nymphaea pubescens, Willdenow 1797. Aiton 1811. Smith 1819. Wight \& Arnott 1834. Planchon $1853 b$. Lehmann 1853 a. Caspary 1888 .

N. lotus, Linnaeus 1753 (in part), fid. specimen in hb. Hermann, now British Museum. Roxburgh 1814 ; 1824 . Hooker \& Thomson 1855 (in part). Miquel 1859 (in part). Caspary 1865 (in part). Kurz Veg. eil. Bangk. (fid. Caspary 1865). Boissier I867 (in part). Blanco I878? N. Coteka, Roxburgh $1806=$ Castalia edulis, Salisbury $1806 b$.

N. esculenta, Roxburgh 1814; 1824 .

N. edulis, DeCandolle 1821 $b$.

N. sagittata, Edgeworth 1845 , fid. specimen coll. M. P. Edgeworth, 1844, in N. W. India, in hb. Kew.

N. semisterilis, Lehmann 1853 a (fid. Hooker \& Thomson 1855, and specimen in hb. Kew).

$N$. bella, Lehmann $1853 a$ as to the leaf, fid. specimen from hb. Lehmann in hb. Berlin. Flower is of N. stellata Willd.

N. Nouchali, Burman 1768, fid. specimen coll. Burman in India, in hb. Delessert $=N$. Naccheli J. F. Gmel. Syst. 1591, fid. Hooker \& Jackson 1893 .

Castalia sacra, Salisbury 1806 b.

DESCRIPTION.-Flowers small to medium size.-Sepals 7 to $9 \mathrm{~cm}$. long, obtuse; green outside, with white veins.-Petals pure white; outer ones broadly obovate, width: length $=\mathrm{I}$ : 2.6. - Quter stamens not lunate-decurrent at insertion, separated from the petals by a wide gap.-Fruit about $4 \mathrm{~cm}$. in diameter. Seed $1.9 \mathrm{~mm}$. long by $1.52 \mathrm{~mm}$. in diameter. 


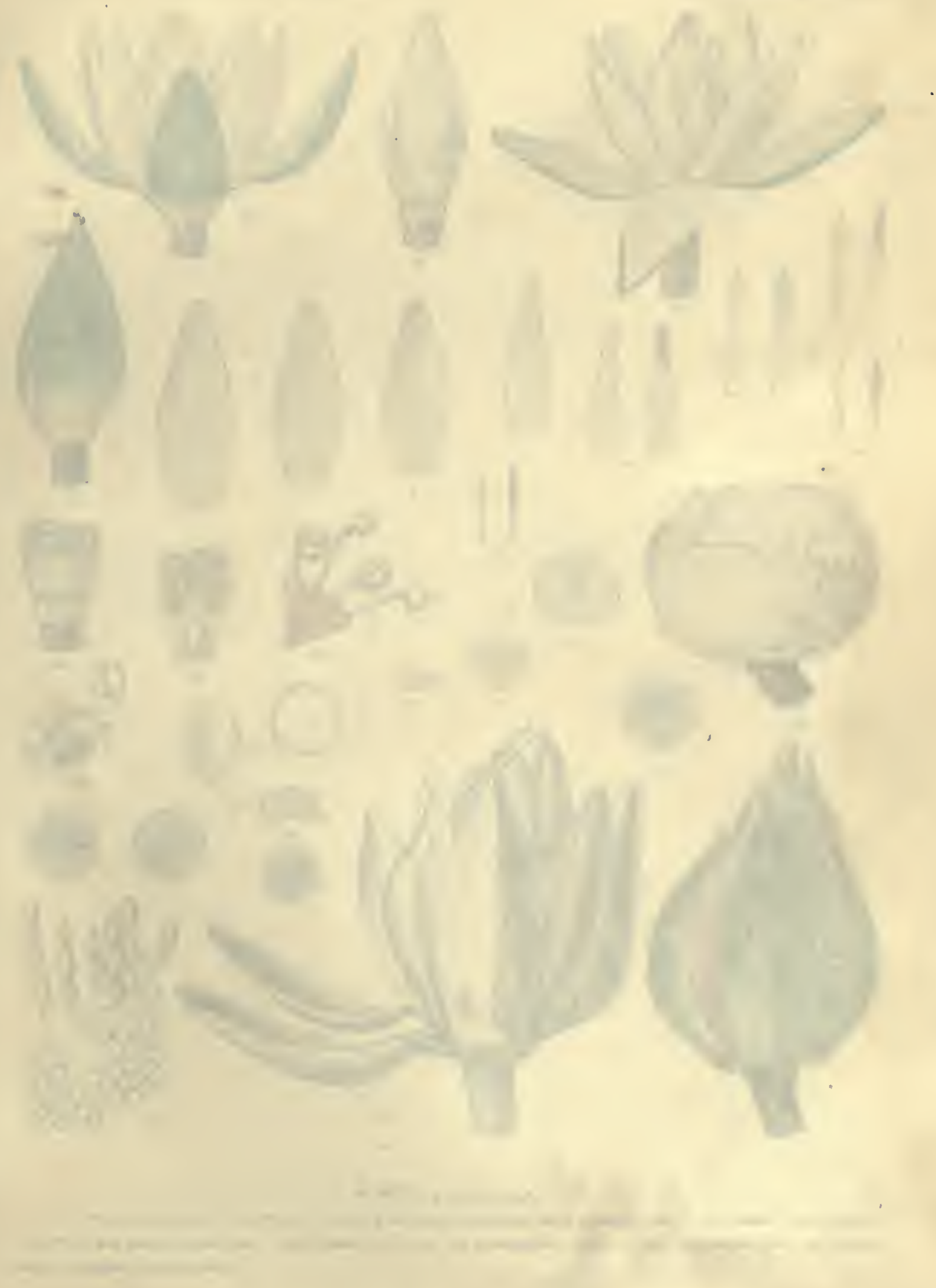




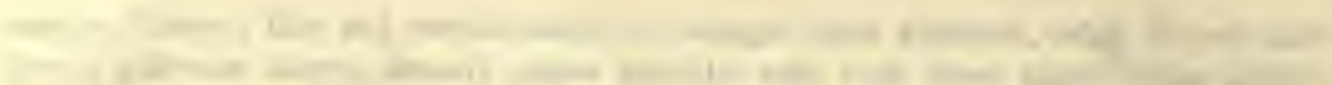

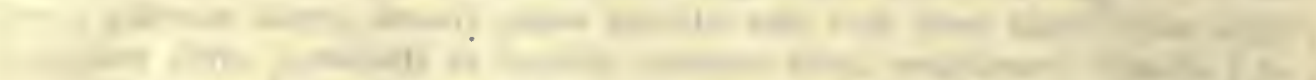

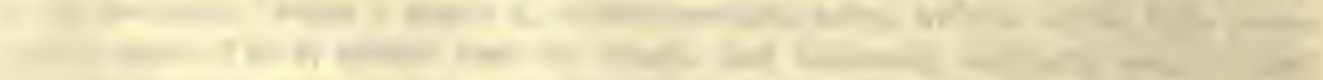
t. -

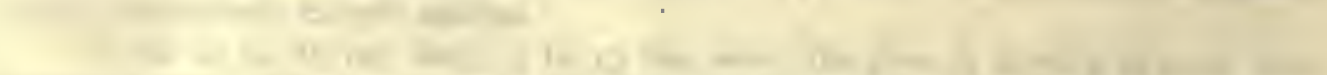

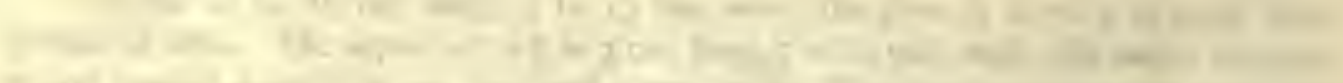

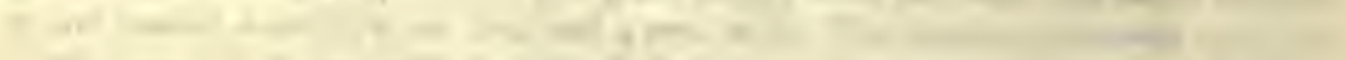

\footnotetext{
$\left(\frac{10}{20}\right.$
}

\section{and}

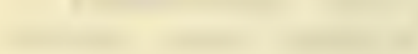

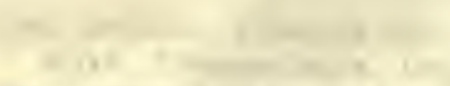

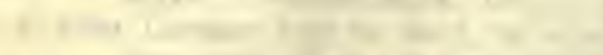

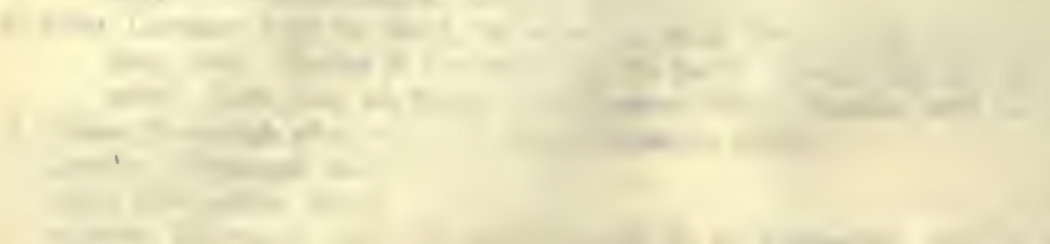

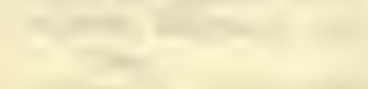

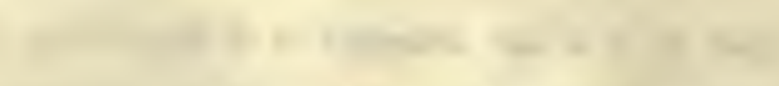

$$
\begin{aligned}
& \text { - } \\
& \cdot
\end{aligned}
$$

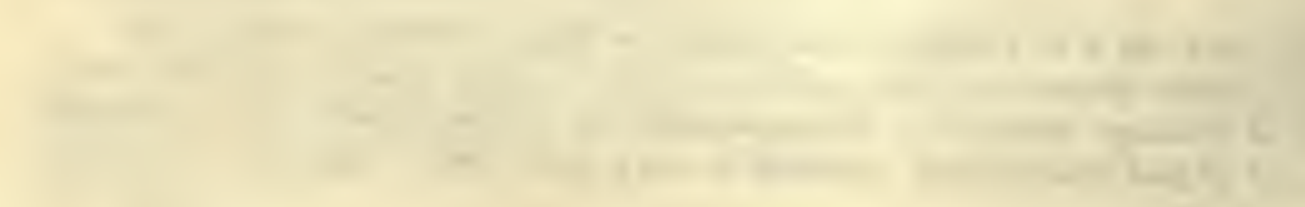


CARNEGIE INSTITUTION OF WASHINGTON.

WATERLILIES, PLATE 20.

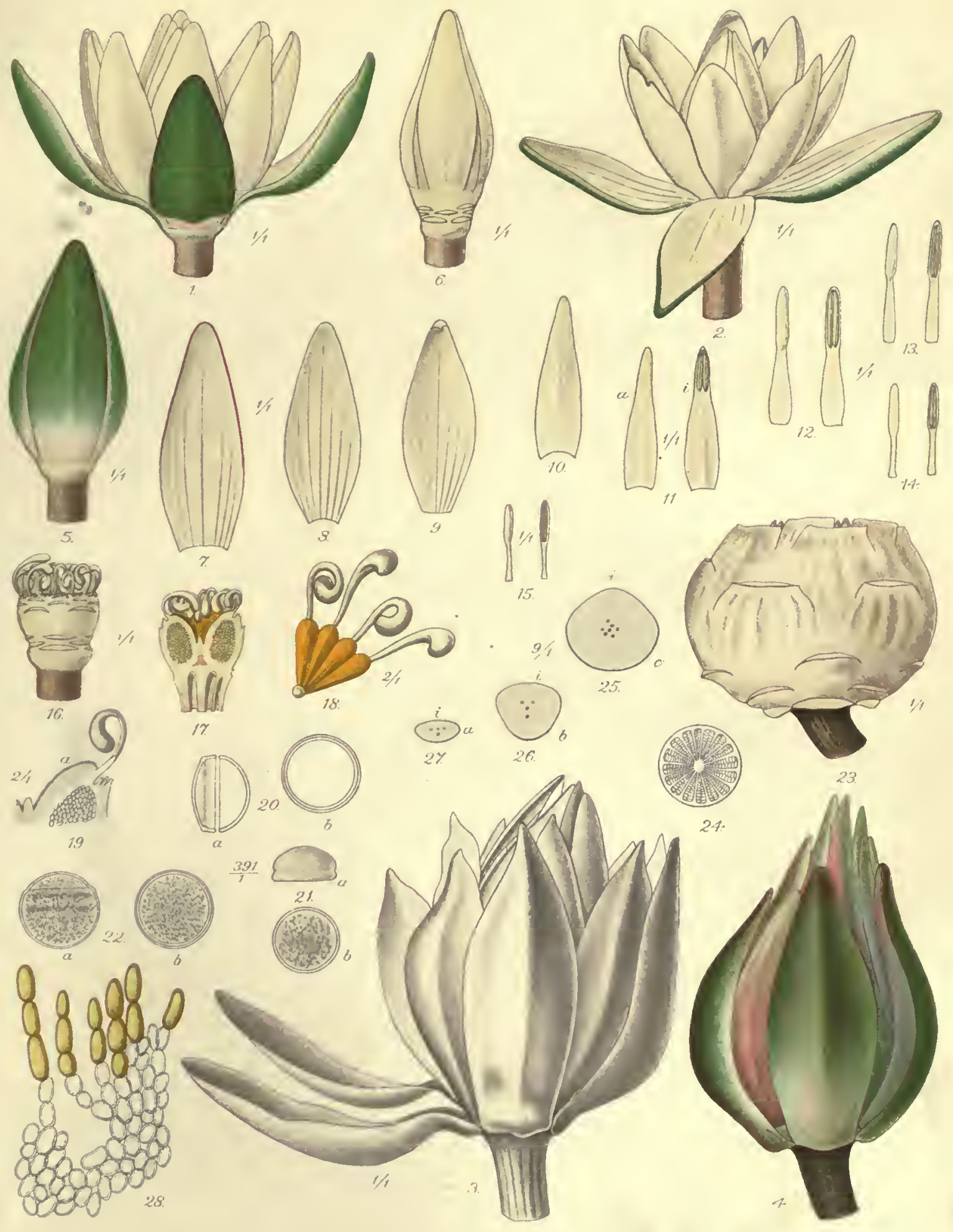

NYMPHAEA RUDGEANA.

1. 2, Views of the flower. 3, 4, Fruith 5, Bud. 6, Same as 5, with outer floral organs removed. 7-10, Petals, 11-15, stamens. 16-19. Views and details of gynrecinm. 20-22, Pollen. 23, Fruit, 24, Cross section of ovary, 25-27, Sections of stvle, 28, vertical section of stigma, showing mapillit. 

Leaves $25 \mathrm{~cm}$. long or less; breadth: length $=\mathrm{I}:$ 1.28. - Sinus open or closed; margin mostly curved. Upper surface of leaf dark green, under surface dull purplish-green, more or less pubescent. Length of pelta : length of leaf = I : I2.

Tuber large, ovoicl. (Other details as in $N$. lotus.)

Geographic Distribution.-British India to the Philippine Islands; south to Java and Australia.

Notes.-Of most of the plants classed above as synonyms descriptions are not available. $N$. sagittata was separated on account of its open sinus and entire, sagittate leaves these were doubtless from a young plant. It was collected at Ambala, province of Sirhind, India. N. semisterilis is said to have the leaves obtusely dentate or crenate. No one except the founders of these two species has ever considered them distinct. The names edulis and esculenta were given in reference to the use of the tubers and seeds in India as food, as is the case with $N$. lotus in Africa.

$N$. pubescens is said to have been introduced into England from India in 1803 . Willdenow took as his type the plate entitled "Ambel" in Van Rheede's Flora Malabarica.

The description and diagnosis given above are based on a plant grown by $\mathrm{Mr}$. Tricker in the Dreer gardens at Riverton, N. J., in I902, from seed sent by Mr. Gollan of Saharanpur, India, corroborated by comparison with herbarium material.

\section{Nymphaea rubra Roxburgh. (Plate XVIII.)}

Flowers deep purplish-red; stamens cinnabar-red, becoming brownish. Leaves large, dark bronzy red, becoming greenish in age. Fruits rare. Seed nearly spherical, dull brown, with fine, prominent, meridional ridges.

Nymphaea rubra, Roxburgh I806; 1814; 1824; fd. color drawings in hb. Kew. Andrews tab. 503 . Sims 1810. Aiton 1811. Smith 1819. DeCandolle 1821 $b$; 1824. Wight \& Arnott 1834 . Wight 1850 . Planchon $1850 b$ and $d$; $1852 a$. Lehmann $1853 a$. Lindley $1853 a$.

$N$. lotus, Hooker \& Thomson 1855 (in part). Miquel 1859 (in part). Caspary 1865 (in part). Boissier 1867 (in part). Not Linn. 1753 .

N. rubra var. rosea, Sims i8ir $b$.

N. rosea, Sweet 1827 .

N. Devoniensis, Hooker $1852 b$, and Lindley $1853 b$, fid. Hooker \& Thoms. 1855. Garden $1883 a$. Castalia magnifica, Salisbury 1806 .

C. lotus flore rubro, Tratinnick 1822 .

DESCRIPTION.-Flowers 15 to $25 \mathrm{~cm}$. across, deep purplish-red, open from $8 \mathrm{p} . \mathrm{m}$. to I I a. m.-Sepals dull purplish-red, about 7 nerved, never opening more than $10^{\circ}$ above horizontal.-Petals 12 to 20 , narrowly oval, breadth: length $=1: 3.15$, rounded at apex, standing at various angles in the open flower from $45^{\circ}$ to the level of the sepals.-Stamens about 55, cinnabar-red, becoming brownish.-Fruits very few, small. -Seeds $1.85 \mathrm{~mm}$. long by $1.6 \mathrm{~mm}$. in diameter.

Leaves large, 25 to $45 \mathrm{~cm}$. across, dark reddish-brown, bronzy, becoming greenish in age; under surface pubescent. (Other details as in N. lotus.)

Geographic Distribution.-British India; Bengal.

NotEs.-In gardens is distinguished $N$. rubra rosea, with leaves bronzy green blotched with brown; flowers large, magenta to dull red, open until 10.30 a. m.; petals narrow, pointed; stamen tips orange-brown. 
We are doubtful if the true $N$. rubra exists in this country. Sced communicated by Mr. Chandradatta of Calcutta has germinated but produced no flowering plants as yet. It was introduced into England in 1803 .

$N$. devoniensis at Lyon House, England, in 1885 produced a flower whose peduncle arose from the axil of a stamen of a previous flower (Barber 1889), and Dr. Kirk, according to Masters (1869), observed a similar abnormality in $N$. lotus in East Africa. The sepals, petals, stamens and even carpels of these species may become leaf-like (Masters 1869).

We have to admit that our arrangement of the Lotos group is far from being satisfactory or final. Important results would certainly follow a study of the plants of various parts of Africa, Asia and the outlying islands. This can only be done effectively on living plants, either in cultivation or in their native haunts. The several forms in gardens have proven useless on account of uncertainty of origin and probable admixture of other stocks by crossing.

\section{Subgenus 5. HYDROCALLIS, Planchon $1852 b$; $1853 a$.}

Flowers nocturnal, floating. Sepals not evidently veined. Petals in whorls of 4 , alternate with the sepals and with each other. Stamens inserted in series with the petals, the outermost 4 or 8 more or less petaloid and in whorls like the petals; anthers dehiscing about simultaneously. Styles slender, cylindric, with enlarged club-shaped tips. Seeds small or minute, with numerous long hairs. Leaves entire, or dentatesinuate with obtuse teeth. Rhizome erect, tuberous, drying off in the resting season. Ten known species, natives of the tropics of the Western Hemisphere.

Hydrocallis, Caspary 1878; 1888.

Castalia (in part), DC. 1821 .

Tribe Leucanthos (in part), Chamaelotus (in part), Lotos (in part) and Castalia (in part), Lehmann $1853 a$.

Nymphaea amazonum, Martius \& Zuccarini. (Plate XIX.)

Number of floral parts 132 to 376 . Sepals ovate-oblong, more or less acuminate. Petals 16 to 20, rows all about equidistant. Stamens 93 to 297. Pollen o.or42 to $0.0174 \mathrm{~mm}$. in diameter. Carpels 19 to 40 . Fruit with funnel-shaped stigmatic disc, the funnel surface curved; sepals and outermost row of petals persistent. Seeds 10,000 to 27,000 , very small, $0.386 \mathrm{~mm}$. wide by $0.756 \mathrm{~mm}$. long to $0.566 \mathrm{~mm}$. by $0.973 \mathrm{~mm}$., dull gray. Mature leaf entire, lobes subacuminate or rounded. Top of petiole bearing a ring of long hairs. Tuber producing stolons throughout its vegetative period. Flowers imperfectly opening two nights, becoming fully open suddenly the second night between 4 and 5 o'clock a. m. Bud ovate-oblong, acuminate.

Nymphaea amazonum, Martius \& Zuccarini 1832, fd. specimens coll. Martius, No. 3313, near Para, Brazil, in hbb. Munich, Berlin. Planchon $1853 b$. Lehmann 1853a. Hooker 1854. Caspary 1878. Sagot 1881. Conard igor $a$.

N. albo-viridis, St. Hilaire 1833, fid. specimen coll. St. Hilaire, Prov. Rio de Janeiro, Brazil, in hb. Paris.

N. blanda, Macfadye: 1837. Hort. Glasnevin (fid. Hooker, 1. c.). Not Meyer 1818.

N. blarda $\beta$ Amazonum, Planchon 1856.

N. Rudgeana $\beta$ Amazonum, Grisebach 1864. Not N. rudgeana Mey. 1818. 


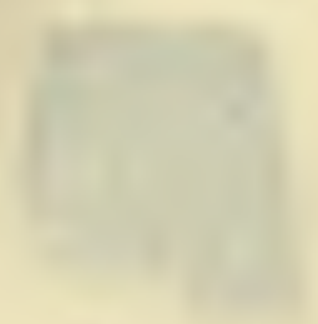

4
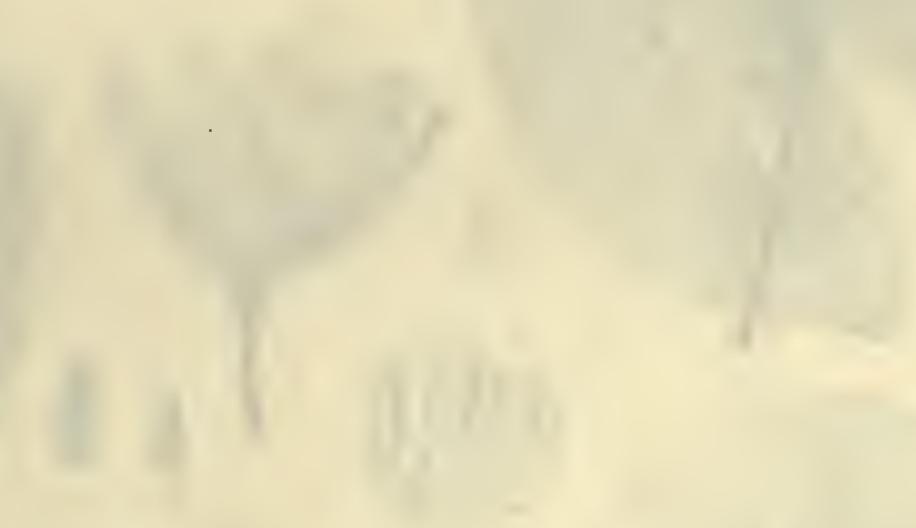


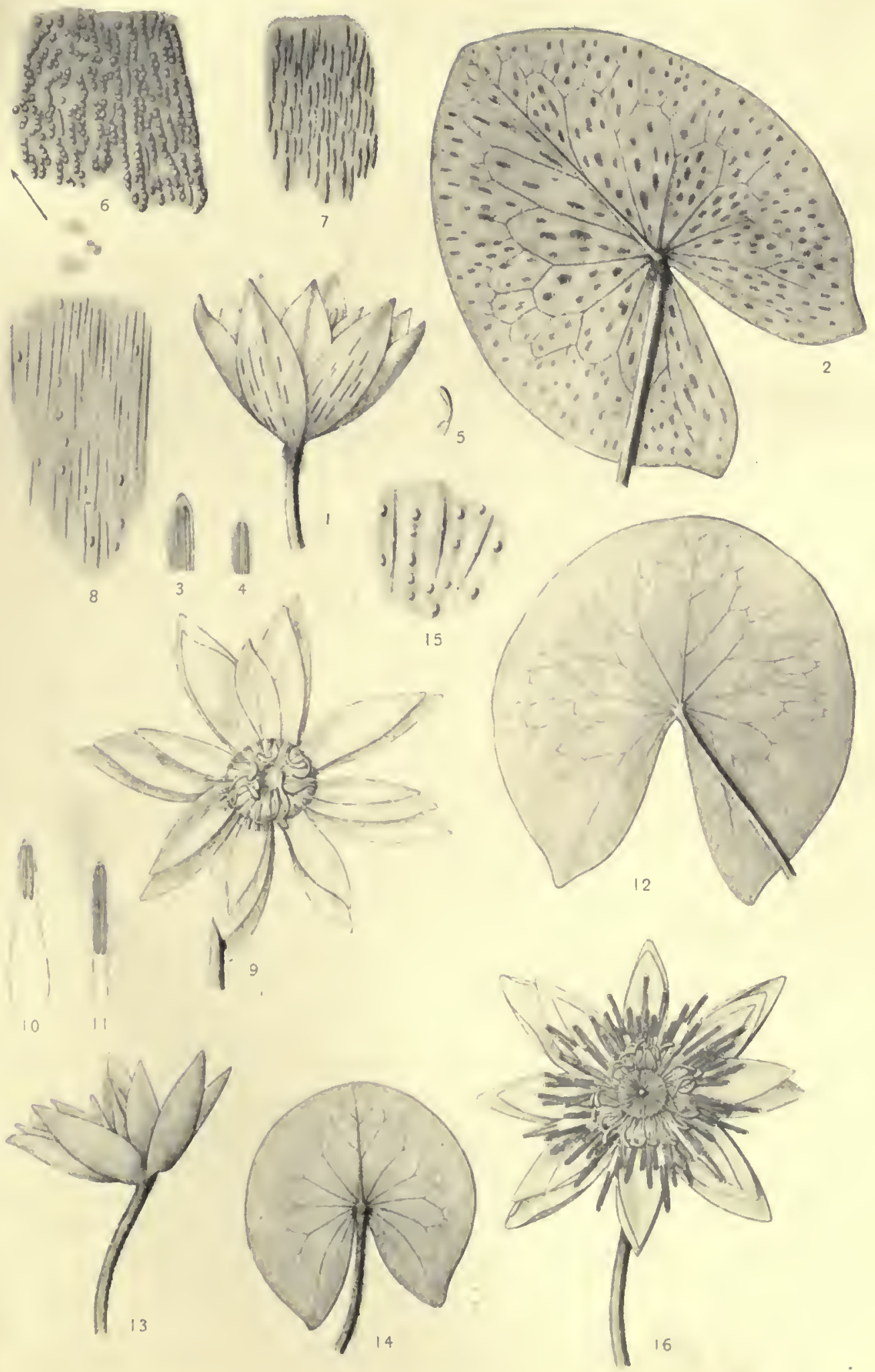

NYMPHAA BLANDA, N. BLANDA FENZLIANA, N. TENERINERVIA, N. STENASPIDOTA.

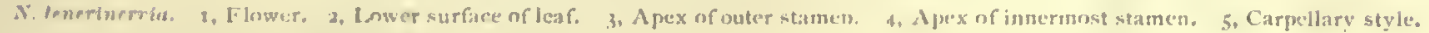

6. Cipper kurface of leaf. 7. Outer surface of scpall.

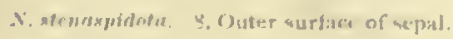

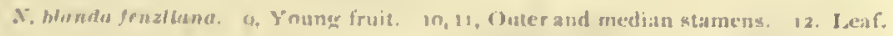

1. Manda. 13, Flower viewed from side, 14, Ieaf. 15, Iart of upper surface of sane leaf, i6, Flower. 

N. integrifolia, Salzmann MS., fid. specimens coll. Salzmann, 1830, at Bahia.

N. foetida, Gardner MS., fid. specimen coll. Gardner, No. 2477, Aug., I839, in the Like of Paranagua, in hb. Berlin.

N. nocturna, March MS. (fid. Hooker, 1. c.),

DesCription.-Flower floating, to to $12 \mathrm{~cm}$. across, opening two nights. The first night, the bud stands with its base about $\mathbf{I} \mathrm{cm}$. or more immersed in the water, and begins to open about 3 o'clock a. m.; it spreads gradually until 4.I5 a. m., when the sepals stand out at about $45^{\circ}$ and the petals are loosened, leaving an aperture I.3 $\mathrm{cm}$. wille into the center of the flower. At $4.45 \mathrm{a}$. m. it begins to close, being completely closed about $6 \mathrm{a} . \mathrm{m}$. The second night the bud has risen till its base is just out of the water, and begins to loosen at the apex at $6.30 \mathrm{p} . \mathrm{m}$.; the sepals spread out rapidly to a horizontal position, followed by the outermost series of petals, which reach nearly the horizontal position; the second series also open slightly from the tip of the bud (about $\mathrm{I} \mathrm{cm}$.) ; this phase is completed by $8 \mathrm{p} . \mathrm{m}$., a tight creamywhite acute bud being left in the center of the flower. The flower remains thus until about $3.30 \mathrm{a} . \mathrm{m}$., when the parts begin to open out more fully, the process being completed about 4.45 a. $m$. At this time the sepals and outermost petals are horizontal in position, the inner petals standing at all angles up to about $40^{\circ}$ above the horizontal; the outermost stamens lie against the innermost petals; from this position the stamens stand at all angles up to the innermost which bend over the stigma. All of the stamens have now dehisced, the flower is warmer than the surrounding air, and has a very faint sweetish odor with a suggestion of peaches. Closure of the flower begins about 5 a. m., and is led by the stamens and petals; these, with exception of I or 2 outermost petals, are united into a tight bud at $5.30 \mathrm{a} . \mathrm{m}$., while the sepals are only $10^{\circ}$ to $15^{\circ}$ above the horizontal. By $60^{\circ}$ clock complete closure is effected, and the flower is retreating below the water, where it becomes completely covered before the middle of the succeeding afternoon, i. e., in eight hours or less. From 7 to 7.30 p. m. and from 4 to $4.30 \mathrm{a}$. m. the movements of the petals and sepals on the second night is very rapid and may easily be seen; the apex of the organ rotates about its base, moving about $1.3 \mathrm{~cm}$. in three minutes; the aperture at the apex of the bud therefore enlarges at twice this rate. In one observation the inmost petals were closed over the stamens at $4 \mathrm{a} . \mathrm{m}$.; at 4.06 their apices stood $5 \mathrm{~cm}$. apart! The closure of the flower after its full maturity is almost as rapid. - Bud 5.4 to $7.3 \mathrm{~cm}$. long by 2.7 to $3.8 \mathrm{~cm}$. in diameter, conical-ovate, broad at base, acuminate above, more or less obtuse, abruptly contracted below to the petiole.-Peduncle 40 to $50 \mathrm{~cm}$. long, 0.6 to $0.8 \mathrm{~cm}$. in diameter, terete, brownish-green, lighter at base, smooth, with 3 minute central aircanals, 6 to 7 main canals and I2 to I4 outer canals, separated by extremely thin partitions.-Receptacle round, pure dark brown, nearly horizontal, distinctly bounded from the sepals at the margins. - Sepals 4, fleshy, ovate, rounded at apex, carinate on back in upper part, the ridge vanishing about two-thirds of the length from the tip. Outer surface dark green above, paler below, the lower quarter being greenish-white; whole surface marked with strong purplish-black lines and dots, the lines becoming bright red on the lower quarter of the sepal. Inner surface apple green above, shading to greenish-white at base, with a few dull brownish spots and streaks on margins in upper half. Innermost (posterior) sepal deeply hooded at apex, i. e., the fleshy tip is 
excavated, forming a scoop-like depression about $0.3 \mathrm{~cm}$. deep, which rcceivcs the tip of the bud and covers it above and on three sides; outermost (antcrior) and right sepal slightly hooded, left sepal very slightly hooded. Margins of innermost sepal covered in the bud, about $0.16 \mathrm{~cm}$. wide, whitish and semi-transparent. All veinless, persistcnt in fruit.-Petals 16 to 20 , of a ycllowish-white color, rather thick and leathery, a little shortcr than the sepals, deeply concave and slightly hooded at apcx; when cut off from the receptaclc (of a closed flower), the basal portion curls inward strongly, showing the tension to which it has been subjected in closure. Outer petal broadly elliptic, obtuse, obscurely II-ncrved; sccond and third series similar; fourth scries similar but broader in proportion at middlc and base, and more rounded at apcx; fifth serics becoming acute at apex.-Stamens 136 to 188 , yellowish-white, with dirty yellow anthers, unappendaged. The lowest series of 8 have broad filaments with a fleshy midrib and parallel anther cells; filaments of second series about one-third as wide as the first, the inner ones becoming more slender and placed without visible order; innermost filaments narrower than their anthers.-Carpels 25 to 35, styles clavatc, about $1.3 \mathrm{~cm}$. long, the cnlarged tip $0.5 \mathrm{~cm}$. long by nearly $0.3 \mathrm{~cm}$. in diameter, purc red around the end, the extreme tip whitish; they stand alternately in two positions-one is bent directly inward so that the tip touches the stigmatic disc two-thirds of the way to its center; the onc on either sidc of this is coiled spirally so that the apex lies beside and against its base, there being but one turn of the coil. Stigmatic disc curved, scarcely depressed at center; papillose area continued $0.3 \mathrm{~cm}$. out on the styles, where it ends obtusely. The stigmatic papillæ break up at the flowering time into a moist powdery mass of cells lying singly or in chains, of a golden yellow color. Axile process $0.25 \mathrm{~cm}$. high by $0.08 \mathrm{~cm}$. in diameter, appearing as a slender acute rod projecting half of its length from a narrow pit at the center of the flower.-Ovary spheroidal, I.6 to $2.4 \mathrm{~cm}$. in diameter, I.I 2 to $I .42 \mathrm{~cm}$. high. Ovules very numerous, very small.-Fruit sub-spherical, with sepals and outer petals standing loosely round it, about $3.9 \mathrm{~cm}$. in diameter.-Seeds very small and very numerous, $0.1 \mathrm{~cm}$. long by $0.074 \mathrm{~cm}$. in diameter, reddish-brown in color, with a silvery appearance due to many scattered long white hairs; raphe scarcely evident.

Germination takes place as soon as seeds are shed. First leaf filiform, short ( $0.95 \mathrm{~cm}$. long). Second leaf spatulate, rounded at apex, tapering at base, $0.8 \mathrm{~cm}$. long by $0.32 \mathrm{~cm}$. wide. Third leaf elliptic ovate.

Leaf of mature plant orbicular-ovate, breadth: length $=I: I .2$ to $I .18(I 7.2 \mathrm{~cm}$. by $14.3 \mathrm{~cm}$ ), rounded at apex, peltatc by about $0.3 \mathrm{~cm}$., thin and soft in texture; margin entire, somewhat wavy up and down; upper surface green, yellowish toward the center, with faint brownish spots. Under surface glabrous, brownish-red, with numerous small spots of a blackish color. Veins all prominent, 7 to 9 on each side. Length of principal area: radius of leaf $=\mathrm{I}: \mathrm{I} .4$ to $\mathrm{I} .47(2.4 \mathrm{~cm} .: 3.5 \mathrm{~cm}$. $)$. Sinus open or closed, depth: length of leaf $=\mathrm{I}: 2.3$ to $2.6(7 \mathrm{~cm} .: 17.2 \mathrm{~cm}$.$) , margins ap-$ proaching or overlapping, nearly straight above, becoming strongly curved outward toward periphery, forming two broad, round, more or less widely separated lobes.Astomatic area small; stomata becoming larger and scattered near it, but stopping rather suddenly.-Petiole glabrous, exccpt a ring of long simple hairs at its junction with the lcaf; 45 to $60 \mathrm{~cm}$. long, $0.9 \mathrm{~cm}$. in diameter; with two transversely placed 
main air-canals, two smaller ones anteriorly and posteriorly, and two still smaller ones beyond these; one lateral canal on either side of main pair, and numerous smaller ones about; main partitions 2 cells thick; one double bundle anteriorly and one posteriorly and two equidistant from these and from each other on either side; numerous smaller bundles. Idioblasts numerous, all stellate, rather short armed.

Rhizome (tuber) erect or semi-erect, thick, about $7 \mathrm{~cm}$. long by $3.8 \mathrm{~cm}$. in diameter, brownish-black, apex protected by leaf-bases and long hairs. Phyllotaxy of a high order, the leaf-bases being very close together. Branches several ( 3 to 5 or $6), 7 \mathrm{~b}$ Io $\mathrm{cm}$. long on short stolon-like stalks, produced throughout the season of vegetation, and sending up leaves and flowers among those of the parent plant.

Geographic Distribution.-In still water; lakes, ponds and ditches. Tropical America between $18^{\circ}$ N., $23^{\circ}$ S., $38^{\circ} \mathrm{W}$., and $78^{\circ} \mathrm{W}$., in Jamaica, Guiana, Surinam, Brazil (Para, Bahia, Rio Janeiro). New Granada. Laguna del Corcho, near Ocuiltzapotlan, Mexico.

Measurements of Stamens (in Centimeters).

\begin{tabular}{|c|c|c|c|c|c|c|c|c|c|}
\hline \multicolumn{4}{|c|}{ FLowhr 1.} & \multicolumn{4}{|c|}{ FLower 2.} & \multicolumn{2}{|c|}{ FLower 3.} \\
\hline Length. & $\begin{array}{l}\text { Width of } \\
\text { Fllament. }\end{array}$ & $\begin{array}{l}\text { Length of } \\
\text { Anther. }\end{array}$ & $\begin{array}{l}\text { Width of } \\
\text { Anther. }\end{array}$ & Length. & $\begin{array}{l}\text { Width of } \\
\text { Filament. }\end{array}$ & $\begin{array}{l}\text { Length of } \\
\text { Anther. }\end{array}$ & $\begin{array}{l}\text { Width of } \\
\text { Anther. }\end{array}$ & Length. & $\begin{array}{l}\text { Width of } \\
\text { Fliamont. }\end{array}$ \\
\hline o 3.75 & 0.95 & I.I & 0.3 & st 3.7 & 1.4 & 0.47 & $\ldots$ & 04.0 & I. 12 \\
\hline 03.5 & 0.7 & I.I & 0.24 & st 3.2 & I.I & 0.64 & ... & 04.0 & 0.8 \\
\hline 3.2 & 0.32 & I.3 & 0.16 & st 3.35 & I.I & 0.64 & ... & ${ }^{2} 3.5$ & 0.48 \\
\hline 2.9 & 0.3 & I.I & 0.16 & 3.0 & 0.56 & 0.9 & 0.24 & $\ldots$ & $\ldots$ \\
\hline 2.8 & 0.16 & I.I & 0.16 & 2.6 & 0.24 & 1.0 & 0.16 & $\ldots$ & ... \\
\hline 1.4 & 0.08 & 0.85 & 0.15 & 2.5 & 0.16 & I.12 & 0.16 & $\ldots$ & $\ldots$ \\
\hline ... & $\ldots$ & ... & ... & 2.23 & 0.08 & 0.95 & 0.15 & $\ldots$ & ... \\
\hline ... & ... & ... & ... & I. 75 & 0.08 & 0.8 & 0. I I & $\ldots$ & ... \\
\hline ... & .... & $\ldots$ & $\cdots$ & I. 42 & 0.08 & 0.64 & 0. I I & $\ldots$ & $\ldots$ \\
\hline
\end{tabular}

$0=$ outer whorl. $s t=$ staminode. $2=$ second whorl.

Number of Floral. Organs.

\begin{tabular}{|c|c|c|c|c|c|c|c|c|c|}
\hline Organ8. & I. & II. & III. & IV. & V. & VI. & VII. & VIII. & Average \\
\hline $\begin{array}{l}\text { Sepals....... } \\
\text { Petals. ..... } \\
\text { Stamens.... } \\
\text { Carpels..... }\end{array}$ & $\begin{array}{r}4 \\
20 \\
172 \\
30\end{array}$ & $\begin{array}{r}4 \\
16 \\
162 \\
30\end{array}$ & $\begin{array}{r}4 \\
16 \\
165 \\
30\end{array}$ & $\begin{array}{r}4 \\
20 \\
178 \\
33\end{array}$ & $\begin{array}{r}4 \\
20 \\
163 \\
32\end{array}$ & $\begin{array}{r}4 \\
16 \\
\ldots \ldots \\
\ldots .\end{array}$ & $\begin{array}{r}4 \\
20 \\
188 \\
35\end{array}$ & $\begin{array}{r}4 \\
17 \\
139 \\
25\end{array}$ & $\begin{array}{c}4 \\
18+ \\
168 \\
30+\end{array}$ \\
\hline Total...... & 226 & 212 & 215 & 235 & 219 & $\ldots$ & 247 & 185 & $219+$ \\
\hline
\end{tabular}

Measurements of Sepals (in centimeters).

\begin{tabular}{|c|c|c|c|c|c|c|}
\hline \multirow{2}{*}{ Sepal. } & \multicolumn{2}{|c|}{ Flower 1.} & \multicolumn{2}{|c|}{ FLow IER 2.} & \multicolumn{2}{|c|}{ Flower 3.} \\
\hline & Length. & Bread th. & Length. & Breadth. & Length. & Breadth \\
\hline $\begin{array}{l}\text { Outermost ...... } \\
\text { Right............ } \\
\text { Left............ } \\
\text { Innermost...... }\end{array}$ & $\begin{array}{l}7 \cdot 3 \\
7 \cdot 5 \\
7 \cdot 3 \\
7 \cdot 3\end{array}$ & $\begin{array}{l}2.9 \\
2.9 \\
2.8 \\
3.0\end{array}$ & $\begin{array}{l}7.0 \\
7.0 \\
7.0 \\
7.0\end{array}$ & $\begin{array}{l}2.7 \\
2.6 \\
2.55 \\
2.7\end{array}$ & $\begin{array}{l}5.6 \\
5.6 \\
5.6 \\
5.7\end{array}$ & $\begin{array}{l}2 \\
2 \\
2 \\
2.4\end{array}$ \\
\hline
\end{tabular}


Measurements of Petals (in centimeters).

\begin{tabular}{|c|c|c|c|c|c|c|}
\hline \multirow{2}{*}{ Series. } & \multicolumn{2}{|c|}{ FLowen 1.} & \multicolumn{2}{|c|}{ FLowER 2.} & \multicolumn{2}{|c|}{ FLOWLR 3.} \\
\hline & Length. & Width. & Lengtb. & Width. & Length. & Width. \\
\hline \multirow{4}{*}{ Outermost............. } & 6 & 2.4 & 6.5 & 02.7 & 5 & 2 \\
\hline & $\ldots$ & $\ldots$ & 6.4 & $r 2.7$ & 4.95 & 2 \\
\hline & $\ldots$ & $\ldots$ & 6.5 & $l 2.7$ & $\ldots$ & ... \\
\hline & $\ldots$ & $\ldots$ & 6.4 & $i 2.7$ & $\ldots$ & $\ldots$ \\
\hline \multirow{2}{*}{ Second................ } & 5.8 & 2.4 & 6.2 & 2.7 & $0.4 \cdot 5$ & I.9 \\
\hline & 6 & 2.7 & $\cdots$ & $\ldots$ & $i 4.5$ & 1.9 \\
\hline \multirow{4}{*}{ Third.................. } & $5 \cdot 3$ & 2.2 & ... & $\ldots$ & $0.4 \cdot 3$ & 1.9 \\
\hline & 5.1 & 2.1 & $\ldots$ & $\ldots$ & $i 4.15$ & 1.75 \\
\hline & $5 \cdot 3$ & 2.2 & $\cdots$ & $\cdots$ & $\ldots$ & $\ldots$ \\
\hline & 5.2 & 2.1 & $\cdots$ & $\cdots$ & $\cdots$ & $\cdots \cdots$ \\
\hline \multirow{4}{*}{ Fourth. } & 495 & 2.4 & $\cdots$ & $\cdots$ & 0.4 .0 & I .9 \\
\hline & $4 \cdot 95$ & 2.1 & $\ldots$ & $\ldots$ & $i 3.7$ & 1.4 \\
\hline & 4.8 & 2.2 & $\cdots$ & $\cdots$ & $\ldots$ & $\cdots$ \\
\hline & $4 \cdot 7$ & 1.9 & $\cdots$ & $\cdots$ & $\cdots$ & $\cdots$ \\
\hline \multirow{4}{*}{ Fifth . } & $4 \cdot 3$ & I. 6 & $\cdots$ & $\ldots$ & 03.5 & 1.4 \\
\hline & 4.6 & 1.9 & $\ldots$ & $\ldots$ & $\ldots$ & $\cdots$ \\
\hline & $4 \cdot 5$ & $\begin{array}{r}1.9 \\
-\quad 1.6\end{array}$ & $\cdots$ & $\cdots$ & $\cdots$ & $\cdots$ \\
\hline & $4 \cdot 3$ & 1.0 & $\ldots$ & $\cdots$ & $\cdots$ & $\cdots$ \\
\hline
\end{tabular}

$o=$ outermost. $r=$ right. $l=$ left. $l=$ lnnermost.

NoTes.-A very interesting species. The tubers may be dried off, but keep better in continuous vegetation, which may be arrested by small pots during the winter. In its native haunts it probably flowers all the year.

The outermost staminodes sometimes have two apices, and resemble a fusion of two such organs. The inner stamens also may be found with two or three anthers, either on the same or on separate connectives.

Var. goudotiana (Planchon) Caspary.

Peduncle bearing a ring of long hairs at top.

Nymphaea Goudotiana, Planchon $1853 a$ and $b$, fid. original specimen in bb. Paris. N. amazonum forma a Goudotiana, Caspary 1878 .

Geograpinic Distribution.-New Granada (Llanos D'Ilbog), coll. Holton, No. 689 in hb. Boissier. Province of Piauhy, Brazil.

NoteS.-Sagot (I88I) records a "forma submersa," with submerged leaves, but without further description, from a specimen coll. Karouany, 1855, No. 25 of hb. Sagot, in French Guiana; now in hb. Kew.

\section{Nymphaea rudgeana, G. F. W. Meyer. (Plate XX.)}

Number of floral parts 80 to I27. Sepals ovate-oblong. Petals of the third whorl separated from the lower ones by a wide interval. Stamens 43 to 83 . Pollen 0.0324 to $0.0362 \mathrm{~mm}$. in diameter. Carpels II to 24. Fruit bearing the deeply funnel-shaped stigma, surrounded by the sepals, petals and stamens, all of which are per- 


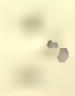

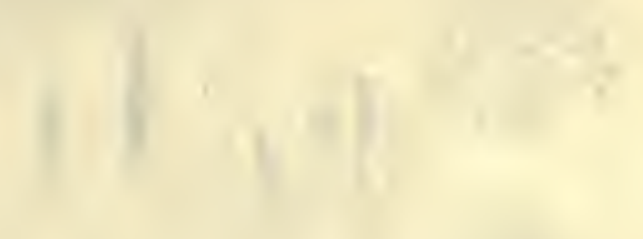
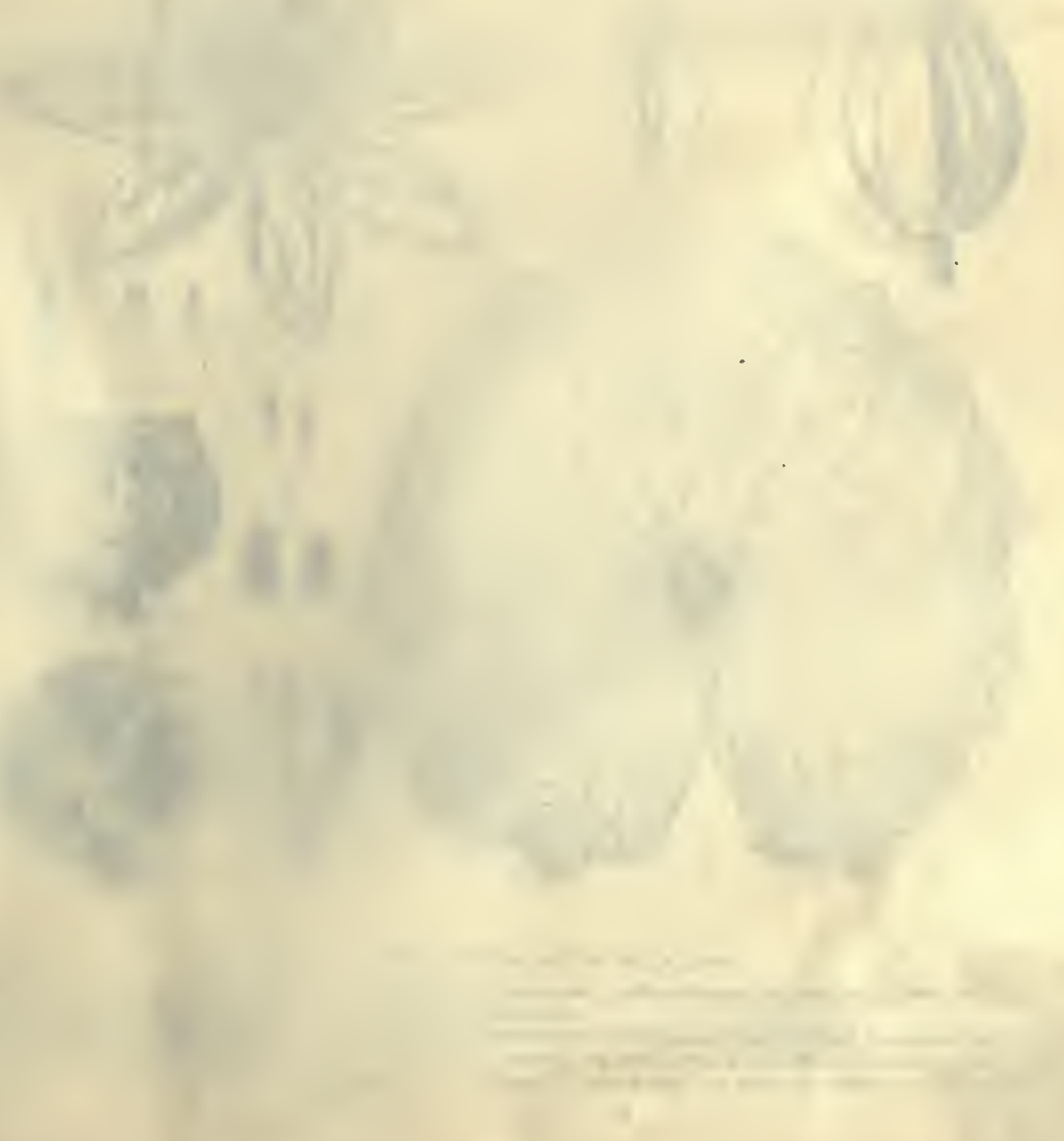

CARNEGIE INSTITUTION OF WASHINGTON

WATERLILIES, PLATE 22

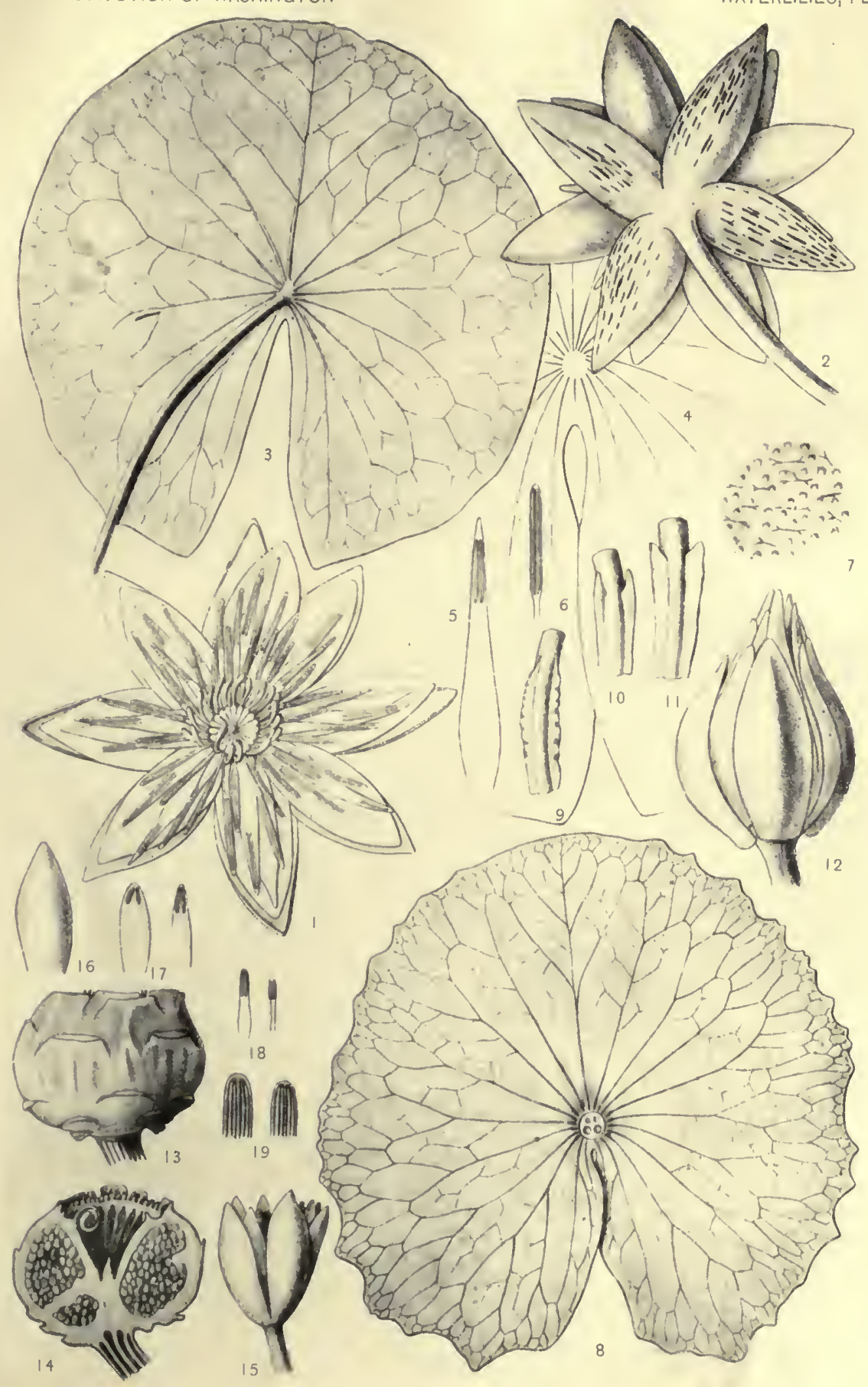

NYMPHAE LASIOPHYLLA AND N, RUDGEANA

V. laslopinylla. 3, 2, Flower from face and back. 3. Leaf, showing lower side. 4, Mart of larger leaf from above, Inhes touching. 5, 6, Outermest and innermost atamens. 7, Part of lower surface of leaf.

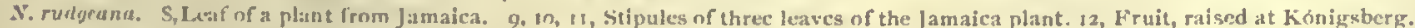

13. Another fruit raised at Konigxberk with sepals and petals removed. 14. Königsberg fruit in median section. 15, Sinall flower, island of Colares. 16, Sepsil of a flower from Brazil. 17, 18, Stamens of same flower. 19, Apices of median and inuermost stamens. 

sistent. Seeds $\mathrm{I}, 000$ to 8,000 , short-elliptic, $1.15 \mathrm{~mm}$. in diameter by $1.6 \mathrm{~mm}$. long, to $1.3 \mathrm{~mm}$. by $2.2 \mathrm{~mm}$., shining, greenish-gray. Mature leaf sinuate-dentate. Petiole naked at point of insertion. Tuber producing stolons only when first germinating from the dry state. Flowers imperfectly open two or three nights, rarely entirely open before midnight. Buds ovate-oblong.

Nymphaea Rudgeana, G. F. W. Meyer 1818. Grisebach 1864. Caspary 1878. Garden $1883 b$. Conard rgor $a$.

N. ampla $\beta$ rudgeana, Planchon $1853 b$. Not N. ampla, DeCandolle $1821 b$.

$N$. blanda, Planchon $1853 b$; 1856 . Caspary MS. in several herbaria, written about 1865 and before. Not Meyer 1818 .

N. blanda $\beta$ amazonum, Planchon 1856 .

N. amazonum, Hort. Glasnevin; Planchon 1856. Not Mart. \& Zucc. 1832.

$N$. tropaeolifolia, Lehmann $1853 a$.

$N$. sinuata, Salzm. MS. as to the leaf, fid. specimens coll. Salzmann, No. 38I, Bahia, in hbb. Kew, Berlin, Paris, Delessert. Flower is of N. ampla.

N. lotus Lunan, Hort. Jam. 2: 271, 1814 (fid. Caspary, 1. c.). Not Linnaeus 1753

$N$. Candolleana, Lehmann $1853 a$, as to the flower, fid. original specimen from hb. Lehmann in hb. Berlin; the lcaf is of $N$. ampla.

N. Planchonii, Caspary MS. as to the leaf, fid. specimen in hb. Bcrlin; flower is of $N$. mexicana, q. v.

DesCription.-Flower 65 to $155 \mathrm{~mm}$. in diameter, open imperfectly on two or three nights from twilight until dawn, or usually closing at 2 or 3 o'clock a. m., or even by II p. m.; sometimes a passage is opened directly into the stigmatic basin, but often the inner petals remain closed over the stamens and do not open at all.-Buds oblong, obovate, not acuminate.-Sepals 4, subcoriaceous, short-oblong, ovate, acute or obtuse, sub-cucullate, obtusely sub-carinate on the back, nerveless; outside yellowish at base, stiffused with red, pale brownish-green above; without spots, or rarely with dull purple lines; inside pale greenish-yellow with 7 to 8 veins.-Petals 12 to 32 , usually 16 or 20, greenish-yellow. Outer petals oblong, elliptic, rather obtuse, 9-veined; petals of second whorl uncinate-cucullate at apex; petals of third whorl attached to the receptacle $3 \mathrm{~mm}$. above the second, close to the inner petals and stamens, shortly ovatelanceolate, attenuate above; inner petals gradually narrower and more attenuate above. - Stamens 43 to 83 , inserted at the summit of the receptacle; outer four petaloid, grading inward to those with linear filaments narrower than their anthers; all of the stamens are pale yellowish. Pollen smooth, with equatorial and parallel circles.Carpels in to 24. Styles spirally coiled inward, shorter and more slender ones alternating with longer and stouter ones, suggesting two alternating whorls. Stigma funnel-shaped, orange yellow. Axile process ovate-cylindric, obtuse.-Fruit depressed globose, truncate, covered by the persistent sepals, petals and outer stamens; stigma deeply funnel-shaped.-Seed with II to 2 I meridians of hairs; raphe prominent.Peduncles terete.

First leaf of germinating plant filiform, followed by 8 to 12 submerged leaves. Second leaf oblong, elliptic or ovate, with one primary vein on each side; petiole winged below; roots two. Fourth or fifth leaf usually sub-cordate; other submerged leaves cordate, with 3 to 4 primary veins on each side. Early floating leaves elliptic to short-oblong, fissi-cordate; lobes obtusely acuminate; margin irregularly sinuate- 
dentate with unequal, distant teeth; primary veins 4 ; under side dull greenisl, suffused with red-brown at apex; upper surface bright green with a narrow red bordcr; marked above and beneath with radiating blue-black spots.-Mature leaf of adult plant $40 \mathrm{~cm}$. long, clliptic to orbicular, fissi-cordate, more or less coriaceous; margins coarsely and uncqually sinuatc-dentate, with obtuse tecth becoming obsolete at apcx of leaf; lobes touching or distant; margins of sinus irrcgularly sinuate-dentate. Primary veins 7 to $\mathrm{II}$; length of principal area: length of radius $=\mathrm{I}: \mathrm{I} .07$ to $\mathrm{I} .5$. Upper surfacc dull greenish, more or less suffused with red-brown, especially toward the margin; both surfaccs marked with a greater or less number of blackish spots.-Petiole terctc, without ring of hairs at top; main air-canals 4 , the two upper ones larger.-Roots 6 to 7 from each leaf-base.

The caudex in the native country vegetates throughout the year and becomes very long and sub-fusiform. Young plants cultivated in ccntral Europe cease growing in wintcr, forming ellipsoid tubers of the size of a hen's egg or larger.-Stolons from tuber cylindric, with I to 4 triangular scale-leaves at base; later leaves as in seedling plant.

Geographic Distribution.-In still and slow-flowing waters; tropical America between $18^{\circ} \mathrm{N}$. and $22^{\circ} \mathrm{S} ., 38^{\circ} \mathrm{W}$. and $78^{\circ} \mathrm{W}$. Jamaica; Martinique; Guiana; Surinam; Brazil (Caspary, 1. c.). Porto Rico (Espinosa 188I). Type collected by Dr. Rodschied in the Essequibo River, British Guiana, in herb. Grisebach (not seen).

Examples.-Coll. Mosén, No. 3339, Prov. S. Paulo, Brazil; coll. Jenman, coast lands of British Guiana, Nov., 1889, No. 5748; coll. Poeppig, No. 2930 and 3033; coll. Burchell, No. 5556. Most of these are marked "N. blanda" in hbb. Kew, British Museum, Delessert, \&c.

Notes. - The above description is taken from Caspary's account in Flora Brasiliensis. He had the plant under cultivation, introduced by Dr. Moore from Spanish Town, Jamaica, in 1854 . We have only seen young plants, in the garden of Oakes Ames, North Easton, Mass., R. M. Grey, gardener. One of these specimens was sent to us by the kindness of $\mathrm{Mr}$. Grey, but, the summer being cool, it did not flower.

The seeds of this species are used for food by American natives.

Nymphaea blanda G. F. W. Meyer. (Plate XXI.)

Sepals densely marked with vcry slender crimson-brown lines, oblong-ovate, rather obtuse, sub-acuminate. Styles linear-clavate, about $8 \mathrm{~mm}$. long. Peduncle covered throughout (or just below the flower) with septate hairs (glabrous in the var.). Leaves small, membranaceous, entire, cordate-clcft, suborbicular or orbicular-elliptic, apex very broadly rounded; lobes slightly produced, sub-acuminate and sub-hastate; pale green, very narrowly peltate (scarcely $1 \mathrm{~mm}$.). Petiole villous at top, or here and thcre, or throughout, or (in the var.) glabrous.

Nymphaea blanda, G. F. W. Meyer 1818. Schomburgk 1848. Seeman 1852. Dalton 1853. Caspary 1878. Hemsley 1888. Conard 1901 a.

N. Rudgeana $\beta$ Amazonum, Grisebach 1857. Not N. rudgeana Meyer 1818.

$N$. Fensliana, Lehmann $1853 a$ and $b ; 1854$.

N. glandulifera, Rodschied in Meyer 1818 . 


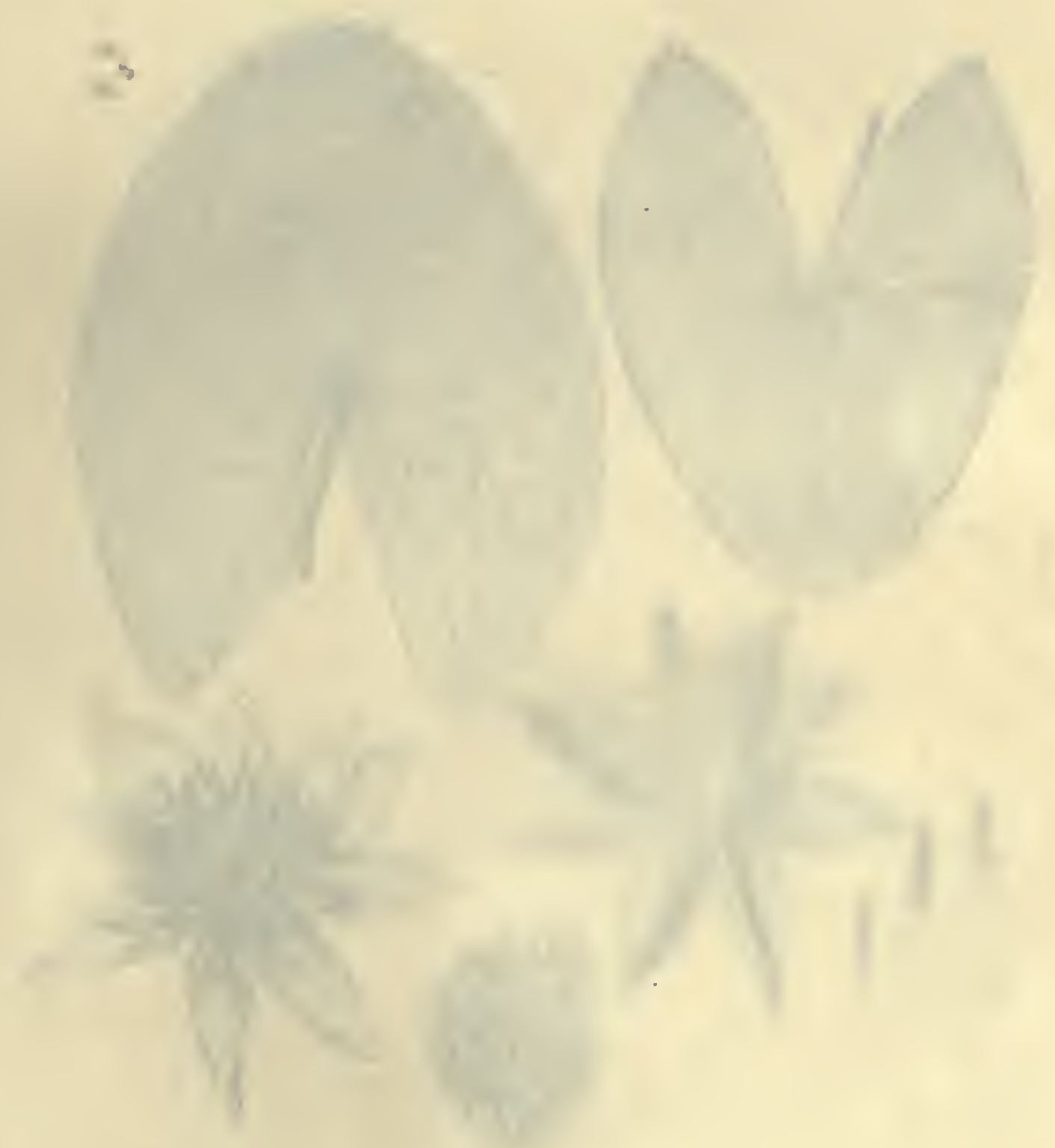





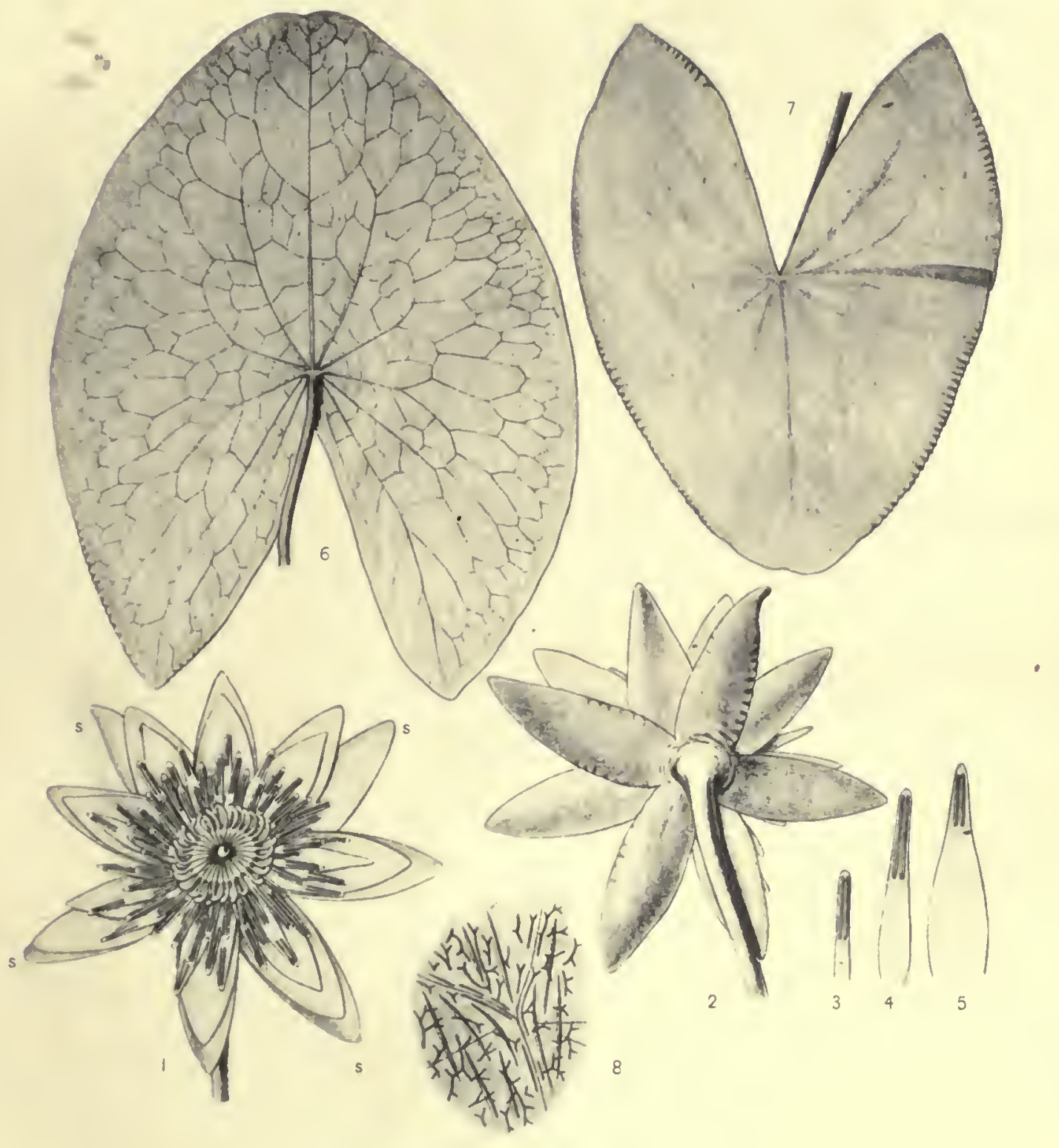



DesCription.-Flower $8 \mathrm{I}$ to $95 \mathrm{~mm}$. across.-Scpals 35 to $44 \mathrm{~mm}$. long by $\mathrm{I} 3$ to $20.5 \mathrm{~mm}$. wide, widest below the middle.-Petals $\mathrm{I} 6$; outer ones $38 \mathrm{~mm}$. long by 15 $\mathrm{mm}$. wide, oblong, ovate; outside sepaloid along the middle, margins and inside yellowish. Inner petals gradually smaller; innermost oblong-lanceolate, acute.Stamens about 65 , outer 4 largest, $25 \mathrm{~mm}$. long, with filaments petaloid, longer than and twice as wide as anthers; inner stamens gradually smaller, the filament becoming short, and narrower than the anther, innermost $14 \mathrm{~mm}$. long; all the stamens are yellowish. Carpels 26; styles 9 to I I $\mathrm{mm}$. long, incurved and purplish-brown at apex. -Peduncle clothed with septate hairs.

Leaf small, entire, membranaceous, elliptic-orbicular, narrowly peltate, green above and below; lobes distant, sub-hastate, sub-acute; margins of sinus gently curved; primary veins 6 on each side.-Petiole clothed with long septate hairs in the upper part or throughout.

Tuber oblong or ovate, small, covered with brownish hairs.

Geographic Distribution.-Mouth of Essequibo River, Guiana, in ponds and streams, collected by Rodschied about 1814. Swamps near city of Panama, coll. Seeman. Guatemala; Jamaica (Hemsley, 1. c.).

Notes.-The description above is taken from Caspary (1. c.), who studied Meyer's type collected by Rodschied in hb. Grisebach, and Parker's collection in hb. Hooker \& Lindley.

Var. fenzliana (Lehmann) Caspary. (Plate XXI.)

Peduncles and petioles glabrous.

N. Fenzliana Lehmann, 1. c.

N. blanda var. Fenzliana Caspary, 1. c., fid. types in hbb. Kew, Berlin.

Description.-Flozver $96 \mathrm{~mm}$. across.-Sepals 40 to $42 \mathrm{~mm}$. long by 12 to 16 mm. wide, oblong, ovate, sub-acuminate, pale green outside, very densely marked with slender red-brown lines 3 to $4 \mathrm{~mm}$. long; inside yellowish.-Petals 16 , pale yellowish; outermost 4 petals 38 to $40 \mathrm{~mm}$. long by I 3 to $15 \mathrm{~mm}$. wide, acute; innermost shorter and narrower, sub-lanceolate.-Outer stamens lanceolate, with anthers $8 \mathrm{~mm}$. long, scarcely appendiculate.-Carpels 23 ; styles about $8 \mathrm{~mm}$. long, I $\mathrm{mm}$. wide at clavate apex.

Leaf floating, coriaceo-membranaceous, entire, sub-orbicular, fissi-cordate, green on both sides; margins of sinus curved; lobes slightly produced, sub-acuminate; primary veins 5 to 6 on each side, not prominent.

Rhizome small, ovate-globose, $20 \mathrm{~mm}$. long. in 1841 .

Geographic Distribution.-Collected in Guatemala near San Juan de Nicaragua

Notes. - Known only from the types in hb. Vienna and hb. Bentham (now Kew), from which Caspary's description was drawn.

Nymphaea lasiophylla Martius \& Zuccarini. (Plate XXII.)

Sepals with a few large black spots, ovate-oblong, sub-acute, sub-acuminate. Styles 6 to $7 \mathrm{~mm}$. long. Leaves large, entire, cordate to orbicular, cleft at base, broadly peltate (i. e., 8 to $16 \mathrm{~mm}$.) ; lobes rather obtuse. Flowers 9.3 to $11.8 \mathrm{~cm}$. in diameter. Petals I6. Stamens above 42. Carpels 15 to 20. 
Nymphaea lasiophylla, Martius \& Zuccarini 1832. Planchon $1852 b$ (name only); $1853 b$ (name and locality only). Caspary 1878.

Description.-Sepals 48 to $50 \mathrm{~mm}$. long by $18 \mathrm{~mm}$. wide.-Petals white, oblong, sub-elliptic; outermost $20 \mathrm{nun}$. wide by $50 \mathrm{~mm}$. long; innermost 4 lanccolate, $8 \mathrm{~mm}$. wide by $42 \mathrm{~mm}$. long; all acute.-Stamens unequal; outcrmost petaloid, lanceolate; middle and inner ones lincar, with anthers wider than the filaments; outermost slightly appendiculate.-Styles 6 to $7 \mathrm{~mm}$. long, I mm. wide at apex; stigina ycllowish; axile process minute.-Leaf coriaceous, sub-orbicular, entire; under side reddish, with brown-purple lines; lobes distant or touching, more or less produced, obtuse; sinus margins curved or nearly straight; primary vcins 7 to II.-Petioles tercte, smooth, rcddisl. (Pubescence of under side of leaf mentioned by Martius \& Zuccarini is a layer of alga. Caspary, 1. c.)

Geographic Distribution.-Collected by Martius, No. 2377, near Joazeiro in Lagodisso, province of Bahia, Brazil ( $9^{\circ} 40^{\circ} \mathrm{S} ., 42^{\circ}$ Io' W.) in March and April. Otherwise unknown. Type seen in hb. Munich.

\section{Nymphaea gardneriana Planchon. (Plate XXIV.)}

Sepals densely marked with long slender fuscous lines, oblong-ovate, distinctly acute, acuminate. Petals 16 to 20 , outermost oblong-ovate, innermost oblong-lanceolate. Stamens 46 to 62, outer filaments petaloid, inner filiform and short. Carpels I5 to $\mathrm{I} 8$; rays of stigma rounded at apex; styles linear-clavate, very long (I2 to I6 $\mathrm{mm}$.), apex I to I.25 mm. in diameter, dark purple; axile process minute. Lcaf floating, $6.5 \mathrm{~cm}$. long, slightly coriaceous or sub-mem branaceous, peltate (pelta 5 to $8 \mathrm{~mm}$. wide), ovate or orbicular-hastate, rarely orbicular, apex rounded or sub-retuse; sinus open, broadly triangular; lobes acute or obtuse; margin entire, often crisped; primary nerves 5 on each side (rarely 4 ); glabrous, irregularly marked above and beneath with dark violet spots.

Nymphaea Gardncriana, Planchon $1852 b$; $1853 a$ and $b$; fid. specimens coll. Gardner, No. 2476, about I840, Paranagua, Brazil. Caspary 1878.

$N$. fragrans, Gardner MS. in hb. Bentham, now Kew.

N. Passifora, Lehmann $1853 a$ and $b$; 1854 ; fid. specimen marked in Lehmann's handwriting in lib. Kew.

Description.-Flower 92 to II $5 \mathrm{~mm}$. across.-Sepals i to $19 \mathrm{~mm}$. wide by 40 to $55 \mathrm{~mm}$. long; outside nerveless, greenish, with long slender fuscous lines.-Petals acute, usually sub-acuminate; innermost oblong-lanccolate; outermost reddish-yellow, innermost reddish-brown (in dried specinens).-Stamens reddish-brown; outermost petaloid, innermost slender.

Leaf small; veins slightly immersed beneath.

Rhizome small, $16 \mathrm{~mm}$. in diameter, sub-globose, covercd with long gray-brown hairs.

Geographic Distribution.-Paranagua, Province Piauhy, Brazil (10 $45^{\prime} \mathrm{S}$., $48^{\circ} 40^{\prime}$ W.) ; Plain of Mbatolio, Paraguay, coll. Balansa, No. $5^{21}$. 


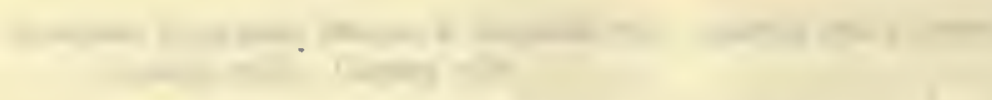

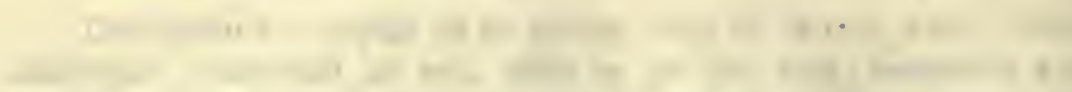

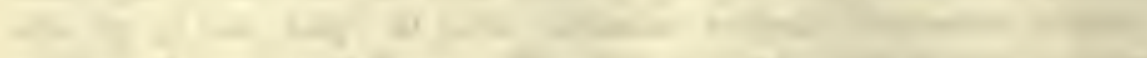

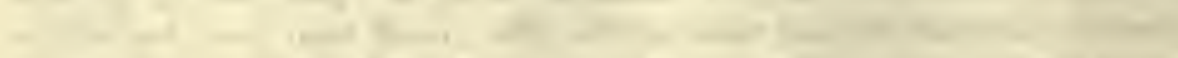

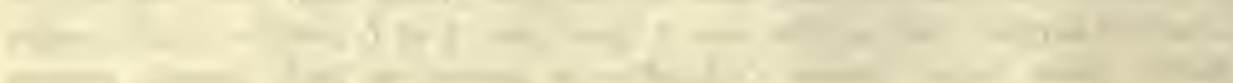

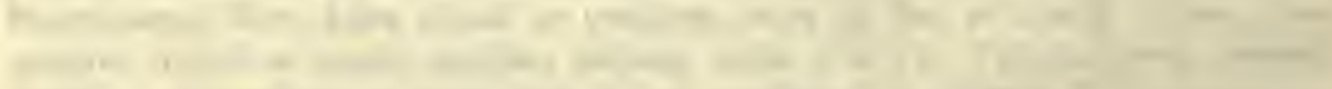

(20)

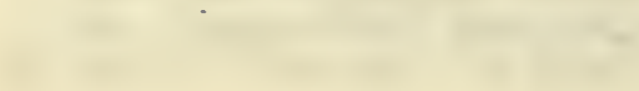

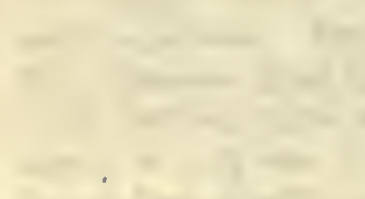

Can

(19)

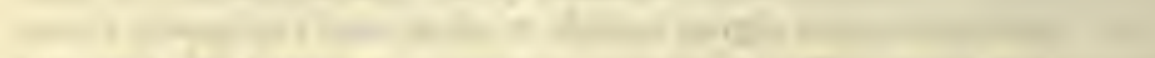

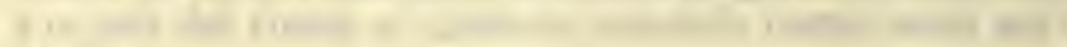

N

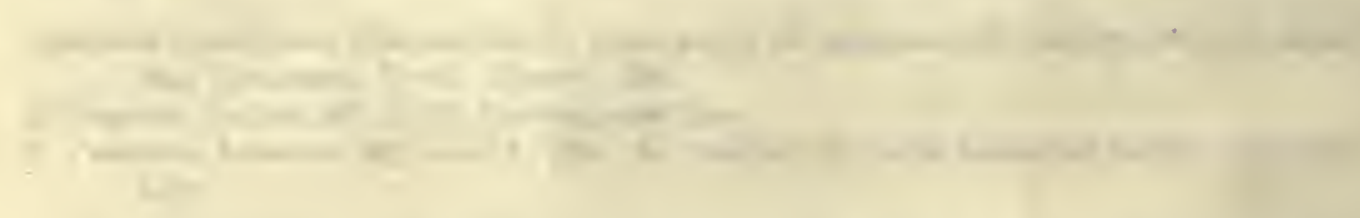

P. $1, \quad 1$ 14: 40

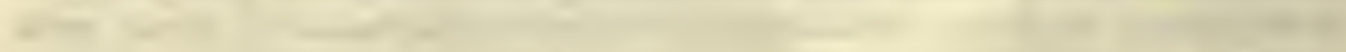

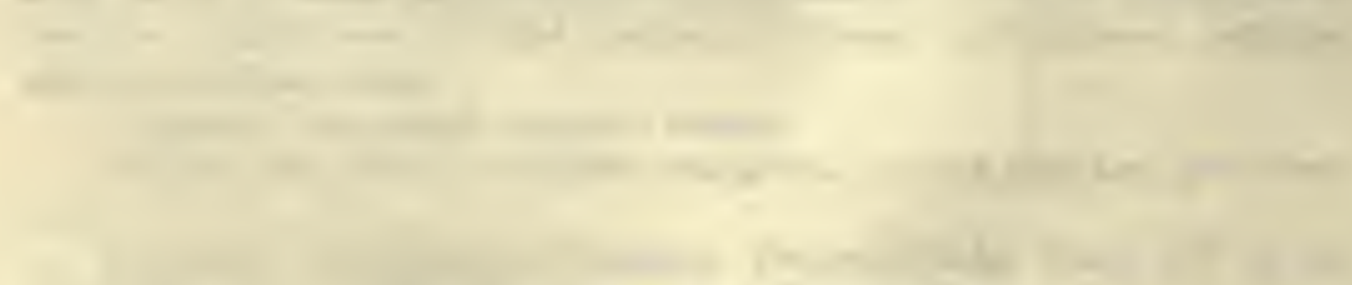

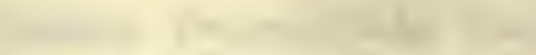




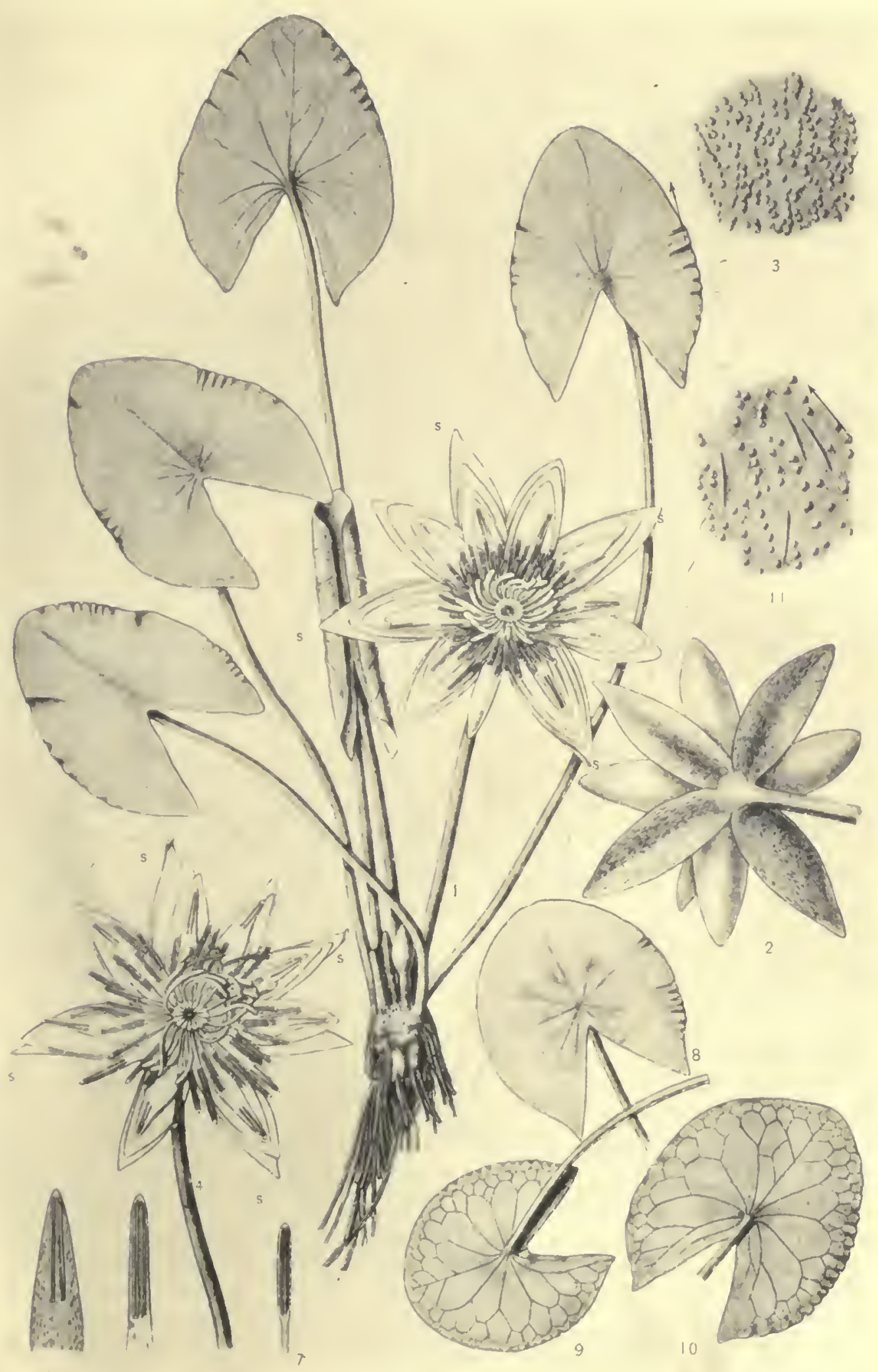



Nymphaea jamesoniana Planchon. (Plate XXIII.)

Flower 87 to $107 \mathrm{~mm}$. in diameter. Sepals green, densely marked from base to apex with long narrow dark crimson lines, 3 to $7 \mathrm{~mm}$. long by 0.1 to $0.05 \mathrm{~mm}$. wide; oblong-ovate, rather obtuse. Petals 16 . Stamens 52 to 65 . Carpels about 30 ; styles 6 to 1o $\mathrm{mm}$. long, clavate, purplish-brown at apex. Leaves sub-coriaceous, ovatecordate, cleft at base, sub-sagittate or elliptic, more or less peltate; margins entire; lobes obtuse or acute; under surface marked with dark purple forked and branching lines.

Nymphaea Jamesoniana, Planchon $1852 b$; $1853 a$ and $b$; fid. original specimen in hb. Delessert. Caspary 1878. Hemsley 1888.

N. sagittariaefolia, Lehmann $1853 a$ and $b ; 1854$; fid. specimen marked in Lehmann's handwriting in $\mathrm{hb}$. Kew.

DESCRIPTION.-Sepals 13 to $21 \mathrm{~mm}$. wide by 40 to $46 \mathrm{~mm}$. long.-Petals $\mathrm{I} 6$, oblong; those of the outer three whorls obtuse, of the inner whorl acute; all brownishyellow (in dried specimens), sub-membranaceous.-Stamens like petals in color and texture; outermost with an acute triangular appendage, innermost obtuse; outermost filaments four times as wide as anthers, innermost filaments and anthers about equal in width.

Leaf thin and membranaceous; lobes approximate or distant; primary veins 6 on each side, very slender, slightly immersed at base, elsewhere level; principal area half as long as radius of leaf.

Geographic Distribution.-Savannah of Guayaquil ( $2^{\circ} \mathrm{II}^{\prime} 25^{\prime \prime} \mathrm{S} ., 80^{\circ} 2^{\prime} 10^{\prime \prime} \mathrm{W}$.) (Caspary 1878). Ecuador (Hemsley I888). Ditches at Hatillo, Añasco, Porto Rico, coll. P. Sintenis, No. 5688 , Dec. 7 , 1886.

Notes.-Fruit, seed, tuber and habits unknown.

\section{Nymphaea stenaspidota Caspary. (Plates XXI, XXIV.)}

Sepals densely marked with long slender fuscous strix, oblong-ovate, somewhat acute, never acuminate. Petals 20 to 24 , short-oblong, obtuse. Stamens 60 to 67 , resembling those of $N$. gardneriana, but with narrower anthers. Carpels 18 , clavate, 4 to $5 \mathrm{~mm}$. long. Leaves ovate-triangular, sagittate, small, rounded at apex, entire, scarcely peltate ( $1 \mathrm{~mm}$. ) ; sinus margins straight.

Nymphaea stenaspidota, Caspary 1878, fid. specimens coll. Gardner, No. 2476, and 3568, in hbb. Berlin, Kew, British Museum.

DESCRIPTION.-Flower 91 to $100 \mathrm{~mm}$. in diameter.-Sepals 18 to $19 \mathrm{~mm}$. wide by $46 \mathrm{~mm}$. long.-Inner petals bearing abortive anthers, very short, elongate-ovate or lanceolate.-Stamens like those of $N$. gardneriana, but narrower; outermost anthers I.5 $\mathrm{mm}$., innermost $1 \mathrm{~mm}$. wide.

Lobes of leaf acute, produced; sinus large, triangular; otherwise as in $N$. gardneriana.

Tuber ovate or sub-globose, small, $15 \mathrm{~mm}$. in diameter, covered above with very long brownish hairs.

Geographic Distribution. - In a small lake at Conceiçao, province Goyaz, Brazil $\left(12^{\circ} 15^{\prime} \mathrm{S} ., 57^{\circ} \mathrm{W}\right.$.), collected by Gardner in 1841 . 


\section{Nymphaea tenerinervia Caspary. (Plate XXI.)}

Sepals with a few scattered linear black marks, ovate-oblong, shortly acuminate, sub-acute. Petals 16 (?), sub-membranaceous, outer ones oblong, innermost sub-lanceolate, acute. Stamens about 40 , three-fourths as long as the petals; outer filaments petaloid, median filaments about as wide as the anthers, innermost filaments very short and slender. Carpels numerous; styles short ( $5 \mathrm{~mm}$. long), clavate, $1 \mathrm{~mm}$. in diameter above, incurved. Leaves ovate-cordate, entire, sub-acute, narrowly peltate, slightly coriaceous; lower surface usually with small, black, oblong, radially placed spots; lobes distant, obtuse, inner margin convex. Top of peduncle and petiole, and thence downward on petiole, clothed with slender multiseptate hairs.

Nymphaea tenerinervia, Caspary 1878 , plate 36 , and MS. in hbb. Munich, Berlin, etc.

$N$. tenuinervia, Caspary, l. c. in text.

$N$. pulchella, Lelımar.n MS. in hb. Königsberg. Not DeCandolle $1821 b$.

N. Maximiliani, Lehmann $1853 a$, as to the leaf; flower is of $N$. odorata gigantea, q. v.

DESCRIPTION.-Flower 86 to $89 \mathrm{~mm}$. in diameter, or larger.-Sepals 15 to 20 $\mathrm{mm}$. wide by $4 \mathrm{I}$ to $5 \mathrm{I} \mathrm{mm}$. long, subcoriaceous, sub-translucent, shining. Innermost filaments narrower than the anthers.-Veins of leaf immersed beneath, the midrib alone prominent; lobes slightly produced.

Geographic Distribution.-On St. Francisco River, province of Bahia, Brazil $\left(40^{\circ} \mathrm{W} ., 9^{\circ} 50^{\prime} \mathrm{S}.\right)$, near Joazeiro, collected by Martius, April, 1819.

\section{Nymphaea oxypetala Planchon. (Plate XXV.)}

Sepals without striæ, lanceolate, oblong below, long caudate-acuminate, apex twisted or hooked. Petals 20 to 30 , shorter than the sepals, lanceolate, acuminate, very acute. Stamens 84 to 106 or more, outermost lanceolate with filaments 4 times wider than anthers, inner ones linear, innermost with filament about as wide as anther. Carpels 20 to 28 , styles very long, linear-clavate, 24 to $26 \mathrm{~mm}$. long. Submerged leaves alone known; thin, membranaceous, sub-lunate-reniform, sub-hastate or obovate, cleft at base, not peltate; lobes very long; margin subrepand, slightly crisped; primary nerves 3 to 7 on each side; petiole slender.

Nymphaea oxypetala, Planchon $1852 b ; 1853 a$ and $b$. Caspary 1878 . $N$. Raja, Lehmann $1853 a$ and $b ; 1854$ (name only).

Description.-Flower 123 to $160 \mathrm{~mm}$. across. Peduncle slender.-Sepals il to I7 $\mathrm{mm}$. wide by $6 \mathrm{I}$ to $74 \mathrm{~mm}$. long.-Outer stamens short-appendiculate ( $1.5 \mathrm{~mm}$.), acute; inner ones obtuse; all the anthers longer than the filaments.

Geographic Distribution.-Guayaquil, Ecuador ( $2^{\circ} 11^{\prime} 25^{\prime \prime}$ S., $79^{\circ} 59^{\prime} 10^{\prime \prime}$ W.), coll. Jameson, March, 1845, No. 334. Types seen in hbb. Delessert, Boissier, British Museum, Berlin.

\section{Nymphaea gibertii (Morong), new comb.}

Leaves oval, entire, rounded at apex; lobes moderately spreading, obtuse; under surface covered with short branching fuscous lines. Flower white, inodorous, 6 to 7 $\mathrm{cm}$. in diameter. Sepals oblong-ovate, 3 to $3^{\mathrm{T} / 2} \mathrm{~cm}$. long, somewhat acute, with numcrous fuscous lines on outer surface. Petals in 3 series [12], a little shorter than the 
4 


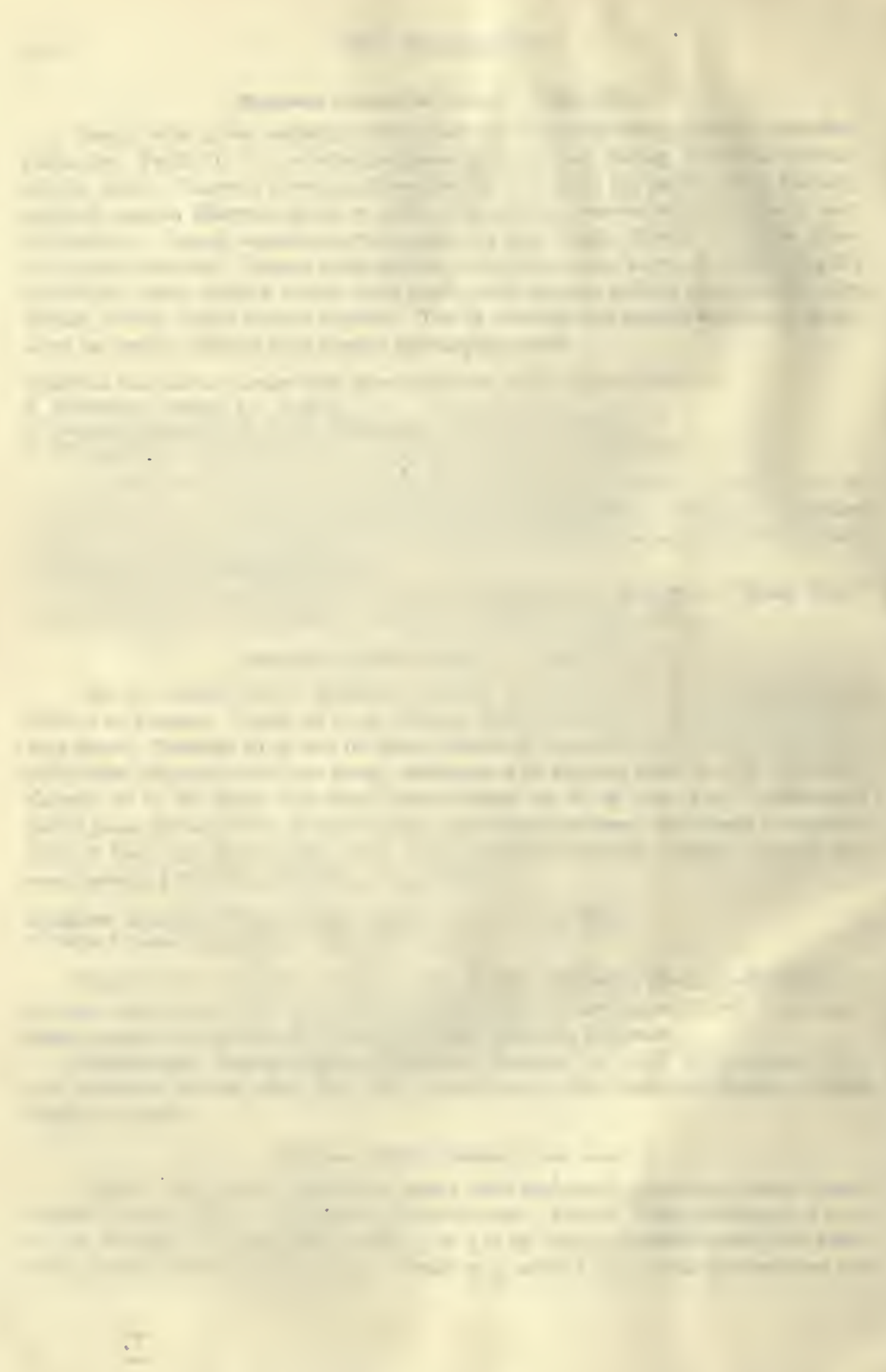


CARNEGIE INSTITUTION OF WASHINGTON

WATERLILIES, PLATE 25

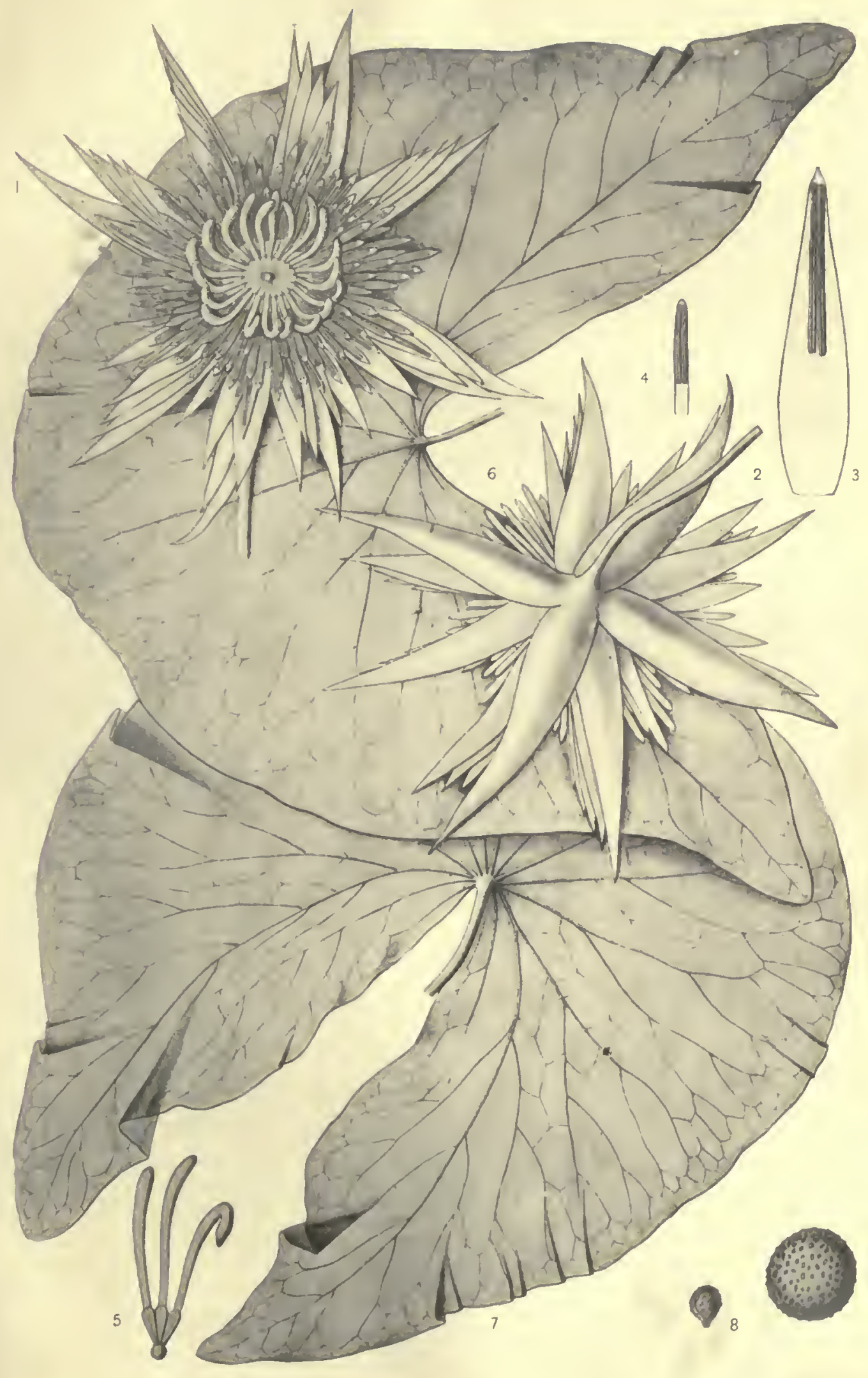

NYMPHEA OXYPETALA.

1. 2, Filower. 3. A, Outermost and innermost stumens. 5, Three carpellary *tyles. 6, 7, Leaties, S, Globme idioblists. 

sepals, marked with faint purplish lines, the outer ones sepaloid on the back, with broad white margins. Stamens in 4 series; outermost with anther cells 6 to $7 \mathrm{~mm}$. long. Carpels about 18.

Castalia Gibertii, Morong 1893, in Morong \& Britton.

Leuconymphaea Gibertii, Morong MS. on co-type in hb. Acad. Nat. Sci. Phila.

Geographic Distribution.-Paraguay, collected on the Pilcomayo River above Asuncion by Gibert in 1858 (in hb. Kew), and by Dr. Thos. Morong $1888-90$, in hbb. New York, etc. Flower, May and June.

NoTES.-The imperfect published description of this species does not give certain evidence as to which section of the genus it belongs in; but from the lines on the sepals, the seriate arrangement of petals and stamens, and the locality in which it was found, we suppose it belongs here.

\section{Names Not Elsewhere ENTEREd.}

Nymphaea albo-rosea, Teijsm., ex Regel., Ind. Sem. Hort. Petrop. (1866) Ior, fid. Index Kewensis. Quid?

N. advena, Soland. $=$ Nuphár.

N. arifolia, Salisb. $=$ Nuphar.

N. Cahlara, Donn, Hort. Cantabr. ed. vii, $159=N$. stellata Willd., fid. Index Kewensis.

N. ceramica, Rump., Amb. 6: 173, pl. $72=$ Menyanthes indica Willd., fid. Roxburgh 1824 .

N. crenata, Amadeo, Bot. \& Veg. Materia Medica of Porto Rico (Ph. J., 3 ser., vol. 18. London 1888, p. 761 ff.). Quid?

N. crcnulata, Raf., in Med. Repos. N. York, 5:354 (1808) name only ; fd. Index Kewensis. Quid? N. exumbonata, Rupr., in Bull. Phys, math. Ac. Petersb. $12: 219$ (1854) $=N$. alba, fid. Index Kew. N. hastata, Michx. $=$ Nuphar.

N. hirta, Kurz ex Teijsm. \& Binn., in Tijds. Nedl. Indie 27:38 (1864); fid. Ind. Kewensis. Quid?

N. Kalmiana, Sims = Nuphar.

$N$. longifolia, Michx. $=$ Nuphar.

$N$. lutea, Linn., Thunb., Walt. $=$ Nuphar spp.

N. macrophylla, Small $=N$ uphar.

N. microphylla, Pers.= Nuphar.

N. minima, Reichb. $=$ Nuphar.

N. nelumbo, Linn. = Nelumbo nucifera, Gacrtn.

$N$. odorata, Willd., Hort. Berol. t. $39=N$. nitida, Sims, fid. Index Kewensis.

$N$. officinalis, Gater., Pl. Montaub. $99=N$. alba, fid. Index Kewensis.

$N$. orbiculata, Harper $=$ Nuphar.

$N$. pentapetala, Walt. $=$ Nelumbo lutea Willd.

N. polysepala, Greene $=N$ uphar.

N. pumila Hoffm. = Nuphar.

N. punctata, Kar. \& Kir., in Bull. Soc. Nat. Mosc. (1841), 376, fid. Index Kewensis. Quid?

N. Reichardiana, Hoffm., Beitr. z. Kenntniss von Central-ostafrika. Inaug. Dissert. Jena, 1889 (not seen). Quid?

N. rubrodisca $=$ Nuphar.

N. rufescens, Willd. ex. Casp., in Journ. Sc. Math. Lisboa n. I6 (1873), reimpr. 8, name only, fid. Index Kewensis. Quid?

N. sagittata, Pers. $=$ Nuphar.

$N$. sagittifolia, Walt. $=$ Nuphar.

N. suaveolens, Dum., in Bull. Soc. Bot. Belg. $3: 7(1864)=N$. alba, fid. Index Kewensis.

N. sumatrana, Miq. F1. Ind. Bat. Suppl. 387, fid. Index Kewensis. Quid

N. umbilicalis, Salisb. = Nuphar.

N. Victoria, Schomb. = Victoria. 



\section{CHAPTER VI.}

\section{DISTRIBUTION.}

On account of their aquatic habits, requiring still water, mostly fresh, and enduring comparatively little sedimentation, the areas in which waterlilies occur are at times scattered. They are found here and there almost all over the world. New Zealand and the Pacific Slope of North Anerica have no representatives of the genus Nymphaea. The Castalia group is wholly restricted to the northern hemisphere, and Brachyceras to the tropics and subtropical regions, but both are found all round the globe. Lotos is mostly tropical, and is restricted to the Eastern Hemisphere, where it ranges from Sierra Leone and Senegambia to the Philippines, while Hydrocallis is native to the tropics of the New World. N. gigantea occurs only in tropical Australia and New Guinea.

Nymphaea is, generally speaking, a genus of the low lands. The Atlantic coastal plain of North America is the home of $N$. odorata, and $N$. flava is found in brackish water in the Little River, Florida. $N . o x y$ petala was collected at Guayaquil, Ecuador. In the West Indies, the Philippines, and Australia they occur along the coastal swamps, and at river mouths. The delta of the Nile is a favorite haunt of $N$. lotus and caerulea. On the other hand, both of these species are reported from central Africa, and similar ones from the interior of India. N. tetragona and alba ascend I 500 meters in Kashmir, and our own $N$. odorata ascends 600 meters in the eastern United States.

The distribution of single species is often very wide, and the variations correspondingly great, insomuch that the limitation of species is, in our present state of knowledge, more than usually arbitrary. Careful studies of plants from many localities under cultivation and hybridization are needed to place this branch of our subject on a better footing. Another uncertain feature is the range of the Hydrocallis species. Their native countries are all so little known botanically that most of them must be left out of account in these generalizations. Outside of the Hydrocallis group, probably the most restricted species is $N$. mexicana, known only from Florida, Texas and Mexico. N. tetragona, on the other hand, 
is, as now constituted, the most widespread species; it extends from Siberia through Kashmir and China to Australia (?), and is known from Granite, Idaho, and Ontario Province, Canada, in North America. N. lotus is also very widespread, but further investigation is needed to determine the relation of the various forms. In $N$. thermalis of the warm springs of Hungary we lave its most northern representative. And its existence here is a problem of extreme interest. The Grosswardein locality was first recorded by Waldstein and Kitaibel (1802). Plants were removed from there by Paul Kitaibel in 1800 and planted in the warm springs of Lucasbad at Budapesth. In the former place the temperature of the water is $33.75^{\circ}$ to $41.25^{\circ} \mathrm{C}$., and the water is quite pure; at the latter station the water is only $26^{\circ} \mathrm{C}$., and is charged with sulphur and other mineral matters. Nevertheless the plant grew equally well in both places, and flowered freely from May to October. The Lucasbad station was, I believe, destroyed by building operations about 1890 (Schilbersky, 1889).

Kitaibel, Boissier, Neilreich, Kerner, Engler, and Simonkai (1 890) considered $N$. thermalis as identical with $N$. lotus of Egypt, but Simkovics ( 1883 ) agrees with DeCandolle in pronouncing it a distinct species. If it could be shown, as some have believed, that the plant was originally introduced here by man, perhaps by the Turks, the question of identity would be settled. But Simonkai considers this theory impossible, since the plant was of no material use; and Staub (189I) agrees that it is almost certainly a relic of a pre-glacial vegetation, when the whole of Europe enjoyed a comparatively warm climate. When the plants of this period were driven back toward the equator by colder conditions, this one remained in the favorable temperature of the thermal springs. Along with it has continued a snail, Melanopsis parreyssi Mühlf., very near of kin to $M$. costata Fér. of Egypt. According to Staub, the genus Melanopsis was common in Europe in the Drift period; and he considers that the warm springs of Grosswardein are older than the Drift. It is also notable that there were in recent geological times throughout Europe waterlilies resembling the Lotos group (Schenck, 1888; Staub, 1. c.) which may have been the ancestors alike of the Egyptian and the Hungarian plants. There are the best of reasons, therefore, for considering $N$. thermalis as truly native in its present habitat. And if we can believe that its specific characters were demarcated as early as the Drift period, and have not changed

\footnotetext{
${ }^{2}$ It must be noted that Staub's paper, as it appears in Engler's Jahrbuch, is full of the most egregious errors concerning the relationships and distribution of living species of Nymphaea; we hope they are misprints!
} 
since, we most follow those botanists who make this name a synonym of $N$. lotus L.

The questions of the place and time of origin of the genus Nymphaea itself are obscure, although several fossils of this and allied genera are known. All of these have been found in Europe. They establish the existence of distinctly Nymphaeaceous types as early as the lower cretaceous. Indeed, at that time the three tribes Nelumboneae, Cabombeae, and Nymphaeinae were already well marked. Saporta (I894 b) records Braseniopsis venulosa (a form very near to Brasenia peltata), two species of Nelumbium and a Nymphaeineous plant from Valle-de-Sobreiros, Portugal. The last-mentioned plant was represented by rhizomes found in a schistose marl. The leaf cushions were distinct and slightly prominent; the petiolar scar showed the traces of many irregularly distributed air-canals; below this were one to four root-scars of irregular size and arrangement. Alternating with the leaf bases are much smaller peduncular scars, with air-canals as above ; these occupy the place of leaves in the phyllotactic spires. We do not know whether this stem was erect or horizontal, but the plant can most readily be considered as a generalized form, from which the tetrasepalous Nymphaeinae, and perhaps Nuphar also, have been derived. Another remarkable fossil from the same beds appears to be a fruit with the stigma and general shape of $N$. alba but wholly superior! If this interpretation be correct, it is a most interesting find.

In the tertiary, the Nymphaeineous stock reached a very high development. The genus Anoectomeria Sap. (1865a,b), of which we may take $A$. brongniartii (Casp.) Sap. as the type, had flowers and fruits resembling those of $N$. alba, but twice as large. It had an outer row of three floral leaves, and within this a second alternating row of three; the rest of the floral leaves were spirally arranged. It was probably apocarpous; at any rate, the fruit broke up readily into elliptic or lunate pieces, though Saporta says these correspond with the bases of the petals. The rhizome was cylindrical and horizontal, and marked with large rhomboidal leaf-cushions. These have the curved scar of a broad stipular plate in front as in Castalia and Victoria. The petiole scar shows two large aircanals and two smaller ones above these. The root scars are arranged as in Eucastalia. The leaf was large $(28$ to $40 \mathrm{~cm}$. long), entire, fissicordate, not peltate. There were 15 to 18 primary veins, which branch and dichotomize to form a very fine network ; they form no primary areas, but run pretty distinctly to the margin of the leaf. Thus we see in the rhizome, stipules, leaf-margin and shape of fruit a marked resemblance to 
Eucastalia, and in air-canals and venation to Lotos, Nelumbo or Victoria ; but the trimerous symmetry has not come down to us in any living form. Anoectomeria brongniartii (Casp.) Sap. (1865a,b) (=Nymphaea Arethusae Brongn., 1822, not of Weber, $1850 ;=N y m p h a c i t e s$ Brongniartii and Arethusae Casp., 1856) flourished in Eocene times, being plentiful in the littoral chalk marls of the Marseilles basin. A. media Sap. (1894 c) occurs in the Aquitanian (Miocene), and A. nana Sap. in the tertiary of Alsace (Mieg, etc., I 890), although Schenk (1888) speaks of the genus as restricted to the Oligocene. Nymphaea polyrhiza Sap. (1865 $a)(=N$. eocenica Sap.,

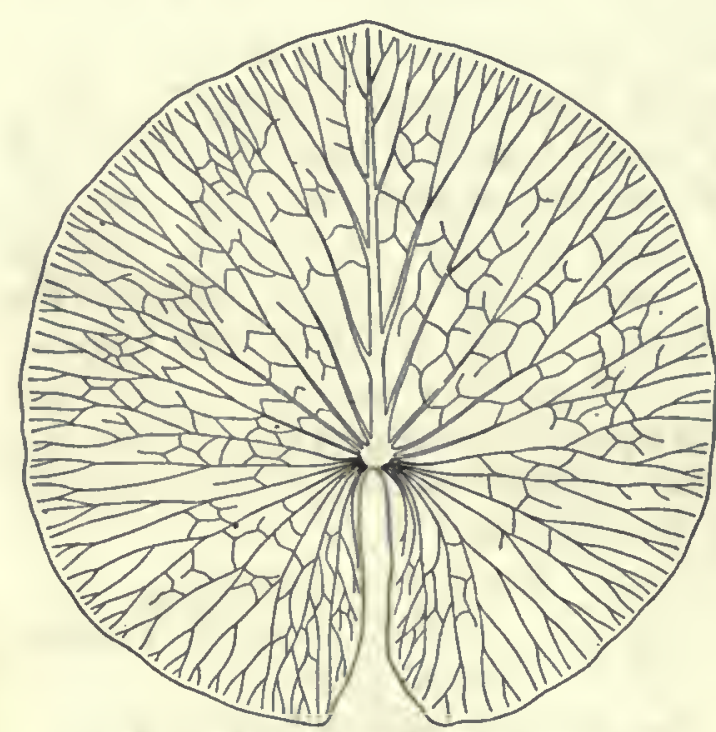

Fra. 76,-Nymphaca dumasli Sap. (after Schenk, 1888). 1861 , in part) from the Aquitanian of St. Jean de Garguier, resembles Anoectomeria in the trimerous flower, and should on that account be removed from the genus Nymphaea; it also has a large number of air-canals in the petiole. In other ways, however, it is near to $N$. gypsorum Sap. (1865a).

On some other species statements are conflicting. $N$. calophylla was at first (Saporta, I86I) said to have denticulate leaves, but in $1894(b)$ the same writer describes the leaves as entire. The venation of this, as of most other tertiary Nymphaeas, was similar to that of Anoectomeria, and very suggestive of the Lotos group; but they had the rhizome and stipules of Eucastalia. Saporta considers that their type has become entirely extinct. In this list are included also $N$. gypsorum Sap., $N$. ameliana Sap., $N$. nalini Sap., $N$. rousseti Sap., and $N$. dumasii Sap. (Fig. 76). $N y m p h a c a$ minuta Sap. is near of kin to $N$. tetragona, and $N$. cordata Sap. to the smaller forms of $N$. alba, while $N$. latior Sap. resembles the large $N$. alba of Greece. Wessel and Weber (1855) compare their $N$. lignitica (= Nymphacites lignitica Casp.) from the lignites of Rott in the lower Rhine region with $N$. alba, with regard to the shape of the leaf. $N$. paroula Sap. and charpentieri Heer (= Nymphacites charpentieri Casp.; I Nelumbium nymphaeoides Ettingsh.) had double flowers like those of N. alba (Saporta, 1879). Nymphaeites microrhizus Sap. is a small form 
with two air-canals in the petiole and one root per leaf; the figure gives it a certain resemblance to $N$. mexicana. Nymphaeites palaeopygmaeus Sap. had also two main air-canals and three to five roots, but Saporta considered it near to Anoectomeria. Nymphaeites weberi Casp. (= Nymphaea Arethusae Weber, 1850 , not of Brongn., 1822 ; = Carpolites granulatus Weber) and Nymphaeites ludwigii Casp. (1856) probably are akin to the Nymphaea calophylla group. Nymphaea dubia Wat. was shown by Bureau (1888) to be really a Nuphar; and of Nymphaea blandusiae Ung., doliolum Ludw., doris Heer, and Nymphaeites saxonica Fried. we have learned nothing but the names.

During the warmer portions of the Tertiary the genus Nymphaea extended far into the arctic zone. $N$. arctica Heer (1869) of Spitzbergen has left quite complete remains. Its rhizome and leaf suggest $N$. alba; there were four main canals in the petiole and a number of evident ones surrounding these. The sepals were elliptic, with slender longitudinal veins. There were about 12 carpels, and the fruit was much enlarged below the narrow ( $6 \mathrm{~mm}$. wide) depressed stigma. It certainly belongs to the Castalia group. Nymphaeites thulensis Heer was found in the same locality, but poorly preserved. In Grinnell Land also Captain Feilden of the English North Polar Expedition found $N$. arctica (Heer, I878 $a, c$ ) and an allied fragment named Nymphaeites tener (Heer, I $878 b$ ).

From such forms and such localities doubtless all of the Castalias of Europe and America are alike derived. The genus Nymphaea probably originated in western Europe and spread over the Arctic continent. Very early, though fossil evidence does not indicate when, the syncarpous and apocarpous groups were separated. Of the latter, $N$. gigantea, from its absence of styles and restricted distribution in the ancient Australian flora, is most primitive. The lowest Brachyceras types are the shortstyled and pale-flowered American forms $N$. elegans and flavo-virens, from which we ascend through $N$. caerulea and stellata to zanzibariensis, the most gorgeously colored, largest-flowered, longest-styled species of the group, and also the farthest removed from the original center of distribution.

Among Syncarpiae, the Castalia group is most primitive, and of these we have already mentioned $N$. mexicana as the lowest, with $N$. tetragona as a close second. In Europe the Lotos section was segregated off from these at a very early date, probably through forms somewhat similar to $N$. calophylla and gypsorum. $N$. lotus is nearest to the parent stock, and $N$. rubra most removed. $N$. thermalis remains to testify to the minimum age of the type. $N$. candida has kept near home and has probably 
changed less than its fellow Castalias, whereas $N$. odorata by its rich odor, and $N$. tuberosa by its rhizome show marked specialization as compared with any other species of Nymplaea. Finally, in the American tropics, Hydrocallis has arisen from the Castalia stock. This group is too little known to assign relationships among the species, but it is probable that

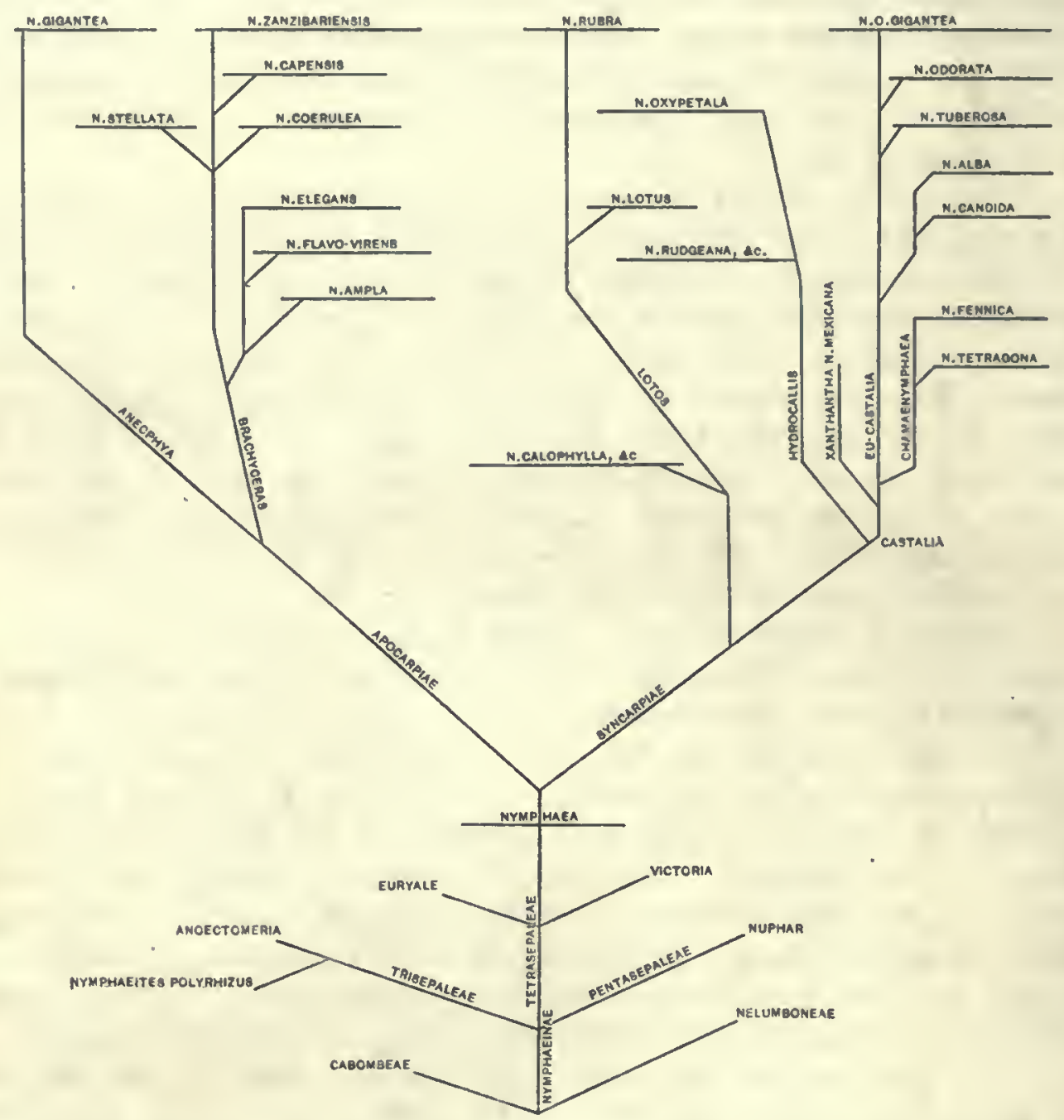

$N$. amazonum, rudgeana, and blanda are lower and $N$. oxypetala one of the highest forms. While these were developing, the genus as a whole was being pushed southward by the increasing coldness of the polar region, until the present distribution was brought about. The above diagram indicates graphically the proposed relationships of the species. 


\section{CHAPTER VII.}

\section{HYBRIDS AND GARDEN VARIETIES.}

Beginning with Nymphaea devoniensis in 1851, a continually increasing number of forms of waterlily has become known to cultivators. The origin of these was in some cases accidental, in others due to artificial hybridization. In the first case there may have been cross-pollination by insects, or variation or mutation-all equally problematical to the systematist and uncertain for the general student. In the second case, careless or ignorant methods leave room for much doubt as to parentage, and very often the facts are withheld or distorted for trade purposes. Only in very few cases, therefore, is our knowledge of the origin of the various garden varieties at all reliable or useful.

For example, $N$. devoniensis, which appears on plate 4665 of the Botanical Magazine, and was first described by Paxton in Gardeners' Chronicle for July 10,1852 , is said in the former article to have been produced by crossing $N$. rubra with $N$. lotus-a red species with a white. The seeds were obtained in autumn of 1850 at Chatsworth, England, and the plant is said to have flowered from April to October, 1851. But the points of difference of the so-called hybrid from $N$. rubra are more robust growth, more floriferous habit, and a very slightly lighter color. In other words, there is almost no trace of the influence of $N$. lotus. Since Hooker and Thomson stated that just such a plant is common and native in India, its hybrid origin is generally disbelieved. It is probably a self-fertilized seedling of N. rubra. As to the color of leaves and flowers, we had in the summer of 190 I three flowering plants of $N$. rubra (?) raised from one and the same tuber. One was grown in a half-barrel of earth in a tank 1.4 meters square, in company with $N$. marliacea-chromatella, $N$. tetragona, and the water-poppy ; the flower was of a light magenta red, and the leaves brownish green. Another was in a half-barrel in a pond with plenty of leaf-room, and had deep red-brown leaves and pure magenta flowers. The third was in a tub of earth 1.6 meters in diameter and $60 \mathrm{~cm}$. deep, with plenty of leaf-room; it resembled the second, but had larger leaves and flowers, and the latter still deeper in color. There is, therefore, great variation, according to conditions of growth. 
On the other hand, $N$. ortgiesiano-rubra, exhibited at Chiswick in May, $185^{2}$, by $M$. van Houtte, and described by Planchon ( $185^{2} a a$ ), is in many respects intermediate between the two parent types. The seed was obtained in the summer of 1850 by M. Ortgies in Van Houtte's aquaria, by removing the stamens from a flower of $N$. rubra and dusting the stigma with pollen of " $N$. ortgiesiana." The comparison of hybrid and parents is well shown in Planchon's parallel column descriptions. The hybrid has bright rose-pink flowers, but they open wide as in $N$. ortgiesiana. The styles are yellow, washed with red in $N$. ortgiesiana, reddish orange in the hybrid, dark brownish red in $N$. rubra. The color of the stamens and upper surface of the leaves is fairly intermediate, but the under surface of the leaf and the character of the stigma are as in $N$. rubra. The robust temperament of $N$. ortgiesiana is reproduced in the hybrid, but it is more floriferous than either parent, probably because no strength is used up in the production of seed. In short, $N$. ortgiesiano-rubra is a well-marked hybrid. Several other hybridizations are recorded by Planchon (1. c.) as productive of seed in $185^{2}$, but no further results reached the public.

In I $853 \mathrm{M}$. Bouché, Inspector of the Royal Botanic Garden of Berlin, obtained another hybrid, named by Planchon (1854) $N$. boucheana. It is to all appearance intermediate between $N$. lotus and $N$. ortgiesiano-rubra, but is of the same parentage as the latter. A slightly different form of $N$. lotus, viz., $N$. dentata, was used as pollen parent. The pale pink petals bordered with pure pink, the yellow stamens, and the bright green leaves show a preponderating influence of $N$. lotus. The sterility of $N$. boucheana attests its hybrid origin.

$N$. kewensis was next to appear. It was published in Gardeners' Chronicle in 1887 (p. 366), and in Botanical Magazine in April, 1888 (tab. 6988). The cross was made at Kew in 1885 by Mr. Watson, with $N$. lotus as seed parent and pollen of $N$. devoniensis. The hybrid has a large number of broad petals of an even rosy pink all over; the stamens are orange colored; the leaves are pure dark green above. In recent years, crossing and re-crossing has been carried on in this group, especially in America, until every shade of color may be had between the white and red types; differences are also noted in shape of petal, size of flower, and color of leaf. They are propagated readily and quite accurately from the tubers, and names have been given to every distinguishable form. $N$. ortgiesiano-rubra and boucheana are not found under those names, but very similar plants are cultivated. The name kewensis is still retained, though the original plant "died without issue"; the present stock was 
8 


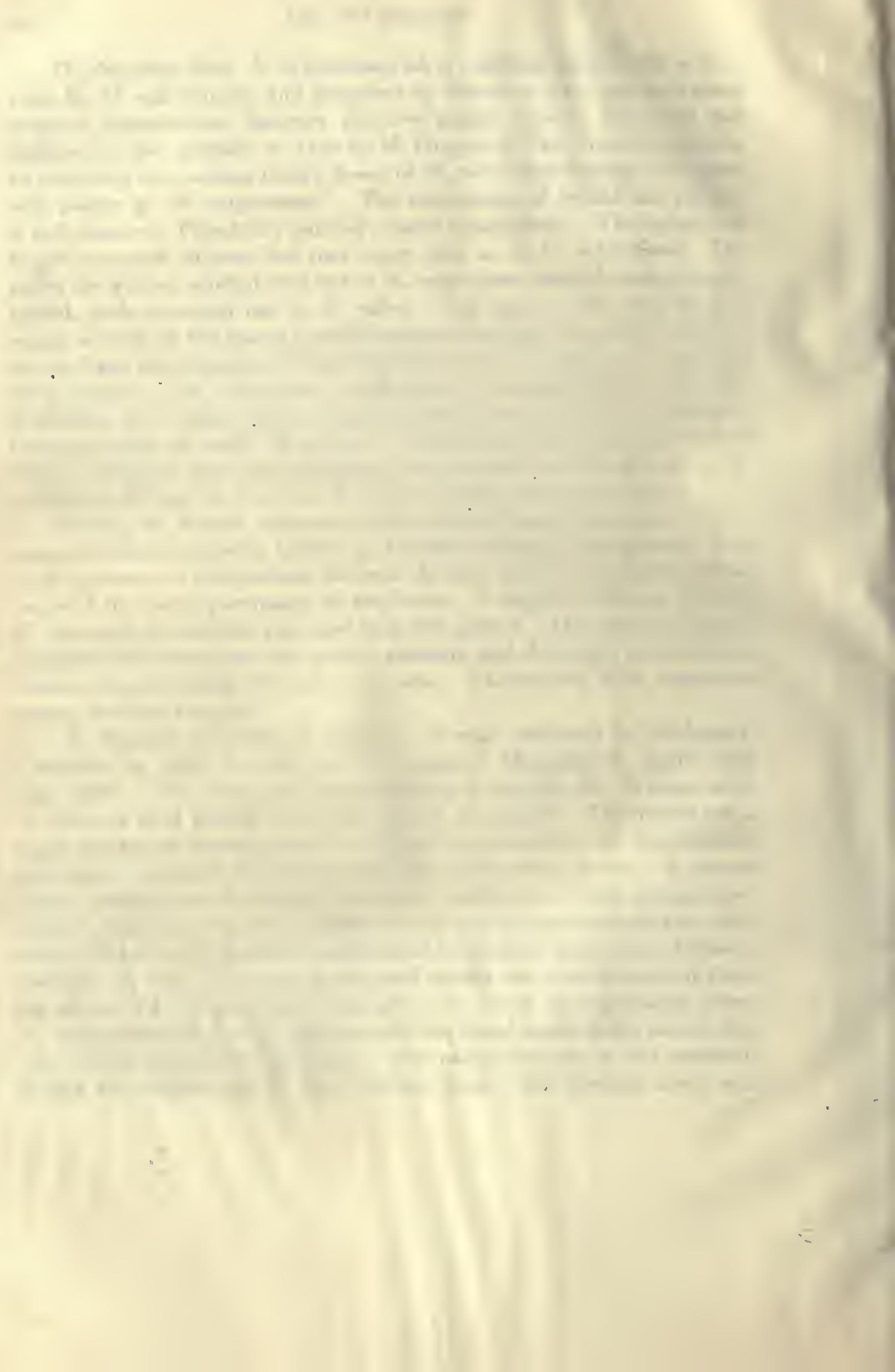




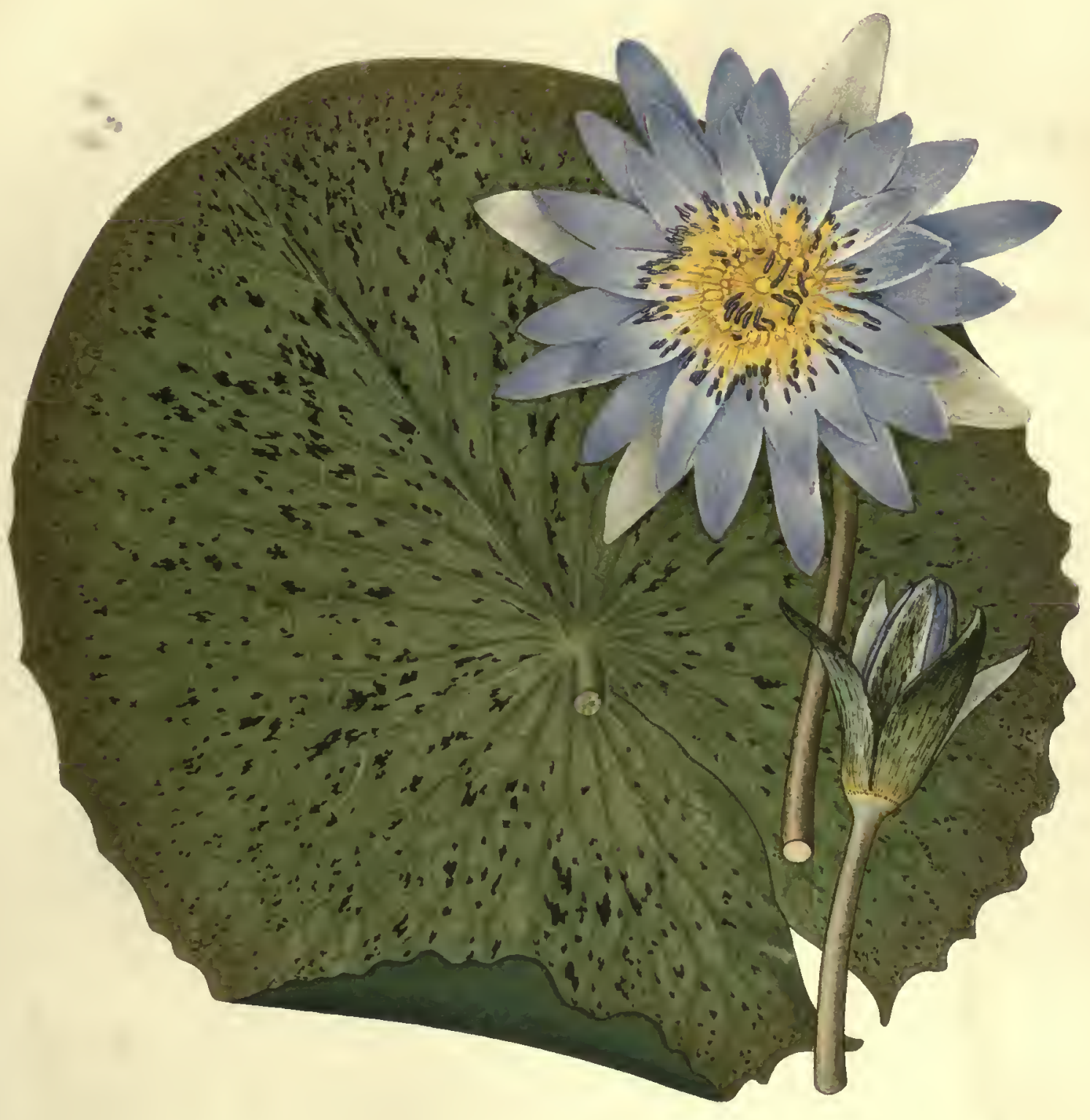

NYMPHFA PENNSYLVANIA. 

obtained independently in America. Hybrids of the Lotos group are known in Germany under an entirely distinct set of names from those used in this country.

In 1885-1890 M. Latour-Marliac, of Temple-sur-Lot, France, drew the attention of flower-lovers everywhere by his magnificent hybrids in the Castalia group-the hardy waterlilies. Probably no one else has done so much for waterlily culture. His earliest achievements won universal admiration; but these have been followed by annual additions of ever increasing splendor. At present, however, the possibilities in that direction seem to be about exhausted. So great was Marliac's lead in this work, and so carefully did he guard the secret of his success, for trade reasons, that only within the last three years have any comparable results been attained, and this only by using Marliac stock for breeding. The parentage of the Marliac hybrids is a matter of speculation. In several cases, however, one or both parents can be indicated with considerable certainty; but which was male and which female will, I fear, never be known. The first members of this series were the yellows, $N$. marliaceachromatella, $N$.odorata sulfurea and $N$. tetragona helvola. All are derived from $N$. mexicana. They are altogether sterile. Of some of the pinks $N$. odorata rosea is one parent, and of those with red tints at the center of the flower $N$. alba rubra is one source.

Within the Brachyceras group, hybridization has been carried on almost exclusively in America. Here Mr. Tricker is the acknowledged leader, so far as the public good is concerned. His $N$. pulcherrima, derived on one side from $N$. caerulea, has been for several years in general cultivation. The new hybrids of $N$. flavo-virens with pollen of $N$. zanzibariensis sent out under the rather unwieldy names Mrs. C. W. Ward and $W m$. Stone, are easily the finest tender day-blooming hybrids yet available. Both have the general habit of $N$. flavo-virens, and in the tuber they follow this parent exactly; but the color of the flower and leaf is beautifully intermediate. $N$. pennsylvania and $N$. elegans $\times$ zanzibariensis, raised in I9OI at the University of Pennsylvania Botanic Garden from seeds of the previous summer, are fairly intermediate in forms, coloring of all parts, and number of floral organs between their respective parents.

In spite of many attempts, no cross has yet succeeded between members of different subgenera of Nymphaea as grouped in this paper. We realize that this is in opposition to M. Marliac's published statements in which he claims $N$. rubra as the source of the red color in his hardy red waterlilies. But so far as naked-eye examination goes (and we acknowl- 
edge that is weak argument) the kind of color shown by the hybrids is totally different from that of $N$.rubra, and no trace of the latter species is to be found in any part of the plant. We are also forced to take issue concerning the supposed hybrids between Lotos and Hydrocallis ${ }^{1}$ raised by Mr. Ames at North Easton, Mass. (Ames, I900; Grey, 1900). I have the greatest confidence in the accuracy of Mr. Ames, and of his able gardener, Mr. Grey, and the latter assures me that the seed-flowers were carefully castrated and kept netted from insects. But the so-called hybrids show absolutely no trace of the influence of a Hydrocallis parent, and it is easier to believe that parthenogenesis or asexual budding from the endosperm or perisperm has occurred in the highly fertile $N$. lotus flower than to imagine a hybrid parentage with one parent obliterated. The case demands, and might well repay, a rigid investigation. Similar crosses of distantly related species have been repeatedly claimed, and by such authorities as Planchon, Tricker, and Sturtevant, but they have either failed to reach the public or have shown no trace of the pollen parent; sometimes, indeed, there is strong evidence of the pollen of some related species.

Natural hybrids, i. e., those produced without human intervention, are of frequent occurrence whenever kindred species are in the same pond. Caspary and others have recorded hybrids of $N$. alba and candida from Europe, and intermediate forms between $N$. odorata rosea and $N$. tuberosa spring up in our gardens; $N$. odorata caroliniana and $N$. o. luciana are of such origin. $N$. flavo-virens always becomes mixed with $N$. zanzibariensis if the two are near each other.

From the fragmentary nature of our knowledge it is impossible to draw any general conclusions on the laws of heredity in waterlilies. So far as we can see, some characteristics are regularly blended in the hybrid offspring, while others are carried over in toto, or even exaggerated, from one or other parent. Thus, the spotting of the calyx so characteristic of $N$. caerulea is not a whit diminished in $N$. pulcherrima and $N$. pennsylvania, while in both the color of petal and size, shape and number of all of the floral parts are decidedly intermediate. In $N$. Wm. Stone, as stated above, the caudex is exactly like that of the seed parent, $N$. flavo-virens, in size, shape, character of leaf-bases, hardiness, and keeping qualities. In Brachyceras all known hybrids are sterile, except $N$. capensis $\times$ zanzibariensis raised in our botanic garden, which is highly fertile, and of which a new

${ }^{1}$ Mr. Ames' N. ampla, which I saw in 1901, is N. rudgeana Mey., collected by Mr. Grey in Cuba. The so-called crosses may be "false-hybrids." 
generation of hybrids is coming on. All of the hardy yellow hybrids are entirely sterile, and crosses of $N$. tetragona with Eucastalia types are also sterile; as examples of these $N$. laydekeri rosea and $N$. pygmaea alba Marliac may be mentioned. Even $N$. alba $\times$ candida is greatly enfeebled in seed-producing capacity. But $N$. alba and $N$. a. rubra, though much more distinct than the last two to the casual observer, are perfectly fertile together and have fertile progeny. $N$. odorata and tuberosa hybrids are not self-fertile, but can be crossed with pure species. In the Lotos group, some forms are sterile, others fertile. Planchon found $N$.ortgiesianorubra to be impotent as to the ovules, but capable of fertilizing $N$. lotus or $N$. rubra. In those now in cultivation, $N$. devoniensis is nearly sterile, but $N$. omarana, which closely resembles $N$. ortgiesiano-rubra, often produces seed. In general, the nearer the hybrid approaches in color to the highly fertile $N$. lotus, the more productive it is. Several seedlings of $N$. omarana have been raised, of which $N$. Geo. Huster deserves special mention. Its flowers are of an extremely deep dark red, more so than $N$. rubra itself, as cultivated here. If the original seed was fertilized by pollen of the same flower, which it is impossible to know, we would have a case of "separation of characters" according to Mendel's theory; but even if $N$. rubra was the pollen parent, the determining elements of the color of the flower in this seedling seem to have lost all trace of the influence of a white ancestor.

We have expressed a belief in the occurrence of variations under cultivation without mixture of blood. Probably $N$. odorata exquisita is such a variant from $N$. odorata rosea, as also $N$. froebelii from $N$. alba rubra, $N$. devoniensis from $N$. rubra, and $N$. gladstoniana from $N$. alba; $N \cdot$ gladstoniana is quite fertile, and has seeds and arils like $N$. alba. Whether $N$. alba candidissima belongs in this class or among the hybrids is uncertain. It is absolutely sterile, and may be a cross of $N$. candida with the large $N$. alba of Greece. Quite comparable with these varietal changes in natural forms are some suddenly appearing peculiarities of hybrids. For example, $N$. robinsoni can be easily recognized by a peculiar crimped notch and fold about the middle of each side of the sinus of the leaf; $N$. gloriosa is uniformly pentamerous; and one of a set of plants of $N$. gladstoniana $\times$ mexicana raised by Mr. Tricker habitually twists the petiole so as to turn the apex of the leaf instead of the sinus toward the center of the plant. $N$. laydekeri rosea prolifera is a fasciated strain, which stools out around the crown to a remarkable degree, whereas the type makes no lateral buds at all. 
Without going farther into isolated details, enough has been said to show that a wide and interesting field lies open to the student in crossing and inverse crossing of waterlilies. It is unfortunate that Caspary's extensive investigations in this line have not been formulated, but his notes, exquisite color sketches, and large collection of pressed specimens are preserved in the Royal Herbarium of Berlin. Among them are such crosses as $N$. capensis $\times$ caerulea; $N$. capensis $\times($ capensis $\times$ caerulea $)$; $N$. caerulea $\times[$ caerulea $\times($ capensis $\times$ caerulea $)] ; N$. caerulea $\times\{$ caerulea $\times$ $[$ caerulea $\times($ capensis $\times$ caerulea $)]\} ; N$. flavo-virens $\times[$ capensis $\times($ caerulea $\times$ micrantha)].
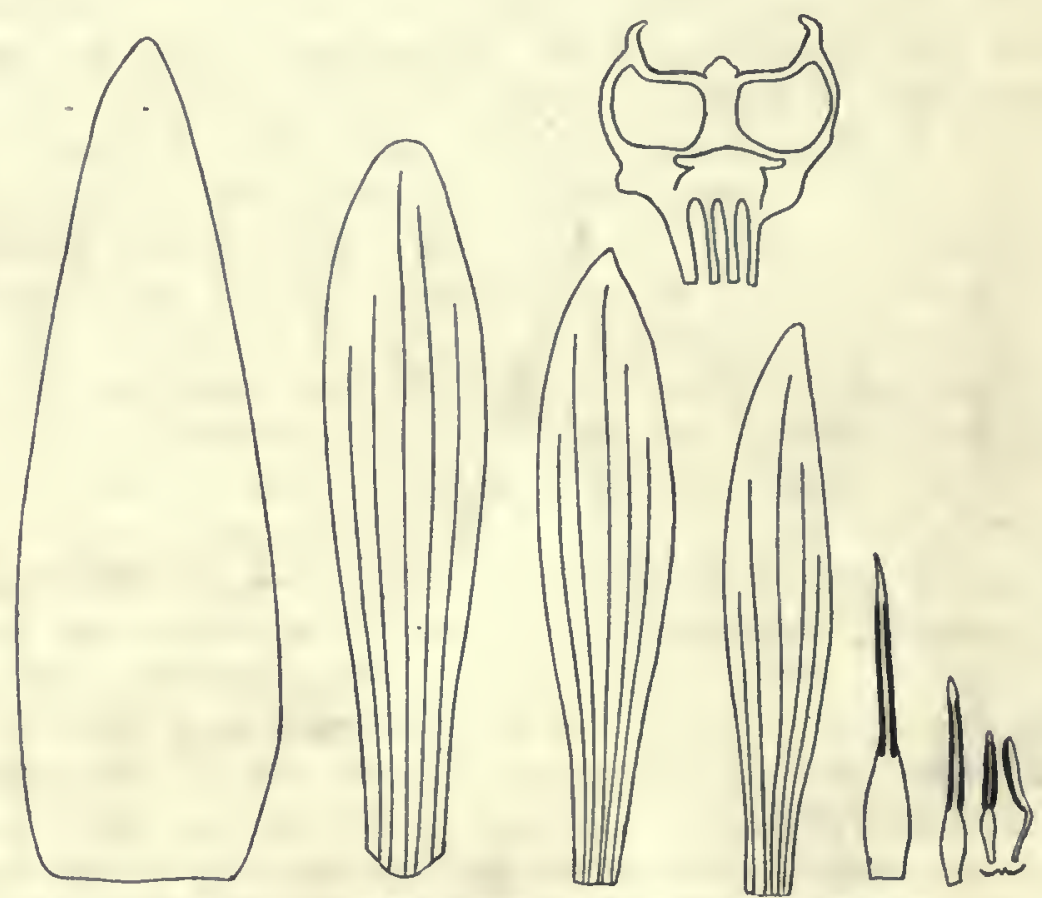

Fra. 77.-Nymphriea pulcherrima Tricker. Sepal, three successive petals; three successive stamens, vertical section of ovary. Two-thirds natural size.

Duplicate specimens of many of these hybrids were distributed to several other herbaria. Time did not permit us to make a study of these. We hope they will be worked over by some scholar, and the interesting results made known. We have, for the convenience of students and cultivators, brought together, in the following pages, some account of the hybrids and garden varieties that have come more directly under our notice. 




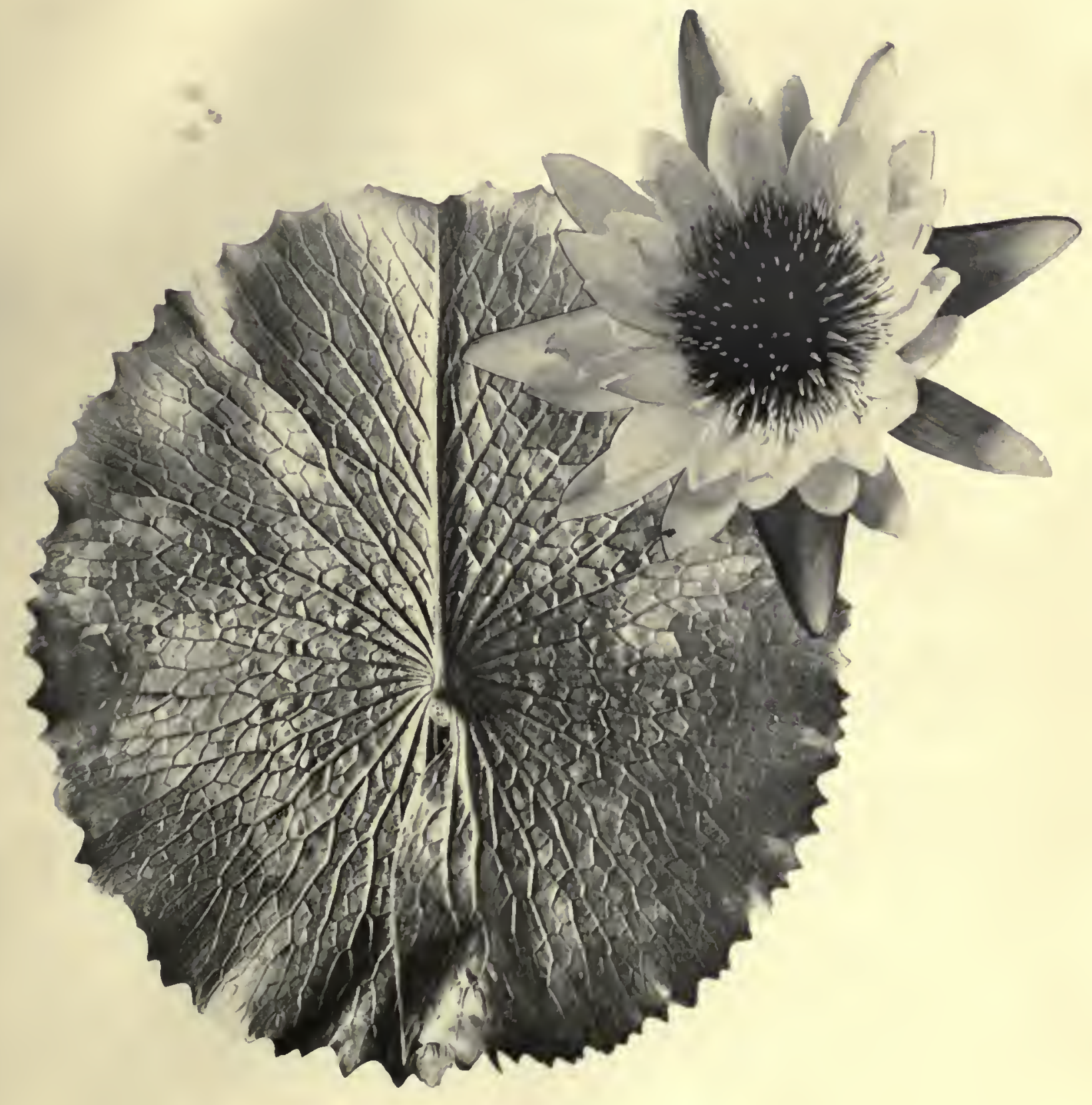

NYMPHAEA CAPENSIS $\times$ ZANZIBARIENSIS. 



\section{Section I. Nymphaeae apocarpiae.}

\section{Subgenus II. BRACHYCERAS.}

I. N. Stellata $X$ caerulea. Mentioned by Caspary (1877) as a sterile hybrid.

2. N. CAERULEA $\times$ CAPENSIS (Focke $188 \mathrm{I}$ ). Raised by Caspary in 1862 . It resembles $N$. caerulea very closely and is generally sterile, though Caspary succeeded in fertilizing it with pollen of other individuals of the same stock and generation, and obtained a second generation of hybrids. These resembled those of the first generation, except one individual, which produced styles as in $N$. capensis, and petals of a deeper color than those of either parent. The small violet-black spots on the calyx of $N$. caerulea are more plentiful in the hybrids. $N$. pulcherrima (Tricker 1897) gives every evidence of having this parentage; the spotting of calyx and under side

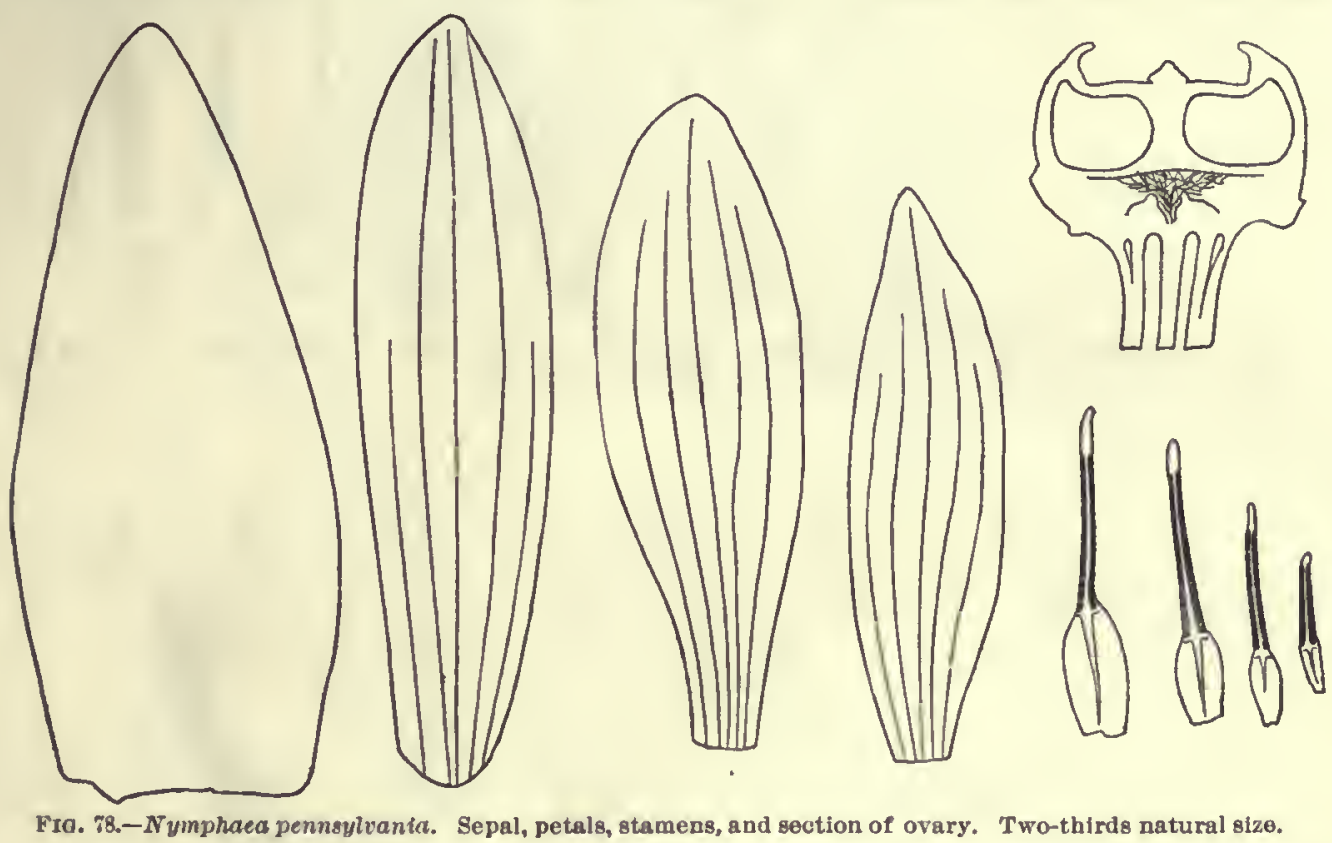

of leaf, the purple margin of the leaf beneath, and the conical buds are reproduced as in $N$. caerulea. The sinuate leaves with acuminate lobes are like those of $N$. capensis. The color of petals and number of floral leaves are fairly intermediate. Sepals 4, petals 20 to 22, stamens 137 to 140 , carpels 24. Sterile. (Fig. 77.)

3. (N. CAERUlea $\times$ CAPENSIS) second generation $\times$ CAERUlea (Caspary I862). Spots of calyx confluent into large areas.

4. N. Caerulea $\times$ (CAerulea $\times$ capensis). Raised by Caspary (i862).

5. N. Caerulea $\times$ zanzibariensis $(=N$. pennsylvania Conard igor $b$ ) (Plate XXVI; Fig. 78). Flowers light blue, open from 8 a. m. to $5 \mathrm{p} . \mathrm{m}$., that is, combining the earliest and latest limits of the two parents. Spotting of calyx and lower surface of leaves as in $N$. caerulea. Shape of bud, shape, number and color of floral organs, and 
outline of leaves strikingly intermediate. The seedlings are like those of $N$. caerulea until the first floating leaf; this is spotted with brown above and suffused bluish beneath as in N. zanzibariensis. Sterile. Raised at the Botanic Garden, University

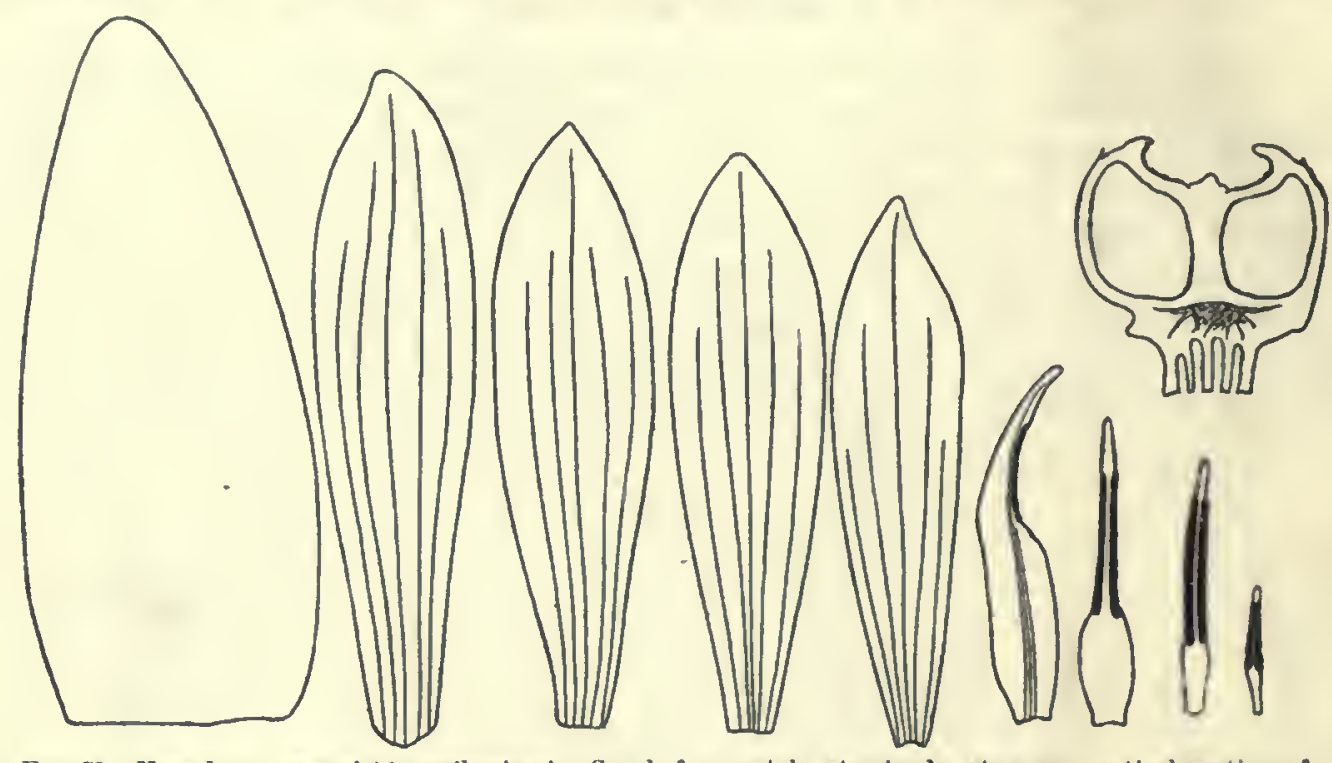

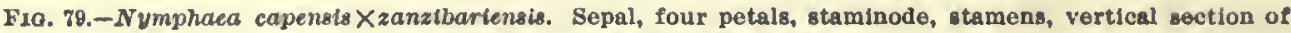
ovary. Two-thirds natural size.

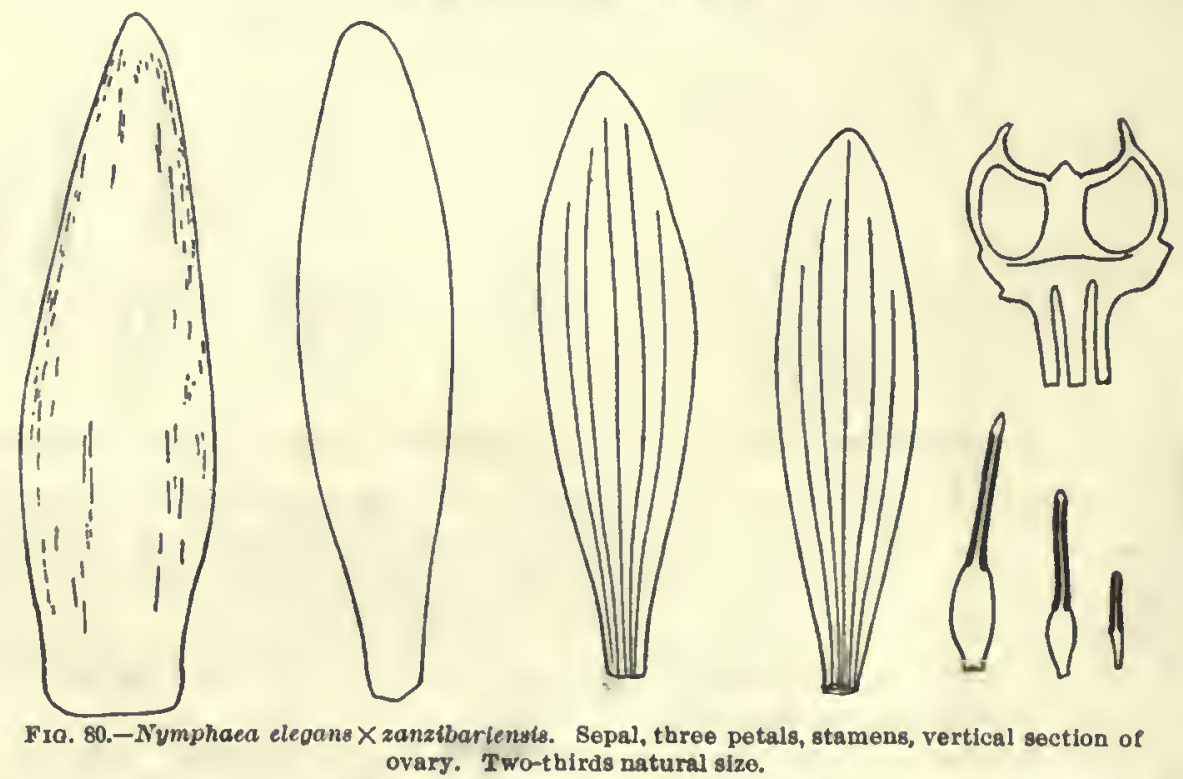

of Pennsylvania, from seed obtained in 1900; flowered I901. Sepals 4, petals 23, stamens I40, carpels 26.

6. N. Capensis $X$ zanzibariensis (Plate XXVII; Fig. 79). Flowers light blue. Floral parts very numerous. Sepals broad, resembling those of N. zanzibariensis. 
t.

$$
\text { • }
$$

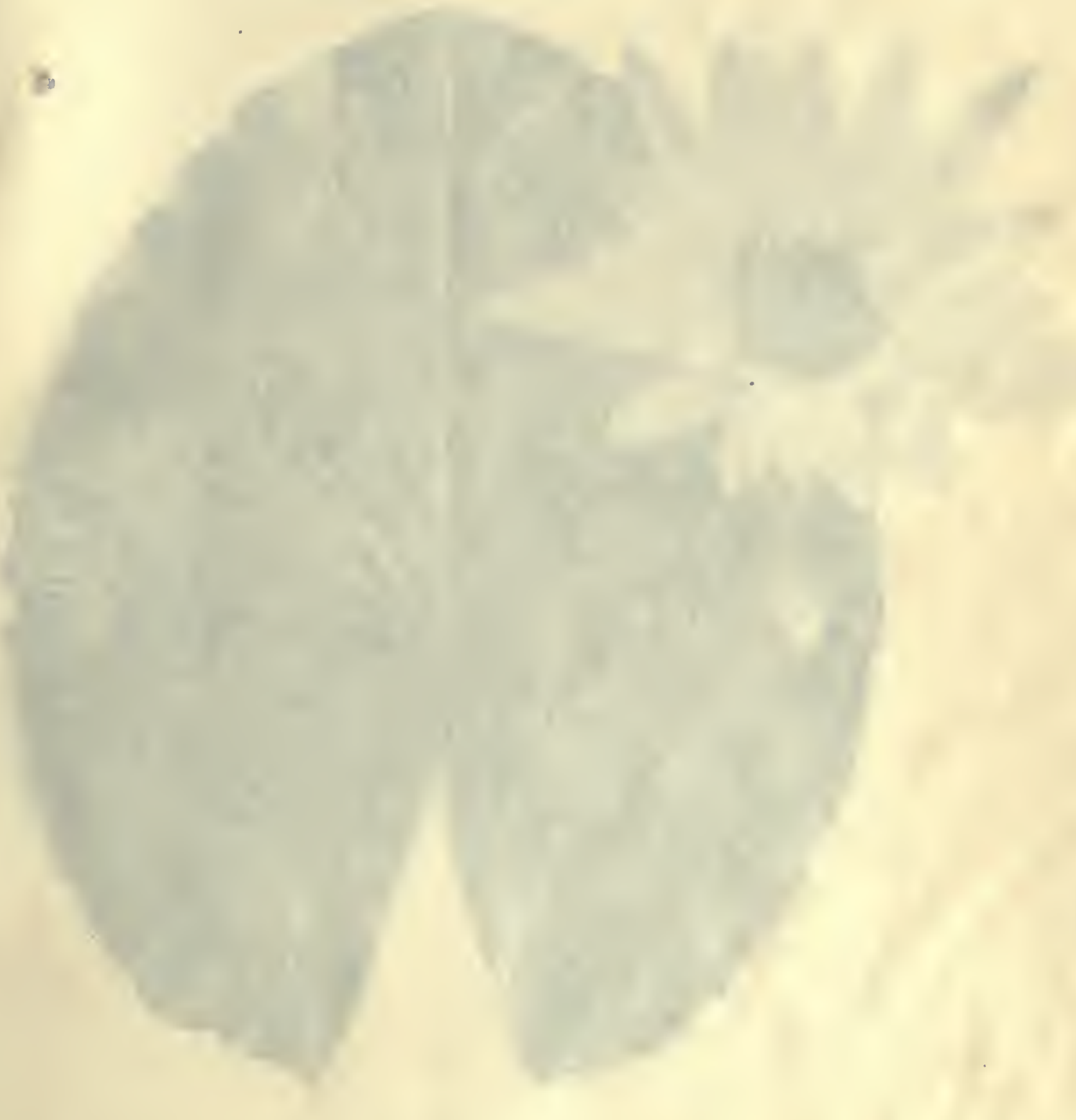




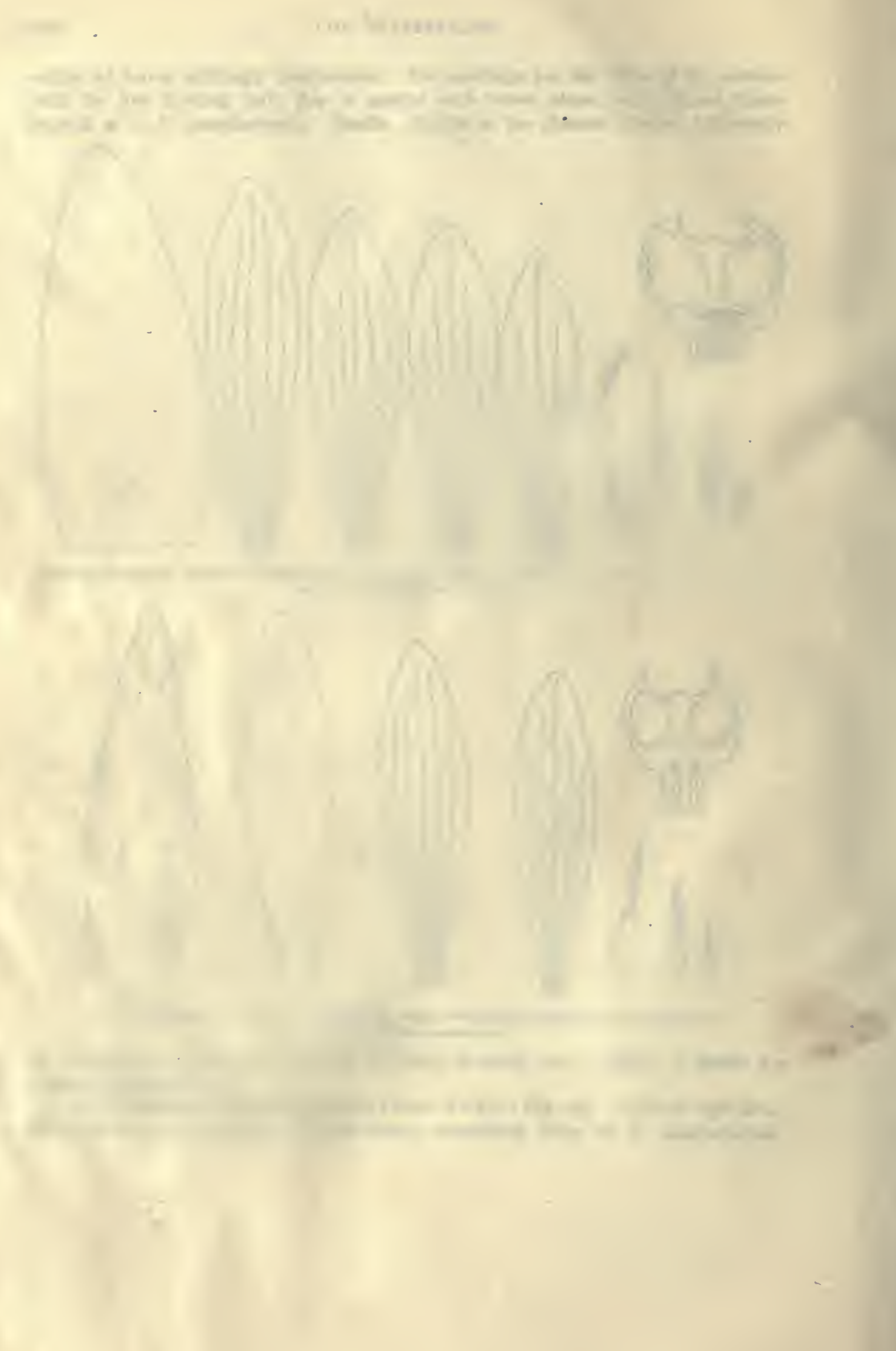




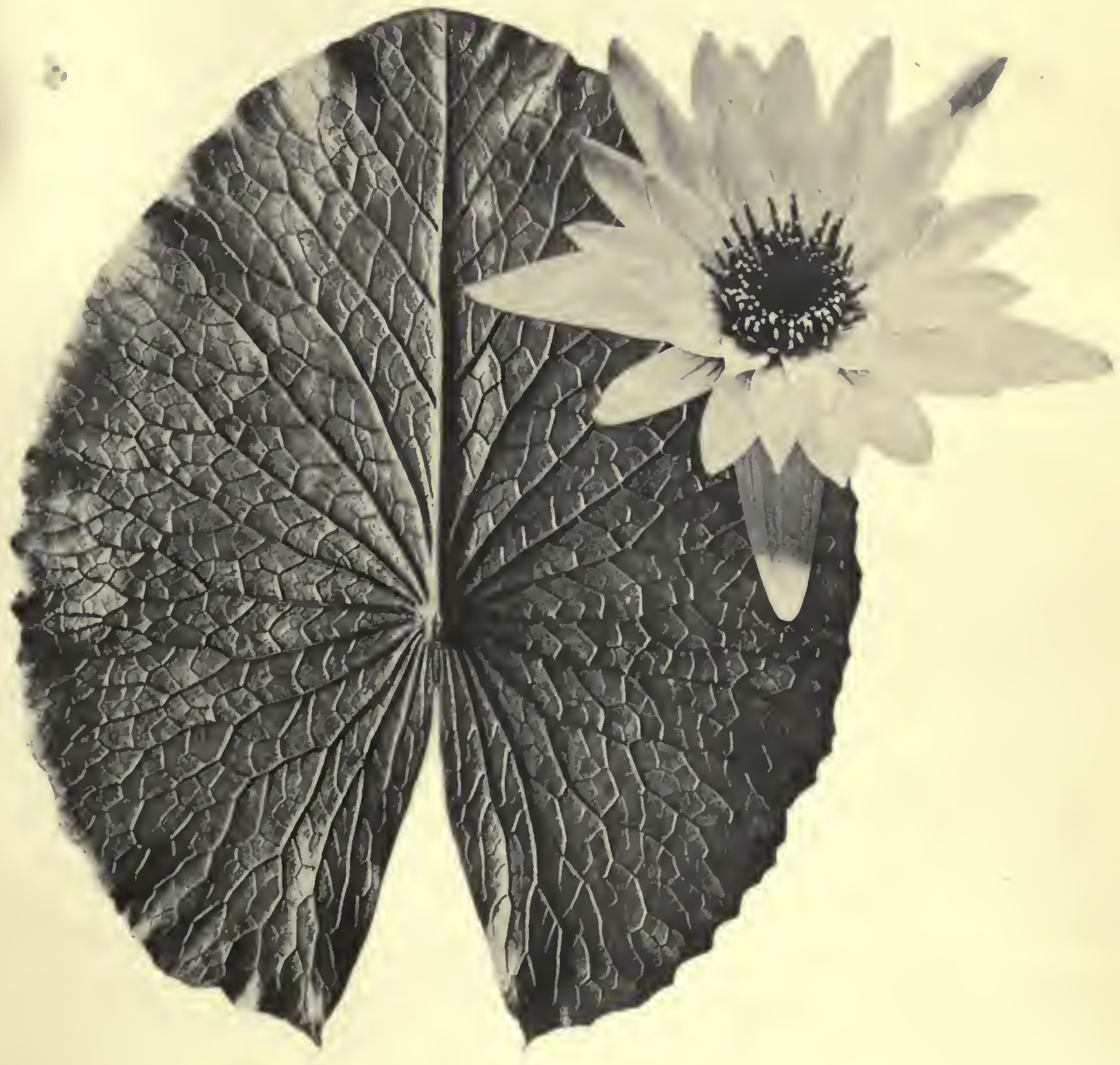

NYMPHAEA ELEGANS X ZANZIBARIENSIS. 

Leaves dull purplish violet beneath, less brilliant than in $N$. zanzibariensis. Self fertile. The types are very much alike, but the hybrid is fairly intermediate. Raised in the Botanic Garden of the University of Pennsylvania from seed obtained in 1900; flowered I90I. Sepals 4, petals 32, stamens 225, carpels 32. N. stellata eastoniensis (Garden and Forest $9: 475$ ) appears to belong here, the cross having been effected by insects. It is described as having steel-blue flowers, with less of the stellate form, and leaves "more deeply toothed" than the type. It was raised by C. Blomberg, gardener to O. Ames, North Easton, Mass., from seed obtained in I895 from "N. stellata" (doubtless $N$. capensis); flowered 1896 .

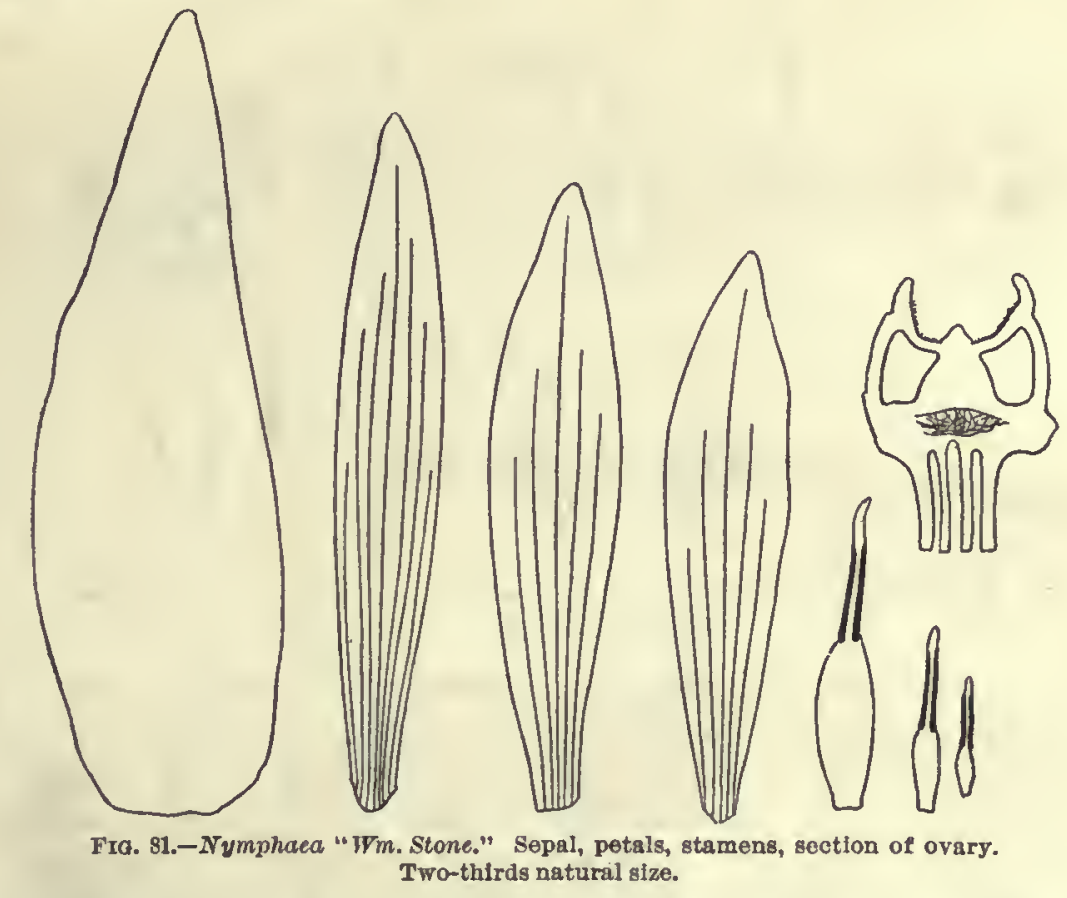

7. N. elegans $\times$ zanzibariensis (Plate XXVIII; Fig. 80). Flowers light blue with a violet tint, much bluer than $N$. elegans. Bud, sepals, and petals shaped as in $N$. elegans, but much larger. Length of styles and appendages of stamens intermediate. Leaves colored as in $N$. zanzibariensis, but intermediate in shape. Sterile. Raised in the Botanic Garden, University of Pennsylvania, from seed obtained in 1900; flowered I90I. Sepals 4, petals 2I, stamens 150.

8. N. zanzIBARIENSIS $\times \longrightarrow$ ? $(=N$. zanzibariensis $\times$ capensis, Conard Igor a). Leaves as in $N$. zanzibariensis, but without brown spots above. Flowers rich blue, open from 9 a. m. to 4 or 5 p. m.; petals and sepals narrower than in $N$. zanzibariensis. Petals 15 to 20 , stamens 60 to Ioo. Very floriferous, but sterile. Cultivated at Horticultural Hall, Fairmount Park, Philadelphia, and formerly at University of Pennsylvania. Said to have been originally obtained from Mr. Tricker.

9. N. flavo-virens $\times$ zanzibariensis (Plate XXIX; Fig. 8I) $(=N$. Greyae, Hort.; N. Wm. Stone Tricker; N. astraea R. M. Grey; $N$. gracilis purpurea, N. g. 
azurea Sturtevant). Sepals, petals and leaves shaped as in $N$. favo-virens, but the last two intermediate in color. Stamens and carpels intermediate. Tuber in all respects like N. Alavo-virens. Petals 20, stamens 70, carpels 21. Sterile. First obtained by Benj. Grey of Malden, Mass., and named in his honor.

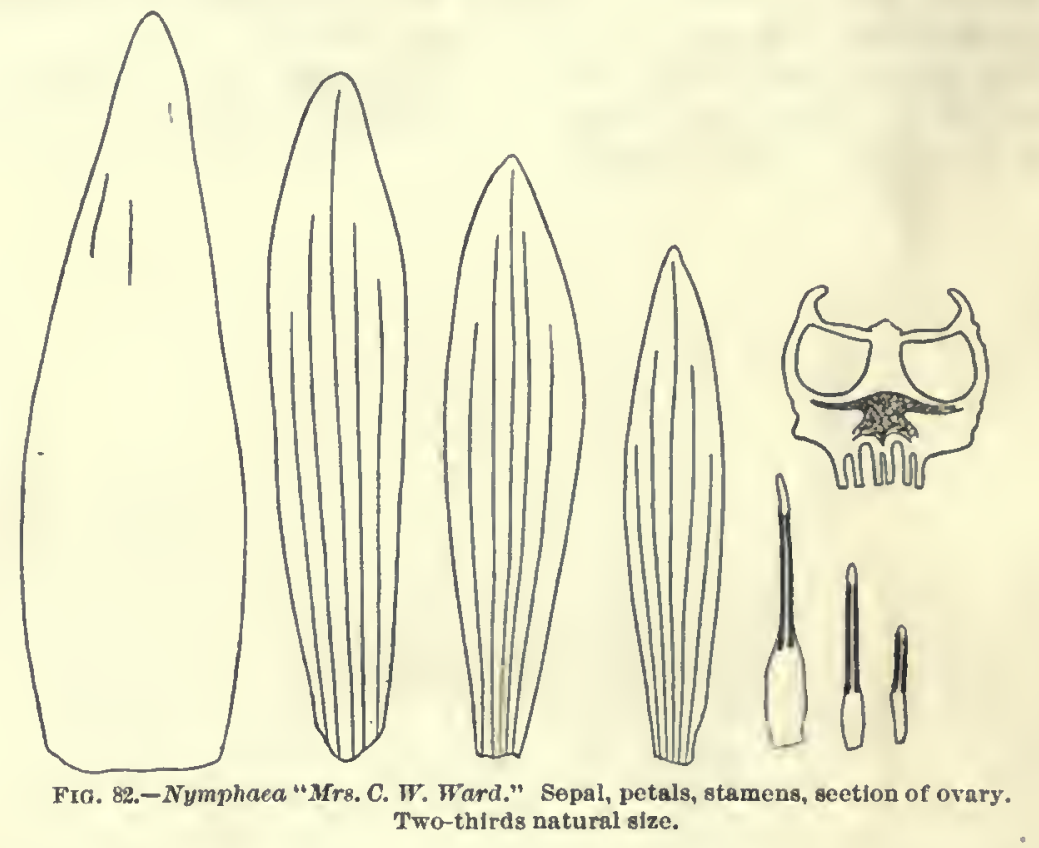

10. N. Flavo-virens $\times$ zanzibariensis Rosea $(=N$. mauvii Henshaw $;$. Mrs. C. W. Ward Tricker; N. astraea rosea R. M. Grey; N. gracilis rosea, N. g. r. perfecta, N. g. rubra Sturtevant). Like No. 9, but with flowers pink instead of blue. Sterile. First obtained by Samuel Henshaw, New Brighton, N. Y., about 1892 . There are slight differences in the quality of the pink color as grown by different persons; it usually contains a shade of blue, but Mr. Sturtevant has nearly a pure pink (perfecta); his rubra variety is rather deeper in color than any others we have seen. (Fig. 82.) 


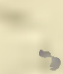

$-$

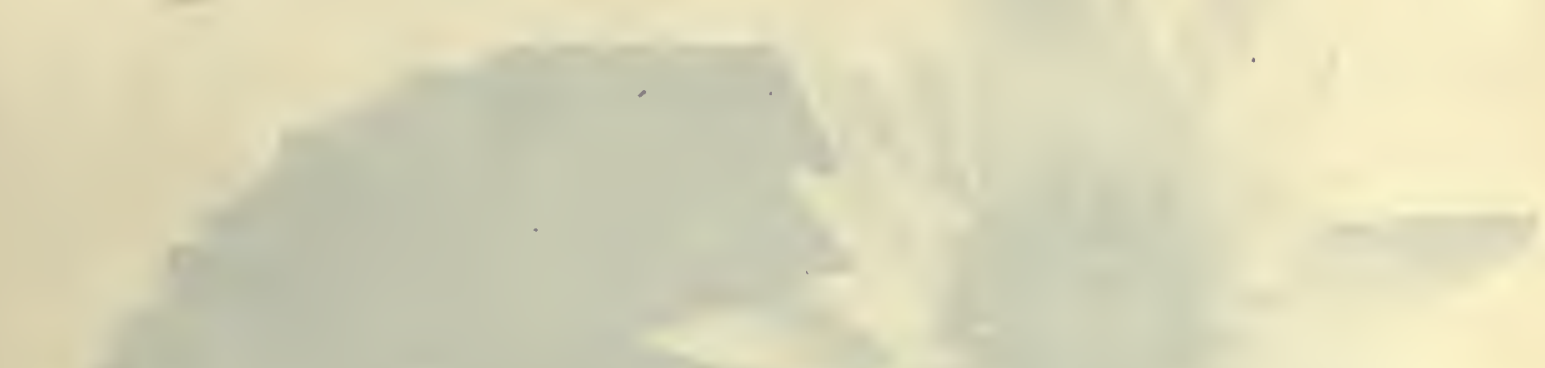





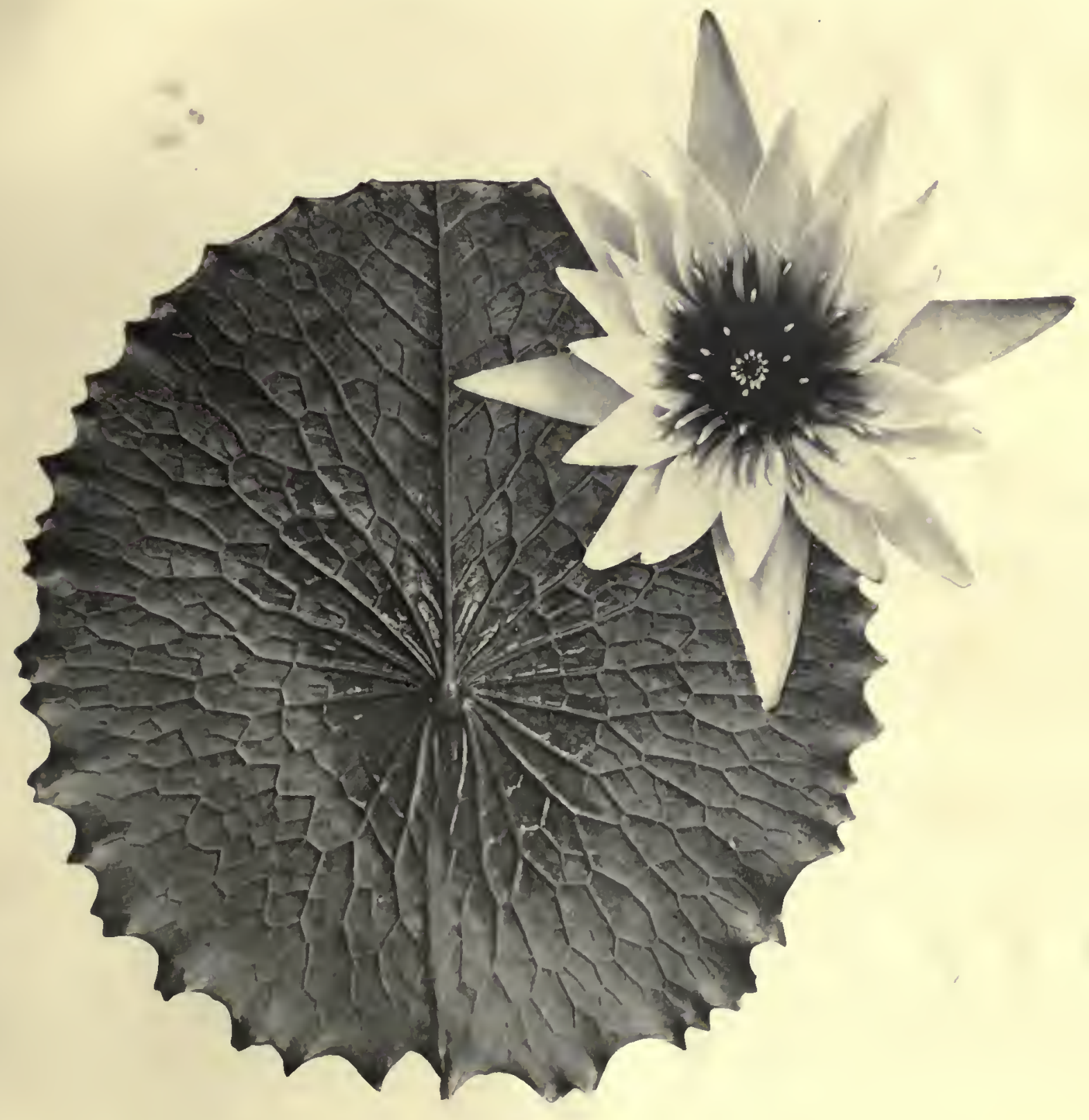

NYMPHFEA FLAVOVIRENS X ZANZIBARIENSIS. 



\section{Section II. Nymphaeae syncarpiae.}

Subgenus III. CASTALIA.

\section{Chamaenymphaea $\times$ Xanthantha.}

II. N. tetragona $\times$ mexicana ( $=N$. pygmaea helvola Marliac; $N$. tetragona helvola Conard I901 $a$; Froebel Cat. I90I). In shape and size of all the parts like $N$. tetragona, with the color in leaves and flowers of $N$. mexicana. The caudex bears many lateral buds, but no runners. Sterile. Produced by Marliac about I890; introduced into America about 1892.

\section{Chinmaenympifaea $\times$ Eu-castalia.}

12. N. tetragona $\times$ alba? (=N. pygmaca alba Marl., in part). Resembles $N$. tetragona in shape and size of flowers, but the leaves are broader and more rounded. The caudex bears no side shoots. Sterile. Sent out by Marliac as N. pygmaea alba in 1893 ; but in other places he uses this name apparently as synonymous with $N$. tetragona.

I3. N. TEtragona $\times$ alba RUBRa? (=N. Laydekeri rosea Marliac; N. Laydekeri Hort.). Closely resembles $N$. tetragona, except in color of flowers; these are of a delicate pink color on opening, changing to rose and deep carmine-rose on succeeding days; this character is drawn from $N$. alba rubra. Sterile and without side shoots. Introduced by Marliac about $189 \mathrm{I}-\mathrm{N}$. laydekeri rosea prolifera Tricker is a fasciated form of the above, producing a great many lateral buds. Introduced by Henry A. Dreer Co., I901. N. laydekeri lilacea André (1895a, col. plate) $(=N$. liliacea Gard. and For. I895, p. 277; N. lilacina 1. c. I897, p. $316 ;$ N. Laydekeri liliacea Tricker in Dreer Cat. I902) has flowers of a soft rosy lilac, shaded bright carmine, with yellow stamens; otherwise as above. Raised by Marliac; introduced into the United States in 1895 .

\section{Eu-Castalia $\times$ Xanthantha.}

I4. N. odoRAta $\times$ MEXicana ( $=N$. odorata sulfurea Marliac; $N$. sulfurea Hort.). The flowers are intermediate in size, shape of parts, and color between the two parents; the leaf combines the copious brown blotching of $N$. flava with the deep red under surface of $N$. odorata. Rhizome slender, nodose, yellow. Sterile. Obtained by Marliac about 1888, and exhibited by Lagrange at the Trocadéro in 1889 . Published with colored plate in Revue Horticole $1890 b$. About 1899 a larger form was sent out by Marliac under the name of $N$. sulfurea grandiflora.

15. N. odoRATA ROSEA $X$ MeXicana? (=N. arc-en-ciel Marliac igor). Known to us only by catalogue description, but apparently of this parentage. "Leaves variegated with several lively and distinct tints. * * * The sweet scented flowers are of a salmon-white color, with sepals splashed with rose color." 
16. N. Alba $\times$ mexicana? ( $=N$. marliacea chromatella Marliac; $N$. chromatella Hort.; N. tuberosa flavesccns of Kew). Leaves orbicular, much blotched with brown, 8 to $20 \mathrm{~cm}$. across; when crowded they may rise as much as $20 \mathrm{~cm}$. above the water, and are not blotched. Flowers bright yellow; petals numerous, broad, concave. Very strong grower, but sterile. Said by Marliac to have the parentage cited above, but believed by some to be $N$. tuberosa $\times$ mexicana. Structurally it bears some resemblance to $N$. tuberosa, and sometimes the brown stripes of the petioles of this species appear on the hybrid; the question cannot yet be decided. Raised by Marliac about 1888.

17. N. ALbA RUBRA $X$ mexicana? Several of the Marliac hybrids undoubtedly have this parentage, but most distinctly $N$. robinsoni ( $N$. robinsoniana Hort.), seignoreti, aurora, and fulva ( $=N$. laydekeri fulva Tricker 1897$)$. The leaves are much mottled with reddish-brown as in $N$. mexicana. The outer petals are more or less yellow, shading through rose to deep red on the inner ones; the stamens are red or orange. Thus we have a beautiful blending of the colors of the parents. $N$. robinsoni is peculiar in having a crimped notch about the middle of each margin of the sinus. There are also differences in the details of the coloring of the flowers. They were first published in Revue Horticole in $1895, N$. robinsoni and seignoreti with a colored plate, p. 258 , and the other two on p. 568 . In the former article $N$. andreana and lucida (=N. laydekeri lucida Tricker 1897 ) are also mentioned, and in the latter place is $N$. laydekeri fulgens with a colored plate. All are productions of Marliac. $N$. andreana appears on a colored plate in the same journal in $1896, \mathrm{pp} .352-353$. The last three also agree in having the leaves mottled with brown, but the yellow color is not nearly so evident in the flower; they may represent a second cross. $N$. chrysantha (Marliac I901) is described in almost the same words as $N$. aurora, and $N$. arethusa (Henry A. Drecr Co. I902) is spoken of as "an improved Laydekcri fulgetus."

\section{Eu-Castalia.}

(To N. alba we refer the following garden forms: N. alba maxima; N. a. plenissima; N. gladstoniana, raised by Richardson of Lordstown, Ohio; $N$. casparyi alba Carrière, Rev. Hort. 1888, p. 300 . To $N$. alba rubra belongs $N$. froebelii. To $N$. odorata rosea we refer $N$. odorata rubra; $N$. rosacea; $N$. exquisita. To $N$. odorata gigantea we refer $N$. gracillima alba Marliac Cat. I90I; $N$. caroliniana nivea Marliac Cat. Igor ; N. eburnea André, Rev. Hortic. 1895, p. 568. To $N$. odorata minor belong $N$. odorata pumila and $N$. union. To $N$. tuberosa we refer $N$. tuberosa richardsoni; N.t. plena.)

I8. N. ALBA $\times$ CANDIDA? (=N. alba candidissima Hort.; N. candidissima Hort.). A large, white, free-flowering variety; very robust. Sterile.

19. N. ALBA $X$ ODORATA? (=N. marliacea albida Marliac). The flower is pure white, stamens yellow, sepals flushed pink; fragrant. Leaves large, deep red beneath. On account of the color of the sepals, and a tendency to pink on the stamens, the pollen parent may have been $N$. o. rosea, and the plant, in that case, belongs with $N$. m. carnea and rosea (No. 20), which it resembles in every respect except color. Sterile. Introduced by Marliac about 1889 . 
20. N. Alba $X$ odorata rosea? ( $N$. marliacea carnea; $N$. m. rosea; $N . W m$. Doogue). Differs from No. 19 only in color of flower, which is from light pearly pink to deep rose; all are strong, luxuriant growers but sterile. Under the first two names it was introduced by Marliac about $1889 ; W m$. Doogue was obtained by Henry A. Dreer Co. ten years later.

21. N. Alba $X$ ODORata rosea? ( $N$. colossea Marliac 1901). Flowers and leaves very large; petals flesh colored. Blooms from early spring until frost. Sweet scented. It may be a second hybrid, $N$. alba candidissima $\times$ odorata rosea.

22. N. ALBA RUBRA $X$ - A large number of hybrids and variants have been introduced recently possessing the characteristic red shading of the Swedish waterlily, and without distinct indications of other parentage. Perhaps $N$. candida has been used (as the flowers are often cup-shaped), or they may be second or third or multiple crosses; the latter is highly likely. Some of the types are fairly distinct, even to an amateur, but most of them can be recognized only by the professional. In $N$. marliacea fammea, $N$. m. ignea, and $N$. gloriosa there is a faint blotching of the leaf which can come only from $N$. mexicana or $N$. tetragona. We have not noted any such character in $N$. ellisiana, sanguinea, marliacea rubra punctata, laydekeri purpurea, $W m$. Falconer, James Gurney, or James Brydon ( $=N$. brydonacea elegans).

23. N. odorata Rosea $X$ tUBERosa? ( $=N$. caroliniana, c. perfecta, c. rosea; $N$. tuberosa superba; $N$. odorata caroliniana, o. carolinensis, o. superba, o. luciana, o. suavissima). This hybrid is a much stronger grower than $N$. odorata rosea, but otherwise resembles it. The cross easily occurs, but was first cultivated by Dr. Bahnsen of Salem, North Carolina, about I8go.

24. N. TUBERosa $X$ ODORATA ROSEA? (=N. tuberosa rosea; N. brakeleyi rosea). Flowers pink. The plant has nearly the habit of $N$. tuberosa, but the rhizome is less tuberiferous. N. tuberosa rubra (Sturtevant $\mathrm{IgOI}$ ) is said to be $N$. brakeleyi rosea $\times$ $N$. rubra; but from the description it is more probably ( $N$. tuberosa $\times$ odorata rosea) $\times$ alba rubra. The "rosy red" flowers and "bright red stamens" indicate this. The plant was not flowering when I saw it in Mr. Sturtevant's garden (June, 1902); the leaves were small, entire, and petioles dark red.

\section{Subgenus IV. LOTOS.}

25. N. LotUS $X$ RUBRA. Successive crosses between these species have been very often made, and every possible gradation between them has been obtained. They differ in color and size of leaf and flower and relative breadth of petal and degree of opening of the flower; the hybrids vary also in texture of leaf and in distribution of color on the petals. In $N$. sturtevantii the leaves are crimped at margin far more than in either parent; and the color of N. Geo. Huster is darker than any strain we have seen of $N$. rubra. According to Focke (188I) N. rubra with $N$. lotus or ortgiesiana gives the same product whichever is used as pollen parent, and the same is true of $N$. lotus and dentata. But in $N$. rubra and dentata the hybrid progeny resembles the female parent in respect to relative length and breadth of early leaves and floral leaves. 
With regard to color, the forms now in cultivation, with originator, date of origin, and reputed parentage, may be arranged in series, thus:

I. $N$. dentata magnifica ( $N$. omarana $\times$ dcntala) Bisset 1902.

2. $N$. dentata grandifiora Sturtevant 1901 . Whitc.

3. $N$. eastonensis ( $N$. omarana $\times$ smithiana) Ames 1900 .

4. N. jubilee, Dreer 1899. Delicate pinkish white. N. Quecn Elizabcth (N. devonicnsis $\times$ ortgiesiana) 1855 (fid. Focke).

5. N. smithiana, Tricker 1893. N. indica Isis (cf. Moenkemeyer 1897). N. laelia (N. colombiano $\times$ smithiana), and $N$. l. colorans (ditto) Ames 1900.

6. $N$. delicatissima. Tricker 1894 . Light pink.

7. N. deaniana, Tricker 1894. N. boucheana (N. rubra $\times$ dentata) Bouché 1853 (cf. Planchon 1854). $N$. indica Spira (cf. Moenkemcyer 1897).

8. N. kezvensis ( $N$. dentata $\times$ devcniensis). Raised at Kew, I885 (cf. Botanical Magazine, tab. 6g88). Pink to red.

9. $N$. sturtevantii ( $N$. devoniensis seedling) Sturtevant 1884 . N. indica Hofgartner Gracbener (cf. Moenkemeyer 1897). N. rubicunda (N. sturtevantii X lotus) Ames 1900.

10. $N$. omarana, Plate XXX ( $N$. dentata $\times$ sturtevantii), Bisset 1894 Magenta. $N$. ortgicsionorubra ( $N$. ortgiesiana $\times$ rubra) Ortgies 1852 (cf. Planchon $1851 a a)$. N. mariae lagrangci ( $N$. lotus $\times$ dentata) Lagrange (cf. André I899). N. niobe ( $N$. ampla $\times$ rubra) Amcs 1900 (cf. page 222 above).

I1. N. diana ( $N$. sturtevantii $\times$ ampla) Grey 1900 (cf. above, p. 222). N. indica Brahnna (Froebel Cat. 1901).

12. $N$. devoniensis ( $N$. rubra $\times$ lotus) at Chatsworth, Eng., 1851. N. arnoldiana Oliver, about 1899 . 13. $N$. columbiana, Tricker 1894 . N. diana grandiflora ( $N$. sturtevantii $\times$ ampla) Ames 1900 (cf. above, p. 222).

14. N. George Huster (N. omarana seedling) Dreer 1899. Dark red.

15. N. Frank Trelease, Gurney 1900.

Focke (188I) mentions, without further comment than is here given, a considerable list of crosses involving species of the Lotos group. We append the list, referring back to p. 22 I for ourviews on those cases where two subgenera are involved.

N. Quecn Elizabeth $\times$ dentata gave red and rose-colored flowers.

N. Queen Elizabeth $\times$ caerulea gave violet flowers.

$N$. rubra $\times$ ortgiesiana $=N$. ortgiesiano-rubra.

$N$. ortgiesiana $\times$ rubra $=N$. ortgiesiano-rubra.

$N$. rubra $\times$ lotus $=N$. lotus $\times$ rubra.

$N$. lotus $\times$ dentata $=N$. dentata $\times$ lotus.

N. alba $X$ ortgiesiano-rubra gave seedlings which never matured. A reported cross of $N$, dcvoniensis and Victoria regia, Focke says is mistaken.

Planchon (l. c.) mentions the following attempts at hybridization, but we can find no further record of the plants :

$N$. thermalis $\times$ rubra; young plants obtained.

$N$. thermalis $\times$ scutifolia; young plants obtained.

$N$. alba $\times$ ortgicsiana; young plants obtained.

$N$. dentata $X$ ortgiesiano-rubra; seedlings obtained.

$N$. alba $\times$ ortgiesiano-rubra; thrce seedlings obtained. 


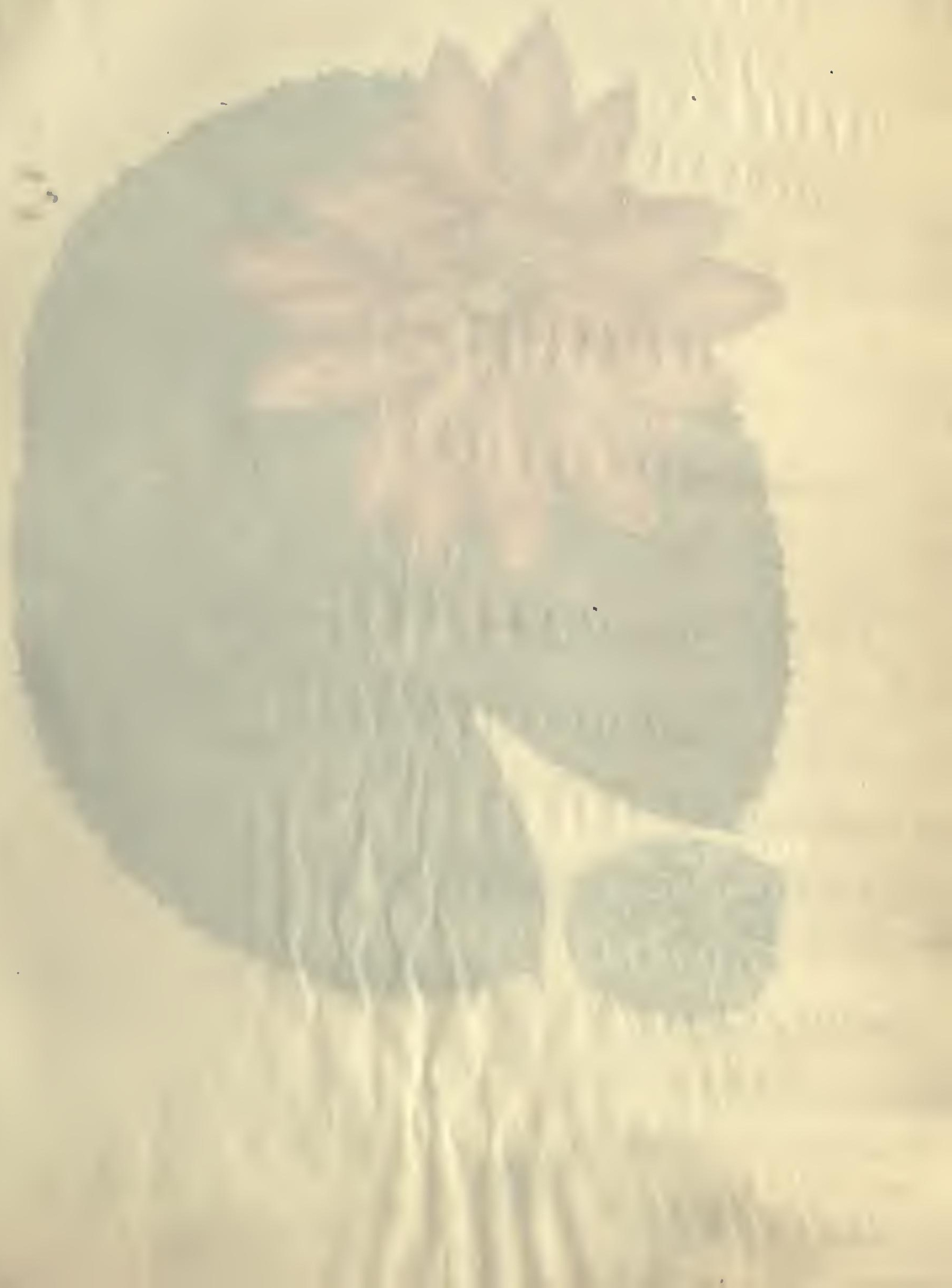


$\sqrt{2}$

4.

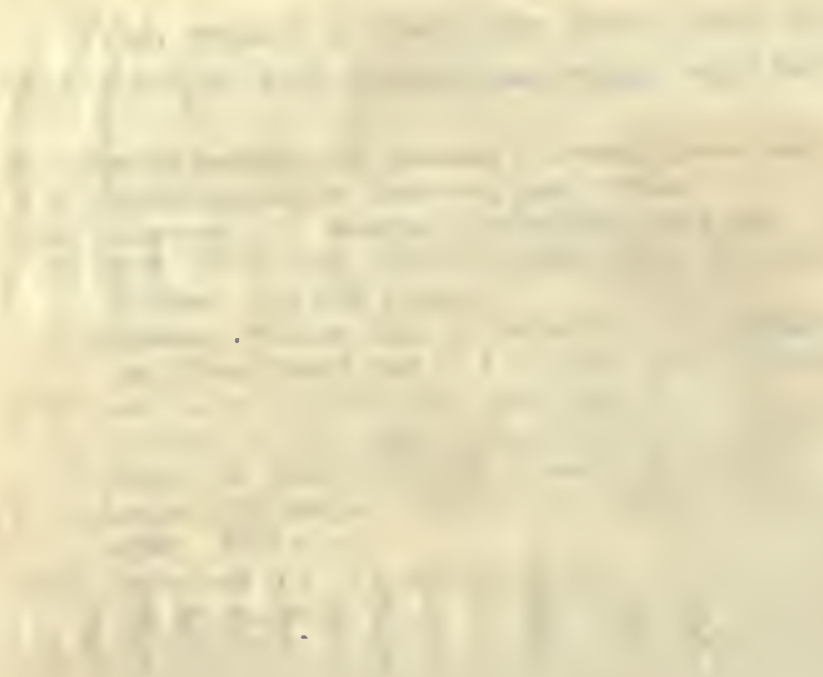

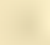
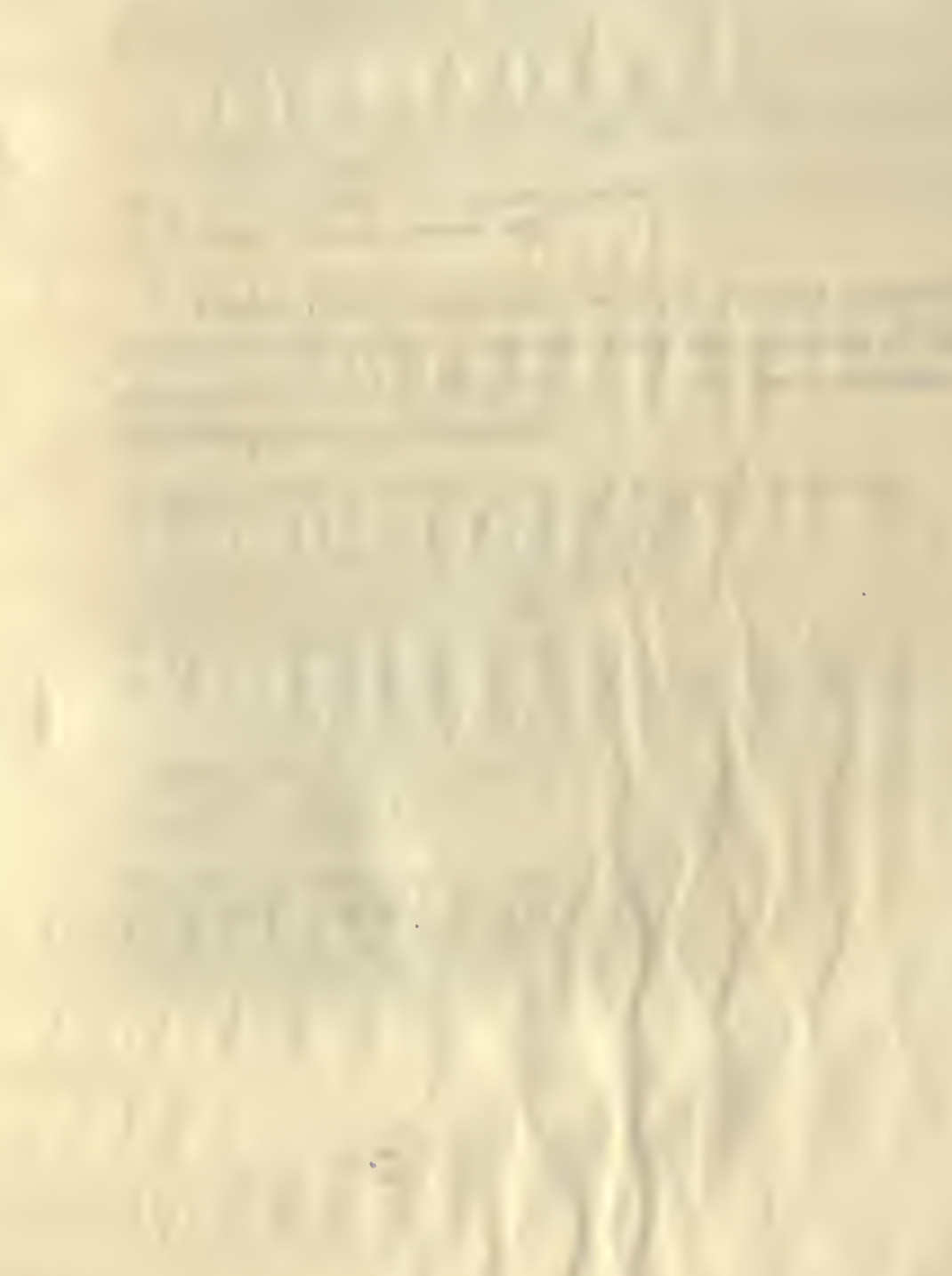


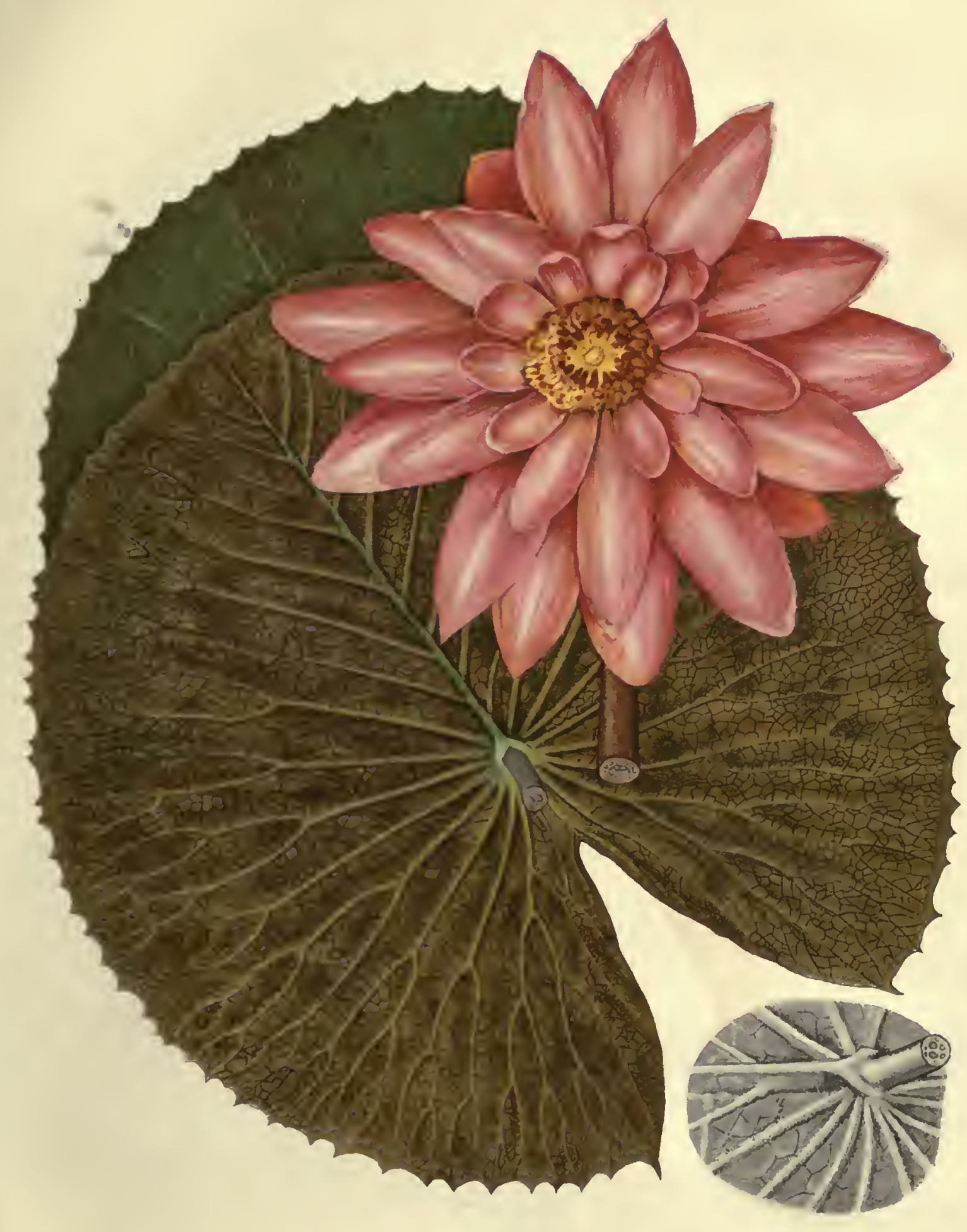



Unsuccessful attempts were made with $N$. scutifolia $\times$ dentata and the reverse; $N$. scutifolia $\times$ rubra and reverse; $N$. odorata $\times$ rubra, and $N$. ortgiesiana $\times$ caerulea. It is notable that all of these failures involved two subgenera.

It would be interesting, could we trace any definite and constant relations among hybrids. A diagram of the pedigree of some of the best known varieties may aid in this. We select $N$. omarana and the "rose and red" flowered hybrids of $N$. Queen Elizabeth and dentata. In each couple we place the pollen parent above.

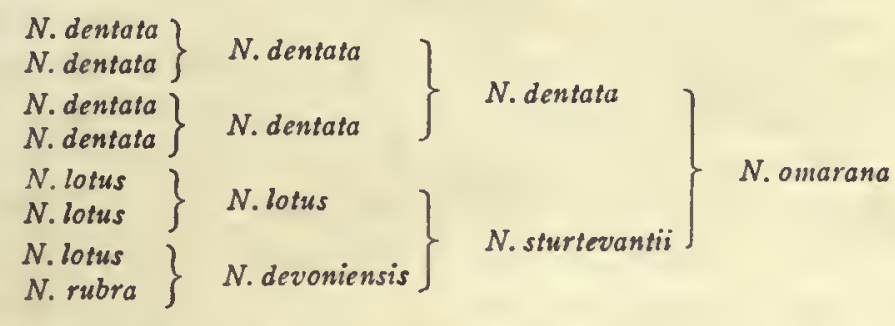

According to this a single infusion of $N$. rubra has sufficed to produce a rich magenta color in the fourth generation. But in $\mathrm{Mr}$. Bisset's new $N$. dentata magnifica ( $N$. omarana $\times$ dentata), the tide is completely turned and the flower is pure white. The next instance, however, is like that of $N$. omarana, viz. :

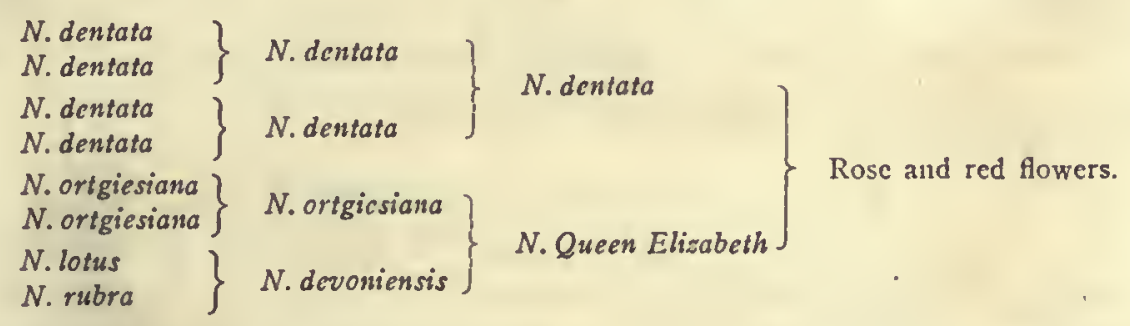

Is red, then, a dominant color in the Mendellian sense, and is it therefore primitive? Discussion would at present be wholly speculative and had best be omitted. A wide field for investigation is opened up. But none of our garden stock can be warranted pure enough to start on. We need fresh importations of the natural species, and a careful comparison of a large number of sister plants. The custom of gardeners is to discard all seedlings whose foliage does not give indications of the desired results; consequently only certain types have been preserved for us. 



\section{CHAP'TER VIII.}

\section{CULTURE AND USES.}

The use of waterlilies for food and ornament among the ancient Egyptians has already been referred to. This still continues to some extent in Egypt, but, on the West Coast of Africa, Nymphaea seeds constitute an important article of food. Travelers describe seeing the native women and children coming in at evening to the villages laden with the ripening fruits. These are laid in heaps until all of the soft parts decay. The seeds are then easily washed out clean, and are dried and stored away. They contain so much starch, oil, and proteid that they should form a very nutritious diet. When dry the seed coat is brittle and the kernel slightly shrunken, so that the two are easily separated. The kernels may be ground into a kind of flour or may be boiled whole. The resting tubers, in the dry season, are almost solid starch, and are eaten boiled or roasted like potatoes. The species used in West Africa are $N$. caerulea and lotus. In Madagascar, $N$. lotus and capensis are similarly used, and the seeds of $N$. gigantea are eaten by the Australians. In Central America also waterlily seeds are used for food. Victoria cruziana is known as "water corn" (Mais del aqua) in Paraguay on account of its large farinaceous seeds.

In the days of empirical medicine and the "doctrine of signatures" the medicinal virtues of Nymphaea were highly overrated. Its leaves were said to be antipyretic, and a decoction of the dried leaves and rhizomes was supposed to be powerfully anaphrodisiac. Although it still holds a place, in the United States Dispensatory, and is mentioned by Tavera (I9OI) in his medical botany of the Philippines, it is probably never used. The whole plant is very astringent and bitter, on account of the presence of tannin and gallic acid (cf. Grüning, I881 ; Niederstadt, I883 ; Fridolin, 1884). Whatever value it has is due to these constituents.

But it is as ornamental plants that Nymphaeas have achieved their present wide-spread fame, especially in Europe and North America. The English colonies in India and Australia are also giving them considerable attention, and a beautifully arranged pond has long been a feature of the Botanic Garden of Buitenzorg in Java. Their culture began in the large 
estates and botanic gardens of England with the introduction of $N$. odorata in 1786. From that time until 1812 several species were brought to English gardens. Then there was a period of inactivity until the appearance of Victoria about 1840 aroused great interest in aquatics. From 1850 to 1860 this wave reached its maximum, when Planchon, Lelimann, and Hooker described several species, and Caspary began his immortal work on the genus. There followed a lull until near 1880. Probably $N$. zanzibaricnsis served to bring its congeners before the public again. A nother wave of waterlily culture set in, which probably has not yet reached its maximum. So magnificent are the results recently achieved, and of so lasting a nature, that this branch of gardening is likely to be of importance as long as flowers are grown for the beautifying of public or private grounds.

For cultural purposes we may divide the genus into two groups-the hardy and the tender varieties. In the first group Castalia stands alone. All others are tender in our climate. In the Botanical Magazine and Flore des Serres brief cultural directions are given for each species described; these are almost wholly intended for tender varieties when grown under glass. But since the extended culture of these plants can only be carried on where the climate will admit of their being for three months at least out of doors, we shall speak only of the latter condition. Out-door culture of tropical forms is of very recent date. So recently as I89 I Herr Borsig's water garden in Berlin was noted as of especial interest. He warmed the pond with waste hot water from his factory. Mr. Vilmorin described the place in Revue Horticole, and the article was reproduced in translation in the London Garden, and in Garden and Forest ( $1891, p .375$ ). In Garden and Forest for I888 (pp. 241-242) cultivation of waterlilies in shallow ponds is urged as both possible and desirable in the eastern United States. In the garden trade the hardy species were slower than the tender ones in getting recognition. Gardeners' Chronicle in I 848 informs a correspondent concerning $N$. alba that "the roots of these things may sometimes be had in the nurseries, but they are not usually kept." In 1849, however, it is stated that $N$. rubra, caerulea, stellata, and ampla may "be had from any of the large nurserymen." Vick's Catalogue for 1883 mentions only $N$. odorata. At present sixty-four varieties are entered in the catalogue of one of the leading American dealers.

The care of them is very simple. The pond or tank may be only a large bucket or a half-barrel; in such accommodations $N$. tetragona, $N$. $t$. helvola, $N$. marliacea chromatella, or even $N$. caerulca, will get along and 
bloom ; the first two will do quite well. But the best thing is a brick and cement pool $60 \mathrm{~cm}$. deep and of as large a size as one can get room for ; after one season's trial the tank will seem too small, at any rate. A single course of brick will be sufficient for a small tank, but a double course is better. Mr. Arnold, of Sharon Hill, gets beautiful results with a pool where the earth was simply scooped out and an even coat of cement laid directly on the ground. In any case it is best to protect the edges of the pond in winter by a coat of litter; if a weak construction is used this is absolutely necessary, as a leak caused by frost would let the water out and the resting rhizomes would be fatally frozen. A natural pond, if not frequented by muskrats, is excellent for hardy varieties, but it would be rare to find one north of Washington warm enough for the tender kinds. $N$. alba candidissima, odorata gigantea, and colossea will do well in water as deep as one or two meters. Select a place for the tank where it will get full sunlight all day. Waterlilies are usually but little shaded in their native haunts, and the tropical species need all the light possible when in our northern climes. It is desirable to have the water-level constant, and to change the water just enough to keep it fresh.

For planting the rhizomes it is only necessary with the stronger hardy varieties in natural waters to tie a stone close to the rhizome and throw it in where the depth will be suitable. If one would be more careful, the rhizomes may be planted in weak splint baskets of earth and put in place. By the time the plant needs more room the basket will be falling to pieces, or at least, will be easily broken, and the roots will have full liberty. Such planting may be done at almost any time of year, but preferably in fall or spring. Sometimes on account of weakness, sometimes because of excessive dominance, it is desirable to keep the plants within prescribed bounds; in that case permanent pots, boxes, or tubs must be provided. This is necessary in artificial ponds. Nothing less than a halfbarrel is really worth while. A tub 100 to $130 \mathrm{~cm}$. in diameter and 45 to $50 \mathrm{~cm}$. deep gives the best results for all of the larger species, but I have seen $N$. elegans and gigantea blooming in tubs only $40 \mathrm{~cm}$. across, and $N$. zanzibariensis will produce pretty little flowers in a "six-inch" pot! Square board boxes of any size may be made to suit circumstances.

The character of the soil for these pots or tubs is of prime importance; it must be very rich. Various prescriptions for its preparation have been given. R. Müller (1885) recommends a mixture of three parts soil, two parts compost, and two parts peat for hardy Nymphaeas. We find nothing equal to well-rotted cow manure for fertilizer, and Mr. Tricker's 
(1 897) preparation of good garden soil or sod compost with one-third to one-half of manure gives the finest possible results. Swamp muck is not at all to be recommended. If well-rotted cow manure can not be had, bone dust may be substituted in the proportion of "a six-inch pot full to a barrow load of soil" (Tricker, l. c.). Even in such strong materials a good plant of any of the larger tender forms will completely exhaust the nutriment in a half-barrel of soil before the end of the season; hence the desirability of larger tubs for the best results. The plants should be placed with the crown on a level with the surface of the soil. This should be covered with I to $3 \mathrm{~cm}$. of clean sand to keep the manure down and to prevent the activities of certain aquatic worms which often carry up much fine matter to the surface of the tub and tend to bury the plant. For the hardy varieties the tub must be placed deep enough in the water to be safe from actually freezing. Tender varieties need to be within 15 to $25 \mathrm{~cm}$. of the water surface in order to take advantage of the greater warmth of the upper strata. The area of water surface required per plant depends upon the species and the size of the tub it is planted in. I have seen $N$. rubra, $N$. marliacea chromatella, and $N$. tetragona in a tank $120 \mathrm{~cm}$. square, with the water-poppy flourishing in whatever space remained; and all four species bloomed freely all summer. Each of the Nymphaeas had one flower every day, and sometimes two, and the water-poppy sometimes had a dozen flowers at once! But they were badly crowded. $N$. tetragona will be satisfied with a space $60 \mathrm{~cm}$. square ; most of the hardy varieties require a space 100 to $120 \mathrm{~cm}$. square for a single shoot; and the tender varieties will cover a space 3 to 5 meters across.

Once placed as above described, the plants need no attention throughout the season except to keep up the water supply and trim off dead leaves and flowers. They should bloom at the rate of a new flower every two or three days, or perhaps one every day. As each flower lasts two to five days, the display is always fine. Of course the varieties differ in production of flowers, and the situation and other circumstances have their effects. Hardy species should not be moved for two or three years at least, but the tender ones must be wintered with considerable care. Large blooming plants may be lifted with a ball of earth 30 to $60 \mathrm{~cm}$. in diameter, potted, and kept in a warm tank with plenty of light. They will then bloom all winter, and may be planted out again. It is best, however, to let old plants of the tender day-blooming species die. The nightbloomers should be taken up in late October or early November, potted in sand or planted under the bench of the conservatory, and allowed 
slowly to dry off. In about a month they will almost certainly produce strong tubers, which should be kept in dry sand but not allowed to become absolutely desiccated. In March or April tubers of all of the tender varieties should be planted in sand in a warm tank. As each stolon gets its first floating leaf it should be carefully detached from the tuber and potted off, and the tuber replanted for the development of additional stolons. With tender day-blooming species (apocarpous) it is important to obtain two or more plants in the spring. One of these should be kept in a 6-inch or 8-inch pot, and dried off about mid-summer to form a tuber for the next season, as the flowering plants usually die. Hardy varieties are propagated from the rhizomes, by cutting and planting out in spring.

Propagation by seed is also easy, but is not possible for hybrids. The ripening fruits are covered with muslin bags; the mouth of the bag is tied fast around the peduncle, and the bag should also be tied to a stick for safe keeping. After the fruit has burst and its parts decayed, the bag is taken in and the seeds washed from the débris. Should the pods burst unexpectedly and the seeds be found floating on the pond, they may be dipped up with a fine wire sieve tied on a pole. Seeds of the Castalia group must be kept in water in a cool place until ready for sowing. Other seed may be dried and kept in the usual way. It is advisable to sow Castalia seeds as soon as ripe; their germination is at best irregular, and it is unusual to get flowering plants the first year. The tender varieties may be sown in flat pans, barely covered with sand, and placed in warm tanks in February. The young plants should be pricked off into small pots and kept moving rapidly; they will produce plants of the largest size the first season. Planting out in the pond must be delayed until all danger of frost, or even of a cold rain storm, is over. The first of June often proves too early in this latitude. $N$. gigantea is especially tender. The labeling of seeds and plants in water can only be successfully done on metal labels. Thin copper or brass on which one writes with a stylus, or with asphalt varnish, makes the only satisfactory and durable label.

Some hints on hybridizing have already been given, but it may be worth while to recapitulate. No haphazard work pays. It is better to get no seeds than to go to the pains of raising a batch of supposed hybrids and find they are all pure species. The flower to be used for seed should be covered with a fine net (finer than mosquito bar) before it begins to open; do it on the previous day. As soon as it opens (or before) all of the stamens must be plucked out. For the greatest accuracy the pollen 
flower should also be kept netted before and after it opens; this is to avoid any mixing of pollen by insects. Now, on the day the seed-flower first opens, the net is removed for a moment while, with a brush, pollen from the chosen male parent is stirred around in the stigmatic fluid. The net is replaced, and in a week or so the result will be indicated by a swelling of the ovary if successful, or by decay of the flower and peduncle if no fertilization was effected. Some consider that the pollen should be applied at the close of the first period of opening of the seed-flower. I have succeeded very well in the Brachyceras group at that time or earlier, but have no successful experience in any other group.

Several enemies attack waterlilies and work great havoc. In the seed beds, algæ may grow up and choke the little plants; the use of less manure and more sand in the pots is a preventive measure, and weak Bordeaux mixture will kill the algx. After the first transplanting, a damping-off fungus sometimes carries off numbers of seedlings; the leaves become transparent in ever-increasing areas until they are all gone. This must be prevented by care in pricking off; if the plants are not wounded, and are not weakened by the shock of moving, they will outstrip the fungus. Snails, too, sometimes devour the leaves, or cut them off and leave them floating on the tank; pick out the offenders and throw them away. The first floating leaves are often seriously weakened by swarms of aphides. A strong spray from hose or syringe will wash them off, and a few sun-fish or paradise fish will effectually prevent their return to the leaves.

As to enemies of mature plants, I can do no better than to quote Mr. Tricker's summary from the Cyclopedia of American Horticulture (1901, p. I104):

Aphides are sometimes troublesome. The best remedy is their natural enemy, the "lady bugs" or "lady birds." A colony of these voracious insects makes short work of the aphides, as do also the lace-winged flies. An insect of recent acquaintance with Nymphaeas is a leaf-miner, the larva of a small fly, which cuts channels through the leaf in all directions. Sometimes only a few of these are in evidence, at other times the leaves are fairly alive with them. The trouble is easily detected. The marks suggest Japanese writing or the efforts of youthful artists. A simple and effective remedy is kerosene emulsion, applied with a fine spray at evening after the flowers are closed. Another troublesome insect has its home in Florida, and has come North to spend the summer in a favored clime. This is a leaf-cutter, Hydrocampa proprialis. The larva cuts out pieces of the leaf and hides between two pieces, which make a kind of tent. In this tent the larva moves about. At first it moves slowly, but as it nears maturity the larva becomes ravenous and then eats the surface of the 
leaves near the center, and cuts off much larger pieces of the leaf for camping-out purposes. The best remedy for this pest is a lamp trap for the mature insect. Frogs and dragon-flies will catch numbers of them.

Nymphaeas are also subject to a fungous disease, a leaf spot which is easily discerned after a spell of warm humid weather. After such a spell of weather, followed by bright sunshine, the leaves are scorched and crumpled up, and as a result, the plant is sadly crippled by being denuded of its foliage; new leaves are weak and smaller, and so too are the flowers, if indeed there are any. This disease must be checked at once or the plants will be severely set back, if not ruined. The only remedy is Bordeaux mixture, or any of the various mixtures with sulphate of copper as the basis. Use a fine spray, and dilute the mixture to half the strength recommended for most plants. It is best to spray twice with a weak solution rather than to spray once with too strong a solution and damage the foliage.

Finally, the ravages of muskrats eating the rhizomes of hardy species in winter must be mentioned. Three fine collections, in my small acquaintance, have been seriously injured or destroyed in this way. Traps and a bounty on hides are two practical aids to the gardener. But here, as in so many cases all along life's journey, "eternal vigilance" is the price of success. And the success, once it is attained, more than repays the labor of love which it costs. 


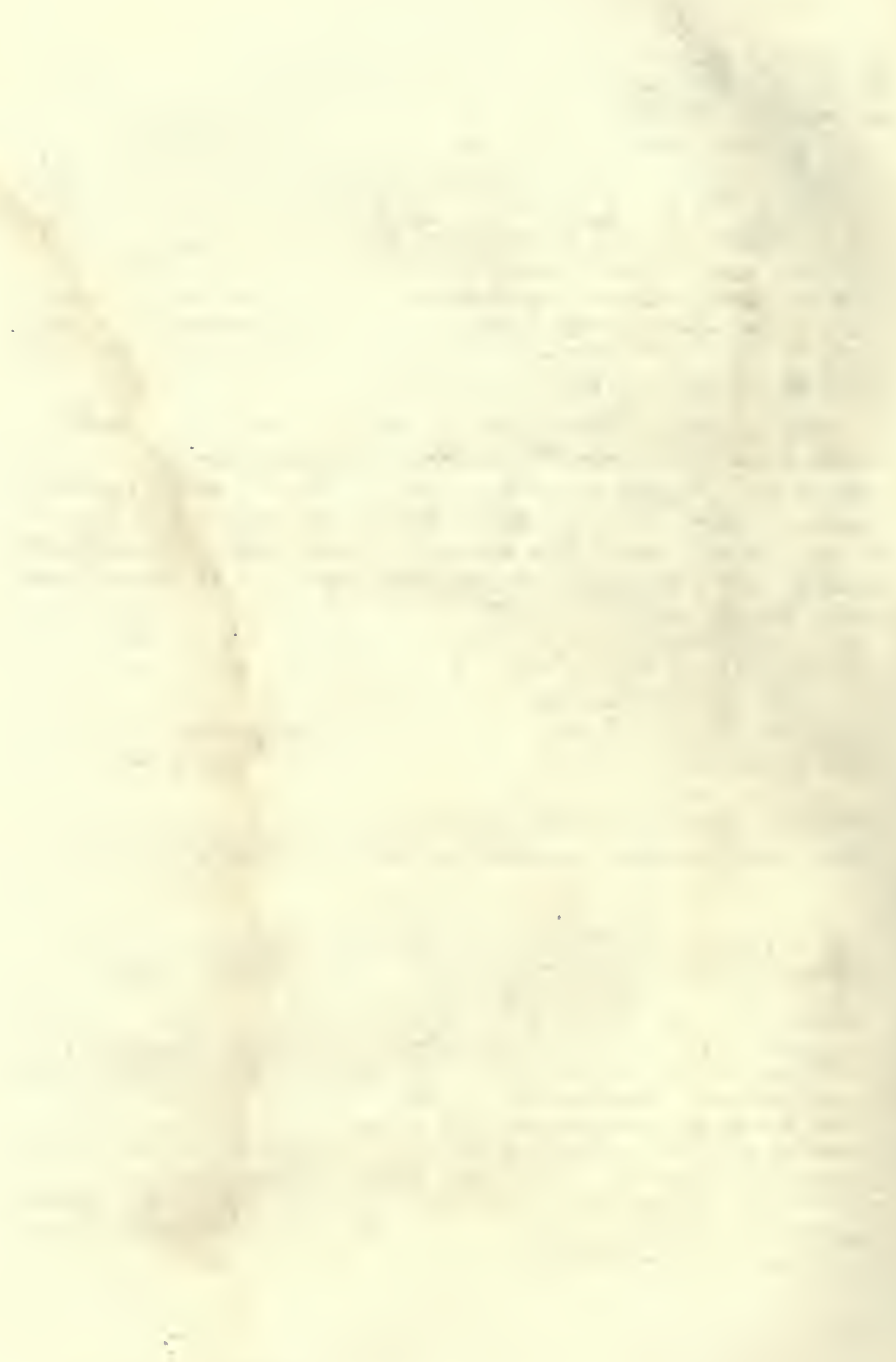




\section{BIBLIOGRAPHY.}

Abbott, C. C. I888. Nymphaca tuberosa in Eastern Waters, in G. \& F. 1: 263.

Abel, L. 1901. Winterharte Nymphaeen und Nelumbien, in Wiener illustrirte Gartenzeitung, 26: 130-134 (not seen).

A. G. (American Gardening). I893, 14: 112 (not seen).

1894, 15: 415 (not seen).

1897, 18: 471 (not seen).

1900, 21: -

Aiton, William. 1789. Hortus Kewensis, 2: 226-228. London.

1811. Hortus Kewensis, Second Edition 3: 292-294. London.

Alpinus, Prosperus. 1592. De Plantis Aegypti liber etc. Venice.

Alpinus, Prosperus, and Veslingius, Joannes. 1735a. Rerum Aegyptiacarum. Leyden. (Opera posthuma, Pars I.)

1735 b. De Laserpitio et Loto Aegyptia (in Opera posthuma, Pars II).

Ameling, E. 1893. "Ueber mittlere Zellgrössen" in Flora, 77: 176-207. Marburg.

Ames, 0. 1900. "An Interesting Group of New Hybrid Blooming Nymphaeas," in American Gardening 2x: 644, No. 301, Sept. 29.

André, Ed. I882. N. zanzibariensis, in Revue Horticole, p. 317-318.

1884. N. alba var. rubra, 1. c., p. 384.

I895 a. Nouveaux Nymphéas, 1. c., p. 258.

1895 b. Les Nymphéacées de Temple-sur-Lot, 1. c., p. 568.

1896. Nouveaux Nymphéas rustiques, 1. c., p. 352-353.

1897. Nouveaux Nymphéas rustiques de M. Latour-Marliac, 1. c., p. 5 I3.

1899. 'Nymphaea Mariae Legrangei,' 1. c., p. 136.

Andrews, Henry C. The Botanist's Repository. London, r799-r8ir.

Appel, 0. I895. Kritische und andere bemerkenswerthe Pflanzen aus der Flora von Coburg, in Mitth. Thür., N. F., 8: 16-20 (not seen). Ref. in Bot. Jhrsber. 1895, 2: 208.

Arcangeli, G. I889. Sulla struttura dei semi della Nymphaea alba, in Nuov. Giorn. Bot. Ital., 2x: 122-125. Firenze 1889.

1890 a. Sulla Emergenze e spine dell' Euryale e sulle cladosclereidi delle Ninfeacee, 1. c. 22: 266-27r. Firenze 189o.

I $890 \mathrm{~b}$. Sulla foglie delle Piante acquatiche e specialmente sopra quelle della Nymphaea e del Nuphar, 1. c., 44I-446.

Arnott, G. A. W. See Wrght, R.

Athenaeus. The Deipnosophists; trans. C. D. Yonge; 3 vols. London, 1854 . Also text and notes of J. Schweighaeuser, in 14 vols., 1805.

Aublet, J. B. C. F. 1775. Histoire des plantes de la Guiane française. London and Paris, I775, 4 vols. 3: 533 .

Bacon, A. 1874. Insects destroyed by vegetables, in Bulletin of the Torrey Botanical Club, 5: 5152. Dec., 1874 .

Bailey, F. M. 1899. The Queensland Flora. Brisbane.

Baillon, H. 1871. Histoire des Plantes, 3: 77-104.

Baldacci, A. 1894. Affinita della Aristolochiacee e dei generi aristolochiacei, in Bull. Soc. Bot. Ital., 1894, p. 49-54. Ref. in Bot. Jhrsber. 1894, 2: 253.

Barber, C. A. 1889. On a Change of Flowers to Tubers in Nymphaea Lotus, var. monstrosa, in Annals of Botany 4: 105-115, with pl. 15 .

Bartélemy, A. 1874. De la respiration et de la circulation des gaz dans les végétaux, in Annales des Sciences Naturelles, Botanique, Série V, 19: 131-I75. 
Bauhin, Caspar. 1623. Pinax theatri botanici, sive Index in Theophrasti, Dioscoridis, Plinii et Botanicorum qui a saeculo scripserunt, etc. Basil. Also, Basil, 167I (the edition I used).

Bauhin, Johannes. I670. Histoire des Plantes de l'Europe, et des plus usitées qui viennent d'Asie, Affrique et Amerique, 2 vols. Lyons.

Baum, H. 1902. Nymphoea Guineensis, in Die Gartenwelt, Aug. 30, 1902, p. 565, with figure (not seen). Ref. in Journ. Roy. Hort. Soc. London. 27: 772. Dec., 1902.

1903. Kunene-Zambesi Expedition, in Auftr. des kolonial-wirthschaftlichen Comités herausgeg. von Prof. O. Warburg. Berlin. Ref. in Bot. Cent. 1903, 93: 492-494.

Beardslee, H. C. 1877 . Some Nymphaeas, in Botanical Gazette 2: 144.

Behm, F1. 1887. Fiån botaniska excursioner i Jemtland och Herjedalen [Sweden], in Botaniske Notiser, I857, p. 176-184 (not seen). Ref. in Bot. Jhrsber., 1887. 2: 396.

Bello y Espinosa, D. D. I881. Apuntes para la flora de Puerto-Rico, in Anales Sociedad Española de Historia Natural, 10: 23I-304. Madrid. Presented Sept. I, I880.

Bellonus, Petrus. I605. See Clusius, 1605.

Bentham, G., and Hooker, J. D. I862. Genera Plantarum, vol. I. London, I862-67; Part I. I862, pp. I-434.

Bentham, G., and Muller, F. von. I863. Flora Australiensis, I: 61-62. London, 1863.

Besler, B. I6I3. Hortus Eystettensis.

Blanco, P. F. M. 1878. Flora de Filipinas, 2: 222-223. Manila.

Blass, J. I891. Untersuchungen über die physiol. Bedeutung des Siebtheils der Gefässbündel, in Pringsheim's Jhrbchr. f. wiss. Bot. 22: 253-292.

Bleicher, G. See MrEg, M.

Blume, C. L. I826. Kruidkundige Waarnemingen, in Linnaea I: 643-668.

Bock, Hieronymus. 155I. Kreuter Buch. Darin unterscheidet Namen und Würckung der Kreuter, etc. Strassburg.

Bodaeus à Stapel. I644. See Theophrastus, I644.

Bolus, H., and Wolley-Dod, A. H. Ig03. A list of the flowering plants and ferns of the Cape Peninsula, etc., in Trans. S. African Philosoph. Soc. 14: 207-373. Ref. in Bot. Cent. I904, p. 405.

Boissier, Edm. 1867. Flora Orientalis I: 104. Basel and Geneva.

1882. Plantes sèches trouvées sur des momies par M. le Dr. Schweinfurth (Extrait d'une lettre du 17 décembre $188 \mathrm{I}$, addressée à Edm. Boissier), in Archives des Sciences Physiques et Naturelles, Troisième Période, 7: 147-149. Geneva.

1888. Flora Orientalis, supplement, 22-23.

Bonavia, E. I894. The Flora of the Assyrian Monuments and its outcomes. Westminster.

Bonnier, G. I890. Observations sur les Berbéridées, Nymphéacées, Papavéracées et Fumariacées de la Flore de France, in Revue Générale de Botanique 2: 276, 446, 549.

Bontius, Jacobus. 1658. See Piso, 1658.

Borbás, V. von. I88I. Ueber Nuphar sericeum Láng in Botan. Centralbl. 6: 42 I-423.

Boreau, Alex. 1859. In Mémoirs de la Société Académique de Maine et Loire. 6: 37-8. Angers.

Brand, F. I894. Ueber die drei Blattarten unserer Nymphaeaceae, in Bot. Centralbl. 57: 168-171. Cassel, I 894 .

Branner, J. C., and Coville, F. V. I888. A list of the plants of Arkansas, corrected by W. Trelease, in Annual Report of the State Geologist, I888, vol. 4, part 2.

Braun, H. I890. Neue Funde aus Ungarn, in Oesterr. Bot. Ztschr. 1890, p. 27-30, 60-68, I36-137 (not seen). Ref. in Bot. Jhrsbr. I890. 2: 394.

Breynius, Jacobus. I680. Prodromi fasciculi rariorum plantarum primus [1680] et secundus [I689], etc., ed. Joh. Philip. Breynii. Gedani, I739.

Britten, J. I888 a. The Nomenclature of Nymphaea, etc, in Journ. of Botany, Brit. and For., 26: 6-10. London, January, 1888.

I888 b. Recent tendencies in American botanical nomenclature, 1. c., p. 257-262.

Britten, J., and Holland, R. 1879. A dictionary of English plant names, Part II. (English Dialect Society: London, I879.) 
Britton, N. L. I889 a. Catalogue of the plants of New Jersey, in Geolog. Survey of N. J., Final Report of the State Geologist, 2: 43. Trenton, 1889.

$1889 \mathrm{~b}$. The A. A. A. S. Botanical Club's Trip to the Lakes of Muskoka, Ontario, Aug. 31 to Sept. 2, 1889, in Bull. Torr. Bot. Cl. 16: 285-290. New York, 1889.

1890. On the naming of "Forms" in the New Jersey Catalogue, in Bull. Torr. Bot. C1. 17: 121-126.

Britton, N. L., and Brown, Ad. I897. An Illustrated Flora of the Northern United States, Canada, and the British Possessions, 2: 42-45. New York, 1897.

Britton, N. L., Coulter, J. M., Rusby, H. H., etc. I894. List of Pteridophyta and Spermatophyta crowing without cultivation in Northeastern North America, in Memoirs of the Torrey Bot. Cl. 5: I53-I54. Nymphaeaceae by Thos. Morong, May 5, I894.

Britton, N. L., Stern, Poggenburg, etc. 1888. A Preliminary Catalogue of Anthophyta and Pteridophyta reported as growing spontaneously within 100 miles of New York City. New York, Apr. 25, r888. See also Morong, T. See also Hollick, A.

Brodhead, G. C. 1878. On the Distribution of Certain Plants in Missouri, in Bot. Gazette 3: 51. Brongniart, A. T. 1822. Sur la classification et la distribution des végétaux fossiles. Paris. 1827. Mémoire sur la génération et le développement de l'embryon dans les végétaux phanérogames, in Ann. Sci. Nat., Bot., 12: 225-296.

1849. Tableau des genres de végétaux fossiles, p. II7-II9.

Brown, Ad. See Britton, N. L.

Brown, R. 1827. Observations on the structure of the unimpregnated ovulum, in Miscellaneous Botanical Works of Robert Brown, I: 439-452. London, I866 (not seen).

Buckhout, W. A. 1891. Notes from a Pennsylvania Garden, in Garden and Forest, 4: 69.

Buckley, Edm. I897. Universal Religion; a course of lessons, historical and scientific, on the various faiths of the world. Chicago.

Bunge, D. A. See Meyer, D. C. A.

Bureau, E. 1888. Études sur la Flore fossile du calcaire grossier parisien, in Mém. publ. par la Soc. Philomath. à l'occasion du cent. de la fécundation, 1788-1888, 2 pl. Paris (not seen). Ref. in Bot. Jhrsber. 1888, 2: 249.

Burman, N. L. 1768. Flora Indica 4: 24I. Leyden.

Burmann, J. I759. Plantarum Americanarum Fasc. 9, p. 205.

Cambessedes, J. 1844. See JACQuemont, 1844.

Campbell, D. H. 1902. On the affinities of certain anomalous dicotyledons, in American Naturalist, 36: 7-12. Jan., I902.

Carrière, E. A. 1878. N. sphaerocarpa, in Revue Horticole.

1879a. Prolification d'un Nymphaea rubra, in Rev. Hort. p. 74-75.

1879 b. Nymphaea Caspary, 1. c., p. 230.

1880. N. Caspari, 1. c., p. 403.

1884. N. Alava, 1. c., p. 479-480.

I888. N. Casparyi alba, 1. c., p. 300 .

Caspary, Robert. 1854. [On growth of leaves.] Versammlung der Naturforscher in Göttingen, Tageblatt, p. 28. Sept. 20. Ref. in Flora, I854, p. 642.

1855. De Nymphaeae albae varietatibus, in Catal. sem., hort. Berol. 1855. Flora, 1856, p. 488-496. Walpers Annales botanices systematicae, 4: 162-166. 1857.

1856. Les Nymphéacées Fossiles, in Annales des Sciences Naturelles, Botanique, Sér. 4; 6: 199-222. Paris, 1856.

1857 a. In Koelner Zeitung, Beilage, I4 Febr. (not. seen).

1857 . Bericht über die Verhandlungen der botanischen Sektion der 33. Versammlung deutscher Naturforscher und Aerzte, gehalten in Bonn vom I8. bis 24. September, 1857, in Botanische Zeitung, 15: 784-792, and in Flora, 1857, p. 717-718.

1858. Monographie der Hydrilleen, in Jhrbchr. f. wiss. Botanik x: 377-513; pl. Xxv-xxIx. 1859. Botanische Verhandlungen der niederrheinischen Gesellsch. f. Natur und Heilkunde zu Bonn im Jahre 1858, in Flora, 1859, p. II8-119, I39, I43-144. 
Caspary, Robert. 1862, in Berliner Monatsber., p. 464 ff. (not seen).

$186_{3}$, in Oesterr. Bot. Ztschr. (not seen).

1865. Nymphaeaceae in Miquel's Annalcs Musci Botanici Lugduno-Batavi, 2: 24 I-253. Amsterdam, I865-66.

1870, in Schr. Phys.-oek. Ges. Königsberg, p. 62 (not seen).

1870, in Abh. Naturf. Ges. zu Halle, 11: 25 I ff. (not scen).

1871. Nymphaea alba L. var. sphaerocarpa Casp. subvar. rubra käuflich, in Botan. Ztg., p. 874 .

1873. Nymphaeaceae a Frederico Welwitsch in Angola lectae, in Journ. de Scienc. Math., Phys., e Nat. da Acad. Real das Sci. de Lisboa. Dec, 1873, p. 312-327.

1877. Nymphaea sansibariensis, n. sp., etc., in Bot. Ztg. Mar. 30, 1877, p. 200-203.

1878. Nymphaeaceae, in de Martius' Flora Brasiliensis 4: part 2, p. 129-184. Leipzig, June, 1878 .

1879. Hvilken utbredning hafva Nymphacacecrna i Skandinavien? in Botaniska Notiser, 1879, p. 65-93. Stockholm (not seen). Ref. in Bot. Jhrsber. 1879, 2: 229-230; 1880, 2: 562 .

1880. Nymphaeaceae, in Reliquiae Rutenbergianae I. in Abhandl. herausgeg. vom Naturwiss. Vereine zu Bremen, 7: IO-II.

1882. N. Zanzibariensis, in Wittmacks Gartenzeitung, 1882, p. I-6.

I883. Bericht ueber die Untersuchungen der Seen der Kreise Graudenz, Kulm und Thorn, I882, in Schr. d. Phys.-Oekonom. Gesellsch. zu Konigsberg, 1883, 24 Jhrg., I Abth. p. 83-87 (not seen). Ref. in Bot. Jhrsber. I883, 2: 280.

1884. Bericht ueber die 22. Versamml. des Preuss. Bot. Vereins zu Maricnberg in Westpreusscn am 9 Oct., I883, 1. c., I884, I Abth. p. 45-III (not seen). Ref. in Bot. Jhrsber. $1884,2: 277$.

1886. Ber. ü. die 23. Versamml. des Preuss. Bot. Ver. zu Memel am 7 Oct., I884, 1. c., I885, p. 40 (not seen). Ref. in Bot. Jhrsber. I886, 2: 419.

1888. Nymphacaceac, in Engler \& Prantl's Natürlichen Pflanzenfamilien, vol. 3, part 2, p. I-10. Published Jan. 17, I888.

Cělakovsks, L. I867. Prodromus der Flora von Bölımen.

Celsus, A. Cornelius. Of Medicine, trans. James Greene, M. D., Ed. III., revised by Geo. Futvoye. London, 1838.

Chabraeus, Dominicus. 1677. Stirpium sciagraphia et icones ex museo Chabr. Geneva.

Chamberlain, J. C. See Coulter, J. M.

Chamisso, Ad. de. 1831. De plantis in Expeditione Romanzoffianz observatis disserere pergitur. Arcticae, in Linnaea 6: 588.

Champollion le jeune. Panthéon Egyptien.

Chapman, A. W. 1883. Flora of the Southern United States.

Chevalier, Aug. I900a. Mon exploration botanique du Soudan français, in Bull. du Muséum d'Histoire naturelle, Paris, 1900, No. 5, p. 248-254.

$1900 \mathrm{~b}$. Mon exploration botanique de la Sénégambie, 1. c. No. 6, p. 302-308.

Chifflot, J. B. J. 1902. Contributions à l'étude de la Classe des Nymphéinées. Annales de l'Univ. de Lyon, Nouv. Sér. I, Sciences, Médecine. Fasc. 40, 294 pp.

1903. Sur la structure de la graine de Nymphaea flava Leitn., in Compt. Rend. 136: 15841586. Ref. in Bot. Ccnt. 93: 200.

Cler, 0. 1873. Ueber einige Pflanzen aus dem Ural, in Schr. d. Uralsch. Gesellsch. der Liebhaber der Naturwiss. 1: 28 (not seen). Ref. in Bot. Jhrsber., 1873, p. 60r.

Clusius, Carolus. 1576. Rariorum aliquot stirpium per Hispanias observatorum Historiae, lib. 2. Antwerp.

1601. Rariorum Plantarum Historia. Antwerp.

I605. Exoticorum libri decem, etc.: item Petri Bellonii observationes. Antwerp.

Commelin, Caspar. I696. Flora Malabarica, sive horti Malabarici catalogus, etc. Leyden.

Conard, H. S. Ig0I $a$. Nymphaea, in Bailey's Cyclopedia of American Horticulture, 3: I IoI-9. 1901 b. A new tender Nymphaea, in American Gardening, 22: 745. Nov. 2. 


\section{BIBLIOGRAPHY.}

Conard, H. S. 1902. Note on the embryo of Nymphaea, in Science, 15: 316, Feb., 1902. Ref. in Bot. Gazette, 33: 389-390.

1903. Nymphaea (sub-gen. Brachyceras) in Africa, in Annuaire du Conservatoire et du Jard. Bot. de Genève. May 15.

Constantin, J. 1885. Sur la structure des feuilles du Nymphaea rubra et du Nuphar luteum, in Bull. Soc. Bot. de France, 32: p. xv (not scen).

1886. Études sur les feuilles des Plantes aquatiques, in Ann. Sci. Nat. Bot. Sér. 7, 3: 94-162.

Constantinus, Robertus. See Theophrastus.

Cook, M. T. 19a2. Development of the Embryo-sac and Embryo of Castalia odorata and Nymhaea advena, in Bull. Torr. Bot. Cl. 29: 211-220, pl. 12, 13. April.

Cooke, T. 1901. Flora of the presidency of Bombay, Part I. Bombay.

Coulter, J. M. 1890, in Contributions from the U. S. Nat. Herb., June 28, 1890, p. 30-65.

I891. Manual of the Phanerogams and Pteridophytes of western Texas, in Contrib. from the U. S. Nat. Herb. 2: II-12. See also Britton, N. L.

Coulter, J. M., and Chamberlain, C. J. I903. Morphology of Angiosperms. New York.

Coville, F. V. See Branner, J. C.

Curtiss, A. H. 1902. The Yellow Water-lily of Florida, in Plant World, 5: 106-9, with Fig. June (not seen).

Dahmen, Max. I892. Anatomisch-physiologische Untersuchungen über den Funiculus der Samen, in Pringsheim's Jhrbchr. f. wiss. Bot. 23: 462.

Dalton, W. 1853. History of British Guiana, 2: 241.

De Bary, A. I884. Comparative Anatomy of the Phanerogams and Ferns.

De Candolle, A. P. 1805. Sur la graine des Nymphaea, in Soc. Philom. Bull. 3: 68. Paris.

1821 $a$. Sur les affinités naturels de la famille des Nymphéacées, in Mém. Soc. Pliys. x: 208-244. Geneva (not seen).

1821 $b$. Regni Vegetabilis Systema Naturale, 2: 49-59.

1824. Prodromus Systematis Naturalis Regni Vegetabilis, Part I, p. II4-II6.

De Halácsy, E. 1900. Conspectus Florae Graecae, 1: 37.

Delessert, B. Icones selectae. Paris, 1820-46.

Delile, A. R. 1802. Observations sur les Lotus d'Egypte, in Annales du Muséum d'Histoire Naturelle, r: $372-382$. Paris.

1813. Florae aegyptiacae illustratio, in Description de l'Egypte. Paris.

Delpino, F. 1869. Alcuni appunti di geogr. botanica, in Bull. d. Soc. geogr. ital., Fasc. 3, p. I7 (not seen).

1871. Eintheilung der Pflanzen nach dem Mechanismus der dichogamischen Befruchtung, und Bemerkungen über die Befruchtungsvorgänge bei Wasserpflanzen, in Bot. Ztg. 29: $443-445,447-459,463-467$.

Dennert, E. See Wigand, A.

Diodorus Siculus, the Historical Library of. Trans. G. Booth. London, I700.

Dioscorides, Pedanios. De Materia Medica libri quinque. Ed. Curtius Sprengel. Leipzig, I829. 2 vols.

Dodonaeus, Rembertus. 1583. Stirpium historiae pemptades sex. Antwerp.

Don, Geo. 1831. A gencral History of dichlamydeous plants, 1: 126.

Donn, J. 1831. Hortus Cantabrigiensis, 12th edition, by Geo. Sinclair. London, p. 25I.

Douliot, H. See Van Tieghem, Pir. 1888.

Dryander, J. I80I. Description of N. caerulea, in Bot. Mag. tab. 552.

Duchartre, P. E. 1858. In Journ. Soc. imp. et cent. d'horticult. 4: 175, with plate (not seen). 1877. In Journ. Soc. Hort. p. 817 (not scen).

Durand, Th., and Schinz, H. 1898. Conspectus Florae Africae, r: 55-56. Brussels, Berlin, and Paris.

See also Wildeman, Ém. DE.

Duppa, R. 1813. Illustrations of the Lotus of Antiquity. London.

1816. Illustrations of the Lotus of the ancients and Tamara of India. London. (Only 25 copies of this were printed; I have secn neither of Duppa's works.) 
Dutt, M. N. 1895. Mahabharata. Prose English translation, 1895-97.

Dyer, Sir Wm. Thistleton. Flora Capensis (not seen).

Edgeworth, M. P. 1845. Descriptions of some unpublished species of plants from North West India, in Trans. Linn. Soc. London. 20: 23-91, 1851. Read June 3, 1845.

Eichler, A. W. 1875. Blüthendiagramme, vol. I. 1878. Blüthendiagramme, 2: 186.

Ellwell. Påli Vocabulary (not seen).

Endlicher, S. L. 1836. Genera Plantarum. Vienna, 1836-50 (not seen).

Endlicher, S. L., and Unger, F. 1843. Grundzüge der Botanik, p. 92, Fig. 94. Wien.

Engler, A. 1879. Versuch einer Entwicklungsgeschichte der Pflanzenwelt. Vol. I, I879; vol. $2,1882$.

1895. Die Pflanzenwelt Ost-Afrikas und der Nachbargebiete, Theil C. Berlin, p. I78. 1898. Syllabus der Pflanzenfamilien, p. II5.

Igor. Beiträge zur Flora von Afrika, in Engler's Bot. Jahrb., 30: 308.

Eriksson, J. 1876. Ueber den Vegetationspunkt der Dikotylen-Wurzeln. Eine vorläufige Mittheilung, in Bot. Ztg., 34: 64I-644.

1877. Ueber das Urmeristem der Dicotylenwurzeln, in Jahrbücher f. wiss. Botanik, I1: $380-435$, pl. 18-27. 1878.

Espinosa. See Bello y Espinosa. I88I.

Ettingshausen, K. von. 1877. Die fossile Flora von Sagor in Krain, in Denkschr. d. math.-naturw. Cl. d. Kais. Akad. d. Wissensch. in Wien., 37: I86.

1888. Die fossile Flora von Leoben in Steiermark, 1. c. 54: 319-384.

Falkenberg, P. 1874. Stammbau der Monocotylen. Vorl. Bericht, in Nachr. v. d. kgl. Ges. d. Wiss. zu Göttingen, 17. Sept. 1874; also Bot. Ztg. I874, p. 731.

1876. Vergleichende Untersuchungen über den Bau der Vegetationsorgane der Monocotyledonen. Stuttgart.

Fischer, H. I8go. Beiträge zur Vergleichenden Morphologie der Pollenkörner. Breslau.

Flacourt, Etienne de. 166r. Histoire de la grande isle Madagascar. Troyes et Paris, I66I [also Paris, 1658 ].

Flahault, Ch. 1878. Recherches sur l'accroissement terminal de la racine chez les Phanérogames, in Ann. Sci. Nat, Bot., Sér. VI, 6: I-I68.

Fliche, P. See Mieg, M.

Flora. 1833, p. 648-651. [Discussion of $N$. alba minor.]

Focke, W. 0. I881. Die Pflanzen-Mischlinge. Berlin, p. 24-27.

Forbes, F. B., and Hemsley, W. B. I899. An enumeration of all the plants known from China proper, Formosa, Hainan, etc., in Journ. Linn. Soc., Botany, 26: 457-538, etc.

Frank, A. B. I868. Beiträge zur Pflanzenphysiologie, p. I50 (not seen).

1872. Ueber die Lage und Richtung schwimmender und submerser Pflanzenteile, in Cohn's Beiträge z. Biol. d. Pflanz., ı: 31-86, Heft. 2.

Freidenfelt, T. Igoo. Studier öfver örtartade växters rötter, in Botaniska Notiser, Heft 5, 15 pp. (not seen). Ref. in Bot. Centralbl. 86: 156-161; 1901.

Friend, H. 1882. A Glossary of Devonshire Plant Names. London. English Dialect Society.

Fridolin, A. 1884. Vergleichende Untersuchungen der Gerbstoffe des $N$. alba, etc. Inaug. Dissert. Dorpat., 94 pp. (not seen).

Fries, E. M. 1836. Botanisch-antiquarischer Ausflug zu den Nymphaeaceen der Griechen. Upsala, 1836 (not seen). Ref. in Bot. Ztg. 3: 463-464 (1845).

1846. Summa Vegetabilium Scandinaviae, 1846-49 (not seen).

1858. Kürzere briefliche Mittheilungen, in Bot. Ztg., p. 73.

Fritsch, K. 1852. Kalender der Flora des Horizontes von Prag (not seen).

Fuchsius, Leonhartus. I55I. Plantarum effigies; Lugduni apud Arnolletum. [Smaller edition from the Historia Stirpium; folio, 1552; Pritzel.]

Gaertner, J. 1788. De Fructibus et Seminibus Plantarum 1: 72-73.

Galenus, Claudius. De simplicium medicamentorum temperamentis ac facultatibus, and De alimentorum facultatibus, in Opera Omnia, ed. C. G. Kuhn, 20 vols. Leipzig 1826. 
Garden, The (London). 1873. N. odorata, 4: 368 (poor).

1879. N. alba rubra, 15: 235.

1882. N. tuberosa, 2x: Iзо.

I883a. N. Devoniensis, 23:-Apr. I4.

1883 b. 23: 334 .

1891. 39: 519 (not seen).

1897. N. tuberosa, 52: 44 (bad).

1899. N. odorata, 55: 179 .

Gave, P. I892. In Proc. Société Dauphinoise, 2d series (not seen).

G. C. (Cardeners' Chronicle). I852. N. devoniensis, p. 435.

1887. N. Kewensis, p. 366.

1899. N. fennica, p. I 38 (Mch. 4).

1900. N. gigantea, p. 77 (with poor wood cut).

Igor a. Hybrid Water Lilies, p. I57, Mch. 9. Condensed from The Garden of Feb. 9.

IgoI $b$. [Exhibit at Royal Horticultural], p. I4I, I55, I60.

IgoI c. Mr. Maurice Pritchard's Christchurch, p. 222-223; also p. 327.

Georgi, J. G. I775. Bemerkungen einer Reise im Russischen Reich im Jahre 1772. I: 220. St. Petersburg, I775 (not seen).

I800. Beschreibung des russischen Reichs. 3: part 4, p. I845.

Gerard, John. 1636. The Herball or Generall Historie of Plantes. Gathered by John Gerard, very much enlarged and amended by Thomas Johnson. (Original ed., 1597, Pritzel).

Gerard, J. N. I8goa. Nymphaea pygmaea alba, in G. \& F., 3: 374.

I 890 b. The Water Garden, in G. \& F., 3: 480 .

I89I. The Water Garden, in G. \& F., 4: 453.

I892. The Water Garden, in G. \& F., 5: 332-3.

1893. The Water Garden, in G. \& F., 6: 347 .

I894. N. Sturtevantii, in G. \& F., 7: $354-356$ (with good half tone of flower).

Gerardus, L. I76r. Flora Gallo-provincialis.

Gericke, H. 1879. Einiges aus dem Boehmerwalde, in Abh. d. Naturforsch. Gesell. zu Goerlitz, 16: 214-261 (not seen). Ref. in Bot. Jhrsber. 1879, 2: 258.

Geyler, H. Th. I882. Verzeichniss der Tertiärflora von Flörsheim a. M., in Ber. ü. d. Senckenberg. naturf. Gesellsch. 1882-83, p. 285-286 (not seen).

G. \& F. (Garden and Forest). 1888. Castalia Leibergi, I: 186, June I3.

I893a. N. gigantea, 6: 40-4I (with good half tone).

I893 b. N. tuberosa, 6: 415-4I6 (with good half tone of flower).

1894 $a$. N. Odorata, 7: 60 .

I894 $b$. Plant notes, 7: 326.

Giles, Herbert Allen. I884. Gems of Chinese Literature. London.

Gilg, E. Ig03. Nymphaeaceae in "Kunene-Zambesi-Expedition," p. 234-236. Cf. Baum Igo3.

Gmelin, J. G. 1769. Flora Sibirica, 4: 183, tab. 71. St. Petersburg.

Godfrin, J. I880. Etude histologique sur les téguments séminaux des Angiospermes. Nancy (not seen).

Godman, F. D., \& Salvin, O. I888. Biologia Centrali-Americana. Botany, I: 24-26, by W. B. Hemsley.

Goebel, K. I886. Zur Entwickelungsgeschichte des unterständigen Fruchtknotens, in Bot. Ztg., 44 Jhrg., p. 729-738.

1887. Outlines of classification and special morphology, trans. by H. E. F. Garnsey.

1893. Pflanzenbiologische Schilderungen, 2: 215-373, Wasserpflanzen.

Goodale, G. L. I886. Wild Flowers of America, Boston, I886 (pl. 38).

Goodyear, W. H. I8gr. The Grammar of the Lotus (not seen).

Graebener, L. 1887. Noch einmal die Nymphaea Zanzibariensis Casp. var. flore rubro, in Wittmack's Gartenflora, 36: 258-259.

Gray, Asa. I850. Plantae Wrightianae, I: 7, in Smithsonian Contributions to Knowledge, vol. 3. Washington, 1852 .

I876. Nymphaea flava, in Silliman's Journal, $\mathbf{x}$ : 416. 
Gray, Asa. I889. Manual of the Botany of the Northern United Statcs, Gth ed. Preface by S. Watson, Dec. 26, 1889 .

See also TORREY, J.

Gray, Asa, S. Watson and B. L. Robinson. 1895. Synoptical Flora of North America, I: part I, p. 75. Oct. 10, I895, fascicle I.

Greene, E. L. 1887 a. Bibliographical notes on well-known Plants; III, Nymphaea and Nuphar, in Bull. Torr. Bot. Cl. I4: 177-179 (September).

1887 b. Bibliographical Notes on well-known Plants; VI, Nymphaea and Nuphar, 1. c., p. 257-258 (December).

1888. Bibliographical Notes on well-known Plants; VII, Castalia and Nymphaea, 1. c. I5: 84-85 (March).

Gremli, A. 1882. Neue Beitrāge zur Flora der Schweiz, Hcft 2, pp. I-55. Aarau, I88z (not seen). Ref. in Bot. Jhrsber. I882, 2: 540.

Grew, Nehemiah. 1672. The Anatomy of Vegetables. London.

1681. Musaeum Regalis Soeietatis. London.

Grey, R. M. 1900. New Hybrid Nymphaeas, in American Gardening, 21: 516, No. 293, Aug. 4.

Grisebach, A. H. R. 1857. Systematische Untersuchungen ueber die Vegetation der Karaiben, in Abhandl. -der königl. Gesellsch. der Wisscnsch. zu Göttingen, 7: 15I-286 (not seen).

I864. Flora of the British West Indian Islands.

_ 1882. Flora Europaea, fragmentum. Reliquiae Grisebachianae, edited by A. Kanitz (not seen). Ref. in Bot. Jhrsber. 1882, 2: 43.

Gronovius, J. F. 1762. Flora Virginica, ed. 2.

Grüning, W. 1881. Beiträge zur Chemie der Nymphaeaceen. Inaug. Dissert. Dorpat. 78 pp. (not seen).

Guettard, J. E. 1747. Observations sur les plantes. Paris (not seen).

Guillemin, A., and Perrottet, S. 1830. Florae Senegambiae tentamen. Paris, 1830-33.

Gwynne-Vaughn, D. T. 1896 a. A New case of polystely in Dicotyledons, in Annals of Botany, 10: $289-291$.

I896 b. The arrangement of vascular bundles in certain Nymphaeaceae, 1. c., p. 624-625.

1897. On some points in the Morphology and Anatomy of the Nymphaeaceae, in Trans. Linn. Soc. London, 5: 287-299, pl. 2I-22.

Haberlandt, G. 1877. Schutzeinriehtungen in der Entwickelung der Keimpflanze. Wien (not seen).

1884. Physiologische Pflanzenanatomic.

Hallier, Hans. I903. Ueber die Verwandschaftsverhältnisse bei Engler's Rosalen, etc., in Abh. aus dem Gebiete der Naturwissensch. Naturw. Vcrein in Hamburg, r8: I-98. Ref. in Bot. Cent. 1904, pp. 223-224.

Hansen, E. C. 1874. Pflanzenreste in den Schichten dänischer Torfmoore, reviewed in Naturforscher, No. 47, p. 448 (not seen).

Hansgirg, A. I880. Floristisches aus der Königgrätzer Gegend in Böhmen, in Oest. Bot. Ztschr., 30: 394-397 (not seen). Ref. in Bot. Jhrsber., I880, 2: 588.

Hanstein, J. 1858. Ueber den Zusammensetzung der Blattstellung mit dem Bau des dicotylen Holzringes, in Jhrbchr. f. wiss. Bot., r: 233.

Harper, R. M. I903. Botanical explorations in Georgia during the summer of Igor, in Bull. Torr. Bot. Cl. 30: 319-342. Ref. in Bot. Cent. 93: 20. 1903. Gives Castalia odorata latifolia, new var.

Harshberger, J. W. I899. Botanists of Philadelphia and their Work. Philadclphia.

Hartman, C. J. I870-71. Handbok i Skandinaviens Flora, ed. 10, p. 86 (not seen).

Harvey, F. W. 1880. Distribution of Nymphaeaceac in Arkansas, in Bot. Gazette, 5: 140.

Harvey, W. H. I838. The Genera of South African Plants, ed. I, Cape Town, I838 (not seen).

Harvey, W. H., and Sonder, O. W. 1859. Flora Capensis, vol. 1, Dublin, 1859-60.

Hasselquist, F. I757. Iter palaestinum. Stockholm (1tot seen).

Hausleutner, J. L. E. I850. Ueber eine neue Nymphaea aus Sehlcsicn, in Bot. Ztg., 8: 905-908.

Heckel, Ed. 1879. Des poils et des glandes pileuses dans quelques genres de Nymphéacées, in Compt. rend. 89 : 758-759 (not scen). 
Heer, 0. I86I. Recherches sur le climat et la végétation du pays tertiaire. Winterthur. (German ed., ibid., 1860). See also Zeitschr. gesammt. Naturwiss. XV: I-42. I859 (not seen).

1865. Die Urwelt der Schweiz, 2d ed. English trans. by J. Heywood. London, 1876.

I869. Die Miocene Flora u. Fauna Spitzbergens, in Svenska Vetensk. Acad. Handl. VIII, No. 7 ; also Zeitschr. gesammt. Naturwiss., hrsg. von C. Giebel u. W. Heintz. 39: 405$408 ; 1872$.

I878 a. Flora fossilis arctica, vol. 5, part I, Die Miocene Flora des Grinnell-Landes. Zürich.

1378 b. Flora fossilis arctica, vol. 5, part 2, Beiträge zur fossilen Flora Sibiriens und des Amurlandes.

I878 c. Notes on Plants discovered in Grinnell Land by Capt. H. W. Feilden, Naturalist of the English North-polar Expedition, in Quart. Journ. Geolog. Soc., I878, p. 66-70.

Hemsley, W. B. 1879. The Hardy Red Water Lily, in The Garden (London), 15: 516 (with fair colored plate).

1888. See Godman \& Salvin, 1888.

See also Forbes, F. B.

Henfrey, A. 1852. On the anatomy of the stem of Victoria regia, in Philos. Transact. 1852, p. 289-294 (not seen).

Henslow, G. I892. A theoretical origin of Endogens from Exogens, in Journ. Linn. Soc. London, Botany, 29: 485-488.

1895. The origin of plant structures by self-adaptation to the environment. London, pp. 136-179.

Hentze, W. 1848 a. Beschreibung einer neuen Nympliaea, in Bot. Ztg., 6: 601-604, Aug. 25.

— I $848 \mathrm{~b}$. Weitere Mittheilung ueber die Untersuchung deutscher Seerosen, in Bot. Ztg., 6: 697-702. Oct. 6.

1852 a. In Ann. Sci. Nat. Bot., Sér. 3, 18: 377.

$1852 b$. Berichtigung, in Bot. Ztg., 10: 745-747. Oct. 22.

Herodotus. Literally translated from the Text of Baehr by Henry Cary, M. A. London, I891.

Hervey, E. W. I899. Observations on the color of flowers. New Bedford, Mass.; I05 pp.

Hildebrandt, F. 1874. Die Verbreitungsmittel der Pfanzen. Leipzig (not seen).

Hildebrandt, J. M. I879. Von Mombassa nach Kitui, in Zeitschr. der Gesellsch. für Erdkunde zu Berlin, 14: 259 (not seen). Ref. in Bot. Jhrsber. 1879, 2: 477.

Hill, E. J. I890. Notes on the Flora of the Lakc Superior Region, I. The Northern Peninsula of Michigan, in Bot. Gazette, 15: 140-149.

1891. Notes on the Flora of the St. Croix Region, 1. c. 16: 126-130.

Hitchcock, A. S. I8go. Catalogue of the Anthophyta and Pteridophyta of Ames, Iowa. Contributions from the Shaw School of Botany, No. 7, in Trans. Acad. Sci. St. Louis, 5: 477-532.

Hofmeister, W. I858. Neuere Beobachtungen über Embryobildung der Phanerogamen, in Jhrb. f. wiss. Bot., $\mathrm{x}: 82$-189.

1867. Handbuch der Physiologischen Botanik, I: part I, Die Lehre von der Pflanzenzelle. Leipzig.

1868. Handbuch der Physiologischen Botanik, 1: part 2, Allgemeine Morphologie der Gcwầchse. Leipzig.

Holfert, J. 1890. Die Nährschicht der Samcnschalen, in Flora, 77: 279-313 (not seen).

Holland, A. See Britten, J.

Holland, P. Sce Pliny.

Hollick, A., and Britton, N. L. 1886. Flora of Richmond County, New York; Additions and New Localities, in Bull. Torr. Bot. Cl. 13: 83-84.

Hooker, J. D. I872. Flora of British India. London; pp. II3-II6.

1881. Nymphaea tuberosa, in Botanical Magazine, tab. 6536.

1883. Nymphaea odorata minor floribus roseis, 1. c., tab. 6708.

1884. Nymphaea alba var. rubra, 1. c., tab. 6736. 
Hooker, J. D. I885. Nymphaea stellata var. Zansibariensis, 1. c., tab. 6843.

1887. Nymphaea flava, 1. c., tab. 6917.

1888. Nymphaea Kewensis, 1. c., tab. 6988.

Igor. Nymphaca flavo-virens, 1. c., tab. 7781.

See also BenthaM, G.

Hooker, J. D., and Jackson, B. D. I893. Index Kewensis. London.

Hooker, J. D., and Thomson, Th. 1855. Flora Indica, x: 285 pp. Ref. in Gard. Chron., I855, p. 723.

Hooker, W. J. 1846. Nymphaea dentata, in Bot. Mag. tab. 4257.

1849. Nymphaea ampla, 1. c. tab. 4469.

1850. Nymphaca micrantha, 1. c. tab. 4535 .

1851. Nymphaea elegans, 1. c. tab. 4604.

1852 a. Nymphaea gigantea, 1. c. tab. 4647 .

1852 b. Nymphaea Devoniensis, 1. c. tab. 4665 .

1854. Nymphaea amazonum, 1. c. tab. 4823 .

Irmisch, T. 1859. Zur Naturgeschichte des Potamogeton densus Lo, in Flora 1859, p. 129-139.

Jackson, B. D. See HoOKER, J. D.

Jacquemont, V. I844. Voyage dans l'Inde, 4: I I-I2, Botanique. Paris, I844.

Jahn, E. I896. Ueber Schwimmblätter, in Beitr. z. wiss. Bot., r: 284-294. Ref. in Rev. Gen. de Bot., Ir: 79.

James, D. L. I881. Nymphaea odorata, in Botan. Gazette, 6: 266-267.

Janczewski, Ed. de. $1874 a$. Recherches sur l'accroissement terminal des racines dans les Phanérogames, in Ann. Sci. Nat., Sér. 5, 20: 162-207.

$1874 b$. Rech. sur le dévelop. des radicelles dans les Phanérogames, 1. c., p. 208-233.

Jeffrey, E. C. Ig00. The morphology of the central cylinder in the Angiosperms; Nymphaeaceae, p. 24-27. Canadian Inst. Trans. vol. 6 (not seen).

Jekyll, G. Igor. Wall and water garden. London; 177 pp. (not seen).

Joret, Charles. I897. Les Plantes dans l'antiquité et au moyen age. Paris.

Jungner, J. R. I895. Wie wirkt träufelndes und fliessendes Wasser auf die Gestaltung des Blattes? in Bibliotheca botanica, Hft. 32 (not seen).

Karelin, Gr., and Kirilow, J. 1842. Enumeratio Plantarum in desertis Songoriae orientalis et in jugo summarum alpium Alatau in anno I84 I collectarum, in Bulletin de la Soc. Imp. des Naturalistes de Moscou, 15: 129-180, 321-453, 503-542. Also separate: Mosquae 1842. $223 \mathrm{p}$.

Karsten, G. 1888. Ueber die Entwickelung der Schwimmblätter bei einigen Wasserpflanzen, in Bot. Ztg., 46: 565-578; 58I-589.

Rerner, A. I886. Schedulae ad floram exsiccatam Austro-Hungaricam IV. Wien (not seen. Ref. in Bot. Jhrsber., I886, $2: 427$.

I895. Natural History of Plants, translated by F. W. Oliver. New York, 1895.

Kerner, J. S. 1795. Hortus sempervirens, 1795-1830; 7 I volumes; 9: tab. 99, 1799 (not seen). Comp. Pritzel, 163.

Kirchner, Oskar. Flora von Stuttgart, p. 275 (not seen).

Kirilow, J. See Karelin, Gr.

Kitaibel, P. See Waldstein, F. A., Graf von.

Klebs, G. I885. Beiträge zur Morphologie und Biologie der Keimung, Untersuchungen aus d. bot. Inst. zu Tübingen, r: 536-635 (not seen). Ref. in Bot. Jhrsber., I885, I: 513-5I9.

Klinggraeff, H. von. I883. Bereisung des Schwetzer Kreises, in Ber. ü. die 5. Versamml. des Westpreuss. Bot.-zoolog. Vereins zu Kulm am 30. Mai I882. Danzig, I883, p. 32-57 (not seen). Ref. in Bot. Jhrsber., 1883, 3: 276.

Klinggraeff, K. J. von. I848. Flora von Preussen (not seen).

Klotsch, J. F. I862. In Peter's Naturw. Reise in Mozambique. Botanik, 1: 152 (not seen).

Koch, G. D. J. I857. Synopsis Florae Germanicae et Helveticae, ed. 3, part I, p. 24. Leipzig.

Koehne, E. I 869 . Ueber Blüthenentwickelung bei den Compositen. Berlin. Inaug. Dissert. (not seen). 
Kohl, F. G. I889. Anatomisch-physiologische Untersuchung der Kalksalze und Kieselsäure in der Pflanze. Ein Beitrag zur Kenntniss der Mineralstoffe im lebenden Pflanzenkörper. Marburg.

Kny, L. 1901. Ueber den Einfluss von Zug und Druck auf die Richtung der Scheidewände in sich theilenden Pflanzenzellen, in Jhrb. f. wiss. Bot., 37: 55-98 (pp. 90-9I).

1900. Ueber das angebliche Vorkommen lebenden Protoplasmas in weiteren Lufträumen der Wasserpflanzen, in Ber. d. d. bot. Gesellsch., 18: 43.

Kops, J. I800. Flora batava, I3 volumes, by Kops, van Hall, etc., with I040 colored plates. I8001868. Vol. 7, 1836, p. 539 (not seen).

Korschins:: S. I892. Flora des Ostens des Europäischen Russlands in ihren systematischen u. geogr. Beziehungen, Part I, in Ber. d. Univers. Tomsk, 5: 71-299 [Russian] (not seen). Ref. in Bot. Jhrsber. $1893,2: 86$.

Kriloff, P. 1882. Material zur Flora des Gouvernements Perm (not seen). Ref. in Engler's Bot. Jhrbch. 4: 147.

Kuntze, 0. I891. Revisio Generum Plantarum, vol. 2. Leipzig.

Kurz, Sulpiz. 1864. Korte schets der Vegetatie van het eiland Bangka, in Tijdschr. voor Nederl. Indië, 27: 142-235; esp. p. 177, fide Caspary 1865.

Lange, J. See Liebmann, F. M.

Lanman, C. R. 1888. Sanskrit Reader.

Lamarck, Jean B. de. 1802. Encyclopédie Methodique Botanique. Article Nymphaea, 4: 455 ff.

Lawson, Geo. 1851. The Royal water-lily of South America and the Water-Lilies of our own land, their history and cultivation. Edinburgh, 1851.

1889. On the Nymphaeaceae, in Trans. Roy. Soc. Canada, 6: 97-123. Section IV. Montreal. Ref. in Bot. Cent. 45: 349-351.

1891. Notes for a Flora of Nova Scotia, in Proc. and Trans. Nova Scotia Inst. of Science, Halifax, 1: 84-110. I891 (not seen). Ref. in Bot. Jhrsber. 1892, 2: 95.

Lechartier, M. G. 1867. Sur le mouvement des gaz dans les plantes aquatiques, in Compt. Rend., 65: 1087-1091.

Ledebour, K. F. 1842. Flora Rossica, 1: 84. Stuttgart (not seen).

Lehmann, J. G. C. 1852 a. Index Seminum in Horto Botanico Hamburgensi collectorum anno 1852 , p. 9 (not seen).

I852 b. In Hamburger Garten- und Blumen-Zeitung (Otto's), 8: 372.

I853 a. "Die Gattung Nymphaea," in Otto's Hamburger Garten- und Blumen-Zeitung, 9: -. Review by Seeman in Bonplandia, 1 : 131-133.

I853 b. In Amtl. Ber. ü. d. 29. Versamml. d. Gesellsch. deutsch. Naturforsch. u. Aertzte z. Wiesbaden, Sitz. d. 22. Sept. (not seen).

1854. Index Seminum in Horto Botanico Hamburgensi collectorum anno 1853, in Ann. Sci. Nat. Bot. Sér. 4, I: 323-327. Paris, I854.

1857. Bemerkungen über einige Arten der Gattung Nymphaea. Auszug aus einem Briefe von Prof. L. etc., in Flora, 1857, p. 233-236.

Leitner. 1838. Nymphaea flava (name only), in Audubon's Birds of America, P1. 4II, large folio edition.

Lemaire, C. 1853. In Jardin fleuriste, 3: pl. 240-241.

Lesquereux, Leo. I860. Botany and Paleontology, in Second Report of a Geological reconnoissance of the middle and southern counties of Arkansas, during 1859-60, p. 295-399. Philadelphia.

Liebmann, F. MI., and Lange, J. 1874. Flora Danica, Supplem. vol. I, fasc. III, p. 7, tab. I4I.

Lindberg, S. 0. I88I. In report of Societas pro Fauna et Flora Fennica zu Helsingfors, Sitz. vom I. Oct. I881, in Bot. Centralbl. 10: 268. 1882.

Lindley, J. I853a. In Paxton's Flower Garden, 2: 63, tab. 50.

- I853 b. N. Devoniensis, 1. c. 3: 123-124, tab. 98. See also Paxton, Jos.

Link, H. F. I831. Handbuch zur Erkennung der nutzbarsten und am häufigsten vorkommenden Gewächse. Berlin. 2: 405. 
Linnaeus, C. 1753. Species Plantarum.

1762. Species Plantarum, ed. 2. vol. I.

See also Wirldenow, C. L.

Lloyd, F. E., and Tracy, S. M. 1901. The insular Flora of Mississippi and Louisiana, in Bull. Torr. Bot. Cl., 28: 61-101.

Lobelius, Matthias. 1576. Plantarum seu stirpium historia. Cui adnexum est Adversariorum volumen. Antwerp.

Loennroth, K. J. 1856. In Botaniska Notiser, p. 124 (fide Hooker, 1884).

Loudon, J. C. 1855. Encyclopedia of Plants. London, p. 462-464.

Lubbock, J. I892. A contribution to our knowledge of seedlings, I: II4-II8. London.

I894. On stipules, their forms and functions, II. Read June 21, 1894. Journ. Linn. Soc. London, 30: 463-532 (p. 468-9).

Ludwig, Christian Gottlieb. 1737. Definitiones generum plantarum in usum auditorum. Leipzig.

Ludwig, F. 1891. Zur Biologie der phanerogamischen Süsswasser-flora, in Zacharias' Die Thierund Pflanzenwelt des Süsswassers. Leipzig. vol. 2 (not seen).

Lyon, H. I. Ig01 a. Preliminary note on the embryogeny of Nelumbo, in Science, 13: 470.

Igor $b$. Observaticns on the embryogeny of Nelumbo, in Minnesota Botanical Studies, Ser. 2, part 5, p. 643-655, pl. 48-50. July 20.

Iyte, Henry. 1578. A Niewe Herball (fide Britten and Holland 1879).

MacCarthy, G. 1885. A botanical tramp in North Carolina, in Botan. Gazette 10: $384-385$.

Macdonell. Sanskrit Dictionary (not seen).

Macfadyen, J. 1837. The Flora of Jamaica, Vol. I; Ranunculaceae to Leguminosac. London, 1837. p. 19-20.

MacIntosh, C. I885. The Book of the Garden, 2: 711-712, 743.

Mackintosh. 1876. Sections of Petioles of Nymphaea, in Quart. Journ. of Microscop. Science, 16: 108-9, new series (not seen). Ref. in Bot. Jhrsber. 1876, 1: 379.

MacMillan, C. I892. The Metaspermae of the Minnesota Valley. Minneapolis, Dec. 29, I892. p. $227-228$.

Macoun, J. I891. Catalogue of Canadian Plants, 5: 300, in Geol. and Nat. Hist. Survey of Canada. Montreal.

Magnin, A. I893. Recherches sur la végétation des lacs du Jura, in Revue Générale de Botanique 5: $241-257,303-316,515-517$.

Malpighi, Marcello. I687. Opera omnia, seu thesaurus locupletissimis botanico-medico-anatomicus, etc. Leyden.

1697. Opera posthuma. London.

Marianus, F. J. 1790. Florae fluminensis seu descriptionum plantarum praefectura fluminensis sponte nascentium etc. MS. prepared in 1790, in Archivos do Museu Nacional do Rio de Janeiro, vol. 5 for I8So. Rio de Janeiro, I88I.

Martius \& Zuccarini. 1832. See ZUCCARINI, 1832a.

Marty, L. 1902. Un Nymphaea fossile, in Feuilles des Jeunes Naturalistes, No. 375, p. 45-49. Ref. in Bot. Cent. 89: 442-443.

Masters, M. T. 1869. Vegetable Teratology.

1878. Nymphaea alba var. rosea, in Gard. Chron., new series, 9: 696; June 1.

1902 $a$. Air canals in the leaf and in the flower-stalk of Nymphaeas, 1. c., 3d series, 3I: 134,165 .

$1902 b$. The arrangement of the air canals in the stalks of Nymphaeas, in Journ. Roy. Hort. Soc. 26: 840-843. London (not seen).

Matthioli, Pietro Andrea. 1598. Opera, quae extant, omnia; hoc est: Commentarii in sex libros Pedacii Dioscoridis Anazarbei de materia medica etc.; nunc a Casparo Bauhino post diversarum editionum collationem infinitis locis aucti, etc. Basil, 1598. (Original ed. Venice 1554, fide Pritzel.)

Meehan, Thos. 1880. Native Flowers and Ferns of the United States, Ser. 2, x: 121-124.

Mela, A. J. 1897. Nymphaea Femica, eine netse europäische Seerose, in Acta Societatis pro Fauna et Flora Fennica, 14: No. 3. Helsingfors. 


\section{BibliograpHy.}

Mellink, J. F. A. I886. Zur Thyllenfrage, in Bot. Ztg., No. 44. Ref. in Bot. Jhrsber., 1886, x: 880; 2: 498 .

Meyer, A. 1898. Erstes mikroskopisches Practicum. Jena.

Meyer, D. C. A., and Bunge, D. A. 1829. Flora Altaica. Berlin.

Meyer, G. F. W. I818. Primitiae Florae Essequiboensis. Göttingen.

Michaux, F. A. I803. Flora Boreali-Americana, I: 3II.

Mieg, M., Bleicher, G., and Fliche, P. I8go. Contribution à l'étudc du terrain tertiare d'Alsace et des environs de Mülhouse, in Bull. Soc. Geol. France, 3 sér., x8: 392-422 (not scen). Ref. Bot. Jhrsber. I890, 2: 226.

Millspaugh, C. F. 1893. Pink water lilies, in Bull. Torr. Bot. Cl., 20: 21-22.

Miquel, F. A. G. I859. Flora Indiae Batavae, $x$ : part 2.

Moenkemyer, W. I897. Sumpf- und Wasser-Pflanzen.

Molisch, H. 1882. Zur Kenntniss der Einlagerung von Kalkoxatcrystallen in der Pflanzenmembran, in Oest. Bot. Zeitschr., No. 12, p. 382-5 (not seen).

Moorcroft, Wm. Travels, 2: 136 (not seen). Ref. in Gard. Chron., 1842, p. 495.

Morong, Thos. I888. A ncw Water-lily, in Botanical Gazette, x3: 124-125.

Morong, Thos., and Britton, N. L. An Enumeration of the Plants collected by Dr. Thos. Morong in Paraguay, I888-189o, in Ann. N. Y. Acad. Sci. 1893, p. 48-49.

Müller, C. 1890. Ein Beitrag zur Kenntniss der Formen des Collenchyms, in Ber. d. d. bot. Gesellsch. 8: I50-I66.

Müller, F. von. 1858. Fragmenta phytographiae Australiae 1: 61. Melbourne, 1858-59.

1861. Fragmenta phytographiae Australiae 2: 141-2. Melbourne, 1860-61.

1862. Annual Report of the Government Botanist and Director of the Botanic Garden of Melbourne, 1862-63, p. II.

1875. Descriptive Notes on Papuan Plants, r: 13, 95.

1887. New Australian Plants. Ref. in Bot. Jhrsber. 1887, 2: 214

I889. Systematic Census of Australian Plants, etc., Fourth Supplement. Melbourne. Ref in Bot. Jhrsber. 1889, 2: 135 .

See also BenthaM, G.

Müller, F. Max. I881. Sacred Books of the East, vol. 1o. Dhammapada. Oxford.

Müller, H. 1883. Fertilisation of Flowers, trans. by D. W. Thompson. London. 1883. p. 93.

Mü'ler, R. I885. Die winterharten Nymphaeen, in Garten-Zeitung, p. 566-567.

Müller-Beeck. I886. Verzeichniss der essbaren Pflanzen Japans, published by Vcrein zur Beförderung des Gartenbaues in den kgl. Preuss. Staaten (not seen). Ref. in Bot. Jhrsber. I886. 2: 13 I.

Nägeli, K. von. Beitr. z. wiss. Botanik, vols. I-4, I858-68; I: I2I (not seen).

Zeitschr. f. wiss. Botanik, I844-1846. Hft. 3 and 4 (not scen).

Nash, G. V. I895. Notes on Some Florida plants, in Bull. Tor:. Bot. Cl., 22: I4I-16I.

Nehring, A. 1892. Die Flora des diluvialen Torflagers von Klinge bei Kottbus, in Naturw. Wochensclir., vol. 7 , No. $24,25,45$.

Neilreich, A. I867. Diagnosis Plantarum Vascularium in Hungaria et Slavonia hucusque observatarum, quae in Koch Synopsi non contentae sunt. Wien. In K. K. Zool.-Bot. Gesellsch. Verhandl. XVII. Beilage.

Nicolai, 0. I865. Das Wachsthum der Wurzel, in Schriften der Königlichen physikalisch-ökonomischen Gesellschaft zu Königsberg, Jahrgang 6, p. 33-76, taf. 2, 3.

Niederstadt. 1883. Landwirt. Versuchsstation, 29: 247-50 (not seen).

Nobbe, Fr. 1876. Handbuch der Samenkunde. Berlin (not seen).

Nuttall, Thos. 1818. The genera of North American Plants, and a catalogue of the species, to the year 1817. Philadelphia, 2 vols.

Oborny, A. I877. Die Flora des Znaimer Kreises, in Verhandl. d. Naturforscl.. Verein in Brünn, I7: II4.

Oliver, Daniel. 1868. Flora of Tropical Africa, I: 52-53.

Paine, J. A. I865. Catalogue of the Plants of Oneida Co., N. Y., in Report of the Regents of the University of New York, p. I32. 
Palačky, J. 1897. Zur Flora von Centralasicn, in Oest. Bot. Ztschr. 47: 361-7, 400-405 (not seen). Rcf. in Bot. Jhrsber. 1897, 2: I86.

Parkinson, John. 1640. Theatrum Botanicum. London.

Parlatore, F. 1881. Tavole per una anatomia delle piante aquatiche. Florenz (not seen). Ref. in Bot. Jhrsber. 1881, $1: 448$.

Paxton, Jos. 1845? Nymphaea rubra, in Magazine of Gardening, 11: 265.

1852. N. Devoniensis, in Gard. Chron., July Io.

Paxton, Jos., and Lindley, J. 1853 a. N. micrantha, in Flower Garden, 1: 140-141, No. 190.

- 1853 b. N. elegans, 1. c. 2: I18-119, No. 393.

1853c. N. elegans, 1. c. 2: 182.

I853 d. N. gigantea, 1. c. $3: 74-75$, No. 546 .

Payer, J. B. 1857. Traité d'organogénic comparée de la fleur. Paris.

Perrottet, S. See Gurllemin, A.

Peter, A. 1901. Botanische Wandtafeln. 39. Nymphaeaceae. Berlin (not seen).

Petit, I. 1888. Le pétiole des Dicotylédons, etc., in Mém. de la soc. des sci. phys. et nat. de Bor-

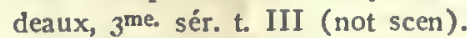

Pickering, Chas. 1879. Chronological History of Plants. Boston.

Pilleterius, Casparus. 1610. Plantarum tum patriarum quam exoticarum in Walacliria, Zeelandiae insula, nascentium synonymia. Middelburg (not seen). (Cf. Ned. krudk. Arch. 1877, Ser. 2, vol 2, p. 359.)

Piso, Gulielmus. 1648. Historia Naturalis Brasiliae. Leyden and Amstcrdam.

1658. Hist. Nat. Brasil., ed. 2, with Jacobi Bontii Historiae naturalis et medicac Indiae orientalis, etc.

Planchon, J. E. 1850 a. Nymphaea dentata, in Flore des Serres 6: 293-296, tab. 627-628. Ghent, 1850-5I.

I850 b. N. rubra, 1. c. p. 297-299, tab. 629 (poor).

1850 c. N. scutifolia, l. c. p. 341, tab. 675 .

1850 d. N. rubra (culture of), 1. c. p. $48 \mathrm{I} c-d$.

I850e. Victoria regia, 1. c. p. 193-224, 249-254.

I85I a. N. caerulea, 1. c. 7: 19-20, tab. 653. Ghent, 185I-52.

1851 $b$. N. gigantea, 1. c. p. 293 (description).

I851 c. N. thermalis, l. c. p. 295 , tab. 706-707.

I852 a. N. rubra, 1. c., 8: 25 tab. 759-760 (good). Ghent, 1852-53.

1852 aa. N. Ortgiesiano-rubra, 1. c. p. 67-73, tab. 775-6.

$1852 b$. Enumeration succincte des espèces de la famille des Nymphéacécs, 1. c. p. 117-20; also in Rev. Horticole, 1853, p. $62-68$.

I852 c. $N$. stellata, in Flore des Serres, $8: 285-286$, tab. 854

I852 d. N. gigantea, 1. c. p. 293, tab. 75 I.

I852 e. N. Ortgiesiana, 1. c. p. 67-73.

1853a. In Revue Horticole, Feb. I6.

I853 b. Études sur les Nymphéacées, in Ann. Sci. Nat. Bot., sér. 3, 19: I7 ff. Paris, 1853.

1854. N. Boucheana, in Flore des Serres, ro: 167, pl. 1033-1034

1856. N. blanda, in Flore des Serres, 11: 21. Ghent, 1856.

See also Triana, J.

Plank, E. N. 1896. A Botanical Journey in Texas, I, in Gard. \& For., 9: 62-63.

Pleyte, W. 1875. De Egyptische Lotus (Nederlandisch Kruidkundig Archicf: Verslogen en Mededeelingen der Nederlandsche Botanische Vcreeniging. July 16, I875. Tweede Serie. 2e Dcel. Nijmegen 1877 ). Ref. in Bot. Jhrsber. 1876, p. 691.

Pliny, Caius, Secundus. The Historic of the World, comınonly called Natural Historie of C. Plin. Sec., trans. Philemon Holland. London 1601.

Plukenet, Leonard. 169r. Phytographia, sive stirpium illustriorum et minus cognitarum Icones. London; vol. I, I691; II, 1692; III, 1696.

_ I6g6. Almagestum Botanicum. London. 
Plukenet, Leonard. I700. Almagesti Botanici Mantissa. London.

1705. Amaltheum Botanicum (ed. 2, by Davies, Payne, etc., London 1769, is the one I have seen).

Poggenburg. Sec Britton, N. L.

Presl, J. W. \& K. B. I822. Deliciae Pragenses, p. 224

Prichard, J. C. 1838. Egyptian Mythology.

Pringle, C. G. I890. Notes on the Mexican Water Lilics, in Gard. and Forest, 3: 415.

1897. Notes of Mexican Travel, XII; My Summer in the Valley of Mexico, in Gard. \& For. 10: 42-43.

Pritzel, G. A. I872. Thesaurus Literaturae Botanicae. Leipzig.

Pursh, F. 1814: Flora Americae Septentrionalis, 2: 368-369.

Raciborski, M. 1894. Die Morphologie der Cabombeen und Nymphaeaccen, in Flora, 78: 2.14-279; 79: 92-108. I894. Ref. in Bot. Jhrsber. 1894. 2: 2S0-81.

Rafinesque, C. S. I830. Medical Flora and Botany of the United States. Philadelphia, 2: 44-45.

Rawlinson, Geo. I882. History of Ancient Egypt. Boston. (The botany of this book is grossly in error.)

Ray, John. 1670. Catalogus Plantarum Angliae et Insularum Adjacentium. London.

1682. Methodus Plantarum nova, etc. (Ed. 4, emendata et aucta; London 1733, I have seen.)

1688. Historia plantarum, etc. London; vol. I, I686; II, I688; III, 1704.

I690. Synopsis methodica stirpium britannicarum. London.

Reichenbach, H. G. L. I830. Flora Germanica. Leipzig.

1842. Flora Saxonica.

Reichenbach, H. G. L. \& G. H. 1845. Icones Florae Germanicae et Helvcticac, $7: 34$, tab. 67, 68, 69, 70, 7r. Leipzig.

Rein, J. J. I886. Japan nach Reisen und Studien, in Auftr. der kgl. preuss. Regierung, vol. 2. Leipzig (not seen). Ref. in Bot. Cent. 31: 275-279, and in Bot. Jhrsber. 1886, 2 : 132-5.

Relhan, R. 1785. Flora Cantabrigiensis, p. 206 (not seen).

Renault, M. B. 1882. Cours de Botanique Fossile (not seen).

Revue Horticole. 1849. p. 264-265, 379-380.

1851 a. Nymphaea dentata, p. 349-355

I85I b. N. elegans, p. $456-458$.

1852 a. N. alba, p. 165 .

1852 b. N. gigantea, p. 390.

1853. N. Ortgiesiano-rubra, p. 110.

1854 a. N. stellata (var. bulbifera, Planch.), p. I50-I5I.

1854 b. N. gigantea, p. 462 .

I855 a. Culture du N. gigantea, p. 91.

I855 b. N. stellata, p. $26 \mathrm{I}-263$.

I879. $N$. caerulea, p. $277-278$.

I881 a. N. odorata rubra, p. 323.

I88 i $b$. N. odorata rubra, p. 406.

I8go a. N. zanzibariensis flore rubro, p. 266.

1890 b. N. odorata sulfurea, p. 540 .

I897. Variétés nouvelles de Nymphaea stellata zanzibariensis, p. 328.

Rimbach, A. I902. Physiological observations on the subterranean organs of some Californian Liliaceae, in Bot. Gaz. 33: 40I-420. June.

Robertson, C. 1889. Flowers and Insects, I; in Bot. Gazette 14: 120-126.

18go. New North American Bees of the gencra Halictus and Prosopis, in Trans. Amer. Entom. Soc. 17: 315-318 (not scen). Ref. in Bot. Jhrsber. 1890. 1: 508.

Robinson, B. L. I8g6. New or Little-known Plants: Nymphaea tetragona, Georgi; in Gard. \& For. 9: 134

See also Grax, AsA.

Robinson, W. I865. Nymphaea gigantea, in Gard. Chron., I865, p. 842.

Roehling, J. C. I833. Deutschlands Flora, ed. 3, by Mertens \& Koch. 4: 28; Vol. I, I823; II, I826; III, I83I; IV, I833; V, I839 (not seen). 
Rose, J. W. I895. Ncw or Little-known Plants: A Blue Water-lily from Mexico, in Gard. \& For. 8: 205, 206.

Rolland, E. r896-99. Flore populaire ou histoire naturellc des plantes dans leur rapports avec la linguistique et le folk-lore. Paris, vol. 1, 1896; vol. 2, 1899 (not seen). Ref. in Bot. Centralbl. 86: $281-285$, 1901.

Roxburgh, Wm. 1806. N. rubra, in Salistury's Parad. Lond. I: tab. I4 1814. Hortus Bengalensis. Scrampore (not secn). 1824. Flora Indica.

Royer, Ch. 1870. Considérations sur les partics souterraincs des Plantes, in Bull. Soc. Bot. France 17: 147-153, 168-172; p. 170.

Rozer. - Flore de la Cōte-d'Or: Nymphéacées (not seen).

Ruprecht, F. J. 1859. Decas plantarum sive Tabulae botanicae X et itinerario D. Maack seorsim editae. St. Petersburg, Akademie der Wisscnschaften; folio, ro tab. 1o foll. (not seen). (Pritzel, 1872.)

Rusby, H. H. Sce Britton, N. L.

Russow, E. 1884. Ueber die Auskleidung der Intercellularen, in Sitzber. d. Dorpater Naturf. Ges., 7: 158-172, and in Bot. Ztg. 1885. p. 491. Rcf. in Bot. Jhrsber. 1884, 1: 201, 210.

Sachs, J. von. 1882. Text book of Botany, trans. by S. H. Vines, ed. 2. London.

1387. Vorlesungen über Pflanzenphysiologie, 2 ed. p. 545.

Saelan, Th. 1879. In Meddelanden af Soc. pro Fauna et Flora Fennica, heft 6, 1881, p. 185-272. Sitzung Dec. 6, 1879 (not seen). Rcf. in Bot. Jhresber. I883, 2: 555

Sagot, P. 1881. Catalogue des Plantes Phaen. et Crypt. vasc. de la Guyane Française, in Ann. Sci. Nat., 6 sér., II: 134-180. Paris.

Saint-Hilaire, A. F. C. P. (Aug. de). 1833. Voyage dans le distriet des diamans, 2: 425 (not seen).

Salisbury, R. A. I806 a. "Nymphaeaceae," in Kocnig and Sims' Annals of Botany, 2: 69-76. Pub. May 1, 1805.

I806 b. Paradisus Londinensis $\mathrm{x}:$ tab. 14. London 1806-7. 2 vols.

Salvin, 0. See Godman, F. D.

Sambuc, C. — Contribution à l'étude de la Flore et la matière médicale de la Sénégambie, p. 27 (not seen).

Saporta, G. de. 1861. Examen analytique des flores tertiaires, in Heer: Rech. sur le climat et la végétation du pays tertiaire, transl. into French by C. T. Gaudin. Zurich.

I865 a. Études sur la végétation du sud-est de la France à l'epoque tertiaire, in Ann. Sci. Nat., sér. 5, Bot., 3: 5-152.

I865 b. Études sur la végétation du sud-est de la France à l'epoque tcrtiaire, l. c., 4: 5-264. 1877. Découvertc de plantes fossiles tertiaires dans le voisinage immédiat du pöle nord, in .Compt. Rend., 85: 562.

1879. Die Pflanzenwelt vor dem Erscheinen des Mcnschen. Braunschweig 1881.

1893. Sur un couche à Nymphéinées récemment exploré et comprise dans l'aquitanien de Manosque, in Compt. Rend. Ir7: 607-610. Paris.

1894 a. Nouvelles Contributions à la flore mesozoique; Imp. de l'Acad. royale des Sc, Lisbon.

1894 b. Nouveaux details concernant les Nymphéinées: Nymphéinées infracrétacées; in Comptes Rend. Irg: $835-837$.

I894 c. Nouveaux details concernant les Nymphéinées: Nymphéinées tertiares, 1. c., 888-892.

Sargent, C. S. 1888. Plant Notes: Nymphaea tuberosa, in Gard. and For., I: 368-9 (with excellent line drawings).

Savigny, J. C. 1798. Decad. Egypt., 3: 74 (not seen).

1802. Description du Nymphaea caerulea, in Annales du Muséum National d'Histoire Naturclle, $1: 366$.

Scaliger, J. C. See Theophrastus.

Schaffner, John H. 1904. Some morphological peculiarities of the Nymphaeaceae and Helobiae, in Ohio Naturalist, 4: 83-92. Columbus, O. 
Schenck, H. 1884. Bildung von centrifugalen Wandvcrdickungen. Inaug. Dissert. Bonn, 42 pp. (not seen).

1885. Die Biologie der Wassergewächse. Bonn, 1885. I62 pp. Ref. in Bot. Jhrsber. 1885, I: $734-6$.

Schenk, A. 1888. In Zittel: Handbuch der Palaeontologie, II Abth., 6 Lief., Dicotylae. Munich and Leipzig.

Schilbersky, K. 1889. Der Standort von N. thermalis DC. bei Budapest, in Termeszettud. Közlöny, 21: 370-4. Budapest (not seen). Ref. in Bot. Jhrsber. 1889, 2: 296.

Schilling, A. J. I894. Anatomisch-biologische Untersuchungen der Schleimbildung der Wasserffanzen, in Flora, 78: $280-360$.

Schinz, H. See Durand, TH.

Schmalhausen, J. 1875. Aufzähling der im Gouvernement von St. Petersburg vorkommenden Bastard- und Zwischenformen, in Bot. Ztg. 1875 , p. 539.

Schomburgk, R. I848. Reisen in Britisch Guyana in den Jahren 1840-44. Vol. 3. Versuch einer Fauna und Flora von Britisch Guiana, p. 838-839.

1875. Handbook of Southern Australia (not seen).

Schonger, J. B. I882. "Kleine Beiträge," in 8. Jhresber. d. Bot. Vereins zu Landshut, I882, p. 171-97 (not seen). Ref. in Bot. Jhrsber. 1882, 2: 483-4.

Schucharđt, T. 1853. Beiträge zur Kenntniss der deutschen Nymphaeen, in Botan. Zeitung, Ir: 497-510. July 15.

Schulz, Aug. I890. Beiträge zur Kenntriss der Bestäubungseinrichtungen und Geschlechtsvertheilung bei den Pflanzen, II, in Bibliotheca Botanica, Heft 17, p. 9. Cassel, I8go.

Schumacher, H. C. F., and Thonning, P. 1829. Beskrivelse af Guineiske Planter, in Dansk. Vid. Selsk. Afh. IV, 1829, p. I-236.

Schumann, K. Neue Untersuchungen ueber den Blüthenanschluss, Leipzig. 519 pp. (not seen). Ref. in Bot. Jhrsber. 1890, 1: 345-9.

1894. Die Untersuchungen des Herrn Raciborski ueber die Nymphaeaceae, etc., in Ber. d. deutsch. Bot. Gesellsch. I2: 173-178. Ref. in Bot. Jhrsbcr. 1894, 2: 281.

1904. Praktikum für morphologische und systematische Botanik. Fischer, Jena. Nymphaea alba, Nuphar luteun, pp. 229-235.

Schweinfurth, G. 1882. See BoISSIER, I882.

I883 a. Neue Beiträge zur Flora des alten Aegyptens, in Bcrichte der dcutschen botanischen Gesellschaft, I: $544-546$.

$1883 \mathrm{~b}$. The Flora of Ancient Egypt, in Nature, 28: I09-114, with figure.

I884a. Further Discoveries in the Flora of Ancient Egypt, in Nature, 29: 312-315, Jan. 31 .

I $88_{4} b$. Neue Funde auf dem Gebiete der Flora des alten Aegyptens, in Engler's Bot. Jhrbch., 5: 189-202. No. 2.

I884 c. Ueber Pflanzenreste aus altaegyptischen Gräbern, in Ber. d. deutsch. bot. Gesellschaft, 2: $35 \mathrm{I}-37 \mathrm{I}$.

I886. Die letzten botanischen Entdeckungen in den Gräbern Aegyptens, in Englcr's Bot. Jhrbch. 8: I-I6, No. I, nach Bulletin de l'Institut Egypticn, Io Sér., No. 6, Cairo, 1886, mit Verbesserungen und Zusätzen des Verf. Ref. in Bot. Jhrsber. 1886, 2: 36-38.

Schwendener, S. I895. Die jüngsten En:wickelungsstadien seitlicher Organe und ihr Anschluss an bereits vorhandene, in S. d. k. Pr. Akad. d. Wiss. zu Berlin, p. 645-63 (not seen). Ref. in Bot. Jhresber. I895, I: 30.

Sebire, A. 18g9. Les Plantes utiles du Sénégal. Paris.

Seeman, B. I852. The Botany of the Voyage of H.M.S. "Herald" during the years I845-5I. London, 1852-57. Part 2, p. 78 (not seen).

Semenow, N. M. 1854. Einige Bemerkungen ueber die moskowischen Seerosen, in Bull. de la Soc. Imp. des Naturalistes de Moscou, 27: 226-232.

Sernander, R. I894. Om vära röda näckrosor, in Botaniska Notiser, 1894, p. 85-88 (not seen). Ref. in Bot. Jhresber. I895, 2: 196.

Siber, W. 1883. Unsere Wasserpflanzen, in Wittmack's Gartenzeitung, 32: 21 1-21 5, 260-264. 1887. Nymphaea zansibariensis Casp. A. rubro, 1. c. 36: 83-84, pl. 1240; also p. 230. 
Van Rheede, Heinric Adrian. 1692. Hortus indicus malabaricus, etc. Amsterdam, vol. I, 1678; II, I679, etc.; XI, 1692; etc.

Van Tieghem, Ph. I871. Mémoire sur la racine, in Ann. Sci. Nat. sér. 5, Bot., 13: 267.

I886a. Sur l'appareil secreteur et les affinités de structure des Nymphéacées, in Bull. de la Soc. Bot. de France, 33: 72-76 (not scen).

I886 b. Sur la croissance terminale de la racine dans les Nymphéacées, 1. c., p. 264-265 (not seen).

1898. Traité de Botanique, $1: 65-67,694 \mathrm{ff}$.

Van Tieghem, $\mathbf{P h}$., and Douliot, H. I888. Recherches comparatives sur l'origine des membres endogénes dans les plantes vasculaires, in Ann. Sci. Nat. Bot., sér. 7, 8: 127-132, 435-438.

Ventenat, E. P. I803. Jardin de la Malmaison, x: tab. 6. Paris.

Veslingius, Joannes. See Alpinus.

Vesque, Julien. r88ז. De l'anatomie des Tissus appliquée à la classification des Plantes, in Nouvelles Archives du Muséum, 2d sér., 4: 5I-53.

Vick, J. 1879. N. odorata in Vick's Magazine, 2: 196 . Rochester, N. Y. 1886. N. odorata in Vick's Magazine, 19: 9. Rochester, N. Y.

Vilmorin, M. L. de. I89I. Les Nymphaea rustiques, in Rev. Hortic., p. I7-22.

Vuyck, L. 1901. Prodromus Florae Batavae, vol. I, Nymcgen (not scen).

wächter, W. I897. Beiträge zur Kenntniss einiger Wasserpflanzen, in Flora, 83: 367-397; 84: 343-348.

Waldstein, F. A., Graf von, and Kitaibel, P. I802. Descriptiones et icones plantarum rariorum Hungariae. Vienna, 1802-12, 3 vols.

Walpers, W. G. I842. Repertorium Botanices Systematicae, I: I06-108.

1848. Annales Botanices Systematicae, I: 22. 1848-49.

1851. Annales Botanices Systematicac, 2: 25. 185I-52.

1852. Annales Botanices Systematicae, 3: 814. 1852-53

1857. Annales Botanices Systematicae, 4: 153-167.

Walter, Thos. 1788. Flora Caroliniana, 154-155. London.

Waters, G. F. I886. Germination of Pond-lily seeds, in Science, 7: 395-396.

Watson, S. I883. In Proc. Am. Acad., 17: 318 (not seen).

1887. List of Plants collected by Dr. Edw. Palmer in the State of Jalisco, Mexico in r886, in Proc. Am. Acad. of Arts and Sciences, 22: 397.

See also Gray, AsA.

Watson, W. 1893 . Notes on Water-lilies, in Gard. \& For., 6: 364-366.

I894. Nymphaca Parkeriana, in Gard. \& For., 7: I64.

Weber, C. A. I892. Ueber Cratopleura holsatica, eine interglaciale Nymplaeacee, und ihre Bzziehung zu Halapleura Victoria Casp., sowie zu recenten Nymphaeaceen, in Neues Jhrbel. f. Mir., Geol., u. Palãont. I: II4 ff. (not seen).

1893. Ueber die diluviale Vegetation von Klinge in Brandenburg, und über ihre Herkunft, in Engler's Jhrbch., Beiblatt, No. 46, vol. 17.

Weber, C. 0. I850. Ueber die Süsswasserquartze von Muffendorf bei Bonn, in Haidinger Naturwissenschaftliche Ablandlungen, 4: part 2, p. 14, pl. IV, fig. I8 (not seen).

Weberbauer, A. I894. Beiträge zur Samenanatomie der Nymphaeaceae, in Engler's Jahrbücher, 18: Heft. 3, 52 pp.

Weinhart, Max. 1890. Beiträge zur Flora von Schwaben und Neuburg, ctc, in 30 . Ber. des Naturwiss. Vcr. für Schwaben und Neuburg. Augsburg, 1890, p. 277-282 (not seen). Ref. in Bot. Jhrsber. 1890, 2: 349 .

Weiss, G. A. 1878. Allgemeine Botanik, I, Anatomie der Pflanzen. Vienna.

Wessel, P., und Weber, C. 0. 1855. Neuer Beitrag zur Tertiär-Flora der niederrheinischen Braunkohlenformation, in Dunker $u$. Meyer, Palaeontographica, 4: 4 .

Wheeler, W. A. 1900. A Contribution to the knowledge of the flora of southeastern Minnesota, in Minn. Botan. Studies, 2 ser., part $4,353-416$.

Whewell, Wm. History of the inductive Sciences (not seen).

Wiedemann, Alfred. 1897. Religion of the Ancient Egyptians. London. 
Wigand, A., and Dennert, E. 1888. Nelumbium speciosum W. Eine monographische Studie, in Bibliotheca Botanica, Hft. II.

Wight, R. I840. Icones Plantarum Indiae Orientalis. Madras, 1840-1856.

1850. Illustrations of Indian Botany. Madras, I84I-50.

Wight, R., and Arnott, G. A. W. I834. Prodromus Florae Peninsulae Indiae Orientalis. London, p. 16-17.

Wildeman, Em. de, and Durand, Th. rgoo. Illustrations de la Flore du Congo, in Annales du Musée du Congo, Sér. 2.-Botanique, vol. I, fasc. 2, p. 2.

Reliquiae Dewevreanae, 1. c., sér. 3, vol. I, fasc. I, p. 7.

Wilkinson. J Gardner. The manners and customs of the ancient Egyptians. Ed. Samuel Birch. Boston, I883.

Willdenow, C. L. 1797. Caroli a Linné Species Plantarum, etc., editio quarta. Berlin, vol. ¿. 1816. Hortus Berolinensis, tab. 39 (not seen).

Williams, Monier. 1856. Sakoontala; or The lost Ring, from the Sanskrit of Kálidása; 3d edition. Hertford.

Wisselingh, C. van. I887. Sur les revêtements des espaces intercellulaires, in Archires Néerlandaises, 21: 19-34 (not seen). Ref. in Bot. Centralbl. 29: 360 (1887); in Bot. Ztg. I887, No. I4, p. 222; in Bot. Jhrsber. I887, 2 : 542.

Withering, Wm. 1776. A botanical arrangement of all the vegetables naturally growing in Great Britain, P. 489 (not seen).

Wolley-Dod, A. H. See BoLUs, H.

Wood, Alph. I880. Class Book of Botany, with a Flora of the United States and Canada.

Woodville, W., and Wood. I806. Castalia, in Rees' Cyclopedia, 6:

Zimmerman, A. 1891. Beiträge zur Morphologie u. Physiologie der Pflanzenzelle, Hft. 2, p. I58. Tübingen.

Zittel, K. A. I890. Handbuch der Palaeontologie. See Schenk, I888.

Zuccarini, J. G. 1832 a. Plantarum novarum vel minus cognitartum descriptio, fasc. I., in Abhandlungen der Mathematisch Physikalischen Classe der Königliche Bayerischen Akademic der Wissenschaften. I: 287-396. München.

1832 b. In Flora, II Deibl., p. 75 . 



\section{INDEX.}

Note.-Synonyms and horticultural names are in Italics. Asterisk (*) after a number indicates a figure. Numbers in heavy-faced type refer to the taxonomic description of a species or group; such descriptlons always treat in order (1) diagnosis, (2) synonymy, (3) detalled description of flower, leaf and stem, (4) geographlc dlstrlbution, (5) notes of miscelianeous lnformatlon.

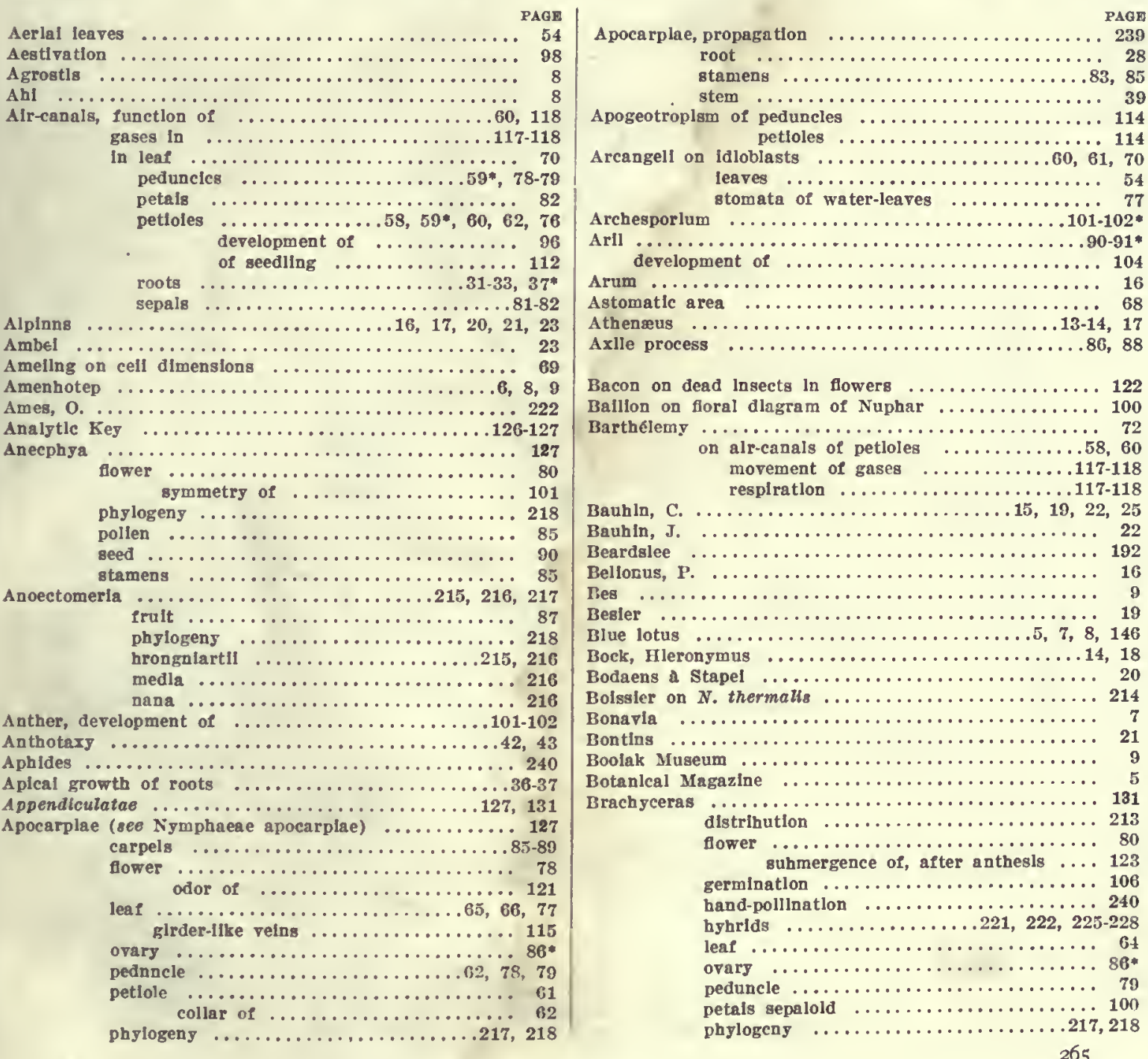




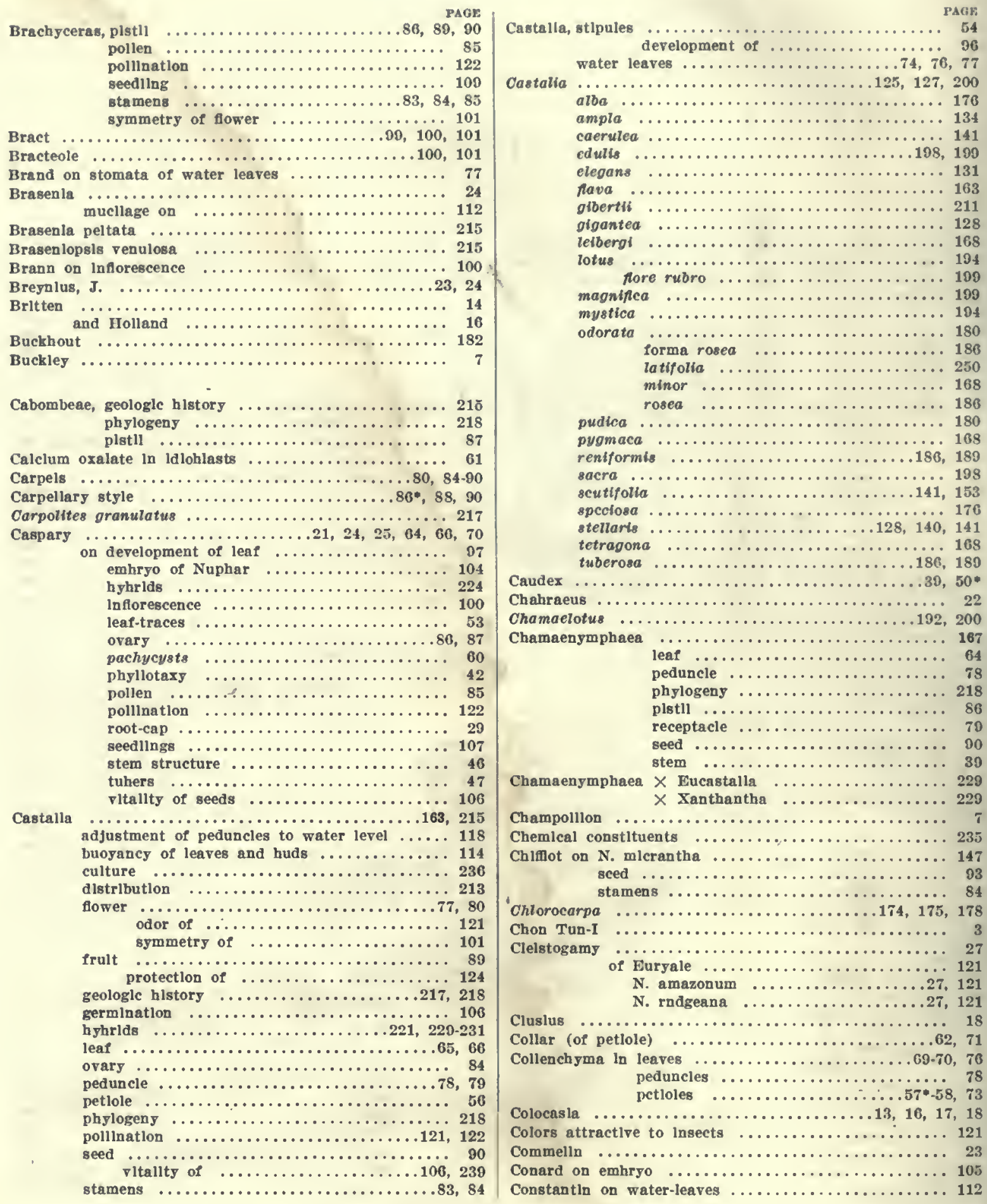




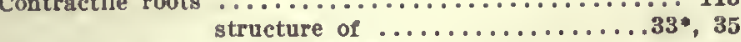
Cook on development of megaspore $\ldots \ldots \ldots \ldots \ldots \ldots 102$ embrso

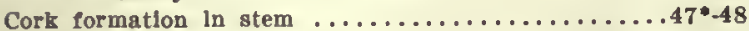

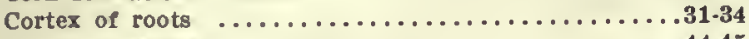

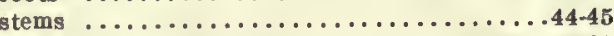

Cotyledons ln germination $\ldots \ldots \ldots \ldots \ldots \ldots \ldots$ 107-109, 108*

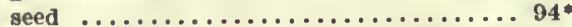

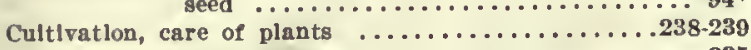

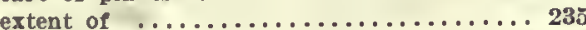
blstory of . . . . . . . . . . .

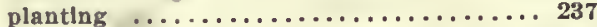

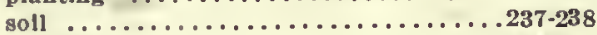
tank for $\ldots \ldots \ldots \ldots \ldots \ldots \ldots \ldots \ldots . \ldots \ldots 236-238$

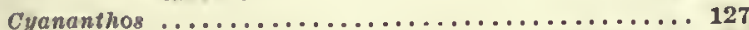
Cyanea ..................... 86, 87, 127, 131

Dahmen on funtculns $\ldots \ldots \ldots \ldots \ldots \ldots \ldots \ldots \ldots \ldots 104$ Date-palm .......................... 9 DeBary on root cap ..................... 29

DeCandolle on Cyanea ..................... 86

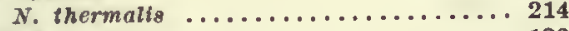
Delplno on polllnatlon $\ldots \ldots \ldots \ldots \ldots \ldots \ldots \ldots \ldots \ldots \ldots 122$ Dhammapada $\ldots \ldots \ldots \ldots \ldots \ldots \ldots \ldots \ldots \ldots \ldots \ldots \ldots .5 .5$ Dlaphragms in alr-canals of roots $\ldots \ldots \ldots \ldots \ldots .37,38^{*}$ Dlodorus slculus ..................... Dloscorldes .......................11-13, 15, 16 Dlseases ............................ 240-241

Dlsscetion of stem apex $\ldots \ldots \ldots \ldots \ldots \ldots \ldots \ldots \ldots . .65$ Dlstribntlon ...................213-214, 217-218

Dodona eus .............................. 18-19

Double flowers ......................... 101

Duppa

Egyptlan lotus $\ldots 1 *, 6,7 *, 9,11,12,13,14,16,17,18,20$ Elchler .........................80, 99-100 Elwell $\ldots \ldots \ldots \ldots \ldots \ldots \ldots \ldots \ldots \ldots \ldots \ldots \ldots \ldots \ldots \ldots \ldots \ldots \ldots \ldots \ldots \ldots \ldots \ldots \ldots, 104-107,105$

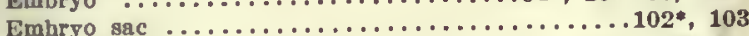

Endosperm .......................94*, 105-106

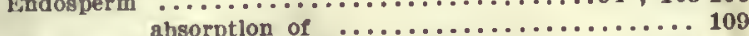

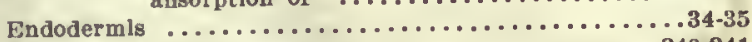

Enemles .............................240-241

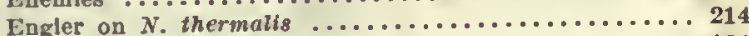

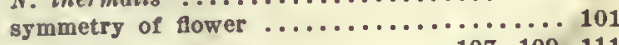

Epleotyl $\ldots \ldots \ldots \ldots \ldots \ldots \ldots \ldots \ldots \ldots \ldots \ldots 10 \ldots \ldots \ldots \ldots \ldots \ldots, 111$ Epldermls of root $\ldots \ldots \ldots \ldots \ldots \ldots \ldots \ldots \ldots \ldots \ldots . . . . .30,31$ Erythrocarpa ........................ 174, 175, 178

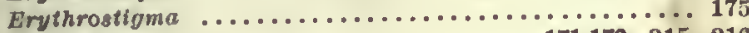
$171.172,215,216$ floral movements .................... 120 frult ....................... 90

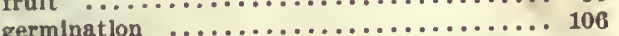

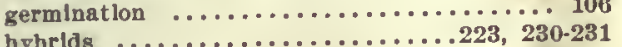
bybrlds $\ldots \ldots \ldots \ldots \ldots \ldots \ldots \ldots \ldots \ldots .6 .64,73,77$

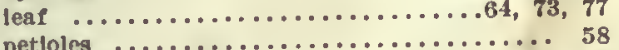

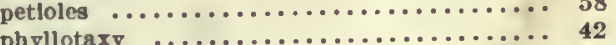

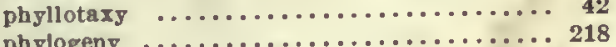

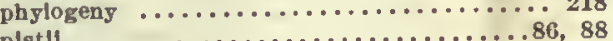
plstl1 $\ldots \ldots \ldots \ldots \ldots \ldots \ldots \ldots \ldots \ldots \ldots \ldots \ldots \ldots, 8{ }_{85}$ pollen $\ldots \ldots \ldots \ldots \ldots \ldots \ldots \ldots \ldots \ldots \ldots \ldots \ldots{ }_{28}$ roots $\ldots \ldots \ldots \ldots \ldots \ldots \ldots \ldots \ldots \ldots \ldots \ldots{ }_{00}^{28}$ seed $\ldots \ldots \ldots \ldots \ldots \ldots \ldots \ldots \ldots \ldots \ldots \ldots \ldots, \ldots \ldots \ldots{ }_{110}$ seedllng $\ldots \ldots \ldots \ldots \ldots \ldots \ldots \ldots \ldots \ldots \ldots \ldots, 54$ Eucastalia $\times$ Xanthantha $\ldots \ldots \ldots \ldots \ldots \ldots \ldots \ldots . \ldots \ldots, 230$
Euryate, clelstogamy of $\ldots \ldots \ldots \ldots \ldots \ldots \ldots \ldots \ldots, 121$

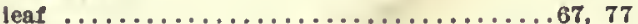

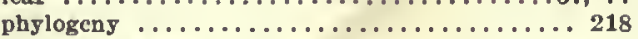
root-halrs ahsent $\ldots \ldots \ldots \ldots \ldots \ldots \ldots \ldots \ldots 111$ stem structure $\ldots \ldots \ldots \ldots \ldots \ldots \ldots \ldots \ldots \ldots \ldots .46$

Faba Aegyptla $\ldots \ldots \ldots \ldots \ldots \ldots \ldots \ldots \ldots \ldots 15^{*}, 16,18,20$ Fagus leaf $\ldots \ldots \ldots \ldots \ldots \ldots \ldots \ldots \ldots \ldots \ldots \ldots \ldots \ldots \ldots, 72$

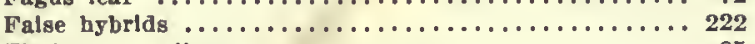
Fischer on pollen $\ldots \ldots \ldots \ldots \ldots \ldots \ldots \ldots \ldots \ldots \ldots \ldots, 85$

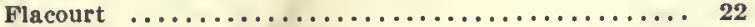
Floral clock ............................ 119 dlagram $\ldots \ldots \ldots \ldots \ldots \ldots \ldots \ldots \ldots \ldots \ldots, 100,101$ Flower $\ldots \ldots \ldots \ldots \ldots \ldots \ldots \ldots \ldots \ldots \ldots \ldots \ldots \ldots . .27,77-80$ adjustment to water level ..............118 anesthesla of $\ldots \ldots \ldots \ldots \ldots \ldots \ldots \ldots \ldots \ldots \ldots 121$ development of $\ldots \ldots \ldots \ldots \ldots \ldots \ldots \ldots .97-99^{*}, 101$ duratlon of $\ldots \ldots \ldots \ldots \ldots \ldots \ldots \ldots \ldots \ldots \ldots$ 119-120 In relation to polllnation .............121-123

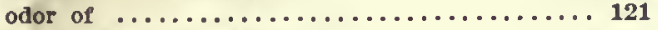
openlng and closing of $\ldots \ldots \ldots \ldots \ldots \ldots \ldots$ 119-121 submergence after anthesls ...........123-124 symmetry of ....................100, 101

Focke on hyhrlds ....................232-233 Food uses $\ldots \ldots \ldots \ldots \ldots \ldots .7,10-12,17,22,170,196,235$ Forgetful lotus $\ldots \ldots \ldots \ldots \ldots \ldots \ldots \ldots \ldots \ldots \ldots, 11$

Frank on position of lamina ...............114-115

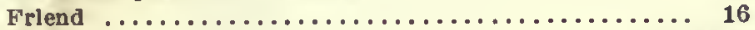

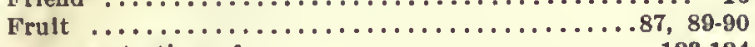
protectlon of $\ldots \ldots \ldots \ldots \ldots \ldots \ldots \ldots \ldots \ldots \ldots$ 123-124 rlpening of $\ldots \ldots \ldots \ldots \ldots \ldots \ldots \ldots \ldots \ldots \ldots \ldots, 27$ Fuchslus $\ldots \ldots \ldots \ldots \ldots \ldots \ldots \ldots \ldots \ldots \ldots \ldots \ldots, 14$

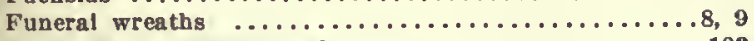
Funleulus, development of $\ldots \ldots \ldots \ldots \ldots \ldots \ldots \ldots \ldots . \ldots \ldots$ structure and contents .............. 104

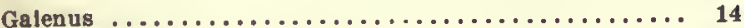

Gaudlchaud $\ldots \ldots \ldots \ldots \ldots \ldots \ldots \ldots \ldots \ldots \ldots \ldots \ldots . \ldots \ldots \ldots$

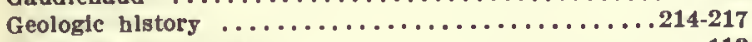

Geotropism of roots $\ldots \ldots \ldots \ldots \ldots \ldots \ldots \ldots \ldots \ldots \ldots 113$

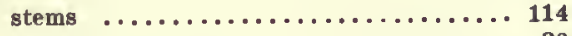

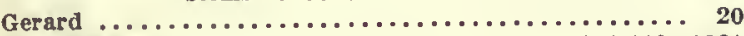
Germlnation $\ldots \ldots \ldots \ldots \ldots \ldots \ldots \ldots \ldots \ldots \ldots \ldots$ 106-110, 108*

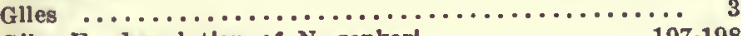
Gllg, E., descrlption of $\mathbf{N}$. zenkert ..........197-198 Goehel on development of flower $\ldots \ldots \ldots \ldots \ldots \ldots \ldots 97,98$ fnnetion of alr-canals $\ldots \ldots \ldots \ldots \ldots \ldots \ldots 60$

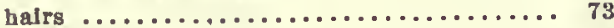

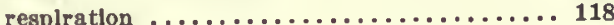
seedllngs $\ldots \ldots \ldots \ldots \ldots \ldots \ldots \ldots \ldots \ldots \ldots 107,109$ symmetry of flower ............... 101

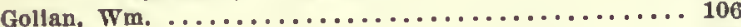
Grew, N. .......................... 25

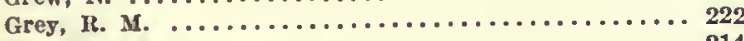

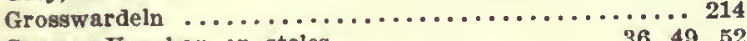
Gwynne-Vaughan on steles $\ldots \ldots \ldots \ldots \ldots \ldots \ldots . . .36,49,52$ structure of seedling $\ldots \ldots \ldots . .111-112$

Hahlts $\ldots \ldots \ldots \ldots . \ldots 27,213$

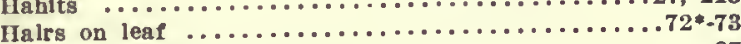

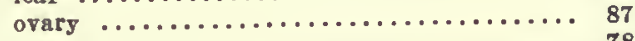
peduncle $\ldots \ldots \ldots \ldots \ldots \ldots \ldots \ldots \ldots \ldots \ldots \ldots$ 78 petlole $\ldots \ldots \ldots \ldots \ldots \ldots \ldots \ldots \ldots \ldots \ldots .56-57,73 *$ seed $\ldots \ldots \ldots \ldots \ldots \ldots \ldots \ldots \ldots \ldots \ldots \ldots, 92.93$ stem ....................... 73* $^{*}$ 


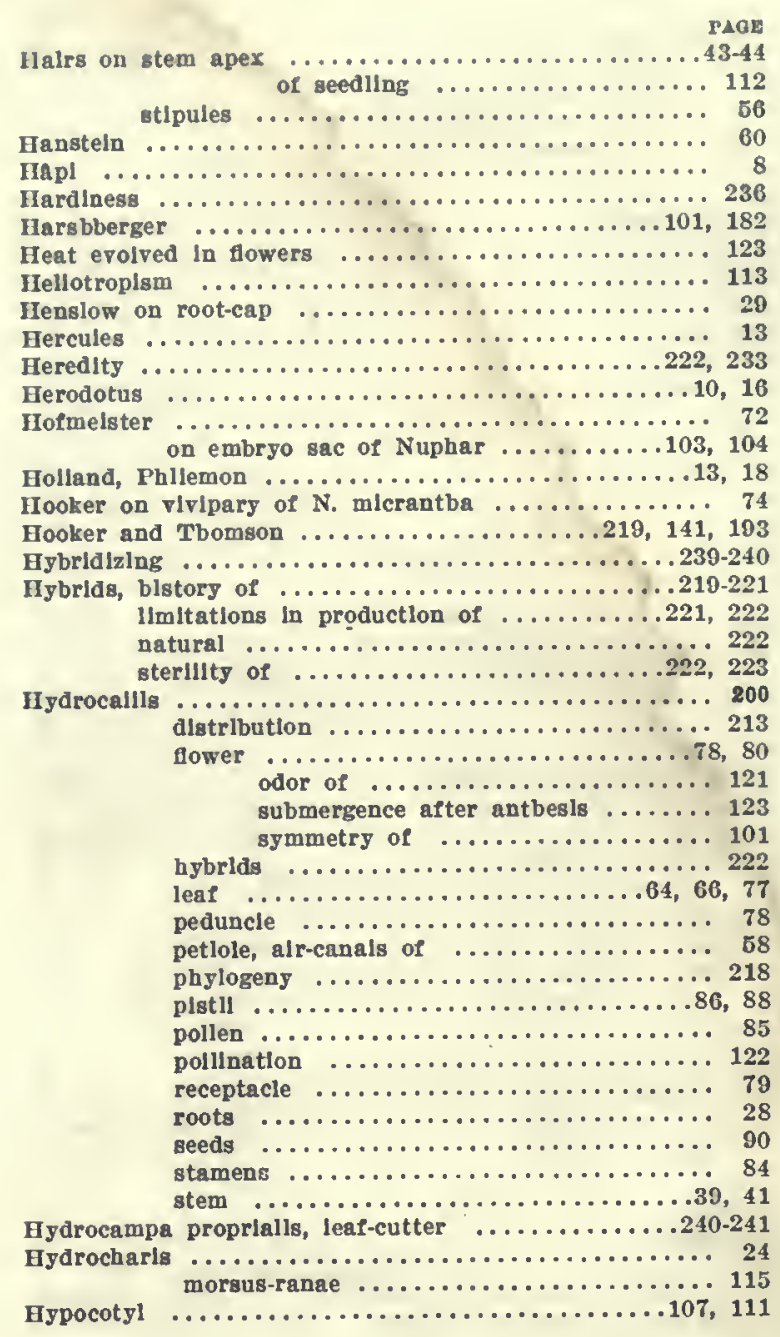

Idloblasts, crystals ln ................... 61

In carpels $\ldots \ldots \ldots \ldots \ldots \ldots \ldots \ldots \ldots .84,85,87,88$ leaf $\ldots \ldots \ldots \ldots \ldots \ldots \ldots \ldots \ldots \ldots \ldots, 70$ peduncle $\ldots \ldots \ldots \ldots \ldots \ldots \ldots \ldots \ldots \ldots \ldots, 79$ petals $\ldots \ldots \ldots \ldots \ldots \ldots \ldots \ldots \ldots \ldots, 83$

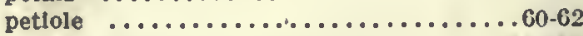
roots ........................... 33 development of $\ldots \ldots \ldots \ldots \ldots \ldots \ldots, 37$ sepals $\ldots \ldots \ldots \ldots \ldots \ldots \ldots \ldots \ldots \ldots . . \ldots 1,82$ stamens $\ldots \ldots \ldots \ldots \ldots \ldots \ldots \ldots \ldots \ldots . . .64,85$ stem $\ldots \ldots \ldots \ldots \ldots \ldots \ldots \ldots \ldots \ldots \ldots, 46$ stipules $\ldots \ldots \ldots \ldots \ldots \ldots \ldots \ldots \ldots \ldots \ldots, 56 \ldots \ldots$ water-leaves $\ldots \ldots \ldots \ldots \ldots \ldots \ldots \ldots \ldots, 77$ Inappendiculatoe $\ldots \ldots \ldots \ldots \ldots \ldots \ldots \ldots \ldots \ldots \ldots 127,163,192$ Inflorescence .........................99, 100

Insects attracted to flowers $\ldots \ldots \ldots \ldots \ldots \ldots \ldots \ldots \ldots \ldots 121$

effectlng pollnation .................122-123

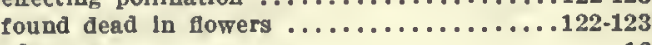

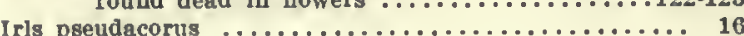

Irmiscb $\ldots \ldots \ldots \ldots \ldots \ldots \ldots \ldots$

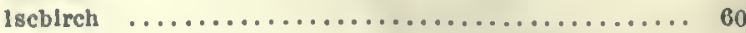

Jabn on causes of shape of leaf $\ldots \ldots \ldots \ldots \ldots \ldots \ldots 115$ Jones, Sir Wm. ..................... Joret $\ldots \ldots \ldots \ldots \ldots \ldots \ldots \ldots \ldots \ldots \ldots \ldots \ldots \ldots$

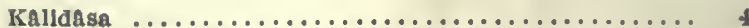

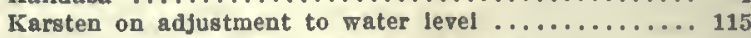
Kerner on opening and closing of N. alba ......... 120

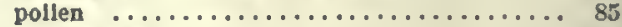

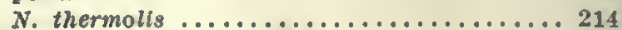

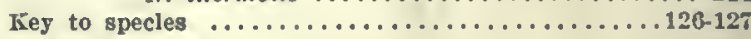
Kltalbel, P. ............................ 214 Klebs on secdllngs ..................... 107 Kny on cuticle of alr-canals ............... 60 Koehne on fuslon of floral leaves witb ovary ....... 98 Kobl .......................60, 61, 70 Kotscby collection from Nubia .............. 146 Kuntze $\ldots \ldots \ldots \ldots \ldots \ldots \ldots \ldots \ldots \ldots \ldots \ldots \ldots \ldots, 25$

Labellng ............................. 239

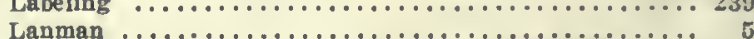

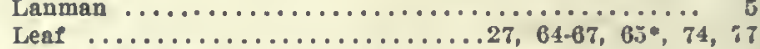
adjustment to water level $\ldots \ldots \ldots \ldots \ldots \ldots \ldots$......114 alr-canals in $\ldots \ldots \ldots \ldots \ldots \ldots \ldots \ldots \ldots \ldots \ldots \ldots \ldots$ 70

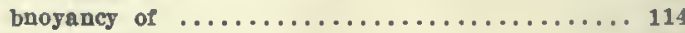
development of $\ldots \ldots \ldots \ldots \ldots \ldots \ldots \ldots \ldots \ldots \ldots . . .95-97$ balrs on ........................... klnds of $\ldots \ldots \ldots \ldots \ldots \ldots \ldots \ldots \ldots \ldots \ldots$ of germinating tuber ...........75*, 100*, 105* seedllng $\ldots \ldots \ldots \ldots \ldots \ldots \ldots \ldots \ldots \ldots 107-110^{*}, 108^{*}$ structure of $\ldots \ldots \ldots \ldots \ldots \ldots \ldots \ldots, 112$

gtructure of $\ldots \ldots \ldots \ldots, 67 * 68 *-72,76,77,115,110$ vascular system of $\ldots \ldots \ldots \ldots \ldots \ldots \ldots \ldots \ldots, 71 *$ venation $\ldots \ldots \ldots \ldots \ldots \ldots \ldots \ldots \ldots \ldots \ldots, 67,115$

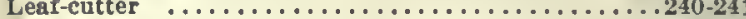

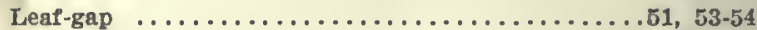
Leaf-scar $\ldots \ldots \ldots \ldots \ldots \ldots \ldots \ldots \ldots \ldots \ldots \ldots \ldots \ldots, 48^{*}$

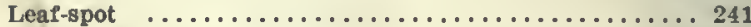

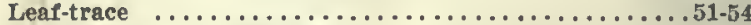
Leaves as food for anlmals ................. 30 Lechartler on function of alr-canals ............ 60 experlments on resplration .........117, 118

Lebmann on vivlpary ................... 7 Leptopleuro. See Lytopleuro.

Louconthos .......................... 200

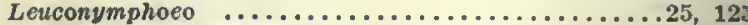
gibertli ...................... 211

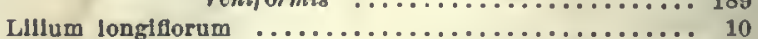

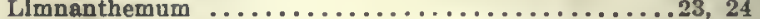
Lobelius ....................15*-16, 18, 20, 22 Lotophagl $\ldots \ldots \ldots \ldots \ldots \ldots \ldots \ldots \ldots \ldots \ldots \ldots \ldots \ldots, 11$

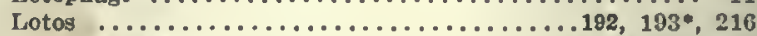
carpels $\ldots \ldots \ldots \ldots \ldots \ldots \ldots \ldots \ldots \ldots 84,86,87,193^{*}$ aistribution $\ldots \ldots \ldots \ldots \ldots \ldots \ldots \ldots \ldots \ldots \ldots .213,217$ flower ...................77, 80, 103*

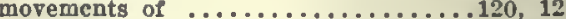

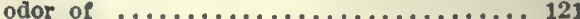
submergence after antbesls ........... 123 symmetry of $\ldots \ldots \ldots \ldots \ldots \ldots \ldots \ldots \ldots \ldots 101$ trult ..................... 89, 90 geologlc blstory $\ldots \ldots \ldots \ldots \ldots \ldots \ldots \ldots \ldots \ldots 214,217$ germination ....................... 106, 105. bybrids ..................221-223, 231-232 
Lotos leat girder-1lke velns $\ldots \ldots \ldots \ldots \ldots \ldots \ldots \ldots, 115$

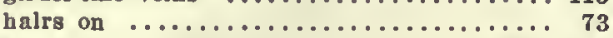

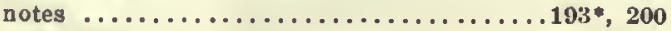
peduncle $\ldots \ldots \ldots \ldots \ldots \ldots \ldots \ldots \ldots \ldots \ldots \ldots \ldots \ldots, 79$ ldloblasts in $\ldots \ldots \ldots \ldots \ldots \ldots \ldots, 62$ petiole, alr-canals of $\ldots \ldots \ldots \ldots \ldots \ldots \ldots \ldots . \ldots, 02$ ldloblasts In $\ldots \ldots \ldots \ldots \ldots \ldots \ldots \ldots, 62$ thyll-llke bodles in $\ldots \ldots \ldots \ldots \ldots \ldots \ldots, 62$ vascular system of $\ldots \ldots \ldots \ldots \ldots \ldots \ldots, 62$ phylogeny $\ldots \ldots \ldots \ldots \ldots \ldots \ldots \ldots \ldots \ldots \ldots \ldots \ldots \ldots \ldots \ldots, 218$

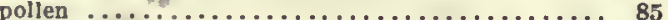
pollination $. . . \ldots \ldots \ldots \ldots \ldots \ldots \ldots \ldots . .121,122$ roots $\ldots \ldots \ldots \ldots \ldots \ldots \ldots \ldots \ldots \ldots \ldots, 28$

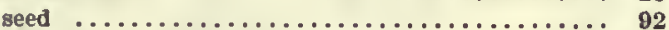

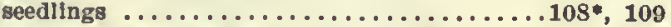
specles, dlscussion of $\ldots \ldots \ldots \ldots \ldots \ldots \ldots \ldots .193$ stamens $\ldots \ldots \ldots \ldots \ldots \ldots \ldots \ldots \ldots \ldots . \ldots, 84,193$ * stem $\ldots . \ldots \ldots \ldots \ldots \ldots \ldots \ldots \ldots \ldots \ldots, \ldots \ldots, 41$

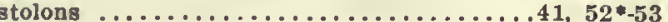
Lotos Lotus ............................ Lotus aegyptia .....................17, 18, 19, 21

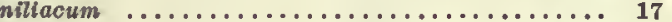

Lotus, blne $\ldots \ldots \ldots \ldots \ldots \ldots, 7,8,146$ Egyptlan $\ldots \ldots \ldots \ldots \ldots 1^{*}, 6,7^{*}, 8,11-14,16-18,20$ genus of Legumlnosae .................. 12

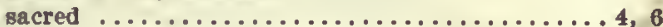

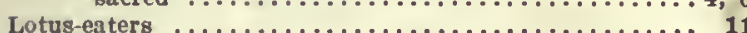

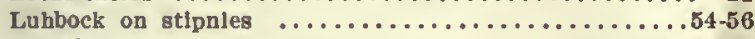

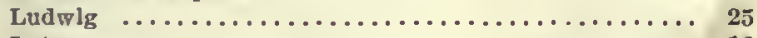

Lyte .................................. 18

Lytopleura $\ldots \ldots \ldots \ldots \ldots \ldots \ldots \ldots \ldots \ldots, 127$

Macdowell ............................... Mackintosh on air-canals of petioles .............

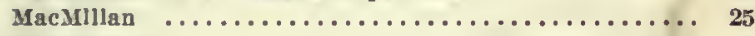

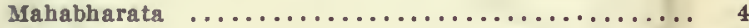
Malplghl ............................... 25 Marllac .............................. 221 Marsilla ........................... 24 Masters on alr-canals of pettoles $\ldots \ldots \ldots \ldots \ldots \ldots \ldots$. 58 Matthlolus $\ldots \ldots \ldots \ldots \ldots \ldots \ldots \ldots \ldots \ldots \ldots, \ldots \ldots \ldots, 16,18,20$

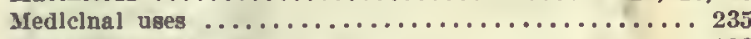
Megaspore, development of .................. 102 Melanopsis costata .......................... 214

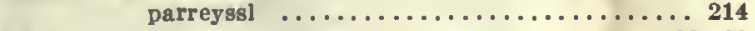
Mellinck ...........................60, 62 Mendel's theory .....................223, 233 Menyanthes Indlea $\ldots \ldots \ldots \ldots \ldots \ldots \ldots \ldots \ldots \ldots, 211$ Meyer, test for cork ..................... 48

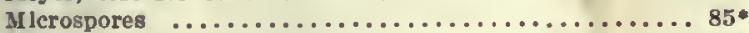

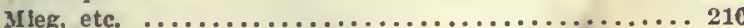

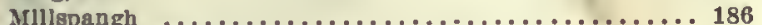
Mlmusops schlmperl $\ldots \ldots \ldots \ldots \ldots \ldots \ldots \ldots \ldots \ldots$. 9 Mollsch on crystals ....................... 61 Movements of floral parts ..................119-121 Mucllage halrs on seeditngs $\ldots \ldots \ldots \ldots \ldots \ldots \ldots \ldots \ldots, 112$ Mrüller, $\mathrm{C}$, on collenchyma $\ldots \ldots \ldots \ldots \ldots \ldots \ldots \ldots, 58$ Mruller, H., on polllnation .................. 122 Miller, R., on soll ......................... 237 Mummy Muskrats $\ldots \ldots \ldots \ldots \ldots \ldots \ldots \ldots \ldots \ldots \ldots \ldots \ldots \ldots \ldots \ldots \ldots \ldots \ldots, 241$

Nigell on leaf-traces $\ldots \ldots \ldots \ldots \ldots \ldots \ldots \ldots \ldots \ldots$ s3

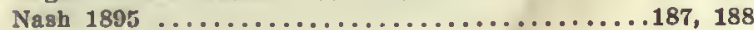

PAGE

(a) 222

Nefer Tom ......................., 8,10 Nelirctch on $N$. thermalis .................... 214 Nelnmblum, geologle hlstory ................215 Nelumbium nymphacoides . ..................... 216 Nelumbo .............................. 210 early notices of $\ldots \ldots \ldots .4,9,11,12,13,14,15$, leaves $16,18,20,21,23,24,25$ prlmary root $\ldots \ldots \ldots \ldots \ldots \ldots \ldots \ldots \ldots, 28$ Nelumbo lutea $\ldots \ldots \ldots \ldots \ldots \ldots \ldots \ldots \ldots \ldots \ldots \ldots, 211$ nnclfera .................4, 6, 10, 11, 211 Nelumboneae, geologlc history ................ 215 phylogeny $\ldots \ldots \ldots \ldots \ldots \ldots \ldots \ldots \ldots, 218$ pistll ...................... 87

Nemphar $\ldots \ldots \ldots \ldots \ldots \ldots \ldots \ldots \ldots \ldots \ldots \ldots \ldots, 18$

Nenufar $\ldots \ldots \ldots \ldots \ldots \ldots \ldots \ldots \ldots \ldots \ldots \ldots, 16,10,21,25$ Nicolal on root-cap ........................ 29 Nodal structure, $N$. Alova ................51*, 53-54

Nuphar $\ldots \ldots \ldots \ldots \ldots \ldots \ldots \ldots \ldots \ldots 49,211,215,217$ bract suhtending lower ............... 98 early notlces of $\ldots . .12,14,15,17,18,20,22,24$ embryo ............................. 104 embryo sac ......................103, 104 foral dlagram $. . \ldots \ldots \ldots \ldots \ldots \ldots \ldots \ldots, 100$ frult $\ldots \ldots \ldots \ldots \ldots \ldots \ldots \ldots \ldots \ldots \ldots, 87$ petlole structure $\ldots \ldots \ldots \ldots \ldots \ldots \ldots \ldots \ldots 76,77$ phylogeny ........................218

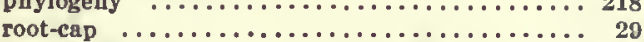
root-halrs ........................... 111

Nuphar advena, emhryo .................... 104 emhryo-sac $\ldots \ldots \ldots \ldots \ldots \ldots \ldots \ldots .6104$

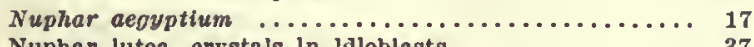
Nuphar lutea, crystals in laloblasts ............... 37 early notlces of $\ldots \ldots \ldots \ldots \ldots \ldots 14,19,25$ embryo sac $\ldots \ldots \ldots \ldots \ldots \ldots \ldots \ldots \ldots \ldots \ldots$

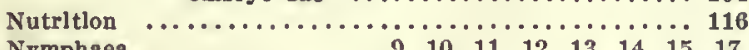
Nymphaea $\ldots \ldots \ldots \ldots \ldots \ldots \ldots .9,10,11,12,13,14,15,17$, $18,20,21,22,23,24,25,125$

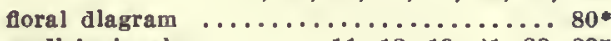
medlclnal value $\ldots \ldots \ldots .11,12,19,21,22,235$

Nymphaea abbreviata $\ldots \ldots \ldots \ldots \ldots \ldots \ldots \ldots \ldots \ldots . \ldots \ldots$

acutiloba .......................... 170

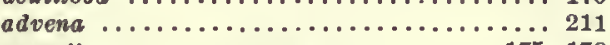

aеsopii ......................... 175,178

Nymphaea alba $. .172,174,175-179,180,189,215,216,217$ carpels ..................... 84 development of lower ........97, 98, 101 leaf $\ldots \ldots \ldots \ldots \ldots .95,90$ dissection of stem apex $\ldots \ldots \ldots \ldots, 05$ distrlbutlon .............171, 177, 213 early notlces of $\ldots 11,12,14,15^{*}, 16,17$, $18,10,20,21,22,23,24,25$ floral movements, time of ......... 120 under anesthetics .. 121

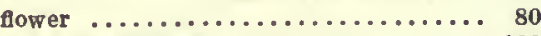
malformed ............... 100 submergence of, after anthesls.. 124 symmetry of ............100, 101 halrs ........................ $72^{*}$ hybrlds ...................222, 223, 232 Introduction to cultivation ........236 leaf $\ldots \ldots \ldots \ldots .54,66,69,72,73,75,77$ Nägell on leaf-traces $\ldots \ldots \ldots \ldots \ldots \ldots .53$ notes on ................177-179, 188 odor of flower $\ldots \ldots \ldots \ldots \ldots \ldots \ldots . . .121$ 
Symphaea alus petlole ................56,

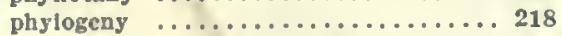
pollen ................. 85 polllnation ...............121, 122 relation to $\mathrm{N}$. candida .....171, 174, 178 resplration $\ldots \ldots \ldots \ldots \ldots \ldots \ldots \ldots \ldots, 117$ roots $\ldots \ldots \ldots \ldots \ldots \ldots \ldots \ldots \ldots \ldots . \ldots \ldots$ seed $\ldots \ldots \ldots \ldots \ldots \ldots \ldots \ldots \ldots . \ldots, 01,02,03$ * stamens ....................83, 84

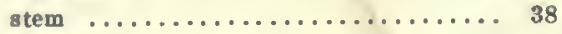
synonymy ..................211 thyll-llke bodles in petiole ......... 62

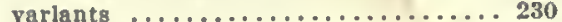

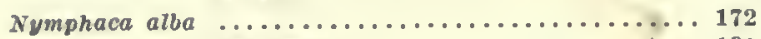
canadensts $\ldots \ldots \ldots \ldots \ldots \ldots \ldots \ldots \ldots$ candidisyima .............223, 230 culturc $\ldots \ldots \ldots \ldots \ldots \ldots 237$ floral movements ...... 119 lear $\ldots \ldots \ldots \ldots \ldots 67,68,72$ scars $\ldots \ldots \ldots \ldots 47^{*}-48^{*}$ peduncle $\ldots \ldots \ldots \ldots \ldots .78$ plstil ............ 88 root structure ....... 30 stem 38 structure .......45, 46 cork formation .... 47

$\times$ odorata rosea ...... 231

depressa .................... 178 Rore pieno odorota ............. 180 intermedia .................... 176

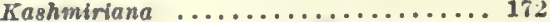

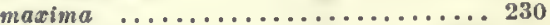
melocarpa ...................175, 178

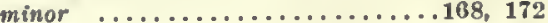
otigostigma .................172, 174 oocarpa ...............172, 174, 178 oviformis .................. 178

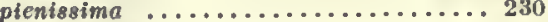

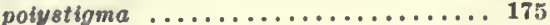
purpurea $\ldots \ldots \ldots \ldots \ldots \ldots \ldots \ldots \ldots \ldots .179$ rosea ....................178, 179

Nymphaea alba rubra (Plate XV) ............ 179 flower $\ldots \ldots \ldots \ldots \ldots \ldots \ldots, 77$ hybrids $\ldots \ldots 78,221,223,229,231$ varlants .............223, 230

$\times$ mexlcana .............. 230

Nymphoea aiba sphaerocarpa .............174, 178 piatystigma erythrocarpa rosea ..........178, 179 rubra ............. 170 urceolata $\ldots \ldots \ldots \ldots \ldots \ldots \ldots \ldots \ldots \ldots$ Nymphaen alba $x$ candlda $\ldots \ldots \ldots \ldots \ldots \ldots 175,223,230$

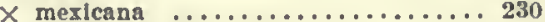
$\times$ odorata .....................230 rosea $\ldots \ldots \ldots \ldots \ldots \ldots \ldots 231$ Nymphaca aibo-rosca $\ldots \ldots \ldots \ldots \ldots \ldots \ldots \ldots \ldots \ldots \ldots . \ldots \ldots 11$

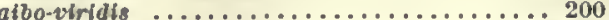
Nymphaea amazonum (Plate XIX) ............200-204 clelstogamy in ...........27, 121 flower, duratlon of .......119, 120 submergence of ........ 123 frult . . leat $\ldots \ldots \ldots \ldots \ldots .69,72,73,77$ peduncle ................ 78 petlole $\ldots \ldots \ldots \ldots \ldots \ldots \ldots 5,59 *, 60$
PAGE Nymphaea amszonum, phylogeny $\ldots \ldots \ldots \ldots \ldots \ldots \ldots 218$ plstll $\ldots \ldots \ldots \ldots \ldots \ldots \ldots \ldots$ seedllng root halrs on $\ldots 110^{*}, 111$ stomata on leaves of .. 112 seeds ................. 00,02 stamens ............... 8 tuber $\ldots \ldots \ldots \ldots \ldots \ldots \ldots \ldots \ldots 40^{\circ}$ Nymphaea amazonum goudotiana ..............204

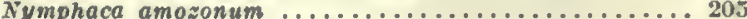
submersa ...............34, 204 Nymphaea amellana $\ldots \ldots \ldots \ldots \ldots \ldots \ldots \ldots \ldots \ldots . \ldots \ldots$ Nymphaea americana ....................... 2 Nymphaea ampla (Plate V) .........134-136, 205, 222 cnlture $\ldots \ldots \ldots \ldots \ldots \ldots \ldots \ldots \ldots .230$ early notlces of $\ldots \ldots \ldots \ldots \ldots .21,24,25$

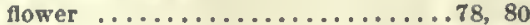

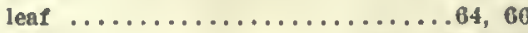
notes $\ldots \ldots \ldots \ldots \ldots \ldots \ldots \ldots$ 135, 136, 139

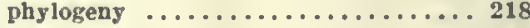

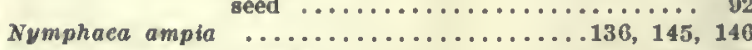
piumier $\ldots \ldots \ldots \ldots \ldots \ldots \ldots \ldots \ldots \ldots 135,136$

Nymphaea ampla pulchella ................136-137 speclosa $\ldots \ldots \ldots \ldots \ldots \ldots \ldots \ldots \ldots 136$

Nymphaea ampla $\beta$ hooker ................ 136 \& rudgeana ................. 205 r salzmanni $\ldots \ldots \ldots \ldots \ldots \ldots \ldots \ldots 136$ ondrcona

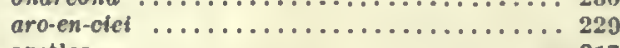

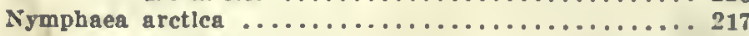

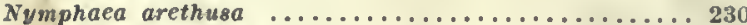
arethusae $\ldots \ldots \ldots \ldots \ldots \ldots \ldots \ldots \ldots . \ldots \ldots, 217$ arifotia $\ldots \ldots \ldots \ldots \ldots \ldots \ldots \ldots \ldots \ldots \ldots .211$

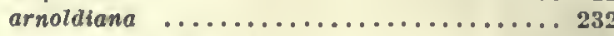
peduncle $\ldots \ldots \ldots \ldots \ldots \ldots \ldots$ astroea $\ldots \ldots \ldots \ldots \ldots \ldots \ldots \ldots \ldots \ldots \ldots \ldots 139,227$

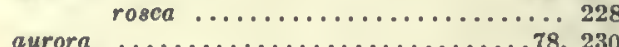

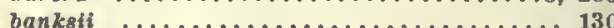

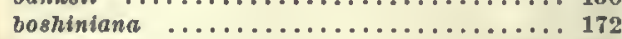
basniniana ...................... 172, beila .......................141, 198 berneriana $\ldots \ldots \ldots \ldots \ldots \ldots \ldots \ldots 153,156,157$ biradiata $\ldots \ldots \ldots \ldots \ldots \ldots \ldots \ldots \ldots \ldots 172,174$

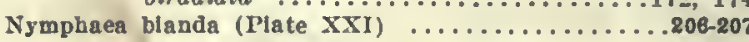
phylogeny ............... 218 seed $\ldots \ldots \ldots \ldots \ldots \ldots \ldots \ldots \ldots \ldots, 02$

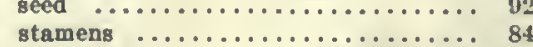
Nymphaca bianda ..............180, 200, 205, 200 Nymphaea blanda lenzllana (Plate XXI) .......... 207 Nymphaea bianda $\beta$ amazonum ..................... 205 Nymphaea blandusiae .................... 217 Nymphaca boucheana .................220, 232

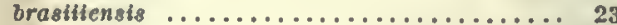
brakeleyt rosea $\ldots \ldots \ldots \ldots \ldots \ldots \ldots \ldots \ldots . . \ldots 231$

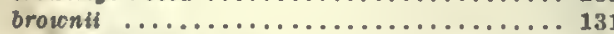
brydonacea elegans ................ 231 cachemiriona ..................172, 174 Nymphaea caerulea (Plate VIII) $\ldots \ldots \ldots 141-146,142 *, 217$ anther $\ldots \ldots \ldots \ldots \ldots \ldots \ldots \ldots \ldots . \ldots \ldots$ carpels $\ldots \ldots \ldots \ldots \ldots \ldots \ldots \ldots . . . .65,142^{*}$ culture $\ldots \ldots \ldots \ldots \ldots \ldots \ldots \ldots \ldots \ldots . \ldots \ldots 230$ distribution ........................ 213 eariy notices of $\ldots \ldots \ldots \ldots .6 .13,17,20$ embryo ....................105* 
Nymphaea caerulea, flower $\ldots \ldots \ldots \ldots \ldots \ldots \ldots \ldots 80,142$ color of ............. 121 development of $\ldots \ldots \ldots .97,98$ duration of $\ldots \ldots \ldots \ldots \ldots, 119$ submergence of $\ldots \ldots \ldots \ldots, 123$ malformed ............. 100 frult $\ldots \ldots \ldots \ldots \ldots \ldots \ldots \ldots \ldots$ 142* germination .............. 106 hybrlds $\ldots .221,222,224,225,226,233$ leaf $\ldots \ldots \ldots \ldots \ldots \ldots \ldots 64-66,75^{*}$ D development of $\ldots \ldots \ldots \ldots . .6$. 95 notes $\ldots \ldots \ldots \ldots \ldots 141,145,146,147$ $150,156,160,182$

ovule, development of peduncle $\ldots \ldots \ldots \ldots \ldots \ldots \ldots .69^{*}, 78$ petlole $\ldots \ldots \ldots \ldots \ldots \ldots \ldots \ldots, 59^{*}$ phyllotaxy phylogens $\ldots \ldots \ldots \ldots \ldots \ldots \ldots \ldots \ldots, 218$ pollen $. . . \ldots \ldots \ldots \ldots \ldots \ldots, \ldots, 8^{*}$ polllnation ................ 122 $\operatorname{root} \ldots \ldots, \ldots, \ldots, \ldots, \ldots, \ldots, \quad 28$ root-cap $\ldots \ldots \ldots \ldots \ldots \ldots \ldots \ldots .29^{*}-30$ seed $\ldots \ldots \ldots \ldots \ldots \ldots \ldots \ldots . .91 .92$ seedling $. \ldots \ldots \ldots \ldots \ldots \ldots \ldots \ldots, 110^{*}$ root-halrs on $\ldots \ldots \ldots \ldots 111$ stomata of $\ldots \ldots \ldots \ldots \ldots 112$ stamens $\ldots \ldots \ldots \ldots \ldots \ldots \ldots \ldots \ldots \ldots 2^{*}$ stem structure $\ldots \ldots \ldots \ldots, \ldots, 44,46^{*}$

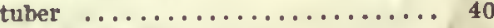
used for food $\ldots \ldots \ldots \ldots \ldots \ldots, 235$

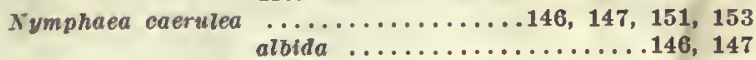
Nymphaea caerulea alblflora $\ldots \ldots \ldots \ldots \ldots \ldots \ldots .145$

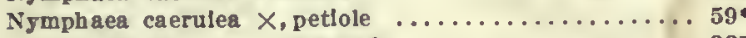
$\times$ capensls $\ldots \ldots \ldots \ldots \ldots \ldots \ldots \ldots \ldots \ldots+225$ malformed flower .... 100 $X$ zanzlbarlensls (Plate XXVI) 225-226 tlme of flora! movements.... 119

Nymphaea cahlara Nymphaca callantha

calophylla $\ldots \ldots \ldots \ldots \ldots \ldots \ldots \ldots \ldots \ldots \ldots \ldots \ldots \ldots .216,218$

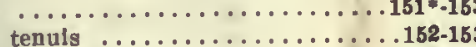
compared with N. Lennica $\ldots .170,171$ alstributlon ............171, 173-174 early notlces of $\ldots \ldots \ldots .14,18,10,20$ flower .................... 80 hybrlds $\ldots \ldots \ldots \ldots \ldots \ldots \ldots \ldots \ldots \ldots \ldots \ldots \ldots, 222,231$ leat $\ldots \ldots \ldots \ldots \ldots \ldots \ldots \ldots \ldots \ldots \ldots 3^{*}$ notes $\ldots \ldots \ldots \ldots \ldots \ldots \ldots \ldots \ldots \ldots+174,178$ phylogeng $\ldots \ldots \ldots \ldots \ldots \ldots 217,218$ seed $\ldots \ldots \ldots \ldots \ldots \ldots \ldots \ldots, 90,02$ sepals $\ldots \ldots \ldots \ldots \ldots \ldots \ldots \ldots \ldots, 81$ stem $\ldots \ldots \ldots \ldots \ldots \ldots \ldots \ldots \ldots, 38$ varletles $\ldots \ldots \ldots \ldots \ldots \ldots \ldots \ldots \ldots \ldots$ 174-175 Nymphaea candida oocarpa $\ldots \ldots \ldots \ldots \ldots \ldots \ldots \ldots \ldots$ semiaperta ...............171, 175 phaeroides $. . . \ldots \ldots \ldots \ldots \ldots \ldots, 175$

Nymphaea candlda $x$ alba $\ldots \ldots \ldots \ldots \ldots \ldots \ldots \ldots . . .175$ vymphaea candidissima ..................... 230 candolleana ....................135, 205 Nymphaea capensls (Plate X)..136, 141, 146, 153-157, 154* early notices of $\ldots \ldots \ldots \ldots \ldots \ldots .22-24$
Nymphaea capensis, flower, movements of ........ 110 hybrlds $\ldots \ldots \ldots \ldots \ldots \ldots \ldots .224-225$ leaf $\ldots \ldots \ldots \ldots \ldots \ldots \ldots \ldots .64,65$ notes $\ldots \ldots \ldots \ldots \ldots \ldots \ldots \ldots \ldots \ldots .156-157,160$ phylogeng $\ldots \ldots \ldots \ldots \ldots \ldots \ldots .218$ pollen $\ldots \ldots \ldots \ldots \ldots \ldots \ldots \ldots, \quad 85$ roots $\ldots \ldots \ldots \ldots \ldots \ldots \ldots \ldots, 28$ seed $\ldots \ldots \ldots \ldots \ldots \ldots \ldots \ldots, 0 . \cdots \cdots, 02$ seedling, root-halrs of $\ldots \ldots \ldots \ldots 111$ stomata on $\ldots \ldots \ldots \ldots, 112$

tuber $\ldots \ldots \ldots, \ldots, \ldots, \ldots, \ldots, 40^{*}$

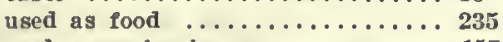

Nymphaea capensls madagascarlensls ............ 157 zanzlbarlensls (Plate XI), 157.161, 158* forma azurea ...... 161 rosea $\ldots \ldots .161$ (See N. zanzibariensis.)

Nymphaea capensls $x$, lcap $\ldots \ldots \ldots \ldots \ldots \ldots \ldots \ldots 7^{*}$ $\times$ zanzibariensis (Plate XXVI).. 222 $223,226^{*}, 227$ pollination ..... 122 tlme of floral movements ... 119 Nymphaea caroliniana ....................231 nivea $\ldots \ldots \ldots \ldots \ldots \ldots \ldots \ldots, 230$ perfecta...$\ldots \ldots \ldots \ldots \ldots .231$ rosea ................... 231 caspari $. . . \ldots \ldots \ldots \ldots \ldots \ldots \ldots \ldots \ldots, 179$ caspary ........................... 179

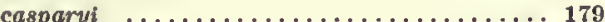

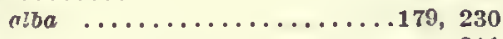
ceramica ........................ 211

Nympbaea charpentiert ...................216

Nymphaea chromatella ................... 230

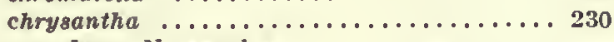
coerulea $=$ N. caerulea.

colossea .....................231, 237 columbiana ...................... 232

Nymphaea cordata $\ldots \ldots \ldots \ldots \ldots \ldots \ldots \ldots \ldots \ldots \ldots 216$

Nymphace coteka ........................... 198

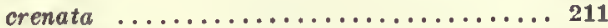

crenulata $. . . \ldots \ldots \ldots \ldots \ldots \ldots \ldots . .211$

cubogermen...$\ldots \ldots \ldots \ldots \ldots \ldots \ldots \ldots$ 174 cyanea $. . . \ldots \ldots \ldots \ldots \ldots \ldots \ldots \ldots \ldots, 140,153$

deaniana ......................... 232

dellcatissima ...................... 232 dentata $\ldots \ldots \ldots \ldots \ldots \ldots \ldots \ldots \ldots \ldots, 194,196$ flower $\ldots \ldots \ldots \ldots \ldots \ldots \ldots \ldots \ldots \ldots \ldots, 78$ movements of $\ldots \ldots \ldots \ldots \ldots, 119$ hybrlds $\ldots \ldots \ldots \ldots \ldots 161,220,231-233$ leaf $\ldots \ldots \ldots \ldots \ldots \ldots \ldots \ldots \ldots, 75,77$ peduncle $\ldots \ldots \ldots \ldots \ldots \ldots \ldots .69^{*}, 78$ petiole, vascular system of $\ldots \ldots .63^{*}$ pollen .................... 85 seed.... vitallty of $\ldots \ldots \ldots \ldots \ldots \ldots, 106$ seedllng, leaf-structure $\ldots \ldots \ldots \ldots, 112$ root-halrs of $\ldots \ldots \ldots \ldots .111$

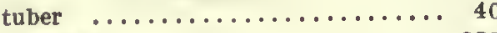
dentata grandifora .................. 232 magnifica ................... 232 devoniensis .............193, 195*, 199, 200 floral movements ........... 119 hlstory of $\ldots \ldots .219,220,223,232$ peduncle $\ldots \ldots \ldots \ldots \ldots \ldots \ldots, 78$ 


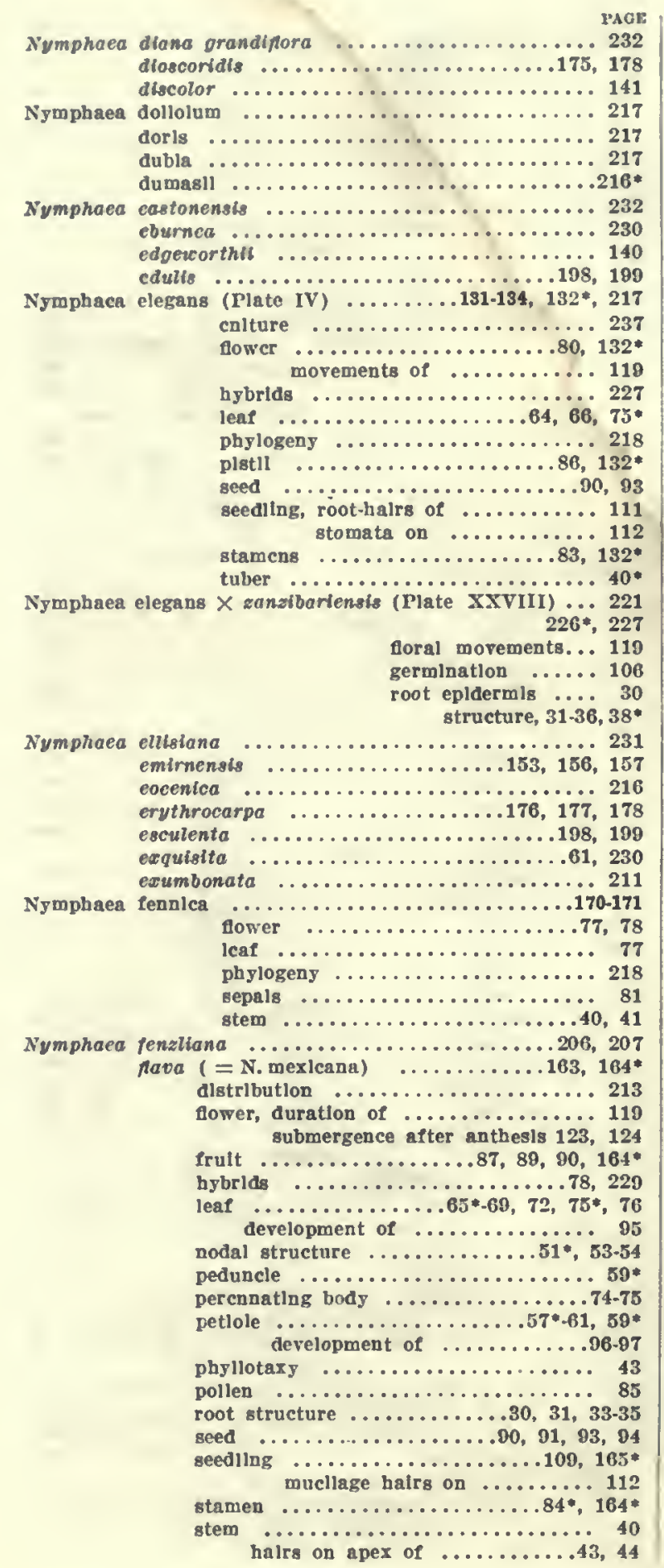

Nymphaea fara, stem, gtructure, $43,45,46,40,500^{\circ}, 53$ stlpules $\ldots \ldots \ldots \ldots \ldots \ldots \ldots \ldots \ldots .55^{*}, 66$ stolons ................. 48-49, 53 Nrmphaea flaro-rirens (Plate VI) .....137-139, 138*, 217 foral movements .......... 119 hybrlds ......221, 222, 224, 228 leat .........64-66, 74-76, 75* peduncle, adjustment to water

level ...................119.

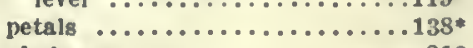
phylogeny .............. 218 plstil $\ldots \ldots \ldots \ldots \ldots \ldots \ldots 86,138^{*}$ pollen .................. 85* root $\ldots \ldots \ldots \ldots \ldots \ldots \ldots \ldots, 28$ contractlle $\ldots \ldots \ldots 33^{*}, 35,113$ structure . $31,33,34,37 *, 38^{*}$ root-cap $\ldots \ldots \ldots \ldots \ldots \ldots \ldots . . .29-30$ seed $\ldots \ldots \ldots \ldots \ldots \ldots \ldots \ldots \ldots, 02^{*}$ stamens $\ldots \ldots \ldots \ldots \ldots \ldots .83,138$. stem $\ldots \ldots \ldots \ldots \ldots \ldots \ldots \ldots . \ldots 39$ stolons $\ldots \ldots \ldots \ldots \ldots \ldots \ldots \ldots . . . .41$ tuber formation ........... 47 Nymphaea flavo-rirens $X$ zanzibariensis (I'late $X X I X)$. 227-228 root, contrac.

tlle $\ldots \ldots . .113$ root, structure 35

Nymphaea flavo-rlrens $\times$ zanzibarlensis rosca $\ldots . . .225$ leaves.. $55^{*}$ 201 cordatis integerrimis $\ldots \ldots \ldots \ldots \ldots \ldots \ldots 168$

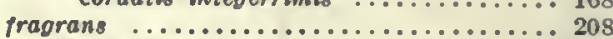
Frank Treleasc $\ldots \ldots \ldots \ldots \ldots \ldots \ldots \ldots 232$ frocbelii ..................223, 230 tulva ........................ 230 Nymphaea gardnerlana (Plate XXIV) ........... 203 Nymphaea George Huster ...........223, 231, 232

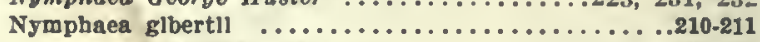
glgantea (Plate III) $\ldots \ldots \ldots \ldots \ldots \ldots \ldots$. 12s-131 culture $\ldots \ldots \ldots \ldots \ldots \ldots \ldots .237,239$ distrlbution ............. 130, 213 flower $\ldots \ldots \ldots \ldots \ldots \ldots \ldots \ldots \ldots, 78$ dnration of $\ldots \ldots \ldots \ldots \ldots . . .118$ malformed ............. 100 leat $\ldots \ldots \ldots \ldots \ldots \ldots \ldots \ldots .6460,75$ petiole $\ldots \ldots \ldots \ldots \ldots \ldots \ldots \ldots \ldots . \ldots \ldots, 59 *$ phyllotaxy $\ldots \ldots \ldots \ldots \ldots \ldots \ldots \ldots, 42$ phylogeny .............217, 218 plstll $\ldots \ldots \ldots \ldots \ldots \ldots \ldots \ldots \ldots \ldots . \ldots . \ldots$ seed $\ldots \ldots \ldots \ldots \ldots \ldots \ldots \ldots \ldots . \ldots 2$ stamens $\ldots \ldots \ldots \ldots \ldots \ldots \ldots \ldots .83,85$ tuber $\ldots \ldots \ldots \ldots \ldots \ldots \ldots \ldots \ldots .40^{*}$ used as food ............... 235 Nymphaea glgantca forma alba ................. 130 rosea ................ 130

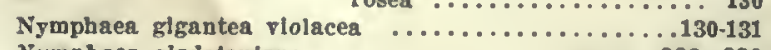

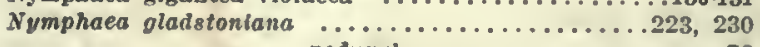
peduncle $\ldots \ldots \ldots \ldots \ldots \ldots \ldots$ ts

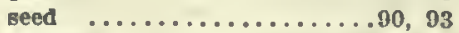
seedling ............... 109 $\times$ mexlcana .............. 223 glandulifera .................... 206 oloriosa .....................223, 231

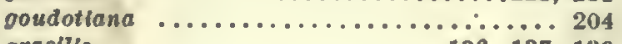
oractlis $\ldots \ldots \ldots \ldots \ldots \ldots \ldots \ldots \ldots \ldots \ldots \ldots \ldots \ldots \ldots \ldots \ldots \ldots, 137,139$ 
INDEX.

Nymphoea gracills, petlale ( $=\mathbf{N}$. flava-vircus $)$ PAGH seed $(=\mathbf{N}$. flavo-vlrens) $\ldots \ldots \ldots \ldots$. azurea $\ldots \ldots \ldots \ldots \ldots \ldots 139,227-228$ purpurea $. \ldots \ldots \ldots \ldots \ldots \ldots \ldots 139,227$ rosca ......................... 228 perfecta $\ldots . \ldots \ldots \ldots \ldots .139,228$ rubra gracillima alba ..................... 230 greyae $\ldots \ldots \ldots \ldots \ldots \ldots \ldots \ldots \ldots \ldots \ldots \ldots \ldots \ldots \ldots \ldots \ldots \ldots, 227$ guianensis. (See N. gulneensis.)

guineensts ............74, 146, 147, 149, 150 Nymphaea gypsorum ........................216, 217 Nymphaea hastata ......................... 211 Nymphrea heudelotll ................147-150, 148*, 153 nana $\ldots \ldots \ldots \ldots \ldots \ldots \ldots \ldots \ldots 9^{*} \cdot 150$

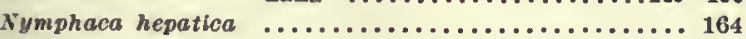

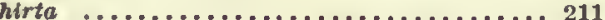

hookerlana $\ldots \ldots \ldots \ldots \ldots \ldots \ldots \ldots \ldots \ldots \ldots \ldots \ldots \ldots, 141$

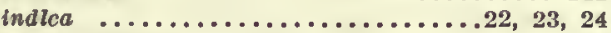
brahma ........................ 232 Hofgartner Graebener ........... 232 1818 . . . . spira $\ldots \ldots \ldots \ldots \ldots \ldots \ldots \ldots \ldots . .232$

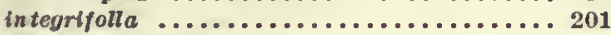
intermedia .......................... 172 James Brydon ..................... 231 James Gurney ..................... 231 Nymphaea jamesonlana (Plate XXIII) ............ 209 Nymphaea jubllee .............................. 232 kalmiana ......................... 211

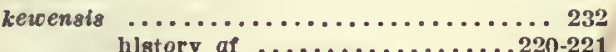
kostcletzkyt .....................172, 174 laclla colorans ....................... 232

Nymphaca laslophylla (Plate XXiI) .............207.208 latlor $\ldots 216$

Nymphaea laydekeri ...................... 229 fulgens $, \ldots \ldots \ldots \ldots \ldots \ldots \ldots \ldots, 230$

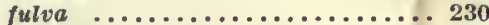
lilacea

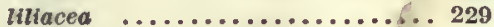
luclda .................... 230 purpurce ..................... 231 rased prollfera $\ldots \ldots \ldots \ldots . .223,229$ lelbaldiana .....................136, 153 Nymphrea llgnltlea $\ldots \ldots \ldots \ldots \ldots \ldots \ldots \ldots \ldots \ldots \ldots, 216$ Nymphaea lllacina .......................... 229

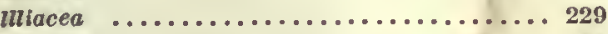

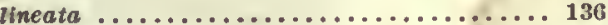

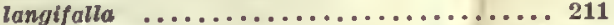

Nymphaea latus (Plate XVi) ................194:196, 199 dlstrlbutlan $\ldots \ldots \ldots \ldots \ldots \ldots 196,213-215$ early natlees of $\ldots 3-12,16,18,20,21-25$

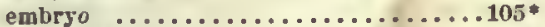
embryo-sac ..................... 103 flawer, develapment af $\ldots . . .07-100,99^{*}$ gubmergence after anthesls ... 123 symmetry of ............. 100 transformed $t a$ tubers..$\ldots \ldots 196$ funlculus $\ldots \ldots \ldots \ldots \ldots \ldots \ldots \ldots . \ldots \ldots$ hybrlds..193, 210, 220, 222, 223, 231, 232 notes $\ldots \ldots \ldots \ldots \ldots 193,196,197,199,200$

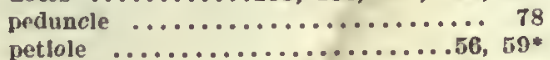

Nymphaea lotus, phylogeny .................. P18

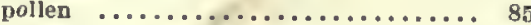

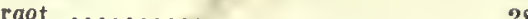

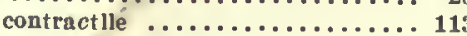
halrs ..................... 111 structure ..............30-34, 30 sced .......................90, 92 seedling leaves $. . . \ldots \ldots \ldots \ldots 110^{*}, 112^{*}$ stamen, develapment of .........101-102 stem st ructure ...................43-40 stlpules $\ldots \ldots \ldots \ldots \ldots \ldots \ldots \ldots \ldots . .65,56$ stolan .......................48, 49 tuber ......................... 40 used as food ................106, 235 varletles $\ldots \ldots \ldots \ldots \ldots \ldots \ldots . \ldots \ldots 3,196,197$ Nymphaca latus $\ldots \ldots \ldots \ldots \ldots \ldots \ldots \ldots . . . \ldots \ldots, 198,190,205$ angusta $\ldots \ldots \ldots \ldots \ldots \ldots \ldots \ldots . . . .193$ lata ......................... 193

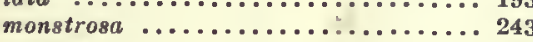
oblonga ...................... 193 stuhlmannil .................. 161

- acgyptia .................... 194

a lotus . ................... 193

в eordlfolla .................. 193

y pubescens $\ldots \ldots \ldots \ldots \ldots \ldots \ldots \ldots \ldots, 103$

Nymphaca lotus $x$ rubra $\ldots \ldots \ldots \ldots \ldots \ldots \ldots \ldots .2231-232$ $\times$ sturtevontii $\ldots \ldots \ldots \ldots \ldots \ldots \ldots \ldots \ldots \ldots \ldots \ldots$ Nymphaca luelda $. . . \ldots \ldots \ldots \ldots \ldots \ldots \ldots \ldots \ldots . . .230$ lutea $\ldots . \ldots .14,16,18-22,25,163,167,211$

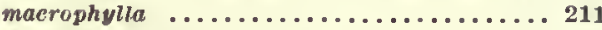

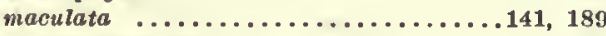
madagascariensis $\ldots \ldots \ldots \ldots \ldots \ldots \ldots \ldots \ldots . . \ldots 157$ early natlces of ........ 22 seed $\ldots \ldots \ldots \ldots \ldots \ldots .92,93$ malobarica .......................23, 140

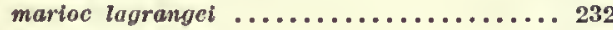
marllacea albida $\ldots \ldots \ldots \ldots \ldots \ldots \ldots \ldots, 230$ cornea $\ldots \ldots \ldots \ldots \ldots \ldots \ldots \ldots .231$ chromatella $\ldots \ldots \ldots \ldots .219,221,230$ eulture $\ldots \ldots \ldots .236,238$ floral mavements ... 119 Idloblasts in petiale.. 62 leaf $\ldots \ldots \ldots \ldots \ldots$...... 69 pedunele....... .78 raat strueture $\ldots .30^{*}, 31$

33,34

flammea .................. 231

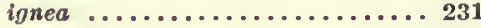

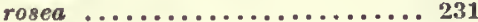

rubra punctata .............. 231

mauvil ........................139, 228 moximiliani .......................186, 210 Nymphaea mexieana (Plate XIII) ..163-167, 164*, 205, 217 distrlbutlon .............167, 213 doral mavements ............ 119 hybrids .........221, 229, 230, 231 leaf $\ldots \ldots \ldots \ldots 4,65,67,68,72,75 *$ perennating body $\ldots . .41,42^{*}, 74,75$ petlole $\ldots \ldots \ldots \ldots \ldots \ldots .57,50 *$, 61 phylogeny $\ldots \ldots \ldots \ldots \ldots \ldots \ldots, 218$ pollen $\ldots \ldots \ldots \ldots \ldots \ldots \ldots \ldots, 85$ stolan $\ldots \ldots \ldots \ldots \ldots \ldots \ldots \ldots \ldots, 41$ (See also $N$. Rava.)

Yymphaed mexicona Nymplaea mlerantlia (Plate IX) ..............146-147 hybrlds $\ldots \ldots \ldots \ldots \ldots \ldots \ldots \ldots . . .624$ 


\begin{tabular}{|c|c|c|c|}
\hline & PAGK & & 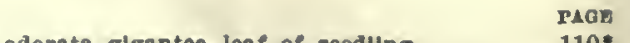 \\
\hline Nymphaea n & mlerantha, vivipary $\quad \ldots \ldots \ldots \ldots \ldots \ldots \ldots, 74$ & Nymphaea & odorata gigantea, leaf of needling \\
\hline \multirow[t]{4}{*}{ Nymphaea } & microphyita $\quad \ldots \ldots \ldots \ldots \ldots \ldots \ldots \ldots \ldots \ldots \ldots \ldots \ldots \ldots$ & & petlole...$\ldots \ldots \ldots \ldots .50^{*}$ \\
\hline & 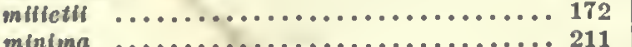 & & phylogeny $\ldots \ldots \ldots \ldots \ldots 218$ \\
\hline & 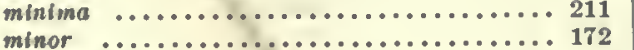 & & varlants $\ldots \ldots \ldots \ldots \ldots .230$ \\
\hline & intea $\ldots \ldots \ldots \ldots \ldots \ldots \ldots \ldots \ldots \ldots \ldots \ldots \ldots \ldots{ }^{172}$ & Nymphaea & $\begin{array}{r}\text { odorata glabra } \ldots \ldots \ldots \ldots \ldots \ldots \ldots \ldots \ldots \ldots \ldots ., 183 \\
\text { luctana } \ldots \ldots \ldots \ldots \ldots \ldots \ldots \ldots \ldots 222,231\end{array}$ \\
\hline \multirow{4}{*}{$\begin{array}{l}\text { Nymphaca } \\
\text { Nymphaea }\end{array}$} & 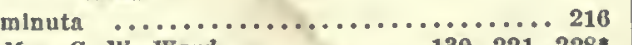 & & maxima $\quad \ldots \ldots \ldots \ldots \ldots \ldots \ldots \ldots \ldots \ldots .192$ \\
\hline & Mrrs. O. W. Ward ............139, 221, 228* & Nymphaca & odorata mlnor $\ldots \ldots \ldots \ldots \ldots \ldots \ldots$ 183-185, 184* \\
\hline & $\begin{array}{l}\text { leat } \ldots \ldots \ldots \ldots \ldots \ldots \ldots \ldots \\
\text { tuher } \ldots \ldots \ldots \ldots \ldots \ldots\end{array}$ & & dower $\ldots \ldots \ldots \ldots \ldots \ldots 78,184^{*}$ \\
\hline & nacchelt $\quad \ldots \ldots \ldots \ldots \ldots \ldots \ldots \ldots \ldots \ldots \ldots \ldots \ldots,{ }^{40}$ & & $\begin{array}{l}\text { movementa of } \ldots \ldots \ldots, 119 \\
\text { lear } \ldots \ldots \ldots \ldots \ldots \ldots \ldots \ldots, 64\end{array}$ \\
\hline dea $n$ & 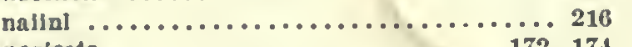 & & petlole $\ldots \ldots \ldots \ldots \ldots \ldots \ldots \ldots \ldots$, 61 \\
\hline \multirow[t]{9}{*}{ Nymphaca } & 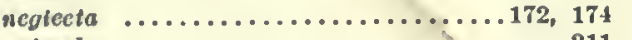 & & plstlI $\ldots \ldots \ldots \ldots \ldots \ldots 87,184^{*}$ \\
\hline & netumbo $\ldots \ldots \ldots \ldots \ldots \ldots \ldots \ldots \ldots . \ldots \ldots 211$ & & root epldermis $\ldots \ldots \ldots \ldots .30$ \\
\hline & nervosa $\ldots \ldots \ldots \ldots \ldots \ldots \ldots \ldots \ldots \ldots \ldots . \ldots \ldots$ & & stem $\ldots \ldots \ldots \ldots \ldots \ldots \ldots .38$ \\
\hline & 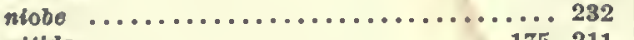 & & variants $\ldots \ldots \ldots \ldots \ldots \ldots .230$ \\
\hline & 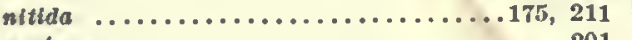 & Nymphaea & odorata minor foribus rosels ........... 186 \\
\hline & nocturna $\ldots \ldots \ldots \ldots \ldots \ldots \ldots \ldots \ldots \ldots . \ldots \ldots . \ldots \ldots$ & & pumila $\ldots \ldots \ldots \ldots \ldots \ldots \ldots \ldots . \ldots \ldots$ \\
\hline & nouehait $\ldots \ldots \ldots \ldots \ldots \ldots \ldots \ldots \ldots \ldots \ldots . \ldots \ldots$ & Nymphaea & odorata rosea $\ldots \ldots \ldots \ldots \ldots \ldots \ldots \ldots \ldots . \ldots . \ldots 186$ \\
\hline & 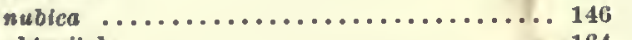 & & flower $\quad \ldots \ldots \ldots \ldots \ldots \ldots \ldots 77$ \\
\hline & obtusitoba $\ldots \ldots \ldots \ldots \ldots \ldots \ldots \ldots \ldots \ldots \ldots 164$ & & hybrids $\ldots \ldots \ldots \ldots 221,222,230$ \\
\hline \multirow[t]{33}{*}{ Nymphaea od } & odorata $\ldots \ldots \ldots \ldots \ldots \ldots \ldots \ldots 3,179-182,181 *$ & & 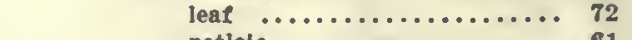 \\
\hline & arll $\ldots \ldots \ldots \ldots \ldots \ldots \ldots \ldots \ldots$. $^{*}, 104$ & & petlole ............... 61 \\
\hline & distribution $\quad \ldots \ldots \ldots \ldots \ldots \ldots$....... 213 & & varlants $\ldots \ldots \ldots \ldots \ldots 223,230$ \\
\hline & embryo $\ldots \ldots \ldots \ldots \ldots \ldots \ldots$. $\ldots 4-105$ & Nymphaea & odorata rosea $\underset{x}{x}$ mexleana $\ldots \ldots \ldots \ldots \ldots .220$ \\
\hline & $\begin{array}{l}\text { embryo-sac } \ldots \ldots \ldots \ldots \ldots \ldots \ldots .102 *, 103 \\
\text { Aower, duration of ............. } 119\end{array}$ & & $x$ tulerosa $\ldots \ldots \ldots \ldots \ldots . . \ldots 231$ \\
\hline & $\begin{array}{r}\text { Bower, duration of } \ldots \ldots \ldots \ldots \ldots \ldots \text {. } 119 \\
\text { odor of } \ldots \ldots \ldots \ldots \ldots \ldots \ldots \text { 121 }\end{array}$ & Nymphaea & 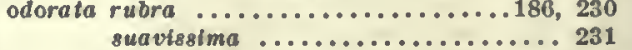 \\
\hline & submergence after anthesis, & & 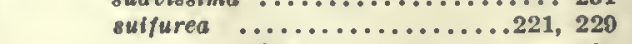 \\
\hline & 123,124 & & petlole $\ldots \ldots \ldots \ldots \ldots \ldots$. $50^{*}$ \\
\hline & germination ................. 107 & & phyllotaxy $\ldots \ldots \ldots \ldots \ldots \ldots$ \\
\hline & hybrids $\ldots \ldots \ldots \ldots \ldots \ldots 223,229,233$ & & superba $\ldots \ldots \ldots \ldots \ldots \ldots \ldots . . \ldots 231$ \\
\hline & Introduction to cultivation $\ldots \ldots \ldots 236$ & & vilfosa $\ldots \ldots \ldots \ldots \ldots \ldots \ldots \ldots$. $\ldots \ldots, 188$ \\
\hline & leat $\ldots \ldots \ldots \ldots \ldots .54,65-73,71 *, 181 *$ & & vilfossissima $\ldots . \ldots \ldots \ldots \ldots \ldots \ldots . . \ldots 188$ \\
\hline & derelopment of (Plate II) $\ldots .05,96$ & Nypaphaea & odorata $\times$ mexleana $\ldots \ldots \ldots \ldots \ldots \ldots . . \ldots 229$. \\
\hline & megaspore $. . \ldots \ldots \ldots \ldots \ldots \ldots \ldots . \ldots 102$ & Nymphaea & omoinatis ........................ 211 \\
\hline & notes $\ldots \ldots \ldots \ldots \ldots \ldots \ldots 182,102,197$ & & omarana (Plate XXX) $\quad \ldots \ldots \ldots \ldots \ldots . \ldots 103,232$ \\
\hline & ovule $\ldots \ldots \ldots \ldots \ldots \ldots \ldots \ldots \ldots 2^{*}$ & & fertillty . . . . . . . . . . . . 223 \\
\hline & pedunele $\ldots \ldots \ldots \ldots \ldots \ldots 59 * 62,78$ & & floral movements $\ldots \ldots \ldots \ldots \ldots . . .119$ \\
\hline & petals $\ldots \ldots \ldots \ldots \ldots \ldots \ldots \ldots 8,181$ & & pedlgree $. . . \ldots \ldots \ldots \ldots \ldots \ldots . . .233$ \\
\hline & petlole $\ldots \ldots \ldots \ldots 56-58,60-62,73^{*}, 76^{*}$ & & .............. 211 \\
\hline & phyllotaxy $\ldots \ldots \ldots \ldots \ldots \ldots \ldots \ldots, 42$ & & ortglesiana $\ldots \ldots \ldots \ldots \ldots \ldots \ldots \ldots \ldots . \ldots . \ldots . \ldots$ \\
\hline & phylogeny $\quad \ldots \ldots \ldots \ldots \ldots \ldots \ldots \ldots 218$ & & hyhrlds $\quad \ldots \ldots \ldots .220,231,232,233$ \\
\hline & pistll $\ldots \ldots \ldots \ldots \ldots \ldots \ldots .87-80,181 *$ & & ortglesiano-rubra .................. 232 \\
\hline & polien $\ldots \ldots \ldots \ldots \ldots \ldots \ldots \ldots \ldots$ & & fertllity $\ldots . \quad \ldots \ldots \ldots .223$ \\
\hline & pollination $\ldots \ldots \ldots \ldots \ldots \ldots \ldots 121,122$ & & h latory .............. 220 \\
\hline & root $\ldots \ldots \ldots \ldots \ldots$ & Nyniphaea & 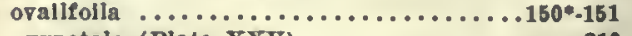 \\
\hline & halrs $\ldots \ldots \ldots \ldots \ldots \ldots \ldots \ldots \ldots \ldots \ldots$ & & oxypetala (Plate XXV) .............. 210 \\
\hline & $\begin{array}{l}\text { origin of } \ldots \ldots \ldots \ldots \ldots \ldots \ldots,{ }^{36} \\
\text { structure }\end{array}$ & & distrlhution $\ldots \ldots \ldots \ldots \ldots \ldots 210,213$ \\
\hline & seed $\ldots \ldots \ldots \ldots \ldots \ldots \ldots \ldots \ldots . .90-94$ & & 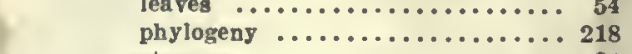 \\
\hline & als $\ldots \ldots \ldots \ldots \ldots \ldots \ldots 81,82,181 *$ & & stamens $\ldots \ldots \ldots \ldots \ldots \ldots \ldots$. 84 \\
\hline & stem (Plate II) $\ldots \ldots \ldots \ldots \ldots \ldots .38$ & Nymphaea & 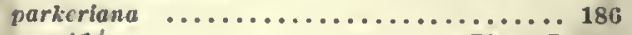 \\
\hline & dlssection of apex $\ldots \ldots$ & & Ifóra $\ldots \ldots \ldots \ldots \ldots \ldots \ldots \ldots$ 176, 177, 178 \\
\hline & $\begin{array}{l}\text { plaglotroplsm of } \ldots \ldots \ldots \\
\text { structure } \ldots \ldots \ldots \ldots \ldots 43\end{array}$ & & ......................... 10,22 \\
\hline & $\begin{array}{l}\text { structure } \\
\text { pules (Plate }\end{array}$ & tea & la $\ldots . .$. \\
\hline \multirow[t]{5}{*}{ Nymphaea } & $\begin{array}{l}\text { pules (Plate II) } \ldots \ldots \ldots \ldots \ldots .65{ }^{*}, 56 \\
\ldots \ldots \ldots \ldots \ldots \ldots \ldots \ldots \ldots \ldots \ldots \ldots\end{array}$ & $x y n$ & passifiora $\ldots . .$. \\
\hline & odorata carolinensis $\ldots \ldots \ldots \ldots \ldots \ldots \ldots$ & & $\ldots \ldots \ldots \ldots \ldots \ldots 172,174$ \\
\hline & $\begin{array}{l}\text { earolinensis } \ldots . . \\
\text { earoliniana } \ldots . . .\end{array}$ & & ifa (Plate XXVI) ..221, 222, 225*-226 \\
\hline & $\begin{array}{l}\text { earoliniana } . \\
\text { ehiorhiza ... }\end{array}$ & & morements $\ldots \ldots \ldots \ldots .119$ \\
\hline & exquista $\ldots$ & & $\ldots \ldots \ldots \ldots \ldots \ldots$ \\
\hline \multirow[t]{4}{*}{ Nymplaea } & odorata gignntea $\ldots \ldots$ & & permixta $\ldots \ldots \ldots \ldots \ldots \ldots \ldots \ldots \ldots$ \\
\hline & $\begin{array}{c}\text { odorata gignntea } \text { e....... } \\
\text { eulture. }\end{array}$ & & peterstana $\ldots \ldots \ldots \ldots \ldots \ldots \ldots \ldots$ \\
\hline & flower $\ldots \ldots \ldots \ldots \ldots$ & & 205 \\
\hline & Icap...$\ldots \ldots \ldots \ldots$ & Nymphaea & 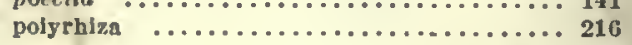 \\
\hline
\end{tabular}


INDEX.

Nymphaea polysepale $\ldots \ldots \ldots \ldots \ldots \ldots \ldots \ldots \ldots \ldots \ldots$

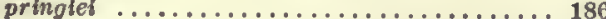
psendopygmaea ................... 148 Nymphaea puhesceos (Plate XVII) ............. 141, 198-199 early notlces of $\ldots \ldots \ldots \ldots \ldots \ldots, 23$

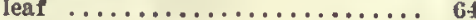
notes $\ldots \ldots \ldots \ldots \ldots \ldots \ldots 193,197,190$ seed $\ldots \ldots \ldots \ldots \ldots \ldots \ldots \ldots \ldots \ldots, 92$

Nymphaea pulchella ..................136, 210 pulcherrima ........146, 221, 222, 224*, 225

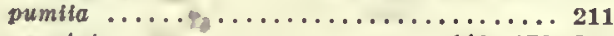
punctata ................140, 172, 211 pyomaea $\ldots \ldots \ldots \ldots \ldots \ldots \ldots \ldots \ldots \ldots . \ldots \ldots$ ovary $\ldots \ldots \ldots \ldots \ldots \ldots \ldots \ldots . \ldots 8$

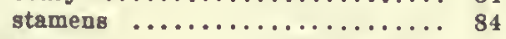
pygmaea alba $\ldots \ldots \ldots \ldots \ldots \ldots \ldots \ldots 168,223,229$
helvola $\ldots \ldots \ldots \ldots \ldots \ldots \ldots \ldots \ldots . .229$

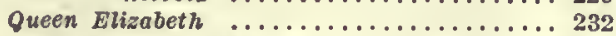
hyhrlds $\ldots \ldots \ldots \ldots \ldots$. 232-233 pedlgree ............. 233

Quccn Elizabeth $\times$ caerulea $\ldots \ldots \ldots \ldots \ldots 232$ $\times$ dentata $\ldots \ldots \ldots \ldots \ldots . \ldots \ldots 232$

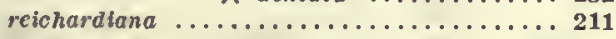

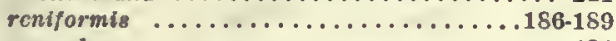

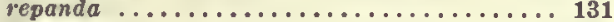
rhodantha ....................... 141 robtnsont ....................223, 230

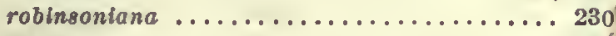
rosacea ........................ 230 rosea .........................186, 109 funlculus $\ldots \ldots \ldots \ldots \ldots \ldots \ldots \ldots \ldots \ldots \ldots$. 104 rotundifolia ............................

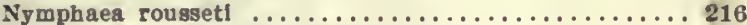
Nymphaea rubtcunda ..................... 232 Nymphaea ruhra (Plate XviII) $\ldots \ldots \ldots \ldots \ldots \ldots \ldots \ldots \ldots$ color in relation to insects ....... 121 coltnre $\ldots \ldots \ldots \ldots \ldots \ldots \ldots \ldots \ldots 236,238$ flower $\ldots \ldots \ldots \ldots \ldots \ldots \ldots \ldots \ldots .7779$ malformed $\ldots \ldots \ldots \ldots \ldots \ldots 100$ movements of ............ 119 hybrids .....193, 219.221, 223, 231, 232 in Hindn literature ............. 3-5 leaf $\ldots \ldots \ldots \ldots 65,67,68 *-71,73,75-77$ ahsorptlon of water by $\ldots \ldots \ldots 116$ development of $\ldots \ldots \ldots \ldots .95,96$ notes $\ldots \ldots \ldots \ldots \ldots \ldots \ldots \ldots 193,199,200$ peduncle $\ldots \ldots \ldots \ldots \ldots \ldots \ldots \ldots . \ldots 78$ petiole $\ldots \ldots \ldots \ldots \ldots 57,58,60,73^{*}, 76^{*}$ growth of $\ldots \ldots \ldots \ldots \ldots \ldots, 115$ phyllotaxy $\ldots \ldots \ldots \ldots \ldots \ldots \ldots \ldots \ldots, 43$ phylogeny ..............217, 218 pollen $\ldots \ldots \ldots \ldots \ldots \ldots \ldots \ldots \ldots, 85$ resplration $\ldots \ldots \ldots \ldots \ldots \ldots \ldots \ldots 118$ seed $\ldots \ldots \ldots \ldots \ldots \ldots \ldots \ldots \ldots \ldots, 02^{*}$ stameas $\ldots \ldots \ldots \ldots \ldots \ldots \ldots \ldots \ldots . .63$ stolon $\ldots \ldots \ldots \ldots \ldots \ldots \ldots \ldots \ldots 48,49,52$

Nymphaca rubra rosca $\ldots \ldots \ldots \ldots \ldots \ldots \ldots \ldots \ldots \ldots \ldots 19 . \ldots \ldots$ floral movements $\ldots \ldots \ldots \ldots \ldots 119$ leat $\ldots \ldots \ldots \ldots \ldots \ldots \ldots \ldots, 65$ peduncle $\ldots \ldots \ldots \ldots \ldots \ldots \ldots, 78$

Nymphrea ruhra $x$ ortgiesiana $\ldots \ldots \ldots \ldots \ldots \ldots \ldots . \ldots 232$ rudgeana (Plate $\mathrm{XX}$ ) .............25, 135, $136,164,200,204-206,222$ cleistogamy $\ldots \ldots \ldots \ldots \ldots \ldots .27,121$ floral movements .........110, 120 leat $\ldots \ldots \ldots \ldots \ldots \ldots \ldots \ldots \ldots, 64$
Nymphaea rudgeana, petlole $\ldots \ldots \ldots \ldots \ldots \ldots \ldots \ldots$ PAGE phylogeny ................ 218 seed $\ldots \ldots \ldots \ldots \ldots \ldots \ldots \ldots \ldots, 02$ stamens $\ldots \ldots \ldots \ldots \ldots \ldots \ldots \ldots . . \ldots 84$

Nymphaea rudgeana $\beta$ amazonum ...........200, 206

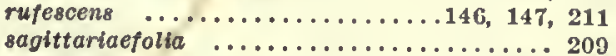
sagittata $\ldots \ldots \ldots \ldots \ldots \ldots \ldots \ldots \ldots, 190,211$ sagittifotia ..................... 211 sanguinea ...................186, 231

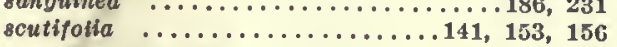
hyhrlds $\ldots \ldots \ldots \ldots \ldots \ldots \ldots \ldots . \ldots 233$

selgnoreti .................78, 230 sémiaperta ..................172, 174

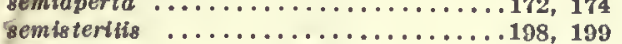

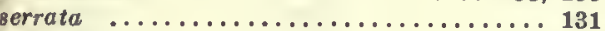

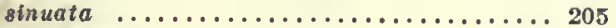
smithtana ..................... 232 spectosa $\ldots \ldots \ldots \ldots \ldots \ldots \ldots \ldots \ldots \ldots \ldots \ldots$ sphaerocarpa $\ldots \ldots \ldots \ldots \ldots \ldots \ldots \ldots \ldots \ldots 179$ rubra $\ldots \ldots \ldots \ldots \ldots \ldots \ldots \ldots 179$

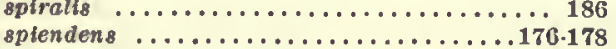
Nymphaea stellata $\ldots \ldots \ldots \ldots \ldots \ldots \ldots \ldots$ 140-141, 198, 217 culture $\ldots \ldots \ldots \ldots \ldots \ldots \ldots \ldots \ldots 236$ early notlces of $\ldots \ldots \ldots \ldots \ldots . ., 5,23$

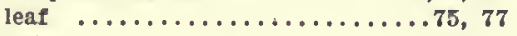
notes $\ldots \ldots \ldots \ldots \ldots \ldots \ldots \ldots 141,146$ phyllotaxy .............42,43 phylogeay $\ldots \ldots \ldots \ldots \ldots \ldots \ldots \ldots 218$ pollnatlon $\ldots \ldots \ldots \ldots \ldots \ldots \ldots \ldots 122$ resplratlon $\ldots \ldots \ldots \ldots \ldots \ldots \ldots \ldots, 118$

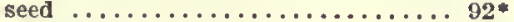
synonymy $\ldots \ldots \ldots \ldots \ldots \ldots \ldots 140,211$ vlvlpary $\ldots \ldots \ldots \ldots \ldots \ldots \ldots \ldots, 74$

Nymphaea steltata ...............131, 141, 153 bulbitlifera ............... 146

Nymphaea stellata cyanea ................. 140 Nymphaea stellata eastonicnsts $\ldots \ldots \ldots \ldots \ldots \ldots \ldots 227$

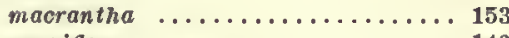
parvifiona .................. 140

Nymphaea stellata verslcolor (Plate ViI) .........140-141

Nymphaea stellata zanzibariensis ..................... 157

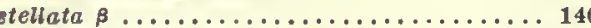

Nymphaea stellata $\times$ caerulea ...............225 stenaspldota (Plate XXI, XXIV) .......209 stnhlmannll $\ldots \ldots \ldots \ldots \ldots \ldots \ldots \ldots \ldots \ldots 161-162^{*}$ flower $\ldots \ldots \ldots \ldots \ldots \ldots \ldots 77,162$

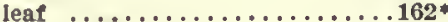

Nymphaea sturtevantii .................231-232 leaf, halrs on $\ldots \ldots \ldots \ldots \ldots$ T3 pedunele $\ldots \ldots \ldots \ldots \ldots \ldots \ldots$ 78 petiole $\ldots \ldots \ldots \ldots \ldots \ldots \ldots \ldots .57$

suaveolens $\ldots \ldots \ldots \ldots \ldots \ldots \ldots \ldots \ldots \ldots \ldots 211$ Nymphaca sulfurea (Plate $\mathrm{xII}$ ) $\ldots \ldots \ldots \ldots \ldots \ldots \ldots 16 \ldots \ldots$

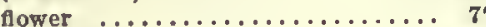

Nymphaea sulfurca .................... 229 grandifiora $\ldots \ldots \ldots \ldots \ldots \ldots \ldots \ldots . \ldots \ldots$

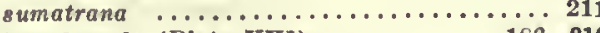
Nymphaea tenerlnervla (Plate XXI) ..........186, 210 Nymphaea tenuinervia .................... 210

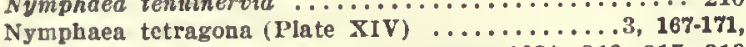
$168^{*}, 216,217,219$ culture .... dlstrlhutlon .........170, 213, 214 flower $\ldots \ldots \ldots \ldots \ldots \ldots .78,80,168^{*}$ 
276

The Waterlilies.
PAGR Nymphoea tulerosa porva .............189, 192 stem $\ldots \ldots \ldots \ldots \ldots \ldots \ldots, 38$

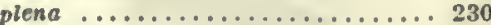
richardsoni ................. 230 development of leaf .. 97 rosea rubra $\ldots \ldots \ldots \ldots \ldots \ldots \ldots \ldots, 231$ superbe $\ldots \ldots \ldots \ldots \ldots \ldots \ldots .231$ germination $\ldots \ldots \ldots \ldots \ldots, 100$ bybrids ............223, 229, 231 leat $\ldots \ldots \ldots \ldots \ldots \ldots .64,64-60,77$ of seeding $\ldots \ldots \ldots \ldots \ldots 110^{*}$ structure of $\ldots 677_{-69}, 72,73,76$

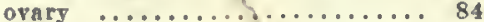
peduncle ................. $59^{*}$ petiole $\ldots \ldots \ldots \ldots \ldots 56-60,59^{*}, 73^{\circ}$ pbylogeny ................. 218 plstil .................... 86 potlen $\ldots \ldots \ldots \ldots \ldots \ldots, \ldots, 85$ stamens $\ldots \ldots \ldots \ldots \ldots \ldots .84,168^{*}$ stem $\ldots \ldots \ldots \ldots \ldots \ldots \ldots \ldots, 40$ used as $\operatorname{cood} \ldots \ldots \ldots \ldots \ldots \ldots \ldots, 170$ varletles ................... 170

Nymphaea tetragona angusta ................. 170 helvola .........221, 220, 236, 237 lata ${ }^{\circ} \ldots \ldots \ldots \ldots \ldots \ldots \ldots \ldots \ldots$ $\times$ alba $\ldots \ldots \ldots \ldots \ldots \ldots \ldots, 229$ $X$ alba rubra $\ldots \ldots \ldots \ldots \ldots \ldots, 220$

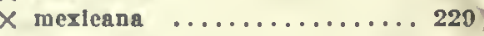

Nymphace tetragonanthos $\ldots \ldots \ldots \ldots \ldots \ldots \ldots \ldots \ldots . \ldots \ldots$ thermalis $\ldots \ldots \ldots \ldots \ldots \ldots \ldots \ldots 194,196,107$

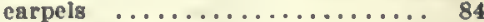
distrlbution ............... 214 leaf $\ldots \ldots \ldots \ldots \ldots \ldots \ldots \ldots \ldots \ldots, 75$ phylogeny .............214, 217 seed $\ldots \ldots \ldots \ldots \ldots \ldots \ldots \ldots, 92$ stamens $\ldots \ldots \ldots \ldots \ldots \ldots \ldots, 84$ $\times$ rubra $\ldots \ldots \ldots \ldots \ldots \ldots \ldots, 232$ X soutifolia ................232 trisepala $\ldots \ldots \ldots \ldots \ldots \ldots \ldots \ldots . \ldots, 135$ tropaeollfolia .....................136, 205 Nympbaea tuberosa .....................189*192 earpels $\ldots \ldots \ldots \ldots \ldots \ldots .84,87,88$ flower, movements of ......... 119 submergenee of ........ 124

hybrlds $\ldots \ldots \ldots \ldots 222,223,230,231$ leat $.54,65,67-69,72,76^{*}, 190^{*}, 191$ * pedunele $\ldots \ldots \ldots \ldots \ldots \ldots \ldots . \ldots 9^{*}, 78$ petlole ldloblasts in ........... 62 vaseular system of $\ldots \ldots, 63^{*}$ phyllotaxy $\ldots \ldots \ldots \ldots \ldots \ldots \ldots, 42$

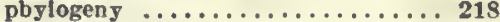
pollination $\ldots \ldots \ldots \ldots \ldots 121,122,192$ root structure $. \ldots \ldots \ldots \ldots \ldots \ldots .30-35$ seed $\ldots \ldots \ldots \ldots \ldots \ldots \ldots \ldots \ldots, 0,92$ sepals $\ldots \ldots \ldots \ldots \ldots \ldots \ldots .61,82,189^{*}$ stamens $\ldots \ldots \ldots \ldots \ldots \ldots \ldots, 84,180^{*}$ stem $\ldots \ldots \ldots \ldots \ldots \ldots \ldots \ldots, 38,39 *$ apex, dissection of $\ldots \ldots \ldots$. 95 balrs on $\ldots \ldots \ldots \ldots \ldots \ldots, 3^{*}$ structure $\ldots \ldots \ldots \ldots \ldots \ldots$. 44-46

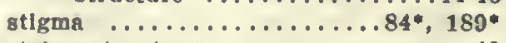
stolon structure $\ldots \ldots \ldots \ldots \ldots \ldots, 49$ stomata $\ldots \ldots \ldots \ldots \ldots \ldots \ldots, 192$ tubers $\ldots \ldots \ldots \ldots \ldots \ldots 38,190^{*}, 192$ variants $\ldots \ldots \ldots \ldots \ldots \ldots \ldots \ldots, 230$

Nymphaea tuberosa navescens $\ldots \ldots \ldots \ldots \ldots \ldots \ldots .230$ moxima ...............189, 192
Nymbaea tuberosa $x$ odorata rosea $\ldots \ldots \ldots \ldots \ldots \ldots . \ldots 231$

Nymphoce tussilaglfolla .................... 186

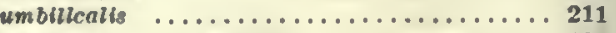
undulat? $\ldots \ldots \ldots \ldots \ldots \ldots \ldots \ldots \ldots \ldots \ldots \ldots \ldots \ldots \ldots, 136$

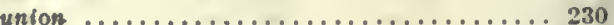

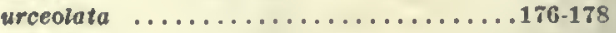
vęnusta ......................176-178 versleolor ....................131, 140 flower $\ldots \ldots \ldots \ldots \ldots \ldots \ldots \ldots, 78$ victoria $\ldots \ldots \ldots \ldots \ldots \ldots \ldots \ldots \ldots \ldots, 211$ vivipara $\ldots \ldots \ldots \ldots \ldots \ldots \ldots \ldots \ldots \ldots, 14,146$ cenzelit $\ldots \ldots \ldots \ldots \ldots \ldots \ldots \ldots \ldots \ldots \ldots \ldots \ldots \ldots, 172$ William Doogue .................. 231 Willam Falconer .................. 231 Willam stone (Plate XXIX) ....139, 221, 222, $227 *-228$ Nymphaca zanzibariensls ..............157, 217, 230 culture $\ldots \ldots \ldots \ldots \ldots \ldots .237$ embryo sac $\ldots \ldots \ldots \ldots \ldots, 103$ (lower.$\ldots \ldots \ldots$ 7 $7,78,80,158^{*}$ movements of ....119, 120

funleulus ............... 104 germination ........... 107 hybrlds $\ldots \ldots . .221,222,226,227$ Introduction Into Europe ... 106 lear .................64-68 structure $\ldots \ldots \ldots 68,70,72$ notes $\ldots \ldots \ldots \ldots \ldots \ldots \ldots .6 .141$ peduncle $\ldots \ldots \ldots \ldots \ldots \ldots, 78,79$ ld loblasts In $\ldots \ldots, 62$ $\ldots \ldots \ldots \ldots \ldots . . . \ldots 9^{*}, 61$ ldioblasts in ...... 62 vaseular strueture of . 63*

pbyllotaxs ............. 42 phylogeny.$\ldots \ldots \ldots \ldots \ldots .218$ plstll ...............86, 158* polten $. . \ldots \ldots \ldots \ldots \ldots, 8,85$ root $\ldots \ldots \ldots \ldots \ldots \ldots \ldots, \quad 28$ batrs .............. 111 seed $\ldots \ldots \ldots \ldots \ldots \ldots \ldots .60$ seedilng leaves ..........110* strueture ........ 112 stamens $\ldots \ldots \ldots \ldots \ldots .63,138^{*}$ tuber ............4 40* Nymphace zonziboriensis roseo, leares .......... $75^{*}$ tuber $\ldots \ldots \ldots \ldots \ldots, 40^{\circ}$ Nymphace zanzllariensls $\times \ldots \ldots \ldots \ldots \ldots \ldots . \ldots 27$ filoral movements $\ldots \ldots \ldots 118$ ovary $\ldots \ldots \ldots \ldots \ldots .87,85$ pednnele $\ldots \ldots \ldots \ldots \ldots, 78$ petlofe $\ldots \ldots \ldots \ldots .57,58,61$ gepals .............. 81 stipules $\ldots \ldots \ldots \ldots \ldots \ldots$. $55 *$

$\times$ eapensis $\ldots \ldots \ldots \ldots \ldots .227$ Nympbaea zenkerl ....................197*-198 Nympbacaceae, flower, symmetry of ............. 101 leaf, development of $\ldots \ldots \ldots \ldots \ldots$. 97

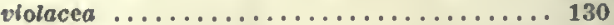


INDEX.

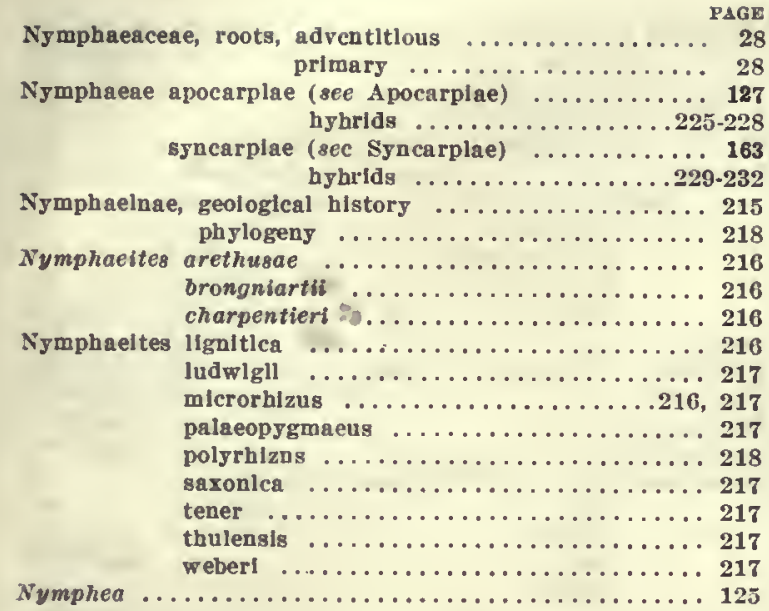

Odors of flowers

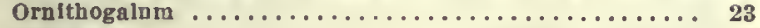
Oslrls $\ldots \ldots \ldots \ldots \ldots \ldots \ldots \ldots \ldots \ldots \ldots \ldots \ldots \ldots \ldots, 8$ Ovary ........................ development of $\ldots \ldots \ldots \ldots \ldots \ldots \ldots \ldots \ldots . . .6899$ morphology of $\ldots \ldots \ldots \ldots \ldots \ldots \ldots \ldots \ldots .86 .87,98$

orules

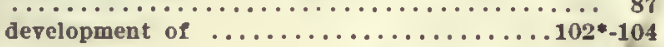

Pachycyst 70 Padma ....................... Papsrus $\ldots \ldots \ldots \ldots \ldots \ldots \ldots \ldots \ldots \ldots \ldots \ldots \ldots, 9$ Parkinson $\ldots \ldots \ldots \ldots \ldots \ldots \ldots \ldots \ldots \ldots \ldots \ldots \ldots .23$ Pariatore on alr-canals of petlole ............ Paxton on vlvipary ................... 74 Payer ............................... 80 on development of flower ..........97-99, 101

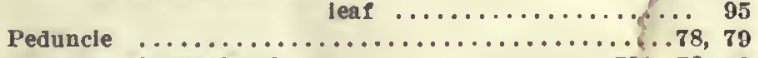
alr-canals of $\ldots \ldots \ldots \ldots \ldots \ldots \ldots \ldots \ldots \ldots 59 *, 78,79$ apogcotropism of $\ldots \ldots \ldots \ldots \ldots \ldots \ldots \ldots . \ldots 114$ development of ................... 99 Idlohlasts in $\ldots \ldots \ldots \ldots \ldots \ldots \ldots \ldots \ldots \ldots, 62$ In frult .......................123-124 vascular structure of $\ldots \ldots \ldots .53,54,59 *, 63,79$

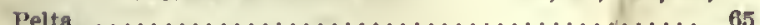

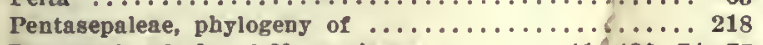
Perennating body of $\mathrm{N}$. mericana ......41, 42*, 74, 75

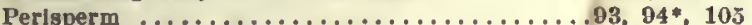
absorption by embryo ................ 109 Petals ......................80,82,83, 90 air-canals in $\ldots \ldots \ldots \ldots \ldots \ldots \ldots \ldots \ldots \ldots \ldots . \ldots 2$ development of .................... $98-99$ morphology of ....................... 100-101

Petiole ............................ 56 adjustment to watcr-level $\ldots \ldots \ldots \ldots \ldots . . .114,115$ alr-canals $\ldots \ldots \ldots \ldots \ldots 58,50^{*}-60,62,76 *, 06,112$

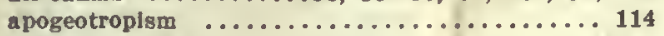

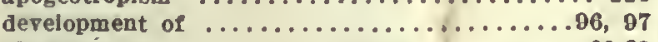
Idiohlasts in ...................60.62 structnre of $\ldots \ldots \ldots \ldots \ldots \ldots 56,57 *-60,62,73 * 76$ vascular system of $\ldots \ldots \ldots \ldots . . \ldots 9^{*}, 62-64,63^{*}, 76-77$ Phyllotaxy ........................42, 43

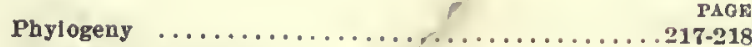
Picclola on politnation ................... 122

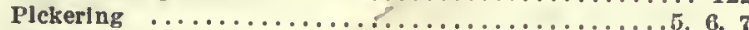

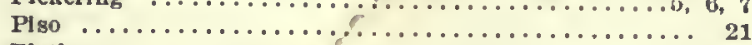

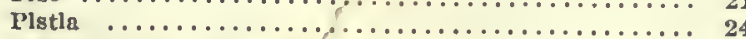
Plstil. (See Carpels.)

Plaglotroplsa of stems ....................... 114

Pianchon on Cyanea $\ldots \ldots \ldots \ldots \ldots \ldots \ldots \ldots \ldots \ldots \ldots . . . \ldots . \ldots . \ldots$ dead insects ln flowers ............. 122 hybrlds $\ldots \ldots \ldots \ldots \ldots \ldots \ldots \ldots 220,223,232$ malformed flower ............... 100 preumatocyst ................... 60

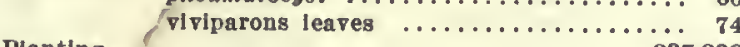

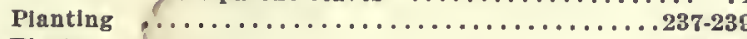

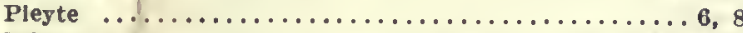

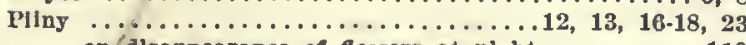
on disappearance of flowers at nlght ........ 119

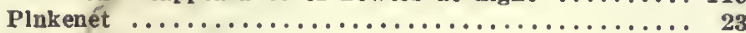

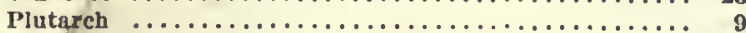

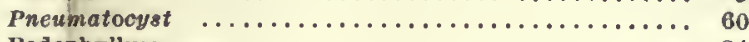

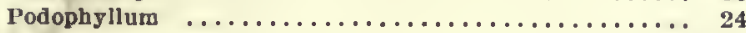
Pollen ............................ 85*

Pollinatlon, arrangements for $\ldots \ldots \ldots \ldots \ldots \ldots \ldots \ldots$ 121-123

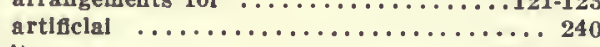

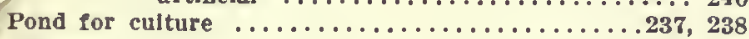
Prlchard ............................ 10 Prlmary root $\ldots \ldots \ldots \ldots \ldots \ldots \ldots \ldots \ldots 28,108^{*}, 109-111,110^{*}$ Princlpal area $\ldots \ldots \ldots \ldots \ldots \ldots \ldots \ldots \ldots \ldots \ldots \ldots \ldots \ldots, 66$

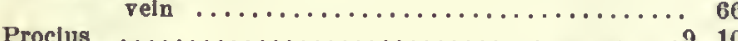
P............................ 10

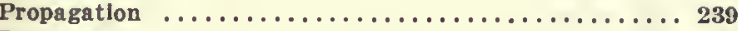
Proterogyny $\ldots \ldots \ldots \ldots \ldots \ldots \ldots \ldots \ldots \ldots \ldots \ldots \ldots \ldots 121$ Pgeudostomata ........................ 72

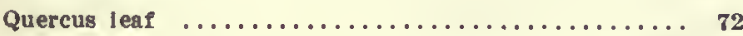

Raclborski on Inflorescence $\ldots \ldots \ldots \ldots \ldots \ldots \ldots \ldots \ldots$. 99 phyllotaxy $\ldots \ldots \ldots \ldots \ldots \ldots \ldots \ldots \ldots \ldots \ldots \ldots \ldots \ldots \ldots \ldots \ldots+43$ Radikofer, suggestion on $\mathbf{N}$. mexicana ........... 167 Ramses II ............................ 6-9 Ranunculus sceleratus .................. 115 Ray, John $\ldots \ldots \ldots \ldots \ldots \ldots \ldots \ldots \ldots \ldots \ldots \ldots \ldots, 22$

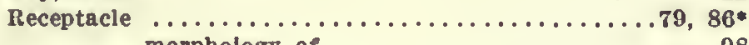
Resplration Rimbach on contractlle roots $\ldots \ldots \ldots \ldots \ldots \ldots \ldots \ldots \ldots \ldots$ Rohertson $\ldots \ldots \ldots \ldots \ldots \ldots \ldots \ldots \ldots \ldots \ldots \ldots \ldots \ldots 188,192$ on pollination $\ldots \ldots \ldots \ldots \ldots \ldots \ldots \ldots 121,122$

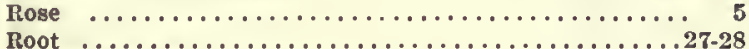

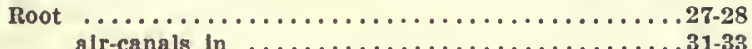

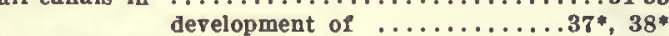

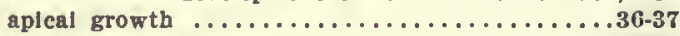

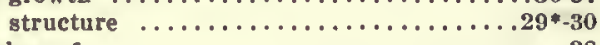
branchlng of $\ldots \ldots \ldots \ldots \ldots \ldots \ldots \ldots \ldots \ldots \ldots, 28$

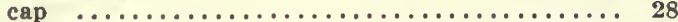

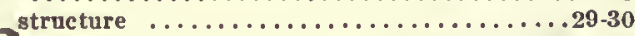
contractlle $\ldots \ldots \ldots \ldots \ldots \ldots \ldots \ldots \ldots .28,33^{*}, 35,113$ cortex of $\ldots \ldots \ldots \ldots \ldots \ldots \ldots \ldots \ldots \ldots \ldots 31-34,32 *$

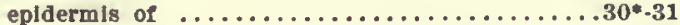
geotropism of $\ldots \ldots \ldots \ldots \ldots \ldots \ldots \ldots \ldots \ldots \ldots \ldots 113$ balrs $\ldots \ldots \ldots \ldots \ldots \ldots \ldots \ldots \ldots \ldots \ldots \ldots \ldots 109,111$

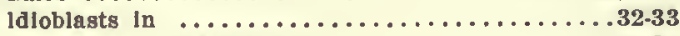
development of ............ 37 structure $\ldots \ldots \ldots \ldots \ldots \ldots \ldots \ldots \ldots \ldots \ldots \ldots 31-36,32 *$

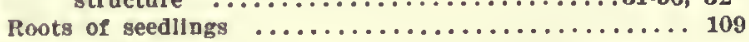




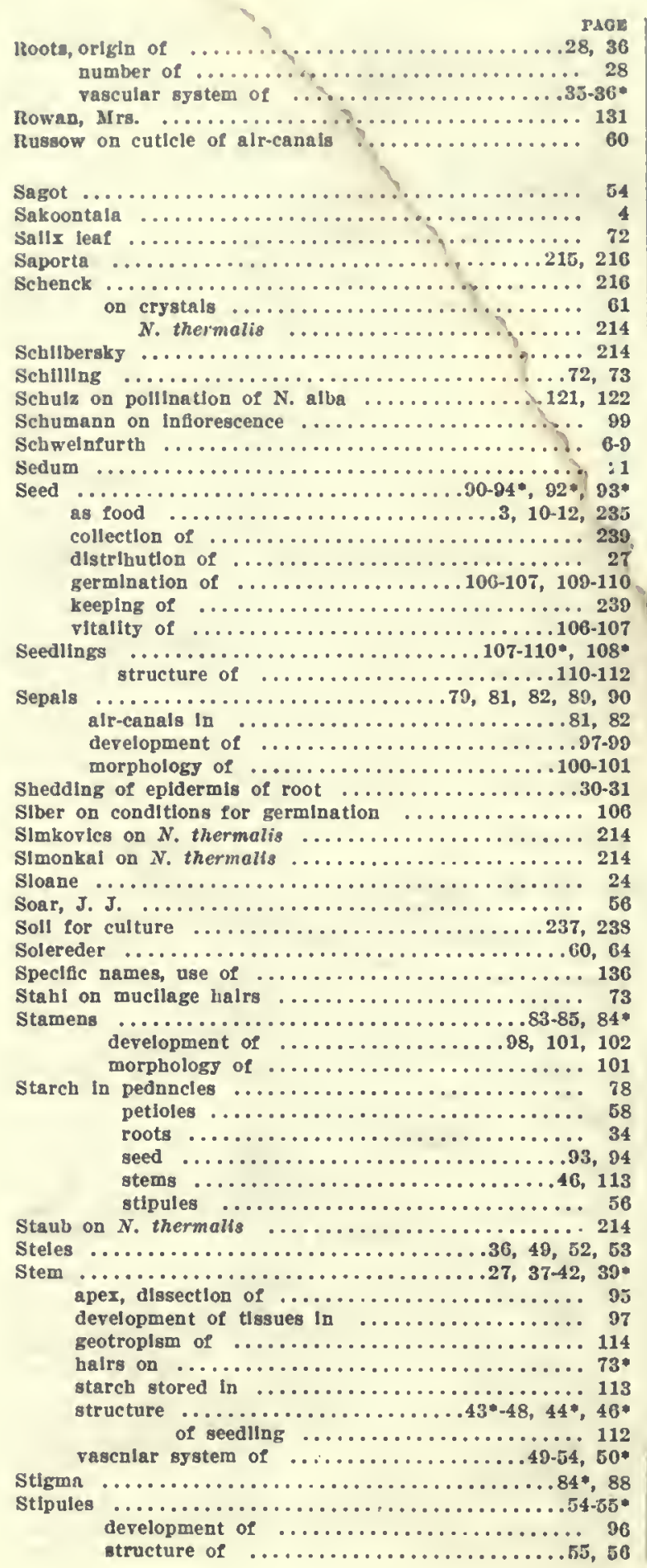
Stolons of Lotos group ..........41, 48, 49, 52*, 53 N. Nata .................48, 49, 83 N. Iavo-vlrens .................. 41 N. mexlcana ................. 41 N. tuherosa $\ldots \ldots \ldots \ldots \ldots \ldots \ldots \ldots \ldots \ldots, 49$ Stomata ...................54,67, 64, 7\%, 192 development of $\ldots \ldots \ldots \ldots \ldots \ldots \ldots \ldots \ldots \ldots .97$ on hack of leaf seedilng leaves $\ldots \ldots \ldots \ldots \ldots \ldots \ldots \ldots \ldots . \ldots \ldots$ sepals $\ldots \ldots \ldots \ldots \ldots \ldots \ldots \ldots \ldots \ldots \ldots, 81$

stamens ................... 84, 85

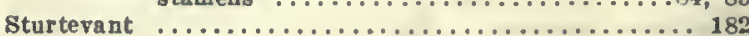
Submergence of flower after anthesis ...........123.124 Suspensor .............................. 105. Symmetry of flower ...................... 100, Symphytopleura ....................... 8

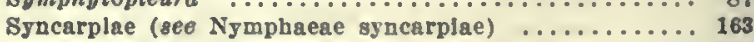

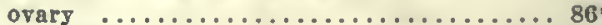
phylogeny ...............217, 218 plstil $\ldots \ldots \ldots \ldots \ldots \ldots \ldots \ldots \ldots \ldots . . .66,87,88$ stamens $\ldots \ldots \ldots \ldots \ldots \ldots \ldots \ldots \ldots \ldots$. 84

Tank for culture ..................236-2:8 Tassl on anesthesla of flowers $\ldots \ldots \ldots \ldots \ldots \ldots \ldots \ldots 121$

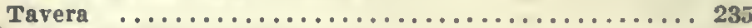
Tetrasepaleae, phylogeny .................. 218 Theophrastus $\ldots \ldots \ldots \ldots \ldots \ldots \ldots \ldots \ldots \ldots \ldots \ldots \ldots \ldots \ldots \ldots \ldots \ldots \ldots \ldots \ldots \ldots, 20,23$ Thyll-1lke hodles $\ldots \ldots \ldots \ldots \ldots \ldots \ldots \ldots \ldots .61,62,77,79$ In sepals ................ 81

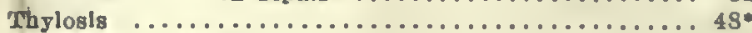

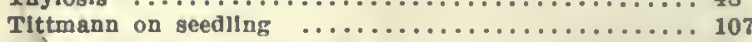

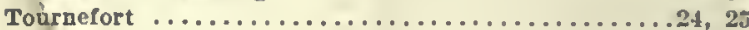
Tragus ............................. 16

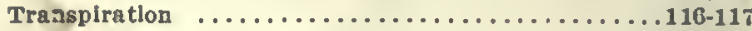
Tratlnnlek $\ldots \ldots \ldots \ldots \ldots \ldots \ldots \ldots \ldots \ldots \ldots \ldots \ldots \ldots \ldots, 6$ Treat, Mrs. Mary, on $N$. flava ............... 40

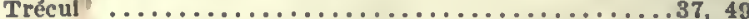

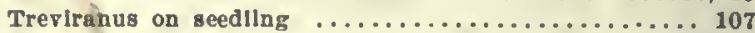

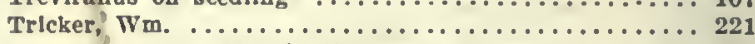
on germination $\ldots \ldots \ldots \ldots \ldots \ldots \ldots, 106,107$ culture $\ldots \ldots \ldots \ldots \ldots .237,238,240,241$ Trientalis ......................... 24

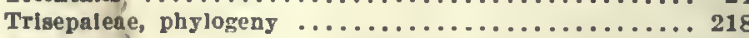
Tuhers .....................40*,47, $190^{\circ}$ as food $\ldots \ldots \ldots \ldots \ldots \ldots \ldots \ldots .3,7,10,17,22,23$ drawn down hy contractlle roots $\ldots \ldots \ldots \ldots .113$ early leaves from .................... 75 of seedilng ......................108*, 110 Turner, wín. ........................ 14

Unger

Vallant $\ldots \ldots \ldots \ldots \ldots \ldots \ldots \ldots \ldots \ldots \ldots \ldots \ldots \ldots \ldots, 25$ Valllsneria spiralls $\ldots \ldots \ldots \ldots \ldots \ldots \ldots \ldots \ldots \ldots \ldots \ldots . . \ldots \ldots$

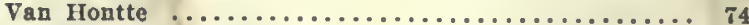

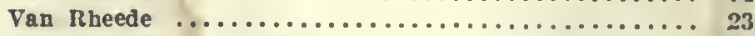

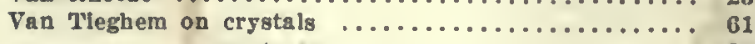

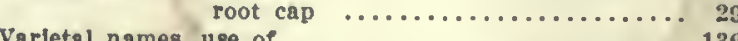
of Vascular system of leaf $\ldots \ldots \ldots \ldots \ldots \ldots \ldots \ldots \ldots, 70,71$. node $\ldots \ldots \ldots \ldots \ldots \ldots \ldots \ldots . \ldots, 53,54$ peduncle $\ldots \ldots \ldots \ldots 53,54,59 * 63,78$ petlole .......69*, 62-64, 63*, 76-77 root $\ldots \ldots \ldots \ldots \ldots \ldots \ldots \ldots \ldots .35-36$. seedling ................111, 112 stem ...............49-54, 50* 


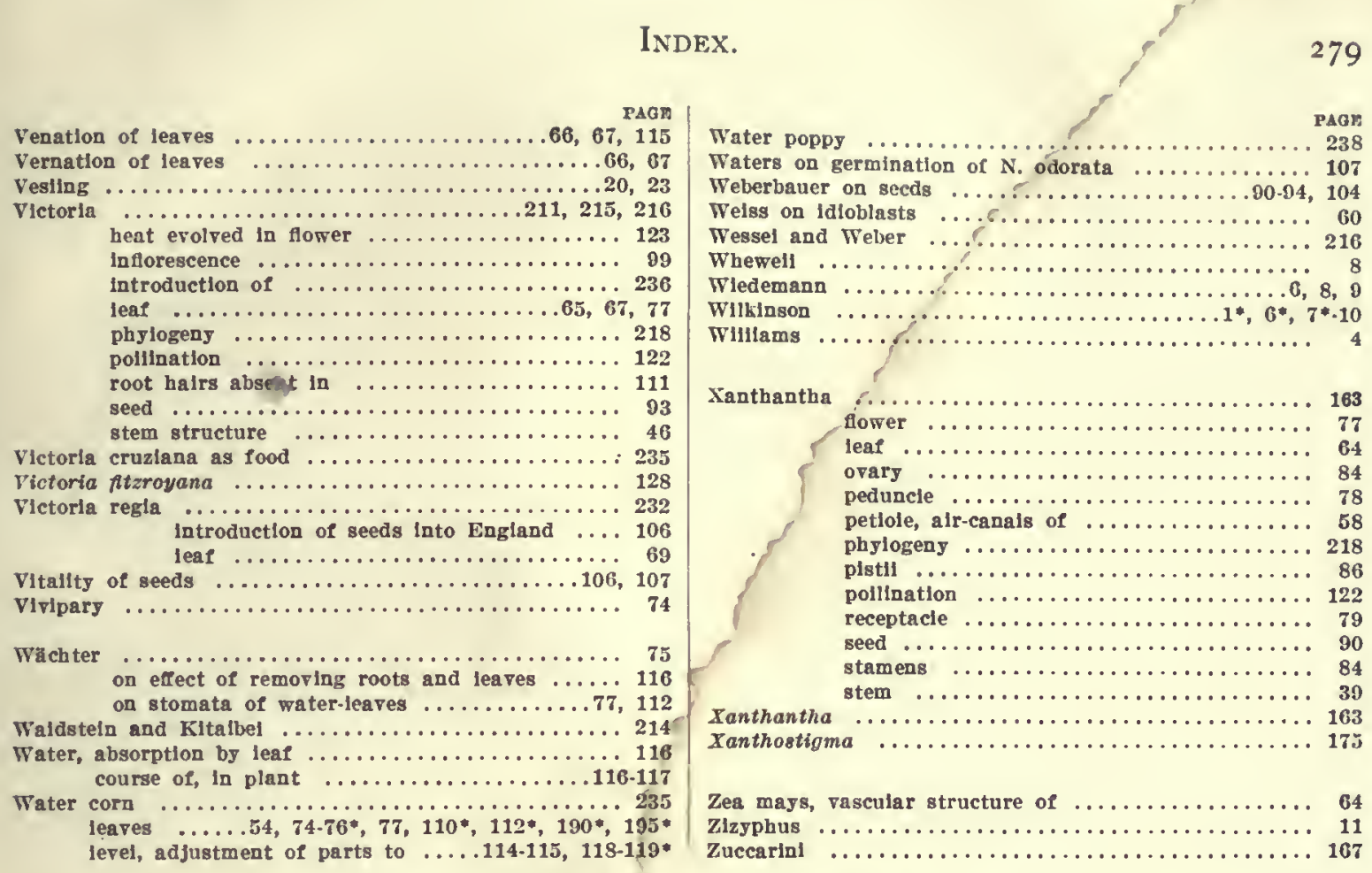

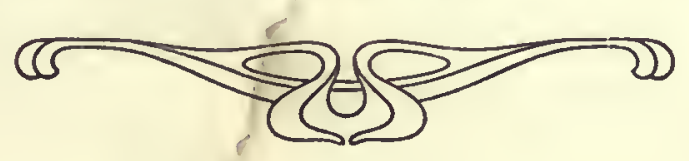




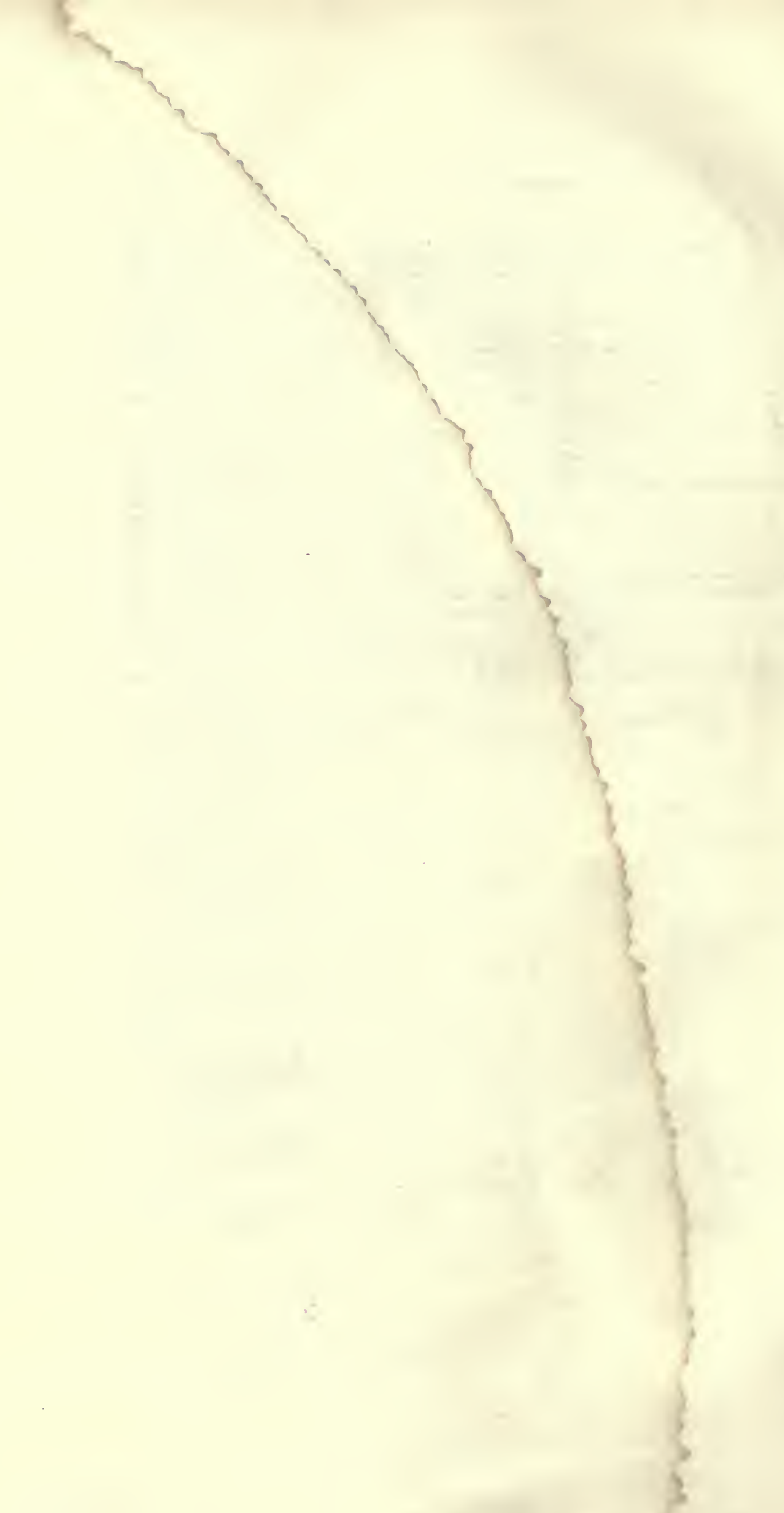





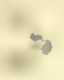





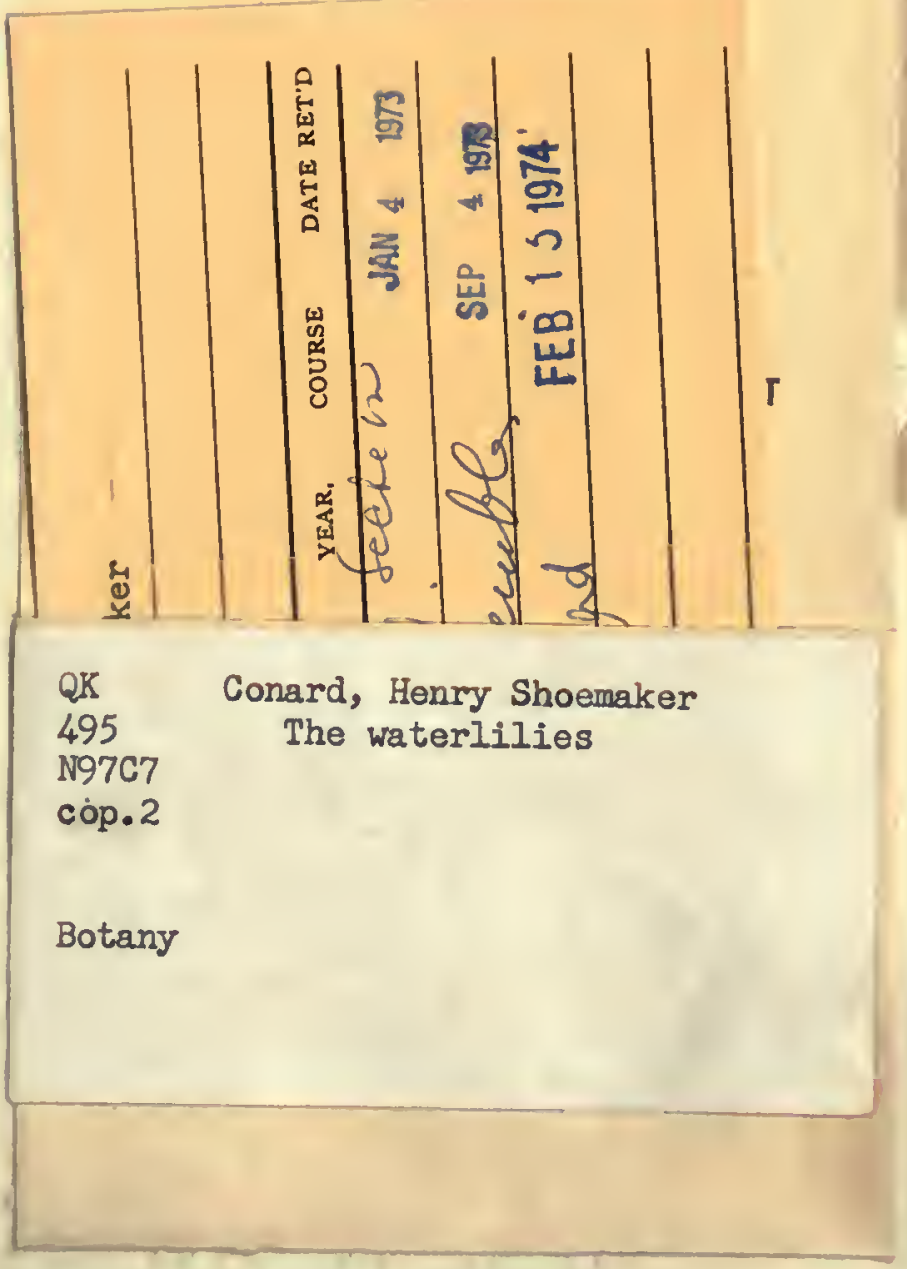


